\title{
FROM ORGANIZATIONAL WELFARE TO BUSINESS SUCCESS: HIGHER PERFORMANCE IN HEALTHY ORGANIZATIONAL ENVIRONMIENTS
}

EDITED BY: Gabriele Giorgi, Mindy Shoss and Annamaria Di Fabio PUBLISHED IN: Frontiers in Psychology

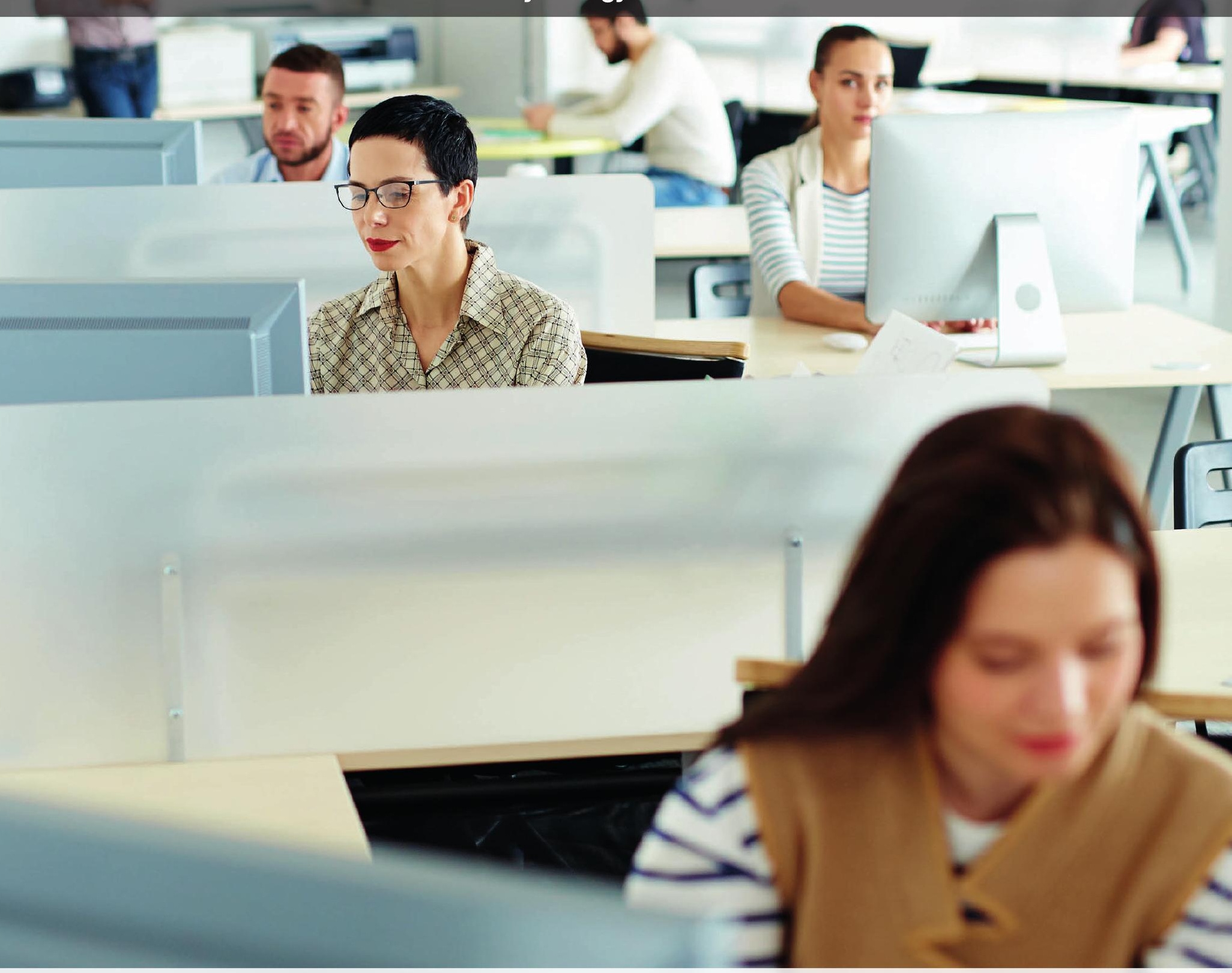




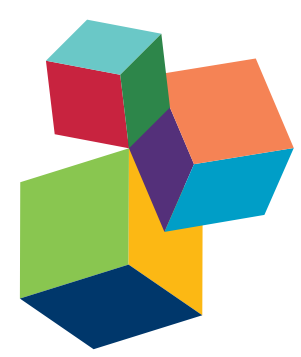

Frontiers Copyright Statement

(c) Copyright 2007-2017 Frontiers Media SA. All rights reserved.

All content included on this site, such as text, graphics, logos, button icons, images, video/audio clips, downloads, data compilations and software, is the property of or is licensed to Frontiers Media SA

("Frontiers") or its licensees and/or subcontractors. The copyright in the text of individual articles is the property of their respective authors, subject to a license granted to Frontiers.

The compilation of articles constituting

this e-book, wherever published,

as well as the compilation of all other content on this site, is the exclusive property of Frontiers. For the conditions for downloading and copying of e-books from Frontiers' website, please see the Terms for Website Use. If purchasing Frontiers e-books from other websites or sources, the conditions of the website concerned apply.

Images and graphics not forming part of user-contributed materials may not be downloaded or copied without permission.

Individual articles may be downloaded and reproduced in accordance with the principles of the CC-BY licence subject to any copyright or other notices. They may not be re-sold as an e-book.

As author or other contributor you grant a CC-BY licence to others to reproduce your articles, including any graphics and third-party materials supplied by you, in accordance with the Conditions for Website Use and subject to any copyright notices which you include in connection with your articles and materials.

All copyright, and all rights therein, are protected by national and international copyright laws.

The above represents a summary only. For the full conditions see the Conditions for Authors and the Conditions for Website Use.

ISSN 1664-8714 ISBN 978-2-88945-315-3

DOI 10.3389/978-2-88945-315-3

\section{About Frontiers}

Frontiers is more than just an open-access publisher of scholarly articles: it is a pioneering approach to the world of academia, radically improving the way scholarly research is managed. The grand vision of Frontiers is a world where all people have an equal opportunity to seek, share and generate knowledge. Frontiers provides immediate and permanent online open access to all its publications, but this alone is not enough to realize our grand goals.

\section{Frontiers Journal Series}

The Frontiers Journal Series is a multi-tier and interdisciplinary set of open-access, online journals, promising a paradigm shift from the current review, selection and dissemination processes in academic publishing. All Frontiers journals are driven by researchers for researchers; therefore, they constitute a service to the scholarly community. At the same time, the Frontiers Journal Series operates on a revolutionary invention, the tiered publishing system, initially addressing specific communities of scholars, and gradually climbing up to broader public understanding, thus serving the interests of the lay society, too.

\section{Dedication to Quality}

Each Frontiers article is a landmark of the highest quality, thanks to genuinely collaborative interactions between authors and review editors, who include some of the world's best academicians. Research must be certified by peers before entering a stream of knowledge that may eventually reach the public - and shape society; therefore, Frontiers only applies the most rigorous and unbiased reviews.

Frontiers revolutionizes research publishing by freely delivering the most outstanding research, evaluated with no bias from both the academic and social point of view. By applying the most advanced information technologies, Frontiers is catapulting scholarly publishing into a new generation.

\section{What are Frontiers Research Topics?}

Frontiers Research Topics are very popular trademarks of the Frontiers Journals Series: they are collections of at least ten articles, all centered on a particular subject. With their unique mix of varied contributions from Original Research to Review Articles, Frontiers Research Topics unify the most influential researchers, the latest key findings and historical advances in a hot research area! Find out more on how to host your own Frontiers Research Topic or contribute to one as an author by contacting the Frontiers Editorial Office: researchtopics@frontiersin.org 


\section{FROM ORGANIZATIONAL WELFARE TO BUSINESS SUCCESS: HIGHER PERFORMANCE IN HEALTHY ORGANIZATIONAL ENVIRONMENTS}

Topic Editors:

Gabriele Giorgi, European University of Rome, Italy

Mindy Shoss, University of Central Florida, United States

Annamaria Di Fabio, University of Florence, Italy

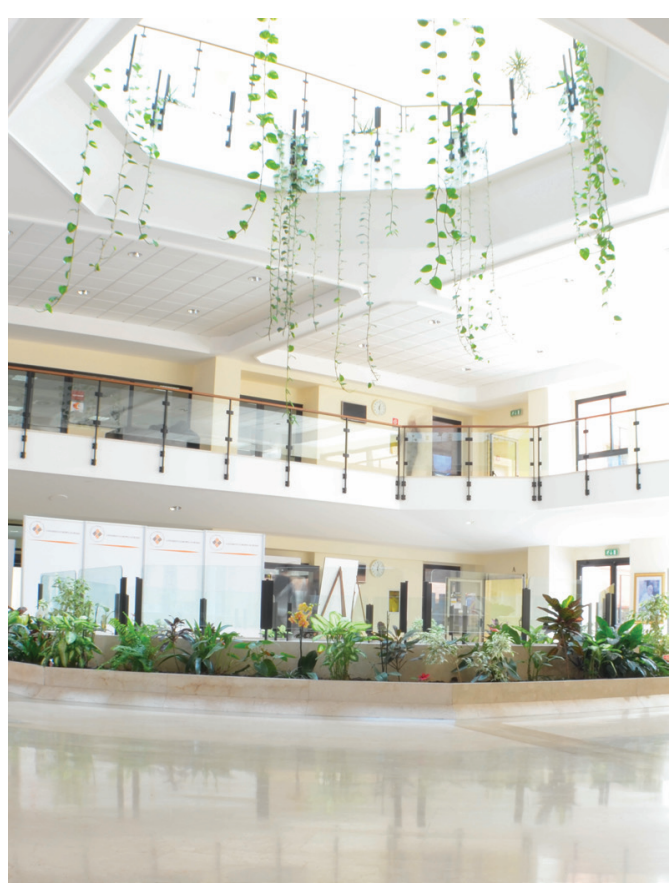

Business doesn't exist without workers' health \& workers' health is business

Image by European University of Rome, Rome, Italy

Cover image: Pressmaster/Shutterstock.com

This e-book provides insight into the link between employee health and productivity/performance, with a focus on how individuals, groups, or organizations can intervene in this relationship to improve both well-being and performance-related outcomes. Given the continuous changes that organizations and employees face, such as the aging workforce and continued economic turbulence, it is not surprising that studies are increasingly finding that employee health is related to job conditions. The papers in this e-book emphasize that organizations make a critical difference when it comes to employees' health and well-being. In turn, healthy employees help 
their organizations to flourish. Such findings are in line with the recent emphasis by both the International Labour Organization (ILO) and the United Nations (UN) on the importance of work for individual well-being and the importance of individual well-being for productive and sustainable economic growth (see e.g., ILO, 1985; World Health Organisation, 2007; UN, 2015).

Overall, the papers report findings from a cumulative sample of nearly 19,000 workers and perspectives from 68 authors. They suggest that performance cannot be successfully achieved at the cost of health and well-being, and provide various perspectives and tools to guide future research and practice.

Citation: Giorgi, G., Shoss, M., Di Fabio, A., eds. (2017). From Organizational Welfare to Business Success: Higher Performance in Healthy Organizational Environments. Lausanne: Frontiers Media. doi: $10.3389 / 978-2-88945-315-3$ 


\section{Table of Contents}

1. Introduction

06 Editorial: From Organizational Welfare to Business Success: Higher Performance in Healthy Organizational Environments

Gabriele Giorgi, Mindy Shoss and Annamaria Di Fabio

\section{Causes \& Consequences of Stressors at Work}

09 Grit or Honesty-Humility? New Insights into the Moderating Role of Personality between the Health Impairment Process and Counterproductive Work Behavior

Andrea Ceschi, Riccardo Sartori, Stephan Dickert and Arianna Costantini

20 Promoting Well-Being:The Contribution of Emotional Intelligence

Annamaria Di Fabio and Maureen E. Kenny

33 Expatriates' Multiple Fears, from Terrorism to Working Conditions: Development of a Model

Gabriele Giorgi, Francesco Montani, Javier Fiz-Perez, Giulio Arcangeli and Nicola Mucci

44 Approaching the Discriminatory Work Environment as Stressor: The Protective Role of Job Satisfaction on Health

Donatella Di Marco, Rocio López-Cabrera, Alicia Arenas, Gabriele Giorgi,

Giulio Arcangeli and Nicola Mucci

54 Anxiety, Stress-Related Factors, and Blood Pressure in Young Adults

Nicola Mucci, Gabriele Giorgi, Stefano De Pasquale Ceratti, Javier Fiz-Pérez,

Federico Mucci and Giulio Arcangeli

64 Walking the Tightrope: Counterproductive Work Behavior as Compensation for Citizenship Demands

Andromachi Spanouli and Joeri Hofmans

\section{Strategies to Improve Health and Well-Being}

71 Engaging in Rather than Disengaging from Stress: Effective Coping and Perceived Control

Maria T. M. Dijkstra and Astrid C. Homan

83 The Role of Psychological Capital and Intragroup Conflict on Employees' Burnout and Quality of Service: A Multilevel Approach

Jose M. Leon-Perez, Mirko Antino and Jose M. Leon-Rubio

94 The Challenge of Fostering Healthy Organizations: An Empirical Study on the Role of Workplace Relational Civility in Acceptance of Change and Well-Being Annamaria Di Fabio, Marco Giannini, Yura Loscalzo, Letizia Palazzeschi, Ornella Bucci, Andrea Guazzini and Alessio Gori 
103 A Longitudinal Study of the Predictors of Perceived Procedural Justice in Australian University Staff

Silvia Pignata, Anthony H. Winefield, Chris Provis and Carolyn M. Boyd

117 Perceived Organizational Support for Enhancing Welfare at Work: A Regression Tree Model

Gabriele Giorgi, David Dubin and Javier Fiz Perez

126 Positive Aging in Demanding Workplaces: The Gain Cycle between Job Satisfaction and Work Engagement

Dina Guglielmi, Lorenzo Avanzi, Rita Chiesa, Marco G. Mariani, Ilaria Bruni and Marco Depolo

136 Active Commuting: Workplace Health Promotion for Improved Employee Well-Being and Organizational Behavior

Nadine C. Page and Viktor O. Nilsson

148 Awareness of Stress-Reduction Interventions on Work Attitudes: The Impact of Tenure and Staff Group in Australian Universities

Silvia Pignata, Anthony H. Winefield, Chris Provis and Carolyn M. Boyd

161 Learning Climate and Job Performance among Health Workers. A Pilot Study Michela Cortini, Monica Pivetti and Sara Cervai

4. Tools to Monitor and Improve Health and Well-Being

167 Rocking at 81 and Rolling at 34: ROC Cut-Off Scores for the Negative Acts Questionnaire-Revised in Serbia

Ivana B. Petrović, Milica Vukelić and Svetlana Čizmić

180 High Entrepreneurship, Leadership, and Professionalism (HELP): Toward an Integrated, Empirically Based Perspective

Annamaria Di Fabio, Ornella Bucci and Alessio Gori

191 Positive Relational Management for Healthy Organizations: Psychometric Properties of a New Scale for Prevention for Workers

Annamaria Di Fabio

200 Users' Support as a Social Resource in Educational Services: Construct Validity and Measurement Invariance of the User-Initiated Support Scale (UISS)

Barbara Loera, Mara Martini, Sara Viotti and Daniela Converso

211 Exploring Physicians' Dissatisfaction and Work-Related Stress: Development of the PhyDis Scale

Monica Pedrazza, Sabrina Berlanda, Elena Trifiletti and Franco Bressan

224 Promoting Safety through Well-Being: An Experience in Healthcare

Andreina Bruno and Fabrizio Bracco 


\section{OPEN ACCESS}

Edited by:

Richard Eleftherios Boyatzis,

Case Western Reserve University,

USA

Reviewed by:

Richard Eleftherios Boyatzis,

Case Western Reserve University,

USA

Joann Farrell Quinn,

University of South Florida Morsan

College of Medicine, USA

Craig Seal,

California State University,

San Bernardino, USA

Anita Howard

Case Western Reserve University,

USA

*Correspondence:

Gabriele Giorg

gabriele.giorgi@unier.it

Specialty section:

This article was submitted to

Organizational Psychology,

a section of the journal

Frontiers in Psychology

Received: 14 February 2017

Accepted: 21 April 2017

Published: 23 May 2017

Citation:

Giorgi G, Shoss $M$ and Di Fabio A (2017) Editorial: From Organizational

Welfare to Business Success: Higher

Performance in Healthy Organizational Environments. Front. Psychol. 8:720.

doi: 10.3389/fpsyg.2017.00720

\section{Editorial: From Organizational Welfare to Business Success: Higher Performance in Healthy Organizational Environments}

\author{
Gabriele Giorgi ${ }^{1 *}$, Mindy Shoss ${ }^{2}$ and Annamaria Di Fabio ${ }^{3}$ \\ ${ }^{1}$ Department of Human Science, Psychology Section, European University of Rome, Rome, Italy, ${ }^{2}$ Department of \\ Psychology, University of Central Florida, Orlando, FL, USA, ${ }^{3}$ Department of Education and Psychology, Psychology Section, \\ University of Florence, Firenze, Italy
}

Keywords: organizational psychology, performance, healthy organization, business, work-related stress, occupational health

\section{Editorial on the Research Topic}

From Organizational Welfare to Business Success: Higher Performance in Healthy Organizational Environments

\section{INTRODUCTION}

This special issue provides insight into the link between employee health and productivity/performance, with a focus on how individuals, groups, or organizations can intervene in this relationship to improve both well-being and performance-related outcomes. Given the continuous changes that organizations and employees face, such as the aging workforce and continued economic turbulence, it is not surprising that studies are increasingly finding that employee health is related to job conditions. The papers in this special issue emphasize that organizations make a critical difference when it comes to employees' health and well-being. In turn, healthy employees help their organizations to flourish. Such findings are in line with the recent emphasis by both the International Labour Organization (ILO) and the United Nations (UN) on the importance of work for individual well-being and the importance of individual well-being for productive and sustainable economic growth (see e.g., ILO, 1985; World Health Organisation, 2007; UN, 2015).

The 21 papers accepted in this special issue are predominately empirical contributions, from authors from different disciplinary sectors (Organizational Psychology, Management, Occupational Medicine, and Engineering) and several different regions (Southern-Europe, Northern-Europe, Eastern-Europe, United States, and Australia). As a result, they offer diverse perspectives on the issue of employee health and performance, and help to promote an international and interdisciplinary approach to research that will enable the progress of science in the businesshealth field.

Taken together, all of the papers in this special issue emphasize three important points. First, issues of employee health and well-being are especially pressing in light of increasing turbulence and instability in business and in the global economy. Second, employee health and well-being are crucial for organizational success. Poor working conditions and environments (including relational environments) ultimately harm performance. In contrast, organizations that foster healthy environments promote both employee and organizational success. Third, efforts to address employee health must be multi-pronged and involve individual, unit, and organizational strategies. 


\section{OVERVIEW OF ARTICLES IN THIS RESEARCH TOPIC}

The 21 papers published in the special issue addressed these issues in a variety of ways.

Two studies examined the impact of personality on well-being, yielding insights into which workers are most susceptible to poor well-being at work. First, the article by Ceschi et al. was conducted in a sample of 208 private service sector Italian employees. Their findings underscored the importance of personality traits in the relationship between health impairment process and the emergence of counterproductive work behavior. Interestingly, honesty-humility seemed to have negative consequences for workers' burnout. In the second article, Di Fabio and Kenny adopted a primary prevention perspective in their examination of emotional intelligence and well-being among Italian high school students. They found that trait emotional intelligence impacts well-being even when controlling for personality and fluid intelligence, and their paper offers insights for developing future workers.

Four articles examined causes and consequences of stressors at work. First, Giorgi et al. presented a new theoretical and empirical model investigating multiple fears in workplace among 265 Italian expatriate workers. Using a structural equation model design, this innovative model explored the relationships of different fears, fear of expatriation, fear of the economic crisis, and dangerous working conditions into an composite framework. Second, in a large study of Italian workers, Di Marco et al. found that perceptions of a discriminatory work environment threaten employee health, and that these effects are partially mediated by job satisfaction. They suggest practical implications for organizations. Third, Mucci et al. examined the impact of anxiety and work-related stress on hypertension among students training to be healthcare professionals. They found evidence linking psychological stressors to students' blood pressure and cardiovascular health. These findings demonstrate that even among a group of relatively young individuals, work-related stressors are related to cardiovascular health. Fourth, Spanouli and Hofmans pointed out that employees might increasingly feel obligated to perform citizenship behaviors at work. Using an experience sampling design, they asked employees to report on their elicited and discretionary organizational citizenship behavior and counterproductive work behavior twice a day for 10 days. Their results suggest that these strategies are likely to backfire as individuals appear to use counterproductive work behavior to compensate for elicited organizational citizenship behavior. Each of these studies suggests areas to intervene to reduce or eliminate threats to health and well-being at work.

Relatedly, the majority of studies featured in this special issue explored individual, unit, and/or organizational strategies to improve health and well-being. The article by Dijkstra and Homan, conducted in a heterogeneous sample of 543 Dutch employees, found that engaged coping strategies such as active confronting and reassuring thoughts were associated with more sense of control and therefore to psychological well-being. This publication suggests that the importance of the concept of coping is nowadays still fundamental. Leon-Perez et al. took a multilevel approach to understanding how intragroup conflict, at the unit level, and psychological capital, at the individual level, impacts employees' burnout and quality of service. In a sample of employees working in a vehicle safety and emissions inspection company in Spain, they found that individual psychological capital impacted both burnout and quality of service. At the unit level, they found that intragroup conflict also predicted burnout, and that units' conflict management climate can buffer the harmful impact of conflict on quality of service. Di Fabio et al. argued that relational incivility is crucial for positive outcomes when organizations undergo change. Their study, conducted with a sample of 261 Italian workers, found that relational civility positively related not only to well-being outcomes, but also to acceptance of change.

The article by Pignata et al. using the Job Demands-Resources theoretical model of stress investigated the antecedents of perceived procedural justice in a two-wave longitudinal sample of 945 employees from 13 Australian universities. The article findings stimulate the development of more fair and transparent processes in the academic setting in order to increase justice perceptions. Relatedly, the article by Giorgi et al. determined the advantage of using recursive partitioning in the prediction of perceived organizational support in a sample of more than 6,000 Italian bankers. A regression tree model was estimated utilizing the tree function party package in $\mathrm{R}$. The emerged results seem strategic both for research and practice. The article by Guglielmi et al. proposes an interesting model of engagement among older workers. They surveyed older workers in Northern Italy and found evidence of a gain cycle wherein job satisfaction increases work engagement, which in turn impacts subsequent job satisfaction. Job demands and age play a role in the strength of this gain cycle.

The article by Page and Nilsson used an innovative approach to improve employees' well-being and organizational behavior. Active commuting using electrically assisted bikes (e-bikes) resulted in more productive and healthy organizational behavior outcomes compared with passive commuters. Pignata et al. shed light on the important issue of awareness of organizational stress interventions. In a two-wave longitudinal study of employees from 13 Australian universities, they find that awareness of stress interventions plays an important role in impacting satisfaction, trust, and for non-academic employees, commitment, and justice perceptions. These results varied depending on organizational tenure, suggesting that organizations might need to promote interventions differently depending on tenure. Finally, Cortini et al. examine the relationship between learning climate and job performance. In a sample of health professionals gathered from a public hospital in Italy, they found evidence that a learning climate promotes job performance by virtue of impacting psychological strain.

Additionally, many of the articles in the special issue offer tools for employees and organizations to monitor and improve health and well-being. First, the article by Petrović et al. examined the cut off scores of the most scientifically recognized instrument of workplace bullying measurement: the Negative Acts Questionnaire Revised (NAQ-R). In the cultural and economic 
context of Serbia, this article is an important reference for researchers and practitioners who wish to use this questionnaire. Second, Di Fabio et al. evaluated the psychometric properties of a new multi-dimensional scale for entrepreneurship, leadership, and professionalism. Entrepreneurship, leadership, and professionalism are increasingly important in today's ever-changing and uncertain business environment. This tool is likely to aid both research and practice. The third tool is addressed in the article by Di Fabio. In particular, this article examined the psychometric properties of the Positive Relational Management Scale (PRMS). This scale demonstrated good psychometric properties, and can serve as another useful tool for assessing and promoting positive experiences at work. Third, Loera et al. offer evidence for the validity and measurement invariance of the User-Initiated Support Scale, which assesses social support from users (e.g., students, patients). This tool assesses a crucial, yet often ignored, source of social support at work. Fourth, Pedrazza et al. reported on the development of a scale to assess physician's dissatisfaction and work-related stress. They explore various dimensions of stressful experiences among physicians and highlight role uncertainty and loss of social esteem as particularly stressful factors. Finally, in a two-year action research project taking place in the operating rooms of six hospitals in Northern Italy, Bruno and Bracco developed an innovative methodology for noticing and monitoring critical threats to safety and well-being. This tool serves as an excellent

\section{REFERENCES}

Danna, K., and Griffin, R. W. (1999). Health and well-being in the workplace: a review and synthesis of the literature. J. Manage. 25, 357-384. doi: 10.1177/014920639902500305

Di Fabio, A., and Kenny, E. M. (2016). From decent work to decent lives: positive self and relational management (PS\&RM) in the twenty-first century. Front Psychol. 7:361. doi: 10.3389/fpsyg.2016. 00361

International Labour Organisation (ILO) (1985). C161 Occupational Health Services Convention (No. 161). Geneva. Available online at: http://www.ilo. org/dyn/normlex/en/f?p=NORMLEXPUB:12100:0::NO::P12100_ILO_CODE: C161

Lerner, D., Rodday, A. M., Cohen, J. T., and Rogers, W. H. (2013). A systematic review of the evidence concerning the economic impact of employee-focused health promotion and wellness programs. J. Occup. Environ. Med. 55, 209-222. doi: 10.1097/JOM.0b013e3182728d3c resource for monitoring and addressing safety and well-being at work in a proactive, team-oriented manner.

\section{CONCLUSIONS}

Overall, the papers in this special issue report findings from a cumulative sample of nearly 19,000 workers and perspectives from 68 authors. They suggest that performance cannot be successfully achieved at the cost of health and well-being, and provide various perspectives and tools to guide future research and practice.

We conclude with a motto of the Business@health laboratory of the European University of Rome (www.uerbusinesshealth. com) "Business doesn't exist without workers' health \& workers' health is business." We hope that this special issue will inspire researchers and practitioners to expand their horizons to integrate occupational health and safety protection as part of activities designed to promote well-being, performance, and productivity (e.g., Danna and Griffin, 1999; Lerner et al., 2013; Di Fabio and Kenny, 2016).

\section{AUTHOR CONTRIBUTIONS}

All authors listed, have made substantial, direct, and intellectual contribution to the work, and approved it for publication.

United Nations (UN) (2015). Sustainable Development Goals. Available online at: http://www.un.org/sustainabledevelopment/economic-growth/

World Health Organisation (2007). Workers' Health: Global Plan of Action. World Health Organisation, Sixtieth World Health Assembly. Available online at: http://www.who.int/occupational_health/WHO_health_assembly_en_web. pdf?ua=1 (Accessed May 23, 2007).

Conflict of Interest Statement: The authors declare that the research was conducted in the absence of any commercial or financial relationships that could be construed as a potential conflict of interest.

Copyright (c) 2017 Giorgi, Shoss and Di Fabio. This is an open-access article distributed under the terms of the Creative Commons Attribution License (CC BY). The use, distribution or reproduction in other forums is permitted, provided the original author(s) or licensor are credited and that the original publication in this journal is cited, in accordance with accepted academic practice. No use, distribution or reproduction is permitted which does not comply with these terms. 
OPEN ACCESS

Edited by:

Annamaria Di Fabio,

University of Florence, Italy

Reviewed by:

M. Teresa Anguera,

University of Barcelona, Spain

Peter Mcllveen,

University of Southern Queensland,

Australia

*Correspondence:

Andrea Ceschi

andrea.ceschi@univr.it

Specialty section:

This article was submitted to

Organizational Psychology,

a section of the journal

Frontiers in Psychology

Received: 13 July 2016 Accepted: 01 November 2016 Published: 01 December 2016

Citation:

Ceschi A, Sartori R, Dickert S and Costantini A (2016) Grit or

Honesty-Humility? New Insights into

the Moderating Role of Personality between the Health Impairment

Process and Counterproductive Work

Behavior. Front. Psychol. 7:1799.

doi: 10.3389/fpsyg.2016.01799
Grit or Honesty-Humility? New Insights into the Moderating Role of Personality between the Health Impairment Process and Counterproductive Work Behavior

\author{
Andrea Ceschi ${ }^{1 *}$, Riccardo Sartori ${ }^{1}$, Stephan Dickert ${ }^{2}$ and Arianna Costantini ${ }^{1}$ \\ ${ }^{1}$ Department of Human Sciences, University of Verona, Verona, Italy, ${ }^{2}$ School of Business and Management, Queen Mary
} University of London, London, UK

It is acknowledged that chronic job demands may be depleting workers' stamina resulting in burnout conditions and ultimately causing further health problems. This relation, known as health impairment process, has recently been considered as a possible explanation for the emergence of counterproductive work behavior (CWB). The present work aims to examine the role of two personality traits (i.e., Grit and HonestyHumility) in this process. The results, based on a sample of 208 private service sector employees, confirm the presence of a fully mediated process and show how HonestyHumility positively moderates the relationship between job demands and exhaustion, whereas Grit has a negative effect on the relation between exhaustion and CWB. Implications for assessment procedure and hiring decisions are discussed.

Keywords: health impairment process, job demands, exhaustion, counterproductive work behavior, honestyhumility, grit

\section{INTRODUCTION}

In line with the burnout literature, it is widely assumed that burnout leads to health problems, such as psychosomatic illness, cardiovascular and coronary heart diseases (Ahola et al., 2005; Ahola and Hakanen, 2007; Toppinen-Tanner et al., 2009). Therefore, burnout plays a prominent role in explaining the relationship between rising job demands and an increase in such health problems. In fact, in the last 20 years organizational research has provided evidence of the link between job demands, burnout and health indicators (Brotheridge and Grandey, 2002; Geurts and Sonnentag, 2006; Piko, 2006; Little et al., 2007; Umehara et al., 2007; Dollard and Bakker, 2010; Idris et al., 2012; Schaufeli and Taris, 2014).

This two-stage process is known as "health impairment" or "energetic process," and it is embedded in the Job Demands Resources (JD-R) model (Demerouti et al., 2001) and empirically supported (Bakker et al., 2004, 2010; Bakker and Demerouti, 2007; Xanthopoulou et al., 2007; Hakanen et al., 2008; Demerouti and Bakker, 2011; Schaufeli and Taris, 2014). Considering research in support of this model, it is likely that the health impairment reflects a more universal process at work, of which the health issue is just one symptom (Balducci et al., 2011). In order to show work-related implications, literature usually provides studies where the health impairment process is associated with outcomes such as organizational well-being or job performance (Bakker et al., 2004, 2008; Idris et al., 2012). The nature of this relationship 
depends both on the types of job demands as well as on the outcomes considered in the study, resulting in a partial or full mediation through burnout. While job demands are usually negatively related to health through a full and negative mediation with burnout, they are positively and directly associated with task performance. For example, Bakker et al. (2004) found that inrole performance was mostly predicted by job demands through workers' exhaustion (a component of burnout), while in another study cynicism (another burnout component) predicted teams' sales performance (Bakker et al., 2008). Based on evidence from research, it is reasonable to assume the presence of two relationships, namely a first path from job demands to burnout (or its components), and a second path from burnout to the outcome considered (e.g., performance, absenteeism, etc.). Finally, we can consider the presence of a third path, when the relation is partially mediated, usually when the outcomes studied are different than health problems (Figure 1).

Considering these types of outcomes, the health impairment process has been examined regarding the effect on performance but rarely used to predict behavioral constructs correlated with burnout. In one notable example, in the JD-R framework, job demands predicted burnout and consequently absence duration (Bakker et al., 2003). More recently, some attempts have been made to study the relationships between job demands and organizational behavior in the health impairment process (Schaufeli et al., 2009; Balducci et al., 2011; Nahrgang et al., 2011). Balducci et al. (2011) studied the emergence of counterproductive work behavior (CWB) as a behavioral stress reaction. Workload, role conflict, and interpersonal demands were related to some CWBs via negative affectivity (i.e., anger, pessimism). Finally, a recent study of Smoktunowicz et al. (2015) has confirmed the presence of job burnout as a mediator of the job demands-CWB relationship. The theoretical framework of their study was based on the Demand Control model (DCM; Karasek, 1998). They found that a high level of job demands was indirectly associated with higher CWB frequency, with an increase in job burnout (primarily exhaustion) operating as a mediator.

Counterproductive work behavior can also be predicted by emotional labor (i.e., emotional demands by which workers manage their feelings toward organizational aims; Bechtoldt et al., 2007). This relationship does not include burnout as a mediator so it is not technically definable as a health impairment process, but it reveals the important role of emotional demands in predicting CWB. Moreover, the relationship between emotional labor/acting deep and CWB is moderated by self-control, such that people with high self-control can perform better by effectively dealing with emotional stressors. This highlights the relevance of considering individual dispositions (e.g., selfcontrol) and personality traits in understanding the antecedence of organizational behavior and CWB.

With the exception of the recent study of Smoktunowicz et al. (2015), literature lacks clear research on the moderating impact of individual differences in the two-stage health impairment process and CWB. The current research aims to fill this gap by developing a model that considers the mediated relationship of such a classic process as the health impairment, and having CWB as the final outcome (Path a: job demands $\rightarrow$ exhaustion; Path b: exhaustion $\rightarrow$ CWB; and eventually Path c: job demands $\rightarrow$ CWB). Moreover, this contribution aims at exploring the moderating role performed by two promising personality traits: Honesty-Humility and Grit. Both such traits are relatively new in the organizational domain in comparison with the other wellknown big five traits (Sartori et al., 2015, 2016; Ceschi et al., 2016), and have been developed based on different personality theories (Ashton and Lee, 2005; Duckworth et al., 2007). They represent two distinct personality traits which do not overlap, but they may have a different (and explicative) role in moderating the relation between the health impairment process and CWB. Whereas Honesty-Humility, which represents the tendency to be faithful/loyal, has already been shown to negatively moderate
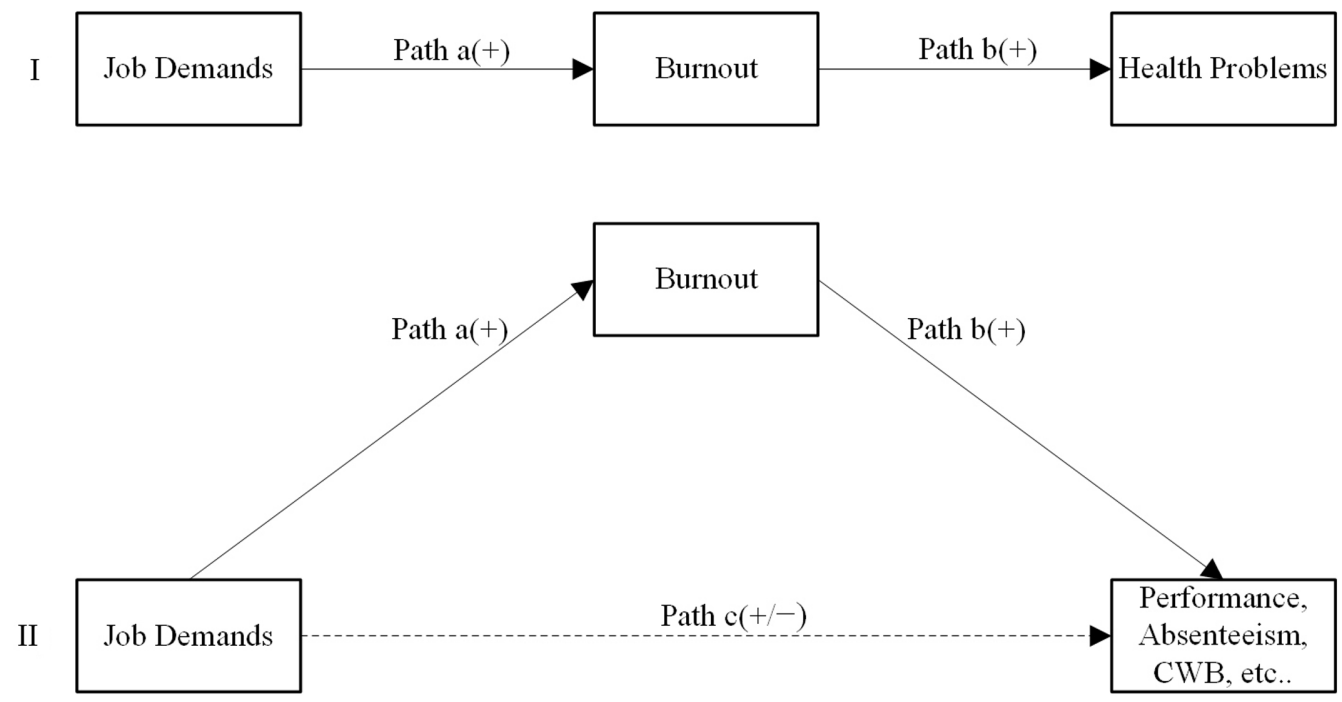

FIGURE 1 | The original health impairment process (I; Demerouti et al., 2001) and a general extension of the model (II). 
the relation between the stressors and CWB (Ashton et al., 2000; Zettler and Hilbig, 2010; Wiltshire et al., 2014; Chirumbolo, 2015), Grit, which predicts success by promoting self-control and goal-persisting at work (Duckworth and Gross, 2014), has rarely been studied in relation to counterproductive behaviors (Littman-Ovadia and Lavy, 2016).

In the next sections, we will first explore CWB as a possible outcome of the health impairment process. Secondly, we will introduce Honesty-Humility and Grit in their relation to the energetic process.

\section{Counterproductive Work Behavior (CWB): Classical Antecedents and Moderators}

Being counterproductive at work involves behavior that is deliberate and opposite to the established interests of the organization (Gruys and Sackett, 2003). It has been described as a range of behaviors that transgress the main organizational norms, to weaken the wellbeing of the organization and threaten the co-workers and customers (Penney and Spector, 2005). Counterproductive behaviors are invasive and destructive phenomena that impair performance and proficiency in the workplace (Spector and Fox, 2005). They have been operationalized in a variety of ways. The most salient form of CWB is physical violence, but it may also take the form of much less stunning behaviors such as gossip, subtle and passive actions, failure to fulfill tasks or pass on information, poor attendance, or intentionally sloppy work (Hershcovis et al., 2007).

The occurrence of CWB has been explained by the stressoremotion model, in which these behaviors are considered as an emotional reaction to frustration at work, due to a number of environmental stressors that hamper work efficiency (Spector and Fox, 2005). These stressors can be job demands such as interpersonal conflict, workload, emotional labor, role conflict and role ambiguity (Barling et al., 2009). Indeed, if CWB is an outcome of the health impairment process (Balducci et al., 2011), and if the role of such job demands in determining the process is clear, the stressor-emotion model implicitly hides how emotional exhaustion (as a manifestation of frustration) is correlated with CWB. Although the relationship between emotional exhaustion and CWB has been examined less frequently than the relation between job stressors and CWB, there is evidence to sustain such a link. In fact, emotionally exhausted individuals enlist more deviant behavior to relieve antagonistic emotions or for some subservient aim (Banks et al., 2012). Also, emotional exhaustion predicts which employees may be more engaged in CWBs (Krischer et al., 2010; Banks et al., 2012) and self-control seems to buffer this relation (Bolton et al., 2012).

The relation exhaustion $\rightarrow$ CWB certainly presents some personal factors as reliable moderators, such as self-control (Marcus and Schuler, 2004), but also several personality traits such as narcissism (Penney and Spector, 2002), anger trait or some of the big five traits (Douglas and Martinko, 2001; Marcus et al., 2007; Grijalva and Newman, 2015). For example, agreeableness and conscientiousness are related to interpersonally directed CWBs, and organizationally directed CWBs, respectively. Similarly, extraversion predicted theft at work, whereas openness to experience predicted work deviance.

Aside from the big five model, other moderator traits may better interact with the presented relations. These traits can be found in the new definitions of personality that are consistent with modern theories of development, practices that are informed by high-quality research, and constructs associated with significant challenges (Clement and Bollinger, 2016).

\section{The Explicative Power of Honesty-Humility in Predicting Unethical Behavior and Workplace Deviance}

Considerable research has been conducted within a personality framework alternative to the well-known Big Five. A different personality structure, named the HEXACO model, includes six dimensions instead of five (Ashton et al., 2007). The most salient property of the HEXACO model is the inclusion of the Honesty-Humility dimension. Honesty-Humility measures the disposition to not take advantage of other individuals, even when there is no risk of unfavorable repercussion for such exploitation (Ashton and Lee, 2008). People low in Honesty-Humility are portrayed as egoistic, lying, haughty, fraudulent, unethical, hypocritical and cunning (Lee and Ashton, 2006).

Considering this description, it is not unexpected that low Honesty-Humility is linked with a certain range of questionable behaviors. Low Honesty-Humility individuals have an inclination to deceive, craft, and break rules, searching for the chance to take part in self-interested behaviors (Lee et al., 2005a). The HEXACO Honesty-Humility dimension has consistently predicted workplace deviance and CWBs (Zettler and Hilbig, 2010; O'Boyle et al., 2012). For example, antisocial behaviors toward the organization and co-workers (i.e., workplace vandalism, absenteeism and alcohol abuse at work) were negatively correlated with the Honesty-Humility trait (Lee et al., 2005b).

In relation to the health impairment process, the HonestyHumility trait has been shown to moderate the effects of a job stressor (i.e., job insecurity) on CWB (Chirumbolo, 2015). Moreover, stressful situational factors, such as the perceived absence of organizational politics, elicit more CWB in individuals with a low score of the Honesty-Humility trait (Wiltshire et al., 2014).

\section{Grit and the Inclination to Persist in Frustrating Behaviors for Long Term Goals}

Scholars have recently proposed a personality construct known as Grit, which represents "perseverance and passion for longterm goals" (Duckworth et al., 2007). Gritty individuals have higher educational achievements, at work and in training, gritty professors promote better educational performance of their students, where cadets who show a high grit score are more 
likely to graduate in an elite military academy (Duckworth et al., 2007; Duckworth and Quinn, 2009; Eskreis-Winkler et al., 2014). Gritty workers outperform their colleagues because they invest more effort in their work, thus allowing people to persevere in tedious and frustrating behaviors (Duckworth et al., 2011). Another important construct protective toward frustrating behaviors is self-control, partially associated to Grit, but distinguished because it focuses on aligning actions and intentions for achieving one's targets. The importance of selfcontrol in the workplace has been documented in relation to $\mathrm{CWB}$, where this construct moderates the relationship with emotional labor. Moreover, individuals with high selfcontrol are capable of nullifying the effects of depersonalization, organizational misidentification, and passive CWBs (Hirschi and Gottfredson, 2000).

Regarding the relationship with job demands, motivational intensity theory, which is based on a model of how people regulate efforts, provides a natural platform for building predictions about how Grit affects job demands' perception (Brehm and Self, 1989). Based on this theory, people's work effort is the sum of the significance given to achievements and the environmental condition for reaching such goals (i.e., team structure, teamwork, etc.). The personal meaning given to success defines how much job demands people are willing to accept to reach their goals. A trait as Grit may affect the inclination to manage job demands toward burnout and its components (Path a) by making the attainment of goals appearing less difficult and stressful (Littman-Ovadia and Lavy, 2016). In contrast to self-control, Grit includes the notion that passion can influence the achievement of goals and also moderate the influence of job demands on perceived exhaustion. For example, a gritty employer might work for extended hours to complete an assignment because he/she feels passionate toward his/her work and does not feel stressed while doing it.

Apart from this evidence, research on Grit in the domain of the classic I/O outcomes is still in its preliminary phase, although some research on the effects of strong character (conceptually close to Grit) on counterproductive behaviors has recently been conducted (Engel, unpublished doctoral dissertation). Considering this premise, Grit seems to be a promising candidate as a moderator of the two relations of the health impairment process.

\section{HYPOTHESES}

As seen, CWBs are a likely manifestation of the psychological strain in reaction to job demands, such as interpersonal conflict, emotional demands, workload, role conflict, and role ambiguity (Spector and Fox, 2005; Barling et al., 2009). High levels of such job demands are found to be related to the occurrence of CWBs in several studies (Fox et al., 2001; Marcus and Schuler, 2004; Krischer et al., 2010; Grijalva and Newman, 2015). Research demonstrated that the relation between such stressors and CWB can be moderated by traits such as Honesty-Humility (Chirumbolo, 2015). On the other hand, if the role of job demands in determining CWB is clear, the stressor-emotion model conceptually bypasses the mediation of exhaustion as a manifestation of frustration that leads to CWB, and it is not exhaustive in explaining the moderators of this two-stage process. Indeed, exhausted employees have a higher inclination toward CWBs, whereas employees with higher self-control seem to be less sensitive to exhaustion (Marcus and Schuler, 2004). Moreover, Smoktunowicz et al. (2015) has recently shown that high job demands are indirectly related to high CWBs, with job burnout operating as a mediator. In their conclusion, the authors state that "Future research needs to clarify if the mediating effect of job burnout in the job demands-CWB relationship may be specific for certain components of burnout..." (p. 345). Certainly, several studies have identified exhaustion as a possible predictor (and mediator) of the emergence of CWB, but its role has never been tested in relation to this two-stage process.

This evidence suggests that the two-stage process of health impairment can be an explicative organizational behavior model for predicting $\mathrm{CWB}$, with exhaustion as a mediator and the personality dimensions of Grit and Honesty-Humility as potential moderators. Personality traits can affect the stressstrain relation in different ways, for instance influencing the reactivity of individuals toward stress perception, as suggested in the reactivity model (Bolger and Zuckerman, 1995). The emergence of CWB is related to the vulnerability model of interaction (Parkes, 1994), where personality is accountable for rendering the individual more or less vulnerable to the effects of stressful events. Recall that in the health impairment process, passion can affect the perception of effort; secondly Grit can also moderate the emergence of CWBs, due to its focus on self-control and the attention for long term goals. Regarding Honesty-Humility, literature has already shown this trait to be one of the strongest predictors and regulators of CWB (Lee et al., 2005a). Less is known instead on the possible interactions between Honesty-Humility and job demands in relation to exhaustion. Competing theories indicate that this relationship could have gone in either direction: it is possible that low Honesty-Humility individuals would be less likely to feel and take care of job demands, thus finding a charged workplace less distressing than high Honesty-Humility individuals; on the other hand, the Honesty-Humility trait is usually negatively related with exhaustion (Wiltshire et al., 2014).

We expect to find a full mediation between: job demands $\rightarrow$ exhaustion (H1a) $\rightarrow$ CWB (H1b), or a partial mediation considering a significant direct effect of job demands on CWB (H1c). We expect a negative moderation effect of HonestyHumility on the relation between exhaustion $\rightarrow$ CWB (H2b); if the model is based on a partial mediation, we expect another negative moderation between job demands $\rightarrow$ CWB (H2c), where for higher levels of exhaustion or of job demands, those high in Honesty-Humility should show lower levels of CWB. We will also explore a possible interaction of Honesty-Humility with job demands $\rightarrow$ exhaustion (H2a), considering that this relationship could have gone in either directions. Concerning Grit, we expect a negative moderation effect on the relation between job demands $\rightarrow$ exhaustion (H3a) or/and on exhaustion $\rightarrow$ CWB (H3b). Specifically, 
we hypothesize that gritty people's job demands will less likely lead to exhaustion, and that for these people also exhaustion will less likely lead to CWB. Moreover, if the model is based on partial mediation, we expect another negative moderation between job demands $\rightarrow$ CWB (H3c; Figure 2).

\section{MATERIALS AND METHODS}

A total of 208 employees operating in the private service sector filled and returned the questionnaire (response rate $80 \%)$. Their age ranges between 20 and 60 years with an average of 41 years $(S D=9.65)$. The majority of the sample has higher vocational training $(24 \%)$ or a high school degree (51\%). Most participants work as clerks (63\%), 4\% are company managers. Most participants (80\%) do not supervise staff; only five participants supervise more than five employees. This study was approved by the Ethical Review Committee at the University of Verona. The present sample belongs to a study designed with multiple research purposes.

\section{Instruments Job Demands}

Three specific job demands have been included in the questionnaire: role conflict, emotional demands and hassles. Role conflict has been assessed by using four items derived from the Ivancevich and Matteson (1980) role conflict scale. An example item is "I receive conflicting requests from two or more people" (from $1=$ never to $5=$ always). Emotional demands are based on a scale developed by Van Veldhoven and Meijman (1994) and include four items. An example is "Does your work put you in emotional situations?" (1 = never, 5 = always). Hassles scale (Bakker, 2014) has been used to detect them and it is composed of six items. Examples are: "I have to deal with administrative hassles"; "I have many hassles to go through to get projects/assignments done"; (1 = never, $5=$ always).

\section{Exhaustion}

Three exhaustion items of the Oldenburg Burnout Inventory (Demerouti and Bakker, 2008) have been used. Example items are "There are days when I feel tired before I arrive at work" and "After my work, I usually feel worn out and weary" ( $1=$ totally disagree, $4=$ totally agree).

\section{CWB}

Counterproductive work behavior has been assessed by using the CWB scale, i.e., a part of the Individual Work Performance Questionnaire (IWPQ), and we have considered the five CWB items (Koopmans et al., 2012). Example items are: "I spoke with colleagues about the negative aspects of my work" and "I spoke with people from outside the organization about the negative aspects of my work." Each item has been rated on a five-point rating scale $(0=$ never, $4=$ very often).

\section{Honesty-Humility}

Participants have completed the Italian version of the 10 -item scale for measuring the Honesty-Humility component of the HEXACO-PI-R (Ashton et al., 2006). "I wouldn't use flattery to get a raise or promotion at work, even if I thought it would succeed" and "I wouldn't pretend to like someone just to get that person to do favors for me." Each item has been rated on a five-point Likert scale ( $5=$ strongly agree; $1=$ strongly disagree).

\section{Grit}

The personality trait of Grit has been assessed by using the Short Grit Scale, an eight-item self-report questionnaire with established construct and predictive validity (Duckworth and Quinn, 2009). Participants have endorsed items by indicating consistency of passions "I have been obsessed with a certain idea or project for a short time but later lost interest" (reverse-scored) and consistency of effort "Setbacks don't discourage me," over time, by using a 5-point Likert-type scale $(5=$ very much like me, $1=$ not at all like me).

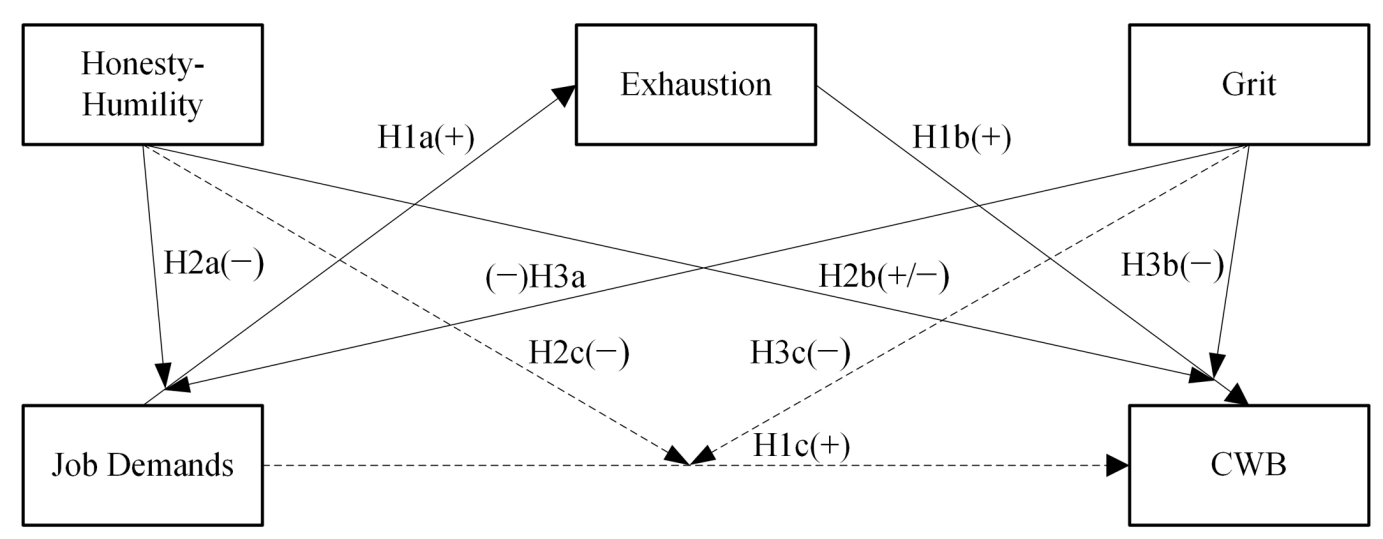

FIGURE 2 | Hypothesized model of the health impairment process on counterproductive work behavior (CWB) with personality traits as moderators. 


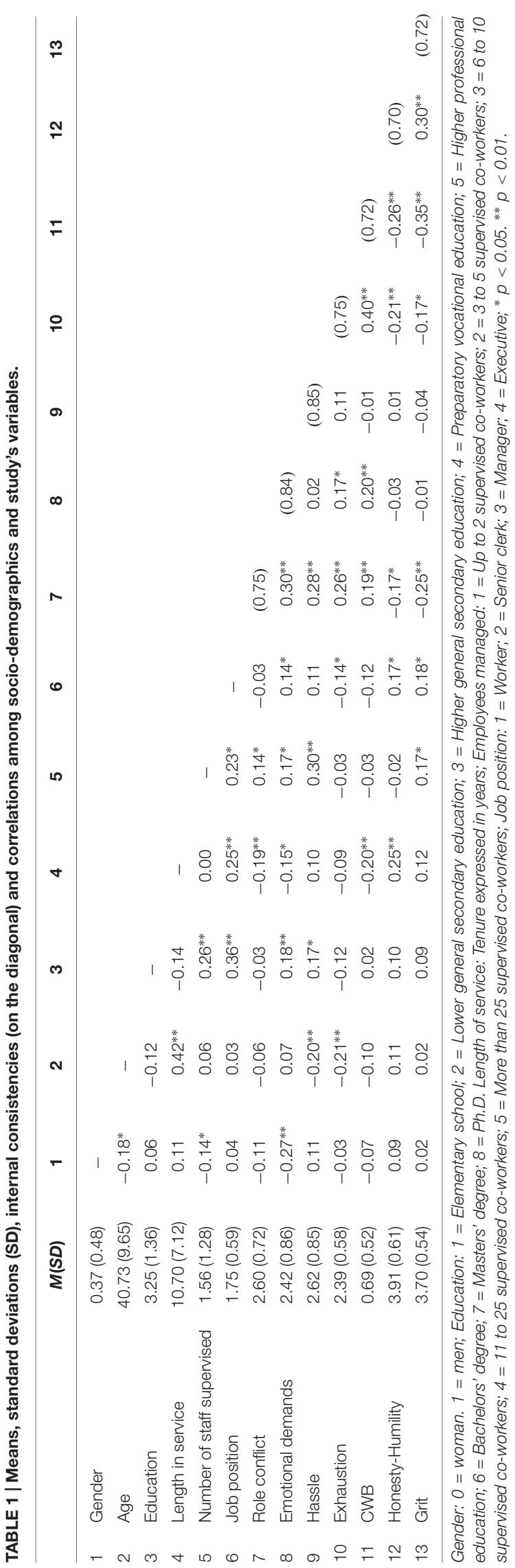

\section{RESULTS}

\section{Descriptive Statistics}

Table 1 shows the means, standard deviations, correlations, and the internal consistency indexes of the scales. All scales present acceptable reliability indexes. In relation to socio-demographic variables, Honesty-Humility shows positive correlations with length in service $(0.25, p<0.01)$ and Grit instead presents a positive correlation with the number of supervised staff (0.17, $p<0.05)$. A significant and positive correlation is found between most of the job demands measures, exhaustion and CWB, by partially confirming the first hypothesis ( $\mathrm{Hla}$; $\mathrm{H} 1 \mathrm{~b}$; H1c). Considering possible moderation effects, HonestyHumility and Grit showed negative correlations with all the constructs mentioned above. Honesty-Humility also shows a positive correlation with length in service, meanwhile Grit with the number of collaborators directed. Both traits are positively correlated between them and with the job role (Table 1).

\section{Hypotheses Testing}

Following the statistical procedure used by Fox et al. (2001) and suggested by Baron and Kenny (1986), we have tested the steps of the health impairment process on CWB (H1a; H1b; H1c). We have also tested the role of Grit and Honesty-Humility at each stage of the process. The single regressions analyses (Table 2) have revealed that the presence of exhaustion as a mediator substantially reduces the direct effect of the job demands on CWB, [job demands $\rightarrow$ CWB: $\beta=0.18, p<0.01$; job demands, (exhaustion) $\rightarrow$ CWB: $\beta=0.08, p>0.05]$. This invalidates the presence of a partial mediation model (H1c) whilst supporting a full mediation (H1a; H1b); it also makes the analyses of the traits' moderation effects on the job demands $\rightarrow$ CWB relationship not relevant to be conducted (H2c; $\mathrm{H} 3 \mathrm{c}$ ). Regarding the moderation effect of Honesty-Humility, results revealed a significant positive effect on the relation between job demands and exhaustion only (H2a), whereas Grit is a significant negative moderator of the relation between exhaustion and CWB ( $\mathrm{H} 3 \mathrm{~b})$.

We next tested the single regression effects found in a comprehensive model, which consists of a full mediation model of exhaustion on job demands-CWB, with the moderations of Honesty-Humility on Path a, and Grit on Path b. We mean-centered and used bootstrapping following the PROCESS procedure recommended by Hayes (2013). The results of these analyses revealed a significant indirect effect of exhaustion $95 \%$ CI $[0.196,0.474]$, that fully mediated the effect of job demands on CWB, as revealed by single regressions. Honesty-Humility significantly moderates the effects of job demands on exhaustion, $\mathrm{B}=0.16, p<0.05$. A simple slope analysis revealed that for lower Honesty-Humility scores, job demands have a stronger positive influence on exhaustion. Data were plotted and the graph (Figure 3) revealed that for higher levels of job demands this effect disappears. For Grit, results showed that for lower scores, exhaustion exerts a higher positive influence on $\mathrm{CWB}, \mathrm{B}=-0.18$, $p<0.05$. As for Honesty-Humility, a simple slope analysis was conducted and data were plotted (Figure 4). The graph showed that at higher levels of exhaustion the effect of Grit is particularly 
TABLE 2 | Regression analyses of moderation effects of Honesty-Humility on Path a, and of Grit on Path b.

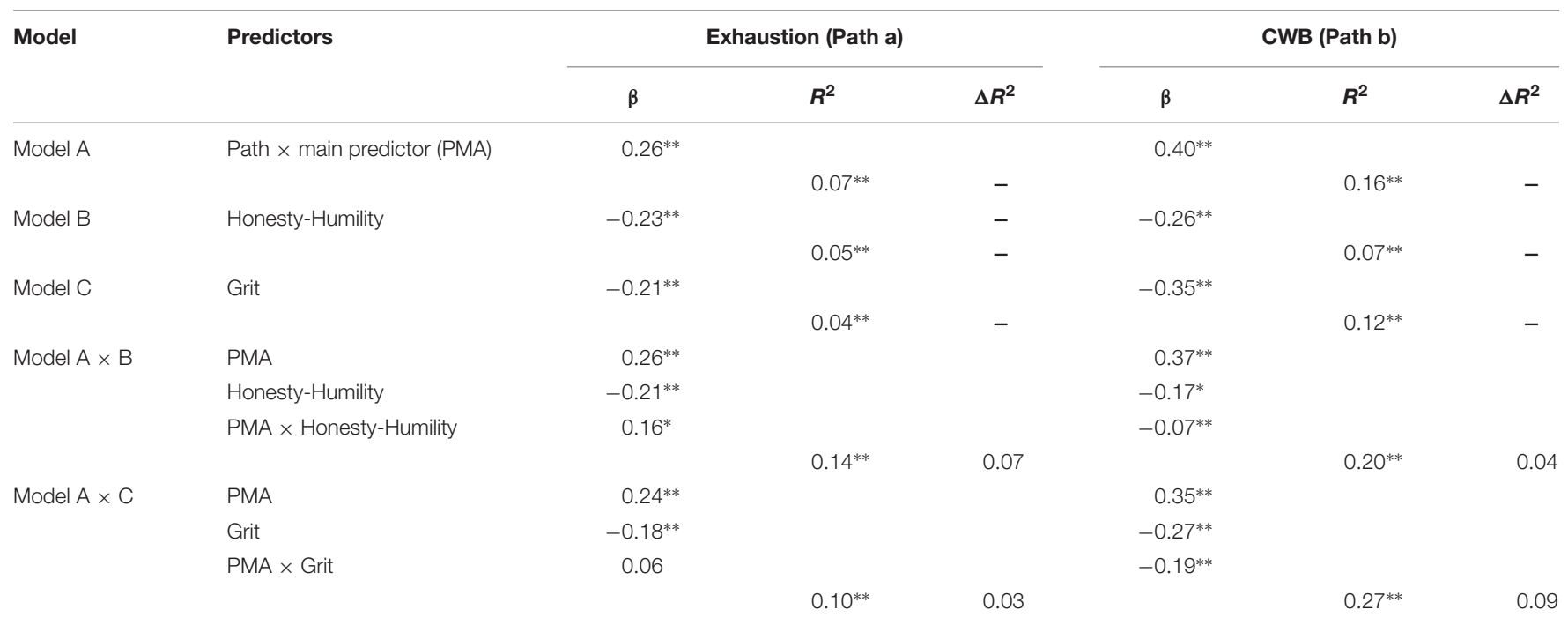

$N=208$. Path a main predictor $=$ Job demands; Path b main predictor $=$ Exhaustion; $R^{2}=$ Explanation rate; $\Delta R^{2}=$ Change in explanation rate in each step; ${ }^{*} p<0.05$. ${ }^{* *} p<0.01$.

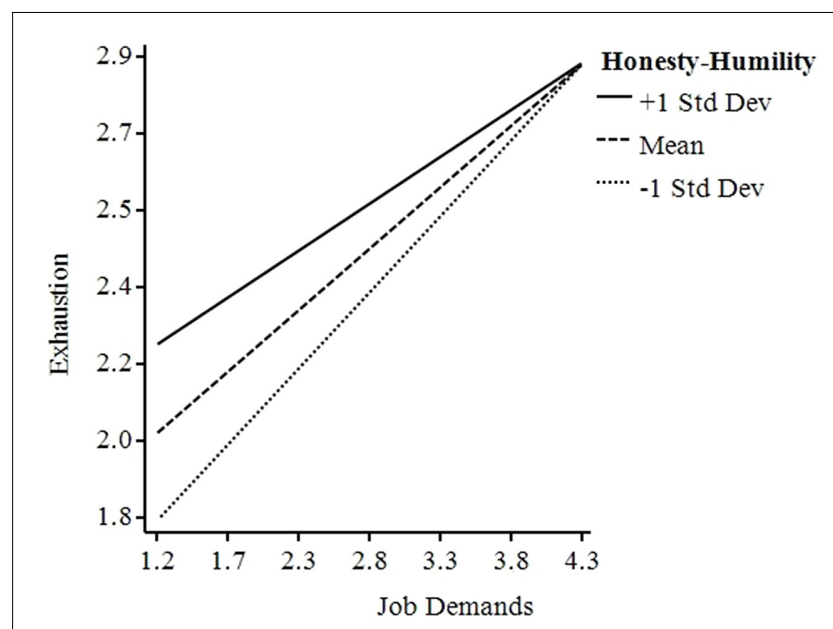

FIGURE 3 | Graphical representation of the moderation effects of Honesty-Humility on Path a.

relevant and robust, such that for those scoring low on Grit, exhaustion has a stronger influence on CWB.

The simple slope analyses revealed that the interactions of both personality traits were significant for all the levels of the moderators (+\-1SD), moreover the moderator effects follow an incremental pattern.

\section{DISCUSSION}

The current results contribute to the job stress literature by providing evidence for the potential applicability of the health impairment process outside the area of health research. The present study satisfies the need for clarification regarding the mediating effect of certain components of burnout (such as exhaustion) in the job demands-CWB relationship. Indeed, as suggested by Balducci et al. (2011), it seems likely that the health impairment process reflects an underlying mechanism of human functioning at work. Specifically, we have found that the health impairment process postulated by the JD-R model (Demerouti et al., 2001) also emerges in relation to CWB. Findings indicate that exhaustion mediates the job demands-CWB relationship. High levels of job demands are indirectly associated with higher CWB frequency, with an increase in exhaustion operating as mediator.

Spector and Fox (2005) suggested that CWB may be a reaction to frustration at work due by job demands, and proposed that frustrations are caused by environmental stressors. Considering this evidence and the recent work of Smoktunowicz et al. (2015), it is more plausible to consider the stressor-emotion model as a two-stage process, fairly associable with the health impairment. This is in line with Bolton et al. (2012), who have showed how exhausted employees could have a general higher propensity to engage in CWB.

These findings contribute to the knowledge on mediating mechanisms, explaining the associations between job demands and CWB. The mediating function of exhaustion can be attributed to the reduction of productive behaviors, so that employees may be more likely to use their working hours for other kinds of behaviors, such as CWB (Smoktunowicz et al., 2015). Concerning the moderating traits, we confirm that Honesty-Humility affects the stressor-strain relation by influencing the reactivity of individuals toward stress perception in relation to job demands, as suggested in the reactivity model (Bolger and Zuckerman, 1995). The emergence of $\mathrm{CWB}$ is instead more related to the vulnerability model of interaction of Parkes (1994), where the personality trait of Grit is accountable for rendering the 


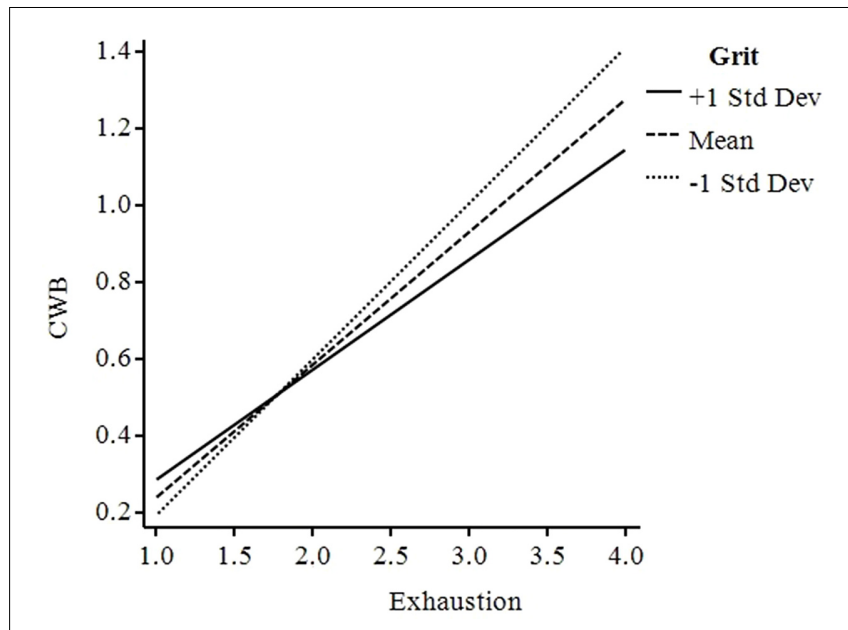

FIGURE 4 | Graphical representation of the moderation effects of Grit on Path b

individual less vulnerable to the effects of stressful events (Figure 5).

\section{The Moderation Effects of the Two Traits on the Health Impairment Process}

The moderations show that for higher Honesty-Humility scores, job demands have a stronger positive impact on exhaustion, while this effect vanishes for lower levels of Honesty-Humility. Individuals with low scores of Honesty-Humility would be less inclined to feel and take care of job demands, finding a charged work environment less distressing than the individuals with high Honesty-Humility scores. Lower levels of HonestyHumility are associated with egoistic and deceitful attitudes. Behaviorally speaking, a person with high Honesty-Humility cooperates with others even when one might take advantage of her/him (e.g., by giving too much workload). This disposition to help others is not present in people with low HonestyHumility. Therefore, they are less likely to experience exhaustion. Literature lacks studies that compare the impact of the HonestyHumility trait on job stress. In the study of Wiltshire et al. (2014), simple slope analyses revealed that the relation between the perceptions of organizational politics and job stress was more robust at lower levels of Honesty-Humility. It is conceivable that those low in Honesty-Humility would be less inclined to perceive the negative effects of organizational politics, for example by finding a politically charged work environment less unpleasant than those high in Honesty-Humility because of their greater disposition to use maneuvers to prosper in that workplace. Regarding the moderation between HonestyHumility and CWB, literature has widely shown this trait to be one of the strongest predictors and this strong relation could have hidden the indirect effect researched (Lee et al., 2005b).

Grit represents perseverance and passion for long-term goals and in this definition lies the sense about how Grit could moderate CWB, mainly because of its focus on developing self-control for long term aims (Duckworth et al., 2007). Grit and strength of character include a wide range of attributes: The specific strength impact on individuals' efficiency at work, mostly related with certain challenging professions (Lavy and Littman-Ovadia, 2016). Grit workers not only dedicate more stamina in a particular task at a given time, but they do it with permanent strength over the years for seeking their long-term goal (Duckworth et al., 2007). For this reason, the relevance accredited to the work domain by highly passionate workers is the capacity of "run a marathon" (Littman-Ovadia and Lavy, 2016) and to avoid CWB, which is the major expression of career short-sightedness.

Certainly, most of the research on Grit is longitudinal for this reason, and this is also the most important limitation of the current research. However, evidence from longitudinal studies in the work stress area clearly shows that organizational demands such as workload, role conflict, and hassles have causal consequence on outcomes such as exhaustion and, ultimately, CWB (Balducci et al., 2011; Smoktunowicz et al., 2015). For this reason, the direction of the relations examined is plausible. Nevertheless, longitudinal data is required for a solid proof of the results found, especially in relation to the Grit interaction effect on CWB. Future research should also consider a more representative sample of workers, considering also careers particularly exposed to exhaustion (Di Fabio, 2014; Di Fabio and Kenny, 2015).

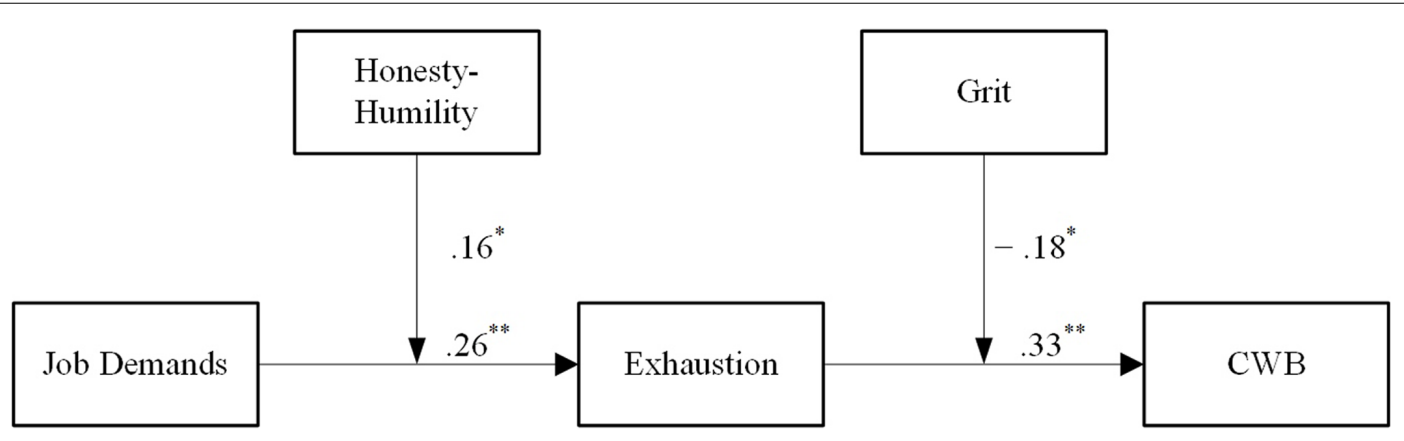

FIGURE 5 | Model of the health impairment process on CWB with personality traits as moderators. 
A direct practical implication of the current research is the interesting question whether organizations should hire honest and humble or gritty workers. While honesty and perseverance are traits that are probably universally considered to be positive qualities in people, our research suggests that at least Honesty-Humility can have negative consequences for workers' burnout. It should be noted, however, that HonestyHumility is positively correlated with length of service, such that people who are more honest also stay longer in their companies. Grit is also positively correlated with the number of supervised staff, which indicates that perseverance may be

\section{REFERENCES}

Ahola, K., and Hakanen, J. (2007). Job strain, burnout, and depressive symptoms: a prospective study among dentists. J. Affect. Disord. 104, 103-110. doi: 10.1016/ j.jad.2007.03.004

Ahola, K., Honkonen, T., Isometsä, E., Kalimo, R., Nykyri, E., Aromaa, A., et al. (2005). The relationship between job-related burnout and depressive disordersresults from the finnish health 2000 Study. J. Affect. Disord. 88, 55-62. doi: 10.1016/j.jad.2005.06.004

Ashton, M. C., and Lee, K. (2005). Honesty-Humility, the big five, and the fivefactor model. J. Pers. 73, 1321-1354. doi: 10.1111/j.1467-6494.2005.00351.x

Ashton, M. C., and Lee, K. (2008). The prediction of honesty-humility-related criteria by the HEXACO and five-factor models of personality. J. Res. Pers. 42, 1216-1228. doi: 10.1037/a0024165

Ashton, M. C., Lee, K., de Vries, R. E., Perugini, M., Gnisci, A., and Sergi, I. (2006). The HEXACO model of personality structure and indigenous lexical personality dimensions in Italian, Dutch, and English. J. Res. Pers. 40, 851-875. doi: 10.1016/j.jrp.2005.06.003

Ashton, M. C., Lee, K., and Goldberg, L. R. (2007). The IPIP-HEXACO scales: an alternative, public-domain measure of the personality constructs in the HEXACO model. Pers. Individ. Differ. 42, 1515-1526. doi: 10.1016/j.paid.2006. 10.027

Ashton, M. C., Lee, K., and Son, C. (2000). Honesty as the sixth factor of personality: correlations with Machiavellianism, primary psychopathy, and social adroitness. Eur. J. Pers. 14, 359-369. doi: 10.1002/1099-0984(200007/08) $14: 4 \$<359:: A I D-P E R 382 \$>\$ 3.0 . C O ; 2-Y$

Bakker, A. (2014). The Job Demands-Resources Questionnaire. Rotterdam: Erasmus University Press.

Bakker, A. B., Boyd, C. M., Dollard, M., Gillespie, N., Winefield, A. H., and Stough, C. (2010). The role of personality in the job demands-resources model: a study of Australian academic staff. Career Dev. Int. 15, 622-636. doi: 10.1108/ 13620431011094050

Bakker, A. B., and Demerouti, E. (2007). The job demands-resources model: state of the art. J. Manag. Psychol. 22, 309-328. doi: 10.1108/02683940710733115

Bakker, A. B., Demerouti, E., De Boer, E., and Schaufeli, W. B. (2003). Job demands and job resources as predictors of absence duration and frequency. J. Vocat. Behav. 62, 341-356. doi: 10.1016/S0001-8791(02)00030-1

Bakker, A. B., Demerouti, E., and Verbeke, W. (2004). Using the job demandsresources model to predict burnout and performance. Hum. Resour. Manage. 43, 83-104. doi: 10.1002/hrm.20004

Bakker, A. B., Van Emmerik, H., and Van Riet, P. (2008). How job demands, resources, and burnout predict objective performance: a constructive replication. Anxiety Stress Coping 21, 309-324. doi: 10.1080/10615800801958637

Balducci, C., Schaufeli, W. B., and Fraccaroli, F. (2011). The job demandsresources model and counterproductive work behaviour: the role of jobrelated affect. Eur. J. Work Organ. Psychol. 20, 467-496. doi: 10.1080/ 13594321003669061

Banks, G. C., Whelpley, C. E., Oh, I.-S., and Shin, K. (2012). (How) are emotionally exhausted employees harmful? Int. J. Stress Manag. 19, 198. doi: 10.1037/ a0029249 an important leadership component. Finally, both personality traits tend to co-occur (i.e., are positively correlated) and are related to workers' job role. This means that the combination of both traits might be particularly suitable for management positions.

\section{AUTHOR CONTRIBUTIONS}

All authors listed, have made substantial, direct and intellectual contribution to the work, and approved it for publication.

Barling, J., Dupré, K. E., and Kelloway, E. K. (2009). Predicting workplace aggression and violence. Annu. Rev. Psychol. 60, 671-692. doi: 10.1146/annurev. psych.60.110707.163629

Baron, R. M., and Kenny, D. A. (1986). The moderator-mediator variable distinction in social psychological research: conceptual, strategic, and statistical considerations. J. Pers. Soc. Psychol. 51, 1173. doi: 10.1037/0022-3514.51.6.1173

Bechtoldt, M. N., Welk, C., Zapf, D., and Hartig, J. (2007). Main and moderating effects of self-control, organizational justice, and emotional labour on counterproductive behaviour at work. Eur. J. Work Organ. Psychol. 16, 479-500. doi: 10.1080/13594320701662618

Bolger, N., and Zuckerman, A. (1995). A framework for studying personality in the stress process. J. Pers. Soc. Psychol. 69, 890. doi: 10.1037/0022-3514.69.5.890

Bolton, L. R., Harvey, R. D., Grawitch, M. J., and Barber, L. K. (2012). Counterproductive work behaviours in response to emotional exhaustion: a moderated mediational approach. Stress Health 28, 222-233. doi: 10.1002/smi. 1425

Brehm, J. W., and Self, E. A. (1989). The intensity of motivation. Annu. Rev. Psychol. 40, 109-131. doi: 10.1146/annurev.ps.40.020189.000545

Brotheridge, C. M., and Grandey, A. A. (2002). Emotional labor and burnout: comparing two perspectives of "people work". J. Vocat. Behav. 60, 17-39. doi: 10.1006/jvbe.2001.1815

Ceschi, A., Costantini, A., Scalco, A., Charkhabi, M., and Sartori, R. (2016). The relationship between the big five personality traits and job performance in business workers and employees' perception. Int. J. Bus. Res. 16, 63-76. doi: 10.18374/ijbr-16-2.5

Chirumbolo, A. (2015). The impact of job insecurity on counterproductive work behaviors: the moderating role of honesty-humility personality trait. J. Psychol. 149, 554-569. doi: 10.1080/00223980.2014.916250

Clement, S., and Bollinger, R. (2016). Perspectives on character virtue development. Res. Hum. Dev. 13, 174-181. doi: 10.1080/15427609.2016.1172445

Demerouti, E., and Bakker, A. B. (2008). The Oldenburg Burnout Inventory: A Good Alternative to Measure Burnout and Engagement. Handbook of Stress and Burnout in Health Care. Hauppauge, NY: Nova Science.

Demerouti, E., and Bakker, A. B. (2011). The job demands-resources model: challenges for future research. SA J. Ind. Psychol. 37, 01-09. doi: 10.1037/ a0019364

Demerouti, E., Bakker, A. B., Nachreiner, F., and Schaufeli, W. B. (2001). The job demands-resources model of burnout. J. Appl. Psychol. 86, 499. doi: 10.1037/ 0021-9010.86.3.499

Di Fabio, A. (2014). Intrapreneurial self-capital: a new construct for the 21st century. J. Employ. Couns. 51, 98-111. doi: 10.1002/j.2161-1920.2014.00045.x

Di Fabio, A., and Kenny, M. E. (2015). The contributions of emotional intelligence and social support for adaptive career progress among Italian youth. J. Career Dev. 42, 48-59. doi: 10.1177/0894845314533420

Dollard, M. F., and Bakker, A. B. (2010). Psychosocial safety climate as a precursor to conducive work environments, psychological health problems, and employee engagement. J. Occup. Organ. Psychol. 83, 579-599. doi: 10.1348/ 096317909X470690

Douglas, S. C., and Martinko, M. J. (2001). Exploring the role of individual differences in the prediction of workplace aggression. J. Appl. Psychol. 86, 547. doi: 10.1037/0021-9010.86.4.547 
Duckworth, A., and Gross, J. J. (2014). Self-control and grit related but separable determinants of success. Curr. Dir. Psychol. Sci. 23, 319-325. doi: 10.1177/ 0963721414541462

Duckworth, A. L., Kirby, T. A., Tsukayama, E., Berstein, H., and Ericsson, K. A. (2011). Deliberate practice spells success why grittier competitors triumph at the national spelling bee. Soc. Psychol. Personal. Sci. 2, 174-181. doi: 10.1177/ 1948550610385872

Duckworth, A. L., Peterson, C., Matthews, M. D., and Kelly, D. R. (2007). Grit: perseverance and passion for long-term goals. J. Pers. Soc. Psychol. 92, 1087. doi: 10.1037/0022-3514.92.6.1087

Duckworth, A. L., and Quinn, P. D. (2009). Development and validation of the short grit scale (GRIT-S). J. Pers. Assess. 91, 166-174. doi: 10.1080/ 00223890802634290

Eskreis-Winkler, L., Shulman, E. P., Beal, S. A., and Duckworth, A. L. (2014). The grit effect: predicting retention in the military, the workplace, school and marriage. Front. Psychol. 5:36. doi: 10.3389/fpsyg.2014. 00036

Fox, S., Spector, P. E., and Miles, D. (2001). Counterproductive work behavior (CWB) in response to job stressors and organizational justice: some mediator and moderator tests for autonomy and emotions. J. Vocat. Behav. 59, 291-309. doi: $10.1006 /$ jvbe. 2001.1803

Geurts, S. A., and Sonnentag, S. (2006). Recovery as an explanatory mechanism in the relation between acute stress reactions and chronic health impairment. Scand. J. Work Environ. Health 32, 482-492. doi: 10.5271/sj weh. 1053

Grijalva, E., and Newman, D. A. (2015). Narcissism and counterproductive work behavior (CWB): meta-analysis and consideration of collectivist culture, big five personality, and narcissism's facet structure. Appl. Psychol. 64, 93-126. doi: 10.1111/apps.12025

Gruys, M. L., and Sackett, P. R. (2003). Investigating the dimensionality of counterproductive work behavior. Int. J. Sel. Assess. 11, 30-42. doi: 10.1111/ 1468-2389.00224

Hakanen, J. J., Schaufeli, W. B., and Ahola, K. (2008). The job demandsresources model: a three-year cross-lagged study of burnout, depression, commitment, and work engagement. Work Stress 22, 224-241. doi: 10.1080/ 02678370802379432

Hayes, A. F. (2013). Introduction to Mediation, Moderation, and Conditional Process Analysis: A Regression-Based Approach. New York, NY: Guilford Press.

Hershcovis, M. S., Turner, N., Barling, J., Arnold, K. A., Dupré, K. E., Inness, M., et al. (2007). Predicting workplace aggression: a meta-analysis. J. Appl. Psychol. 92, 228. doi: 10.1037/0021-9010.92.1.228

Hirschi, T., and Gottfredson, M. R. (2000). In defense of self-control. Theor. Criminol. 4, 55-69. doi: 10.1177/1362480600004001003

Idris, M. A., Dollard, M. F., Coward, J., and Dormann, C. (2012). Psychosocial safety climate: conceptual distinctiveness and effect on job demands and worker psychological health. Saf. Sci. 50, 19-28. doi: 10.1016/j.ssci.2011.06.005

Ivancevich, J. M., and Matteson, M. T. (1980). Stress and Work: A Managerial Perspective. Glenview, IL: Scott Foresman.

Karasek, R. (1998). Demand/control model: a social, emotional, and physiological approach to stress risk and active behaviour development. Encycl. Occup. health Saf. 2, 34.6-34.14.

Koopmans, L., Bernaards, C., Hildebrandt, V., van Buuren, S., van der Beek, A. J., and de Vet, H. C. (2012). Development of an individual work performance questionnaire. Int. J. Product. Perform. Manage. 62, 6-28. doi: 10.1108/ 17410401311285273

Krischer, M. M., Penney, L. M., and Hunter, E. M. (2010). Can counterproductive work behaviors be productive? CWB as emotion-focused coping. J. Occup. Health Psychol. 15, 154. doi: 10.1037/a0018349

Lavy, S., and Littman-Ovadia, H. (2016). My better self using strengths at work and work productivity, organizational citizenship behavior, and satisfaction. J. Career Dev. doi: 10.1177/0894845316634056

Lee, K., and Ashton, M. C. (2006). Further assessment of the HEXACO personality inventory: two new facet scales and an observer report form. Psychol. Assess. 18, 182. doi: 10.1037/1040-3590.18.2.182

Lee, K., Ashton, M. C., and de Vries, R. E. (2005a). Predicting workplace delinquency and integrity with the HEXACO and fivefactor models of personality structure. Hum. Perform. 18, 179-197. doi: 10.1207/s15327043hup1802_4
Lee, K., Ashton, M. C., and Shin, K. H. (2005b). Personality correlates of workplace anti-social behavior. Appl. Psychol. 54, 81-98. doi: 10.1111/j.1464-0597.2005. 00197.x

Little, L. M., Simmons, B. L., and Nelson, D. L. (2007). Health among leaders: positive and negative affect, engagement and burnout, forgiveness and revenge. J. Manage. Stud. 44, 243-260. doi: 10.1111/j.1467-6486.2007.00687.x

Littman-Ovadia, H., and Lavy, S. (2016). Going the extra mile perseverance as a key character strength at work. J. Career Assess. 24, 240-252. doi: 10.1177/ 1069072715580322

Marcus, B., Lee, K., and Ashton, M. C. (2007). Personality dimensions explaining relationships between integrity tests and counterproductive behavior: big five, or one in addition? Pers. Psychol. 60, 1-34. doi: 10.1111/j.1744-6570.2007. 00063.x

Marcus, B., and Schuler, H. (2004). Antecedents of counterproductive behavior at work: a general perspective. J. Appl. Psychol. 89, 647. doi: 10.1037/0021-9010. 89.4.647

Nahrgang, J. D., Morgeson, F. P., and Hofmann, D. A. (2011). Safety at work: a meta-analytic investigation of the link between job demands, job resources, burnout, engagement, and safety outcomes. J. Appl. Psychol. 96, 71. doi: 10.1037/ a0021484

O'Boyle, E. H. Jr., Forsyth, D. R., Banks, G. C., and McDaniel, M. A. (2012). A meta-analysis of the dark triad and work behavior: a social exchange perspective. J. Appl. Psychol. 97, 557. doi: 10.1037/a00 25679

Parkes, K. R. (1994). Personality and coping as moderators of work stress processes: models, methods and measures. Work Stress 8, 110-129. doi: 10.1080/ 02678379408259984

Penney, L. M., and Spector, P. E. (2002). Narcissism and counterproductive work behavior: do bigger egos mean bigger problems? Int. J. Sel. Assess. 10, 126-134. doi: 10.1111/1468-2389.00199

Penney, L. M., and Spector, P. E. (2005). Job stress, incivility, and counterproductive work behavior (CWB): the moderating role of negative affectivity. J. Organ. Behav. 26, 777-796. doi: 10.1002/job.336

Piko, B. F. (2006). Burnout, role conflict, job satisfaction and psychosocial health among Hungarian health care staff: a questionnaire survey. Int. J. Nurs. Stud. 43, 311-318. doi: 10.1016/j.ijnurstu.2005.05.003

Sartori, R., Ceschi, A., Costantini, A., and Scalco, A. (2015). Big Five for work and organizations: FLORA (role related personal profile), an Italian personality test based on the Five-Factor Model and developed for the assessment of candidates and employees. Qual. Quant. 50, 1-17. doi: 10.1007/s11135-0150250-9

Sartori, R., Costantini, A., Ceschi, A., and Scalco, A. (2016). Not only correlations: a different approach for investigating the relationship between the Big Five personality traits and job performance based on workers and employees' perception. Qual. Quant. 1-13. doi: 10.1007/s11135-0160406-2

Schaufeli, W. B., Bakker, A. B., and Van Rhenen, W. (2009). How changes in job demands and resources predict burnout, work engagement, and sickness absenteeism. J. Organ. Behav. 30, 893-917. doi: 10.1002/ job.595

Schaufeli, W. B., and Taris, T. W. (2014). A Critical Review of the Job Demands-Resources Model: Implications for Improving Work and Health Bridging Occupational, Organizational and Public Health. Berlin: Springer, 43-68.

Smoktunowicz, E., Baka, L., Cieslak, R., Nichols, C. F., Benight, C. C., and Luszczynska, A. (2015). Explaining counterproductive work behaviors among police officers: the indirect effects of job demands are mediated by job burnout and moderated by job control and social support. Hum. Perform. 28, 332-350. doi: 10.1080/08959285.2015.102 1045

Spector, P. E., and Fox, S. (2005). "The stressor-emotion model of counterproductive work behavior," in Counterproductive Work Behavior: Investigations of Actors and Targets, eds S. Fox and P. E. Spector (Washington, DC: American Psychological Association), 151-174.

Toppinen-Tanner, S., Ahola, K., Koskinen, A., and Väänänen, A. (2009). Burnout predicts hospitalization for mental and cardiovascular disorders: 10-year prospective results from industrial sector. Stress Health 25, 287-296. doi: 10. $1002 /$ smi. 1282 
Umehara, K., Ohya, Y., Kawakami, N., Tsutsumi, A., and Fujimura, M. (2007). Association of work-related factors with psychosocial job stressors and psychosomatic symptoms among Japanese pediatricians. J. Occup. Health 49, 467-481. doi: 10.1539/joh.49.467

Van Veldhoven, M., and Meijman, T. (1994). Measuring Psychosocial Workload by Means of a Questionnaire: Questionnaire on the Experience and Evaluation of Work VBBA. Amsterdam: NIA.

Wiltshire, J., Bourdage, J. S., and Lee, K. (2014). Honesty-humility and perceptions of organizational politics in predicting workplace outcomes. J. Bus. Psychol. 29, 235-251. doi: 10.1007/s10869-013-9310-0

Xanthopoulou, D., Bakker, A. B., Demerouti, E., and Schaufeli, W. B. (2007). The role of personal resources in the job demands-resources model. Int. J. Stress Manage. 14, 121. doi: 10.1037/1072-5245.14.2.121
Zettler, I., and Hilbig, B. E. (2010). Honesty-humility and a person-situation interaction at work. Eur. J. Pers. 24, 569-582.

Conflict of Interest Statement: The authors declare that the research was conducted in the absence of any commercial or financial relationships that could be construed as a potential conflict of interest.

Copyright (C) 2016 Ceschi, Sartori, Dickert and Costantini. This is an open-access article distributed under the terms of the Creative Commons Attribution License (CC BY). The use, distribution or reproduction in other forums is permitted, provided the original author(s) or licensor are credited and that the original publication in this journal is cited, in accordance with accepted academic practice. No use, distribution or reproduction is permitted which does not comply with these terms. 
OPEN ACCESS

Edited by:

Pablo Fernández-Berrocal, University of Málaga, Spain

Reviewed by:

Riccardo Sartori,

University of Verona, Italy Harsha Perera,

University of New South Wales,

Australia

*Correspondence.

Annamaria Di Fabio

adifabio@psico.unifi.it

Specialty section:

This article was submitted to

Organizational Psychology,

a section of the journal

Frontiers in Psychology

Received: 25 May 2016

Accepted: 25 July 2016

Published: 17 August 2016

Citation:

Di Fabio A and Kenny ME (2016) Promoting Well-Being:

The Contribution of Emotional

Intelligence. Front. Psychol. 7:1182.

doi: 10.3389/fpsyg.2016.01182

\section{Promoting Well-Being: The Contribution of Emotional Intelligence}

\author{
Annamaria Di Fabio ${ }^{1 *}$ and Maureen E. Kenny ${ }^{2}$ \\ ${ }^{1}$ Department of Psychology, University of Florence, Florence, Italy, ${ }^{2}$ Lynch School of Education, Boston College, Boston, \\ MA, USA
}

Adopting a primary prevention perspective, this study examines competencies with the potential to enhance well-being and performance among future workers. More specifically, the contributions of ability-based and trait models of emotional intelligence (El), assessed through well-established measures, to indices of hedonic and eudaimonic well-being were examined for a sample of 157 Italian high school students. The Mayer-Salovey-Caruso Emotional Intelligence Test was used to assess ability-based El, the Bar-On Emotional Intelligence Inventory and the Trait Emotional Intelligence Questionnaire were used to assess trait El, the Positive and Negative Affect Scale and the Satisfaction With Life Scale were used to assess hedonic well-being, and the Meaningful Life Measure was used to assess eudaimonic well-being. The results highlight the contributions of trait El in explaining both hedonic and eudaimonic well-being, after controlling for the effects of fluid intelligence and personality traits. Implications for further research and intervention regarding future workers are discussed.

Keywords: ability based emotional intelligence, trait emotional intelligence, hedonic well-being, eudaimonic wellbeing, primary prevention perspective, health promotion, healthy business, healthy organization

\section{INTRODUCTION}

As a construct of long-standing interest in the field of psychology, well-being deserves additional attention for its primary prevention potential for fostering health and performance in the workplace (Zelenski et al., 2008; Heuvel et al., 2010). While mental health professionals focus on restoring a state of well-being to workers who suffer from psychological distress, primary prevention and health promotion professionals seek to promote well-being and enhance factors that protect individuals from the negative effects of psychological risk (Hage et al., 2007). Interest in study of health promotion and well-being is expanding as numerous social, economic, biological, psychological and cultural factors pose threats to the attainment of well-being. In Italy, for example, young people as future workers are growing up in an era of rapid social change, job instability, and high unemployment. Economic insecurity, unstable and shifting work opportunities, and the subsequent increase in the number of people living in poverty pose risks to well-being for many youth and young adults (Masten, 2014; Di Fabio and Bucci, 2016; Di Fabio and Palazzeschi, 2016). While psychologists recognize the importance of systemic change to remedy these social and economic problems, they are also interested in identifying individual factors that foster well-being among future workers and can serve as assets that protect individuals from psychological harm and ultimately foster well-being and performance in the workplace (DeNeve and Cooper, 1998; Friedman and Kern, 2014; Gori et al., 2015). 
Researchers (Antonovsky, 1987a; Seligman and Csikszentmihalyi, 2000) in the field of positive psychology recognize that optimal human functioning requires more than the absence of risk or pathology and have been seeking to identify factors that contribute to the development of hedonic and eudaimonic well-being (Ryan and Deci, 2001; Ryff and Singer, 2008; Waterman et al., 2010). Hedonic well-being entails the realization of happiness, pleasure attainment and pain avoidance, while eudaimonic well-being refers to the fulfillment or actualization of one's full potential (Ryan and Deci, 2001). Hedonic well-being has been defined in research as subjective well-being (SWB) (Kahneman et al., 1999), operationalized as the prevalence of positive affect (PA) over negative affect (NA). In addition to these affective dimensions of SWB, life satisfaction is often considered a cognitive component of SWB (Pavot and Diener, 1993; Diener et al., 1999), although there is some debate about whether a precise definition of SWB should be restricted to affective indicators (Diener et al., 1999; Deci and Ryan, 2008). Lent (2004), however, suggests that life satisfaction entails both affective and cognitive dimensions, which has been supported by research (e.g., Arrindell et al., 1991; Lucas et al., 1996; Keyes et al., 2002) documenting moderate to strong relationships between positive-negative affect and life satisfaction. Research by Keyes et al. (2002) supports the conceptualization of PWB psychological well-being and SWB as conceptually distinct constructs and the inclusion of life satisfaction as a dimension of SWB, despite some overlap across several indicators of SWB and PWB.

Eudaimonic well-being, referred to in research as both PWB (Ryff and Singer, 2008) and EWB - eudaimonic well-being (Waterman et al., 2010), emphasizes personal growth, mastery, life purpose and meaning (Ryff and Singer, 2008). Although a sense of SWB often accompanies PWB, pleasureful activities are considered insufficient to nurture and sustain PWB in the long-term (Ryan and Deci, 2001). PWB thus goes beyond the attainment of SWB (Ryff and Singer, 2008) and is derived from a sense of fulfillment, meaning, and self-realization. Research has found PWB to be broadly associated with indices of physical and mental health (Deci and Ryan, 2000) and is recognizably relevant to prevention, health promotion, and vocational psychology for its attention to selecting life goals and activities that are congruent with the true self and with deeply held values. To the extent that work is a source of identity, meaning, and personal connection (Blustein, 2006), work uncertainty and instability threaten both SWB and PWB.

Emotional intelligence (EI) has gained attention as a focus of research and intervention for its promise as a set of skills that can be taught to enhance coping resources and promote well-being (Schutte et al., 2007; Martins et al., 2010; Sánchez-Álvarez et al., 2015, 2016; Fernández-Berrocal, 2016). The connection between EI and a range of positive outcomes across the academic, social, psychological and career domains among adolescents has been well-documented (Di Fabio et al., 2014; Perera and DiGiacomo, 2015). Research has also found EI to be associated with a variety of individual and social resources, such as resilience, positive self-evaluation, and social support (Di Fabio and Kenny, 2012a; Di Fabio and Saklofske, 2014b; Perera and DiGiacomo,
2015). With regard to intervention, Di Fabio and Kenny (2011) found that a 10-h school-based intervention was effective in increasing EI and reducing career indecision among Italian high school students. Research with young adults in Belgium also demonstrated that EI can be increased with training, with EI gains sustained over a 6 months period (Nelis et al., 2009). Subsequent research applying the same EI intervention with Belgian university students revealed that intervention gains in EI led to positive changes in personality characteristics (increased agreeableness and extraversion and decreased neuroticism) assessed 6 months following intervention. Gains in psychological well-being, subjective health, quality of social relationships, and employability as reported by a prospective employer were also demonstrated at completion of the intervention in comparison with students receiving a different intervention or no intervention (Nelis et al., 2011).

A significant association between EI and well-being is supported by conceptual models that explain the possible causal mechanisms through which EI might influence well-being and by existing research that document some of those relationships. In a review of existing literature pertaining to EI, health, and well-being, Zeidner et al. (2012) suggest that EI influences SWB by fostering adaptive methods of coping with social challenges, social stress and interpersonal conflicts; promoting the development of supportive social networks; decreasing negative and increasing positive emotions; and enhancing emotional regulation. EI is also conceptually related to the PWB focus on personal growth and self-actualization (Zeidner et al., 2012). Skills in interpersonal (social) and intrapersonal (emotional awareness and internal self-regulation) EI should contribute to positive relationships with others and the capacity for mastery over one's environment that allow for personal growth, a sense of meaning in life, and self-actualization (Zeidner and Olnick-Shemesh, 2010; Friedman and Kern, 2014). These conceptualizations of the pathways between EI and well-being are supported by studies documenting relationships between EI and social support (e.g., Di Fabio and Kenny, 2012a; Perera and DiGiacomo, 2015) and between EI and coping efficiency, stress reduction and emotional regulation (Mikolajczak et al., 2008, 2009).

Emotional intelligence has been conceptualized and assessed according to several different models and numerous measures, which has contributed to some controversy and complexity in the literature. Stough et al. (2009) identify the two primary approaches to defining and measuring EI as ability-based (Mayer and Salovey, 1997) and trait-based self-report (BarOn, 1997; Petrides and Furnham, 2000, 2001). The abilitybased model conceptualizes EI as a set of skills best assessed by performance-based problem-solving measures (Austin and Saklofske, 2014). The Mayer-Salovey-Caruso Intelligence Scale (MSCEIT; Mayer et al., 2002) is a frequently utilized performance measure of ability-based EI that assesses skills in the perception, understanding and management of emotions and the integration of emotion and cognition to enhance problem solving.

The trait model views EI as an emotion and personality-related disposition that is best assessed by self-report questionnaires. A number of trait-based self-report EI measures are available, 
with the Bar-On Emotional Quotient Inventory (EQ-i; Bar-On, 1997) and the Trait Emotional Intelligence Scale (TeiQue Petrides and Furnham, 2000, 2001) being among the most common. The Bar-On model is sometimes referred to as a "mixed-model" that includes self-reports of social-emotional personality dimensions and self-competencies (Bar-On, 1997), such as adaptability, stress-management, intrapersonal, and interpersonal awareness. The TEIQue focuses on selfperceptions of social-emotional personality factors, such as self-control, emotionality, and sociability. The TEIQue includes a dispositional measure of well-being entailing self-esteem, trait happiness, and trait optimism and the Bar-On includes an assessment of general mood that overlap with dispositional measures of personality and have some overlap with, but are not identical with state measures of affect or well-being (Mikolajczak et al., 2009). Moderate correlations have been found among various trait EI measures (Brackett and Mayer, 2003), suggesting that they overlap but are not identical (Freudenthaler et al., 2008).

Debate has focused on the extent to which EI is best understood and assessed as a set of emotion-focused abilities or as a blend of personality traits and social and emotional abilities (Zeidner et al., 2012). Ability-based and self-report trait measures of EI have been found to be generally uncorrelated, with overlap emerging only across subscales or dimensions of ability-based and trait-based measures that relate to similar affective content (Brackett and Mayer, 2003; Parker et al., 2011). For example with regard to overlap, persons who rate themselves positively on intrapersonal EI as assessed by traitbased measures also performed well in identifying and describing their own feelings and were knowledgeable about the influences of specific moods and emotions on reasoning and behavior as assessed through ability-based measure (Parker et al., 2011). The lack of overlap between trait and ability measures has been understood as a function of method variance related to different assessment methods (self-report vs. performance) and as a function of different individual difference domains (intelligence vs. personality) (Parker et al., 2011). Although both ability-based and trait EI constructs have some association with measures of personality and fluid intelligence, ability-based models assessed by performance measures have been found to overlap more with fluid intelligence, and trait models assessed by self-report measures overlap more with personality measures (Di Fabio and Palazzeschi, 2009). With regard to method variance, it is possible that the trait models of EI correlate with selfreports of personality because both measures assess positive self-perceptions (Zeidner et al., 2012). Although some scholars view the limited overlap between trait and ability measures as an indication of incompatibility of the two approaches (Mayer et al., 2008), other scholars argue that the two approaches focus on unique and complementary dimensions of EI (Austin et al., 2008; Mikolajczak et al., 2008; Parker et al., 2011).

To analyze the validity of EI as a construct distinct from personality and intelligence, programmatic research has assessed the contributions of both ability-based EI as assessed through the MSCEIT and trait models of EI assessed through the EQi and TeiQue to a variety of academic, social and career outcomes, controlling for the effects of fluid intelligence and personality. For example, both ability-based and trait measures explain academic grade point for high school and college students beyond the effects of fluid intelligence and personality, with ability-based measures explaining a greater share of the variance than selfreport trait measures (Di Fabio and Palazzeschi, 2009). Perceived social support was also related, aside from the influences of fluid intelligence and personality, with both ability-based and trait EI, although trait EI was the more robust predictor for this outcome (Di Fabio and Kenny, 2012a). Studies of career decisionmaking also found both ability-based and trait EI to be significant predictors, but that trait EI was more robust than abilitybased EI in explaining varied dimensions of decision-making (Di Fabio and Kenny, 2012b; Di Fabio and Saklofske, 2014a). Because both trait and ability-based EI explain academic, social, and career outcomes beyond the contributions of personality, evidence suggests that EI is distinct from the major dimensions of personality. Moreover, overall findings suggest that when dependent variables are self-reported, trait EI is the stronger predictor (Di Fabio and Kenny, 2012b; Di Fabio and Saklofske, 2014b), and that when the dependent variables are performance measures, ability-based EI explains more variance than selfreport (Di Fabio and Palazzeschi, 2009). As mentioned above, the latter findings may be attributed to method variance as well as conceptual distinctions in EI as a personality construct and type of intelligence (Parker et al., 2011).

An emerging body of research has begun to examine relationships between EI and indices of hedonic well-being and eudaimonic well-being. The limited literature reveals some consistencies, but is also complicated by the use of varied measures of EI and well-being among different population samples. With regard to the relationships between self-reported trait EI and hedonic well-being, for example, research has consistently identified significant and positive relationships across studies of university students in Spain and community samples in Australia (Palmer et al., 2002; Extremera and Fernández-Berrocal, 2005; Gannon and Ranzijn, 2005; Gignac, 2006; Gallagher and Vella-Brodrick, 2008). Among high school students in Italy, Di Fabio and Saklofske (2014b) found that hedonic well-being was associated with trait measures of EI, but not with ability-based measures. Studies of trait EI and eudaimonic well-being are limited, but reveal positive findings. For example, an association between self-report measures of EI and eudaimonic well-being has been documented among professional employees in India (Raina and Bakhshi, 2013). Tennant et al. (2007) developed a new measure of EI, including items reflecting both eudemonic and hedonic domains, that was correlated with self-report measures of EI among university students in the United Kingdom. Perera and DiGiacomo (2015) found that trait EI was related to well-being, as measured by the Tennant et al. (2007) instrument. Evidence was found for a direct relationship and an indirect relationship mediated through perceived social support and engagement coping.

Findings for ability-based EI are more limited and reveal inconsistencies. Whereas Di Fabio and Saklofske (2014b) found no significant association between hedonic well- being and ability-based EI as assessed by the MSCEIT among Italian high 
schools students, Burrus et al. (2012) found a robust association between ability-based EI and hedonic and eudaimonic well-being for a US. sample of college and university students. Burrus et al. (2012) used a newly developed performance measure of emotional management, the Situational Judgment Test of Emotion Management (STEM; MacCann and Roberts, 2008), for assessing ability-based EI. The STEM presents participants with brief scenarios describing emotional situations that could potentially elicit negative emotions and asks participants to choose which of four options offered would be the best approach for managing the given situation. In a study of Spanish university students, Extremera et al. (2011) found that ability-based EI as assessed with the well-established MSCEIT measure was related with concurrent levels of both hedonic and eudaimonic wellbeing and with gains over a 12-week time period for both wellbeing constructs. Moreover, the gains in well-being explained by ability-based EI were greater for eudaimonic than for hedonic well-being. Inconsistencies in existing research are difficult to assess given the variations in measures of EI used across varied samples. As noted by Zeidner et al. (2012) in their research review, a systematic and fine grained approach to measurement of both criterion and predictor variables may be helpful in offering clarification for the field and providing a research base for preventive intervention.

The current study was designed to replicate and clarify understanding of the associations between EI and eudaimonic and hedonic well-being among young people preparing for work and further education, to inform the knowledge base for developing appropriate competencies for healthy personal and work lives (Di Fabio and Saklofske, 2014b; Di Fabio and Kenny, 2015). This study parallels prior research that examines the distinct contribution of EI by controlling for both fluid intelligence and personality (e.g., Di Fabio and Palazzeschi, 2009; Extremera et al., 2011; Di Fabio and Saklofske, 2014a). Controlling for personality, for example, is desirable as a method for accounting for the overlap between trait measures of EI and self-reports of personality (Zeidner et al., 2012). This study adds systematically and specifically to the limited existing research on hedonic and eudaimonic well-being by assessing for a single sample the relative contribution of ability-based EI and two models of trait EI, in explaining two types of wellbeing. The findings extend current research by using two wellestablished measures of self-report trait EI and a well-established performance measure of ability-based EI in explaining hedonic and eudaimonic well-being for students attending Italian high schools. Based upon theoretical conceptualization and the significant findings observed in prior research assessing selfreported trait and ability models of EI, we hypothesized that:

H1. Ability-based EI (Mayer et al., 2002) and trait EI based on both the Bar-On (1997) and the Petrides and Furnham $(2000,2001)$ and models will explain a significant percentage of incremental variance beyond the variance explained by fluid intelligence and personality traits in relation to hedonic well-being (PA, NA and life satisfaction).

H2. Ability-based EI (Mayer et al., 2002) and trait EI based on both the Bar-On (1997) and the Petrides and Furnham
(2000, 2001) models will explain a significant percentage of incremental variance beyond the variance explained by fluid intelligence and personality traits in relation to eudaimonic well-being (meaningfulness).

\section{MATERIALS AND METHODS}

\section{Participants}

One hundred and fifty seven high school students, 46 males (29.30\%) and 111 females (70.70\%), attending their last year of high school in Tuscany participated in the study. Participants were mostly White and from middle-class families and ranged from 17 to 21 years of age $(M=18.31 ; S D=0.54)$. Participants were recruited in a school system located in the province of Florence with different addresses: classical (12.7\%), linguistic (38.2\%), scientific (33.1\%), psycho-socio-pedagogic (16.9\%).

\section{Measures}

\section{Advanced Progressive Matrices (APM)}

To assess fluid intelligence, the APM test (Raven, 1962) in the Italian version (Di Fabio and Clarotti, 2007) was administered. The test has two series of items: Series I composed of 12 items and Series II composed of 36 items. Participants are asked to choose one correct response from eight possible options for each item. The Cronbach's alpha as reported by Di Fabio and Clarotti (2007) was 0.91 , and the alpha for the current study was 0.90 .

\section{Big Five Questionnaire (BFQ)}

To assess personality traits, the (Caprara et al., 1993) was administered. The questionnaire has 132 items assessing five personality dimensions, with response options on a 5-point Likert scale format, from $1=$ Absolutely false to $5=$ Absolutely true. Reliability of the questionnaire scales was examined by using Cronbach's alpha coefficient that ranged from a value of 0.73 for Agreeableness to 0.90 for Emotional Stability. The Cronbach's alpha coefficients are: 0.81 for Extraversion, 0.73 for Agreeableness, 0.81 for Conscientiousness, 0.90 for Emotional Stability, and 0.75 for Openness.

\section{Mayer-Salovey-Caruso Emotional Intelligence Test (MSCEIT)}

To assess ability-based EI, the Mayer Salovey Caruso Emotional Intelligence Test (Mayer et al., 2002) in the Italian version (D'Amico and Curci, 2010) was administered. The measure has 141 items and provides a total score and four subscale scores: Perceiving Emotions (PE), Facilitating Thought (FT), Understanding Emotions (UE), and Managing Emotions (ME). The total score was used in the current study. Split half reliabilities for subscales reported by D'Amico and Curci (2010) are: 0.72 for ME, 0.75 for UE, 0.77 for FT, 0.90 for PE (D'Amico and Curci, 2010). The split half reliability for the total score for the current sample was 0.83 .

\section{Bar-On Emotional Intelligence Inventory (Bar-On EQ-i)}

To assess trait EI, the Bar-On Emotional Intelligence Inventory (Bar-On EQ-i, Bar-On, 1997) in the Italian version (Franco and 
Tappatà, 2009) was administered. The questionnaire has 133 items with Likert scale response options ranging from $1=$ Not at all true of me to $5=$ Absolutely true for me. The measure yields a total Emotional Quotient (QE) and scores for five subscales: Intrapersonal, Interpersonal, Adaptability, Stress Management, and General Mood. Reliabilities were examined using Cronbach's alpha coefficient for the Italian version of the EQ-I and they are the following: 0.95 for the total score, 0.91 for Intrapersonal, 0.84 for Interpersonal, 0.81 for Adaptability, 0.87 for Stress Management, 0.83 for General Mood (Franco and Tappatà, 2009).

\section{Trait Emotional Intelligence Questionnaire (TeiQue)}

The Italian version (Di Fabio, 2013) of the TeiQue (Petrides and Furnham, 2004) was also used assess trait EI. The questionnaire has 153 items with Likert scale response options ranging from $1=$ Completely disagree to $7=$ Completely agree. The measure provides a total score, and four subscale scores: Well-being, Self-Control, Emotionality, and Sociability. Cronbach's alpha coefficient for the total score in the Italian version was 0.96 (Di Fabio et al., 2016). Cronbach's alpha coefficients for the four subscales are also adequate and they are the following: 0.93 for Well-being, 0.81 for Self-Control, 0.92 for Emotionality, and 0.80 for Sociability (Di Fabio et al., 2016). The alpha for the total score for the current sample was 0.92 .

\section{Positive and Negative Affect Schedule (PANAS)}

Positive Affect and Negative Affect were assessed as affective components of hedonic well-being using the Italian version (Terracciano et al., 2003) of the PANAS (Watson et al., 1988). The measure consists of 20 adjectives, 10 referring to PA (i.e., enthusiastic, interested, determined) and 10 referring to NA (i.e., afraid, upset, distressed). A participant specifies the intensity of affect experienced, using a Likert scale ranging from $1=$ Very slightly or not at all to $5=$ Extremely. The Cronbach's alpha was 0.72 for PA and 0.83 for NA.

\section{Satisfaction With Life Scale (SWLS)}

Life satisfaction was also assessed as a component of hedonic well-being, consistent with the argument that life satisfaction entails an affective assessment of feelings about one's life (Lent, 2004), using the Italian version (Di Fabio and Gori, 2015) of the Satisfaction With Life Scale (SWLS, Diener et al., 1985). The questionnaire consists of five items, which are rated using a 7 -point Likert scale that ranges from $1=$ Strongly disagree to 7 = Strongly agree. The Cronbach's alpha coefficient reported by Di Fabio and Gori (2015) was 0.85, and for the current sample, the Cronbach's alpha was 0.90 .

\section{Meaningful Life Measure (MLM)}

Life meaningfulness was measured as a component of eudaimonic well-being, using the Italian translation (Di Fabio, 2014) of the MLM (Morgan and Farsides, 2009). The questionnaire consists of 23 items with a Likert response format ranging from $1=$ Strongly disagree to $7=$ Strongly agree. The scale assesses five dimensions of life meaningfulness: Exciting life, Accomplished life, Principled life, Purposeful life, Valued life. Cronbach's alpha coefficients for the five dimensions are adequate for the Italian version: 0.87 for Exciting life to, 0.86 for
Accomplished life, 0.85 for Principled life, 0.84 for Purposeful life, 0.87 for Valued life (Di Fabio, 2014). The Cronbach's Alpha for the total score used in this study was 0.85 .

\section{Procedure and Data Analysis}

Questionnaires were administered, following Italian laws for privacy, by a trained research assistant to students in their high school classes. The administration of the questionnaires adhered to the requirements of privacy and informed consent in Italian law (Law Decree DL-196/2003) and the ethical standards for research of the Declaration of Helsinki revised in Fortaleza (World Medical Association [WMA], 2013), followed and approved by the Department of Education and Psychology of the University of Florence (Italy). Informed consent was recollected for each participant. Questionnaires were administered in counterbalanced order to control for ordering effects. Ten-minute breaks were provided after the APM and after the BFQ to limit fatigue.

In reference to preliminary data, the following analyses were performed: descriptive statistics, including means and standard deviations.

The Pearson's correlation was then conducted in order to investigate the relation between the variables under investigation.

Eight separate hierarchical regression analyses were completed to examine predictors of hedonic and eudaimonic well-being, with PA, NA, and life satisfaction as separate indices of hedonic well-being, and with life meaningfulness as the index of eudaimonic well-being. For all analyses, fluid intelligence was entered at the first step, personality traits at the second step, and ability-based EI at the third step. For step four, trait EI assessed through TeiQue was entered in four of the analyses and trait EI assessed through EQ-i was entered for the other four analyses. In evaluating the accuracy of regression analyses standard errors and confidence intervals were considered. There were no missing data in the data set.

\section{RESULTS}

Means, standard deviations and correlations among APM, BFQ, MSCEIT, TeiQue, Bar-On EQ-I, PANAS PA, PANAS NA, SWLS, MLM are reported in Table $\mathbf{1 .}$

In the analyses explaining hedonic well-being as assessed by PA, fluid intelligence was not significant in step one. In step two, personality traits explained a significant $32 \%$ of the variance; at the third step, ability-based EI was not significant; at the fourth step, trait EI assessed through the TeiQue explained an additional and significant $2 \%$ of the variance (Table 2). When trait EI assessed through the EQ-i was entered at the fourth step instead of trait EI assessed through the TeiQue, the fourth step explained an additional and significant $8 \%$ of the variance (Table 4 ).

In the analyses explaining hedonic well-being as assessed by $\mathrm{NA}$, fluid intelligence was not significant in step one. At the second step, personality traits explained a significant $16 \%$ of the variance; at the third step, ability-based EI was not significant; at step four, trait EI assessed through the TeiQue explained an additional $2 \%$ of the variance (Table 2 ). When trait EI assessed 


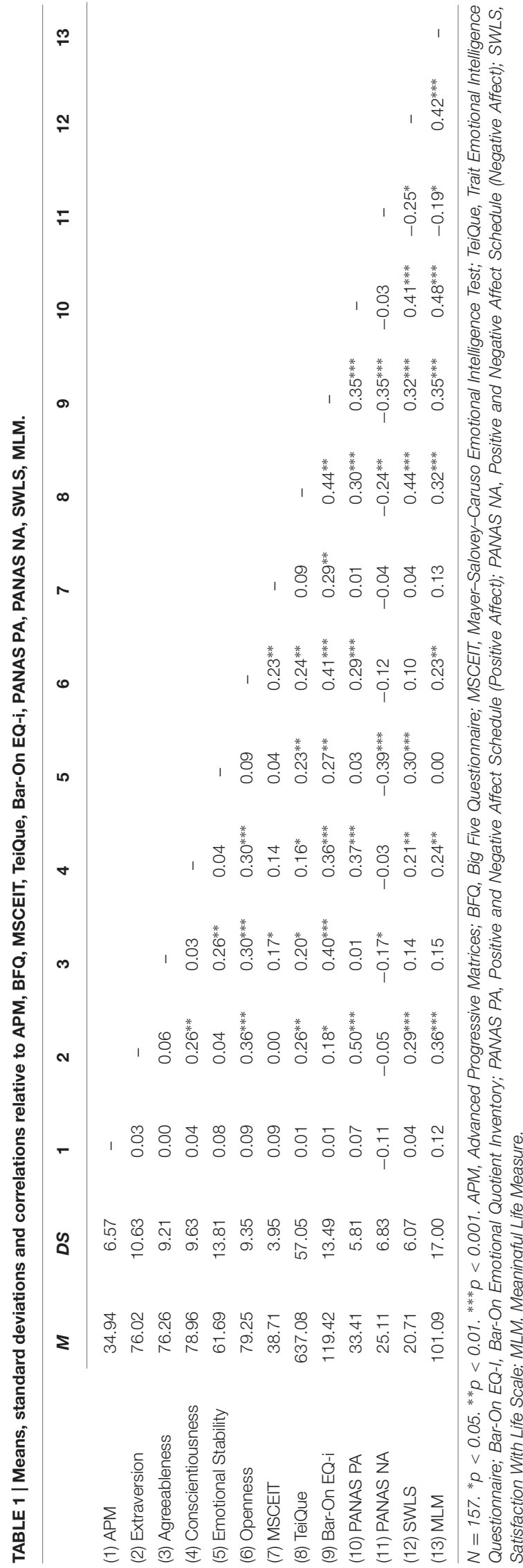

through the EQ-i was entered at the fourth step instead of trait EI assessed through the TeiQue, the EQ-i explained an additional significant $8 \%$ of the variance (Table 4 ).

In the analyses assessing hedonic well-being as assessed by life satisfaction, fluid intelligence was not significant at the first step. At the second step, personality traits explained a significant $21 \%$ of the variance; at the third step, ability-based EI was not significant; at the fourth step, trait EI assessed through the TeiQue explained an additional and significant $9 \%$ of the variance (Table 2). When trait EI assessed through EQ-i was entered at the fourth step instead of trait EI assessed through TeiQue, the EQ-i explained a significant $7 \%$ of the variance (Table 4 ).

For the analyses assessing life meaningfulness as a component of eudaimonic well-being, fluid intelligence was not significant at the step one. At the second step, personality traits explained a significant $18 \%$ of the variance; at the third step, ability-based EI was not significant; at the fourth step, trait EI assessed through the TeiQue explained an additional significant $4 \%$ of the variance (Table 3). When trait EI assessed through the EQ-i was entered at the fourth step instead of trait EI assessed through the TeiQue, trait EI assessed through the EQ-i explained an additional and significant $10 \%$ of variance over step three (Table 5).

\section{DISCUSSION}

The current study was designed to examine the contribution of EI, including ability-based EI and two measures of self-report trait EI, to indices of hedonic and eudaimonic well-being in young people, with concern from a prevention perspective for their well-being as future workers. Analyses were completed to assess the incremental variance, beyond the effects of fluid intelligence and personality traits, of ability-based EI and two different self-report EI models.

The overall findings partially support the two main hypotheses that focused on the contributions of EI, in explaining hedonic and eudaimonic well-being beyond the variance explained by fluid intelligence and personality traits. More specifically, trait EI, as assessed through the TeiQue (Petrides and Furnham, 2000, 2001) and the EQ-i (Bar-On, 1997), explained significant variance across the three indices of hedonic well-being and the MLM of eudaimonic well-being. These findings with Italian high school students thus confirm prior research documenting relationships between self-report measures of EI and hedonic well-being with Italian college students (Di Fabio and Saklofske, 2014b), with Spanish university students (Extremera and Fernández-Berrocal, 2005), and with community samples in Australia (Palmer et al., 2002; Gannon and Ranzijn, 2005; Gignac, 2006; Gallagher and Vella-Brodrick, 2008). The current results are also consistent with prior research that has found self-report measures of EI to be associated with eudaimonic well-being (Tennant et al., 2007; Raina and Bakhshi, 2013), indicating that self-ratings of one's EI are related to the self-ratings of one's life as meaningful and pleasant.

Our hypothesis that ability-based EI would be associated with both hedonic and eudaimonic well-being was not supported which conflicts with some prior findings. The discrepancy 


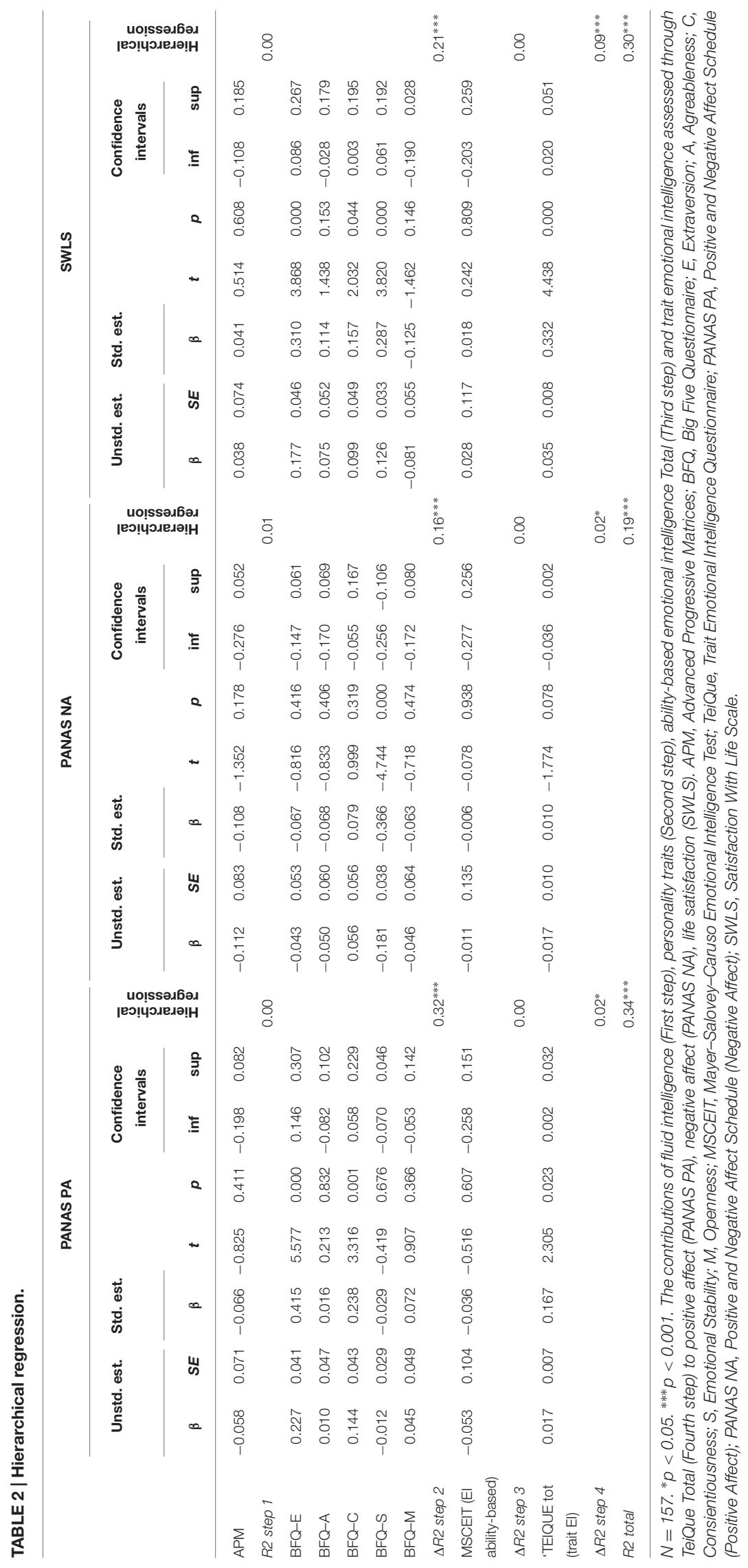




\begin{tabular}{|c|c|c|c|c|c|c|c|c|}
\hline & \multicolumn{8}{|c|}{ MLM } \\
\hline & \multicolumn{2}{|c|}{ Unstd. est. } & \multirow{2}{*}{$\begin{array}{c}\text { Std. est. } \\
\beta\end{array}$} & \multirow[b]{2}{*}{$t$} & \multirow[b]{2}{*}{$p$} & \multicolumn{2}{|c|}{ Confidence intervals } & \multirow{2}{*}{$\begin{array}{c}\text { Hierarchical } \\
\text { regression }\end{array}$} \\
\hline & $\beta$ & SE & & & & inf & sup & \\
\hline APM & 0.325 & 0.206 & 0.125 & 1.575 & 0.117 & -0.083 & 0.732 & \\
\hline R2step 1 & & & & & & & & 0.00 \\
\hline BFQ-E & 0.509 & 0.130 & 0.318 & 3.923 & 0.000 & 0.253 & 0.765 & \\
\hline BFQ-A & 0.312 & 0.148 & 0.169 & 2.104 & 0.037 & 0.019 & 0.606 & \\
\hline$B F Q-C$ & 0.267 & 0.138 & 0.151 & 1.930 & 0.055 & -0.006 & 0.540 & \\
\hline BFQ-S & -0.066 & 0.094 & -0.054 & -0.705 & 0.482 & -0.251 & 0.119 & \\
\hline BFQ-M & 0.031 & 0.157 & 0.017 & 0.198 & 0.843 & -0.279 & 0.341 & \\
\hline$\Delta R 2$ step 2 & & & & & & & & $0.18^{* * *}$ \\
\hline El ability-based & 0.320 & 0.330 & 0.074 & 0.968 & 0.334 & -0.333 & 0.972 & \\
\hline$\Delta R 2$ step 3 & & & & & & & & 0.01 \\
\hline TEIQUE tot & 0.067 & 0.023 & 0.225 & 2.875 & 0.005 & 0.021 & 0.113 & \\
\hline$\Delta R 2$ step 4 & & & & & & & & $0.04^{* *}$ \\
\hline R2 total & & & & & & & & $0.24 * * *$ \\
\hline
\end{tabular}

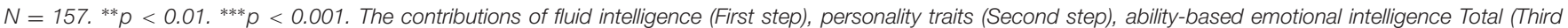

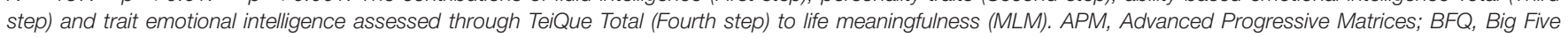

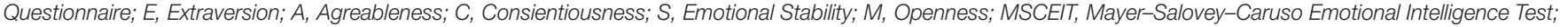
TeiQue, Trait Emotional Intelligence Questionnaire; MLM, Meaningful Life Measure.

between the current and other findings might be understood by variations in measures used. Burrus et al. (2012), for example, used a new and unique measure of EI with US students. In their study of Spanish university students, Extremera et al. (2011) employed the well-established MSCEIT, as used in the current study for measuring ability-based EI, but employed a measure of well-being that was different than the current study. Our findings are consistent with previous research among Italian high school students, which found no relation between abilitybased EI as assessed by the MSCEIT and hedonic well-being (Di Fabio and Saklofske, 2014b). Further research will be needed to discern whether the difference in our findings and the Extremera et al. (2011) findings are related to national, developmental, or measurement differences.

Our findings do confirm prevailing evidence that self-report measures of EI are more robust than ability-based EI in explaining well-being and other psychological constructs assessed through self-report (Zeidner et al., 2012). While this may partly be understood as an issue of method variance, we have also found that when EI is conceptualized affectively, rather than cognitively, EI is more strongly related to other self-perceptions, including well-being (Di Fabio and Kenny, 2012b; Di Fabio et al., 2014). Our finding that trait EI explains well-being beyond the variance explained by personality, however, suggests that trait EI cannot be understood simply as a broad based personality factor. While trait EI, as assessed by both the EQ-i and TeiQue, is clearly associated with trait dimensions of personality, such as extraversion, agreeableness, emotional stability, and openness assessed in this study, our findings and a preponderance of prior evidence (Di Fabio et al., 2014) suggest that trait EI goes beyond those factors in explaining a variety of important psychological outcomes. The current study expands that body of literature by affirming the contributions of two measures of trait EI beyond personality factors in explaining both hedonic and eudaimonic well-being and suggests that the two trait measures of EI contribute somewhat differently to well-being.

While the current study confirms prior research on the contributions of trait EI to other self-report psychological constructs, our findings also affirm complexities and variations based upon the self-report measures employed. The current results are most similar to research that has employed similar measures of trait EI (e.g., Di Fabio and Saklofske, 2014b), and illustrate that the extent to which trait EI explains hedonic wellbeing can vary depending on the conceptualization and choice of measure. In this study, the variance accounted for by the EQ-i was more robust than for the TeiQue in explaining dimensions of both hedonic and eudaimonic well-being. In prior research (Di Fabio and Saklofske, 2014a,b), the TeiQue was more robust, explaining twice as much variance as the EQ-i in relation to three career dimensions, resilience, and positive core self-evaluation. While the explanation for these differences in not clear, our findings highlight how results can vary across studies related to measures and selected outcome variables and that different measures and models of trait EI, while overlapping, are not identical. Although further research is necessary to replicate and expand the current findings, it is possible that the EI components incorporated in the EQ-i, such as adaptability, stress management, and general mood, are more aligned with wellbeing, and whereas self-control and sociability as assessed by the TeiQue are more aligned with career decision-making. Further research might examine these nuances.

Given the interest among proponents of positive psychology in the promotion of meaningfulness and optimal functioning in the work environment (Bakker and Schaufeli, 2008; Heuvel et al., 2010), the promise of EI as a contributor to eudaimonic well-being is noteworthy. Heuvel et al. (2010) emphasize the 


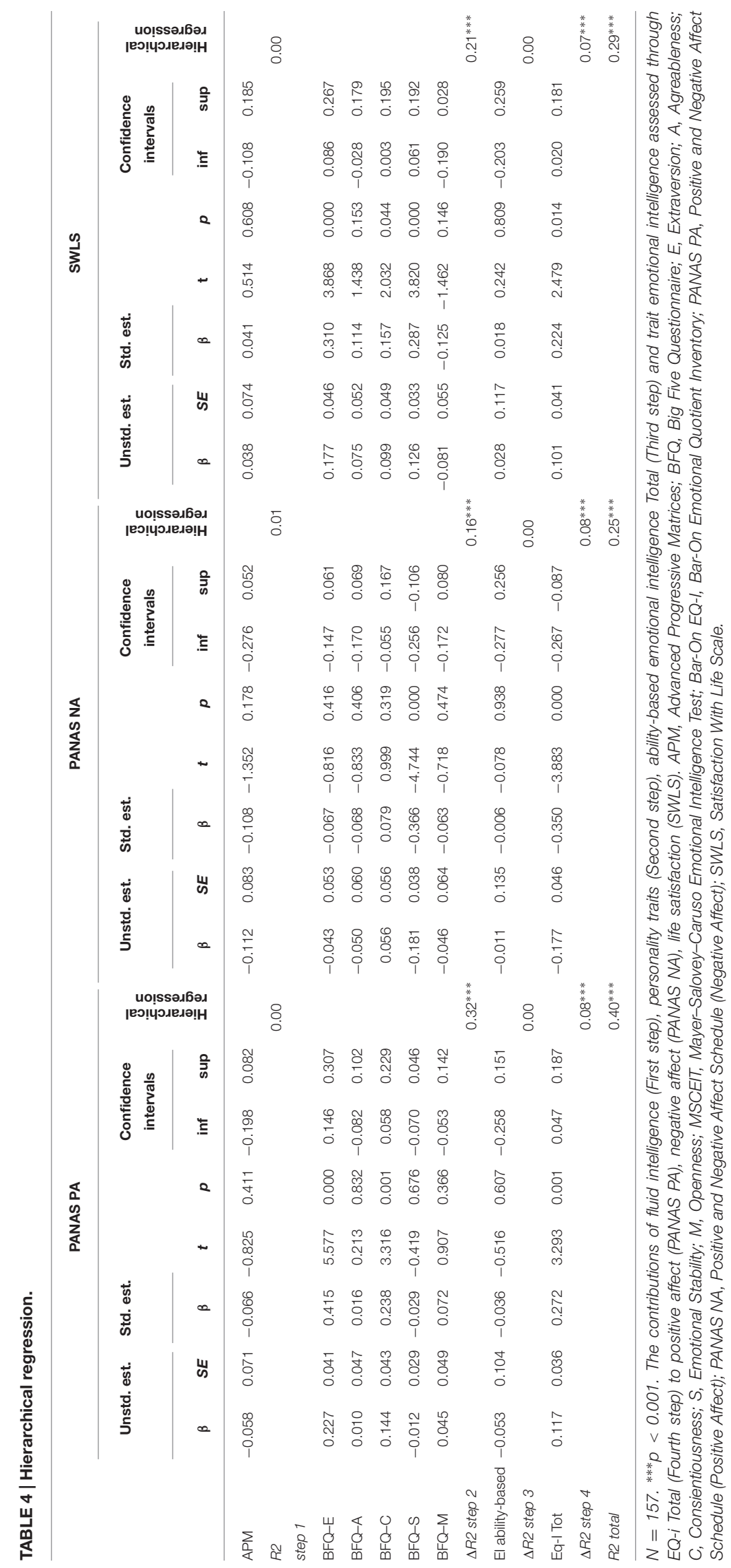




\begin{tabular}{|c|c|c|c|c|c|c|c|c|}
\hline & \multicolumn{8}{|c|}{ MLM } \\
\hline & \multicolumn{2}{|c|}{ Unstd. est. } & \multirow{2}{*}{$\begin{array}{c}\text { Std. est. } \\
\beta\end{array}$} & \multirow[b]{2}{*}{$t$} & \multirow[b]{2}{*}{$p$} & \multicolumn{2}{|c|}{ Confidence intervals } & \multirow{2}{*}{$\begin{array}{c}\text { Hierarchical } \\
\text { regression }\end{array}$} \\
\hline & $\beta$ & Standard error & & & & inf & sup & \\
\hline APM & 0.325 & 0.206 & 0.125 & 1.575 & 0.117 & -0.083 & 0.732 & \\
\hline R2step 1 & & & & & & & & 0.02 \\
\hline$B F Q-E$ & 0.509 & 0.130 & 0.318 & 3.923 & 0.000 & 0.253 & 0.765 & \\
\hline $\mathrm{BFQ}-\mathrm{A}$ & 0.312 & 0.148 & 0.169 & 2.104 & 0.037 & 0.019 & 0.606 & \\
\hline$B F Q-C$ & 0.267 & 0.138 & 0.151 & 1.930 & 0.055 & -0.006 & 0.540 & \\
\hline$B F Q-S$ & -0.066 & 0.094 & -0.054 & -0.705 & 0.482 & -0.251 & 0.119 & \\
\hline$B F Q-M$ & 0.031 & 0.157 & 0.017 & 0.198 & 0.843 & -0.279 & 0.341 & \\
\hline$\Delta R 2$ step 2 & & & & & & & & $0.18^{* * *}$ \\
\hline El ability-based & 0.320 & 0.330 & 0.074 & 0.968 & 0.334 & -0.333 & 0.972 & \\
\hline$\Delta R 2$ step 3 & & & & & & & & 0.01 \\
\hline Eq-I tot & 0.355 & 0.114 & 0.282 & 3.125 & 0.002 & 0.131 & 0.580 & \\
\hline$\Delta R 2$ step 4 & & & & & & & & $0.10^{* * *}$ \\
\hline R2 total & & & & & & & & $0.31 * * *$ \\
\hline
\end{tabular}

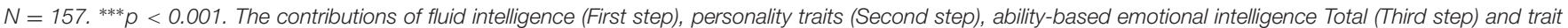

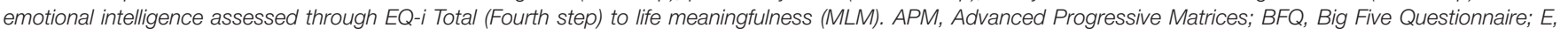

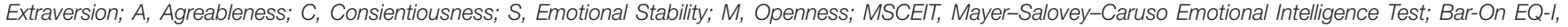
Bar-On Emotional Quotient Inventory; MLM, Meaningful Life Measure.

importance of identifying personal competencies/resources, as well as organizational factors, that enable employees to be happy, engaged and productive in the new and ever-changing workplace. Our findings suggest that the promotion of trait EI may function not only as a method for enhancing hedonic well-being, including PA, life satisfaction, and reduced NA, but may also serve to enhance a sense of a meaningful life. Given the threats posed to well-being by social and economic change and work uncertainty, factors associated with life meaning are worthy of continued research attention and consideration for intervention for fostering healthy individuals and organizations (Zeidner et al., 2012; Friedman and Kern, 2014; Snyder et al., 2014).

Despite the contribution of the current study in documenting the contributions of trait EI, based on both the Bar-On (1997) and the Petrides and Furnham (2000, 2001) models, for both hedonic and eudaimonic well-being, the limitations of the study should be considered. Our results are correlational and causality cannot be concluded. Further research is needed to determine how trait EI can best be enhanced and whether those gains can lead to gains in both hedonic and eudaimonic well-being. Longitudinal research is also needed to systematically test the causal mechanisms that promote well-being as a function of EI intervention. We have noted differences in prior research based upon sample characteristics, such that the findings of this study based on high school students in the Tuscany Region of Italy cannot be generalized to other samples. The current findings deserve replication with participants more representative of all Italians across geography and age and could be also replicated in other national contexts. We studied only one aspect of eudaimonic well-being, such that the relationship of EI to other components of eudaimonic well-being, such as existential fulfillment (Längle et al., 2003), sense of coherence (Antonovsky, 1987b), and authenticity (Wood et al., 2008), should also be studied. This study controlled for the association of EI and personality measures among the predictor variables, but other potential confounds between EI and the criterion measures (e.g., well-being and mood as a component of trait EI) need to be considered and controlled. The use of objective measures of well-being will help in this regard. While well-being is a subjective construct and thus reasonably assessed through selfreport, further research should include more objective indices of well-being, including physical health, educational or work productivity, and creative achievements.

Despite the limitations of the current study, the findings add to and extend the literature highlighting the positive associations and potential benefit of diverse models of trait EI, suggesting promise of the construct for continued research in positive psychology (Seligman and Csikszentmihalyi, 2000) and positive organizational behavior (Bakker and Schaufeli, 2008). While continued research is needed to support the evidence base for EI intervention (Zeidner et al., 2012), trait EI could be a potential focus for enhancing the subjective and psychological well-being of young and future workers and for maintaining and fostering health and performance in a challenging work environment (Di Fabio, 2015; Di Fabio and Palazzeschi, 2015; Arnoux-Nicolas et al., 2016).

\section{AUTHOR CONTRIBUTIONS}

$\mathrm{AD}$ and $\mathrm{MK}$ conceptualized the study, chose the theoretical framework and chose the measures. AD collected the data and with MK wrote the methods and results. Then the authors wrote the paper together and read and revised the manuscript several times. 


\section{REFERENCES}

Antonovsky, A. (1987a). The salutogenic perspective: toward a new view of health and illness. Advances 4, 47-55.

Antonovsky, A. (1987b). Unravelling the Mystery of Health: How People Manage Stress and Stay Well. San Francisco, CA: Jossey-Bass.

Arnoux-Nicolas, C., Sovet, L., Lhotellier, L., Di Fabio, A., and Bernaud, J.-L. (2016). Perceived work conditions and turnover intentions: the mediating role of meaning of life and meaning of work. Front. Psychol. 7:704. doi: 10.3389/fpsyg.2016.00704

Arrindell, W. A., Meeuswesen, L., and Huyse, F. J. (1991). The satisfaction with life scale (SWLS): psychometric properties in a non-psychiatric medical outpatients sample. Personal. Individ. Differ. 12, 117-123. doi: 10.1016/01918869(91)90094-R

Austin, E. J., Parker, J. D. A., Petrides, K. V., and Saklofske, D. H. (2008). "Emotional intelligence," in The SAGE Handbook of Personality Theory and Assessment, Vol. 1, eds G. J. Boyle, G. Matthews, and D. H. Saklofske (London: SAGE), 576-596.

Austin, E. J., and Saklofske, D. H. (2014). Introduction to the special issue on emotional intelligence. Person. Individ. Differ. 65, 1-2. doi: 10.1016/j.paid.2014.02.006

Bakker, A. B., and Schaufeli, W. B. (2008). Positive organizational behavior: engaged employees in flourishing organizations. J. Organ. Behav. 29, 147-154. doi: 10.1002/job.515

Bar-On, R. (1997). The Emotional Intelligence Inventory (EQ-i): Technical manual. Toronto, ON: Multi-Health Systems.

Blustein, D. L. (2006). The Psychology of Working: A New Perspective for Career Development, Counseling, and Public Policy. Mahwah, NJ: Lawrence Erlbaum.

Brackett, M. A., and Mayer, J. D. (2003). Convergent, discriminant and incremental validity of competing measures of emotional intelligence. Personal. Soc. Psychol. Bull. 29, 147-158. doi: 10.1177/0146167203254596

Burrus, J., Betancourt, A., Holtzman, S., and Minsky, J. (2012). Emotional intelligence relates to well-being: evidence from the situational judgment test of emotional management. Appl. Psychol. Health Well-Being 4, 151-166. doi: 10.1111/j.1758-0854.2012.01066.x

Caprara, G. V., Barbaranelli, C., and Borgogni, L. (1993). BFQ: Big Five Questionnaire, 2nd Edn. Firenze: Giunti O.S.

D’Amico, A., and Curci, A. (2010). Mayer-Salovey-Caruso Emotional Intelligence Test (MSCEIT). Firenze: Giunti O.S.

Deci, E. L., and Ryan, R. M. (2000). The «what» and «why» of goal pursuits: human needs and the self-determination of behavior. Psychol. Inq. 11, 227-268. doi: 10.1207/S15327965PLI1104_01

Deci, E. L., and Ryan, R. M. (2008). Hedonia, eudaimonia, and well-being: an introduction. J. Happiness Stud. 9, 1-11. doi: 10.1007/s10902-006-9018-1

DeNeve, K. M., and Cooper, H. (1998). The happy personality: a meta-analysis of 137 personality traits and subjective well-being. Psychol. Bull. 124, 197-229. doi: 10.1037/0033-2909.124.2.197

Di Fabio, A. (2013). Trait emotional intelligence questionnaire (TEIQue): un contributo alla validazione della versione italiana [Trait emotional intelligence questionnaire (TEIQue): a contribution to the validation of the Italian version]. Couns. G. Ital. Ric. Appl. 6, 351-362.

Di Fabio, A. (2014). Meaningful life measure: primo contributo alla validazione della versione italiana [Meaningful Life Measure: first contribution to the validation of the Italian Version]. Couns. G. Ital. Ric. Appl. 7, 307-315.

Di Fabio, A. (2015). Beyond fluid intelligence and personality traits in social support: the role of ability-based emotional intelligence. Front. Psychol. 6:395. doi: 10.3389/fpsyg.2015.00395

Di Fabio, A., and Bucci, O. (2016). "Green positive guidance and green positive life counseling for decent work and decent lives: some empirical results," in From Meaning of Working to Meaningful Lives: The Challenges of Expanding Decent Work. Research Topic in Frontiers in Organizational Psychology, Vol. 7, eds A. Di Fabio and D. L. Blustein (Lausanne: Frontiers), 503.

Di Fabio, A., and Clarotti, S. (2007). Matrici Progressive di Raven. Adattamento Italiano [Advanced Progressive Matrices: Italian Adaptation]. Firenze: Giunti O.S.

Di Fabio, A., and Gori, A. (2015). Measuring adolescent life satisfaction: psychometric properties of the Satisfaction With Life Scale in a sample of
Italian adolescents and young adults. J. Psychoeduc. Assess. 34, 501-506. doi: $10.1177 / 0734282915621223$

Di Fabio, A., and Kenny, M. E. (2011). Promoting emotional intelligence and career decision making among Italian high school students. J. Career Assess. 19, 21-34 doi: $10.1177 / 1069072710382530$

Di Fabio, A., and Kenny, M. E. (2012a). Emotional intelligence and perceived social support among Italian high school students. J. Career Dev. 39, 461-475. doi: $10.1177 / 0894845311421005$

Di Fabio, A., and Kenny, M. E. (2012b). The contribution of emotional intelligence to decisional styles among Italian high school students. J. Career Assess. 20, 404-414. doi: 10.1177/1069072712448893

Di Fabio, A., and Kenny, M. E. (2015). The contributions of emotional intelligence and social support to adaptive career progress among Italian youth. J. Career Dev. 42, 48-49. doi: 10.1177/0894845314533420

Di Fabio, A., Kenny, M. E., and Minor, K. (2014). "Emotional intelligence and positive psychology in the schools," in Handbook of Positive Psychology in the Schools, 2nd Edn, eds M. J. Furlong, R. Gilman, and E. S. Huebner (New York: Routledge, Taylor and Francis), 450-464.

Di Fabio, A., and Palazzeschi, L. (2009). An in-depth look at scholastic success: fluid intelligence, personality traits or emotional intelligence? Personal. Individ. Differ. 46, 581-585. doi: 10.1016/j.paid.2008.12.012

Di Fabio, A., and Palazzeschi, L. (2015). Hedonic and eudaimonic well-being: the role of resilience beyond fluid intelligence and personality traits. Front. Psychol. 6:1367. doi: 10.3389/fpsyg.2015.01367

Di Fabio, A., and Palazzeschi, L. (2016). "Marginalization and precariat: the challenge of intensifying life construction intervention," in From Meaning of Working to Meaningful Lives: The Challenges of Expanding Decent Work Research Topic in Frontiers in Organizational Psychology, Vol. 7, eds A. Di Fabio and D. L. Blustein (Lausanne: Frontiers), 444.

Di Fabio, A., and Saklofske, D. H. (2014a). Comparing ability and self-report trait emotional intelligence, fluid intelligence, and personality traits in career decision. Personal. Individ. Differ. 64, 174-178.

Di Fabio, A., and Saklofske, D. H. (2014b). Promoting individual resources: the challenge of trait emotional intelligence. Personal. Individ. Differ. 65, 19-23. doi: 10.1016/j.paid.2014.01.026

Di Fabio, A., Saklofske, D. H., and Tremblay, P. F. (2016). Psychometric properties of the italian trait emotional intelligence questionnaire (ITEIQue). Personal. Individ. Differ. 96, 198-201. doi: 10.1016/j.paid.2016. 03.009

Diener, E., Emmons, R. A., Larsen, R. J., and Griffin, S. (1985). The satisfaction with life scale. J. Pers. Assess. 49, 71-75. doi: 10.1207/s15327752jpa4901_13

Diener, E., Suh, E. M., Lucas, R. E., and Smith, H. L. (1999). Subjective well-being: three decades of progress. Psychol. Bull. 125, 276-302. doi: 10.1037/00332909.125.2.276

Extremera, N., and Fernández-Berrocal, P. (2005). Perceived emotional intelligence and life satisfaction: predictive and incremental validity using the trait metamood scale. Personal. Ind. Differ. 39, 937-948. doi: 10.1016/j.paid.2005.03.012

Extremera, N., Ruiz-Aranda, D., Pineda-Galán, C., and Salguero, J. M. (2011). Emotional intelligence and its relation with hedonic and eudaimonic well-being: a prospective study. Personal. Individ. Differ. 51, 11-16. doi: 10.1016/j.paid.2011.02.029

Fernández-Berrocal, P. (2016). Commentary: dimensions of emotional intelligence related to physical and mental healthy and to health behaviors. Front. Psychol. 7:441. doi: 10.3389/fpsyg.2016.00441

Franco, M., and Tappatà, L. (2009). EQ-iTM Emotional Quotient Inventory. Validazione italiana [EQ-iTM Emotional Quotient Inventory. Italian validation]. Firenze: Giunti O. S.

Freudenthaler, H. H., Neubauer, A. C., Gabler, P., Scherl, W. G., and Rindermann, H. (2008). Testing and validating the trait emotional intelligence questionnaire (TeiQue) in German-speaking sample. Personal. Individ. Differ. 45, 673-678. doi: 10.1016/j.paid.2008.07.014

Friedman, H. S., and Kern, M. L. (2014). Personality, well-Being, and Health. Annu. Rev. Psychol. 65, 719-742. doi: 10.1146/annurev-psych-010213-115123

Gallagher, E. N., and Vella-Brodrick, D. A. (2008). Social support and emotional intelligence as predictors of subjective well-being. Personal. Individ. Differ. 44, 1551-1561. doi: 10.1016/j.paid.2008.01.011 
Gannon, N., and Ranzijn, R. (2005). Does emotional intelligence predict unique variance in life satisfaction beyond IQ and personality? Personality and Individual Differences 38, 1353-1364. doi: 10.1016/j.paid.2004. 09.001

Gignac, G. E. (2006). Self-reported emotional intelligence and life satisfaction: testing incremental predictive validity hypotheses via structural equation modeling (SEM) in a small sample. Personal. Individ. Differ. 40, 1569-1577. doi: 10.1016/j.paid.2006.01.001

Gori, A., Craparo, G., Giannini, M., Loscalzo, Y., Caretti, V., La Barbera, D., et al (2015). Development of a new measure for assessing insight: psychometric properties of the insight orientation scale (IOS). Schizophr. Res. 169, 298-302. doi: 10.1016/j.schres.2015.10.014

Hage, S. M., Romano, J. L., Conyne, R. K., Kenny, M., Matthews, C., Schwartz, J. P., et al. (2007). Best practice guidelines on prevention practice, research, training, and social advocacy for psychologists. Counsel. Psychol. 35, 493-566. doi: $10.1177 / 0011000006291411$

Heuvel, M., Demerouti, E., Schaufeli, W., and Bakker, A. B. (2010). "Personal resources and work engagement in the face of change," in Contemporary Occupational Health Psychology: Global Perspectives on Research and Practice, eds J. Houdmont and S. Leka (Chichester: John Wiley \& Sons), 124-150.

Kahneman, D., Diener, E., and Schwarz, N. (1999). Well-Being: The Foundations of Hedonic Psychology. New York, NY: Russell Sage Foundation.

Keyes, C. L. M., Shmotkin, D., and Ryff, C. D. (2002). Optimizing well-being: the empirical encounter of two traditions. J. Pers. Soc. Psychol. 82, 1007-1022. doi: 10.1037/0022-3514.82.6.1007

Längle, A., Orgler, C., and Kundi, M. (2003). The existence scale: a new approach to assess the ability to find personal meaning in life and to reach existential fulfillment. Euro. Psychother. 4, 135-146.

Lent, R. W. (2004). Toward a unifying theoretical and practical perspective on well-being and psychosocial adjustment. J. Counsel. Psychol. 51, 482-509. doi: 10.1037/0022-0167.51.4.482

Lucas, R. E., Diener, E., and Suh, E. (1996). Discriminant validity of well-being measures. J. Pers. Soc. Psychol. 71, 616-628. doi: 10.1037/0022-3514.71.3.616

MacCann, C., and Roberts, R. D. (2008). New paradigms for assessing emotional intelligence: theory and data. Emotion 8, 540-551. doi: 10.1037/a00 12746

Martins, A., Ramalho, N., and Morin, E. (2010). A comprehensive meta-analysis of the relationship between emotional intelligence and health. Personal. Individ. Differ. 49, 554-564. doi: 10.1016/j.paid.2010.05.029

Masten, A. (2014). Global perspectives on resilience in children and youth. Child Dev. 85, 6-20. doi: 10.1111/cdev.12205

Mayer, J. D., and Salovey, P. (1997). "What is emotional intelligence?," in Emotional Development and Emotional Intelligence: Educational Implications, eds $\mathrm{P}$. Salovey and D. Sluyter (New York, NY: Basic Books), 3-31.

Mayer, J. D., Salovey, P., and Caruso, D. R. (2002). Mayer-Salovey-Caruso Emotional Intelligence Test (MSCEIT): User's manual. Toronto, ON: MultiHealth Systems.

Mayer, J. D., Salovey, P., and Caruso, D. R. (2008). Emotional intelligence: new ability or eclectic traits? Am. Psychol. 63, 503-517. doi: 10.1037/0003066X.63.6.503

Mikolajczak, M., Nelis, D., Hansenne, M., and Quoidbach, J. (2008). If you can regulate sadness, you can probably regulate shame: associations between trait emotional intelligence, emotion regulation and coping efficiency across discrete emotions. Personal. Individ. Differ. 44, 1356-1368. doi: 10.1016/j.paid.2007.12.004

Mikolajczak, M., Petrides, K. V., Coumans, N., and Luminet, O. (2009). The moderating effect of trait emotional intelligence on mood deterioration following laboratory-induced stress. Int. J. Clin. Health Psychol. 9, 455-477.

Morgan, J., and Farsides, T. (2009). Measuring meaning in life. J. Happiness Stud. 10, 197-214. doi: 10.1007/s10902-008-9093-6

Nelis, D., Kotsou, I., Quoidbach, J., Hansenne, M., Weytens, F., Dupuis, P., et al. (2011). Increasing emotional competence improves psychological and physical well-being, social relationships, and employability. Emotion 11, 354-366. doi: 10.1037/a0021554

Nelis, D., Quoidbach, J., Mikolajczak, M., and Hansenne, M. (2009). Increasing emotional intelligence:(How) is it possible? Personal. Individ. Differ. 47, 36-41. doi: $10.1016 /$ j.paid.2009.01.046
Palmer, B., Donaldson, C., and Stough, C. (2002). Emotional intelligence and life satisfaction. Personal. Individ. Differ. 33, 1091-1100. doi: 10.1016/S01918869(01)00215-X

Parker, J. D. A., Keefer, K. V., and Wood, L. M. (2011). Toward a brief multidimensional assessment fo emotional intelligence: psychometric propoerties of emotional quotient inventory - short form. Psychol. Assess. 23, 762-777. doi: 10.1037/a0023289

Pavot, W., and Diener, E. (1993). The affective and cognitive context of selfreported measures of subjective well-being. UNSW Soc. Indic. Res. 28, 1-20. doi: 10.1007/BF01086714

Perera, H. N., and DiGiacomo, M. (2015). The role of trait emotional intelligence in academic performance during the university transition: an integrative model of mediation via social support, coping, and adjustment. Personal. Individ. Differ. 83, 208-213. doi: 10.1016/j.paid.2015.04.001

Petrides, K. V., and Furnham, A. (2000). On the dimensional structure of emotional intelligence. Personal. Individ. Differ. 29, 313-320. doi: 10.1016/S01918869(99)00195-6

Petrides, K. V., and Furnham, A. (2001). Trait emotional intelligence: psychometric investigation with reference to established trait taxonomies. Eur. J. Pers. 15, 425-428. doi: 10.1002/per.416

Petrides, K. V., and Furnham, A. (2004). Technical Manual of the Trait Emotional Intelligence Questionnaire (TeiQue). London: University of London, Institute of Education.

Raina, M., and Bakhshi, A. (2013). Emotional intelligence predicts eudaimonic well being. IOSR J. Humanit. Soc. Sci. 11, 42-47. doi: 10.9790/0837-113 4247

Raven, J. (1962). Advanced Progressive Matrices: Set II. Oxford: Oxford Psychologist Press.

Ryan, R. M., and Deci, E. L. (2001). "To be happy or to be self-fulfilled: a review of research on hedonic and eudaimonic well-being," in Annual Review of Psychology, Vol. 52, ed. S. Fiske (Palo Alto, CA: Annual Reviews), 141-166.

Ryff, C. D., and Singer, B. H. (2008). Know thyself and become what you are: a eudaimonic approach to psychological well-being. J. Happiness Stud. 9, 13-39. doi: 10.1007/s10902-006-9019-0

Sánchez-Álvarez, N., Extremera, N., and Fernández-Berrocal, P. (2015). Maintaining life satisfaction in adolescence: affective mediators of the influence of perceived emotional intelligence on overall life satisfaction judgments in a two-year longitudinal study. Front. Psychol. 6:1892. doi: 10.3389/fpsyg.2015.01892

Sánchez-Álvarez, N., Extremera, N., and Fernández-Berrocal, P. (2016). The relation between emotional intelligence and subjective well-being: a meta-analytic investigation. J. Positive Psychol. 11, 276-285. doi: 10.1080/17439760.2015.1058968

Schutte, N. S., Malouff, J. M., Thorsteinsson, E. B., Bhullar, N., and Rooke, S. E. (2007). A meta-analytic investigation of the relationship between emotional intelligence and health. Personal. Individ. Differ. 42, 921-933. doi: 10.1016/j.paid.2006.09.003

Seligman, M. E. P., and Csikszentmihalyi, M. (2000). Positive psychology: an introduction. Am. Psychol. 55, 5-14. doi: 10.1037/0003-066X 55.1 .5

Snyder, C. R., Lopez, S., and Teramoto Pedrotti, J. (2014). Positive Psychology: The Scientific and Practical Explorations of Human Strengths. London: Sage.

Stough, C., Saklofske, D., and Parker, J. (2009). Assessing Emotional Intelligence: Theory, Research, and Applications. New York, NY: Springer.

Tennant, R., Hiller, L., Fishwick, R., Platt, S., Joseph, S., Weich, S., et al. (2007). The warwick-edinburgh mental well-being scale (WEMWBS): development and UK validation. Health Qual. Life Outcomes 5, 1-13. doi: 10.1186/14777525-5-63

Terracciano, A., McCrae, R. R., and Costa, P. T. Jr. (2003). Factorial and construct validity of the Italian Positive and Negative Affect Schedule (PANAS). Eur. J. Psychol. Assess. 19, 131-141. doi: 10.1027//1015-5759. 19.2.131

Waterman, A. S., Schwartz, S. J., Zamboanga, B. L., Ravert, R. D., Williams, M. K., Bede Agocha, V., et al. (2010). The questionnaire for eudaimonic well-being: psychometric properties, demographic comparisons, and 
evidence of validity. J. Positive Psychol. 5, 41-61. doi: 10.1080/174397609034 35208

Watson, D., Clark, L. A., and Tellegen, A. (1988). Development and validation of brief measures of positive and negative affect: the PANAS Scales. J. Pers. Soc. Psychol. 54, 1063-1070. doi: 10.1037/0022-3514.54.6. 1063

Wood, A. M., Linley, P. A., Maltby, J., Baliousis, M., and Joseph, S. (2008). The authentic personality: a theoretical and empirical conceptualization, and the development of the Authenticity Scale. J. Counsel. Psychol. 55, 385-399. doi: 10.1037/0022-0167.55.3.385

World Medical Association [WMA] (2013). WMA Declaration of Helsinki Ethical Principles for Medical Research Involving Human Subjects. Available at: http://www.wma.net/en/30publications/10policies/b3/ (accessed 1 October, 2013).

Zeidner, M., Matthews, G., and Roberts, R. D. (2012). The emotional intelligence, health, and well-being nexus: what have we learned and what have we missed? Appl. Psychol. Health Well-Being 4, 1-30. doi: 10.1111/j.1758-0854.2011.01062.x
Zeidner, M., and Olnick-Shemesh, D. (2010). Emotional intelligence and subjective well-being revisited. Personal. Individ. Differ. 48, 431-435. doi: 10.1016/j.paid.2009.11.011

Zelenski, J. M., Murphy, S. A., and Jenkins, D. A. (2008). The happy-productive worker thesis revisited. J. Happiness Stud. 9, 521-537. doi: 10.1007/s10902-0089087-4

Conflict of Interest Statement: The authors declare that the research was conducted in the absence of any commercial or financial relationships that could be construed as a potential conflict of interest.

Copyright $\odot 2016$ Di Fabio and Kenny. This is an open-access article distributed under the terms of the Creative Commons Attribution License (CC BY). The use, distribution or reproduction in other forums is permitted, provided the original author(s) or licensor are credited and that the original publication in this journal is cited, in accordance with accepted academic practice. No use, distribution or reproduction is permitted which does not comply with these terms. 


\section{OPEN ACCESS}

Edited by:

Sara Bonesso,

Ca' Foscari University of Venice, Italy

Reviewed by:

Chiara Ghislieri,

University of Turin, Italy

Riccardo Sartori,

University of Verona, Italy

${ }^{*}$ Correspondence:

Nicola Mucci

nicola.mucci@unifi.it

Gabriele Giorgi

prof.gabriele.giorgi@gmail.com

Specialty section

This article was submitted to

Organizational Psychology,

a section of the journal

Frontiers in Psychology

Received: 12 May 2016 Accepted: 27 September 2016

Published: 13 October 2016

Citation:

Giorgi G, Montani F, Fiz-Perez J, Arcangeli $G$ and Mucci N (2016) Expatriates' Multiple Fears, from Terrorism to Working Conditions:

Development of a Model.

Front. Psychol. 7:1571 doi: 10.3389/fpsyg.2016.01571

\section{Expatriates' Multiple Fears, from Terrorism to Working Conditions: Development of a Model}

\author{
Gabriele Giorgi ${ }^{1 *}$, Francesco Montani ${ }^{2}$, Javier Fiz-Perez ${ }^{1}$, Giulio Arcangeli ${ }^{3}$ and \\ Nicola Mucci3* \\ ${ }^{1}$ Department of Psychology, European University of Rome, Rome, Italy, ${ }^{2}$ Montpellier Business School, Montpellier, France, \\ ${ }^{3}$ Department of Experimental and Clinical Medicine, University of Florence, Florence, Italy
}

Companies' internationalization appears to be fundamental in the current globalized and competitive environment and seems important not only for organizational success, but also for societal development and sustainability. On one hand, global business increases the demand for managers for international assignment. On the other hand, emergent fears, such as terrorism, seem to be developing around the world, enhancing the risk of expatriates' potential health problems. The purpose of this paper is to examine the relationships between the emergent concept of fear of expatriation with further workplace fears (economic crisis and dangerous working conditions) and with mental health problems. The study uses a quantitative design. Self-reported data were collected from 265 Italian expatriate workers assigned to both Italian and worldwide projects. Structural equation model analyses showed that fear of expatriation mediates the relationship of mental health with fear of economic crisis and with perceived dangerous working conditions. As expected, in addition to fear, worries of expatriation are also related to further fears. Although, the study is based on self-reports and the cross-sectional study design limits the possibility of making causal inferences, the new constructs introduced add to previous research.

Keywords: expatriate workers, work-related stress, economic stress, fear in the workplace, stress, health promotion, workplace, occupational medicine

\section{INTRODUCTION}

The globalization of markets that has taken place in recent decades was a great opportunity for companies to become known and to operate in a wider context (Biemann and Andresen, 2010; Andresen et al., 2014). This phenomenon led to the possibility that many of the managers who served in a national territory could be transferred to foreign countries, characterized by different cultures and work processes (Sims and Schraeder, 2005).

However, working globally involves changes in occupational dynamics and in the levels of job complexity, and it also requires great skills of adaptation and adjustment (Black et al., 1991; Black and Gregersen, 1999). Most of the researches conducted on adjustment in a foreign country concerned so-called expatriate workers or expatriates (Sims and Schraeder, 2005), who are those workers sent from their own organization to follow projects or to lead company sectors abroad. An expatriate can be properly defined as one who works in a foreign country for a period of at least 6 months (Birdseye and Hill, 1995; Jones, 2000; Chan et al., 2015). However, shorter forms of expatriation also exist, as shown in the present study. 
Supporting expatriates in performing their tasks in a new environment is nowadays essential for companies. Accordingly, researchers have studied expatriated performance and adaptation and evaluated the influence of specific practices of human resource management on their behavior. Relevant dimensions have been identified (Mol et al., 2005; Cheng and Lin, 2009), such as training, to support expatriates in dealing with different cultural values, unexpected behavioral rules, and language barriers. On the other hand, the dark sides of the expatriation experience have also been studied, such as the possible failure of the assignment, leaving without having finished the task, or psychologically withdrawing and performing worse than they usually would. Failure may be particularly expensive in human and monetary terms (Baruch, 2004).

However, adaptation/adjustment may be defined as the comfort degree (or the stress absence) associated with the role of the expatriate (Bhaskar-Shrinivas et al., 2005); expatriates who fail to face the demands of a job and do not properly adapt to a new environment may experience high levels of stress (Perone et al., 2008).

The scenario of stressors among expatriates seems complex, from the micro-environment and the macro-environment to the mega-environment (Lei et al., 2004). In particular, according to Bhaskar-Shrinivas et al. (2005), work assignments to be carried out abroad lead to greater stress when the following situations occur:

(a) when the leader perceives his role as unclear, or rather he does not understand which tasks are actually his and what the company expects from him;

(b) when the leader feels he has a low decision latitude; if he does not feel free to make decisions without first having to ask and obtain the green light from his company;

(c) if the position is considered too demanding, difficult or new; or in a situation that the leader does not feel up to the task of handling because of lack of experience or lack of capacity;

(d) when the manager recognizes that there is a conflict, such as in a case where certain tasks cannot be completed because that would hamper the achievement of other business objectives he is trying to achieve.

Black et al. (1991) observed that expatriates tend to suffer a greater number of relapses after periods of stress. Jones (2000), in a review, identified some risk factors that could not only adversely affect health, but could also lead to developing fear and anxiety of expatriation: risk of being involved in accidents; quality of living conditions; working conditions; risk of disease contagion; fear of being involved in violence; kidnappings and terrorist acts.

These risk factors are analyzed below:

- Risk of being involved in accidents. This fear is typically supported by the objective evidence that in some countries there are very low driving standards and poor road safety. Moreover, in some countries the roads are of low quality.

- Quality of living conditions. The quality of food and hygiene is one of the most important factors to ensure the adaptation of an expatriate to the new job environment. For example, good water quality cannot be ensured in all countries. Drinking poor quality water could cause the development of oral infections or gastrointestinal problems. The same effects can also be produced by eating non-controlled food. As far as lifestyle is concerned, a lack of leisure activities and difficulties in communication (for example, poor Internet and telephone functionality) may be a concern.

- Working conditions. There are higher psychological and physical strains in developing countries, which can inhibit the expatriate's ability to cope with perceived stress and can eventually increase unsafe practices. Heavy traffic and low control of industrial gas emissions could also affect the health of expatriates. Also, the presence of pristine nature in some working locations might interact negatively with a lower standard of safety and health.

- Chances of disease contagion. Expatriates should be informed on the prevalence of diseases in the host country before their trip or during their stay. The possibility of having specific vaccines would be an important protective factor against possible contagion. However, the fear of contagion from some illness might be always present in some countries. Psychological susceptibility to become stressed by the potential contagion also appears important.

- Fear of being involved in violence, kidnappings, and terrorist acts. This issue, once confined to few world regions, seems now to be more widespread (Bader and Schuster, 2015).

Given that anxiety could significantly decrease people's psychological well-being and mental health, there is increasing empirical research on the effect of fear in the workplace (Mueller and Tschan, 2011). Fear, especially if chronic, may damage, in particular, the immune, the nervous and the cardiovascular systems (Shiba et al., 2016).

The human body may be weakened by states of fear, especially if chronic. In particular, the immune, the nervous and the cardiovascular systems are damaged, but equally, the gastrointestinal tract and the reproductive system are not spared. In particular, the fear may compromise the decoding of emotions and decision making processes, making the subject susceptible to intense emotions and impulsive reactions and, consequently, to making inappropriate actions. Fatigue, depression, accelerated aging, and even premature death may be the further consequences of long-term fear (Shiba et al., 2016).

Furthermore, the literature shows that expatriate workers have an increased risk of consuming psychotropic and narcotic substances as well as of abusing of psychotropic drugs (Aubry et al., 2012; Bianchi et al., 2014; Kaeding and Borchers, 2016).

Our study enhanced the literature by being the first to look at a set of important fears among expatriates. In particular, we aimed to find out how the emergence of fear of expatriation, induced by mental health problems, might impact on the expatriate's further fears in the workplace, using data from a survey of 265 Italian expatriate workers.

Building on the stress perspective (Lazarus and Folkman, 1984; Lazarus, 1991), we have, in particular, examined the following issues: how mental health is associated with fear; the relationship between fear of expatriation and fear of economic crisis as well as perceived dangerous working conditions; the 
mediation of fear with mental health and the development of further fears.

We intend to conceptualize fear of expatriation due to the risk factors discussed above. Indeed, this study contributes to the literature on expatriates' health by testing an emergent model for the prevention of mental health issues. This paper proceeds as follows. First of all, we present the conceptual model and the derived hypotheses. Then, we explain the methodology used. Finally, the results and discussion (including limitations and research perspectives) are considered.

\section{Model Development}

Expatriate workers often experience difficulties in their adjustment to new work and living situations and, consequently, they are at risk of developing mental health problems (Costa et al., 2015; Zhu et al., 2016). This situation may enhance the fear of violence and of poor living and working conditions during the experience abroad (Lazarus and Folkman, 1984). This fundamental concept is the basis of our conceptual model (Figure 1).

With this in mind, workers can be severely traumatized not only by actual violence but also from any potential violence (Bader et al., 2015). For instance, terrorism is quickly spreading (Leistedt, 2013).

Data from the Global Terrorism Database (GTD) of the National Consortium for the Study of Terrorism and Responses to Terrorism (START) (2015) regarding global terrorism shows that in 2014 such attacks relate to 95 countries. In 2014, the worldwide attacks numbered 13,463 (35\% more than in 2013), which led to more than 32,700 deaths and more than 34,700 injured people. The geographical distribution is highly concentrated. Sixty percent of these attacks took place in five countries (Iraq, India, Afghanistan, Pakistan, and Nigeria), while $78 \%$ of the fatalities caused by terrorism took place in five countries (Iraq, Nigeria, Afghanistan, Pakistan, and Syria). The strategy of the most developed terroristic groups - e.g., Islamic State of Iraqi and the Levant (ISIL) and Boko Haram - not only provides for violent attacks on military or civilian points, but also for kidnapping, torture, and rape. These practices increase the fear of the people - particularly those who are located in the directly involved geographical areas - and of international public opinion. Workers with mental health problems might be particularly vulnerable to developing fears of these practices. The use of social media by ISIL has allowed for the extreme visibility of this organization with a widespread dissemination of its terroristic contents (United States Department of State Publication Bureau of Counterterrorism, 2015) and might increase anxiety in workers with pre-existent mental health problems or stress (Solberg et al., 2015; Glad et al., 2016; Paz García-Vera et al., 2016).

The context of living and working conditions in the host country is another factor associated with expatriates' psychological well-being. Frazee (1998) pointed out that healthcare is one of the main issues for expatriates: more than one-third of international assignments are dissatisfied with the health assistance they receive.

The standard of healthcare around the world varies in a very important way. However, discrepancies may exist even among different regions of the same country. In addition, expatriates might be afraid of not receiving an adequate and timely treatment for all types of injury and, moreover, the sanitary conditions might not be good, increasing the risks of contagions or illness. These concerns affect virtually all expatriate workers, but may result in real states of fear in subjects with mental health problems and may generate the acute and chronic worsening of any already existing clinical situation (Pierre et al., 2013; Cleary et al., 2014; Wilde and Gollogly, 2014).

Hypothesis 1: Mental health problems generate fear of expatriation.

The second part of the model is focused on the development of further fears in the workplace.

Despite the numerous relevant stressors in global assignments, in our conceptual framework we mainly focused on two areas of fear of expatriation. The first is related to violence, intended both as physical and psychological. The second is related to the perceived impeded living and working conditions (including workplace safety, illness contagion, and lifestyle).

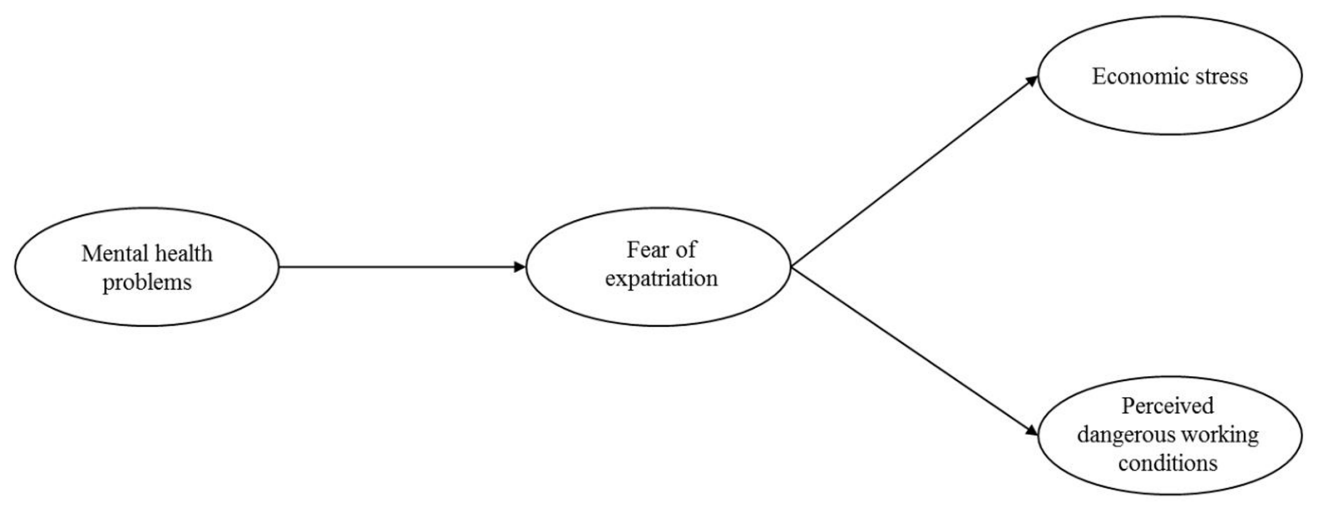

FIGURE 1 | Conceptual model. 
As already explained, the presence of a pre-existing state of fear or anxiety may enhance the likelihood of negative stimulus to elicit fear. Indeed, emotions are specific to the context and imply a person-environment relationship. More specifically, emotions embody a particular theme, reflecting the way the individual sees his/her relationship with the environment in a given situation (Lazarus, 2001).

The fear of expatriation might negatively influence the perception of the safety environment and the anxiety caused by economic crisis. Moreover, expatriates are often exported to societies with weaker and less expensive H\&S policies (Heymann, 2003), raising a perception of unsafe working conditions (Curcuruto et al., 2015).

In our model we expect a mediation process of fear of expatriation among mental health and further fears in the workplace. First, mental health problems generate anxiety and fear. Fear can impair the formation of long-term memories and can cause damage to certain parts of the brain, such as the hippocampus (Besnard and Sahay, 2016). This can make it even more difficult to regulate fear and can leave a person anxious most of the time. The threats to our security impact our mental wellbeing, whether they are real or perceived, generating multiple fears.

Hypothesis 2: Mental health problems, through the mediation of fear of expatriation, influence further fears in the workplace: dangerous working conditions and economic stress.

\section{MATERIALS AND METHODS}

\section{Procedure and Participants}

This study was conducted in a large international company dealing with technology and services in heavy industry. The expatriate managers employed in this company were all invited to participate in the study. Expatriation services in this company are usually in short form. Expatriates spend cyclically 28 days outside the workplace (often in platforms or yards located worldwide). The final respondents were 265 employees (response rate $=70 \%$ ) working in multiple locations (Italy, Europe, Middle East, Asia, Africa, Australia, etc.).

The survey was administered through the corporate Intranet, ensuring anonymity, and privacy rules. A video, in which an industrial psychologist and an occupational physician explained the procedure of questionnaire compilation and the survey aims, was also made available through the corporate Intranet.

The sample consisted of only men in managerial positions. Workers were, on average, relatively young: $18.9 \% 30$ years old or younger, $48.3 \%$ from 31 to 40 years old, $23.4 \%$ from 41 to 50 years old, and only $9.4 \%$ were over 50 . Regarding job tenure, $23.8 \%$ of the participants had worked from 0 to 5 years, $30.9 \%$ of participants had worked from 6 to 10 years, $30.9 \%$ of the participants had worked from 11 to 20 years, and $14.3 \%$ of participants more than 20 years. Finally, the majority of employees had long working hours (17.4\% 50 h per week, $26.6 \%$ 50-60 h per week, $56 \%$ more than $60 \mathrm{~h}$ per week).

\section{Measures}

After collecting some socio-demographic variables, participants completed the scales on fear of expatriation, economic stress, dangerous working conditions and psychological distress. The scales used in this study are described below.

\section{Fear of Expatriation}

Fear of expatriation was measured by a new questionnaire, developed by our research group and called Fear of expatriation scale (Supplementary Material).

The measure is composed of two dimensions:

(a) fear of violence/terrorism - (two items) employees are scared of being subjected to violence/terrorism (e.g., "I am scared of being the object of physical violence - kidnapping, terrorism, etc.");

(b) fear of the working and living conditions - (three items) employees are worried about the working and living conditions and about healthcare (e.g., "I am scared of contracting a disease").

The scores were collected, for each dimension, through a fivepoint Likert scale (from 1: "strongly disagree" to 5: "strongly agree"). As this instrument was developed for this research, we evaluated the construct validity and reliability of the fear of expatriation scale in order to investigate its psychometric properties. We assessed the construct validity (convergent validity and discriminant validity) of the scale by conducting a confirmatory factor analysis (CFA) in order to compare the hypothesized factorial model involving two distinct factors fear of violence/terrorism and fear of the working and living conditions - with a one-factor model. Results showed that the hypothesized two-factor model yielded a good fit to the data $\left(\chi^{2}[4]=9.35, n s ; \mathrm{CFI}=0.99 ; \mathrm{RMSEA}=0.07 ; \mathrm{SRMR}=0.02\right)$ and outperformed that of the one-factor solution $\left(\chi^{2}[4]=20.25\right.$, $p<0.01 ;$ CFI $=0.97$; RMSEA $=0.11$; SRMR $=0.02$; $\left.\Delta \chi^{2}(1)=10.90, p<0.01\right)$, thus supporting the distinctiveness between the two sub-dimensions of fear of violence/terrorism and fear of the working and living conditions. Furthermore, standardized regression coefficients of items on each factor were all higher than 0.50 (Hair et al., 2007), thus supporting the convergent validity of the factors (range $=0.62-0.85$ ). However, CFA results also indicated that the correlation among latent constructs was higher than 0.89. This therefore suggests that the two dimensions might be best combined on an overall scale of fear of expatriation (Kline, 2011). Accordingly, in our subsequent analyses to test Hypotheses 1 and 2, we considered only the overarching fear of expatriation scale, and not its separate dimensions. Finally, internal consistency, which was assessed by the calculation of reliability coefficients (Cronbach's alpha), was $0.86,0.76$, and 0.80 for the overall fear of expatriation scale, the fear of violence/terrorism dimension and the fear of the working and living conditions dimension, respectively. Thus, this indicated good internal consistency of the measure (Nunnally, 1978). 


\section{Economic Stress}

Economic stress was measured with the scale about subjective economic stress included in the recent Stress Questionnaire (SQ), developed and validated in Italy (Giorgi et al., 2013; Mucci et al., 2015). The economic stress measure is composed of two dimensions:

(a) fear of the economic crisis (five items) - employees perceive that the organization is suffering from the economic crisis (e.g., "I am scared that my organization is affected by the economic crisis; I am scared that my organization, due to the economic crisis, will be subjected to downsizing");

(b) non-employability (five items) - employees perceive that their working competencies would not permit them to acquire another job in the market (Caricati et al., 2016) [e.g., "My professionalism is not spendable (recognized) in the labor market; My staying in the organization is linked to the difficulty of outplacement in the labor market"].

Each dimension includes five items in a five-point Likert scale (from 1: "strongly disagree" to 5: "strongly agree").

\section{Dangerous Working Conditions}

We used a scale, included in the above mentioned Stress Questionnaire (Giorgi et al., 2013; Mucci et al., 2015), that covers two factors in a five-point Likert scale (from 1: "strongly disagree" to 5: "strongly agree"):

(a) dangerous working conditions (four items) - this measures the extent to which the organization's working conditions are dangerous for employees' H\&S (e.g., "Working methods are dangerous for my own and employees' health; The ergonomics of my work are harmful for my health");

(b) working conditions (five items) this measures the lack of general working conditions in the workplace, e.g., "Risk of accidents is low in my workplace (reverse scored); My workplace is free of workplace health hazards, chemical gas, smoke, etc. (reverse scored)."

\section{Psychological Distress}

This was measured with the General Health Questionnaire (GHQ-12; Goldberg and Hillier, 1979; Fraccaroli et al., 1991). The scale asks whether the respondent has experienced a particular symptom or behavior related to general psychological health recently. Each item is rated on a four-point Likert-type scale (01-2-3). A higher score indicates a greater degree of psychological distress. In this study we particularly focus on the sub-dimension "anxiety and insomnia" (seven items, e.g., "Considering the last few weeks, have you recently [... f felt constantly under strain?").

\section{RESULTS}

Following Anderson and Gerbing's (1988) two-step structural equation modeling (SEM) procedure, we tested a measurement model (CFA) by determining whether each measure's estimated loading on its expected underlying factor was significant. This allowed us to establish discriminant validity among the study constructs. Then, a structural model was performed to estimate the fit to the data of the hypothesized model in which fear of expatriation mediates the relationship of mental health problems with economic stress and perceived dangerous working conditions (Hypotheses 1 and 2). A CFA was, therefore, performed with Mplus, version 7.11 (Muthén and Muthén, 1998-2010), with the four variables measuring mental health problems, fear of expatriation, economic stress, and perceived dangerous working conditions. Moreover, the variables' dimensions were used as indicators of their corresponding latent constructs in the measurement and structural models. These dimensions were formed by averaging the items of each sub-scale for the four latent variables. We therefore obtained three indicators for mental health problems, two indicators for fear of expatriation, two indicators for economic stress, and two indicators for perceived dangerous working conditions.

To evaluate the model fit, we considered chi-square (the higher the values are, the worse is the model's correspondence to the data), and used both absolute and incremental fit indexes. Absolute fit indexes evaluate how well an a priori model reproduces the sample data. In our study, we focused on three absolute fit indexes: the standardized root mean square residual (SRMR), for which values of less than 0.08 are favorable, and the root-mean-square error of approximation (RMSEA), which should not exceed 0.10 (Browne and Cudeck, 1993; Kline, 2011). Incremental fit indexes measure the proportionate amount of improvement in fit when a target model is compared with a more restricted, nested baseline model (Schreiber et al., 2006). We considered the comparative fit index (CFI), for which values of 0.90 or greater are recommended (Schreiber et al., 2006).

As expected, the hypothesized four-factor model yielded a good fit to the data: $\chi^{2}(20)=61.17, \mathrm{CFI}=0.95$, RMSEA $=0.09$, SRMR $=0.05$ (Table 1). Additionally, as shown in Table 2, this model had a significantly better fit than alternative, more parsimonious models $(p<0.01)$, supporting the distinctiveness of the study variables. Table 2 displays the descriptive statistics, correlations, and reliability coefficients of the variables.

In order to examine the hypothesized model, we performed SEM with Mplus. SEM offers the following advantages:

(a) controlling for measurement errors when the relationships among variables are analyzed (Hoyle and Smith, 1994);

(b) comparing the goodness-of-fit of the hypothesized model with other alternative models (Cheung and Lau, 2008).

Thus, we tested our proposed structural model and compared it with alternative models. Additionally, when conducting SEM analyses, we controlled for the effects of age and organizational tenure on both the mediator and the dependent variables. Fit indexes for each tested model are presented in Table 3.

The hypothesized model (Model 1), which is a full mediation model, displayed a good fit to the data: $\chi^{2}(35)=70.37$, $\mathrm{CFI}=0.96$; $\mathrm{RMSEA}=0.06$; $\mathrm{SRMR}=0.06$. Specific inspection of direct relationships further revealed that mental health problems were positively associated with fear of expatriation $(\beta=0.64$, $p<0.01$ ), thus supporting Hypothesis 1 . Additionally, fear of 
TABLE 1 | Fit indices for confirmatory factor analyses.

\begin{tabular}{|c|c|c|c|c|c|c|c|}
\hline Model & $x^{2}$ & $d f$ & $\Delta \chi^{2}$ & $\Delta d f$ & CFI & RMSEA & SRMR \\
\hline Hypothesized four-factor model & $61.175^{*}$ & 20 & - & - & 0.95 & 0.09 & 0.05 \\
\hline \multicolumn{8}{|l|}{ Three-factor models } \\
\hline Combining MHP and FEX & $128.08^{*}$ & 23 & * & 3 & 0.87 & 0.13 & 0.07 \\
\hline Combining MHP and FEC & $94.25^{*}$ & 23 & $*$ & 3 & 0.91 & 0.11 & 0.07 \\
\hline Combining MHP and DWC & $185.43^{*}$ & 23 & $*$ & 3 & 0.80 & 0.16 & 0.10 \\
\hline Combining FEX and FEC & $153.02^{*}$ & 23 & $*$ & 3 & 0.84 & 0.15 & 0.07 \\
\hline Combining FEX and DWC & $184.11^{*}$ & 23 & $*$ & 3 & 0.80 & 0.16 & 0.10 \\
\hline Combining FEC and DWC & $274.90^{*}$ & 23 & $*$ & 3 & 0.69 & 0.20 & 0.18 \\
\hline \multicolumn{8}{|l|}{ Two-factor model } \\
\hline Combining MHP, FEX and FEC & $159.29 *$ & 25 & $*$ & 5 & 0.83 & 0.14 & 0.07 \\
\hline Combining MHP, FEX and DWC & $247.55^{*}$ & 25 & $*$ & 5 & 0.73 & 0.18 & 0.10 \\
\hline Combining MHP, FEC, and DWC & $211.30^{*}$ & 25 & $*$ & 5 & 0.77 & 0.17 & 0.10 \\
\hline Combining FEX, FEC, and DWC & 263.09* & 25 & $*$ & 5 & 0.71 & 0.19 & 0.11 \\
\hline One-factor model & $269.46^{*}$ & 26 & $*$ & 6 & 0.70 & 0.19 & 0.10 \\
\hline
\end{tabular}

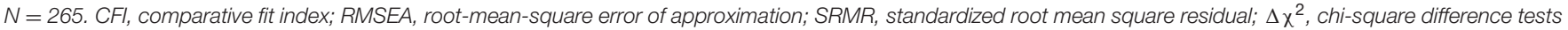

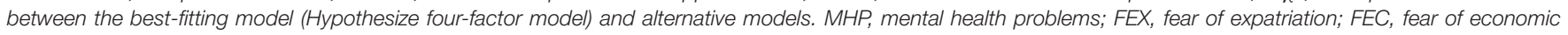
crisis; DWC, perceived dangerous working conditions. ${ }^{*} p<0.01$.

TABLE 2 | Descriptive statistics and correlations.

\begin{tabular}{|c|c|c|c|c|c|c|c|c|}
\hline Variables & $M$ & $S D$ & 1 & 2 & 3 & 4 & 5 & 6 \\
\hline (1) Age & - & - & - & & & & & \\
\hline (2) Organizational tenure & - & - & $0.57^{* *}$ & - & & & & \\
\hline (3) Mental health problems & 10.60 & 5.09 & -0.11 & -0.05 & $(0.80)$ & & & \\
\hline (4) Fear of expatriation & 7.05 & 2.33 & $-0.22^{* *}$ & -0.02 & $0.52^{* *}$ & $(0.86)$ & & \\
\hline (5) Fear of economic crisis & 2.55 & 0.55 & -0.02 & 0.00 & $0.36^{* *}$ & $0.29 * *$ & $(0.84)$ & \\
\hline (6) Perceived dangerous working conditions & 3.37 & 0.68 & $-0.22^{* *}$ & 0.04 & $0.34 * *$ & $0.57^{* *}$ & $0.19 * *$ & $(0.84)$ \\
\hline
\end{tabular}

$N=265$. Internal Consistency coefficients (Cronbach's alphas) appear along the diagonal in parentheses. ${ }^{* *} p<0.01$.

expatriation, in turn, was positively related to economic stress $(\beta=0.40, p<0.01)$ and perceived dangerous working conditions $(\beta=0.66, p<0.01)$, thus providing preliminary support for Hypothesis 2. Completely standardized path coefficients for Model 1 are depicted in Figure 2.

To assess whether the hypothesized model was the best representation of the data, we then compared its fit to that of different alternative models. First, we assessed a partial mediation model, which included two additional direct paths from mental health problems to economic stress and perceived dangerous working conditions. This model yielded an adequate fit to the data $\left(\chi^{2}[33]=67.21, \mathrm{CFI}=0.96\right.$; $\mathrm{RMSEA}=0.06$; $\left.\mathrm{SRMR}=0.05\right)$, but it was not significantly better than Model 1 , as revealed by the chi-square difference $\left(\Delta \chi^{2}[1]=3.16, n s\right)$. Moreover, the additional direct relationships of workplace mental problems with economic stress $(\beta=0.13, n s)$ and dangerous working conditions were not significant $(\beta=0.03, n s)$.

Next, we compared the hypothesized model with a nonmediation model (Model 3), which only included direct paths from mental health problems and fear of expatriation to economic stress and perceived dangerous working conditions. Results revealed that the non-mediation model was a slightly worse fit to the data than the hypothesized fully-mediated model $\left(\chi^{2}[35]=81.61, \mathrm{CFI}=0.95 ; \mathrm{RMSEA}=0.07 ; \mathrm{SRMR}=0.06\right)$.
However, because this model had the same degrees of freedom as the hypothesized model, the statistical significance of the chisquare difference could not be calculated. Accordingly, we used the Akaike Information Criterion (AIC), instead of the chisquare, to compare the two models. The hypothesized model is considered to be superior to the non-mediation model if the former has an AIC value lower than the latter by four or more units (Burnham and Anderson, 2002). Results revealed that Model 3 had an AIC of 7301.58 compared to an AIC of 7290.35 for Model 1, suggesting that the hypothesized full mediation model represents a superior fit to the data than the non-mediation model $(\triangle \mathrm{AIC}=11.23)$.

Furthermore, because mental health problems, fear of expatriation, economic stress, and perceived dangerous working conditions were all measured at the same time, reverse relationships could also be expected between the four variables. In order to rule out this possibility, we therefore compared the hypothesized model against a set of alternative models that specified all the possible reverse indirect relationships among the study variables, namely: the indirect relationship of economic stress and perceived dangerous working conditions with fear of expatriation via mental health problems (Model 4); the indirect relationship of economic stress and perceived dangerous working conditions with mental health problems 
TABLE 3 | Fit indices for nested structural models.

\begin{tabular}{|c|c|c|c|c|c|c|c|c|c|c|}
\hline Model & Structure & $x^{2}$ & $d f$ & $\Delta \chi^{2}$ & $\Delta d f$ & CFI & RMSEA & SRMR & AIC & $\Delta \mathrm{AIC}$ \\
\hline Model 1 (Hypothesized full mediation model) & MHI & $70.37^{*}$ & 35 & - & 0 & 0.96 & 0.06 & 0.06 & 7290.34 & - \\
\hline Model 2 (Partial mediation model) & $\mathrm{MHP}=$ & $67.21^{*}$ & 33 & 3.16 & 0 & 0.96 & 0.06 & 0.05 & 7291.18 & 0.84 \\
\hline Model 3 (non-mediation model) & & $81.16^{*}$ & 35 & - & 2 & 0.95 & 0.07 & 0.06 & 7301.58 & 11.23 \\
\hline Model 4 & & $129.19^{*}$ & 37 & $58.46^{*}$ & 2 & 0.89 & 0.10 & 0.07 & 7345.16 & 54.82 \\
\hline Model 5 & & $89.49^{*}$ & 37 & $18.76^{*}$ & 2 & 0.94 & 0.07 & 0.06 & 7305.47 & 15.13 \\
\hline Model 8 & & $108.13^{*}$ & 35 & - & 0 & 0.91 & 0.09 & 0.07 & 7328.11 & 37.77 \\
\hline
\end{tabular}

$N=$ 265. CFI, comparative fit index; RMSEA, root-mean-square error of approximation; SRMR, standardized root mean square residual; Akaike Information Criterion $\Delta \chi^{2}=$ chi-square difference tests between the best-fitting model (Model 1) and alternative models; $\triangle$ AlC, Akaike difference test between the best-fitting model (Model 1) and alternative models. FEX, fear of expatriation; FEC, fear of economic crisis; DWC, dangerous working conditions; MHP, mental health problems. ${ }^{*} p<0.05$.

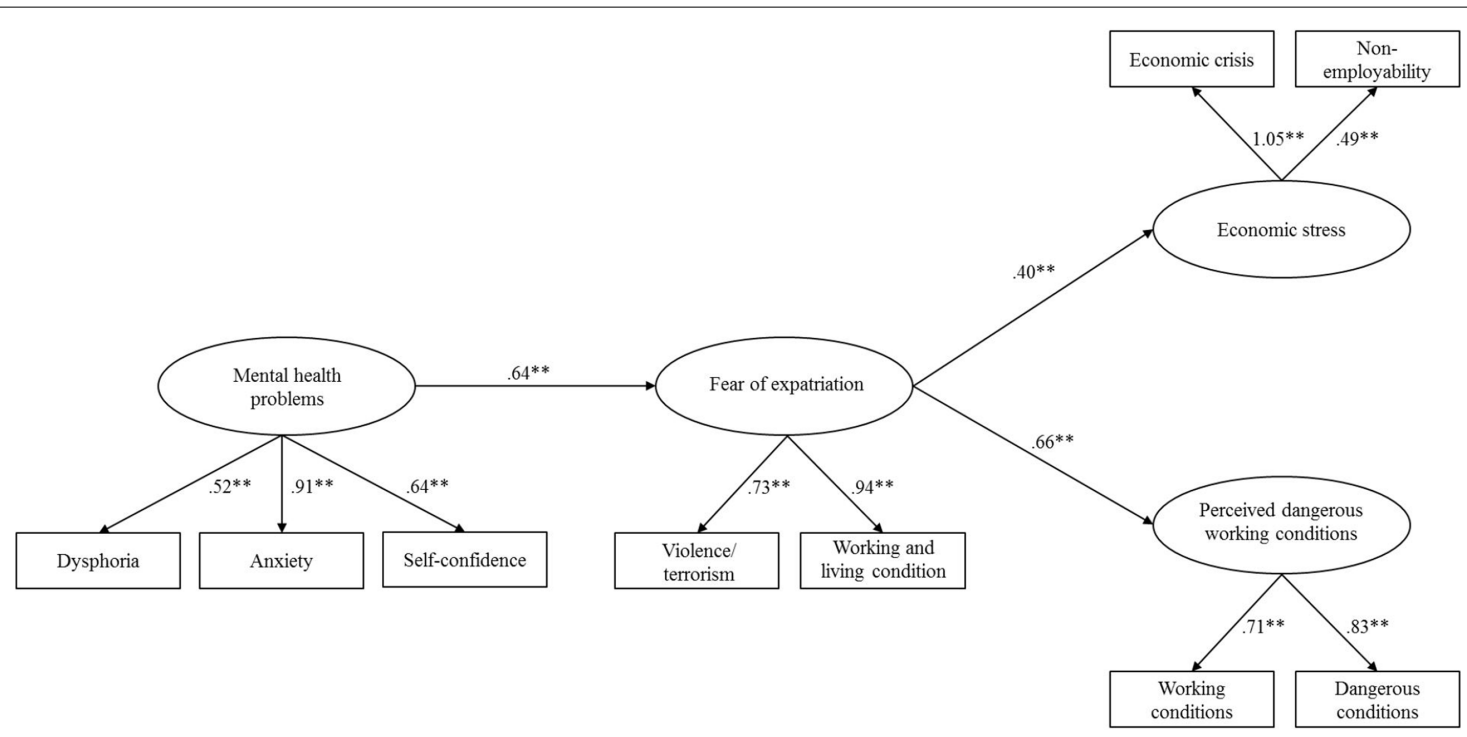

FIGURE 2 | Completely standardized path coefficients for Model 1. ${ }^{* *} p<0.01$.

via fear of expatriation (Model 5); the indirect relationship between mental health problems and fear of expatriation via economic stress and perceived dangerous working conditions (Model 6); the indirect relationship of fear of expatriation with economic stress and perceived dangerous working conditions via mental health problems (Model 7); the relationship between fear of expatriation and mental health problems via economic stress and perceived dangerous working conditions (Model 8). Again, because Models 6-8 had the same degrees of freedom as the hypothesized model, we compared the model fit by using the AIC difference test. As can be seen from Table 3, Models 4-8 all yielded a worse fit to the data than the hypothesized model. Overall, results from model comparison suggested that Model 1 was the best fitting model. We therefore retained the hypothesized fully-mediated model.

Finally, in order to assess whether the indirect relationship of mental health problems with economic stress and perceived dangerous working conditions through fear of expatriation was significant (Hypothesis 2), we calculated 95\% bootstrapping 
confidence intervals (Preacher and Hayes, 2008; Preacher and Kelley, 2011). Based on 5,000 bootstrap replications, results indicated that mental health problems had an indirect positive effect on economic stress (indirect effect $=0.18 ; 95 \% \mathrm{CI}=0.12$, 0.24 ) and perceived dangerous working conditions (indirect effect $=0.18 ; 95 \% \mathrm{CI}=0.12,0.24)$ via fear of expatriation. Hypothesis 2 was therefore fully supported.

\section{DISCUSSION}

In a globalized working environment with turbulence in the economy and in the security expatriate workers are confronted with several stressors, making international assignments potentially stressful. Accordingly, expatriate managers might report lower psychological well-being and anxiety (Wang and Kanungo, 2004; Shaffer et al., 2006; Wang and Nayir, 2006).

At the same time, fears are now increasing in the workplace, marked by emotional discomfort, apprehension, or concerns about the internal and external environment, and expatriates seem particularly at risk. These symptoms can progress to more severe psychosomatic symptoms, including further anxiety and additional fears (Blum et al., 2010; Besnard and Sahay, 2016).

In our model, fear of expatriation is particularly associated with mental health problems. This result is in line with the field literature (i.e., Perone et al., 2008; Andresen et al., 2014; Arac1, 2015). In addition, an expatriate might go through several personal and professional problems. In fact, expatriation is associated with a lot of unhealthy issues such as stress, anxiety, loneliness and homesickness, generating a sort of potential and prolonged cultural shock (Barón et al., 2014). Finally, it must be emphasized that expatriates cannot count on the support of family and/or other trusted people if they need it (Bhaskar-Shrinivas et al., 2005).

Fear of expatriation might generate a spiraling effect in which people, feeling more anxious, might become less engaged in the workplace, developing beliefs that money and extrinsic reward are the most important aspects of employment (Gerhart and Fang, 2015). At the same time, they may be more worried about their financial situation and their ability to hold on to their jobs and their benefits, developing their fear of economic crisis.

On one hand, from a subjective point of view, H\&S measures under certain circumstances (for instance, the emergence of fear in the workplace) - do not necessarily express feelings of safety, but rather can be interpreted as latent danger (Bader and Berg, 2012) generating a widespread anxiety. On the other hand, from an objective point of view, expatriates are often exported to societies with weaker and less expensive H\&S policies and less organized labor forces, bringing potentially stressful and unsafe working conditions (Heymann, 2003) to expatriates. This might raise a perception of dangerous working conditions. Moreover, $\mathrm{H} \& \mathrm{~S}$ procedures are usually highly specific to each country and with very important differences - related to the various national legislations and traditions - and working conditions abroad are generally perceived as less familiar and presenting higher risk (Taylor et al., 2007).
Expatriates are a group of people with a high cumulative risk of exposure to illness and injury (including the increased risk of certain vaccine-preventable illnesses) due to changes in travel patterns and activities, lifestyle alterations, and increased interaction with local populations. Pre-travel immunization management provides one safe and reliable method of preventing infectious illness in this group; however, this might not be enough to cope with anxiety (Vaid et al., 2013; Shepherd and Shoff, 2014). In addition, there are diseases that are not preventable with vaccines. These diseases, in particular of a viral nature, seem to spread faster nowadays - such as, for example, the recent Ebola or Middle East Respiratory Syndrome (MERS) outbreaks - and might be frightening for expatriates (Cohen et al., 2016; Regan et al., 2016).

In summary, the non-optimal H\&S perception (Beeley et al., 1993), the risk of contracting infectious diseases (Jones, 1999; Hamlyn et al., 2007) and the unsuitability of medical care (Pierre et al., 2013) were also evaluated under the construct of the fear of expatriation.

In our study, expatriates reported being frightened by the risk of becoming involved in accidents during their frequent moves from one country to another. In particular, this fear seemed to be greater for traffic accidents (Wilks et al., 1999), but a fear of flying was also described (Hack-Polay, 2012).

A further and significant stress factor for expatriate workers is the managers' fear of terrorist attacks or other fatal events involving the governments of countries where there are companies' headquarters (Leistedt, 2013; Bader and Schuster, 2015). Finally, in our model we consider the concerns about the working and living conditions (Costa et al., 2015; Zhu et al., 2016).

In addition, our model has shown that the presence of fear of expatriation may, in turn, generate further fears in the workplace. In particular, fears of both the economic crisis and of the foreign working conditions are mediated by fear of expatriation. In fact, fear could adversely disturb human thinking and decision-making processes, leaving the individual more susceptible to generating further fears, as in a vicious circle (Barón et al., 2014; Besnard and Sahay, 2016).

Our findings are in line with the basic propositions of Lazarus and the "affective events theory" (AET; Weiss and Cropanzano, 1996). The latter pointed out that an emotion experienced by a worker (e.g., fear) may impact on later within-person emotions (e.g., fear again), influencing different organizational outcomes.

As far as economic crisis is concerned, economic stress might be more frightening for those who have more invested in the company, such as expatriates. In fact, these workers, being away from home for extended periods of time, are completely absorbed by their job and, therefore, they may be an easier target for contagious negative emotional cycles (Quantin et al., 2012). Moreover, they could be most affected by the psychological impacts of the economic crisis and its consequences as they have lower levels of social support (Fernandez et al., 2015).

Similarly, fear of expatriation may significantly lead to perceiving a priori all foreign working conditions as being more dangerous. These findings support our assumption and the 
literature (Perone et al., 2008; Andresen et al., 2014). The impact of working and living conditions - resulting, for instance, in perceived risks of harms - might be higher if expatriates are scared by the impeded living conditions or by the threat of violence. This might have several negative implications as often expatriates have the tendency to "get the job done" as smoothly as possible, so they can return home again (Arac1, 2015). However, this specific issue should be investigated in future studies.

Our findings provide interesting contributions both to the literature and to the managerial practices in the field of foreign work.

First, we believe that the subjects in the process of leaving their own country should be mentally healthy and not feeling frightened by either the place of destination or the assigned tasks. According to Lazarus and Folkman (1984), if an expatriate is worried and anxious, it is less likely that he/she will ever adjust. Therefore, it is essential to help expatriates to prevent the development of any type of fear. Strategies of prevention and rationalization, particularly useful in this sense, can be implemented through several instruments: specific training for foreign services, company's reference facilities in countries where employees come to work, remote counseling (on-line/phone) provided by occupational physicians and psychologists affiliated with the company, company procedures for immediate repatriation in the case of adverse events (e.g., terrorism, infective outbreaks, and health problems), etc.

In the second place, stress management training is also recommended. From this perspective, issue-focused coping strategies seem crucial to counteract fearful feelings as well as to minimize the states of anxiety and distress (Folkman et al., 1986).

Thirdly, companies should conduct preventive screening to identify the human resources to be sent to foreign countries, favoring those who have demonstrated both a highly qualified professionalism in their field and robust mental health (Stone, 1991; Di Fabio, 2014, 2015).

Consequently, a process for the successful management of expatriation needs to be adopted using both individual and organizational strategies to reduce the possibilities of stress among expatriates. At the organizational level, selection, training, healthcare activities, and counseling need to be implemented and monitored in order to prevent the diffusions of workplace fears. At the individual level, expatriates should be psychologically supported, e.g., with mentoring and coaching, analyzing competencies, health perceptions, and mood over time (De Paul and Bikos, 2015).

Our study has many and innovative strengths but is not without limitations. Although the expatriates worked worldwide, the sample was limited to a single company, limiting the generalizability of the results. In addition, the sample was composed only of men. However, by virtue of family demands, men expatriate much more frequently than women. Our scale fear of the expatriation is new in the literature and, consequently, a replication of this study is needed. In addition, we look forward to more large studies whose starting points are the results of the first application of our scale. In particular, comparative research evaluating stress responses between Italian and other ethnic populations around the world would be particularly helpful.

This study used a cross-sectional design, resulting in the impossibility of determining causal relationships. Longitudinal research is needed in order to provide further evidence that mental health problems cause fear of expatriation, which, in turn, may generate additional workplace fears.

In summary, following this new research path, we have developed a new model, formulated a new theory that found an association between mental health and fears in the workplace, and explored different fears in the workplace and their links.

Our results confirmed our innovative hypothesis and we suggest that companies' key people take into account the construct of fear of expatriation for business health purposes. With this in mind, companies need proper advice from qualified consultants such as occupational physicians and industrial psychologists. An investment dedicated to the prevention and protection of the H\&S of expatriate workers is not only an instrument of risk assessment - in the context of the obligations under the laws of EU countries in the field (e.g., the Italian Legislative Decree n. 81 and subsequent amendments) - but also, and moreover, a significant tool to improve the company's business.

Some studies have estimated that the cost associated with the failure of expatriation would be about one million USD (Insch and Daniels, 2002; Wentland, 2003). Overall, considering the aggregate data about the American situation, Punnett (1997) has calculated that US companies spend a total of up to two billion USD annually to address the failures of their expatriate managers. In such a context, it is legitimate to expect that intervention strategies - such as a careful selection of personnel to be devoted to foreign missions and the development of actions aimed at improving the real and perceived well-being in destination countries - will lead to significant returns on investment (ROI) for the companies.

\section{AUTHOR CONTRIBUTIONS}

GG, FM, JF-P, GA, and NM equally contributed to all the following issues of the research: conception and design of the work; acquisition, analysis, or interpretation of data for the work; drafting the work and critically revising it; final approval of the version to be published; agreement to be accountable for all aspects of the work in ensuring that questions related to the accuracy or integrity of any part of the work are appropriately investigated and resolved.

\section{SUPPLEMENTARY MATERIAL}

The Supplementary Material for this article can be found online at: http://journal.frontiersin.org/article/10.3389/fpsyg. 2016.01571 


\section{REFERENCES}

Anderson, J. C., and Gerbing, D. W. (1988). Structural equations modeling in practice: a review and recommended two-step approach. Psychol. Bull. 103, 411-423. doi: 10.1037/0033-2909.103.3.411

Andresen, M., Bergdolt, F., Margenfeld, J., and Dickmann, M. (2014). Addressing international mobility confusion-developing definitions and differentiations for self-initiated and assigned expatriates as well as migrants. Int. J. Hum. Resour. Manag. 25, 2295-2318. doi: 10.1080/09585192.2013.877058

Arac1, M. (2015). The barriers to increasing the productivity in expatriate management: examples in the world and Turkey. Procedia Soc. Behav. Sci. 195, 993-1002. doi: 10.1016/j.sbspro.2015.06.326

Aubry, C., Gaudart, J., Gaillard, C., Delmont, J., Parola, P., Brouqui, P., et al. (2012). Demographics, health and travel characteristics of international travellers at a pre-travel clinic in Marseille. France. Travel. Med. Infect. Dis. 10, 247-256. doi: 10.1016/j.tmaid.2012.09.004

Bader, B., and Berg, N. (2012). An empirical investigation of terrorism-induced stress on expatriate attitudes and performance. J. Int. Manag. 19, 163-175. doi: 10.1016/j.intman.2013.01.003

Bader, B., Berg, N., and Holtbrügge, D. (2015). Expatriate performance in terrorism-endangered countries: the role of family and organizational support. Int. Bus. Rev. 24, 849-860. doi: 10.1016/j.ibusrev.2015.03.005

Bader, B., and Schuster, T. (2015). Expatriate social networks in terrorismendangered countries: an empirical analysis in Afghanistan, India, Pakistan, and Saudi Arabia. J. Int. Manag. 21, 63-77. doi: 10.1016/j.intman.2014.09.004

Barón, S. B. V., Mendoza, A. R. R., and Ríos, M. S. O. (2014). "Cultural shock, acculturation and reverse acculturation: the case of Mexican citizens traveling to and back from China and their competitiveness level," in Proceedings of the Global Conference on Business \& Finance Proceedings, Vol. 9, (Hilo, HI: Institute for Business \& Finance Research), 658-664.

Baruch, Y. (2004). Managing Careers: Theory and Practice. Upper Saddle River, N.J: FT-Prentice-Hall.

Beeley, J. M., Smith, D. J., and Oakley, E. H. (1993). Environmental hazards and health. Br. Med. Bull. 49, 305-325.

Besnard, A., and Sahay, A. (2016). Adult hippocampal neurogenesis, fear generalization, and stress. Neuropsychopharmacology 41, 24-44. doi: 10.1038/ npp.2015.167

Bhaskar-Shrinivas, P., Harrison, D. A., Shaffer, M. A., and Luk, D. M. (2005). Input-based and time-based models of international adjustment: meta-analytic evidence and theoretical extensions. Acad. Manage. Rev. 48, 257-281. doi: 10.5465/AMJ.2005.16928400

Bianchi, F., Bisceglie, F., Dugheri, S., Arcangeli, G., Cupelli, V., del Borrello, E., et al. (2014). Ionic liquid-based solid phase microextraction necklaces for the environmental monitoring of ketamine. J. Chromatogr. A 2014, 1-9. doi: 10.1016/j.chroma.2014.01.012

Biemann, T., and Andresen, M. (2010). Self-initiated foreign expatriates versus assigned expatriates. Two distinct types of international careers?. J. Manage. Psychol. 25, 430-448. doi: 10.1108/02683941011035313

Birdseye, M. G., and Hill, J. S. (1995). Individual, organizational/work, and environmental influences on expatriate turnover tendencies: an empirical study. J. Int. Bus. Stud. 26, 787-813. doi: 10.1057/palgrave.jibs. 8490820

Black, J. S., and Gregersen, H. B. (1999). The right way to manage expats. Harvard. Bus. Rev. 77, 52-63.

Black, J. S., Mendenhall, M., and Oddou, G. (1991). Toward a comprehensive model of international adjustment: an integration of multiple theoretical perspectives. Acad. Manage. Rev. 16, 291-317. doi: 10.5465/AMR.1991.4278938

Blum, J. A., Pfeifer, S., and Hatz, C. F. (2010). Psychiatric manifestations as the leading symptom in an expatriate with dengue fever. Infection 38, 341-343. doi: 10.1007/s15010-010-0029-9

Browne, M. W., and Cudeck, R. (1993). "Alternative ways of assessing model fit," in Testing Structural Equation Models, eds K. A. Bollen and J. S. Long (Beverly Hills, CA: Sage), 136-162.

Burnham, K. P., and Anderson, D. R. (2002). Model Selection and Multimodel Inference: A Practical Information-Theoretic Approach. New York, NY: Springer-Verlag.

Caricati, L., Chiesa, R., Guglielmi, D., and Mariani, M. G. (2016). Real and perceived employability: a comparison among Italian graduates. J. Higher Educ. Pol. Manage. 38, 1-13. doi: 10.1080/1360080X.2016.1182668
Chan, I. Y., Leung, M. Y., and Liu, A. M. (2015). Occupational health management system: a study of expatriate construction professionals. Accid. Anal. Prev 93, 280-290. doi: 10.1016/j.aap.2015.11.003

Cheng, H. L., and Lin, C. Y. Y. (2009). Do as the large enterprises do? Expatriate selection and overseas performance in emerging markets: the case of Taiwan SMEs. Int. Bus. Rev. 18, 60-75. doi: 10.1016/j.ibusrev.2008.12.002

Cheung, G. W., and Lau, R. S. (2008). Testing mediation and suppression effects of latent variables: bootstrapping with structural equation models. Organ. Res. Methods. 11, 296-325. doi: 10.1177/1094428107300343

Cleary, M., Walter, G., Siegfried, N., and Jackson, D. (2014). Contemplating an expatriate health care position? Key factors to consider. Issues Ment. Health Nurs. 35, 406-409. doi: 10.3109/01612840.2014.899301

Cohen, N. J., Brown, C. M., Alvarado-Ramy, F., Bair-Brake, H., Benenson, G. A., Chen, T. H., et al. (2016). Travel and border health measures to prevent the international spread of Ebola. MMWR. Suppl. 2016, 57-67. doi: 10.15585/mmwr.su6503a9

Costa, M., Oberholzer-Riss, M., Hatz, C., Steffen, R., Puhan, M., and Schlagenhauf, P. (2015). Pre-travel health advice guidelines for humanitarian workers: a systematic review. Travel. Med. Infect. Dis. 13, 449-465. doi: 10.1016/j.tmaid.2015.11.006

Curcuruto, M., Conchie, S. M., Mariani, M. G., and Violante, F. S. (2015). The role of prosocial and proactive safety behaviors in predicting safety performance. Safety. Sci. 80, 317-323. doi: 10.1016/j.ssci.2015.07.032

De Paul, N. F., and Bikos, L. H. (2015). Perceived organizational support: a meaningful contributor to expatriate development professionals' psychological well-being. Int. J. Intercult. Relat. 49, 25-32. doi: 10.1016/j.ijintrel.2015. 06.004

Di Fabio, A. (2014). Intrapreneurial self-capital: a new construct for the 21 st century. J. Employ. Couns. 51, 98-111. doi: 10.1002/j.2161-1920.2014.00045

Di Fabio, A. (2015). Beyond fluid intelligence and personality traits in social support: the role of ability based emotional intelligence. Front. Psychol. 6:395. doi: 10.3389/fpsyg.2015.00395

Fernandez, A., Garcia-Alonso, J., Royo-Pastor, C., Garrell-Corbera, I., RengelChica, J., Agudo-Ugena, J., et al. (2015). Effects of the economic crisis and social support on health-related quality of life: first wave of a longitudinal study in Spain. Br. J. Gen. Pract. 65, e198-e203. doi: 10.3399/bjgp15X 684025

Folkman, S., Lazarus, R. S., Dunkel-Schetter, C., DeLongis, A., and Gruen, R. J. (1986). Dynamics of a stressful encounter: cognitive appraisal, coping, and encounter outcomes. J. Pers. Soc. Psychol. 50, 992-1003. doi: 10.1037/00223514.50.5.992

Fraccaroli, F., Depolo, M., and Sarchielli, G. (1991). L'uso del general health questionnaire di Goldberg in una ricerca su giovani disoccupati. B. Psicol. Appl. 197, 13-19.

Frazee, V. (1998). Keeping your expatriates happy. Workforce 6, 18-23.

Gerhart, B., and Fang, M. (2015). Pay, intrinsic motivation, extrinsic motivation, performance, and creativity in the workplace: revisiting long-held beliefs. Annu. Rev. Organ. Psychol. Organ. Behav. 2, 489-521. doi: 10.1146/annurev-orgpsych032414-111418

Giorgi, G., Arcangeli, G., and Cupelli, V. (2013). Stress Questionnaire (SQ). Florence: Hogrefe Press.

Glad, K. A., Jensen, T. K., Hafstad, G. S., and Dyb, G. (2016). Posttraumatic stress disorder and exposure to trauma reminders after a terrorist attack. J. Trauma. Dissociation 17, 435-447. doi: 10.1080/15299732.2015.1126777

Goldberg, D. P., and Hillier, V. F. (1979). A scaled version of the general health questionnaire. Psychol. Med. 1979, 139-145. doi: 10.1017/S003329170 0021644

Hack-Polay, D. (2012). When Home Isn't home - a study of homesickness and coping strategies among migrant workers and expatriates. Int. J. Psychol. Stud. 4, 62-72. doi: 10.5539/ijps.v4n3p62

Hair, J. F., Black, W. C., Babin, B. J., and Anderson, R. E. (2007). Multivariate Data Analysis, 7th Edn. Englewood Cliffs, NJ: Prentice Hall.

Hamlyn, E., Peer, A., and Easterbrook, P. (2007). Sexual health and HIV in travellers and expatriates. Occup. Med. (Lond.). 57, 313-321. doi: $10.1093 /$ occmed/kqm044

Heymann, J. (2003). Global Inequalities at Work: Work's Impact on the Health of Individuals, Families, and Societies New York. New York, NY: Oxford University Press. 
Hoyle, R. H., and Smith, G. T. (1994). Formulating clinical research hypotheses as structural equation models: a conceptual overview. J. Consult. Clin. Psychol. 62, 429-440. doi: 10.1037/0022-006X.62.3.429

Insch, G. S., and Daniels J. D. (2002). Causes and consequences of declining early departures from foreign assignments. Bus. Horiz. 45, 39-48. doi: 10.1016/S0007-6813(02)00259-8

Jones, M. E. (1999). HIV and the returning expatriate. J. Travel. Med. 6, 99-106. doi: 10.1111/j.1708-8305.1999.tb00840.x

Jones, S. (2000). Medical aspects of expatriate health: health threats. Occup. Med. (Lond.). 50, 572-578. doi: 10.1093/occmed/50.8.572

Kaeding, C. C., and Borchers, J. (2016). Issues for the traveling team physician. J. Knee. Surg. 29, 364-369. doi: 10.1055/s-0036-1584193

Kline, R. B. (2011). Principles and Practice of Structural Equation Modeling, 3rd Edn. New York, NY: Guilford Press.

Lazarus, R. S. (1991). Emotion and Adaptation. London: Oxford University Press.

Lazarus, R. S. (2001). "Relational meaning and discrete emotions," in Appraisal Processes in Emotion: Theory, Methods, Research, eds K. Scherer, A. Schorr, and T. Johnstone (New York, NY: Oxford University Press), 37-67.

Lazarus, R. S., and Folkman, S. (1984). Stress, Appraisal and Coping. New York, NY: Springer Publishing.

Lei, L., Liang, Y. X., and Krieger, G. R. (2004). Stress in expatriates. Clin. Occup. Environ. Med. 4, 221-229. doi: 10.1016/j.coem.2003.12.001

Leistedt, S. J. (2013). Behavioural aspects of terrorism. Forensic. Sci. Int. 228, 21-27. doi: 10.1016/j.forsciint.2013.02.004

Mol, S. T., Born, M. P., Willemsen, M. E., and Molen, H. T. V. D. (2005). Predicting expatriate job performance for selection purposes: a quantitative review. J. Cross. Cult. Psychol. 36, 339-353. doi: 10.1177/002202210 5278544

Mucci, N., Giorgi, G., Cupelli, V., Gioffrè, P. A., Rosati, M. V., Tomei, F., et al. (2015). Work-related stress assessment in a population of Italian workers. The stress questionnaire. Sci. Total Environ. 502, 673-679. doi: 10.1016/j.scitotenv.2014.09.069

Mueller, S., and Tschan, F. (2011). Consequences of client-initiated workplace violence: the role of fear and perceived prevention. J. Occup. Health Psychol. 16, 217-229. doi: 10.1037/a0021723

Muthén, L. K., and Muthén, B. O. (1998-2010). Mplus User's Guide, 6th Edn. Los Angeles, CA: Muthén and Muthén.

Nunnally, J. C. (1978). Psychometric Theory. New York, NY: McGraw-Hill.

Paz García-Vera, M., Sanz, J., and Gutiérrez, S. (2016). A systematic review of the literature on posttraumatic stress disorder in victims of terrorist attacks. Psychol. Rep. 119, 328-359. doi: 10.1177/0033294116658243

Perone, S. A., van Beerendonk, H., Avril, J., Bise, G., and Loutan, L. (2008). Stress and mental health in expatriates. Rev. Med. Suisse. 4, 1206-1211.

Pierre, C. M., Lim, P. L., and Hamer, D. H. (2013). Expatriates: special considerations in pretravel preparation. Curr. Infect. Dis. Rep. 15, 299-306. doi: 10.1007/s11908-013-0342-4

Preacher, K. J., and Hayes, A. F. (2008). Asymptotic and resampling strategies for assessing and comparing indirect effects in multiple mediator models. Behav. Res. Methods 40, 879-891. doi: 10.3758/BRM.40.3.879

Preacher, K. J., and Kelley, K. (2011). Effect size measures for mediation models: quantitative strategies for communicating indirect effects. Psychol. Methods 16, 93-115. doi: 10.1037/a0022658

Punnett, B. J. (1997). Towards effective management of expatriate spouses. J. World Bus. 32, 243-257. doi: 10.1016/S1090-9516(97)90010-9

Quantin, C., Abbas, R., Hagi, M., Breton, G. L., Romestaing, M., and Carnet, D. (2012). Comparison of British and French expatriate doctors' characteristics and motivations. BMJ. Open 2:e001706. doi: 10.1136/bmjopen-2012-001706

Regan, J. J., Jungerman, M. R., Lippold, S. A., Washburn, F., Roland, E., Objio, T., et al. (2016). Tracing airline travelers for a public health investigation: middle east respiratory syndrome coronavirus (MERS-CoV) Infection in the United States, 2014. Public Health Rep. 131, 552-559. doi: 10.1177/00333549166 62213

Schreiber, J. B., Stage, F. K., King, J., Nora, A., and Barlow, E. A. (2006). Reporting structural equation modeling and confirmatory factor analysis results: a review. J. Educ. Res. 99, 323-337. doi: 10.3200/JOER.99.6.3 23-338
Shaffer, M. A., Harrison, D. A., Gregersen, H., Black, J. S., and Ferzandi, L. A. (2006). You can take it with you: individual differences and expatriate effectiveness. J. Appl. Psychol. 91, 109-125. doi: 10.1037/0021-9010.91.1.109

Shepherd, S. M., and Shoff, W. H. (2014). Vaccination for the expatriate and long-term traveler. Expert. Rev. Vaccines 13, 775-800. doi: 10.1586/14760584.2014.913485

Shiba, Y., Santangelo, A. M., and Roberts, A. C. (2016). Beyond the Medial Regions of Prefrontal Cortex in the Regulation of Fear and Anxiety. Front. Syst. Neurosci. 10:12. doi: 10.3389/fnsys.2016.00012

Sims, R. H., and Schraeder, M. (2005). Expatriate compensation: an exploratory review of salient contextual factors and common practices. Career. Dev. Int. 10, 98-108. doi: 10.1108/13620430510588301

Solberg, Ø., Blix, I., and Heir, T. (2015). The aftermath of terrorism: posttraumatic stress and functional impairment after the 2011 Oslo bombing. Front. Psychol. 6:1156. doi: 10.3389/fpsyg.2015.01156

Stone, R. J. (1991). Expatriate Selection and Failure. Hum. Resour. Plan. 14, 9-18. doi: $10.1007 / \mathrm{s} 00268-014-2559-2$

Taylor, A., Angerer, J., Arnaud, J., Claeys, F., Kristiansen, J., Mazarrasa, O., et al. (2007). Differences in national legislation for the implementation of lead regulations included in the European directive for the protection of the health and safety of workers with occupational exposure to chemical agents (98/24/EC). Int. Arch. Occup. Environ. Health 80, 254-264. doi: 10.1007/s00420006-0118-3

United States Department of State Publication Bureau of Counterterrorism (2015). Country Reports on Terrorism 2014. Available at: http://www.state. gov/documents/organization/239631.pdf (accessed October 3, 2016).

Vaid, N., Langan, K. M., and Maude, R. J. (2013). Post-exposure prophylaxis in resource-poor settings: review and recommendations for pre-departure risk assessment and planning for expatriate healthcare workers. Trop. Med. Int. Health 18, 588-595. doi: 10.1111/tmi.12080

Wang, X., and Kanungo, R. N. (2004). Nationality, social network and psychological well-being: expatriates in China. Int. J. Hum. Resour. Man. 15, 775-793. doi: 10.1080/0958519042000192942

Wang, X., and Nayir, Z. (2006). How and when is social networking important? Theoretical examination and a conceptual model. Int. J. Cross Cult. Manag. 2, 321-337. doi: 10.1177/147059580223003

Weiss, H. M., and Cropanzano, R. (1996). "Affective events theory: a theoretical discussion of the structure, causes and consequences of affective experiences at work," in Research in Organizational Behavior: An Annual Series of Analytical Essays and Critical Reviews, eds B. M. Staw and L. L. Cummings (Greenwich, CT: JAI Press), 1-74.

Wentland, D. M. (2003). A new practical guide for determining expatriate compensation: the comprehensive model. Compens. Benefits Rev. 35, 45-50. doi: $10.1177 / 0886368703035003006$

Wilde, H., and Gollogly, J. G. (2014). Health and social welfare of expatriates in Southeast Asia. Travel. Med. Infect. Dis. 12, 102-105. doi: 10.1016/j.tmaid.2013.05.002

Wilks, J., Watson, B. C., Johnston, K. L., and Hansen, J. A. (1999). International drivers in unfamiliar surroundings: the problem of disorientation. J. Travel. Med. Int. 17, 162-167.

Zhu, J., Wanberg, C. R., Harrison, D. A., and Diehn, E. W. (2016). Ups and downs of the expatriate experience? Understanding work adjustment trajectories and career outcomes. J. Appl. Psychol. 101, 549-568. doi: 10.1037/apl0000073

Conflict of Interest Statement: The authors declare that the research was conducted in the absence of any commercial or financial relationships that could be construed as a potential conflict of interest.

Copyright (c) 2016 Giorgi, Montani, Fiz-Perez, Arcangeli and Mucci. This is an open-access article distributed under the terms of the Creative Commons Attribution License (CC BY). The use, distribution or reproduction in other forums is permitted, provided the original author(s) or licensor are credited and that the original publication in this journal is cited, in accordance with accepted academic practice. No use, distribution or reproduction is permitted which does not comply with these terms. 


\section{OPEN ACCESS}

Edited by:

Ronald H. Humphrey,

Lancaster University, UK

Reviewed by:

Peter J. Jordan,

Griffith University, Australia

Mindy E. Bergman,

Texas A\&M University, USA

*Correspondence:

Donatella Di Marco

ddimarco@us.es

Specialty section:

This article was submitted to

Organizational Psychology,

a section of the journal

Frontiers in Psychology

Received: 13 May 2016 Accepted: 17 August 2016 Published: 30 August 2016

Citation

Di Marco D, López-Cabrera R, Arenas A, Giorgi G, Arcangeli $G$ and Mucci N (2016) Approaching the Discriminatory Work Environment as Stressor: The Protective Role of Job Satisfaction on Health

Front. Psychol. 7:1313. doi: 10.3389/fpsyg.2016.01313

\section{Approaching the Discriminatory Work Environment as Stressor: The Protective Role of Job Satisfaction on Health}

\author{
Donatella Di Marco ${ }^{*}$, Rocio López-Cabrera ${ }^{1}$, Alicia Arenas ${ }^{1}$, Gabriele Giorgi ${ }^{2}$, \\ Giulio Arcangeli ${ }^{3}$ and Nicola $\mathrm{Mucci}^{3}$
}

${ }^{1}$ Department of Social Psychology, University of Seville, Seville, Spain, ${ }^{2}$ Department of Psychology, European University of Rome, Rome, Italy, ${ }^{3}$ Department of Experimental and Clinical Medicine, University of Florence, Florence, Italy

Discrimination is a complex phenomenon with adverse consequences at personal and organizational levels. Past studies have demonstrated that workers who are victims of discrimination might show less job satisfaction, less organizational commitment and worse levels of health and productivity. Although most research has focused on the effects of discrimination on victims, less is known about the extent to which discrimination produces consequences on workers who perceive the existence of a discriminatory work environment. The goal of this article is to analyze the consequences of the perception of a discriminatory work environment on employees' health. The importance of this relationship is studied taking into account the mediating effect of job satisfaction. In order to reach this goal a cross-sectional study was carried out with a sample of 1633 Italian workers (male $=826$, female $=764$ ), employed in private and public sectors, and in different hierarchical positions. Results suggest that the perception of a discriminatory work environment is negatively associated with employees' health. This relationship is partially mediated by job satisfaction $\left(R^{2}=0.17\right)$. This study demonstrates that perceiving a discriminatory work environment might have a negative impact on workers' health. A higher level of job satisfaction might buffer this effect. These findings have several practical implications. On the one hand, Human Resource Managers need to intervene in order to recognize and diminish implicit biases, creating a healthy and inclusive environment (e.g., through training, diversity policies, etc.). On the other hand, promoting job satisfaction (e.g., providing mechanisms of voice) might help workers to preserve their well-being, coping with the negative effects of a discriminatory work environment.

\footnotetext{
Keywords: discriminatory work environment, job satisfaction, employees' health, human resource management, Italian workers, workplace, work-related stress, occupational medicine
}

\section{INTRODUCTION}

In the last few years, numerous studies about discrimination at work on the basis of gender and ethnic origin have been carried out (Dovidio et al., 2002; Cortina et al., 2013). Recently, researchers have focused their attention on other vulnerable groups, such as disabled people, lesbian, gay, bisexual and transsexual (LGBT) workers, younger/older employees, people who 
belong to minority religions or beliefs, people who perform menial or strenuous tasks, people who work at unsocial hours, etc. (Hebl et al., 2002; Baldasseroni et al., 2005; Arcangeli and Mucci, 2009; Mucci et al., 2012; Di Marco et al., 2015). These studies shed light on the prejudicial outcomes of discrimination at personal and organizational levels. Although many societies offer legislative tools to employees who have received discriminatory treatment (Goldman et al., 2006), and the prevalence of open discrimination has decreased, data on discrimination in the workplace appears alarming (Goldman et al., 2006; European Commission, 2012, 2015). According to the last Eurobarometer (European Commission, 2015), European citizens reported an increment in their perceptions of discrimination in their countries, including data about discrimination on the bases of ethnic origin, sexual orientation, gender identity, disability, and religion or beliefs, which has been increasing. The same report showed disheartening data about the perceptions of discrimination in Italy. In fact, much more than half of participants believe that discrimination on the basis of ethnic origin, sexual orientation, gender identity, and disability is widespread $(73,73,71$, and 52\%, respectively; European Commission, 2015).

Most of the research in this area has focused on the effects of discrimination on victims, while little is known about the extent to which perceiving a discriminatory environment might have consequences for people who are not directly involved in discrimination. Can the witnesses of discriminatory behaviors be affected by such acts? What are the consequences of perceiving the work environment as discriminatory?

The goal of this article is to analyze the consequences of the perception of a discriminatory environment on workers' health. Moreover, we try to identify the role of an affective and cognitive mediator (job satisfaction) on this relationship.

The article will be structured in the following way: firstly, we will revise past theoretical contributions on discrimination and health; secondly, we will explain why job satisfaction could mediate the relationship between discrimination and health; and finally, we will describe and discuss the results obtained. Theoretical and practical implications will be presented at the end.

\section{Workplace Discrimination and Health}

The term discrimination refers to an unequal treatment people receive for being part of a specific group (Goldman et al., 2006; Triana et al., 2015).

Prejudice - negative attitude against people who belong to a group - and stereotypes - beliefs related to that group are responsible for this process. In fact, in order to simplify the world, people tend to associate each person with a specific social category which is, in turn, connected to beliefs that change with the historical moment (Dovidio, 2001). For example, beliefs associated with the role of women in societies have changed throughout history. Some decades ago, their role was restricted to the family domain and women who went beyond this sphere were judged negatively by society (Sánchez, 2012). Nowadays, in western countries, open prejudice and negative stereotypes against working women are not judged positively.
However, sometimes people do not know that they are bringing prejudice and stereotypes against a specific group at an implicit level. Indeed, a recent study demonstrated that people still maintain traditional gender beliefs (role behaviors, occupations, etc.; Heines et al., 2016). As discrimination is socially undesirable, prejudice, and stereotypes might be stored in an unconscious level, generating implicit bias which, in turn, might shape a discriminatory work environment. Its consequences are equally as prejudicial for people involved as for those experiencing explicit bias (Cortina, 2008; Jones et al., 2016).

Past studies have analyzed the negative consequences of discriminatory behaviors for victims (e.g., poorer health, lower job satisfaction, etc.) and organizations (e.g., monetary losses, higher job rotation, etc.; Cortina et al., 2001; Ensher et al., 2001; Dipboye and Halverson, 2004; Ragins, 2004; Goldman et al., 2006; Wated and Sanchez, 2006; Pascoe and Smart Richman, 2009; Williams and Mohammed, 2009; Di Marco et al., 2015; Trau, 2015; Triana et al., 2015).

In order to understand the effects of perceived discrimination on well-being, past studies have applied the Job DemandResources (JD-R) model (Demerouti et al., 2001), which considers that discriminatory behaviors act as stressors (Volpone and Avery, 2013). Job Demand refers to the physical and psychological efforts required by a job which produce cost for the employee at a physical or a psychological level (Demerouti et al., 2001; Volpone and Avery, 2013). High Job Demand might affect employees' well-being negatively, and at the same time it might provoke disengagement (Volpone and Avery, 2013). On the contrary, Job Resources, as social support and organizational resources, are those aspects which lead to a decrement of Job Demand and its effects (Demerouti et al., 2001). Moreover, Job Resources enrich the employee, letting him or her participate in the decision making process, and increasing the worker's control over his or her work, etc. (Demerouti et al., 2001). An expression of the presence of Job Resources is a higher level of job satisfaction (Nielsen et al., 2011; Yeh, 2015).

Previous research has considered perceived discrimination as a stressor or a Job Demand, highlighting the negative consequences on victims' health (Kessler et al., 1999; Pascoe and Smart Richman, 2009; Volpone and Avery, 2013). In this sense, "Minority stress" is the concept used to refer to the consequences experienced by the victims. It is the process by which "stigma, prejudice, and discrimination create a hostile and stressful social environment that causes mental health problems" (Meyer, 2003) for people who belong to stigmatized groups. However, little is known about the effects of perceiving a discriminatory work environment on employees who are not part of a vulnerable group but who witness discrimination. A study about bullying showed that being bystanders of workplace bullying might affect observers' health negatively (Vartia, 2001; Hoel et al., 2004; Lutgen-Sandvik et al., 2007). Moreover, research carried out with lesbian and gay (LG) professionals (Trau, 2015) demonstrated that a discriminatory climate might be perceived by workers, which in turn might have consequences at personal and organizational levels (Ragins, 2004). Perceiving a discriminatory environment might be considered a stressor, even if people do not experience discrimination directly. In order 
to overcome the lack of studies about the effect of perceiving a discriminatory environment on employees who do not belong to a vulnerable group, we are going to test the following hypothesis:

Hypothesis 1: The perception of a discriminatory work environment will negatively affect employees' health.

Past studies have demonstrated that certain people are more vulnerable than others even if they have never experienced discrimination, due to historical reasons. Women (Lim et al., 2008) and blue-collar workers (Gil-González et al., 2013; Mariani et al., 2015) might suffer worse consequences on health than men and white-collar workers, respectively, if they perceive a discriminatory environment. Moreover, although previous research about the prevalence of discrimination in public and private sectors appears inconclusive (Byron, 2010; Leasher and Miller, 2012), we believe that the sector might play a significant role into the experience of workplace discrimination. Italian public and private sectors operate following different procedures; for example, during the hiring and firing processes. Generally, the public sector builds the selection process on rigorous procedures (e.g., a public call followed by a selection based on exams), while, in the private sector, selection might depend on the recruiter's decision, which might be more likely affected by implicit biases. For the same reason, employees who belong to a stigmatized group might perceive their position as more vulnerable if they work in the private sector. For this reason, we believe it is necessary to explore the extent to which employees' health is affected more severely by the perception of a discriminatory work environment, depending on the sector. For these reasons the following hypotheses state:

Hypothesis 2: The effect of a discriminatory work environment on health will be moderated by gender, sector, and job position.

Hypothesis 2a: Women will report poorer health than men when they perceive a discriminatory work environment.

Hypothesis 2b: People who work in the private sector will report poorer health than people who work in the public sector when they perceive a discriminatory work environment.

Hypothesis 2c: Blue-collar workers will report poorer health than white-collar workers and managers when they perceive a discriminatory work environment.

\section{Job Satisfaction as Mediator}

The research about job satisfaction has a long tradition. Many studies have attempted to recognize its affective and cognitive dimensions, trying to identify the best way to measure it (Brief and Weiss, 2002). Job satisfaction has been defined as a positive evaluation that people express after assessing their job at a cognitive and an affective level (Brief, 1998; Brief and Weiss, 2002; Judge and Kammeyer-Mueller, 2012). Judge and KammeyerMueller's (2012) revision collected some positive consequences of higher levels of job satisfaction. Satisfied employees showed higher job performance (Edwards et al., 2008), more citizenship behaviors (Kurland and Hasson-Gilad, 2015) and fewer thoughts of leaving (Hom and Kinicki, 2001; Baruch et al., 2016). Also, job satisfaction affects employees' health (Faragher et al., 2005). Given the numerous outcomes of job satisfaction, it is important to identify possible antecedents which have a positive or detrimental effect on employees' job satisfaction. Past studies have demonstrated that shared time pressure (Silla and Gamero, 2014), job characteristics (e.g., autonomy, skill variety, etc.; Hackman and Oldham, 1976) and social support (Morgeson and Humphrey, 2006; Baruch et al., 2016) might affect employees' evaluations of their own jobs positively or negatively.

Moreover, previous research has attributed a valuable role to job satisfaction as a mediator variable (Allisey et al., 2014; Silla and Gamero, 2014; Yuan et al., 2014). In a study carried out by Silla and Gamero (2014), job satisfaction played a mediating role in the relationship between shared time pressure and employees' self-reported health. They considered job satisfaction as an indicator of work adjustment that refers to "employees' subjective evaluation of the meaning of their work and the view of themselves as functioning members of their organization" (Silla and Gamero, 2014). Job satisfaction and organizational commitment are seen as indicators of work adjustment. Studies framed by the JD-R model found that job satisfaction might be enhanced by organizational resources (Nielsen et al., 2011; Yeh, 2015), whose presence also reduces the negative effects of Job Demand (Bakker and Demerouti, 2007). In line with this, we can hypothesize that the negative effects of the perception of a discriminatory work environment on health might be eliminated by job satisfaction. Indeed, job satisfaction might work as a mediator:

Hypothesis 3: Job satisfaction mediates the relationship between the perception of a discriminatory environment and employees' health.

\section{MATERIALS AND METHODS}

\section{Participants}

Data were gathered on several Italian organizations from both private and public sectors, using a set of self-reported questionnaires. Even though a total of 1721 responses were collected (1132 from the private sector and 589 from the public sector), 88 incomplete questionnaires were deleted from further analyses, in order to avoid subsequent statistical biases.

The final sample consisted of a total of 1633 employees, $50.6 \%$ male and $46.8 \%$ female, who were employed in the public (35.5\%) and private $(64.3 \%)$ sectors on three different hierarchical levels: as managers $(12.3 \%)$, white collars $(62 \%)$, and blue collars (15.3\%).

This study was designed by means of anonymous self-report questionnaires. Employees from Italian private and public sectors were invited to take part in the research. A letter code was assigned to each participant to guarantee their anonymity based on their grandparents' and mothers' initials. Three different scales were used in order to obtain all of the required data regarding participants' perceptions of their work environment, health, and job satisfaction. 


\section{Discriminatory Environment}

Employees' perceptions of a discriminatory environment were measured using a seven-item subscale of the Stress Questionnaire (SQ) developed by Mucci et al. (2015). The subscale explores the possibility of suffering higher levels of distress by being discriminated against in one's organization due to race, age, sexual orientation, religion, disabilities, or ideology. Each item was assessed using a 5-point response scale (from $1=$ "strongly disagree" to $5=$ "strongly agree"). An example of an item is: "People in this organization may be exposed to stress or risks to a greater extent because of their ideology/way of thinking." Cronbach's $\alpha$ value for this scale indicates a high reliability $(\alpha=0.72)$.

\section{Health}

Employees' health was measured using an Italian version of the General Health Questionnaire (GHQ; Goldberg, 1972), developed by Fraccaroli et al. (1991). This scale evaluates participants' perceptions concerning their general health during the last week. A total of 12 items were rated according to a 4point scale (Less than usual, No more than usual, More than usual, or Much more than usual). However, in order to analyze the obtained data, responses were transformed into a 4-point Likert scale (from 0 to 3 ) in which a higher score evidences a higher degree of psychological distress; therefore, participants' final results in this scale may oscillate between a minimum of 0 points and a maximum of 36 points. An example of an item contained in this questionnaire is "You had the impression of not being able to overcome difficulties." Cronbach's $\alpha$ for this test was 0.86 .

\section{Job Satisfaction}

Employees' job satisfaction at work was measured using a five-item subscale obtained from Hartline and Ferrell's (1996) questionnaire, which analyses this concept in terms of salary/wage, job security, social support, supervisors' accuracy in decision making processes, and global satisfaction with the job. Items were graded on a 5-point Likert scale basis (from $1=$ "Not satisfied at all" to $5=$ "Very satisfied"). For instance, one of the statements that participants scored was: "The degree of security that the job offers me." The internal consistency of this scale was high (Cronbach's $\alpha=0.70$ ).

\section{Sociodemographic Data}

Participants also reported gender (male or female), job position (manager, white-collar, or blue-collar), and work sector (public or private).

\section{Analyses}

Descriptive analyses were conducted for each variable involved in the presented model. Additionally, correlations among the main variables were also analyzed. In order to explore the data, one-way ANOVA analyses were conducted, identifying the impact that gender, job position and sector have on participants' perceptions of discrimination at work, job satisfaction and health. To test our hypotheses, the influence of employees' perceived discriminatory work environment on health has been analyzed by means of multiple linear regression analyses, considering the moderating effects that gender, job position, and work sector exert on this relationship. In order to conduct this analysis, moderators were transformed into dummy variables and $Z$-scores for each component, avoiding collinearity biases. Then the multiple regressions were calculated.

Finally, simple regression analyses and a mediation analysis based on multiple regression processes were conducted using the PROCESS macro for SPSS (Model 4) developed by Hayes (2013), in order to analyze how job satisfaction influences the relationship between employees' perceptions of a discriminatory work environment and their health, as well as the ways in which gender, sector, and job position affect the relationship between a discriminatory environment and health.

\section{RESULTS}

Internal consistency results, as well as means, standard deviation, and Pearson correlations among the main variables, are presented in Table 1. Regarding the perceived discriminatory work environment $(M=2.07, S D=0.70)$, on average, participants report intermediate levels of this variable. Punctuations of job satisfaction $(M=3.50, S D=0.70)$ reflect a relatively high level of satisfaction at work. Finally, participants report moderated levels of health $(M=10.65, S D=5.40)$. In order to interpret these variable correlations, it must be considered that health presents a reverted score; thus, a higher reported value is worse for this variable. Therefore, those who are discriminated against have worse job satisfaction $(r=-0.40)$ and worse health $(r=0.20)$.

Regarding the one-way ANOVA analyses conducted, results suggest that workers' perceptions of discriminatory work environment, as well as their satisfaction and health, are related to personal and organizational factors such as their gender and job position and the sector to which they belong.

The statistically significant results obtained show that men $(M=2.13, S D=0.74)$ perceive a more discriminatory work environment than women $[M=1.99, S D=0.64$; $F(1,1588)=16.47, p=0.000]$. Differences between private $(M=2.07, S D=0.71)$ and public $(M=2.06, S D=0.68)$ sectors regarding the discriminatory work environment are not statistically significant. The results are significant for bluecollar workers $[F(2,1460)=38.60, p=0.000]$, who reported higher scores in those items concerning the discriminatory environment compared to white-collar workers and managers. Post hoc comparisons using the Bonferroni test indicate that the mean scores for managers $(M=1.83, S D=0.60)$, whitecollar workers $(M=2.04 ; S D=0.70)$, and blue-collar employees $(M=2.38 ; S D=0.69)$ are significantly different $(p<0.05)$ regarding the perceived discriminatory environment.

Moreover, there are no statistically significant differences between male and female workers regarding their reported job satisfaction. However, analyses show that job satisfaction is statistically and significantly higher among private company workers $(M=3.53, S D=0.71)$ than among public sector ones $[M=3.40, S D=0.67 ; F(1,1631)=11.53, p=0.001]$. Along the same line, job satisfaction is lower among blue-collar workers 
TABLE 1 | Internal consistencies, means, standard deviations, and correlations among variables.

\begin{tabular}{|c|c|c|c|c|c|c|c|c|}
\hline & $M$ & $S D$ & 1 & 2 & 3 & 4 & 5 & 6 \\
\hline 1. Gender (1, Men; 2, Women) & 1.50 & 0.50 & - & & & & & \\
\hline 2. Job position (1, Managers; 2, White collars; 3, Blue collars) & 2.03 & 0.55 & $-0.13^{* *}$ & - & & & & \\
\hline 3. Sector (1, Private; 2, Public) & 1.36 & 0.50 & $0.16^{* *}$ & $-0.36 * *$ & - & & & \\
\hline 4. Discriminatory work environment & 2.07 & 0.70 & $-0.10^{* *}$ & $0.22^{* *}$ & -0.01 & $(0.72)$ & & \\
\hline 5. Job satisfaction & 3.50 & 0.70 & -0.02 & $-0.13^{* *}$ & $-0.08^{* *}$ & $-0.32^{* *}$ & $(0.70)$ & \\
\hline 6. Health & 10.65 & 5.40 & $0.06^{*}$ & -0.03 & 0.03 & $0.20^{* *}$ & $-0.40^{* *}$ & $(0.86)$ \\
\hline
\end{tabular}

$N=1633 ; * p<0.05 ; * * p<0.01$. Internal consistencies among of each variable are shown between parentheses.

than among white-collar workers and ultimately managers $[F(2,1460)=13.74, p=0.000]$. The Bonferroni test results also indicate that there are significant differences $(p<0.05)$ between job positions: managers $(M=3.68$; $S D=0.64)$, whitecollar workers $(M=3.48 ; S D=0.69)$, and blue-collar workers $(M=3.34 ; S D=0.72)$.

Concerning participants' health, the results show that men $(M=10.33, S D=5.09)$ perceive themselves to be healthier than their female coworkers $[M=10.95, S D=5.57 ; F(1,1588)=5.36$, $p=0.021]$. Differences between private and public sectors in relation to workers' perceptions of health are not significant. Finally, white-collar workers report less health results than managers and blue-collar workers $[F(2,1460)=3.56, p=0.030]$. Post hoc comparisons using the Bonferroni test indicate that the differences between the means for white-collar workers $(M=10.95 ; S D=5.68)$ and those for blue-collar workers $(M=9.97 ; S D=5.28)$ with regard to health punctuations are statistically significant $(p<0.05)$; however, that it is not the case for managers $(M=10.44 ; S D=4.27)$.

Multiple linear regression analyses were conducted to analyze how, on the one hand, a perceived discriminatory work environment influences employees' health and, on the other hand, how gender, job position, and sector affect that relationship as moderators. The results obtained show that the perception of a discriminatory work environment $(\beta=0.19$, $t=7.72 ; p<0.001$ ) has a statistically significant effect on employees' health, explaining $3.5 \%$ of the variance $\left[R^{2}=0.035\right.$; $F(1,1631)=59.65 ; p<0.001]$. Therefore, $\mathrm{H} 1$ is confirmed; perceiving a discriminatory workplace impairs employees' health.

In order to test $\mathrm{H} 2$, employees' gender $(\mathrm{H} 2 \mathrm{a})$, sector $(\mathrm{H} 2 \mathrm{~b})$, and job position $(\mathrm{H} 2 \mathrm{c})$ were included in the regression analyses as moderators (Table 2). Regarding gender, Model 1 explains 4.3\% $\left(R^{2}=0.043\right)$ of the variance $[F(2,1587)=35.30 ; p<0.001]$, so discriminatory environment and gender have a statistically significant effect on health as independent variables. However, although Model 2, which explains 4.3\% $\left(R^{2}=0.043\right)$ of the variance, is statistically significant $[F(3,1586)=23.75 ; p<0.001]$, the moderation effect of gender is not. In fact, the $F$ change is not statistically significant either, as is shown in Table 2. The Durbin-Watson $d=1.97$, which is between the two critical values of $1.5<\mathrm{d}<2.5$, indicating that there is no first order linear auto-correlation in the multiple linear regression data.

Concerning the work sector, Model 1 explains $3.7 \%$ $\left(R^{2}=0.037\right)$ of the variance $[F(2,1630)=30.94 ; p<0.001]$, showing that the direct effects of a discriminatory environment and work sector on health are significant. However, Model 2 , which explains the same percentage of variance, $3.7 \%$ $\left(R^{2}=0.037\right)$, indicates that although the model is statistically significant $[F(3,1629)=21.01 ; p<0.001]$, the work sector has no moderation effect. As is presented on Table 2, the F change is not statistically significant. There is no first order linear auto-correlation in the multiple linear regression data, since the Durbin-Watson $d=1.99$ value is between the two critical values of $1.5<\mathrm{d}<2.5$.

Finally, the job position as moderator has been analyzed based on white-collar workers and blue-collar workers, given the dummy codification of the variables. In terms of whitecollar workers, Model 1 explains 4.5\% $\left(R^{2}=0.045\right)$ of the total variance $[F(2,1460)=34.72 ; p<0.001]$, so the discriminatory environment and working as a white-collar worker as an independent variable have a statistically significant effect on health. According to Model 2, which explains 4.5\% $\left(R^{2}=0.045\right)$ of the total variance, it is statistically significant $[F(3,1459)=23.15 ; p<0.001]$; however, as is shown in Table 2, there is no significant moderation effect of this job position. Indeed, the $\mathrm{F}$ change is not statistically significant either. The Durbin-Watson $d=1.96$, which is between the two critical values of $1.5<\mathrm{d}<2.5$, indicates that there is no first order linear auto-correlation in the multiple linear regression data. Similar results were obtained considering blue-collar workers. Model 1 explains $5 \%\left(R^{2}=0.05\right)$ of the total variance $[F(2,1460)=38.55$; $p<0.001]$ and Model 2 explains 5.1\% $\left(R^{2}=0.05\right)$ of the total variance $[F(3,1459)=25.53 ; p<0.001]$. Although Model 2 is statistically significant, the moderation effect of this job position is not. Moreover, the $\mathrm{F}$ change value is not significant either. The Durbin-Watson $d=1.96$, which is between the two critical values of $1.5<\mathrm{d}<2.5$, indicates that there is no first order linear auto-correlation in the multiple linear regression data.

To sum up, the results for gender $(\beta=0.042, t=0.833$; $p>0.05)$, sector $(\beta=0.055, t=1.071 ; p>0.05)$, and job position, white-collar $(\beta=-0.13, t=-0.233 ; p>0.05)$ and blue-collar $(\beta=0.067, t=0.966 ; p>0.05)$ were not statistically significant when their moderation effects were analyzed separately. Therefore, $\mathrm{H} 2, \mathrm{H} 2 \mathrm{a}, \mathrm{H} 2 \mathrm{~b}$, and $\mathrm{H} 2 \mathrm{c}$ were not confirmed, and it is concluded that the only factor that influences employees' health is their perception of discrimination in the workplace.

Mediation analysis (Table 3) confirmed the buffering effect of job satisfaction on the relationship between workers' perceptions of a discriminatory work environment and their 
TABLE 2 | Change statistics for multiple regression models at values of moderators.

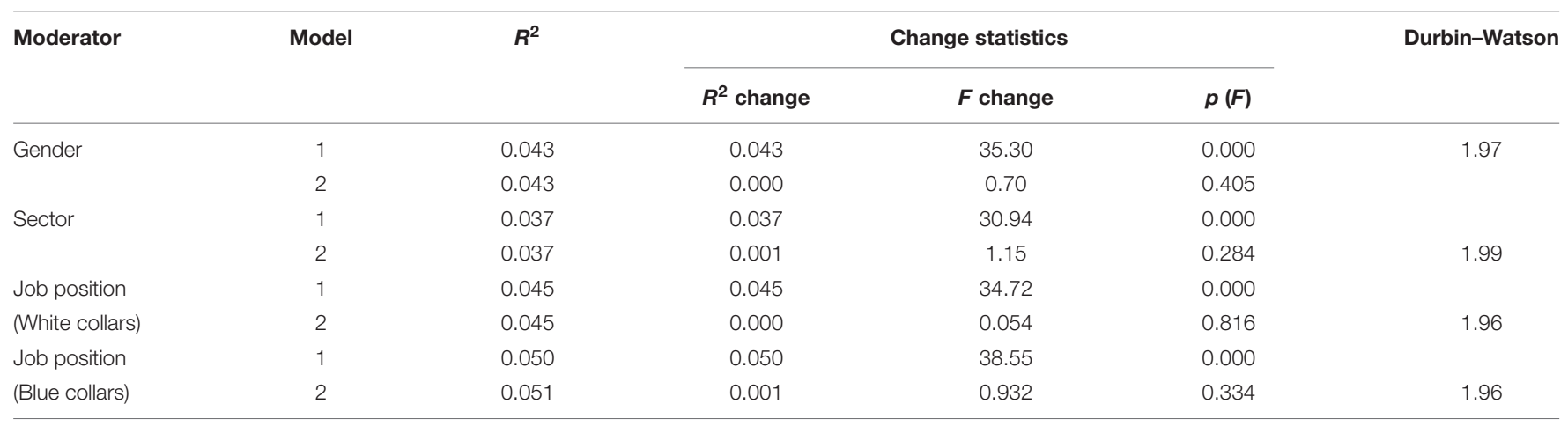

TABLE 3 | Regression results for mediation.

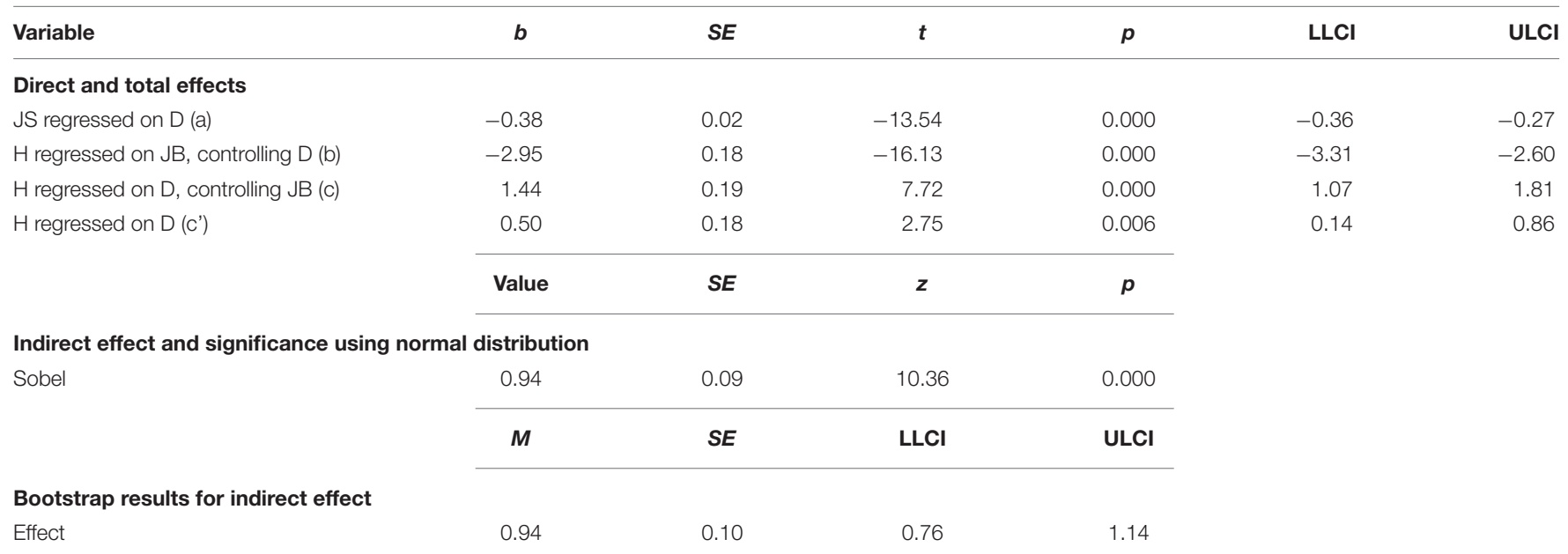

$N=1633 . D$, discriminatory environment; JS, job satisfaction; H, health; LL, lower limit; UL, upper limit; Cl, confidence interval. Unstandardized regression coefficients are reported. Bootstrap sample size $=10000$.

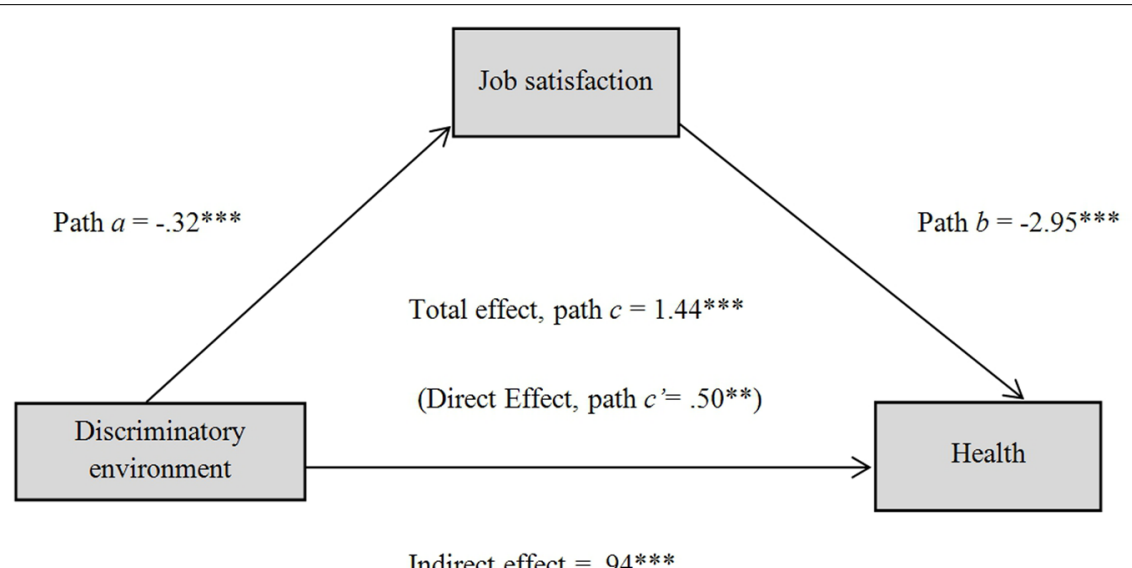

FIGURE 1 | Mediating effect of job satisfaction on the association between discriminatory environment and health $\left({ }^{* *} p<0.01 ;{ }^{* * *} p<0.001\right)$.

health (Figure 1). Results revealed that the perception of a discriminatory environment was negatively and significantly related with job satisfaction (path $a, p<0.001 ; R^{2}=0.10$ ) and that job satisfaction was negatively and significantly associated with health (path $b, p<0.001 ; R^{2}=0.17$ ). Additionally, when job satisfaction is included as a mediator, the relationship between discriminatory work environment and health remains marginally significant (total effect, path $c, p<0.001 ; R^{2}=0.03$ ). Also, the resampling procedure (10,000 bootstrap samples) indicates a significant indirect effect, since the confidence 
interval at $95 \%$ does not include the value zero $\left(k^{2}=0.12\right.$; bootstrapped 95\% CIs of 0.10-0.14; Preacher and Hayes, 2008). This mediation model explains $17 \%$ of the employees' health variance $[F(2,1630)=164.70 ; p<0.001]$. Therefore, H3 is partially supported.

Further analyses were conducted to go deeply in demographic characteristics that might explain why job satisfaction only has a partial mediation effect on the relationship between a perceived discriminatory environment and health. Based on the ANOVA analyses previously mentioned, regarding job satisfaction, means are significantly different between employees who work in the private and public sectors, as well as between managers, white-collar workers and blue-collar workers; therefore, the hypothesized model was replicated, dividing up the sample according to this classification.

For public sector employees, the results revealed that the perception of a discriminatory environment was negatively and significantly related with job satisfaction (path $a, p<0.001$; $R^{2}=0.073$ ) and that job satisfaction was negatively and significantly associated with health (path $b, p<0.001$; $R^{2}=0.13$ ). Additionally, when job satisfaction is included as a mediator, the relationship between discriminatory work environment and health is not significant (total effect, path $c$, $\left.p<0.001 ; R^{2}=0.021\right)$. Also, the resampling procedure $(10,000$ bootstrap samples) indicates a significant indirect effect, since the confidence interval at $95 \%$ does not include the value zero $\left(k^{2}=0.091\right.$; bootstrapped $95 \%$ CIs of $0.95-0.13$; Preacher and Hayes, 2008). This mediation model explains 13\% of employees' health variance $[F(2,580)=42.98 ; p<0.01]$.

Mediation analysis for the private sector showed that the perception of a discriminatory environment was negatively and significantly related with job satisfaction (path $a, p<0.001$; $R^{2}=0.12$ ) and that job satisfaction was negatively and significantly associated with health (path $b, p<0.001$; $\left.R^{2}=0.20\right)$. Additionally, when job satisfaction is included as a mediator, the relationship between discriminatory work environment and health is not significant (total effect, path $c$, $\left.p<0.001 ; R^{2}=0.045\right)$. Also, the resampling procedure $(10,000$ bootstrap samples) indicates a significant indirect effect, since the confidence interval at $95 \%$ does not include the value zero $\left(k^{2}=0.14\right.$; bootstrapped $95 \%$ CIs of $0.11-0.17$; Preacher and Hayes, 2008). This mediation model explains $20 \%$ of employees' health variance $[F(2,1047)=122.37 ; p<0.01]$.

Regarding job position, for managers the results revealed that the perception of a discriminatory environment was negatively and significantly related with job satisfaction (path $a$, $p<0.001 ; R^{2}=0.32$ ) and that job satisfaction was negatively and significantly associated with health (path $b, p<0.001 ; R^{2}=0.42$ ). When job satisfaction is included as a mediator, the relationship between discriminatory work environment and health is not significant (total effect, path $c, p<0.001 ; R^{2}=0.08$ ). Also, the resampling procedure (10,000 bootstrap samples) indicates a significant indirect effect, since the confidence interval at $95 \%$ does not include the value zero $\left(k^{2}=0.10\right.$; bootstrapped $95 \%$ CIs of 0.047-0.18; Preacher and Hayes, 2008). This mediation model explains $42 \%$ of employees' health variance $[F(2,198)=21.43$; $p<0.01]$.
The results revealed that when the hypothesized model was tested for white-collar workers, the perception of a discriminatory environment was negatively and significantly correlated with job satisfaction (path $a, p<0.001 ; R^{2}=0.10$ ) and that job satisfaction was negatively and significantly associated with health (path $b$, $\left.p<0.001 ; R^{2}=0.21\right)$. Also, when job satisfaction is included as a mediator, the relationship between discriminatory work environment and health is not significant (total effect, path $c$, $\left.p<0.001 ; R^{2}=0.036\right)$. Also, the resampling procedure $(10,000$ bootstrap samples) indicates a significant indirect effect, since the confidence interval at $95 \%$ does not include the value zero $\left(k^{2}=0.14\right.$; bootstrapped $95 \%$ CIs of $0.015-0.056$; Preacher and Hayes, 2008). This mediation model explains $21 \%$ of employees' health variance $[F(2,1009)=133.22 ; p<0.01]$.

Finally, the mediation analysis results for blue-collar workers are presented in Figure 2. They revealed that the perception of a discriminatory environment was negatively and significantly related with job satisfaction (path $a, p<0.001 ; R^{2}=0.046$ ) and that job satisfaction was negatively and significantly associated with health (path $b, p<0.001 ; R^{2}=0.18$ ). Additionally, when job satisfaction is included as a mediator, the relationship between discriminatory work environment and health remains marginally significant (total effect, path $c, p<0.001 ; R^{2}=0.078$ ). Also, the resampling procedure $(10,000$ bootstrap samples) indicates a significant indirect effect, since the confidence interval at 95\% does not include the value zero $\left(k^{2}=0.07\right.$; bootstrapped $95 \%$ CIs of 0.03-0.081; Preacher and Hayes, 2008). This mediation model explains $18 \%$ of employees' health variance $[F(2,247)=27.75$; $p<0.01]$. Therefore, for blue-collar workers, job satisfaction is not a sufficient health protector against a discriminatory environment.

\section{DISCUSSION}

The goal of this study was to understand the consequence of perceiving a discriminatory work environment on employees' health. Moreover, this research aimed to identify a mediating effect of job satisfaction in the relationship between employees' perceptions of a discriminatory work environment and their health. With regard to Hypothesis 1, the data confirmed that a relationship exists between employees' perceptions of a discriminatory work environment and their health. When people consider that their organization is being discriminatory against colleagues who belong to a vulnerable group, their health is affected negatively.

Contrary to expectations, this relationship is not moderated by variables such as gender, job position, or work sector (Hypothesis 2). Our findings demonstrated that the negative effect of a discriminatory work environment affects everybody in the organization, regardless of their belonging to a vulnerable group (e.g., women), regardless of the position they occupy within the organization (e.g., blue-collar workers) and regardless of the work sector. Therefore, Hypotheses $2 \mathrm{a}, 2 \mathrm{~b}$, and $2 \mathrm{c}$ were not confirmed.

With regard to Hypothesis 3, our findings showed that the negative relationship between perceiving a discriminatory work 


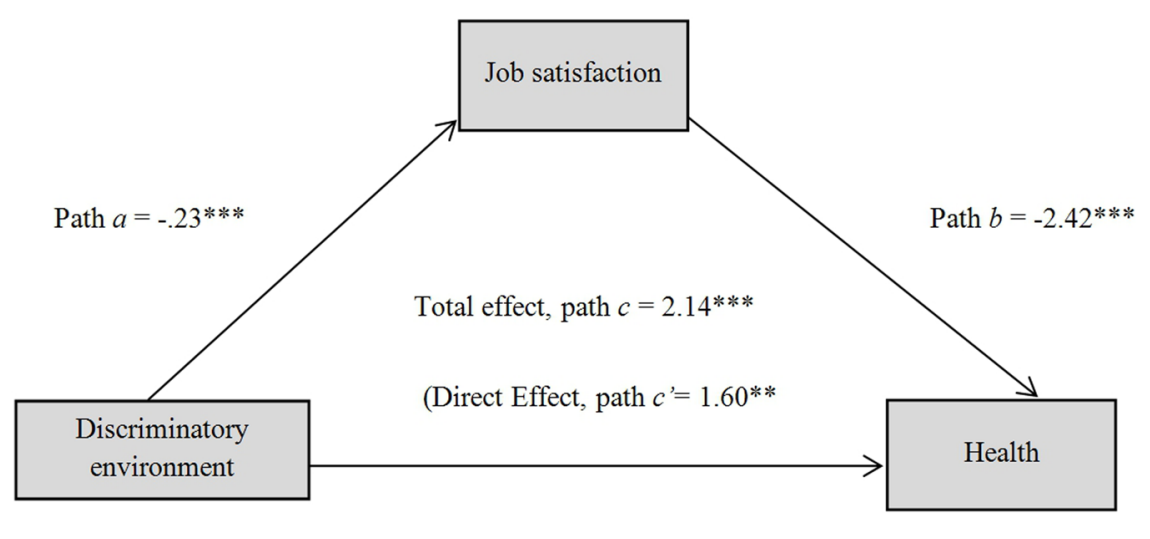

Indirect effect $=.55 * * *$

FIGURE 2 | Mediating effect of job satisfaction on the association between discriminatory environment and health for blue collars $\left({ }^{* *} p<0.01\right.$; $* * * p<0.001)$.

environment and employees' health is partially mediated by job satisfaction. Thus, if employees are satisfied, the impact of perceiving a discriminatory work environment on workers' health is lower but it still exists. Additional analysis was carried out after dividing up the sample, taking into account work sector and job position. The results demonstrated that job satisfaction almost always mediates totally the relationships between the perceptions of discrimination and workers' health. However, the mediation is still partial when the model is applied to blue-collar employees alone. For them, job satisfaction is not sufficient in order to eliminate the negative effect of perceiving a discriminatory environment on their health. Therefore, Hypothesis 3 was partially supported.

These findings are in line with studies framed by the JD-R model (Demerouti et al., 2001). According to the JD-R model, workplace discrimination acts as a stressor, as a demand which has negative consequences on both victims and witnesses' health (Vartia, 2001; Hoel et al., 2004; Lutgen-Sandvik et al., 2007). In line with past studies, which pointed out the effects on health for bystanders of bullying (Hoel et al., 2004), witnessing discrimination might create a climate of fear and people who are bystanders might anticipate the possibility of becoming the next victims of discriminatory acts. Moreover, people who do not support colleagues who have been discriminated against may feel guilty for not intervening (Hoel et al., 2004). Perceiving discriminatory acts does not have an effect on employees' health alone. Recent studies have demonstrated that negative or rude behaviors might be "contagious"; people who are either victims or bystanders of uncivil acts might enter into a spiral of aggression, behaving in the same manner with other colleagues (Andersson and Pearson, 1999; D'Cruz and Noronha, 2011). The negative effects of discrimination might increase greatly as well as the prejudicial consequences at personal and organizational levels.

This study has several theoretical and practical implications. At a theoretical level, this study extends the knowledge about the role played by job satisfaction as a mediating variable (Silla and Gamero, 2014). Also, our findings demonstrate that a discriminatory workplace is a danger to the whole organization; if it is obvious that it affects vulnerable groups, then it is also true that everybody is a victim of a discriminatory environment. Due to methodological reasons, we cannot talk about "a climate of discrimination," even though it is reasonable to suppose that it exists (Trau, 2015). Future studies should explore this issue.

This research also has practical implications. Due to the positive effect of job satisfaction on employees' health, organizations should try to improve this variable. According to the JD-R model (Demerouti et al., 2001; Bakker and Demerouti, 2007), job satisfaction is seen as an indicator of the balance between job demands and organizational resources. Therefore, Human Resource Managers should work to equilibrate such balance, fostering social support, improving autonomy, giving career opportunities, eliminating role ambiguity and role conflict, enriching the task, etc. During this process, it is important to take into account the needs of specific groups (such as blue-collar workers). In order to identify which elements are effective in increasing job satisfaction, mechanisms of voice might be applied (Van Dyne et al., 2003; Verhezen, 2010).

Future studies should explore why job satisfaction loses part of its mediating effect in the case of blue-collar workers. Also, future research should analyze which other factors might be improved in order to protect the health of this work group from the prejudicial consequences of perceiving a discriminatory workplace. Researchers have demonstrated that the perception of justice (Wu et al., 2012) and trust (Chancey et al., 2015) might play an important role within the organization. Future research should investigate whether their presence is effective in eliminating the detrimental role played by perceiving a discriminatory work environment on employees' health.

However, organizations have to remember that enhancing job satisfaction is not enough; it is important to fight against discrimination at any level. In this line, eliminating implicit biases is the starting point. Educate people about behaviors that 
transmit implicit discrimination, eliminate stereotypical beliefs about vulnerable groups, engage key organizational actors in activities which combat discriminatory behaviors (Ross, 2014), and create a trusting climate (Capell et al., 2016); all of these are necessary for shaping a safe environment for all employees.

To conclude, some limitations should be pointed out. Firstly, this is a cross-sectional study. Therefore, it is impossible to state robust conclusions about the causality or direction of the mediation (Zapft et al., 1996), given that data were collected at one time. Moreover, data were gathered using a self-reported questionnaire. Another limitation is connected to the number and type of sociodemographic variables collected. Future studies should include variables such as age. Also, other mediating variables might affect the relationship between perceiving a discriminatory work environment and employees' health (e.g., organizational justice). Finally, we do not have any information about participants' experience of discrimination as victims. Therefore, being victims of discrimination might have strengthened the relationship between the variables analyzed.

\section{REFERENCES}

Allisey, A., Noblet, A., LaMontagne, A., and Houdmont, J. (2014). Testing a model of officer turnover intentions: the mediating effects of job stress and job satisfaction. Crim. Justice Behav. 41, 751-771. doi: 10.1177/00938548135 09987

Andersson, L. M., and Pearson, C. M. (1999). Tit for tat? The spiraling effect of incivility in the workplace. Acad. Manage. Rev. 24, 452-471.

Arcangeli, G., and Mucci, N. (2009). Health problems in the working occupation of young people in handicraft factories. G. Ital. Med. Lav. Ergon. 31, 303-306.

Bakker, A. B., and Demerouti, E. (2007). The job demands-resources model: state of the art. J. Manage. Psychol. 22, 309-328. doi: 10.1108/02683940710733115

Baldasseroni, A., Abrami, V., Arcangeli, G., Cupelli, V., Fioriti, M., Guarducci, L., et al. (2005). Longitudinal study for assessing the efficacy of preventive measures in a population of health workers exposed to the risk of patient lifting. G. Ital. Med. Lav. Ergon. 27, 101-105.

Baruch, Y., Wordsworth, R., Mills, C., and Wright, S. (2016). Career and work attitudes of blue-collar workers, and the impact of a natural disaster chance event on the relationships between intention to quit and actual quit behaviour. Eur. J. Work Organ. Psychol. 25, 459-473. doi: 10.1080/1359432X.2015.1113168

Brief, A. P. (1998). Attitudes in and Around Organizations. Thousand Oaks, CA: Sage.

Brief, A. P., and Weiss, H. M. (2002). Organizational behavior: affect in the workplace. Annu. Rev. Psychol. 53, 279-307. doi: 10.1146/annurev. psych.53.100901.135156

Byron, R. A. (2010). Discrimination, complexity, and the Public/Private sector question. Work Occup. 37, 435-475. doi: 10.1177/0730888410380152

Capell, B., Tzafrir, S. S., and Dolan, S. L. (2016). The disclosure of concealable stigmas: analysis anchored in trust. Cogent Psychol. 3, 1-24. doi: 10.1080/23311908.2015.1121066

Chancey, E. T., Bliss, J. P., Proaps, A. B., and MadHavan, P. (2015). The role of trust as a mediator between system characteristics and response behaviors. Hum. Factors 57, 947-958. doi: 10.1177/0018720815582261

Cortina, L. M. (2008). Unseen injustice: incivility as modern discrimination in organizations. Acad. Manage. Rev. 33, 55-75. doi: 10.5465/AMR.2008.27745097

Cortina, L. M., Kabat-Farr, D., Leskinen, E. A., Huerta, M., and Magley, V. J. (2013). Selective incivility as modern discrimination in organizations: evidence and impact. J. Manag. 39, 1579-1605.

Cortina, L. M., Magley, V. J., Williams, J. H. N., and Langhout, R. D. (2001). Incivility in the workplace: incidence and impact. J. Occup. Health Psychol. 6, 64-80. doi: 10.1037/1076-8998.6.1.64

D'Cruz, P., and Noronha, E. (2011). The limits to workplace friendship. Managerialist HRM and bystander behaviour in the context of workplace
Although many societies have overcome many forms of open discrimination, discriminatory acts are still present at a subtle level. Discrimination does not only generate adverse consequences for people who belong to vulnerable groups. It is a process that involves everybody within the organization. Hence, organizations need to recognize the adverse consequences that these processes might have for victims and bystanders, fostering those aspects that help people to eliminate the negative consequences generated by a discriminatory work environment, such as job satisfaction.

\section{AUTHOR CONTRIBUTIONS}

The authors contributed to the conception and design of the work; the acquisition, analysis, and interpretation of data for the work. They drafted the work and revised it critically. The authors gave the final approval of the manuscript before the submission. They participated at any step of the research.

bullying. Employee Relat. 33, 269-288. doi: 10.1108/014254511111 21777

Demerouti, E., Bakker, A. B., Nachreiner, F., and Schaufeli, W. B. (2001). The job demands-resources model of burnout. J. Appl. Psychol. 86, 499-512. doi: 10.1037/0021-9010.86.3.499

Di Marco, D., Hoel, H., Arenas, A., and Munduate, L. (2015). Workplace incivility as modern sexual prejudice. J. Interpers. Violence doi: $10.1177 / 0886260515621083$ [Epub ahead of print].

Dipboye, R. L., and Halverson, S. K. (2004). "Subtle (and not so subtle) discrimination in organizations," in The Dark Side of Organizational Behavior, eds R. W. Griffin and A. M. O’Leary-Kelly (San Francisco: Jossey-Bass), 131-158.

Dovidio, J. F. (2001). On the nature of contemporary prejudice: the third wave. J. Soc. Issues 57, 829-849. doi: 10.1111/0022-4537.00244

Dovidio, J. F., Gaertner, S. L., Kawakami, K., and Hodson, G. (2002). Why can't we just getalong? Interpersonal biases and interracial distrust. Cultur. Divers. Ethnic. Minor. Psychol. 8, 88-102. doi: 10.1037/1099-9809.8.2.88

Edwards, B. D., Bell, S. T., Arthur, W. A., and Decuir, A. D. (2008). Relationships between facets of job satisfaction and task and contextual performance. Appl. Psychol. 57, 441-465. doi: 10.1111/j.1464-0597.2008.00328.x

Ensher, E. A., Grant-Vallone, E. J., and Donaldson, S. I. (2001). Effects of perceived discrimination on job satisfaction, organizational commitment, organizational citizenship behavior, and grievances. Hum. Resour. Dev. Rev. 12, 53-72. doi: 10.1002/1532-1096(200101/02)12:1<53::AID-HRDQ5>3.3.CO;2-7

European Commission (2012). Special Eurobarometer 393. Discrimination in the UE in 2012. Available at: http://ec.europa.eu/public_opinion/archives/ebs/ ebs_393_en.pdf [accessed April 30, 2016].

European Commission (2015). Special Eurobarometer 437. Discrimination in the UE in 2015. Available at: http://www.equineteurope.org/IMG/pdf/ebs_ 437_en.pdf [accessed April 30, 2016].

Faragher, E. B., Cass, M., and Cooper, C. L. (2005). The relationship between job satisfaction and health: a meta-analysis. Occup. Environ. Med. 62, 105-112. doi: 10.1136/oem.2002.006734

Fraccaroli, F., Depolo, M., and Sarchielli, G. (1991). L'uso del general health questionnaire di Goldberg in una ricerca su giovani disoccupati. Boll. Psycol. Appl. 197, 13-19.

Gil-González, D., Vives-Cases, C., Borrell, C., Agudelo-Suárez, A. A., and Álvarez-Dardet, C. (2013). Social determinants of self-perceived discrimination in Spain. Public Health 127, 223-230. doi: 10.1016/j.puhe.2012. 11.009

Goldberg, D. P. (1972). The Detection of Psychiatric Illness by Questionnaire: A Technique for the Identification and Assessment of Non-Psychotic Psychiatric Illness. London: Oxford University Press. 
Goldman, B. M., Gutek, B. A., Stein, J. H., and Lewis, K. (2006). Employment discrimination in organizations: antecedents and consequences. J. Manage. 32, 786-830.

Hackman, J. R., and Oldham, G. R. (1976). Motivation through the design of work: test of a theory. Organ. Behav. Hum. Perform. 16, 250-279. doi: 10.1016/00305073(76)90016-7

Hartline, M. D., and Ferrell, O. C. (1996). The management of customer contact service employees: an empirical investigation. J. Mark. 60, 52-70. doi: $10.2307 / 1251901$

Hayes, A. F. (2013). Introduction to Mediation, Moderation, and Conditional Process Analysis: A Regression-Based Approach. New York, NY: The Guilford Press.

Hebl, M. R., Bigazzi, J., Mannix, L. M., and Dovidio, J. F. (2002). Formal and interpersonal discrimination: a field study of bias toward homosexual applicants. Pers. Soc. Psychol. Bull. 28, 815-825. doi: 10.1177/0146167202289010

Heines, E. L., Deaux, K., and Lofaro, N. (2016). The times they are a-changing. . . or are they not? A comparison of gender stereotypes, 1983-2014. Psychol. Women Q. 40, 353-363. doi: 10.1177/0361684316634081

Hoel, H., Faragher, E. B., and Cooper, C. (2004). Bullying is detrimental to health, but all bullying behaviours are not necessarily equally damaging. Br. J. Guid. Counc. 32, 367-387. doi: 10.1080/03069880410001723594

Hom, P. W., and Kinicki, A. J. (2001). Toward a greater understanding of how dissatisfaction drives employee turnover. Acad. Manag. J. 44, 975-987. doi: $10.2307 / 3069441$

Jones, K. P., Peddie, C. I, Gilrane, V. L., King, E. B. Y., and Gray, A. L. (2016). Not so subtle: a meta-analytic investigation of the correlates of subtle and overt discrimination. J. Manag. 42, 1588-1613. doi: 10.1177/0149206313506466

Judge, T. A., and Kammeyer-Mueller, J. D. (2012). Job attitudes. Ann. Rev. Psychol. 63, 341-367. doi: 10.1146/annurev-psych-120710-100511

Kessler, R. C., Mickelson, K. D., and Williams, D. R. (1999). The prevalence, distribution, and mental health correlates of perceived discrimination in the United States. J. Health Soc. Behav. 40, 208-230. doi: 10.2307/2676349

Kurland, H., and Hasson-Gilad, D. R. (2015). Organizational learning and extra effort: the mediating effect of job satisfaction. Teach. Teach. Educ. 49, 56-67. doi: $10.1016 /$ j.tate.2015.02.010

Leasher, M. K., and Miller, C. E. (2012). Discrimination across the sectors: a comparison of discrimination trends in private and public organizations. Public. Pers. Manage. 41, 281-326. doi: 10.1177/009102601204100205

Lim, S., Cortina, L. M., and Magley, V. J. (2008). Personal and workgroup incivility: impact on work and health outcomes. J. Appl. Psychol. 93, 95-107. doi: 10.1037/0021-9010.93.1.95

Lutgen-Sandvik, P., Tracy, S. J., and Alberts, J. K. (2007). Burned by bullying in the American workplace: prevalence, perception, degree and impact. J. Manag. Stud. 44, 837-862. doi: 10.1111/j.1467-6486.2007.00715.x

Mariani, M. G., Soldà, B. L., and Curcuruto, M. (2015). Employee safety motivation: perspectives and measures on the basis of the self-determination theory. Med. Lav. 106, 333-341.

Meyer, I. H. (2003). Prejudice, social stress, and mental health in Lesbian, Gay, and bisexual populations: conceptual issues and research evidence. Psychol. Bull. 129, 674-697. doi: 10.1037/0033-2909.129.5.674

Morgeson, F. P., and Humphrey, S. E. (2006). The work design questionnaire (WDQ): developing and validating a comprehensive measure for assessing job design and the nature of work. J. Appl. Psychol. 91, 1321-1339. doi: 10.1037/0021-9010.91.6.1321

Mucci, N., Giorgi, G., Cupelli, V., Gioffrè, P. A., Rosati, M. V., Tomei, F., et al. (2015). Work-related stress assessment in a population of Italian workers. The Stress Questionnaire. Sci. Total Environ. 502, 673-679. doi: 10.1016/j.scitotenv.2014.09.069

Mucci, N., Montalti, M., Bini, C., Cupelli, V., and Arcangeli, G. (2012). Evaluation of the impact of night-work on health in a population of workers in Tuscany. G. Ital. Med. Lav. Ergon. 34(3 Suppl.), 381-384.

Nielsen, M. B., Mearns, K., Matthiesen, S. B., and Eid, J. (2011). Using the job demands-resources model to investigate risk perception, safety climate and job satisfaction in safety critical organizations. Scand. J. Psychol. 52, 465-475. doi: 10.1111/j.1467-9450.2011.00885.x
Pascoe, E. A., and Smart Richman, L. (2009). Perceived discrimination and health: a meta-analytic review. Psychol. Bull. 135, 531-554. doi: 10.1037/a0016059

Preacher, K. J., and Hayes, A. F. (2008). Asymptotic and resampling strategies for assessing and comparing indirect effects in multiple mediator models. Behav. Res. Methods 40, 879-891. doi: 10.3758/BRM.40.3.879

Ragins, B. R. (2004). Sexual orientation in the workplace: the unique work and career experiences of gay, lesbian and bisexual workers. Res. Pers. Hum. Res. 23, 35-129.

Ross, H. (2014). Everyday Bias. Further Explorations into How the Unconscious Mind Shapes Our World at Work. Available at: http://cookross.com/services/ thought-leadership/free-thought-papers/ [accessed April 30, 2016].

Sánchez, P. (2012). "Individuas de dudosa moral," in Mujeres Bajo Sospecha. Memoria y Sexualidad 1930-1980, ed. R. Osborne (Madrid: Editorial Fundamentos), 105-121.

Silla, I., and Gamero, N. (2014). Shared time pressure at work and its healthrelated outcomes: job satisfaction as a mediator. Eur. J. Work Organ. Psychol. 23, 405-418. doi: 10.1080/1359432X.2012.752898

Trau, R. N. C. (2015). The impact of discriminatory climate perceptions on the composition of intraorganizational developmental networks, psychosocial support, and job and career attitudes of employees with an invisible stigma. Hum. Res. Manage. 54, 345-366. doi: 10.1002/hrm.21630

Triana, M. C., Jayasinghe, M. J., and Pieper, J. R. (2015). Perceived workplace racial discrimination and its correlates: a meta-analysis. J. Organ. Behav. 36, 491-513. doi: 10.1002/job.1988

Van Dyne, L., Ang, S., and Botero, I. C. (2003). Conceptualizing employee silence and employee voice as multidimensional constructs. J. Manage. Stud. 40, 1359-1392. doi: 10.1111/1467-6486.00384

Vartia, M. A. L. (2001). Consequences of workplace bullying with respect to the well-being of its targets and the observers of bullying. Scand. J. Work Environ. Health 27, 63-69. doi: 10.5271/sjweh.588

Verhezen, P. (2010). Giving voice in a culture of silence. From a culture of compliance to a culture of integrity. J. Bus. Ethic. 96, 187-206. doi: 10.1007/s10551-010-0458-5

Volpone, S. D., and Avery, D. R. (2013). It's self defense: how perceived discrimination promotes employee withdrawal. J. Occup. Health Psychol. 18, 430-448. doi: 10.1037/a0034016

Wated, G., and Sanchez, J. (2006). The role of accent as a work stressor on attitudinal and health-related work outcomes. Int. J. Stress Manag. 13, 329-350. doi: 10.1037/1072-5245.13.3.329

Williams, D. R., and Mohammed, S. A. (2009). Discrimination and racial disparities in health: evidence and needed research. J. Behav. Med. 32, 20-47. doi: 10.1007/s10865-008-9185-0

Wu, M., Huang, X., Li, C., and Liu, W. (2012). Perceived interactional justice and trust-in-supervisor as mediators for paternalistic leadership. Manage. Organ. Rev. 8, 97-121. doi: 10.1111/j.1740-8784.2011.00283.x

Yeh, H. J. (2015). Job demands, job resources, and job satisfaction in East Asia. Soc. Indic. Res. 121, 47-60. doi: 10.1007/s11205-014-0631-9

Yuan, L., Tan, X., Huang, C., and Zou, F. (2014). Mediating effect of job satisfaction on the relationship between emotional intelligence and perceived general health. Soc. Behav. Pers. 42, 1057-1068. doi: 10.2224/sbp.2014.42.7.1057

Zapft, D., Dormann, C., and Frese, M. (1996). Longitudinal studies in organisational stress research: a review of the literature with reference to methodological issues. J. Occup. Health Psychol. 1, 145-169. doi: 10.1037/10768998.1.2.145

Conflict of Interest Statement: The authors declare that the research was conducted in the absence of any commercial or financial relationships that could be construed as a potential conflict of interest.

Copyright (C) 2016 Di Marco, López-Cabrera, Arenas, Giorgi, Arcangeli and Mucci. This is an open-access article distributed under the terms of the Creative Commons Attribution License (CC BY). The use, distribution or reproduction in other forums is permitted, provided the original author(s) or licensor are credited and that the original publication in this journal is cited, in accordance with accepted academic practice. No use, distribution or reproduction is permitted which does not comply with these terms. 


\section{Anxiety, Stress-Related Factors, and Blood Pressure in Young Adults}

\author{
Nicola Mucci ${ }^{*}$, Gabriele Giorgi ${ }^{2}$, Stefano De Pasquale Ceratti ${ }^{2}$, Javier Fiz-Pérez ${ }^{2}$, \\ Federico $\mathrm{Mucci}^{3}$ and Giulio Arcangeli ${ }^{1}$
}

${ }^{1}$ Department of Experimental and Clinical Medicine, University of Florence, Florence, Italy, ${ }^{2}$ Department of Psychology, European University of Rome, Rome, Italy, ${ }^{3}$ Department of Clinical and Experimental Medicine, University of Pisa, Pisa, Italy

Hypertension $(\mathrm{HT})$ is a long-term medical condition characterized by persistently elevated blood pressure (BP) in the arterial vessels. Although HT initially is an asymptomatic condition, it chronically evolves into a major risk factor for cardiovascular, cerebrovascular, and renal diseases that, in turn, represent crucial causes of morbidity and mortality in industrialized countries. HT is a complex disorder that is estimated to affect more than a quarter of the world's adult population. It is classified on the basis of both its pathophysiology (primary and secondary $\mathrm{HT}$ ) and on the resting BP values (elevated systolic, diastolic, and pulse pressure). It originates from a complicated interaction of genes and several environmental risk factors including aging, smoking, lack of exercise, overweight and obesity, elevated salt intake, stress, depression, and anxiety. Anxiety and depressive disorders are the most commonly diagnosed mental disorders, affecting millions of people each year and impairing every aspect of everyday life, both of them characterized by affective, cognitive, psychomotor, and neurovegetative symptoms. Moreover, work-related stress has been considered as an important risk factor for HT and cardiovascular diseases (CVDs). Although different authors have investigated and suggested possible relations between $\mathrm{HT}$, stress, anxiety, and depression during the last decades, a full understanding of the underlying pathophysiological mechanisms has not been satisfactorily achieved, especially in young adults. The aim of this study was to investigate the impact of anxiety and workrelated stress in the development of $\mathrm{HT}$ amongst young health care profession students and the possible related consequences of early CVDs.

Keywords: blood pressure, anxiety, work-related stress, students, health care professions, health promotion, workplace, occupational medicine

\section{INTRODUCTION}

The blood pressure (BP) is the pressure that the blood flow exerts against the walls of blood vessels. It varies in the different parts of the human body according to the phases of contraction of heart and to the conditions of health, exercise, stress, etc. If the term BP is used without further specification, usually refers by antonomasia to the arterial pressure in the systemic circulation. BP is usually expressed in terms of the systolic BP (SBP, maximum pressure), over diastolic BP (DBP, minimum pressure) (Hodgkinson et al., 2015). It is usually measured at a person's upper arm and is measured in millimeters of mercury $(\mathrm{mmHg})$ because the traditional device used to measure $\mathrm{BP}$, a sphygmomanometer, used a glass column filled with mercury and calibrated in millimeters. 
Normal resting BP in an adult is within the range of $100-$ $140 \mathrm{mmHg}$ systolic and $60-90 \mathrm{mmHg}$ diastolic (Mancia et al., 2013).

Moreover, during the last two decades, pulse pressure (PP), defined as the difference between SBP and DBP within a normal range of $30-80 \mathrm{mmHg}$, has received growing attention as an independent predictor of cardiovascular risk (Tin et al., 2002). Some authors, in a meta-analysis of 2,000 combining studies that previously examinated over 8,000 elderly subjects, demonstrated that the risk of major cardiovascular complications and mortality increased by nearly $20 \%$ within an increase of $10 \mathrm{~mm} \mathrm{Hg}$ in PP (Blacher et al., 2000). On the other hand, studies on young adults are still meager and results often contradictory, therefore motivating the increasing need of researching on these subjects in order to fulfill an adequate prevention of such invalidating diseases (Ritvanen et al., 2003; Riese et al., 2004).

Hypertension (HT) is either defined as a transitory or persistent elevation of arterial BP with, arbitrarily, a systolic measures $>160 \mathrm{mmHg}$ or more and diastolic measures $>90 \mathrm{mmHg}$ (Wright and Diamond, 2006; Poulter et al., 2015). HT represents a worldwide problem afflicting more than a quarter of the world's adult population, in both developed (333 million) and in developing countries (639 million) (Santulli, 2013). It represents a major preventable risk factor for premature death and disability and, in particular, a crucial risk factor in the development of cardiovascular diseases (CVDs), such as hypertensive heart disease, coronary artery disease, stroke, aortic aneurysm, peripheral artery disease, cerebrovascular disease, and chronic kidney disease (Jennings and Touyz, 2013; Floyd, 2015).

Coronary heart diseases (CHDs) in men are negligible until the age of 40 years, they emerge between 40 and 50 years and then grow exponentially with age; in women occur at ages $50-$ 60 years and grow rapidly. The disadvantage of men compared to women is more pronounced in young people and tends to decrease with age: the lowest frequency of ischemic heart disease in women than in men is particularly evident in the reproductive age. The prevalence difference between the sexes is accompanied by differences in clinical manifestations: women suffer, in fact, more frequently from sudden death, silent heart attack, and angina pectoris (Maas and Appelman, 2010; Khamis et al., 2016).

Notwithstanding the strategies of screening, prevention, and treatment, the prevalence of HT is increasing throughout the lifespan, along with the increasing of population aging, sedentary life-style and high-calorie food intake (Hansen et al., 2007; Floyd, 2015). Moreover, an appropriate BP control is achieved only by less than a half of patients receiving treatment (Lewington et al., 2002; Falaschetti et al., 2014). Last but not least, the financial burden for EU health systems associated with CVDs has been estimated to be nearly $€ 110$ billion in 2006 (corresponding to $10 \%$ of total health care expenditure across $\mathrm{EU}$ ), and the direct cost associated with HT was estimated to be $€ 51.3$ billion (Mennini et al., 2015).

Although the etiology of HT has been widely studied in depth during the last decades, it still remains far to be completely understood, as it results from a complicated interaction of genetic and several environmental risk factors. Furthermore, the development of HT is associated with several demographic, lifestyle, and psychosocial variables (Pilic et al., 2016). Examples of demographic variables related to CVDs are aging, ethnic group, geographic regions, lower income, lower educational attainment, difficulty of access, and lower quality of public health services (Ferguson et al., 2008; Hosey et al., 2014). As far as lifestyle variables are concerned, robust evidence is available that aging, smoking, alcohol consumption, lack of exercise, disruption of circadian rhythms, diet poor in fruit and vegetables, overweight, obesity [pathological elevation of the body mass index (BMI)] and elevated salt intake are related to an increased risk of HT and any CVDs (Tanuseputro et al., 2003; Pilic et al., 2016).

Other risk factors, such as psychosocial ones and mental disorders, have also been investigated by several authors, nevertheless the relation with HT results less clear and, sometimes, controversial (Kessler et al., 2005; Sparrenberger et al., 2009; Spruill, 2010; Graham and Smith, 2016; Mermerelis et al., 2016; Ventura and Lavie, 2016). However, literature agrees that perceived stress amongst health care profession students is high and that a significant number of them may develop a psychological morbidity (Pryjmachuk and Richards, 2008; Nechita et al., 2014; Wallace et al., 2015).

Work-related stress is involved in the development of HT and a consistent number of studies examined different common work-related aspects including job insecurity, strain and control (job quality), satisfaction, wages, work hours, and perceived dissatisfaction (Baldasseroni et al., 2005; Rau, 2006; Wright et al., 2011; Johansson et al., 2012; Leigh and Du, 2012; James et al., 2013; Modrek and Cullen, 2013; Smith et al., 2013; Ford, 2014). Other research had already shown how stress may cause changes in BP, increased cholesterol blood levels, triglycerides, hematocrit, fibrinogen, and blood fluidity. Mental stress may cause an abnormal activation of the sympathetic nervous system (SNS) triggering hormonal cascades that interfere with BP, increased coagulation and platelet activity, factors that can act as "triggers" of cerebrovascular events (Marazziti et al., 1990; Jönsson et al., 2015; Hirokawa et al., 2016).

A recent review of literature underlined how unemployment, extended work hours, job instability, low wages, job strain, and sleep disorders were linked to an increased risk of HT (Cuffee et al., 2014). Recently, some authors (Trudel et al., 2016) evaluated the effect of repeated job strain and effort-reward imbalance (ERI; Siegrist, 1996) reporting that men chronically exposed to an active job, compared with not exposed men, presented a cumulative incidence of HT over 5 years. On the other hand, women who had experienced onset of ERI exposure were found to have a higher systolic ambulatory BP, in contrast with non-exposed women. Some authors reported a positive significant association between job strain and arterial stiffness in working men, while they did not found the same evidences in women, and others, instead, reported a negative association in a group of healthy male employees (Nordstrom et al., 2001; Hintsanen et al., 2005; Nomura et al., 2005; Bugajska et al., 2008).

Epidemiological studies have repeatedly investigated the association between anxiety and HT, with unclear results. Pan et al. (2015), in a recent systematic review and meta-analysis, summarized the current evidence from cross-sectional and 
prospective studies and their results suggest that there is an association between anxiety and increased risk of HT. These results support early detection and management of anxiety in hypertensive patients.

Depression is a significant and independent risk factor for HT, especially in young people (Shah et al., 2011; Jackson et al., 2016; Mermerelis et al., 2016). Depression could lower the heart rate variability, a normal feature of the heart rhythm: a too low value indicates a greater chance of dying as a result of CVDs. Again, the psychological condition may worsen the inflammatory response or raise the levels of blood cortisol (Shah et al., 2011). Amongst women its role seems to be even pair to traditional factors such as smoking, obesity, diabetes, and HT. Not surprisingly, Shah et al. (2011) observed that women with a history of suicide attempts present a greatest risk of dying from CVDs, three times more than the other (for males was 2.4 times higher than the other). Moreover, the authors have highlighted that these women have a 14 times greater risk of dying from heart attack (men stops to 3.5 times).

Nonetheless the growing body of evidences, the pathophysiological mechanisms underlying the relations between psychosocial factors and elevated BP remains still unclear or even contradictory and needs further investigation, especially in young people. Indeed, adolescents and young adults constitute a population with specific characteristics, which must be taken into account in the management of occupational risks (Caricati et al., 2016). In this sense, considering also the lifestyles that young people are taking in recent years, the evaluation of cardiovascular risk at early age is becoming increasingly important (Mangena et al., 2016).

Effort-rewarding balance could also explain the phenomenon of over identification in special groups of young people, such as health care profession students. In fact, these students experience-in addition to a repeated job strain - a continuous ERI for the whole course of studies due not only to the specific characteristics of a health care profession but, moreover, to the difficulty in entering into employment and in the precariousness of employment contracts. These problems may be even more evident in the current economic crisis (Van Hal, 2015).

Psychological wellbeing has consistently been shown to be related to job satisfaction (Wright et al., 2007; Merino and Privado, 2015). Melamed et al. (2001) have hypothesized that job complexity affects changes in BP levels and job satisfaction over 2-4 years of follow-up. Accordingly, job dissatisfaction has been reported to be an important and powerful source of psychological strain, in particular associated to elevated BP in women with low levels of social support (Ford, 2014).

In particular, chronic exposure to stressors would trigger a vicious cycle consisting in changes of emotional set points. These changes would bolster chronic readiness for future stressors and, finally, culminate in chronically altered affective states and perceived stress. SNS is also involved, as emotional accommodations are actually able to affect its set points especially in shifting basal physiological arousal and altering resting or baseline BP levels (Ganzel et al., 2010; Ganzel and Morris, 2011; Ford, 2014). It has long been known that perceived dissatisfaction at work should be considered a relevant chronic stressor, directly involved either on mental and on physical health, especially BP (Lindgärde et al., 1987; Kivimäki et al., 2008; Virtanen et al., 2013). For these reasons, it has been proposed to check periodically the pulse of employees in order to perform a simple yet accurate screening of heart disease risk, specifically focusing their attention on working population of 50 years old and older (Mathile, 2013). Amongst this age-range, Wright et al. (2007) report that $\mathrm{BP}$ differences of $60 \mathrm{mmHg}$ (or more) are more risky for CVDs and that both employees and employers should be aware of the potential problems resulting. On the other hand, there is a lack of studies investigating screening of BP, chronic work stressors and anxiety in young people. Anyhow, studies of this kind may be relatively uneasy to perform due to the enormous number of variables involved, of confounding factors and of the umpteen existing methods (Rosenthal and Alter, 2012).

Therefore, the aim of this paper was to study the role of work-related stress and anxiety in the development of HT in a sample of young health care profession students and the potential consequences of early CVDs. While considering the literature analyzed above, poor student satisfaction and over-identification with University may be considered as stress-related factors. Based on theoretical and empirical arguments, we propose the following three hypotheses:

Hypothesis 1: Controlling for differences in gender and age, life style variables, and anxiety and stress-related variables, will be related to systolic pressure in a young population of students.

Hypothesis 2: Controlling for differences in gender and age, life style variables, and anxiety and stress-related variables, will be related to diastolic pressure in a young population of students.

Hypothesis 3: Controlling for differences in gender and age, life style variables, and anxiety and stress-related variables, will be related to the overall cardiovascular health and PP in a young population of students.

In investigating our hypotheses, we followed the recommendations of leading cardiovascular schools (Frese and Zapf, 1988; Kristensen, 1996; Kasl, 1998) of incorporating objective-based cardiovascular measurements in the study designs. Both SBP and DBP were considered separately since they seem differently related to $\mathrm{CHD}$, and, as an integrated measurement, with PP.

\section{MATERIALS AND METHODS}

Data were collected between 2015 and 2016. A survey was administered by resident physicians in occupational medicine to a consistent sample of European students of an Italian university. In total, 412 students-belonging to several health care profession courses-participated in the study: 283 participants were women $(68.7 \%)$ and 129 were men $(31.3 \%)$. The average age \pm standard deviation was $23.9 \pm 7.5$ years.

Moreover, besides the mandatory health surveillance pursuant to the Italian Legislative Decree no. 81/2008 and subsequent amendments, the occupational physicians of a large Italian 
University Hospital investigated with particular attention health behaviors and cardiovascular health of the participants.

DBP and SBP readings were obtained by using the same professional aneroid sphygmomanometer on each student's right arm in a seated position maintained for at least $5 \mathrm{~min}$ in a constant room temperature. The instrument, owned by the University Hospital, is regularly calibrated by professional technicians. The diastolic scores ranged between 70 and $90 \mathrm{mmHg}$; the systolic scores ranged between 100 and $170 \mathrm{mmHg}$.

Life-style variables were also investigated during the medical consultation. Smoking status was categorized into non-smoker, former smoker, or smoker. Drinking alcohol was categorized into non-drinker, occasional drinker, drinker.

The frequency of physical activity including sport, stretching exercise, and walking was dichotomously categorized into yes or not. BMI was calculated following the literature recommendation. Students' height and mass were measured during the medical examination.

\section{Instruments}

\section{The Anxiety Scale of the Italian Version of the General Health Questionnaire (GHQ-12)}

The Italian version of the scale assesses whether the respondent has recently experienced a particular symptom or behavior. Each item is rated on a 4-point scale (less than usual, no more than usual, rather more than usual, or much more than usual) measuring a perception of psychological distress. A higher score indicates a greater degree of psychological distress (Piccinelli et al., 1993).

\section{Student Satisfaction}

Overall student satisfaction was assessed on a single item: "How satisfied are you with your present studies?" A metaanalysis, in which single-item measures were correlated with scales measuring overall job satisfaction, found that single-item measures were sufficiently reliable (Wanous et al., 1997). This scale was adapted for the student setting.

\section{University Identification}

The present study aimed to use a specific model of identification, especially developed for students. We used a single-item graphic scale for the measurement of identification with university adapted by the study of Shamir and Kark (2010). The scale was based on conceiving of identification in terms of distance or overlap between entities in a cognitive space. The content, construct, and predictive validity of this single-item measure have previously been investigated (Shamir and Kark, 2010).

\section{Control Variables}

Gender and age were included as control variables because they have been identified as possible confounders of the relation between stress-related factors anxiety and BP as explained in the Section "Introduction."

\section{Procedure and Data Analysis}

Descriptive statistics, Pearson's $r$ correlation and hierarchical regressions were performed on the study data using SPSS version 20 (SPSS Inc., Chicago, IL, USA). We used hierarchical regression as an analytical strategy because it provides statistical tests that allow for predictive conclusions: (1) the power of each block of variables (i.e., demographics, lifestyle variables, and anxiety); (2) the unique relationship between each predictor within each block and the dependent variable; and (3) the predictors with the strongest relationship with the dependent variable across blocks of variables (Midgley and Urdan, 2001; Wolters, 2004).

In order to better highlight the incremental contribution of each psychological variable (anxiety, student satisfaction, and university identification), our analyses proceeded in three blocks; these blocks are shown in Tables 2-4. In the first block, we added demographic variables (age and gender). In the second block, we added lifestyles variables (smoking status, alcohol consumption, BMI, and sport/exercising). These were followed by psychological variables in the third block.

\section{RESULTS}

Descriptive statistics and the correlations between demographics, anxiety, stress-related factors, and BP are reported in Table $\mathbf{1}$.

Tables 2-4 show the results of the regression analyses. The first analysis was the hierarchical regression with SBP as dependent variable and with demographics in the first block and life style variables and anxiety related stress respectively in the second and third block. In the first block, demographic data account for $4 \%$ of variance in DBP, with only gender statistically significant. When lifestyle variables were added in the second block, the model was significant, and this dimensions accounted for increased $4 \%$ of variance with smoking status, alcohol consumption, and sport/exercising significant. Finally, when anxiety, student satisfaction, and university identification were added in the third block, the model was significant, and these dimensions accounted for a total of $11 \%$ of in variance. The final model pertains the significance of all variables with the only exception of smoking status. In anxiety, student satisfaction, and university identification resulted significant and increased the explained variance of $3 \%$ over demographics and lifestyle variables. All the psychological variables were significant in the explanation of the SBP. Interestingly, higher level of identification with university was associated positively with higher SBP.

The second analysis used DBP as dependent variable. Demographics accounted for $2 \%$ with the significant role played by gender. Lifestyle variables in the second block added 3\% of incremental variance with only sport/exercising significant. The final model in the third block with psychological variables added accounted for a total $7 \%$ of variance. University and identification and anxiety resulted significant, whereas student satisfaction not.

Finally, when PP was used as dependent variable, the model was significant, and the considered dimensions accounted for a total of $7 \%$ of variance. In the final model only gender and student satisfaction were significant pointing out the peculiar role played by this variables. No lifestyle variables were significant. 


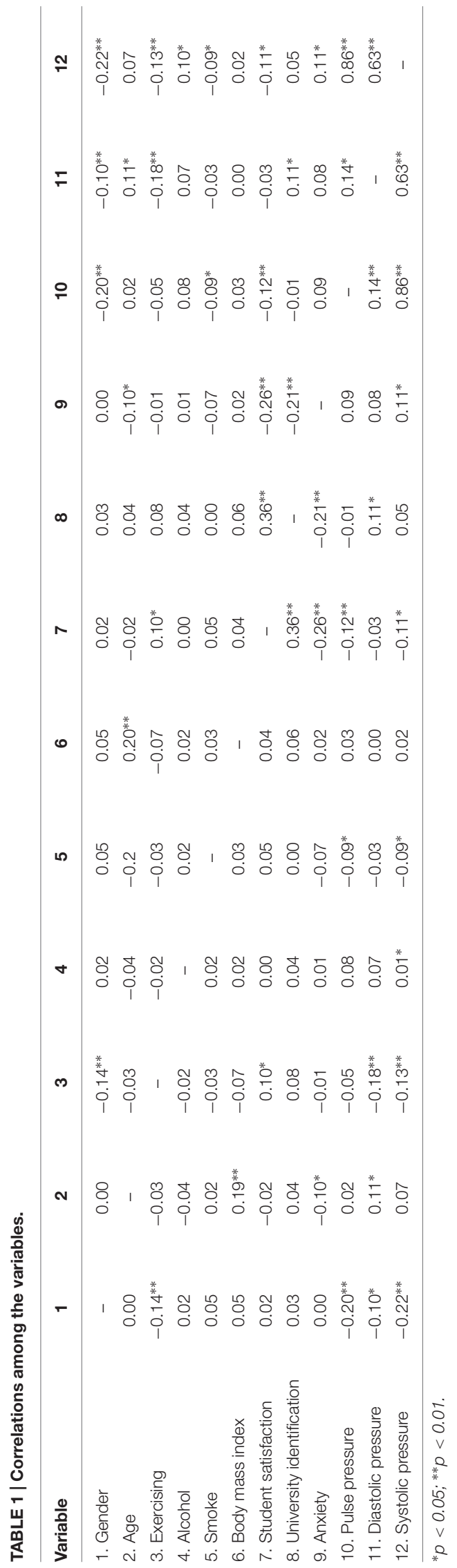

\section{DISCUSSION}

The models explain, as expected, a limited portion of the variance since the cardiovascular risk is considerably influenced by age. However, it is interesting to note that in such a young population (average age $23.9 \pm 7.5$ years old) these variables, in particular the psychological ones, may be related to an increase of the BP.

The present findings add further useful information and insight on the role of psychological stressors (and in particular student satisfaction) in determining young students BP and, therefore, cardiovascular health. These results seem to be in line with current literature (Backé et al., 2011; Hirokawa et al., 2016; Lazaridis et al., 2016), although this study is the first of its kind focusing on a sample of young students (average age $23.9 \pm 7.5$ years old), unlike the vast majority of the researches on cardiovascular risk and work-related stress. SBP appears to be significantly associated to anxiety and to university identification as well as to alcohol use and to sport/exercise (hypothesis 1). University identification and anxiety resulted to be significantly associated to DBP along sport/exercise and gender (hypothesis 2). Gender and student satisfaction were significantly associated to PP (hypothesis 3). Amongst demographic variables, life styles appear important and, in particular, sport/exercising appear significant $(p<0.001)$ in both the first and the second model.

In fact, the evidence of the several benefits provided by physical activity either on cardiovascular and internal diseases or on psychosocial disorders is well known and exhaustively described in scientific literature. Scott (1960) hypothesized that physical activity would ameliorate anxiety by becoming a sort of distraction from its symptoms and that following a healthy lifestyle may improve social contacts in patients and, therefore, the feedback from their environment.

Positive effects of physical activity on people who experienced normal or increased anxiety levels have been reported in several randomized trials (Bartley et al., 2013; Wegner et al., 2014; Pedersen and Saltin, 2015). Herring et al. (2010), comparing 40 studies in a meta-analysis, infer that anxiety symptoms in people suffering from chronic illnesses, such as CVDs, can be reduced by physical exercise.

Evidence of clinically relevant lowering of $\mathrm{BP}$ in hypertensive subjects engaged in physical training is larger and several metaanalyses are in agreement with the results of beneficial effect of physical activity on resting BP (Fagard and Cornelissen, 2007; Cornelissen et al., 2013; Garcia-Hermoso et al., 2013; Carlson et al., 2014; Huang et al., 2014). Neurohormonal, vascular, and structural adaptation mechanisms seem to be triggered by physical exercise and involved in the lowering effect of BP (Predel et al., 2001). Shah et al. (2016), considering a cohort of more than 4,000 young adults followed for an average of 26.9 years, have highlighted the importance of cardiorespiratory fitness as an independent risk factor for CVDs, and found a reduction of $15 \%$ of total mortality and $12 \%$ of the first cardiovascular event in three decades for each minute of exercise.

A complete understanding of the underlying nature of the existing relationships amongst job strain, identification, satisfaction, work stress, anxiety, and HT remains still unclear and difficult to comprehend because of the several complicated 
TABLE 2 | Hierarchical regression with SBP as criterion variable.

\begin{tabular}{lccc}
\hline & \multicolumn{3}{c}{ SBP } \\
\cline { 2 - 4 } Predictors & Block 1 & Block 2 & Block 3 \\
\hline Age & 0.07 & 0.07 & 0.07 \\
Gender & $-0.21^{* * *}$ & $-0.23^{* * *}$ & $-0.23^{* * *}$ \\
Alcohol consumption & - & $0.10^{*}$ & $0.10^{*}$ \\
BMl & - & 0.01 & 0.00 \\
Smoking status & - & $-0.08^{*}$ & -0.07 \\
Sport/exercising & - & $-0.16^{* * *}$ & $-0.16^{* * *}$ \\
Anxiety & - & - & $0.11^{*}$ \\
Student satisfaction & - & - & $-0.12^{*}$ \\
University identification & - & - & $0.10^{*}$ \\
$R^{2}$ & $0.04^{* * *}$ & $0.08^{* * *}$ & $0.11^{* * *}$ \\
$\Delta R^{2}$ & - & $0.04^{* * *}$ & $0.03^{* * *}$ \\
\hline$* p<0.05 ; * * * p<0.001$. & & &
\end{tabular}

TABLE 3 | Hierarchical regression with DBP as criterion variable.

\begin{tabular}{lccc}
\hline & \multicolumn{3}{c}{ DBP } \\
\cline { 2 - 4 } Predictors & Block 1 & Block 2 & Block 3 \\
\hline Age & $0.10^{*}$ & $0.11^{*}$ & $0.12^{*}$ \\
Gender & $-0.10^{*}$ & $-0.13^{* *}$ & $-0.13^{* *}$ \\
Alcohol consumption & - & 0.07 & 0.06 \\
BMl & - & -0.02 & -0.02 \\
Smoking status & - & -0.03 & -0.03 \\
Sport/exercising & - & $-0.20^{* * *}$ & $-0.21^{* * *}$ \\
Anxiety & - & - & $0.11^{*}$ \\
Student satisfaction & - & - & 0.02 \\
University identification & - & - & $0.15^{* *}$ \\
$R^{2}$ & $0.02^{* *}$ & $0.05^{* * *}$ & $0.07^{* * *}$ \\
$\Delta R^{2}$ & - & $0.03^{* * *}$ & $0.02^{* * *}$ \\
\hline$* p<0.05 ; * *<0.01 ; * * * p<0.001$. & &
\end{tabular}

and confounding factors (Pan et al., 2015; Jackson et al., 2016; Maatouk et al., 2016). At the same time, it represents a challenging opportunity to earlier identify possible risk factors and, possibly, novel intervention strategies especially in the young population, that is in the study of cardiovascular risk.

It is noteworthy that the identification factor with university appeared to be positively related to elevated BP. Although it is difficult to establish an accurate underlying mechanism we may speculate that, possibly, an excessive identification results to be more stressful for the students and eventually expressing itself in a rise of the pressure values. In spite of the fact that several authors have been trying to investigate on the impact of stressful psychosocial work environments on health, focusing in particular on the ERI model (Siegrist, 1996) that combines extrinsic and intrinsic factors in studying work-related health (Birgit et al., 2013; Rasmussen et al., 2016; Siegrist and Li, 2016), available data in students and young people are meager. The concept of social reciprocity is the main core of the ERI model whereby money, esteem, and career opportunities (promotion and job security) become rewards achieved throughout job efforts. According to
TABLE 4 | Hierarchical regression with pulse pressure as criterion variable.

\begin{tabular}{lccc}
\hline & \multicolumn{3}{c}{ Pulse pressure } \\
\cline { 2 - 4 } Predictors & Block 1 & Block 2 & Block 3 \\
\hline Age & $0.10^{*}$ & 0.01 & 0.01 \\
Gender & $-0.10^{*}$ & $-0.20^{* * *}$ & $-0.21^{* * *}$ \\
Alcohol consumption & - & 0.08 & 0.08 \\
BMl & - & 0.02 & 0.02 \\
Smoking status & - & $-0.09^{*}$ & -0.08 \\
Sport/exercising & - & -0.08 & -0.07 \\
Anxiety & - & - & 0.05 \\
Student satisfaction & - & - & $-0.12^{*}$ \\
University identification & - & $0.05^{* * *}$ & 0.06 \\
$R^{2}$ & $0.03^{* *}$ & $0.02^{* * *}$ & $0.07^{* * *}$ \\
$\Delta R^{2}$ & - & & $0.02^{* * *}$ \\
\hline$* p<0.05 ; * * p<0.01 ; * * * p<0.001$. & &
\end{tabular}

the ERI model, an elevated job effort combined with a poor reward (lack of reciprocity) triggers consistent negative emotions and stress responses that finally result in adverse long-term effects on health. People who show an excessive engagement and a desire of being in control when trying to cope with exacting work situations are expected to exhibit a high susceptibility to these stress responses ("over-commitment", OC; Siegrist and Li, 2016). If we hypothesize to apply the ERI model to an excessive identification in university, our finding would result to be in line with the bulk of studies proving the association between $\mathrm{OC}$ and elevated SBP over time (Gilbert-Ouimet et al., 2012; Trudel et al., 2013; Xu et al., 2013).

Moreover, over-committed people show elevated levels of atherogenic lipids, glucose, and fibrinogen, increased proinflammatory activity, and decreased activity of natural killer cells and suffer from fatigue and insomnia. Weiner (1992) hypothesized the existence of an underlying and chronic arousal of the sympathetic-adrenergic system not equilibrated by restoring recovery processes provided by the parasympathetic nervous system. On the other hand, an individual may independently develop overindulgence with his/her work, in presence of increasing self-imposed demands and inability to regulate his/her work habits. Robinson (1998) interpreted this condition as workaholism, pointing out that it becomes problematic when the need to work becomes excessive to the point to create a substantial interference with personal health, happiness, family relationships, and social functioning. Workaholic people develop initially aggressiveness, elevated inner tension, and inability to relax (Marazziti et al., 2014) and, subsequently, either psychiatric symptoms such as anxiety, depression, and irritability, either physical problems such as HT, heart and kidney complications (Elowe, 2010).

It is noteworthy that in our study the only significant variable for PP-in addition to the gender (which is the control anyway) - is the student satisfaction. This variable is crucial to the institutional success: an effective institution has satisfied "customers." In such a context, the satisfaction of the students may have several implications. First of all, satisfied students are more likely to continue their studies and achieve success positions 
in academia. This is crucial to improve the financial position and reputation of the University. In addition, a high student satisfaction may be also useful to attract new students, which in turn may increase the University's reputation (Aherne et al., 2016; Grilo Diogo et al., 2016).

Several theories have been proposed in an effort to better understanding the psychosocial dynamics of student satisfaction. For example, the happy-productive student theory (Cotton et al., 2002) suggests that student satisfaction is mediated by psychosocial factors such as coping, stress and well-being. Based on this theory, the authors provided evidence that high levels of psychological distress at university related to lower satisfaction. There is a need to identify and manage the causes of dissatisfaction among students in order to improve their psychological state.

The investment model explains the relationship between student satisfaction, dropout, and academic performance. Satisfaction increases when the rewards of study increase (higher grades; Hatcher et al., 1992). The model allows an early identification of students at risk of dropout, as well as to implement specific interventions with proper counseling and support measures.

There is also a third approach, which is based on the theory of consumer satisfaction (Churchill and Surprenant, 1982). It considers the satisfaction as a function of the extent to which the expectations of the students are positively confirmed during their course of study.

Some limitations of our study should be acknowledged. First of all, it cannot prove causality since its design was crosssectional. Consequently, the use of a longitudinal design is suggested. A second limitation is the use of some single-item research tools; similarly, the stress construct could be better defined (e.g., workload, support of the leaders, etc.). However, we are of the opinion that the collection and the processing of data were easy and more accessible. A third limitation concerns the sample that is not representative of the population of the Italian university students. In fact, our sample consisted of students from one university only, albeit from several health care profession degree courses. A fourth limitation relates to student satisfaction, which is not strictly a stress factor. However, different studies showed how it is an important determinant of a state of wellbeing (Warr, 1990; Faragher et al., 2005; Schéle et al., 2012; Alexopoulos et al., 2014). A fifth limitation is the single-time and manual measurement of BP. A dynamic monitoring of BP in the $24 \mathrm{~h}$ would have provided more reliable results but, at the same time, would have reduced students' participation in the research, because it is a method not widely accepted. Finally, the explained variance, as already explained above, is low. However, since the pressure values are usually low in people in the age range of our sample, we were expecting an even lower explained variance. Moreover, we observed that other studies, in which the parameter of BP was evaluated in combination with stress (e.g., Ford, 2014), did not report high associations also.

The present study definitely deserves follow-up to reach its assigned purposes, in particular by widening the sample and by extending the research to other university students. It would be interesting to evaluate also the consumption of caffeine from the students. On this topic the research perspectives are interesting. For example, a recent Italian study (Palatini et al., 2016) — which involved more than 1,200 patients over 12 years-showed that the heavy coffee drinkers show a risk of cardiovascular events (especially myocardial infarction) four times higher than nondrinkers, while moderate coffee drinkers they have a tripled risk. These effects could be mediated by the long-term influence of caffeine on BP and glucose metabolism (Palatini et al., 2016). However, coffee is not the only source of intake of caffeine. Especially in young people it is necessary to carefully evaluate the consumption of sugary drinks containing caffeine and, in particular, high caffeine content drinks (energy drinks), whose sales have increased worldwide over the past decade (Harris and Munsell, 2015; Brothers et al., 2016; Katz, 2016). Finally, it may need to consider other psychological variables, such as emotional intelligence (Di Fabio, 2014, 2015). Recently, Cabello and Fernández-Berrocal (2015) found that women and young adults in general were more likely to be incremental theorists than men and older adults. Furthermore, they found that emotion and emotional intelligence theories mediated the relationship of gender and age with ability emotional intelligence.

We are confident that our results, confirming the three innovative hypotheses, may be profitably transferred within the University organizations not only as an instrument of risk assessment-mandatory under the laws of EU countries (e.g., the Italian Legislative Decree n. 81/2008 and subsequent amendments) - but also, and moreover, to improve their institutional success. With this in mind, we believe that universities should adopt strategies encompassing the consultation of occupational physicians and industrial psychologists, aimed at assessing the satisfaction of health care profession students and at promoting their health. For the first aspect it may be useful, for example, providing constantly updated information about the professional opportunities of each study profile, encourage meetings with the world of work (especially, but not only, with the University hospitals), predispose strategies of stress management training and organize interventions for the prevention of dropouts. As far as the second aspect is concerned, the data collected during the health surveillance of students (such as BP) are a first, valuable, source for developing health promotion programs in both group and individual levels.

\section{AUTHOR CONTRIBUTIONS}

NM, GG, SDPC, JF-P, FM, and GA equally contributed to all the following issues of the research: conception and design of the work; acquisition, analysis, or interpretation of data for the work; drafting the work and critically revising it; final approval of the version to be published; agreement to be accountable for all aspects of the work in ensuring that questions related to the accuracy or integrity of any part of the work are appropriately investigated and resolved. 


\section{REFERENCES}

Aherne, D., Farrant, K., Hickey, L., Hickey, E., McGrath, L., and McGrath, D. (2016). Mindfulness based stress reduction for medical students: optimising student satisfaction and engagement. BMC Med. Educ. 16:209. doi: 10.1186/s12909-016-0728-8

Alexopoulos, E. C., Palatsidi, V., Tigani, X., and Darviri, C. (2014). Exploring stress levels, job satisfaction, and quality of life in a sample of police officers in Greece. Saf. Health Work 5, 210-215. doi: 10.1016/j.shaw.2014.07.004

Backé, E. M., Seidler, A., Latza, U., Rossnagel, K., and Schumann, B. (2011). The role of psychosocial stress at work for the development of cardiovascular diseases: a systematic review. Int. Arch. Occup. Environ. Health 85, 67-79. doi: 10.1007/s00420-011-0643-6

Baldasseroni, A., Abrami, V., Arcangeli, G., Cupelli, V., Fioriti, M., Guarducci, L., et al. (2005). Longitudinal study for assessing the efficacy of preventive measures in a population of health workers exposed to the risk of patient lifting. G. Ital. Med. Lav. Ergon. 27, 101-105.

Bartley, C. A., Hay, M., and Bloch, M. H. (2013). Metaanalysis: aerobic exercise for the treatment of anxiety disorders. Prog. Neuropsychopharmacol. Biol. Psychiatry 45, 34-39. doi: 10.1016/j.pnpbp.2013.04.016

Birgit, E., Gunnevi, S., and Ann, Ö (2013). Work experiences among nurses and physicians in the beginning of their professional careers - analyses using the effort-reward imbalance model. Scand. J. Caring Sci. 27, 36-43. doi: 10.1111/j.1471-6712.2012.00997.x

Blacher, J., Staessen, J. A., Girerd, X., Gasowski, J., Thijs, L., Liu, L., et al. (2000). Pulse pressure not mean pressure determines cardiovascular risk in older hypertensive patients. Arch. Intern. Med. 160, 1085-1089. doi: 10.1001/archinte.160.8.1085

Brothers, R. M., Christmas, K. M., Patik, J. C., and Bhella, P. S. (2016). Heart rate, blood pressure and repolarization effects of an energy drink as compared to coffee. Clin. Physiol. Funct. Imaging doi: 10.1111/cpf.12357 [Epub ahead of print].

Bugajska, J., Widerszal-Bazyl, M., Radkiewicz, P., Pasierski, T., Szulczyk, G. A., Zabek, J., et al. (2008). Perceived work-related stress and early atherosclerotic changes in healthy employees. Int. Arch. Occup. Environ. Health 81, 1037-1043. doi: 10.1007/s00420-007-0297-6

Cabello, R., and Fernández-Berrocal, P. (2015). Implicit theories and ability emotional intelligence. Front. Psychol. 6:700. doi: 10.3389/fpsyg.2015. 00700

Caricati, L., Chiesa, R., Guglielmi, D., and Mariani, M. G. (2016). Real and perceived employability: a comparison among Italian graduates. J. High. Educ. Policy Manag. 38, 490-502. doi: 10.1080/1360080X.2016.1182668

Carlson, D. J., Dieberg, G., Hess, N. C., Millar, P. J., and Smart, N. A. (2014). Isometric exercise training for blood pressure management: a systematic review and meta-analysis. Mayo Clin. Proc. 89, 327-334. doi: 10.1016/j.mayocp.2013.10.030

Churchill, G. A., and Surprenant, C. (1982). An investigation into the determinants of customer satisfaction. J. Mark. Res. 9, 491-504. doi: 10.2307/3151722

Cornelissen, V. A., Buys, R., and Smart, N. A. (2013). Endurance exercise beneficially affects ambulatory blood pressure: a systematic review and metaanalysis. J. Hypertens. 31, 639-648. doi: 10.1097/HJH.0b013e32835ca964

Cotton, S. J., Dollard, M. F., and de Jonge, J. (2002). Stress and student job design: satisfaction, well-being, and performance in university students. Int. J. Stress Manag. 9, 147-162. doi: 10.1023/A:1015515714410

Cuffee, Y., Ogedegbe, C., Williams, N. J., Ogedegbe, G., and Schoenthaler, A. (2014). Psychosocial risk factors for hypertension: an update of the literature. Curr. Hypertens. Rep. 16, 483. doi: 10.1007/s11906-014-0483-483

Di Fabio, A. (2014). Intrapreneurial self-capital: a new construct for the $21 \mathrm{st}$ century. J. Employ. Couns. 51, 98-111. doi: 10.1002/j.2161-1920.2014.00045.x

Di Fabio, A. (2015). Beyond fluid intelligence and personality traits in social support: the role of ability based emotional intelligence. Front. Psychol. 6:395. doi: 10.3389/fpsyg.2015.00395

Elowe, J. (2010). Workaholism: between illusion and addiction. Encephale 36, 285-293. doi: 10.1016/j.encep.2009.12.002

Fagard, R. H., and Cornelissen, V. A. (2007). Effect of exercise on blood pressure control in hypertensive patients. Eur. J. Cardiovasc. Prev. Rehabil. 14, 12-17. doi: 10.1097/HJR.0b013e3280128bbb
Falaschetti, E., Mindell, J., Knott, C., and Poulter, N. (2014). Hypertension management in England: a serial cross-sectional study from 1994 to 2011. Lancet 383, 1912-1919. doi: 10.1016/S0140-6736(14)60688-7

Faragher, E. B., Cass, M., and Cooper, C. L. (2005). The relationship between job satisfaction and health: a meta-analysis. Occup. Environ. Med. 62, 105-112. doi: 10.1136/oem.2002.006734

Ferguson, T. S., Younger, N. O., Tulloch-Reid, M. K., Wright, M. B., Ward, E. M., Ashley, D. E., et al. (2008). Prevalence of prehypertension and its relationship to risk factors for cardiovascular disease in Jamaica: analysis from a cross-sectional survey. BMC Cardiovasc. Disord. 8:20. doi: 10.1186/14712261-8-20

Floyd, C. N. (2015). Hypertension - state of the art 2015. Clin. Med. (Lond). 16, 52-54. doi: 10.7861/clinmedicine.16-1-52

Ford, M. T. (2014). Perceived unfairness at work, social and personal resources, and resting blood pressure. Stress Health 30, 12-22. doi: 10.1002/smi.2491

Frese, M., and Zapf, D. (1988). "Methodological issues in the study of work stress: objective vs subjective measurement of work stress and the question of longitudinal studies," in Causes, Coping and Consequences of Stress at Work, eds C. L. Cooper and R. Payne (New York, NY: John Wiley \& Sons), 375-387.

Ganzel, B. L., and Morris, P. A. (2011). Allostasis and the developing human brain: explicit consideration of implicit models. Dev. Psychopathol. 23, 955-974. doi: 10.1017/S0954579411000447

Ganzel, B. L., Morris, P. A., and Wethington, E. (2010). Allostasis and the human brain: Integrating models of stress from the social and life sciences. Psychol. Rev. 117, 134-174. doi: 10.1037/a0017773

Garcia-Hermoso, A., Saavedra, J. M., and Escalante, Y. (2013). Effects of exercise on resting blood pressure in obese children: a meta-analysis of randomized controlled trials. Obes. Rev. 14, 919-928. doi: 10.1111/obr.12054

Gilbert-Ouimet, M., Brisson, C., Vézina, M., Milot, A., and Blanchette, C. (2012). Repeated exposure to effort-reward imbalance, increased blood pressure, and hypertension incidence among white-collar workers: effortreward imbalance and blood pressure. J. Psychosom. Res. 72, 26-32. doi: 10.1016/j.jpsychores.2011.07.002

Graham, N., and Smith, D. J. (2016). Comorbidity of depression and anxiety disorders in patients with hypertension. J. Hypertens. 34, 397-398. doi: 10.1097/HJH.0000000000000850

Grilo Diogo, P., Moreira, A., Coimbra, A., Coelho Silva, A., Nixon Martins, A., Mendonça, C., et al. (2016). Study on portuguese medical schools' learning conditions: a national analysis on student satisfaction, student-tutor ratios and number of admissions. Acta Med. Port. 29, 301-309. doi: 10.20344/amp.6795

Hansen, M. L., Gunn, P. W., and Kaelber, D. C. (2007). Underdiagnosis of hypertension in children and adolescents. JAMA 298, 874-879. doi: 10.1001/jama.298.8.874

Harris, J. L., and Munsell, C. R. (2015). Energy drinks and adolescents: what's the harm? Nutr. Rev. 73, 247-257. doi: 10.1093/nutrit/nuu061

Hatcher, L., Kryter, K., Prus, J. S., and Fitzgerald, V. (1992). Predicting college student satisfaction, commitment, and attrition from investment model constructs. J. Appl. Soc. Psychol. 22, 1273-1296. doi: 10.1111/j.15591816.1992.tb00950.x

Herring, M. P., O'Connor, P. J., and Dishman, R. K. (2010). The effect of exercise training on anxiety symptoms among patients: a systematic review. Arch. Intern. Med. 170, 321-331. doi: 10.1001/archinternmed.2009.530

Hintsanen, M., Kivimäki, M., Elovainio, M., Pulkki-Råback, L., Keskivaara, P., Juonala, M., et al. (2005). Job strain and early atherosclerosis: the cardiovascular risk in young finns study. Psychosom. Med. 67, 740-747. doi: 10.1097/01.psy.0000181271.04169.93

Hirokawa, K., Ohira, T., Nagayoshi, M., Kajiura, M., Imano, H., Kitamura, A., et al. (2016). Occupational status and job stress in relation to cardiovascular stress reactivity in Japanese workers. Prev. Med. Rep. 4, 61-67. doi: 10.1016/j.pmedr.2016.05.010

Hodgkinson, J. A., Tucker, K. L., Martin, U., Beesley, L., and McManus, R. J. (2015). The use of ambulatory blood pressure measurement. Br. J. Hosp. Med. (Lond). 76, 631-637. doi: 10.12968/hmed.2015.76.11.631

Hosey, G. M., Samo, M., Gregg, E. W., Padden, D., and Bibb, S. G. (2014). Socioeconomic and demographic predictors of selected cardiovascular risk factors among adults living in Pohnpei, Federated States of Micronesia. BMC Public Health 14:895. doi: 10.1186/1471-2458-14-895 
Huang, T., Larsen, K. T., Ried-Larsen, M., Moller, N. C., and Andersen, L. B. (2014). The effects of physical activity and exercise on brain-derived neurotrophic factor in healthy humans: a review. Scand. J. Med. Sci. Sports 24, 1-10. doi: 10.1111/sms.12069

Jackson, C. A., Pathirana, T., and Gardiner, P. A. (2016). Depression, anxiety and risk of hypertension in mid-aged women: a prospective longitudinal study. J. Hypertens. 34, 1959-1966. doi: 10.1097/HJH.00000000000 01030

James, D., Yates, J., and Ferguson, E. (2013). Can the 12-item general health questionnaire be used to identify medical students who might 'struggle' on the medical course? A prospective study on two cohorts. BMC Med. Educ. 13:48. doi: 10.1186/1472-6920-13-48

Jennings, G. L., and Touyz, R. M. (2013). Hypertension guidelines: more challenges highlighted by Europe. Hypertension 62, 660-665. doi: 10.1161/hypertensionaha.113.02034

Johansson, G., Evans, G. W., Cederström, C., Rydstedt, L. W., Fuller-Rowell, T., and Ong, A. D. (2012). The effects of urban bus driving on blood pressure and musculoskeletal problems: a quasi-experimental study. Psychosom. Med. 74, 89-92. doi: 10.1097/PSY.0b013e31823ba88f

Jönsson, P., Österberg, K., Wallergård, M., Hansen, A. M., Garde, A. H., Johansson, G., et al. (2015). Exhaustion-related changes in cardiovascular and cortisol reactivity to acute psychosocial stress. Physiol. Behav. 151, 327-337. doi: 10.1016/j.physbeh.2015.07.020

Kasl, S. V. (1998). Measuring job stressors and studying the health impact of the work environment: an epidemiologic commentary. J. Occup. Health Psychol. 34, 390-401. doi: 10.1037/1076-8998.3.4.390

Katz, D. L. (2016). Energy drink consumption in Israeli youth: Public health \& the perils of energetic marketing. Isr. J. Health Policy Res. 10, 9. doi: 10.1186/s13584016-0069-4

Kessler, R. C., Chiu, W. T., Demler, O., Merikangas, K. R., and Walters, E. E. (2005). Prevalence, severity, and comorbidity of 12-month DSM-IV disorders in the National Comorbidity Survey Replication. Arch. Gen. Psychiatry 62, 617-627. doi: 10.1001/archpsyc.62.6.617

Khamis, R. Y., Ammari, T., and Mikhail, G. W. (2016). Gender differences in coronary heart disease. Heart. Heartjnl 2014, 306463. doi: 10.1136/heartjnl2014-306463

Kivimäki, M., Ferrie, J. E., Shipley, M., Gimeno, D., Elovainio, M., de Vogli, R., et al. (2008). Effects on blood pressure do not explain the association between organizational justice and coronary heart disease in the Whitehall II study. Psychosom. Med. 70, 1-6. doi: 10.1097/PSY.0b013e31815aaca3

Kristensen, T. S. (1996). Job stress and cardiovascular disease: a theoretic critical review. J. Occup. Health. Psychol. 1, 246-260. doi: 10.1037/1076-8998.1. 3.246

Lazaridis, K., Jovanović, J., Jovanović, J., Šarac, I., and Jovanović, S. (2016). The impact of occupational stress factors on temporary work disability related to arterial hypertension and its complications. Int. J. Occup. Saf. Ergon. 2, 1-8. doi: 10.1080/10803548.2016.1179524

Leigh, J. P., and Du, J. (2012). Are low wages risk factors for hypertension? Eur. J. Public Health 22, 854-859. doi: 10.1093/eurpub/ckr204

Lewington, S., Clarke, R., Qizilbash, N., Peto, R., Collins, R., and Prospective Studies Collaboration. (2002). Age-specific relevance of usual blood pressure to vascular mortality: a meta-analysis of individual data for one million adults in 61 prospective studies. Lancet 360, 1903-1913. doi: 10.1016/S01406736(02)11911-8

Lindgärde, F., Furu, M., and Ljung, B. O. (1987). A longitudinal study on the significance of environmental and individual factors associated with the development of essential hypertension. J. Epidemiol. Community Health 41, 220-226. doi: 10.1136/jech.41.3.220

Maas, A. H. E. M., and Appelman, Y. E. A. (2010). Gender differences in coronary heart disease. Neth. Heart. J. 18, 598-602. doi: 10.1007/s12471-010-0 841-y

Maatouk, I., Herzog, W., Böhlen, F., Quinzler, R., Löwe, B., Saum, K. U., et al. (2016). Association of hypertension with depression, and generalized anxiety symptoms in a large population-based sample of older adults. J. Hypertens. 34, 1711-1720. doi: 10.1097/HJH.0000000000001006

Mancia, G., Fagard, R., Narkiewicz, K., Redon, J., Zanchetti, A., Böhm, M., et al. (2013). $2013 \mathrm{ESH} / \mathrm{ESC}$ guidelines for the management of arterial hypertension: the task force for the management of arterial hypertension of the European
Society of Hypertension (ESH) and of the European Society of Cardiology (ESC). Eur. Heart. J. 34, 2159-2219. doi: 10.1093/eurheartj/eht151

Mangena, P., Saban, S., Hlabyago, K. E., and Rayner, B. (2016). An approach to the young hypertensive patient. S. Afr. Med. J. 106, 36-38. doi: 10.7196/SAMJ.2016.v106i1.10329

Marazziti, D., Falcone, M. F., Rosa, C., and Ghione, S. (1990). Changes in serotoninergic mechanisms in essential hypertension. Ann. Ital. Med. Int. 5, 459-463.

Marazziti, D., Presta, S., Baroni, S., Silvestri, S., and Dell'Osso, L. (2014). Behavioral addictions: a novel challenge for psychopharmacology. CNS Spectr. 19, 486-495. doi: 10.1017/S1092852913001041

Mathile, C. (2013). Run Your Business, Don't Let It Run You. San Francisco, CA: Berrett-Koehler Publishers, Inc.

Melamed, S., Fried, Y., and Froom, P. (2001). The interactive effect of chronic exposure to noise and job complexity on changes in blood pressure and job satisfaction: a longitudinal study of industrial employees. J. Occup. Health Psychol. 6, 182-195. doi: 10.1037/1076-8998.6.3.182

Mennini, F. S., Marcellusi, A., von der Schulenburg, J. M., Gray, A., Levy, P., Sciattella, P., et al. (2015). Cost of poor adherence to anti-hypertensive therapy in five European countries. Eur. J. Health Econ. 16, 65-72. doi: 10.1007/s10198013-0554-4

Merino, M. D., and Privado, J. (2015). Does employee recognition affect positive psychological functioning and well-being? Span. J. Psychol. 18, E64. doi: $10.1017 /$ sjp. 2015.67

Mermerelis, A., Kyvelou, S. M., Vellinga, A., Papageorgiou, C., Stefanadis, C., and Douzenis, A. (2016). Association between anxiety and depression symptoms with resistant hypertension and central hemodynamics: a pilot study. Hellenic J. Cardiol. 57, 203-204. doi: 10.1016/j.hjc.2016.07.004

Midgley, C., and Urdan, T. (2001). Academic self-handicapping and achievement goals: a further examination. Contemp. Educ. Psychol. 26, 61-75. doi: 10.1006/ceps.2000.1041

Modrek, S., and Cullen, M. R. (2013). Health consequences of the 'Great Recession' on the employed: evidence from an industrial cohort in aluminum manufacturing. Soc. Sci. Med. 92, 105-113. doi: 10.1016/j.socscimed.2013.04.027

Nechita, F., Streba, C. T., Vere, C. C., Nechita, D., and Rogoveanu, I. (2014). Stress in romanian first year nursing students. Curr. Health Sci. J. 40, 210-213. doi: 10.12865/CHSJ.40.03.10

Nomura, K., Nakao, M., Karita, K., Nishikitani, M., and Yano, E. (2005). Association between work-related psychological stress and arterial stiffness measured by brachial-ankle pulse-wave velocity in young Japanese males from an information service company. Scand. J. Work Environ. Health 31, 352-359. doi: $10.5271 /$ sjweh.918

Nordstrom, C. K., Dwyer, K. M., Merz, C. N., Shircore, A., and Dwyer, J. H. (2001). Work-related stress and early atherosclerosis. Epidemiology 12, 180-185. doi: 10.1097/00001648-200103000-00009

Palatini, P., Fania, C., Mos, L., Garavelli, G., Mazzer, A., Cozzio, S., et al. (2016). Coffee consumption and risk of cardiovascular events in hypertensive patients. Results from the HARVEST. Int. J. Cardiol. 212, 131-137. doi: 10.1016/j.ijcard.2016.03.006

Pan, Y., Cai, W., Cheng, Q., Dong, W., An, T., and Yan, J. (2015). Association between anxiety and hypertension: a systematic review and meta-analysis of epidemiological studies. Neuropsychiatr. Dis. Treat. 11, 1121-1130. doi: 10.2147/NDT.S77710

Pedersen, B. K., and Saltin, B. (2015). Exercise as medicine-evidence for prescribing exercise as therapy in 26 different chronic diseases. Scand. J. Med. Sci. Sports 25(Suppl.), 1-72. doi: 10.1111/sms.12581

Piccinelli, M., Bisoffi, G., Bon, M. G., Cunico, L., and Tansella, M. (1993). Validity and test-retest reliability of the Italian version of the 12-item General Health Questionnaire in general practice: a comparison between three scoring methods. Compr. Psychiatry 34, 198-205. doi: 10.1016/0010-440X(93)90048-9

Pilic, L., Pedlar, C. R., and Mavrommatis, Y. (2016). Salt-sensitive hypertension: mechanisms and effects of dietary and other lifestyle factors. Nutr. Rev 74, 645-658. doi: 10.1093/nutrit/nuw028

Poulter, N. R., Prabhakaran, D., and Caulfield, M. (2015). Hypertension. Lancet 386, 801-812. doi: 10.1016/S0140-6736(14)61468-9

Predel, H. G., Mainka, W., Schillings, W., Knigge, H., Montiel, J., Fallois, J., et al. (2001). Integrated effects of the vasodilating beta-blocker nebivolol on 
exercise performance, energy metabolism, cardiovascular and neurohormonal parameters in physically active patients with arterial hypertension. J. Hum. Hypertens. 15, 715-721. doi: 10.1038/sj.jhh.1001257

Pryjmachuk, S., and Richards, D. A. (2008). Predicting stress in pre-registration midwifery students attending a university in Northern England. Midwifery 24, 108-122. doi: 10.1016/j.midw.2006.07.006

Rasmussen, V., Turnell, A., Butow, P., Juraskova, I., Kirsten, L., Wiener, L., et al. (2016). Burnout among psychosocial oncologists: an application and extension of the effort-reward imbalance model. Psychooncology 25, 194-202. doi: 10.1002/pon.3902

Rau, R. (2006). The association between blood pressure and work stress: the importance of measuring isolated systolic hypertension. Work Stress 20, 84-97. doi: 10.1080/02678370600679447

Riese, H., Van Doornen, L. J., Houtman, I. L., and De Geus, E. J. (2004). Job strain in relation to ambulatory blood pressure, heart rate, and heart rate variability among female nurses. Scand. J. Work Environ. Health 30, 477-485. doi: $10.5271 /$ sjweh.837

Ritvanen, T., Louhevaara, V., Helin, P., Halonen, T., and Hänninen, O. (2003). Psychophysiological stress in high school teachers. Int. J. Occup. Med. Environ. Health 16, 255-264.

Robinson, B. E. (1998). Chained to the Desk. New York, NY: New York University Press.

Rosenthal, T., and Alter, A. (2012). Occupational stress and hypertension. J. Am. Soc. Hypertens. 6, 2-22. doi: 10.1016/j.jash.2011.09.002

Santulli, G. (2013). Epidemiology of cardiovascular disease in the 21st century: updated numbers and updated facts. J. Cardiovasc. Dis. Res. 1, 1-2.

Schéle, I. A., Hedman, L. R., and Hammarström, A. (2012). A model of psychosocial work environment, stress, and satisfaction among dental students in Sweden. J. Dent. Educ. 76, 1206-1217.

Scott, M. G. (1960). The contributions of physical activity to psychological development. Res. Q. 31, 307-320.

Shah, A. J., Veledar, E., Hong, Y., Bremner, J. D., and Vaccarino, V. (2011). Depression and history of attempted suicide as risk factors for heart disease mortality in young individuals. Arch. Gen. Psychiatry 68, 1135-1142. doi: 10.1001/archgenpsychiatry.2011.125

Shah, R. V., Murthy, V. L., Colangelo, L. A., Reis, J., Venkatesh, B. A., Sharma, R., et al. (2016). Association of fitness in young adulthood with survival and cardiovascular risk: the Coronary Artery Risk Development in Young Adults (CARDIA) Study. JAMA Intern. Med. 176, 87-95. doi: 10.1001/jamainternmed.2015.6309

Shamir, B., and Kark, R. (2010). A single-item graphic scale for the measurement of organizational identification. J. Occup. Organ. Psychol. 77, 115-123. doi: 10.1348/096317904322915946

Siegrist, J. (1996). Adverse health effects of high-effort/low-reward conditions. J. Occup. Health Psychol. 1, 27-41. doi: 10.1037/1076-8998. 1.1 .27

Siegrist, J., and Li, J. (2016). Associations of extrinsic and intrinsic components of work stress with health: a systematic review of evidence on the effortreward imbalance model. Int. J. Environ. Res. Public Health 13, E432. doi: 10.3390/ijerph13040432

Smith, P. M., Mustard, C. A., Lu, H., and Glazier, R. H. (2013). Comparing the risk associated with psychosocial work conditions and health behaviours on incident hypertension over a nine-year period in Ontario, Canada. Can. J. Public Health 104, e82-e86.

Sparrenberger, F., Cichelero, F. T., Ascoli, A. M., Fonseca, F. P., Weiss, G., Berwanger, O., et al. (2009). Does psychosocial stress cause hypertension? A systematic review of observational studies. J. Hum. Hypertens. 23, 12-19. doi: 10.1038/jhh.2008.74

Spruill, T. M. (2010). Chronic psychosocial stress and hypertension. Curr. Hypertens. Rep. 12, 10-16. doi: 10.1007/s11906-009-0084-8

Tanuseputro, P., Manuel, D. G., Leung, M., Nguyen, K., Johansen, H., and Canadian Cardiovascular Outcomes Research Team. (2003). Risk factors for cardiovascular disease in Canada. Can. J. Cardiol. 19, 1249-1259.

Tin, L. L., Beevers, D. G., and Lip, G. Y. (2002). Systolic vs diastolic blood pressure and the burden of hypertension. J. Hum. Hypertens. 16, 147-150. doi: 10.1038/sj.jhh.1001373
Trudel, X., Brisson, C., Milot, A., Masse, B., and Vézina, M. (2013). Psychosocial work environment and ambulatory blood pressure: independent and combined effect of demand-control and effort-reward imbalance models. Occup. Environ. Med. 2013, 815-822. doi: 10.1136/oemed-2013-101416

Trudel, X., Brisson, C., Milot, A., Masse, B., and Vézina, M. (2016). Adverse psychosocial work factors, blood pressure and hypertension incidence: repeated exposure in a 5-year prospective cohort study. J. Epidemiol. Community Health 70, 402-408. doi: 10.1136/jech-2014-204914

Van Hal, G. (2015). The true cost of the economic crisis on psychological well-being: a review. Psychol. Res. Behav. Manag. 8, 17-25. doi: 10.2147/PRBM.S44732

Ventura, H. O., and Lavie, C. J. (2016). Impact of comorbidities in hypertension. Curr. Opin. Cardiol. 31, 374-375. doi: 10.1097/HCO.00000000000 00302

Virtanen, M., Nyberg, S. T., Batty, G. D., Jokela, M., Heikkilä, K., Fransson, E. I., et al. (2013). Perceived job insecurity as a risk factor for incident coronary heart disease: systematic review and meta-analysis. BMJ 347, f4746. doi: $10.1136 /$ bmj.f4746

Wallace, L., Bourke, M. P., Tormoehlen, L. J., and Poe-Greskamp, M. V. (2015). Perceptions of Clinical Stress in Baccalaureate Nursing Students. Int. J. Nurs. Educ. Scholarsh. 12. doi: 10.1515/ijnes-2014-0056

Wanous, J. P., Reichers, A. E., and Hudy, M. J. (1997). Overall job satisfaction: how good are single-item measures? J. Appl. Psychol. 82, 247-252. doi: 10.1037/00219010.82.2.247

Warr, P. (1990). The measurement of well-being and other aspects of mental health. J. Occup. Organ. Psychol. 63, 193-210. doi: 10.1111/j.2044-8325.1990.tb00 521.x

Wegner, M., Helmich, I., Machado, S., Nardi, A. E., Arias-Carrion, O., and Budde, H. (2014). Effects of exercise on anxiety and depression disorders: review of metaanalyses and neurobiological mechanisms. CNS Neurol. Disord. Drug Targets 13, 1002-1014. doi: 10.2174/18715273136661406121 02841

Weiner, H. (1992). Perturbing the Organism: The Biology of Stressful Experience. Chicago, IL: Chicago University Press.

Wolters, C. A. (2004). Advancing achievement goal theory: using goal structures and goal orientations to predict students' motivation, cognition, and achievement. J. Educ. Psychol. 96, 236-250. doi: 10.1037/0022-0663.96. 2.236

Wright, B. R., Barbosa-Leiker, C., and Hoekstra, T. (2011). Law enforcement officer versus non-law enforcement officer status as a longitudinal predictor of traditional and emerging cardiovascular risk factors. J. Occup. Environ. Med. 53, 730-734. doi: 10.1097/JOM.0b013e318220c2da

Wright, T. A., Cropanzano, R., and Bonett, D. G. (2007). The moderating role of employee positive well-being on the relation between job satisfaction and job performance. J. Occup. Health Psychol. 12, 93-104. doi: 10.1037/10768998.12.2.93

Wright, T. A., and Diamond, J. W. (2006). Getting the pulse of your employees: the use of cardiovascular research in better understanding behavior in organizations. J. Organ. Behav. 27, 395-401. doi: 10.1002/ job.374

Xu, W., Yu, H., Hang, J., Gao, W., Zhao, Y., and Guo, L. (2013). The interaction effect of effort-reward imbalance and overcommitment on hypertension among Chinese workers: findings from SHISO study. Am. J. Ind. Med. 6, 1433-1441. doi: 10.1002/ajim.22254

Conflict of Interest Statement: The authors declare that the research was conducted in the absence of any commercial or financial relationships that could be construed as a potential conflict of interest.

Copyright (c) 2016 Mucci, Giorgi, De Pasquale Ceratti, Fiz-Pérez, Mucci and Arcangeli. This is an open-access article distributed under the terms of the Creative Commons Attribution License (CC BY). The use, distribution or reproduction in other forums is permitted, provided the original author(s) or licensor are credited and that the original publication in this journal is cited, in accordance with accepted academic practice. No use, distribution or reproduction is permitted which does not comply with these terms. 
OPEN ACCESS

Edited by:

Gabriele Giorgi,

European University of Rome, Italy

Reviewed by:

Javier Fiz Pérez,

European University of Rome, Italy

Giulio Arcangeli,

University of Florence, Italy

*Correspondence:

Andromachi Spanoul

andromachi.spanouli@vub.ac.be

Specialty section:

This article was submitted to Organizational Psychology,

a section of the journal

Frontiers in Psychology

Received: 13 May 2016

Accepted: 20 September 2016

Published: 03 October 2016

Citation:

Spanouli A and Hofmans J (2016) Walking the Tightrope: Counterproductive Work Behavior as Compensation for Citizenship Demands. Front. Psychol. 7:1530 doi: 10.3389/fpsyg.2016.01530

\section{Walking the Tightrope: Counterproductive Work Behavior as Compensation for Citizenship Demands}

\author{
Andromachi Spanouli* and Joeri Hofmans
}

Work and Organizational Psychology, Department of Psychology, Faculty of Psychology and Educational Sciences, Vrije Universiteit Brussel, Brussels, Belgium

Amidst a struggling economy, organizations are ruled by the survival of the fittest paradigm but it is the employees who tend to pay the price, with increased demands which, oftentimes, fall outside their job scope. In the present paper, we examined whether pressuring people to engage in such organizational citizenship behaviors (OCB) might in fact backfire and lead to increased Counterproductive Work Behavior (CWB) because of compensatory mechanisms. We propose a typology of OCB that distinguishes between discretionary and elicited $\mathrm{OCB}$, hypothesizing that elicited but not discretionary $\mathrm{OCB}$, positively relates to $\mathrm{CWB}$. By doing so, we wanted to examine if such a distinction can explain conflicting past results concerning the within-person OCBCWB link, and to test whether increased citizenship demands can have an adverse effect for the organization. Our hypothesis was tested by asking 29 employees twice a day for 10 consecutive working days to report on the elicited and discretionary OCB and CWB they performed ( $N=210$ responses). Multilevel logistic regression analyses showed that elicited OCB was positively related to CWB, whereas discretionary OCB was not related to CWB. This finding steers theorizing away from the conventional classification of employees as bad apples versus good soldiers, by revealing that CWB can positively relate to $\mathrm{OCB}$ as a result of compensatory mechanisms. From a practical point of view, our results imply that employers should be mindful of the unintended consequences that OCB might entail when employees perceive that they are expected to engage in such behaviors.

Keywords: organizational citizenship behaviors (OCB), counterproductive work behavior (CWB)

\section{INTRODUCTION}

Traditionally, work and organizational researchers and practitioners alike have strongly focused on enhancing behaviors that are deemed beneficial for organizations, often without questioning whether they are actually effective, and if so, at what cost (Bolino et al., 2004). Organizational citizenship behavior (OCB) undoubtedly belongs to this category of behaviors, representing employee behavior that lies outside the spectrum of tasks included in the job description and that promotes organizational functioning (Lee and Allen, 2002). Although OCB has long been considered to have only positive consequences both for the organization and the employee, cracks 
are starting to appear in its exclusively constructive image (Bolino and Turnley, 2005; Bolino et al., 2010). This awareness is particularly important as research indicates that today's employees not only experience greater in-role work requirements than employees in former times (Feldman, 2002; Brett and Stroh, 2003), but that they also often experience pressures to engage in extra-role behaviors such as OCBs (Bolino et al., 2010). As a result of the recent economic crisis, this trend has only accelerated with employees facing an increasing amount of stressors, such as heightened job demands and role conflict (Giorgi et al., 2015a). The result of these increases in work stressors is that both the mental and general health of the workforce is affected, as shown by increased rates of depression, anxiety, cardiovascular diseases, and respiratory health problems (Mucci et al., 2016). In reference to $\mathrm{OCB}$, research has shown that pressuring employees to engage in OCB can seriously endanger employee wellbeing as it might, for example, lead to increased levels of work-family conflict, work-leisure conflict and job stress (Bolino and Turnley, 2005; Bolino et al., 2010). In the present paper, we take research on OCB one step further by examining the relationship between OCB and counterproductive work behavior (CWB), which consists of employee acts that harm the organization and/or its members (Spector and Fox, 2002), In doing so, we put forward the idea that pressuring people to engage in OCB might not only be detrimental for employee wellbeing, but also for the organization itself, as elicited OCB might backfire and lead to increased CWB because of compensatory mechanisms.

On the basis of their construct definitions, OCB and CWB have traditionally been considered semantic opposites. This conceptualization has led to the formulation of the so-called continuum hypothesis (Heckert and Heckert, 2002) which states that $\mathrm{OCB}$ and $\mathrm{CWB}$ are two extremes of the same continuum, representing behaviors and acts that help and harm the organization, respectively (Dalal et al., 2009). The continuum hypothesis has been the prevailing proposition to date, with a great deal of empirical evidence pointing toward a strong negative relationship at the between-person level (e.g., Bennett and Stamper, 2001; Sackett, 2002), suggesting a clear differentiation of employees in two groups: those who generally perform OCB (and not CWB) and those who generally perform CWB (and not $\mathrm{OCB})$. However, despite this initial apparent support, the meta-analysis of Dalal (2005) demonstrated that methodological artifacts distorted the OCB-CWB relationship, and that when these artifacts are accounted for, the OCB-CWB relationship is actually modestly negative. Moreover, recent studies at the within-person level also reported weak negative, and in some cases even positive OCB-CWB relationships (Dalal et al., 2009; Ilies et al., 2013).

With the present study, we aim to provide an explanation for these mixed findings by studying the circumstances under which the within-person OCB-CWB relationship may differ. Toward that end, we introduce a distinction between discretionary and elicited OCB. Discretionary OCB concerns behaviors that employees choose to perform out of free will, while elicited OCB refers to behaviors that employees engage in as a result of a perceived obligation. Elicited OCB is in line with Spector and Fox's (2010) concept of demand-elicited OCB, which pertains to citizenship behaviors that are performed due to demands that elicit such behavior; thus introducing an element of obligation to the traditional OCB construct while stripping it from its voluntary components. Moreover, it bears similarities with Vigoda-Gadot's (2006) compulsory citizenship behavior and Bolino et al.'s (2010) citizenship pressure. Although we are not the first to introduce the idea of elicited OCB, previous studies were either theoretical (Vigoda-Gadot, 2006; Spector and Fox, 2010), tested elicited OCB in relation to different antecedents or outcomes (Bolino et al., 2010), or focused on the betweenperson level (Vigoda-Gadot, 2007). This study takes the current state of affairs a step further by empirically testing the effect of both OCB types on CWB at the within-person level, thereby trying to explain how the same individual may engage in both forms of behavior. To this end, we draw from different theoretical frameworks that provide the groundwork for understanding these relationships. But first, we zoom in on the main constructs of this study: OCB and CWB.

\section{OCB and CWB}

Organizational citizenship behavior has received extensive research attention since the seminal work by Smith et al. (1983) and Organ (1988). In its early conceptualizations, OCB was defined as "individual behavior that is discretionary, not directly or explicitly recognized by the formal reward system, and that in the aggregate promotes the effective functioning of the organization" (Organ, 1988, p. 4). Three distinct components are clear in this initial definition: (1) the lack of compensation for such behaviors, (2) their discretional nature, and (3) the beneficial effect that they have for the organization.

Much has changed since this initial conceptualization as critics have raised points concerning each of these components. In terms of (1) the lack of compensation, studies have revealed that managers actually do take into consideration citizenship behaviors when rating their subordinates performance (e.g., Podsakoff et al., 2000, 2009), a finding which led to the exclusion of this component from current definitions. Concerning (2) the discretional nature of such behaviors, although there have been scholars who challenged this assumption, these studies often form a parallel stream of literature, frequently coupled with distinct constructs and conceptualizations, thus treating nondiscretionary OCB as a separate phenomenon (Vigoda-Gadot, 2006, 2007; Bolino et al., 2010). Hence, although there seems to be consent that OCBs are often not voluntary, the conceptualization and often the corresponding measurement in the majority of the existing studies do not allow for such a differentiation. To account for this issue, we introduce the distinction between elicited and discretionary motives as two distinct drivers for the same types of citizenship behaviors. Regarding (3) the beneficial effect OCBs have for the organization, meta-analytic studies were able to confirm positive relationships of OCB with organizational outcomes such as performance, reduced costs and customer satisfaction (Nielsen et al., 2009; Podsakoff et al., 2009). However, there have also been, if only but a few, studies that have warned about the possible negative consequences that OCB may bare, both for organizations and for their enactors (for an overview, see 
Bolino et al., 2013). In this paper, we take stand with this account by introducing CWB as a potential outcome of OCB.

Counterproductive work behavior is an umbrella term that can encompass such distinct behaviors as production deviance, abuse, and withdrawal (Spector et al., 2006). Though its components are so distant from each other, they all share the principle of being considered harmful for an organization (Sackett, 2002; for a different approach, see Krischer et al., 2010). CWB has traditionally been studied at the between-person level, with its main predictors being personal or situational characteristics (Penney and Spector, 2005; Iliescu et al., 2015). Although the behaviors that comprise this construct are as equally distinct as the reasons why one would engage in such behaviors, only a few studies have focused on the variation of CWB within individuals (Dalal et al., 2009; Ilies et al., 2013; Debusscher et al., 2016). In the present study, we examine how CWB can fluctuate within the individual in relation to OCB. In order to do so, we proceed with presenting some theoretical approaches that explain how elicited and discretionary OCB and CWB can be related at the within-person level.

\section{Theoretical Approaches}

One size does not fit all individual behaviors; therefore, we chose to present three theoretical frameworks which complement each other in regards to the predictions they offer on how OCB and CWB might relate at the within person level: equity theory (Adams, 1965), conservation of resources (COR) theory (Hobfoll, 1989), and self-determination theory (SDT) (Deci and Ryan, 1985) (for other theoretical accounts, see Spector and Fox, 2010 and Klotz and Bolino, 2013).

\section{Equity Theory and Fairness Model}

Equity theory (Adams, 1965) focuses on individuals perception of fairness. More specifically, it maintains that employees' equity perceptions are determined by comparing whether the ratio of their own contributions (input) and the benefits they receive in response (output), matches that of a comparison other. The fairness model (Carrell and Dittrich, 1978) extends equity theory by establishing that an external comparison entity is not a prerequisite and that an internally derived standard can also be used for such comparison. According to both models, whenever individuals find themselves in an inequitable situation, they take actions directed at restoring equity levels.

Drawing on equity theory and the fairness model, we posit that elicited OCB is considered as an input by its enactor as it consists of positive investments that one is obliged to fulfill for the benefit of the organization. As a result of this obligation, the enactor feels entitled to receive a fair output in return. If employees perceive that their organization fails to provide something in return and that their inputs outweigh their outcomes, they can experience distress since they are not free to withhold elicited $\mathrm{OCB}$ as a strategy to balance their inputs and outputs. Moreover, since OCB typically lies outside their contractual obligations, employees may perceive the pressure to engage in such behaviors as unfair (Vigoda-Gadot, 2006). Therefore, in an attempt to restore their equity levels employees may seek restitution by engaging in CWB (Beauregard, 2014).
Performances of discretionary $\mathrm{OCB}$, on the other hand, although they contribute to the benefit of the organization, are not necessarily performed for the organization. We posit that individuals who voluntarily choose to engage in such behaviors do not consider them as inputs and thus do not expect a certain organizational output in return. Hence, we argue that discretionary OCB has no impact on its agents' input/output ratio and by extension neither on their equity perceptions. Conclusively, we expect that discretionary OCB will not be related to manifestations of CWB.

\section{Conservation of Resources Theory}

Conservation of resources theory maintains that individuals go to great lengths to preserve or increase their existing pool of resources, to the extent that, when individuals face an actual, or even a potential resource loss, they experience psychological stress (Hobfoll, 1989, 2002). What constitutes resources depends on what people value or what people use in order to acquire what they value (Wells et al., 1999), which ultimately falls into four main categories: objects (e.g., house), personal characteristics (e.g., self-esteem), conditions (e.g., marriage), and energies (e.g., time).

Energy resources fluctuate greatly since they are the resources that individuals tend to invest in order to acquire more resources (Hobfoll, 1989). In a work context, employees are expected to invest both time and energy to fulfill their job requirements. However, as OCB falls outside their formally assigned tasks, employees may experience the obligation to engage in $\mathrm{OCB}$ as a superfluous constraint, which will potentially deplete their energy resources. When faced with such constraints, individuals try to restrain their (potential) losses and one such strategy is by engaging in CWB (Fox and Spector, 1999; Krischer et al., 2010).

On the contrary, when employees themselves choose whether or not and when they engage in $\mathrm{OCB}$, this shall not pose a threat to their pool of resources since they will also have the choice to cease this behavior. What is more, employees may even regard some forms of OCB (i.e., helping behavior) as a resource investment (Hobfoll, 1989), and therefore their engagement in discretionary OCB will not relate with acts of CWB.

\section{Self-determination Theory}

Self-determination theory holds that motivation varies not only in regards to its quantity but also to its quality (Deci and Ryan, 2008). The theory discerns among six types of motivation (for more info, see Deci and Ryan, 1985; Ryan and Deci, 2002) which fall under three main categories: amotivation, controlled motivation, and autonomous motivation. As its name gives away, amotivation refers to lack of intention to act or, otherwise stated, lack of motivation. Controlled motivation concerns motivation that is externally regulated, whereas autonomous motivation encompasses self-motivated behaviors (Ryan and Deci, 2000). Although the different types of motivation are clearly distinguishable among each other, they are not static (Bidee et al., 2016). According to SDT, individuals experience motivation in relation to the satisfaction of three psychological needs: the need for competence, the need for relatedness and 
the need for autonomy (Deci and Ryan, 2008; Vandercammen et al., 2014). Satisfaction of these needs can thus transform a controlled motivated behavior to autonomous, with studies showing that one key element for such a transformation is the satisfaction of the need for autonomy (Gagné and Deci, 2005).

In relation to OCB, although the performance of two such acts may seem identical, the motivation that drives these behaviors can lead to different outcomes. In particular, when employees feel obliged to engage in $\mathrm{OCB}$, they are less likely to experience autonomous motivation, since their behavior has an external locus of control, which can hinder an individual's need for autonomy. As a result, employees may choose to engage in CWB in order to balance these demands.

Conversely, when employees choose themselves to engage in OCB, they are more likely to do so as a result of autonomous motivation. They may choose to perform OCB due to a genuine interest or due to the values they attach to such behaviors. In any case, when they choose such an activity voluntarily, their needs satisfaction is not under threat and therefore their engagement in discretionary OCB would not result in CWB.

Combining the insights of equity theory, COR theory and SDT, we expect that elicited OCB will be positively related to CWB whereas discretionary OCB will be unrelated to CWB:

\section{H1. Elicited OCB relates positively to CWB at the within-person} level.

H2. Discretionary OCB is unrelated to CWB at the within-person level.

\section{MATERIALS AND METHODS}

\section{Participants and Procedure}

Twenty-nine employees, of whom 17 were females, participated in an experience sampling study which took place in Belgium. Respondents were on average 30 years old $(S D=9.70)$ and their organizational tenure varied between 0 and 24 years $(S D=5.92)$. They all held full time jobs, and were employed in a variety of sectors including, among others, healthcare, banking, education, justice, and journalism. The majority of them $(51.7 \%)$ held a Master's degree.

As our hypotheses pertain to within-person fluctuations in OCB and CWB, traditional cross-sectional designs do not suffice since they do not allow the capturing of such day-to-day fluctuations. Instead, we used an experience sampling design, which is currently considered to be the best available option when the goal is to capture short-term changes in real time and in the person's actual environment (Fisher and To, 2012). In our experience sampling study, participants were given a smartphone for 10 consecutive working days on which they received a survey at midday and another one at the end of their working day. At both points in time, they completed the same survey, measuring $\mathrm{OCB}, \mathrm{CWB}$ and a number of discrete emotions (note that the emotions are not used in the study). The study was approved by the Human Research Ethics Committee of the Vrije Universiteit Brussel (reference number ECHW_049). All respondents signed an informed consent form prior to participating, and in this informed consent it was indicated that they had the choice to withdraw from the study at any point. Out of a maximum 580 observations (29 participants $\times 10$ days $\times 2$ measurement moments), 210 observations were recorded, which equals a $36.2 \%$ response rate.

\section{Measures}

Organizational citizenship behavior and counterproductive work behavior were measured using Dalal et al.'s (2009) scale, which was specifically designed for experience sampling research. Participants were requested to indicate whether they performed the behaviors since that morning (if it was the midday beep) or since the previous beep (if it was the end-of-the-workingday beep). As previous studies have argued in favor of facet dimensionality (Bennett and Robinson, 2000; Dalal et al., 2009), we chose to distinguish behaviors directed toward individuals (OCBI and $\mathrm{CWBI}$ ) from those targeted at the organization (OCBO and CWBO). Six OCBI and six OCBO items comprised the OCB scale. Example items were "I tried to help a co-worker" and "I went above and beyond what was required for the work task." The same distinction pertained to CWB, including six CWBI and six CWBO items. Example items were "I spoke poorly about a co-worker to others" and "I worked slower than necessary." Response options were "yes" or "no."

The distinction between elicited and discretionary OCB was accomplished with an additional item. When employees indicated that they performed a particular OCB, they received a follow-up question asking whether they performed the behavior either because they felt obliged or because they wanted to themselves, representing elicited and discretionary OCB, respectively.

\section{Analysis}

We first dummy coded the OCB and CWB scale scores because they were heavily skewed with little differentiation in the scale scores besides the absence/presence of OCB and CWB. Subsequently, we tested the relationships between the different types of OCB and CWB. In order to account for the hierarchical structure of our data and because the outcome variables (i.e., CWBI and $\mathrm{CWBO}$ ) were dichotomous in nature, we tested our hypotheses using multilevel logistic regression in the lme4 package in $\mathrm{R}$.

Two series of multilevel logistic regression models were tested. Elicited OCBI/O and discretionary OCBI/O were separately entered as predictors, while CWBI served as the outcome variable in the first and CWBO in the second series. For each of these models we tested whether the effect of the predictor was fixed or random across participants by comparing the model with a fixed slope to that with a random slope using a $\chi^{2}$ difference test. If the random slope model fitted the data significantly better than the fixed slope model, the random slope model was retained; if not, the fixed slope model was the final model (Hox, 2010). Because all hypotheses pertain to the fixed effects, we report only these effects in the "Results" section. 


\section{RESULTS}

Table 1 contains descriptive statistics, intra-class correlation coefficients (ICC) and within-person correlations for all study variables. The ICC's reveal that a substantial amount of variability in all study variables was situated at the within-person level. Because very little variability was found on the day-level, we proceeded with two-level regression models (Hox, 2010).

Regarding the relationship between elicited OCB and CWB, we found a positive same-target effect of OCBI on CWBI $(\gamma=1.36 ; p=0.003)$, and no same-target effect of OCBO on CWBO $(\gamma=-0.04 ; p=0.913)$. For the cross-target effects, we found a positive relationship both between OCBO and CWBI $(\gamma=1.01 ; p=0.006)$, and between OCBI and CWBO $(\gamma=0.73$; $p=0.080)$, with the latter relationship approaching conventional levels of significance. Together, these findings show that, when individuals felt obliged to engage in OCB (either toward the organization or toward co-workers), they were more likely to engage in CWB as well. As a result, our findings generally supported Hypothesis 1.

In line with Hypothesis 2, discretionary OCB was unrelated to CWB. Non-significant effects were found both for same-target $(\gamma=0.47 ; p=0.573$ for OCBI with CWBI and $\gamma=-0.38$; $p=0.409$ for OCBO with CWBO) and cross-target relationships $(\gamma=-0.23 ; p=0.614$ for OCBO with CWBI and $\gamma=0.61$; $p=0.485$ for OCBI with CWBO). In other words, when individuals voluntarily engaged in OCB (either toward the organization or toward co-workers), they were equally likely to engage in CWB when they did not voluntarily engage in OCB.

\section{DISCUSSION}

In the present paper, we challenged the idea that OCB and CWB are located at the extreme ends of the same continuum and should therefore be highly negatively correlated (Heckert and Heckert, 2002). Instead, we suggest that the relationship between $\mathrm{OCB}$ and $\mathrm{CWB}$ can differ depending on the reason why one engages in citizenship behaviors. Our findings generally supported this idea and showed that distinguishing between elicited and discretionary OCB helps to arrive at a better understanding of the OCB-CWB relationship. In particular, when individuals engage in discretionary $\mathrm{OCB}$, they do so, as its name indicates, out of free-will, and therefore such manifestations of discretionary OCB do not relate to manifestations of CWB. On the other hand, when employees have no choice but to engage in OCB because of a perceived obligation, they may seek restitution with behavioral responses such as CWB. Although we also found a weak marginally significant relationship between OCBI and CWBO, these CWBs turned out to be primarily targeted toward other individuals. One reason for this might be that, because employees view the behaviors targeted toward the organization as more closely related to their overall job performance (Dalal et al., 2009), they may perceive that CWBs toward the organization have more severe consequences for their performance evaluations and thus avoid engaging in them.

By showing that elicited but not discretionary OCB related to $\mathrm{CWB}$, our findings provide strong counterevidence for the continuum hypothesis, thereby steering theorizing away from the conventional classification of employees as bad apples versus good soldiers. Moreover, they might explain why recent withinperson studies on the relationship between OCB and CWB found mixed results (Dalal et al., 2009; Ilies et al., 2013). From a practical stance, the results suggest that organizations and managers should be mindful of the consequences that increased demands may bring upon, as demands for enhanced OCBs can coincide with unwarranted CWBs. This implication is particularly relevant nowadays, as the boundaries between in-role and extra-role performance seem to be increasingly obscured, especially in economies that were hit by the recent crisis. Finally, our study also complements the findings of recent studies on the effect of increased demands (during for example the economic crisis) by showing that these increased demands take their toll not only on employees (Mucci et al., 2016), but also on organizations.

Despite its strengths, this study also comes with some limitations. Although we used an experience sampling design, which is currently regarded as the "golden standard" when it comes to the tracing of human activity in everyday life (Kahneman et al., 2004), all study variables were self-reported, which can give rise to concerns of common method bias. Yet, the presence of some non-significant relationships suggests that common method bias may not be a major problem in our data (Lindell and Whitney, 2001). Second, it is important to note that the Dalal et al.'s (2009) scale contains semantic opposites in the OCB and CWB scales (e.g., "chose to work rather than to take a break" for the OCB and "took an unnecessary break" for the CWB scale). This could have the implication of inflating the relationship for the same target effects (Dalal, 2005). However, as we found no significant same target relationships for discretionary $\mathrm{OCB}$ and $\mathrm{CWB}$ and neither for elicited $\mathrm{OCB}$

TABLE 1 | Study means, standard deviations, and within-person correlations.

\begin{tabular}{|c|c|c|c|c|c|c|c|c|c|c|}
\hline & $M$ & $S D$ & $I C C_{\text {Person }}$ & $I C C_{\text {Day }}$ & $I C C_{\text {Moment }}$ & 1 & 2 & 3 & 4 & 5 \\
\hline 1. CWBI & 0.46 & 0.50 & 0.28 & 0.06 & 0.66 & & & & & \\
\hline 2. CWBO & 0.54 & 0.50 & 0.24 & 0.00 & 0.76 & -0.06 & & & & \\
\hline 3. Discretionary OCBI & 0.96 & 0.20 & 0.64 & 0.00 & 0.36 & 0.06 & -0.00 & & & \\
\hline 4. Discretionary OCBO & 0.82 & 0.39 & 0.58 & 0.00 & 0.42 & -0.04 & -0.08 & $0.15^{*}$ & & \\
\hline 5. Elicited OCBI & 0.23 & 0.42 & 0.34 & 0.07 & 0.59 & $0.18^{* *}$ & 0.13 & -0.05 & -0.07 & \\
\hline 6. Elicited OCBO & 0.32 & 0.47 & 0.31 & 0.07 & 0.62 & $0.24^{* *}$ & -0.07 & 0.05 & $-0.26^{* *}$ & $0.23^{* *}$ \\
\hline
\end{tabular}

${ }^{*} p<0.05 ; * * p<0.01$. 
and CWB toward the organization, we are confident that this does not pose a serious issue. We also need to address that severe counterproductive behaviors were not covered by the CWB measure (Dalal et al., 2009). Given our study design, however, it was very unlikely that such severe behaviors would commonly occur during a relatively short period of 10 working days. Third, we cannot rule out reversed causality. It might for example be that the positive relationship between elicited OCB and CWB is the result of employees' reframing of their OCB's as obligatory simply to justify their engagement in CWB. Future research remains to resolve this riddle with the use of time lags. Finally, whereas we drew from equity theory (Adams, 1965), COR theory (Hobfoll, 1989) and SDT (Deci and Ryan, 1985) to make the case that elicited but not discretionary OCB would positively relate to CWB, we did not explicitly test the mechanisms proposed by these theories. Thus, although our study revealed that elicited and discretionary OCB related differently to CWB, future research is needed to identify what the mechanisms are underlying these relationships.

Future studies could also examine the role of other motives to engage in OCBs, by expanding our classification with the addition of motives such as impression management, organizational concern (Rioux and Penner, 2001), or reciprocity (Spitzmuller and Van Dyne, 2013). We are also in need of more research focusing on the aftermath of CWBs for the enactors. If we are to assume that employees use CWBs to compensate for increased demands or stressors, research focusing on daily recovery or general indicators of wellbeing, can determine whether this strategy is effective. Finally, as leaders appear to reflect their own feelings of stress to subordinates (Giorgi et al., 2015b), it is interesting to research this dyadic relationship, and examine whether the leaders' perceived pressure to engage in citizenship behaviors spills over to their subordinates.

In summary, we uphold that the OCB typology presented in this paper may give rise to a fruitful line of research with important potential implications for theory and practice. On

\section{REFERENCES}

Adams, J. S. (1965). "Inequality in social exchange," in Advances in Experimental Psychology, ed. L. Berkowitz (New York, NY: Academic Press), 267-299.

Beauregard, T. A. (2014). Fairness perceptions of work- life balance initiatives: effects on counterproductive work behaviour. Br. J. Manag. 25, 772-789. doi: $10.1111 / 1467-8551.12052$

Bennett, R. J., and Robinson, S. L. (2000). Development of a measure of workplace deviance. J. Appl. Psychol. 85, 349-360. doi: 10.1037//0021-9010.85. 3.349

Bennett, R. J., and Stamper, C. L. (2001). "Corporate citizenship and deviancy: a study of work behavior," in International Research in the Business Disciplines: Strategies and Organizations in Transition, eds C. Galbraith and M. Ryan (Amsterdam: Elsevier Science), 265-284.

Bidee, J., Vantilborgh, T., Pepermans, R., Griep, Y., and Hofmans, J. (2016). Temporal dynamics of need satisfaction and need frustration. Two sides of the same coin? Eur. J. Work. Organ. Psychol. 25, 1-14. doi: 10.1080/1359432X.2016.1176021

Bolino, M. C., Klotz, A. C., Turnley, W. H., and Harvey, J. (2013). Exploring the dark side of organizational citizenship behavior. J. Organ. Behav. 34, 542-559. doi: $10.1002 /$ job. 1847

Bolino, M. C., and Turnley, W. H. (2005). The personal costs of citizenship behavior: the relationship between individual initiative and role overload, a theoretical level, the distinction between discretionary and elicited OCB not only allows to explain mixed findings on the OCB-CWB relationship, but it might also shed light on previous conflicting results considering OCB's relation with other antecedents and outcomes (e.g., work-family conflict). Our field can benefit from examining traditional concepts through different lenses, as we showed in this study that the generally considered constructive citizenship behaviors can in fact backfire and cause harm to the organization. In the same manner, CWBs, although generally depicted as malevolent acts, have the potential to help employees counterbalance the increased demands they face, and possibly even protect their wellbeing in the long run. Regarding the practical side, being aware of the distinction between elicited and discretionary $\mathrm{OCB}$ and its potential consequences for its relationship with CWB might make organizations and managers more reticent of pressuring people to engage in $\mathrm{OCB}$, which in the end might benefit both the employee and the organization.

\section{AUTHOR CONTRIBUTIONS}

All authors listed, have made substantial, direct and intellectual contribution to the work, and approved it for publication.

\section{FUNDING}

This research was supported by Fonds Wetenschappelijk Onderzoek - Vlaanderen (FWO) [grant number G.0237.13N].

\section{ACKNOWLEDGMENT}

We thank Quentin Geeraerts for collecting the data.

job stress, and work-family conflict. J. Appl. Psychol. 90, 740-748. doi: 10.1037/0021-9010.90.4.740

Bolino, M. C., Turnley, W. H., Gilstrap, J. B., and Suazo, M. M. (2010). Citizenship under pressure: what's a "good soldier" to do? J. Organ. Behav. 31, 835-855. doi: 10.1002/job.635

Bolino, M. C., Turnley, W. H., and Niehoff, B. P. (2004). The other side of the story: reexamining prevailing assumptions about organizational citizenship behavior. Hum. Resour. Manage. R. 14, 229-246. doi: 10.1016/j.hrmr.2004.05.004

Brett, J. M., and Stroh, L. K. (2003). Working 61+ hours a week: why do managers do it? J. Appl. Psychol. 88, 67-78. doi: 10.1037/0021-9010.88.1.67

Carrell, M. R., and Dittrich, J. E. (1978). Equity theory: the recent literature, methodological considerations, and new directions. Acad. Manage. Rev. 3, 202-210. doi: 10.5465/AMR.1978.4294844

Dalal, R. S. (2005). A meta-analysis of the relationship between organizational citizenship behavior and counterproductive work behavior. J. Appl. Psychol. 90, 1241-1255. doi: 10.1037/0021-9010.90.6.1241

Dalal, R. S., Lam, H., Weiss, H. M., Welch, E. R., and Hulin, C. L. (2009). A within-person approach to work behavior and performance: concurrent and lagged citizenship-counterproductivity associations, and dynamic relationships with affect and overall job performance. Acad. Manage. J. 52, 1051-1066. doi: 10.5465/AMJ.2009.44636148

Debusscher, J., Hofmans, J., and De Fruyt, F. (2016). The effect of state core self-evaluations on task performance, organizational citizenship behaviour, and 
counterproductive work behaviour. Eur. J. Work. Organ. Psychol. 25, 89-104. doi: 10.1080/1359432X.2015.1063486

Deci, E. L., and Ryan, R. M. (1985). Intrinsic Motivation and Self-Determination in Human Behaviour. New York, NY: Plenum Press.

Deci, E. L., and Ryan, R. M. (2008). Self-determination theory: a macrotheory of human motivation, development, and health. Can. Psychol. 49, 182-185. doi: $10.1037 / \mathrm{a} 0012801$

Feldman, D. C. (2002). Managers' propensity to work longer hours: a multilevel analysis. Hum. Resour. Manage. R. 12, 339-357. doi: 10.1016/S10534822(02)00064-5

Fisher, C. D., and To, M. L. (2012). Using experience sampling methodology in organizational behavior. J. Organ. Behav. 33, 865-877. doi: 10.1002/job.1803

Fox, S., and Spector, P. E. (1999). A model of work frustration-aggression. J. Organ. Behav. 20, 915-931. doi: 10.1002/(SICI)1099-1379(199911)20:6<915::AIDJOB918> 3.3.CO;2-Y

Gagné, M., and Deci, E. L. (2005). Self-determination theory and work motivation. J. Organ. Behav. 26, 331-362. doi: 10.1002/job.322

Giorgi, G., Arcangeli, G., Mucci, N., and Cupelli, V. (2015a). Economic stress in the workplace: the impact of fear of the crisis on mental health. Work 51, 135-142. doi: 10.3233/wor-141844

Giorgi, G., Mancuso, S., Perez, F. J. F., Montani, F., Courcy, F., and Arcangeli, G. (2015b). Does leaders' health (and work-related experiences) affect their evaluation of followers' stress? Saf. Health Work 6, 249-255. doi: 10.1016/j.shaw.2015.07.005

Heckert, A., and Heckert, D. M. (2002). A new typology of deviance: integrating normative and reactivist definitions of deviance. Deviant Behav. 23, 449-479. doi: 10.1080/016396202320265319

Hobfoll, S. E. (1989). Conservation of resources: a new attempt at conceptualizing stress. Am. Psychol. 44, 513-524. doi: 10.1037/0003-066x.44.3.513

Hobfoll, S. E. (2002). Social and psychological resources and adaptation. Rev. Gen. Psychol. 6, 307-324. doi: 10.1037/1089-2680.6.4.307

Hox, J. J. (2010). Multilevel Analysis: Techniques and Applications, 2nd Edn. New York, NY: Routledge.

Ilies, R., Peng, A. C., Savani, K., and Dimotakis, N. (2013). Guilty and helpful: an emotion-based reparatory model of voluntary work behavior. J. Appl. Psychol. 98, 1051-1059. doi: 10.1037/a0034162

Iliescu, D., Ispas, D., Sulea, C., and Ilie, A. (2015). Vocational fit and counterproductive work behaviors: a self-regulation perspective. J. Appl. Psychol. 100, 21-39. doi: 10.1037/a0036652

Kahneman, D., Kreuger, A. B., and Schkade, D. A. (2004). A survey method for characterizing daily life experience: the day reconstruction method. Science 306, 1776-1780. doi: 10.1126/science.1103572

Klotz, A. C., and Bolino, M. C. (2013). Citizenship and counterproductive work behavior: a moral licensing view. Acad. Manage. Rev. 38, 292-306. doi: 10.5465/amr.2011.0109

Krischer, M. M., Penney, L. M., and Hunter, E. M. (2010). Can counterproductive work behaviors be productive? CWB as emotion-focused coping. J. Occup. Health Psychol. 15, 154-166. doi: 10.1037/a0018349

Lee, K., and Allen, N. J. (2002). Organizational citizenship behavior and workplace deviance: the role of affect and cognitions. J. Appl. Psychol. 87, 131-142. doi: 10.1037//0021-9010.87.1.131

Lindell, M. K., and Whitney, D. J. (2001). Accounting for common method variance in cross-sectional research designs. J. Appl. Psychol. 86, 114-121. doi: 10.1037//0021-9010.86.1.114

Mucci, N., Giorgi, G., Roncaioli, M., Fiz Perez, J., and Arcangeli, G. (2016). The correlation between stress and economic crisis: a systematic review. Neuropsychiatr. Dis. Treat. 12, 983-993. doi: 10.2147/ndt.s98525

Nielsen, T. M., Hrivnak, G. A., and Shaw, M. (2009). Organizational citizenship behavior and performance: a meta-analysis of group-level research. Small Group. Res. 40, 555-577. doi: 10.1177/1046496409339630

Organ, D. W. (1988). Organizational Citizenship Behavior: The Good Soldier Syndrome. Lexington, MA: Lexington Books.

Penney, L. M., and Spector, P. E. (2005). Job stress, incivility, and counterproductive work behavior (CWB): the moderating role of negative affectivity. J. Organ. Behav. 26, 777-796. doi: 10.1002/job.336
Podsakoff, N. P., Whiting, S. W., Podsakoff, P. M., and Blume, B. D. (2009). Individual- and organizational-level consequences of organizational citizenship behaviors: a meta-analysis. J. Appl. Psychol. 94, 122-141. doi: 10.1037/a00 13079

Podsakoff, P. M., MacKenzie, S. B., Paine, J. B., and Bachrach, D. G. (2000) Organizational citizenship behaviors: a critical review of the theoretical and empirical literature and suggestions for future research. J. Manage. 26, 513-563. doi: $10.1177 / 014920630002600307$

Rioux, S. M., and Penner, L. A. (2001). The causes of organizational citizenship behavior: a motivational analysis. J. Appl. Psychol. 86, 1306-1314. doi: 10.1037/0021-9010.86.6.1306

Ryan, R. M., and Deci, E. L. (2000). Self-determination theory and the facilitation of intrinsic motivation, social development, and well-being. Am. Psychol. 55, 68-78. doi: 10.1037/0003-066x.55.1.68

Ryan, R. M., and Deci, E. L. (2002). "An overview of self-determination theory," in Handbook of Self-Determination Research, eds E. L. Deci and R. M. Ryan (Rochester, NY: University of Rochester Press), 3-33.

Sackett, P. R. (2002). The structure of counterproductive work behaviors: dimensionality and relationships with facets of job performance. Int. J. Select. Assess. 10, 5-11. doi: 10.1111/1468-2389.00189

Smith, C. A., Organ, D. W., and Near, J. P. (1983). Organizational citizenship behavior: its nature and antecedents. J. Appl. Psychol. 68, 653-663. doi: 10.1037/0021-9010.68.4.653

Spector, P. E., and Fox, S. (2002). An emotion-centered model of voluntary work behavior: some parallels between counterproductive work behavior and organizational citizenship behavior. Hum. Resour. Manage. R. 12, 269-292. doi: 10.1016/S1053-4822(02)00049-9

Spector, P. E., and Fox, S. (2010). Theorizing about the deviant citizen: an attributional explanation of the interplay of organizational citizenship and counterproductive work behavior. Hum. Resour. Manage. R. 20, 132-143. doi: 10.1016/j.hrmr.2009.06.002

Spector, P. E., Fox, S., Penney, L. M., Bruursema, K., Goh, A., and Kessler, S. (2006). The dimensionality of counterproductivity: are all counterproductive behaviors created equal? J. Vocat. Behav. 68, 446-460. doi: 10.1016/j.jvb.2005. 10.005

Spitzmuller, M., and Van Dyne, L. (2013). Proactive and reactive helping: contrasting the positive consequences of different forms of helping. J. Organ. Behav. 34, 560-580. doi: 10.1002/job.1848

Vandercammen, L., Hofmans, J., and Theuns, P. (2014). The mediating role of affect in the relationship between need satisfaction and autonomous motivation. J. Occup. Organ. Psychol. 87, 62-79. doi: 10.1111/joop.12032

Vigoda-Gadot, E. (2006). Compulsory citizenship behavior: theorizing some dark sides of the good soldier syndrome in organizations. J. Theor. Soc. Behav. 36, 77-93. doi: 10.1111/j.1468-5914.2006.00297.x

Vigoda-Gadot, E. (2007). Leadership style, organizational politics, and employees' performance: an empirical examination of two competing models. Pers. Rev. 36, 661-683. doi: 10.1108/00483480710773981

Wells, J. D., Hobfoll, S. E., and Lavin, J. (1999). When it rains, it pours: the greater impact of resource loss compared to gain on psychological distress. Pers. Soc. Psychol. B. 25, 1172-1182. doi: 10.1177/01461672992512010

Conflict of Interest Statement: The authors declare that the research was conducted in the absence of any commercial or financial relationships that could be construed as a potential conflict of interest.

The reviewer JP and the handling Editor declared their shared affiliation, and the handling Editor states that the process nevertheless met the standards of a fair and objective review.

Copyright (c) 2016 Spanouli and Hofmans. This is an open-access article distributed under the terms of the Creative Commons Attribution License (CC BY). The use, distribution or reproduction in other forums is permitted, provided the original author(s) or licensor are credited and that the original publication in this journal is cited, in accordance with accepted academic practice. No use, distribution or reproduction is permitted which does not comply with these terms. 


\section{OPEN ACCESS}

Edited by:

Gabriele Giorgi,

European University of Rome, Italy

Reviewed by:

Nicola Mucci,

University of Florence, Italy

Milica Vukelic,

University of Belgrade, Serbia

*Correspondence:

Astrid C. Homan

ac.homan@uva.n

Specialty section:

This article was submitted to

Organizational Psychology,

a section of the journal

Frontiers in Psychology

Received: 28 April 2016 Accepted: 05 September 2016

Published: 21 September 2016

Citation:

Dijkstra MTM and Homan AC (2016) Engaging in Rather than Disengaging from Stress: Effective Coping and

Perceived Control.

Front. Psychol. 7:1415

doi: 10.3389/fpsyg.2016.01415

\section{Engaging in Rather than Disengaging from Stress: Effective Coping and Perceived Control}

\author{
Maria T. M. Dijkstra ${ }^{1}$ and Astrid C. Homan ${ }^{2 *}$ \\ ${ }^{1}$ Organization Sciences, VU University Amsterdam, Amsterdam, Netherlands, ${ }^{2}$ Work and Organizational Psychology, \\ University of Amsterdam, Amsterdam, Netherlands
}

Being able to cope effectively with stress can help people to avoid negative consequences for their psychological well-being. The purpose of this study was to find out why some coping strategies are effective in reducing the negative effect of stressors on well-being and some are not. We argue that the degree to which such coping strategies engage or disengage people from stressful incidents is related to their perceived control of the situation that, in turn, is positively associated with their psychological well-being. We thus propose that the relationship between coping and psychological well-being is mediated by the extent of perceived sense of control. We collected cross-sectional data from a large heterogeneous sample $(N=543)$ in the Netherlands. We assessed seven different coping strategies, perceived control, and psychological well-being. Our results indeed revealed that strategies reflecting more engaged coping such as active confronting and reassuring thoughts, were associated with more sense of control and therefore to psychological well-being. In contrast, strategies reflecting disengagement coping, such as passive reaction pattern, palliative reaction, and avoidance, were associated with less perceived control, which in turn was negatively associated with psychological well-being. Results regarding the coping strategies expressing emotions and seeking social support were less straightforward, with the former being negatively associated with perceived control and psychological well-being, even though this strategy has stress engaging elements, and the latter only showing a positive indirect effect on psychological well-being via perceived control, but no positive main effect on well-being. These findings are discussed from the perspective of stress being an environment-perception-response process.

Keywords: coping, perceived sense of control, stress, psychological well-being, (dis)engagement

\section{INTRODUCTION}

One of the most well-documented and supported effects in stress research includes the finding that stressful life events significantly increase health risks in terms of cardiovascular disease (Hemingway and Marmot, 1999; Steptoe and Kivimäki, 2012; Buckley and Shivkumar, 2016), cancer (Antoni et al., 2006; Bower et al., 2014), and depression (Slavich and Irwin, 2014). Additionally, stress at the workplace is related to turnover (Bridger et al., 2013) and loss of productivity (for a review see Wolever et al., 2012). The associated economic costs of stress-induced outcomes as estimated by the International Labor Organization (ILO) amounted to EUR 
9.2 billion in the EU, $£ 1.1-1.2$ billion in the U.K and USD 6.6 billion in the US (Mino et al., 2006). More recently, according to the statistical data released by the UK Health and Safety Executive (2013/2014), work-related stress, depression, or anxiety accounted for 39\% (487,000 cases) of all work-related illnesses, with 11.3 million workdays being lost.

It is therefore crucial to understand the stress process in order to avoid or at least reduce its harmful physical, psychological, and economic consequence. Conducting such research is even more relevant in light of the global and severe stressful event that constitutes the financial and economic crisis, which started in the US in 2007-2008 and has spread around world, continuing in many countries today (Acharya et al., 2009; Goodman and Mance, 2011; Giorgi et al., 2014; Mucci et al., 2016).

Importantly, what specific outcomes the stress process will generate, and how severe its consequences are, largely depends on the way people handle potentially threatening events (e.g., unemployment, increased workload), referred to as stressors. Coping with stressors, therefore, became a key subject within stress literature (e.g., Carver et al., 1989; Aspinwall and Taylor, 1997; Skinner et al., 2003; Inzlicht and Kang, 2010).

Coping refers to as a person's efforts to manage demands that are appraised as taxing or exceeding their resources (Lazarus and Folkman, 1984). Coping can explain how stressors affect people and when and why people experience more or less detrimental consequences in terms of health and well-being (Skinner et al., 2003). At present, there is theoretical as well as empirical evidence that coping matters and that some coping strategies work better than others (e.g., Skinner et al., 2003; Britt et al., 2016). It is however unclear why certain coping strategies have more beneficial effects than others. In this study we wish to provide an answer to that question.

\section{Coping with Stressful Life Events}

Stress is most generally agreed upon as to be an environmentperception-response process (e.g., Spector and Jex, 1998; Pindek and Spector, 2016). As such it aligns with the transactional stress theory (Lazarus, 1991; Perrewe and Zellars, 1999) holding that environmental stressors (e.g., organizational constraints, economic crises) are experienced as threats to well-being that consequently lead to strains.

Within this theoretical framework, research on stress is concerned with the (inadequate) adaptation of individuals to environmental demands that are appraised as taxing or exceeding a person's resources (Lazarus and Folkman, 1984). In spite of their high potential for harming the health and well-being of people (Hemingway and Marmot, 1999; Antoni et al., 2006; Garcia-Bueno et al., 2008), stressors do not automatically induce such negative effects. What consequences stressors have largely depend on the specific behavior that people engage in or on the technique(s) they use to handle the particular threatening condition or event in order to counteract its effects on their well-being (Moos, 1990; Le Fevre et al., 2006; Dijkstra et al., 2009; Bridger et al., 2013). In other words, it is not primarily the stressor; it is how people cope with the stressor that will determine the consequences for health and well-being.
Aspinwall and Taylor (1997) define coping as "activities undertaken to master, tolerate, reduce, or minimize environmental or intra-psychic demands perceived to represent potential threats, existing harm, or losses" (p. 417; see also Lazarus and Folkman, 1984; Folkman and Lazarus, 1985; Latack, 1986). Previous research has shown that different coping strategies differ in their success in influencing stress-related outcomes. For instance, Koeske et al. (1993) showed in a study among case managers who were working with clients with mental illness, that active coping styles served as work stress buffers while the use of avoiding strategies resulted in higher general levels of negative consequences three months later. Similarly, research among bank employees revealed that initiating direct action in response to a stressor positively predicted job satisfaction and negatively predicted psychological distress (Fortes-Ferreira et al., 2006). In addition, a study on depression among medical students revealed that students who were likely to use avoidant coping strategies, and unlikely to engage in active strategies tended to have higher stress levels (Chu-Lien Chao, 2011). Furthermore, in a study among patients with type 2 diabetes mellitus, Shah et al. (2012) showed that the group of patients that used more avoidance and passive resignation coping reported more depressive symptoms. Finally, Britt et al. (2016) examined the effectiveness of coping strategies in military basic training, a work environment characterized by the presence of unavoidable demands and low autonomy. Results showed that more use of the "active coping" strategy was related to a reduction in mental health symptoms, whereas the greater use of the coping strategy "denial/self-criticism" was associated with an increase in mental health symptoms.

These previous results strongly suggest that coping strategies reflecting direct "action," thereby facing the stressor and/or its related emotions, are more successful in preventing negative consequences of stress, than more avoidant types of coping, which imply diverting from the stressor and/or its related emotions. The latter types of coping have shown to "typically work against people" (Carver and Scheier, 1994, p. 184).

Despite the numerous categories of coping (for a review see Skinner et al., 2003), we follow Carver and Connor-Smith (2010) in their conclusion that "The distinction that appears to have greatest importance is engagement vs. disengagement" (p. 687). Their "engagement" category of coping reflects coping strategies in which "a person takes charge in tone" (Latack, 1986, p. 378), by facing the stressor and/or its related emotions. The "disengagement" category of coping involves strategies that are aimed at diverting from the stressor and/or its related emotions. Research has shown that people who use disengagement coping generally are not able to deal with the stressor and as a result are more likely to experience the negative consequences of the stressor compared to people who engage in more active coping strategies (e.g., Fortes-Ferreira et al., 2006; Chu-Lien Chao, 2011). We propose that these effects are driven by the degree to which these coping strategies provide the person with a sense of being in control of the stressful situation.

During the past decades, research has demonstrated that people's ability to gain and maintain a sense of control is an important personal resource (Turner, 1988), is associated with 
their well-being being (Mirowsky and Ross, 1990; Thoits, 1995; Turner and Lloyd, 1999; Chipperfield et al., 2004; Dijkstra et al., 2011) and is essential for their evolutionary survival (Shapiro et al., 1996). In a recent study, Vander Elst et al. (2016) showed that personal control mediated the relationship between job insecurity (serving as the stressor) and physical and mental health complaints. Based on these studies, we argue that perceived control might be the driving ingredient that explains why engagement coping strategies have more positive effects for psychological well-being than disengagement strategies. People who actively deal with the situation at hand, are more likely to experience that they are in charge of the situation and are able to change something about it, whereas those that avoid or ignore stressful events experience a lack of possibilities to confront the stressor (Latack, 1986; Dijkstra et al., 2009).

Below, we present a cross-sectional study run in The Netherlands, in which we examined the role of perceived control as an explaining mechanism underlying successful and unsuccessful coping efforts. To assess the coping strategies respondents employed, we used the Utrecht Coping List (UCL; Schreurs et al., 1993) because this is a validated and originally Dutch scale. The scale contains seven subscales, which, as we propose below, could be categorized into either engagement or disengagement coping.

The first coping style, active confronting, refers to directly and consciously facing the stressor. Handling the stressor in this "hands on" way embodies an engagement coping strategy. Second, seeking social support means actively asking others to help you. By involving others to eliminate or at least diminish the stressful event, one employs an engagement coping strategy. Third, reassuring thoughts signifies putting things in perspective and looking for ways to acknowledge that "it's not the end of the world." By taking such a course of action one exercises an engagement coping strategy. Fourth, expressing emotions refers to explicitly venting feelings and therefore represents an engagement coping strategy. Fifth, passive reaction pattern is "wallowing" in negativity and not really addressing the stressor, but instead in a helpless kind of way, letting your self be submerged by the stressful event. Responding like this reflects a disengagement coping strategy. Sixth, palliative reaction denotes a disassociating from the stressor by letting the stressful event numb you. As such, this coping strategy represents a disengagement coping strategy. Finally, avoiding is taking a lethargic stance toward the stressor, which symbolizes a disengagement coping strategy.

In sum, we predict that the relationship between coping with stressors and reduced psychological well-being strongly depends on the amount of perceived control that is related to the particular coping strategy. More specifically, we predict that strategies reflecting more engaged coping (i.e., active confronting, seeking social support, reassuring thoughts, and expressing emotions) will be related to more perceived control and in turn to better psychological well-being. Strategies reflecting more disengaged coping (i.e., passive reaction pattern, palliative reaction, and avoidance) on the other hand will be related to less perceived control and therefore to less psychological well-being (see Figures 1, 2).

\section{MATERIALS AND METHODS}

\section{Sample and Procedure}

Data were collected in the context of a broader research question concerning coping, well-being, and cultural differences between Hindustan and other Dutch inhabitants of The Netherlands (Ramlal, 2007). The study was carried out in accordance with the recommendations of the ethics regulations of Leiden University. At the time of the study (in 2006), Leiden University did not have an ethics committee for this type of unobtrusive research projects, which implied that the study did not receive an IRB number. All respondents received an information brochure from the research team, inviting them to participate in the study emphasizing the importance of participating as well as its voluntary and anonymous character. Sample participants filled in the questionnaires either by paper and pencil or online. Some participants were approached in public spaces, whereas others were approached online.

Out of 575 questionnaires 543 were returned (response rate: $94.44 \%)$. Of all respondents 279 (51.4\%) were male and the mean age was 35.20 years $(S D=12.65$; range $15-75)$. Parents provided active consent for the 11 minors in our sample. Analysing the data excluding the eleven minors did not change the pattern or conclusion of the results. Respondents were categorized as Caucasian-Dutch $(37.3 \%, n=202)$ or non-Caucasian-Dutch ethnicity. The educational level of the employees in our sample ranged from elementary school $(1.8 \%, n=10)$ through mid-level $(40.7 \%, n=220)$ and higher level $(38.4 \%, n=208)$ vocational education, university $(16.5 \%, n=89)$ to post-academic education

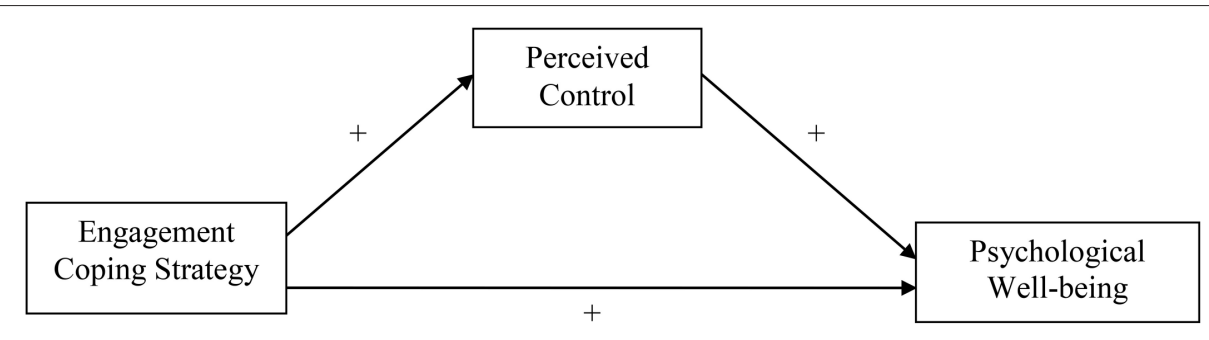

FIGURE 1 | Conceptual model capturing the proposed relationships between engagement coping strategy, perceived control, and psychological well-being. 


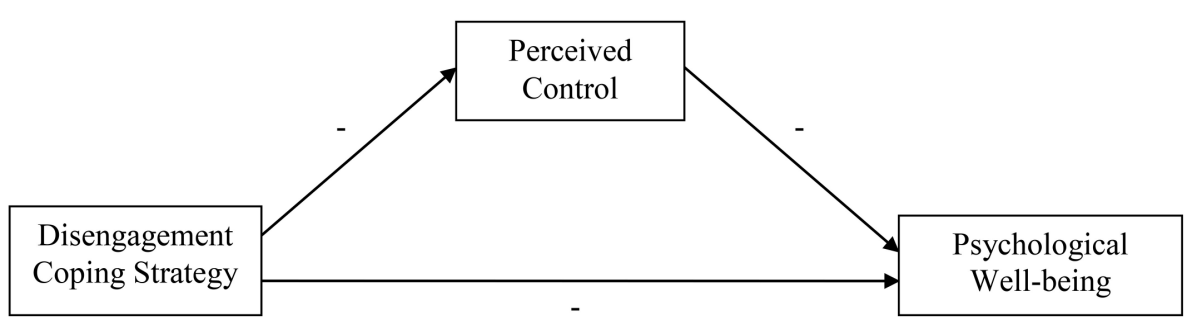

FIGURE 2 | Conceptual model capturing the proposed relationships between disengagement coping strategy, perceived control, and psychological well-being.

$(2.6 \%, n=14)$. Two participants had missing values for gender, ethnicity, and educational level. Three participants did not report their age.

\section{Measures}

\section{Psychological Well-Being}

We used the five-item version of the Mental Health Inventory (MHI-5) developed by Veit and Ware (1983) which has proven to be equally good as the MHI-18 (Berwick et al., 1991). Participants were asked, "How much of the time, during the last month, have you...” and a sample item was, “...been a happy person.” Response categories ranged from 1 (all of the time) to 6 (none of the time). Cronbach's alpha for the scale was 0.84 . Higher scores on the scale indicate more favorable health.

\section{Coping Strategy}

To measure coping strategy, the Utrecht Coping List (UCL; Schreurs et al., 1993) was used. This is a validated questionnaire (47 items) that quantifies dispositional coping characteristics for problems and unpleasant events in daily life. In contrast to state measures, trait measures like the UCL allow for greater comparison of coping styles across different samples and situations.

Participants responded to the question "how often do the following behaviors apply to you?" Each item had four response choices, ranging from 1 (never) to 4 (very often). Sub-scores were used to describe individual tendency to seven coping strategies: (a) Active confronting involved eight items (Cronbach's alpha was 0.83 ) and a sample item was "In order to solve the problem I consciously addressed the matter." (b) Seeking social support involved five items $(\alpha=0.80)$, and a sample item was: "I asked someone for help." (c) Reassuring thoughts was measured with seven items $(\alpha=0.70)$. A sample item was "I realized more serious things can happen." (d) Expressing emotions involved five items ( $\alpha=0.68$; e.g., "I showed my anger toward the person that was responsible for the problem"). (e) Passive reaction pattern was assessed with seven items $(\alpha=0.73)$, and a sample item was "I was overpowered by the problem." (f) Palliative reaction involved nine items $(\alpha=0.74)$ and a sample item was "I tried to think of things that were not related to the problem." (g) Finally, avoidance was measured with six items $(\alpha=0.67)$ and a sample item was "I let things happen." A higher score indicated an increased tendency toward that particular coping strategy.

\section{Perceived Sense of Control}

We used 4 items developed by Cohen et al. (1983) that rated the frequency of their feelings of control related to events and situations that occurred in the last month $(\alpha=0.78)$. A sample item was, "How often have you felt that you were not in control of important things in your life?" Each item was rated on a five point Likert-type scale ranging from 1 (never) to 5 (very often). Higher scores indicated less perceived control.

\section{Control Variables}

Past work on stress at work revealed gender differences in coping with stressors (e.g., Ptacek et al., 1994; Almeida and Kessler, 1998; Matud, 2004). Furthermore, there are consistent gender differences in anxiety and depression (e.g., Barnett et al., 1987; Nolen-Hoeksema, 1987). We thus included gender as a control variable (dummy-coded: $0=$ male, $1=$ female) Like gender, age seemed a relevant control variable as well. Not only does age correlate with well-being (Siu et al., 2001), it is also associated with control beliefs and locus of control (Lachman and Weaver, 1998). We also controlled for education level because it has also been associated with well-being (Bryant and Veroff, 1984). Educational background was coded on a 5-point scale (higher numbers represent higher educational level). Finally, as the study was originally developed to examine differences between Hindustan and other Dutch inhabitants of The Netherlands, we controlled for participant cultural background (dummy-coded: $0=$ Dutch, $1=$ Hindustani).

\section{RESULTS}

\section{Descriptive Statistics}

Means, standard deviations, and zero-order correlations among study variables can be found in Table 1 . The control variables cultural background, sex, age, and educational background showed some significant, but no consistent, relationships with the key variables in our study. In order to account for these relationships, we controlled for these variables when testing our predictions.

\section{Data Analyses}

We regressed psychological well-being and perceived control on the seven coping strategy variables. We applied a Bonferroni correction by adjusting the test for significant effects relative to the number of repeated analyses. More specifically, we divided 


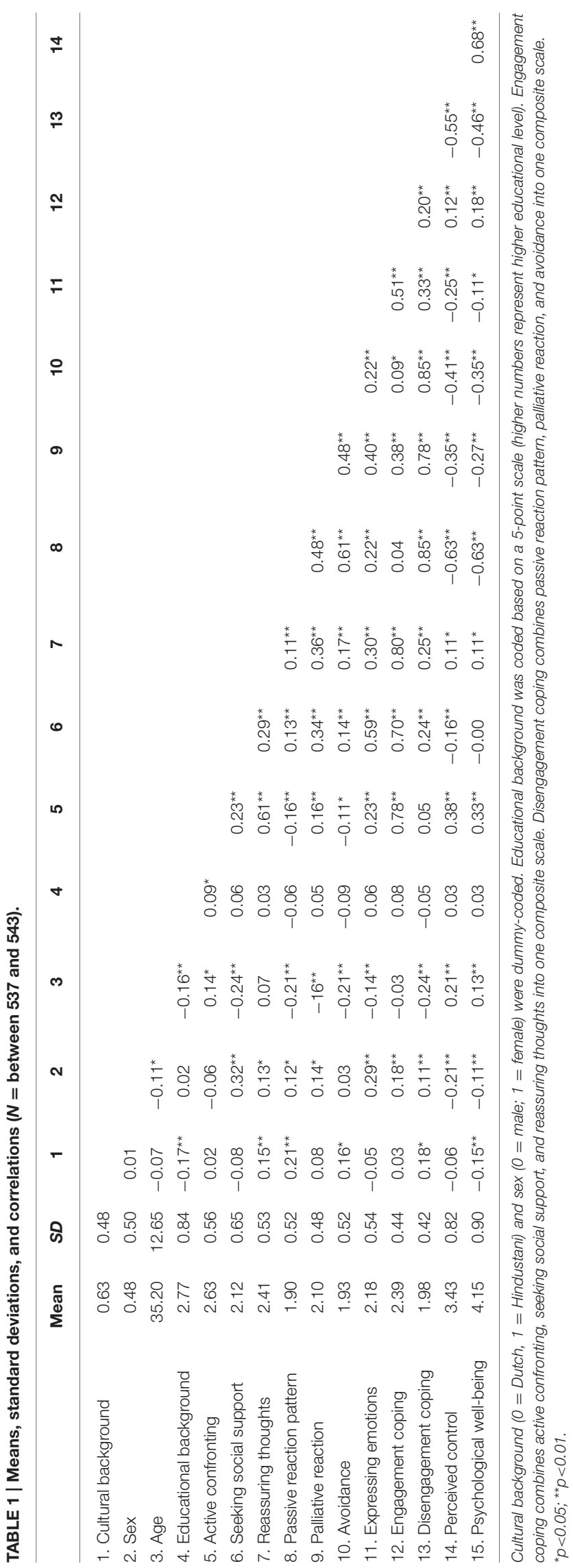

our $p$-value of 0.05 by seven, because we ran a separate analysis for every different coping style (adjusted cut-off $p$-value $=$ 0.007). In the first step we entered the control variables, and in the second step we entered the main effect of the coping strategy of interest. Finally, we tested mediation by perceived control in the relationship between coping and psychological well-being following the mediation analysis approach of Baron and Kenny (1986). Results are shown in Tables 2, 3. Additionally, we employed the PROCESS procedure for SPSS (Hayes, 2013; Model 4) calculating bias-corrected confidence intervals (CI) to examine the indirect effect based on 10,000 bootstrap samples (Preacher and Hayes, 2004; Hayes, 2013). If the CI excludes zero, there is evidence for a significant indirect effect.

\section{Engagement Coping}

We argued that active confronting, seeking social support, reassuring thoughts, and expressing emotions would be more engaged coping styles. We proposed that more engaged coping styles should be associated with higher perceived control, which in turn should be associated with higher psychological well-being.

\section{Active Confronting}

People who scored higher on active confronting experienced a higher sense of control and higher psychological well-being. When including both active confronting and perceived sense of control in the regression analysis, we found that the strength of the relationship between active confronting and psychological well-being was reduced, while the effect of perceived sense of control was significant, supporting partial mediation. A Sobel test indicated that the mediation was significant $(z=8.09, p<0.001)$. Similarly, the bootstrap approach supported an indirect effect between active confronting and psychological well-being via perceived sense of control (point estimate $=0.37, S E=0.05,99 \%$ bias corrected CI $[0.25,0.50])$. Indeed, this suggests that people who use more active confronting reported higher well-being due to a higher perceived sense of control.

\section{Seeking Social Support}

Opposite to our reasoning, seeking social support was not significantly associated with perceived control and psychological well-being. We thus found no support for seeking social support as a potentially effective coping strategy.

\section{Reassuring Thoughts}

People who scored higher on reassuring thoughts experienced a higher sense of control and higher psychological well-being. When including both reassuring thoughts and perceived sense of control in the regression analysis, we found that the relationship between reassuring thoughts and psychological well-being was no longer significant, while the effect of perceived sense of control was significant, supporting full mediation (Sobel test: $z=8.24$, $p<0.001$ ). Similarly, the bootstrap approach showed that the indirect effect was significant (point estimate $=0.15, S E=0.05$, $99 \%$ bias corrected CI $[0.02,0.28]$ ). These results imply that people who use more reassuring thoughts reported higher wellbeing due to a higher perceived sense of control. 
TABLE 2 | Results of hierarchical regression analyses examining the role of separate coping strategies on perceived control $(N=536)$.

\begin{tabular}{|c|c|c|c|c|c|c|c|}
\hline & \multicolumn{7}{|c|}{ Coping strategy } \\
\hline \multicolumn{8}{|c|}{ MODEL, R SQUARE CHANGE } \\
\hline 1 & $0.09^{*}$ & $0.09^{*}$ & $0.09^{\star}$ & $0.09^{\star}$ & $0.09^{*}$ & $0.09^{\star}$ & $0.09^{\star}$ \\
\hline 2 & $0.12^{*}$ & 0.00 & $0.02^{*}$ & $0.03^{\star}$ & $0.33^{*}$ & $0.09^{\star}$ & $0.13^{\star}$ \\
\hline Cultural background & -0.05 & -0.05 & -0.05 & -0.05 & -0.05 & -0.05 & -0.05 \\
\hline Sex & $-0.19^{*}$ & $-0.19^{*}$ & $-0.19^{*}$ & $-0.19^{*}$ & $-0.19^{*}$ & $-0.19^{\star}$ & $-0.19^{\star}$ \\
\hline Age & $0.19^{*}$ & $0.19^{\star}$ & $0.19^{\star}$ & $0.19^{*}$ & $0.19^{\star}$ & $0.19^{*}$ & $0.19^{\star}$ \\
\hline Education & 0.04 & 0.04 & 0.04 & 0.04 & 0.04 & 0.04 & 0.04 \\
\hline \multicolumn{8}{|c|}{ STEP 2 (MAIN EFFECT) } \\
\hline
\end{tabular}

Standardized regression weights are reported $(\beta)$. Step 1 results are the same for all coping strategies. Cultural background $(0=D u t c h-C a u c a s i a n, 1=0$ ther $)$ and sex $(0=$ male;

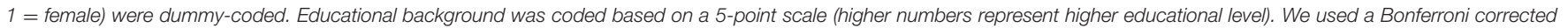
$p$-value for significance testing.

${ }^{*} p<0.007$.

TABLE 3 | Results of hierarchical regression analyses examining the role of separate coping strategies on psychological well-being and mediation by perceived control $(N=536)$.

\begin{tabular}{|c|c|c|c|c|c|c|c|}
\hline & \multicolumn{7}{|c|}{ Coping strategy } \\
\hline & $\begin{array}{c}\text { Active } \\
\text { confronting }\end{array}$ & $\begin{array}{l}\text { Seeking social } \\
\text { support }\end{array}$ & $\begin{array}{l}\text { Reassuring } \\
\text { thoughts }\end{array}$ & $\begin{array}{l}\text { Expressing } \\
\text { emotions }\end{array}$ & $\begin{array}{c}\text { Passive reaction } \\
\text { pattern }\end{array}$ & $\begin{array}{l}\text { Palliative } \\
\text { reaction }\end{array}$ & Avoidance \\
\hline \multicolumn{8}{|c|}{ MODEL, R SQUARE CHANGE } \\
\hline 1 & $0.05^{\star}$ & $0.05^{\star}$ & $0.05^{\star}$ & $0.05^{\star}$ & $0.05^{\star}$ & $0.05^{\star}$ & $0.05^{\star}$ \\
\hline 2 & $0.10^{*}$ & 0.00 & $0.02^{\star}$ & 0.01 & $0.35^{\star}$ & $0.06^{\star}$ & $0.10^{\star}$ \\
\hline \multicolumn{8}{|l|}{ STEP 1 (CONTROLS) } \\
\hline Cultural background & $-0.14^{*}$ & $-0.14^{\star}$ & $-0.14^{*}$ & $-0.14^{\star}$ & $-0.14^{\star}$ & $-0.14^{\star}$ & $-0.14^{*}$ \\
\hline Sex & -0.10 & -0.10 & -0.10 & -0.10 & -0.10 & -0.10 & -0.10 \\
\hline Age & 0.11 & 0.11 & 0.11 & 0.11 & 0.11 & 0.11 & 0.11 \\
\hline Education & 0.03 & 0.03 & 0.03 & 0.03 & 0.03 & 0.03 & 0.03 \\
\hline Perceived control & $0.64^{*}$ & $0.69^{*}$ & $0.67^{\star}$ & $0.68^{\star}$ & $0.48^{\star}$ & $0.67^{\star}$ & $0.65^{\star}$ \\
\hline$R^{2}$ (step 1 and 2) & $0.14^{*}$ & $0.05^{\star}$ & $0.07^{\star}$ & $0.06^{\star}$ & $0.39^{*}$ & $0.10^{*}$ & $0.15^{\star}$ \\
\hline$R^{2}$ (step 3) & $0.48^{*}$ & $0.48^{*}$ & $0.47^{\star}$ & $0.42^{*}$ & $0.53^{*}$ & $0.47^{\star}$ & $0.48^{\star}$ \\
\hline
\end{tabular}

Standardized regression weights are reported $(\beta)$. Step 1 results are the same for all coping strategies. Cultural background $(0=$ Dutch-Caucasian, $1=0$ ther) and sex $(0=$ male;

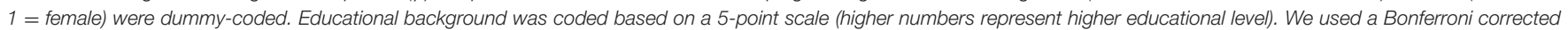
$p$-value for significance testing.

${ }^{*} p<0.007$.

\section{Expressing Emotions}

Expressing emotions was not significantly associated with psychological well-being, and negatively associated with perceived control. We thus found no support for expressing emotions as a potentially effective coping strategy. We did test for a potential indirect effect using the bootstrap approach (point estimate $=-0.21, S E=0.06,99 \%$ bias corrected CI $[-0.36$, $-0.07])$. Even though expressing emotions was not directly associated with psychological well-being, this analysis indicates that there was an indirect effect via perceived control. However, in contrast to our theoretical reasoning, this relationship was negative rather than positive. 


\section{Disengagement Coping}

We argued that passive reaction pattern, palliative reaction, and avoidance would be more disengaged coping styles. For these disengaged coping styles, we argued these are associated with lower perceived control, which in turn should be associated with lower psychological well-being.

\section{Passive Reaction Pattern}

People who scored higher on passive reaction pattern experienced a lower sense of control and lower psychological well-being. When including both passive reaction pattern and perceived sense of control in the regression analysis, we found that the strength of the relationship between passive reaction pattern and psychological well-being was reduced, while the effect of perceived sense of control was significant, supporting partial mediation. A Sobel test indicated that this mediation was significant $(z=7.31, p<0.001)$. Similarly, the bootstrap approach supported an indirect effect between relationship between passive reaction pattern and psychological well-being via perceived sense of control (point estimate $=-0.51, S E=0.06$, $99 \%$ bias corrected CI $[-0.69,-0.36])$. Indeed, it seems to be the case that people who use more passive reaction pattern reported lower well-being due to a reduced perceived sense of control.

\section{Palliative Reaction}

Palliative reaction showed a negative relationship with both perceived control and psychological well-being. When entering both palliative reaction and perceived control in the analysis, the original significant association between palliative coping and psychological well-being became non-significant, while the association between perceived control and psychological wellbeing was significant. The Sobel test was significant $(z=8.17$, $p<0.001)$. The bootstrap approach also supported a significant indirect effect (point estimate $=-0.38, S E=0.06,99 \%$ bias corrected CI $[-0.54,-0.23])$.

\section{Avoidance}

People who scored higher on avoidance experienced a lower sense of control and lower psychological well-being. When including both avoidance and perceived sense of control in the regression analysis, we found support for full mediation $(z=8.09, p<0.001)$. Similarly, the bootstrap approach showed that the indirect effect was significant (point estimate $=-0.43$, $S E=0.06,99 \%$ bias corrected CI $[-0.57,-0.29])$. These results suggest that people who use more avoidance reported lower well-being due to a lower perceived sense of control.

\section{Exploratory Factor Analysis}

Above, we reported the analyses for each coping strategy separately. However, we categorized different coping strategies in engagement and disengagement coping. To probe whether our data support this distinction in coping strategies, we subjected the 47 coping items of the the Utrecht Coping List (UCL; Schreurs et al., 1993) to an exploratory factor analysis with varimax rotation requesting two factors. This first factor analysis showed that the expressing emotions items did not clearly distinguish between the two factors. We therefore omitted these items from the analyses below, and subjected the remaining 42 items to another exploratory factor analysis requesting two factors. The results indicated that the items assessing active confronting, seeking social support, and reassuring thoughts loaded high on the "engagement" factor (20 items; Eigenvalue $=6.29$; variance explained $=15.00 \%$ ), whereas the items measuring passive reaction pattern, palliative reaction, and avoidance loaded high on the "disengagement" factor (22 items; Eigenvalue $=6.06$; variance explained $=14.42 \%)$. Consequently, we computed an engagement $(M=2.39, S D=0.44 ; \alpha=0.85)$ and $a$ disengagement $(M=1.98, S D=0.42 ; \alpha=0.85)$ coping strategy variable. In an exploratory fashion, we re-ran the analyses for these two composite coping variables (see Table 4).

\section{Engagement Coping Composite Variable}

People who scored higher on engagement coping experienced a higher sense of control and higher psychological well-being. When including both engagement coping and perceived sense of control in the regression analysis, we found that the strength of the relationship between engagement coping and psychological well-being was reduced, while the effect of perceived sense of control remained significant, supporting partial mediation (Sobel test: $z=4.09, p<0.001)$. The bootstrap approach supported a significant indirect effect (point estimate $=0.24, S E=0.06$, $99 \%$ bias corrected CI $[0.09,0.40])$. Again, it seems to be the case that people who use more engagement coping strategies reported higher well-being due to a higher perceived sense of control.

\section{Disengagement Coping Composite Variable}

Disengagement coping was negatively related to perceived sense of control and psychological well-being. When including both disengagement coping and perceived sense of control in the analysis, the strength of the relationship between disengagement coping and psychological well-being was reduced, while the effect of perceived sense of control stayed significant, indicating partial mediation (Sobel's $z=10.46, p<0.001$ ). Again, the bootstrap approach supported the mediating role of perceived control in the relationship between disengagement coping and psychological well-being (point estimate $=-0.67, S E=0.08,99 \%$ bias corrected CI $[-0.88,-0.50])$. These findings lend support for our prediction that a disengaged way of handling stressors is related to lower well-being because it is associated with less perceived control.

\section{Testing Alternative Models with Different Directionality}

Given the cross-sectional nature of our study, we also examined two alternative models in an exploratory fashion. In the first alternative indirect effect model, we examined perceived control as independent variable, coping strategies as mediator, and psychological well-being as dependent variable. The PROCESS results show weaker support for this model than for our theoretical model (see Table 5). These weaker effects were also found for the two composite coping strategy variables (for engagement strategies: point estimate $=0.02, S E=0.01,99 \%$ bias corrected CI [0.00, 0.05]; for disengagement strategies: point estimate $=0.10, S E=0.03,99 \%$ bias corrected CI $[0.04,0.19]$. 
TABLE 4 | Results of hierarchical regression analyses examining the role of the composite coping strategy variables on perceived control and psychological well-being and the mediating role of perceived control $(N=536)$.

\begin{tabular}{|c|c|c|c|c|}
\hline & \multicolumn{2}{|c|}{ Perceived control } & \multicolumn{2}{|c|}{ Psychological well-being } \\
\hline & Engagement & Disengagement & Engagement & Disengagement \\
\hline \multicolumn{5}{|c|}{ MODEL, R SQUARE CHANGE } \\
\hline 1 & $0.09^{\star \star \star}$ & $0.09^{\star \star \star}$ & $0.05^{\star \star \star}$ & $0.05^{\star \star \star}$ \\
\hline 2 & $0.03^{\star \star \star}$ & $0.26^{\star \star \star}$ & $0.04^{\star \star \star}$ & $0.22^{\star \star \star}$ \\
\hline \multicolumn{5}{|c|}{ STEP 1 (CONTROLS) } \\
\hline Cultural background & -0.05 & & $-0.14^{\star}$ & \\
\hline Sex & $-0.19^{\star \star \star}$ & & $-0.10^{*}$ & \\
\hline Age & $0.19^{\star \star \star}$ & & $0.11^{*}$ & \\
\hline Education & 0.04 & & 0.03 & \\
\hline Coping strategy & & & $0.10^{\star \star}$ & $-0.18^{\star \star \star}$ \\
\hline Perceived control & & & $0.66^{\star \star \star}$ & $0.59^{\star \star \star}$ \\
\hline$R^{2}$ & & & $0.48^{\star \star \star}$ & $0.49^{\star \star \star}$ \\
\hline
\end{tabular}

Standardized regression weights are reported ( $\beta)$. Step 1 results are the same for both coping strategies. Cultural background $(0=$ Dutch-Caucasian, $1=$ Other $)$ and sex $(0=$ male; $1=$ female) were dummy-coded. Educational background was coded based on a 5-point scale (higher numbers represent higher educational level).

${ }^{*} p<0.05 ;{ }^{* *} p<0.01 ;{ }^{* \star *} p<0.001$

TABLE 5 | Indirect effects with 99\% bias-corrected Cl's pertaining to the proposed theoretical model and two alternative models.

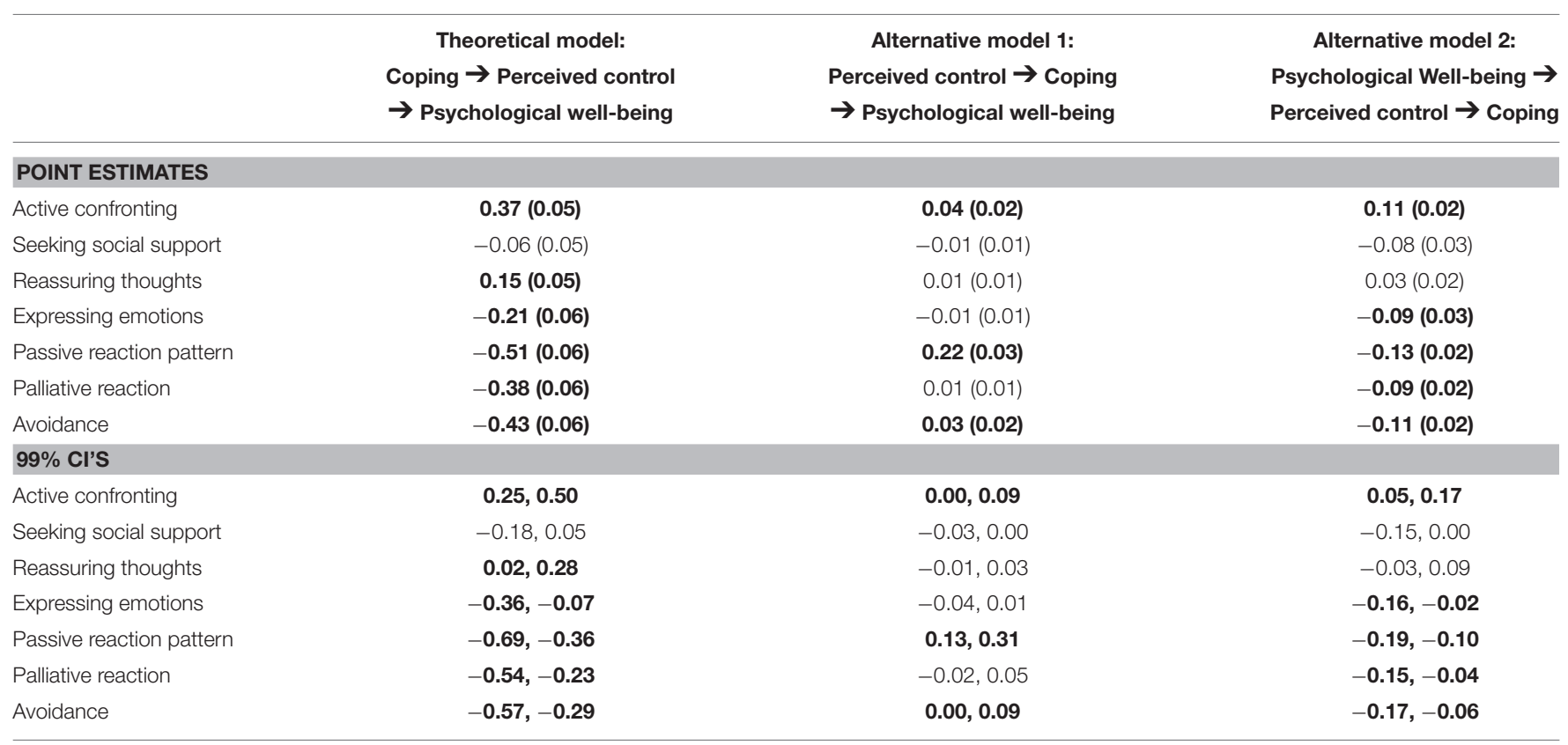

Standard errors are reported in parentheses. Significant conditional indirect effect estimates and Cl's are typed bold. In the second column, the specific coping strategy was tested as the independent variable. In the third column, the specific coping strategy was tested as the mediator. Finally, in the fourth column, the specific coping strategy was tested as dependent variable.

In the second alternative model, we tested the complete reversed directional model (from psychological well-being to control to coping strategies). Again, these results are weaker than for our theoretical model (see Table 5). The results concerning the two composite coping strategy variables (for engagement strategies: point estimate $=0.02, S E=0.02,99 \%$ bias 
corrected CI [-0.03, 0.07]; for disengagement strategies: point estimate $=-0.11, \mathrm{SE}=0.02,99 \%$ bias corrected CI $[-0.16$, -0.07] also became weaker. These exploratory analyses seem to suggest stronger support for our theoretical model than for models in which the direction of the relationships between the variables is (partially) reversed.

\section{DISCUSSION}

The purpose of this study was to find out why some coping strategies are effective in reducing the negative effect of stressors on well-being and some are not. We proposed that the use of more engaged coping strategies, aimed at taking charge in tone, by facing the stressor and/or its related emotions, are related to more perceived control, which in turn is positively related to psychological well-being. We further proposed that when employing more disengaged coping, aimed at diverting from the stressor and/or its related emotions, perceived control was also lower, which in turn was related to deteriorated psychological well-being.

Our results showed that the coping strategies of passive reaction pattern, palliative reaction and avoidance were consistently and negatively related to perceived control and therefore to less well-being. The commonality between these three strategies is that their coping behavior is directed at turning away from the stressful event and/or the emotions that go along side with it. Such disengaged behaviors lead a person to experience a lack of control, and potentially a lack of possibilities to confront the stressor (Latack, 1986; Dijkstra et al., 2009).

Our results concerning active confronting and reassuring thoughts revealed a positive relationship with perceived control and through perceived control with more well-being. Seeking social support, however, was not related to either well-being or control and therefore could not be regarded as an effective coping strategy. Although seeking social support clearly implies activity and could therefore be considered to be an engagement coping strategy and directed toward the stressor and/or its emotions, the strategy obviously is an exception where it concerns its association with perceived control. Elaborating on this further it can be argued that the extent to which seeking social support will be related to perceived control is contingent on the success of the search. In other words is seeking social support resulting in actually getting social support? If not, for example when asked support when in fear of job loss is being denied, a lack of possibilities to confront the stressor might be experienced. Indeed, in light of the importance of social support for health and well-being (Tian et al., 2013; Emadpoor et al., 2016) such rejection might function as an additional stressor (Platt et al., 2013).

The coping strategy expressing emotions also was not related to well-being but there was a significant relationship with perceived control. This relationship was, however, in the opposite direction of what we expected. In line with this inconsistent finding, our exploratory factor analysis indicated that expressing emotions did not clearly map onto engagement (or disengagement) coping, but was negatively related to control, and indirectly negatively to well-being. When examining the items pertaining to this coping style (e.g., "shown your feelings," "let off steam," "shown your frustration," "shown that you were angry with those responsible for the problem"), it becomes clear that these items might indeed load on both these factors, given that some items indicate a more engaged and activating handling of the stressor (anger toward those responsible) and others might be less engaged and diverge more from the stressor (letting off steam). Finally, expressing anger or frustration might be associated with a lack of perceived control, given that these emotions do not help to reappraise or handle the stressor, and as such might be associated with diminished well-being (Leonard and Alison, 1999).

Whereas past research has clearly supported control as being relevant for well-being (Mirowsky and Ross, 1990; Thoits, 1995; Turner and Lloyd, 1999; Chipperfield et al., 2004; Dijkstra et al., 2011; Vander Elst et al., 2016) and even survival (Shapiro et al., 1996), our data provide preliminary evidence of a relationship between ways of coping and perceived sense of control. The main contribution of this study therefore is that it suggests an important role of control in the stress process and that it deepens our understanding of the differential effectiveness of different coping strategies (Britt et al., 2016). Indeed, perceived sense of control might be identified as an important explaining variable in the relationship between coping and psychological well-being. Rather than merely activating or de-activating someone, the lack of engagement implied by disengagement strategies is correlated to feeling that the situation is outside of someone's control, which in turn is associated with negative consequences.

In line with the theoretical reasoning that the most insightful distinction in coping strategies is engagement vs. disengagement (Carver and Connor-Smith, 2010), an exploratory factor analysis illustrated that most of the coping styles nicely mapped onto these two categories. Conceptually it makes sense that active confronting, seeking social support, and reassuring thoughts loaded onto an engagement factor, given that these items include strategies in which a person takes charge in tone, by facing the stressor and/or its related emotions. Similarly, passive reaction pattern, palliative reaction, and avoidance involve strategies that are aimed at diverting from the stressor and/or its related emotions. However, given that expressing emotions did not satisfactorily fit in with one of the two factors, and that reassuring thoughts when analyzed separately showed no effects, our findings also suggest that when categorizing coping styles into broader categories, certain styles might involve a variety of strategies and behaviors. This points to the importance of theoretical development based on fundamental research, and a potential more fine-grained examination of these relationships in future research.

\section{Limitations and Future Research}

We acknowledge that our data are of cross-sectional nature. This means that we cannot claim that the relationships really are in the direction we propose them to be. We are relatively confident, however, that our results will replicate in a more robust research design. This confidence is based on our examination of two different exploratory indirect effect models in which (a) coping 
strategies were the mediator, perceived control the independent variable, and psychological well-being as the outcome, and (b) psychological well-being influenced coping strategies via perceived control. Inspection of these models revealed (far) less strong indirect effects, some null-effects which were previously significant (e.g., for reassuring thoughts and palliative reaction), and confidence intervals much closer to zero. However, in order to develop stronger theoretical notions concerning the role of control in the stress process, a thorough examination of the different coping strategies as to their potential to elicit a sense of control is needed. Since its purpose of developing theory, such research would preferably be of experimental nature. Creating conditions in which different coping strategies are induced would allow for more causal explanations concerning the relationship between a particular coping strategy and perceived sense of control. These relationship could then be further examined conducting longitudinal research in order to test whether more engagement coping will indeed lead to more perceived control over time, which in turn might be positively related to psychological well-being.

Apart from the correlational nature of our study, a second limitation is the lack of information on the participant's locus of control. As locus of control has been discussed as a potential predictor of the use of certain coping strategies (e.g., Anderson, 1977), it would be interesting to control for personal locus of control in future research. However, locus of control is often seen as a relatively stable trait, which is difficult to influence. Our data seem to indicate that perceived control is influenced by coping strategies, and thus can vary depending on which coping style is employed. As the two composite coping styles are positively correlated, it seems unlikely that locus of control is an alternative explanation of our findings. Additionally, although our findings seem to indicate that influencing someone's sense of control might be a fruitful intervention for dealing with stress, future research might empirically test such an intervention.

Finally, in the current study, we did not investigate the context in which the coping strategy was employed. In line with the less consistent findings regarding seeking social support and expressing emotions, it might be the case that certain coping

\section{REFERENCES}

Acharya, V., Philippon, T., Richardson, M., and Roubini, N. (2009). The financial crisis of 2007-2009: causes and remedies. Financ. Mark. Inst. Instrum. 18, 89-137. doi: 10.1111/j.1468-0416.2009.00147_2.x

Almeida, D. M., and Kessler, R. C. (1998). Everyday stressors and gender differences in daily distress. J. Pers. Soc. Psychol. 75, 670-680. doi: 10.1037/00223514.75.3.670

Anderson, C. R. (1977). Locus of control, coping behaviors, and performance in a stress setting: a longitudinal study. J. Appl. Psychol. 62, 446-451. doi: 10.1037/ 0021-9010.62.4.446

Antoni, M. H., Lutgendorf, S. K., Cole, S. W., Dhabhar, F. S., Sephton, S. E., McDonald, P. G., et al. (2006). The influence of bio-behavioural factors on tumor biology: pathways and mechanisms. Natl. Rev. Cancer 6, 240-248. doi: $10.1038 / \mathrm{nrc} 1820$

Aspinwall, L. G., and Taylor, S. E. (1997). A stitch in time: self-regulation and proactive coping. Psychol. Bull. 121, 417-436. doi: 10.1037/0033-2909.121.3.417 strategies are more or less needed or become more or less effective in certain contexts, for certain people, or in certain situations (Mucci et al., 2015; Reed, 2016). For instance, control might be more relevant to the degree that the stressful situation is more ambiguous, certain coping strategies might be more effective for more optimistic people, and one's standing in the organizational hierarchy might affect the opportunity to employ certain coping strategies. It would be interesting for future research to take such moderating factors into account.

\section{CONCLUSION}

In sum, our data provide some preliminary insights into why different coping strategies can have negative or positive effects on psychological well-being. By increasing a sense of control, some coping strategies that are more engaging (i.e., active confronting and reassuring thoughts) are able to positively affect psychological well-being, whereas disengagement strategies (i.e., passive reaction pattern, palliative reaction, and avoidance) make people experience a lack of control and as such are likely to lower psychological well-being. Organizations could use these findings to actively coach and train their employees to seek effective control over stressful situations, and to teach them to employ engaged rather than disengaged coping styles.

\section{AUTHOR CONTRIBUTIONS}

$\mathrm{AH}$ provided substantial contributions to the research conception and design. $\mathrm{MD}$ and $\mathrm{AH}$ analyzed and interpreted the data. $\mathrm{MD}$ wrote the paper, $\mathrm{AH}$ provided critical revisions of the paper. $\mathrm{MD}$ and $\mathrm{AH}$ both attended to the revision of the paper. $\mathrm{MD}$ and $\mathrm{AH}$ both approved of this version of the paper to be published. The authors thank Nishi Ramlal for collecting the data.

\section{FUNDING}

This open access publication was made possible by a NWO Aspasia grant awarded to $\mathrm{AH}$.

Barnett, R. C., Biener, L., and Baruch, G. K. (1987). Gender and Stress. New York, NY: The Free Press.

Baron, R. M., and Kenny, D. A. (1986). The moderator-mediator variable distinction in social psychological research: conceptual, strategic, and statistical considerations. J. Pers. Soc. Psychol. 51, 1173-1182. doi: 10.1037/00223514.51.6.1173

Berwick, D. M., Murphy, J. M., Goldman, P. A., Ware, J. E. Jr., Barsky, A. J., and Weinstein, M. C. (1991). Performance of a five-item mental health screening test. Med. Care 29, 169-176. doi: 10.1097/00005650-199102000-00008

Bower, J. E., Crosswell, A. D., and Slavich, G. M. (2014). Childhood adversity and cumulative life stress risk factors for cancer-related fatigue. Clin. Psychol. Sci. 2, 108-115. doi: 10.1177/2167702613496243

Bridger, R. S., Day, A. J., and Morton, K. (2013). Occupational stress and employee turnover. Ergonomics 56, 1626-1639. doi: 10.1080/00140139.2013.836251

Britt, T. W., Crane, M., Hodson, S. E., and Adler, A. B. (2016). Effective and ineffective coping strategies in a low-autonomy work environment. J. Occup. Health Psychol. 21, 154-168. doi: 10.1037/a0039898 
Bryant, F. B., and Veroff, J. (1984). Dimensions of subjective mental health in American men and women. J. Health Soc. Behav. 25, 116-135. doi: 10.2307/ 2136664

Buckley, U., and Shivkumar, K. (2016). Stress-induced cardiac arrhythmias: the heart-brain interaction. Trends Cardiovasc. Med. 26, 78-80. doi: 10.1016/j.tcm.2015.05.001

Carver, C. S., and Connor-Smith, J. (2010). Personality and coping. Annu. Rev. Psychol. 61, 679-704. doi: 10.1146/annurev.psych.093008.100352

Carver, C. S., and Scheier, M. F. (1994). Situational coping and coping dispositions in a stressful transaction. J. Pers. Soc. Psychol. 66, 184-195. doi: 10.1037/00223514.66.1.184

Carver, C. S., Scheier, M. F., and Weintraub, J. K. (1989). Assessing coping strategies: a theoretically based approach. J. Pers. Soc. Psychol. 56, 267-283. doi: 10.1037/0022-3514.56.2.267

Chipperfield, J. G., Campbell, D. W., and Perry, R. P. (2004). Stability in perceived control: implications for health among very old community-dwelling adults. J. Aging Health 16, 116-147. doi: 10.1177/0898264303260447

Chu-Lien Chao, R. (2011). Managing stress and maintaining well-being: social support, problem-focused coping, and avoidant coping. J. Couns. Dev. 89, 338-348. doi: 10.1002/j.1556-6678.2011.tb00098.x

Cohen, S., Kamarck, T., and Mermelstein, R. (1983). A global measure of perceived stress. J. Health Soc. Behav. 24, 385-396. doi: 10.2307/2136404

Dijkstra, M. T. M., Beersma, B., and Evers, A. (2011). Reducing conflict-related strain employee strain: the benefits of an internal locus of control and a problem-solving conflict management strategy. Work Stress 25, 167-184. doi: 10.1080/02678373.2011.593344

Dijkstra, M. T. M., De Dreu, C. K. W., Evers, A., and Van Dierendonck, D. (2009). Passive responses to interpersonal conflict at work amplify employee strain. Eur. J. Work Organ. Psychol. 18, 405-432. doi: 10.1080/135943208025 10880

Emadpoor, L., Lavasani, M. G., and Shahcheraghi, S. M. (2016). Relationship between perceived social support and psychological well-being among students based on mediating role of academic motivation. Int. J. Ment. Health Addict. 14, 284-290. doi: 10.1007/s11469-015-9608-4

Folkman, S., and Lazarus, R. S. (1985). If it changes it must be a process: study of emotion and coping during 3 stages of a college-examination. J. Pers. Soc. Psychol. 48, 150-170. doi: 10.1037/0022-3514.48.1.150

Fortes-Ferreira, L., Peiró, J. M., Conzález-morales, G., and Martin, I. (2006). Work-related stress and well-being: the roles of direct action coping and palliative coping. Scand. J. Psychol. 47, 293-302. doi: 10.1111/j.1467-9450.2006. 00519.x

Garcia-Bueno, B., Caso, J. R., and Leza, J. C. (2008). Stress as a neuroinflammatory condition in brain: damaging and protective mechanisms. Neurosci. Biobehav. Rev. 32, 1136-1151. doi: 10.1016/j.neubiorev.2008.04.001

Giorgi, G., Arangeli, G., Mucci, N., and Cupelli, V. (2014). Economic stress in workplace: the impact of fear the crisis on mental health. Work 51, 135-142. doi: 10.3233/WOR-141844

Goodman, C. J., and Mance, S. M. (2011). Employment loss and the 2007-09 recession: an overview. Monthly Labor Rev. 134, 3-12. Retrieved from: http:// stats.bls.gov/opub/mlr/2011/04/artlfull.pdf

Hayes, A. F. (2013). Introduction to Mediation, Moderation, and Conditional Process Analysis. New York, NY: The Guilford Press.

Hemingway, H., and Marmot, M. (1999). Evidence based cardiology: psychosocial factors in the aetiology and prognosis of coronary heart disease: systematic review of prospective cohort studies. Br. Med. J. 318, 1460-1467. doi: 10.1136/bmj.318.7196.1460

Inzlicht, M., and Kang, S. K. (2010). Stereotype threat spillover: how coping with threats to social identity affects aggression, eating, decision making, an attention. J. Pers. Soc. Psychol. 99, 467-481. doi: 10.1037/a0018951

Preacher, K. J., and Hayes, A. F. (2004). SPSS and SAS procedures for estimating indirect effects in simple mediation models. Behav. Res. Methods Instrum. Comput. 36, 717-731. doi: 10.3758/BF03206553

Koeske, G. F., Kirk, S. A., and Koeske, R. D. (1993). Coping with job stress: which strategies work best? J. Occup. Organ. Psychol. 66, 319-335. doi: 10.1111/j.20448325.1993.tb00542.x

Lachman, M. E., and Weaver, S. L. (1998). Socio-demographic variations in the sense of control by domain: findings from the MacArthur Studies of Midlife. Psychol. Aging 13, 553-562. doi: 10.1037/0882-7974.13.4.553
Latack, J. C. (1986). Coping with job stress: measures and future directions for scale development. J. Appl. Psychol. 71, 377-385. doi: 10.1037/0021-9010.71.3.377

Lazarus, R. S. (1991). Emotion and Adaptation. New York, NY: Oxford University Press.

Lazarus, R. S., and Folkman, S. (1984). Stress, Appraisal and Coping. New York, NY: Springer.

Le Fevre, M. L., Kolt, G. S., and Matheny, J. (2006). Eustress, distress and their interpretation in primary and secondary occupational stress management interventions: which way first? J. Manag. Psychol. 21, 547-565. doi: 10.1108/02683940610684391

Leonard, R., and Alison, L. (1999). Critical incident stress debriefing and its effects on coping strategies and anger in a sample of Australian police officers involved in shooting incidents. Work Stress 13, 144-161. doi: 10.1080/026783799296110

Matud, M. P. (2004). Gender differences in stress and coping styles. Pers. Individ. Dif. 37, 1401-1415. doi: 10.1016/j.paid.2004.01.010

Mino, Y., Babazono, A., Tsuda, T., and Yasuda, N. (2006). Can stress management at the workplace prevent depression? A randomized controlled trial. Psychother. Psychosom. 75, 177-182. doi: 10.1159/000091775

Mirowsky, J., and Ross, C. E. (1990). Control or defense? Depression and the sense of control over good and bad outcomes. J. Health Soc. Behav. 31, 71-86. doi: $10.2307 / 2137046$

Moos, R. H. (1990). Conceptual and empirical approaches to developing familybased assessment procedures: resolving the case of the family environment scale. Fam. Process 28, 199-208. doi: 10.1111/j.1545-5300.1990.00199.x

Mucci, N., Giorgi, G., Cupelli, V., Gioffrè, P. A., Rosati, M. V., Tomei, F., et al. (2015). Work-related stress assessment in a population of Italian workers. the Stress Questionnaire. Sci. Total Environ. 502, 673-679. doi: 10.1016/j.scitotenv. 2014.09.069

Mucci, N., Giorgi, G., Roncaioli, M., Fiz Perez, J., and Arcangeli, G. (2016). The correlation between stress and economic crisis: a systematic review. Neuropsychiatr. Dis. Treat. 12, 983-993. doi: 10.2147/NDT.S98525

Nolen-Hoeksema, S. (1987). Gender differences in unipolar depression: evidence and theory. Psychol. Bull. 101, 259-282. doi: 10.1037/0033-2909.101.2.259

Perrewe, P. L., and Zellars, K. L. (1999). An examination of attributions and emotions in the transactional approach to the organizational stress process. J. Organ. Behav. 20, 739-752.

Pindek, S., and Spector, P. E. (2016). Organizational constraints: a meta-analysis of a major stressor. Work Stress 30, 7-25. doi: 10.1080/02678373.2015.1137376

Platt, B., Cohen Kadosh, K., and Lau, J. Y. F. (2013). The role of peer rejection in adolescent depression. Depress. Anxiety 30, 809-821. doi: 10.1002/da.22120

Ptacek, J. T., Smith, R. E., and Dodge, K. L. (1994). Gender differences in coping with stress: when stressors and appraisal do not differ. Pers. Soc. Psychol. Bull. 20, 421-430. doi: 10.1177/0146167294204009

Ramlal, N. (2007). De Relatie Tussen Coping en Psychisch Welbevinden bij Hindoestanen en de rol van Karma in het Copingproces (The Relationship Between Coping and Psychological Wellbeing in Hindustani and the Role of Karma in the Coping Process). Unpublished Master's thesis. Leiden University, Leiden, The Netherlands.

Reed, D. J. (2016). Coping with occupational stress: the role of optimism and coping flexibility. Psychol. Res. Behav. Manag. 9, 71-79. doi: 10.2147/PRBM. S97595

Health and Safety Executive (2013/2014). Stress-Related and Psychological Disorders in Great Britain 2014. Available online at: http://www.hse.gov.uk/ statistics/causdis/stress/index.htm (Accessed April 20, 2015).

Schreurs, P. J. G., Van de Willige, G., Brosschot, J. F., Telligen, B., and Graus, G. M. H. (1993). The Utrecht Coping List: UCL. Handling problems and events. [De Utrechtse Coping Lijst: UCL. Omgaan met problemen en gebeurtenissen]. Lisse: Swets en Zeitlinger B.B.

Shah, B. M., Gupchup, G. V., Borrego, M. E., Raisch, D. W., and Knapp, K. K. (2012). Depressive symptoms in patients with Type 2 Diabetes Mellitus: do stress and coping matter? Stress Health 28, 111-122. doi: 10.1002/smi.1410

Shapiro, D. H. Jr., Schwarz, C. E., and Astin, J. A. (1996). Controlling ourselves, controlling our world: psychology's role in understanding positive and negative consequences of seeking and gaining control. Am. Psychol. 51, 1213-1230. doi: 10.1037/0003-066X.51.12.1213

Siu, O., Spector, P. E., Cooper, C. L., and Donald, I. (2001). Age differences in coping and locus of control: a study of managerial stress in Hong Kong. Psychol. Aging 16, 707-710. doi: 10.1037/0882-7974.16.4.707 
Skinner, E. A., Edge, K., Altman, J., and Sherwood, H. (2003). Searching for the structure of coping: a review and critique of category systems for classifying ways of coping. Psychol. Bull. 129, 216-269. doi: 10.1037/0033-2909.129.2.216

Slavich, G. M., and Irwin, M. R. (2014). From stress to inflammation and major depressive disorder: a social signal transduction theory of depression. Psychol. Bull. 140, 774-815. doi: 10.1037/a0035302

Spector, P. E., and Jex, S. M. (1998). Development of four self-report measures of job stressors and strain: interpersonal conflict at work scale, organizational constraints scale, quantitative workload inventory, and physical symptoms inventory. J. Occup. Health Psychol. 3, 356-367. doi: 10.1037/1076-8998.3.4.356

Steptoe, A., and Kivimäki, M. (2012). Stress and cardiovascular disease. Nat. Rev. Cardiol. 9, 360-370. doi: 10.1038/nrcardio.2012.45

Thoits, P. A. (1995). Stress, coping, and social support processes: where are we? What next? J. Health Soc. Behav. SI, 53-79.

Tian, L., Liu, B., Huang, S., and Huebner, E. S. (2013). Perceived social support and school well-being among Chinese early and middle adolescents: the mediational role of self-esteem. Soc. Indic. Res. 113, 991-1008. doi: 10.1007/ s11205-012-0123-8

Turner, R. J. (1988). Physical disability and depression: a longitudinal analysis. J. Health Soc. Behav. 29, 23-37. doi: 10.2307/2137178

Turner, R. J., and Lloyd, D. A. (1999). The stress process and the social distribution of depression. J. Health Soc. Behav. 40, 374-404. doi: 10.2307/26 76332
Vander Elst, T., De Cuyper, N., Baillien, E., Niesen, W., and De Witte, H. (2016). Perceived control and psychological contract breach as explanations of the relationships between job insecurity, job strain and coping reactions: towards a theoretical integration. Stress Health 32, 100-116. doi: 10.1002/ smi.2584

Veit, C. T., and Ware, J. E. (1983). The structure of psychological distress and well-being in general populations. J. Consult. Clin. Psychol. 51, 730-742. doi: 10.1037/0022-006X.51.5.730

Wolever, R. Q., Bobinet, K. J., McCabe, K., Mackenzie, E. R., Fekete, E., Kusnick, C. A., et al. (2012). Effective and viable mind-body stress reduction in the workplace: a randomized controlled trial. J. Occup. Health Psychol. 17, 246-258. doi: $10.1037 / \mathrm{a} 0027278$

Conflict of Interest Statement: The authors declare that the research was conducted in the absence of any commercial or financial relationships that could be construed as a potential conflict of interest.

Copyright $\odot 2016$ Dijkstra and Homan. This is an open-access article distributed under the terms of the Creative Commons Attribution License (CC BY). The use, distribution or reproduction in other forums is permitted, provided the original author(s) or licensor are credited and that the original publication in this journal is cited, in accordance with accepted academic practice. No use, distribution or reproduction is permitted which does not comply with these terms. 


\section{OPEN ACCESS}

Edited by:

Annamaria Di Fabio,

University of Florence, Italy

Reviewed by:

Carmen Paz-Aparicio, Charles III University of Madrid, Spain

Krystyna Golonka,

Jagiellonian University, Poland

*Correspondence:

Jose M. Leon-Perez

leonperez@us.es

Specialty section:

This article was submitted to

Organizational Psychology,

a section of the journal

Frontiers in Psychology

Received: 01 June 2016

Accepted: 25 October 2016

Published: 14 November 2016

Citation:

Leon-Perez JM, Antino M and Leon-Rubio JM (2016) The Role of Psychological Capital and Intragroup Conflict on Employees' Burnout and

Quality of Service: A Multilevel Approach. Front. Psychol. 7:1755.

doi: 10.3389/fpsyg.2016.01755

\section{The Role of Psychological Capital and Intragroup Conflict on Employees' Burnout and Quality of Service: A Multilevel Approach}

\author{
Jose M. Leon-Perez ${ }^{1,2 *}$, Mirko Antino ${ }^{2}$ and Jose M. Leon-Rubio ${ }^{1}$ \\ ${ }^{1}$ Universidad de Sevilla, Social Psychology, Sevilla, Spain, ${ }^{2}$ Instituto Universitário de Lisboa (ISCTE-IUL), Lisbon, Portugal
}

Previous studies have found a negative association between intragroup conflict and both employees' health and performance, including the quality of service that employees provide. However, some authors have indicated that such negative effects of intragroup conflict depend on how conflict is managed. In addition, at individual level, research is increasingly emphasizing the role of psychological strengths (i.e., psychological capital) as predictors of health and performance. Thus, this research addresses both a main effect at individual level (psychological capital on burnout/quality of service) and a moderated cross-level model (2-2-1: intragroup conflict, conflict management climate and burnout/quality of service) in a cross-sectional survey study ( $N=798$ workers nested in 55 units/facilities). Results revealed a main effect of psychological capital on both burnout $(r=-0.50)$ and quality of service $(r=0.28)$. Also, there was an association between intragroup relationship conflict and burnout $(r=0.33)$. Finally, there was an interaction effect in which conflict management climate buffers the negative association between intragroup conflict and quality of service. Practical implications of these results for developing positive and healthy organizations that prevent potential psychosocial risks at group level while promote individual strengths are discussed.

Keywords: psychological capital, workplace conflict, conflict management, well-being, performance

\section{INTRODUCTION}

Traditionally, the absence of distress at work together with the development of health promotion initiatives has been considered pivotal indicators of healthy organizations. However, recent developments in the field of psychology have led to a shift in the ultimate goal of occupational health research: from reducing negative events at work and their concomitant psychological, physical, and economic costs to facilitate positive experiences that promote health and well-being (e.g., Bono et al., 2013). Indeed, recent trends in organizational behavior focus on the concept of positive and healthy organizations ( $\mathrm{PHO}$ ), which refers to such organizations that emphasize the importance of achieving positive organizational outcomes (i.e., financial success, high quality service, and organizational survival) by promoting employees' flourishing in a healthy work environment over time (e.g., Cooper and Cartwright, 1994; Grawitch et al., 2006; Day and Randell, 2014).

PHO has its roots in the Human Relations Movement, which (a) proposes that satisfied workers are more productive than others (i.e., "the happy-productive worker hypothesis": Wright et al., 2007), and (b) calls for a psychology focusing on building organizations that facilitate employee 
development and promote quality of life (i.e., positive psychology: Seligman and Csikszentmihalyi, 2000). Thus, research on "this area focuses on building strengths at work rather than fixing weaknesses" both at the individual and organizational level (for a review, see Gilbert and Kelloway, 2014).

However, Hackman (2009) cautioned that this positive approach, when applied to organizational context, has too much emphasis on individual-level interventions and ignores problems in organizations that need attention prior to introducing positive interventions. Furthermore, Bono et al. (2013) pointed out the lack of integration of both the traditional approach focusing on preventing resource-depleting (negative) experiences and their associated negative outcomes (e.g., distress and health complaints), and the more recent positive approach focusing on facilitating resource-building (positive) experiences and their associated positive outcomes (e.g., work engagement and thriving).

In order to shed some light on this debate (see also Fineman, 2006; Roberts, 2006), this study uses a cross-level design to address how both psychological strengths at individual level (i.e., PsyCap) and both negative and positive experiences at group level (i.e., intragroup conflict and conflict management climate) interplay and are associated to employees' well-being (i.e., reduced burnout) and performance (i.e., self-reported quality of service). In doing so, we first focus on psychological capital (i.e., positive psychological resources) as a relevant factor contributing to workers' well-being and performance at individual level, particularly we assume that workers' psychological capital is an essential resource at individual level both to cope with job demands or work stressors and to trigger positive experiences at work, which are key features of positive and healthy organizations. Then, considering the pivotal role of teams in nowadays organizations, we turn to a group level of analysis and emphasize how positive group dynamics, such as the capacity of the team to openly discuss disagreements and constructively manage conflict, can both prevent negative environments and foster positive social interactions in order to enhance employees' well-being and performance.

\section{PHO at Individual Level}

There is a renewed interest in the value of positively oriented human resource strengths and psychological capacities that allow individuals and organizations to flourish (e.g., Avey et al., 2008; Bakker and Schaufeli, 2008). According to this positive approach, Luthans et al. (2007) and (Luthans et al. (2015) have proposed the concept of psychological capital (PsyCap), which is a multidimensional construct consisting of hope (positive subjective appraisals of goal-related capabilities), efficacy (confidence in one's own abilities to successfully perform tasks), resiliency (positive coping and bouncing back from adversity), and optimism (mental attitude to interpret situations and events in a positive way).

From a stress prevention perspective, Folkman and Moskowitz (2000) indicated that positive emotions have an adaptive function under stress conditions because they "may provide a psychological break or respite, support continued coping efforts, and replenish resources that have been depleted by the stress" (p. 649: see also Fredrickson, 2001). In a similar vein, resilience and optimism, components of psychological capital, appear to play an important role in the capacity to tolerate and copy with stressful events, and have been associated with reduced stress (e.g., Ong et al., 2006; Carver and Scheier, 2014). In that sense, Baron et al. (2016) found that PsyCap increases well-being through the reduction of perceived stress in a sample of entrepreneurs. Furthermore, a recent meta-analysis summarizing data from 51 independent samples, documented a significant negative relationship between PsyCap and both job stress and anxiety (Avey et al., 2011).

Similarly, some studies have confirmed the negative association between PsyCap and burnout in various professions such as school teachers (Cheung et al., 2011), bank employees (Li et al., 2015), or nurses (Ding et al., 2015); which suggests that having these psychological resources can help workers tolerating stressful situations or confront their demands at work without suffering chronic stress or burnout. Moreover, Laschinger and Fida (2014) conducted a two-wave survey with Canadian newly graduated nurses and found that nurses' PsyCap was related to both lower initial levels of burnout and lower increases in burnout after their first year of practice.

In addition, these psychological resources have been widely reported in the literature as precursors of well-being and happiness (e.g., Lyubomirsky et al., 2005; Wood et al., 2011). In organizational contexts, according to Hobfoll's (1989, 2001, 2002) Conservation of Resource (COR) theory, several authors have considered PsyCap as cumulative resource gains that increase well-being over time (gain spirals: Avey et al., 2010; Culbertson et al., 2010). More recently, longitudinal studies have associated PsyCap with increased overall well-being and work happiness over time (e.g., Luthans et al., 2013; Williams et al., 2015) and a meta-analysis has shown that PsyCap is a significant predictor of psychological well-being and other desirable employee attitudes (e.g., job satisfaction: Avey et al., 2011).

Moreover, the role of PsyCap can go beyond reducing stress at work to increasing the positive experience of work and improving work engagement and performance. For example, Peterson et al. (2011) conducted a longitudinal study with three data collection times from a large financial service organization. Their results revealed that PsyCap is related to both objective (i.e., sales revenue) and subjective performance (i.e., supervisor ratings) over time. Also, Avey et al. (2011) meta-analysis reported a significant positive relationship between PsyCap and multiple measures of performance (self, supervisor evaluations, and objective). Furthermore, the effect size of such relationship was stronger in the service sector compared to those organizations based in the manufacturing industry, probably because performance in the service sector "relies more on social interactions that require emotional norms favoring the expression of positive affect" (Avey et al., 2011, p. 146). However, although quality of service can be considered a competitive advantage related to organizations' productivity as it enhances customer satisfaction and build a long-term relationship with customers (e.g., Rust et al., 2002), to authors' knowledge no 
previous study has explored the impact of PsyCap on the quality of service that workers provide to their customers.

Nevertheless, based on previous literature on the association between PsyCap and performance, it seems that people with higher PsyCap will succeed in providing a high quality of service because they will perceive they have necessary skills to perform their tasks (self-efficacy) and being successful (optimism). Hence, these cognitive schemas will allow them to put the necessary effort to (self-efficacy), redirect their courses of action to (hope), and being persistent to (resilience) successfully providing highquality of service. For example, empirical evidence indicates that positive cognitive judgments about ones' capabilities (e.g., self-efficacy beliefs) and cognitive abilities (e.g., emotional intelligence) are crucial regulatory mechanisms for effective performance in a wide range of tasks that require specific social competencies (for a meta-analysis see Stajkovic and Luthans, 1998; Joseph and Newman, 2010; although for contradictory results see also the meta-analysis of Sitzmann and Yeo, 2013).

Building on these rationales and findings, we propose that PsyCap is negatively associated to burnout (H1) and positively associated to perceived quality of service $(\mathrm{H} 2)$.

\section{PHO at Group Level}

Following the idea that $\mathrm{PHO}$ are organizations that both prevent or successfully manage negative environments and group dynamics and foster positive social interactions in order to enhance employees' well-being and performance, we turned our focus to the role of workplace conflict, which is inherent to social interactions at work and constitutes one of the most important sources of stress at workplace. Indeed, Keenan and Newton (1985) using an open-ended method found that interpersonal conflict was one of the most frequently reported sources of stress in a sample of young engineers. Also at the individual level, Spector and Jex (1998) conducted a meta-analysis and concluded that interpersonal conflict at work is related to individual negative consequences such as frustration, anxiety, and depression. Similarly, more recent cross-sectional and diary studies have shown that interpersonal conflict can be considered a job stressor that leads to high levels of stress and correlates with stress-related outcomes (i.e., strain) such as anxiety, emotional exhaustion or psychosomatic complaints (e.g., Dijkstra et al., 2009, 2011; Meier et al., 2014).

However, these studies are at individual level while an interpersonal conflict is usually a group process (i.e., intragroup conflict) that affects the whole team or unit. Indeed, autonomous working groups for delivering high-quality products and services are on the most common ways of designing work in current organizations because collaboration usually yields superior outcomes compared to individual efforts (Deutsch and Coleman, 2000). In addition, these studies have rarely taken into consideration the typology of intragroup conflict based on their nature (Jehn, 1997; Jehn and Mannix, 2001): (a) taskrelated conflict (TC) or conflicts concerning the perception of disagreement among individuals about the content of their inter-related tasks, which usually involves differences in points of view, ideas and opinions; (b) relationship conflict (RC) or conflicts concerning perceptions of interpersonal incompatibilities, usually including gossip and disagreement about personal beliefs; and (c) process conflict (PC) or conflicts concerning controversies about how task accomplishment will proceed, usually involving disagreement about procedures, protocols and guidelines.

According to such typology and considering conflict at group level, recent meta-analyses have highlighted that such types of intragroup conflict have different consequences (see De Dreu and Weingart, 2003; de Wit et al., 2012): while relationship and process conflict have negative relationships with personal and group outcomes (i.e., well-being and performance), task conflict can be productive under certain circumstances depending on how the group conceive conflict and deal with it (i.e., conflict management climate or employees' shared beliefs that disagreement can be discussed and intragroup conflicts are generally managed well and fairly in their unit: Einarsen et al., 2016). For example, relationship and process intragroup conflict can be detrimental to the quality of service that employees provide because it deteriorates the group's affective climate (Gamero et al., 2008) and service climate (Benítez et al., 2012).

On the other hand, task conflict can improve performance when teams have open discussion norms (Jehn and Mannix, 2001) and a climate of psychological safety exists (Bradley et al., 2012). Consequently, several authors have highlighted that the way how conflict is managed determines its outcomes rather than the kind of conflict (e.g., Behfar et al., 2008; Tekleab et al., 2009). Similarly, Tjosvold (2008) argued that teams need to rely on cooperative management of conflict for their successfully internal functioning, which can have significant benefits for both individuals and organizations, including increased performance as recent follow-up training studies have suggested. For example, employees working in a call center who were trained for cooperative conflict management improved their performance (i.e., fewer turnover rates, more calls answered, fewer customer complaints, and better quality examination scores) after the training compared to their non-trained colleagues (Tjosvold et al., 2014). Also, Leon-Perez et al. (2016) trained 258 healthcare workers in cooperative conflict management skills and reported that the training was successful in reducing the number of patients' complaints and the level of absenteeism of trained workers, whereas their non-trained colleagues working in the same Spanish hospital exhibited no corresponding changes over time. At team level, teams working in a Chinese leading hightechnology company reported higher creativity and productivity after being trained for cooperative teamwork and constructive controversy (Lu et al., 2010).

These results are in line with previous research showing that teams discussing their differences openly and constructively can improve decision-making processes and relational bonds, helping teams to resolve their conflicts satisfactorily and therefore being more innovative (Chen et al., 2005; Song et al., 2006), increasing their performance (Alper et al., 2000; Behfar et al., 2008; Tekleab et al., 2009; Somech et al., 2009), and preventing conflict escalation or potential negative cycles of hostilities among members (Greer et al., 2008; Leon-Perez et al., 2015). Moreover, a recent meta-analysis concluded that "Conflict processes, that is, how teams interact regarding their differences, 
are at least as important as conflict states, that is, the source and intensity of their perceived incompatibilities" (DeChurch et al., 2013, p. 559).

Thus, we hypothesize a cross-level main effect in which intragroup conflict is positively associated to burnout $(\mathrm{H} 3$ : relationship conflict $\mathrm{H} 3 \mathrm{a}$; process conflict $\mathrm{H} 3 \mathrm{~b}$; task conflict $\mathrm{H} 3 \mathrm{c}$ ) and negatively associated to perceived quality of service (H4: relationship conflict $\mathrm{H} 4 \mathrm{a}$; process conflict $\mathrm{H} 4 \mathrm{~b}$; whereas task intragroup conflict has a positive relationship with quality of service $\mathrm{H} 4 \mathrm{c}$ ). Additionally, we propose that the conflict resolution mechanism of the group (i.e., conflict management climate) buffers the positive association between intragroup conflict and burnout (H5: relationship conflict $\mathrm{H} 5 \mathrm{a}$; process conflict $\mathrm{H} 5 \mathrm{~b}$; task conflict $\mathrm{H} 5 \mathrm{c}$ ) as well as the negative association between intragroup conflict and quality of service (H6: relationship conflict $\mathrm{H} 6 \mathrm{a}$ and process conflict $\mathrm{H} 6 \mathrm{~b}$; whereas conflict management climate enhances the positive association between task intragroup conflict and quality of service: H6c).

In sum, this study seeks to contribute to the existing literature by examining the interplay between individuals' strengths and group dynamics in fostering employees' well-being and performance. In doing so, we try to overcome limitations in previous research that has tended to treat working conditions and group processes as relatively stable characteristics of an environment, often neglecting their dynamic and multilevel nature. Our hypotheses are graphically represented in Figure 1. The confirmation of these hypotheses may have relevant practical implications for developing positive and healthy organizations that prevent potential psychosocial risks at group level while promoting individual strengths.

\section{METHODS}

\section{Sample and Procedure}

After obtaining the consent of the company's CEO, data was gathered in a vehicle safety and emissions inspection company in Spain. Participation in this cross-sectional survey study was voluntary and confidential. According to the American Psychological Association's (APA) Ethical Principles of Psychologists and Code of Conduct, participants were informed about the aim of the study and requisites for participation, and all participants gave their written informed consent. Indeed, surveys were administered to groups of workers in company time with a research assistant present to answer any questions. Participants placed their completed questionnaires in a sealed box to ensure the anonymity of responses. From the 815 returned questionnaires (response rate $=61.7 \%$ ) we obtained 798 valid questionnaires. Thus, hypotheses were tested in a sample of 798 workers nested in 55 units/facilities $(M=35.87$ years old; $S D=8.49 ; 81.8 \%$ male; $94.5 \%$ permanent full-time contracts), who reported job tenure of 9.77 years $(S D=6.37)$.

\section{Measures}

\section{Psychological Capital (PsyCap)}

We used the Psychological Capital Questionnaire (Luthans et al., 2007) in its 12-items reduced version validated in Spanish (Leon-Perez et al., in press). This questionnaire measures a composite higher-order construct termed as psychological capital (PsyCap), consisting of four positive psychological states: efficacy (confidence in one's own abilities to successfully perform tasks), hope (positive subjective appraisals of goal-related capabilities), resiliency (positive coping and bouncing back from adversity), and optimism (mental attitude to interpret situations and events in a positive way). The 12 items of this questionnaire (e.g., "I feel confident analyzing a long-term problem to find a solution"; "If I should find myself in a jam at work, I could think of many ways to get out of it") were presented with a 6-point Likert-type scale $(1=$ completely disagree, $6=$ completely agree). Reliability estimated through Cronbach's Alpha was satisfactory $(\alpha=0.85)$.

\section{Intragroup Conflict}

Intragroup conflict was measured using the Intragroup Conflict Scale in its 14-item version (Jehn et al., 2008) translated into Spanish following a back-translation procedure. This scale includes three types of intragroup conflicts: task conflict or disagreements related to the content of the tasks that workers have to perform (e.g., "How much did this team have to work through disagreements about varying opinions?"), relationship conflict or disagreements about personal issues [e.g., "We disagreed about non-work (social or personality things,")] and process conflict or disagreements regarding the planning and delegation issues of task accomplishment (e.g., "How much disagreement was there about task responsibilities within this team?"). All items were rated on a 5-point Likert-type scale ranging from $1=$ "almost never" to $5=$ "very often." Reliability estimated through Cronbach's Alphas were satisfactory for all the three dimensions of the intragroup conflict: 0.89 for task, 0.85 for relationship, and 0.92 for process, respectively.

\section{Conflict Management Climate}

The existing measures of conflict management at team level lack of validation into Spanish and usually refer either to the conflict management styles the team uses to solve conflicts (e.g., cooperative vs. competitive: Somech et al., 2009; reactive vs. preemptive: Tekleab et al., 2009) or directly to the effective resolution of conflicts (e.g., conflict resolution: Greer et al., 2008) but not to both essential components for effective conflict management in teams: cooperation and effective resolution (Tjosvold, 2008). In response, we used a single item that captures employees' shared beliefs that disagreement can be discussed and intragroup conflicts are generally managed well and fairly in their unit (i.e., "In my team/unit conflict arises as in all teams everywhere; however, my team openly discusses disagreements and conflicts are effectively managed and solved").

\section{Burnout}

Burnout was measured with the Shirom-Melamed Burnout Measure (SMBM: Shirom and Melamed, 2006) in its Spanish version available from Shirom's personal website (http://www. shirom.org/arie/index.html). This measure consists of 14 items that are measured on a 7-point Likert scale (ranging from 1 $=$ never to $7=$ always) that comprise the physical (6 items: e.g., "I feel tired"), cognitive (5 items: e.g., "I have difficulty concentrating"), and emotional (3 items: e.g., "I feel I am not 


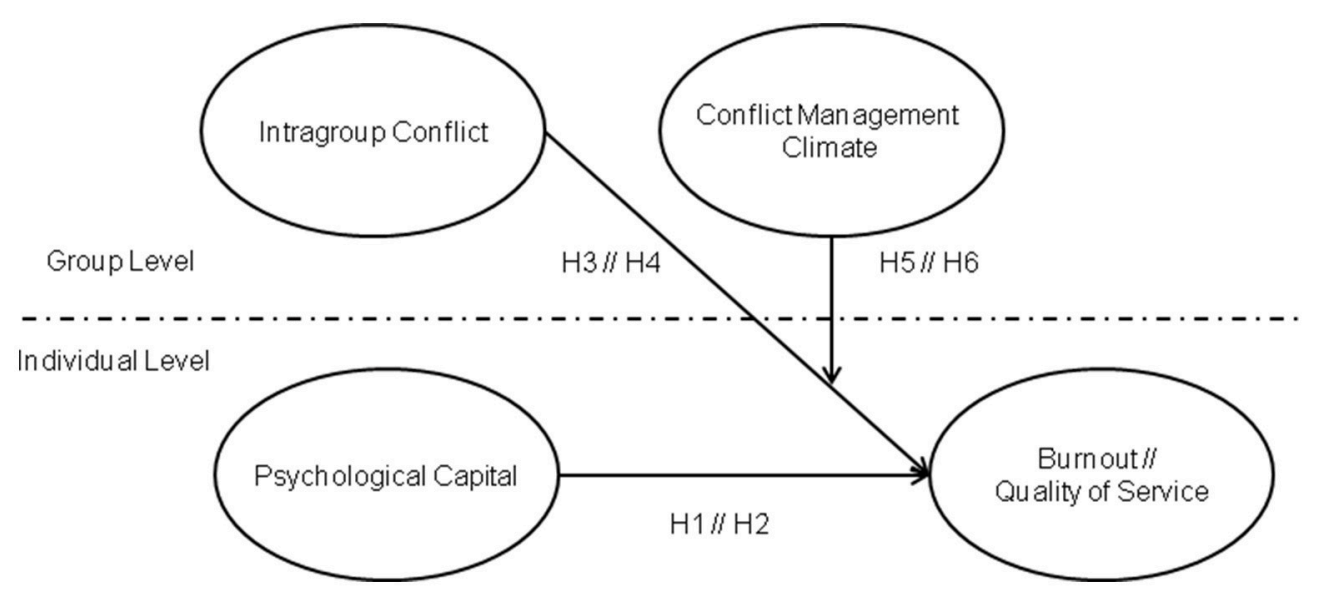

FIGURE 1 | Research model.

capable of investing emotionally in coworkers and customers") dimensions of being burned-out. Reliability estimated through Cronbach's Alpha was satisfactory $(\alpha=0.95)$.

\section{Quality of Service}

Quality of Service was measured with a self-reported 10-item questionnaire developed by Salanova et al. (2005) to measure perceived quality of service through three dimensions: service climate (e.g., "Employees in our organization have knowledge of the job and the skills to deliver superior quality work and service,") empathy (e.g., "Employees understand specific needs of customers") and excellent job performance (e.g., "Employees deliver an excellent service quality that is difficult to find in other similar organizations.") All items were scored on a 7-point rating scale ranging from 1 (completely agree) to 5 (completely disagree). Reliability estimated through Cronbach's Alpha was satisfactory $(\alpha=0.89)$.

\section{Control Variables}

Beyond socio-demographic variables such as age, sex, and job tenure, we included the Positive and Negative Affect Schedule (PANAS: Watson et al., 1988) in its Spanish version (Sandín et al., 1999) to measure participants' affect. It comprises two mood scales, one measuring positive affect and the other measuring negative affect. Each item is rated on a 5-point scale ranging from $1=$ very slightly or not at all to $5=$ extremely to indicate the extent to which the respondent usually feels this way. In this study, Cronbach's Alphas were satisfactory for both dimensions: 0.74 for positive affect, and 0.70 for negative affect, respectively. This variable was used as control since previous studies have shown its association to conflict experiences (see Griffith et al., 2014).

\section{RESULTS}

\section{Descriptives and Correlations among Variables}

First, we computed the internal consistency of each measure as well as Means, standard deviations and correlations among the main variables in this study, as shown in Table $\mathbf{1}$ for the variables at the first level of analysis (worker) and in Table 2 for the variables aggregated at the second level (units or facilities); in this second table we also include the aggregation indexes.

\section{Tests of the Hypotheses}

To test our hypotheses 1 and 3 that included burnout as an outcome or dependent variable, we employed hierarchical linear modeling (HLM), using the software SPSS. We tested a first model (Model 1) entering our control variables, namely sex, role within the company, age, as well as positive and negative affects. In Model 2 we added our first level predictor psychological capital. In Model 3 we included our second level (units or facilities) predictors, which were task conflict, relationship conflict and process conflict. This procedure is based on recent recommendations in the literature (Aguinis et al., 2013).

Table 3 reports the parameters of interest of the different models used to test Hypothesis 1 and 3. Before estimating the 3 mentioned models, we checked for the amount of variance of Burnout that is attributable to the between units/facilities differences: $13.2 \%$, a proportion worthy to be studied with a multilevel approach (Hayes, 2006).

Among the control variables, we did not find significant effects for sex, age and role within the organization. Nevertheless, positive affect was negatively related to burnout $(r=-1.08$, $p<0.01)$ while negative affect was positively related to burnout $(r=1.09, p<0.01)$. In support of hypothesis 1 , which stated a negative relationship between psychological capital and burnout, we found a significant and negative relationship $(r=-0.50$; $p<0.01)$. Regarding hypothesis $\mathrm{H} 3 \mathrm{a}$, which stated a positive effect of relationship conflict on burnout, we found a weak but worthy to be mentioned relationship $(r=0.33, p<0.10)$; however, we did not found a significant relationship either between process conflict and burnout ( $\mathrm{H} 3 \mathrm{~b}, r=-0.01, p=\mathrm{ns})$ nor between task conflict and burnout (H3c, $r=0.14, p=\mathrm{ns}$ ).

To test hypothesis H5, we allowed the slope to vary for each type of conflict and we introduced the Conflict Management 
TABLE 1 | Descriptive statistics and bivariate correlations among the level 1 variables of the study $(N=798)$.

\begin{tabular}{|c|c|c|c|c|c|c|c|c|c|c|}
\hline Variables & $M$ & $S D$ & Age & Sex & Con. & PA & NA & Psy & QoS & BN \\
\hline Age & 35.87 & 8.49 & - & & & & & & & \\
\hline Sex & 0.82 & 0.39 & -0.02 & - & & & & & & \\
\hline Contract & 0.95 & 0.23 & $-0.14^{\star \star}$ & $-0.13^{* *}$ & - & & & & & \\
\hline Pos. Aff. & 3.01 & 0.50 & $-0.21^{\star *}$ & 0.04 & $0.13^{\star \star}$ & $(0.74)$ & & & & \\
\hline Neg. Aff. & 2.17 & 0.49 & $-0.10^{\star \star}$ & $0.09^{\star}$ & 0.04 & $0.32^{\star \star}$ & $(0.70)$ & & & \\
\hline PsyCap & 4.83 & 0.59 & $-0.10^{\star \star}$ & -0.05 & $0.11^{\star \star}$ & $0.42^{\star \star}$ & $-0.12^{\star \star}$ & $(0.85)$ & & \\
\hline Qual. Serv & 3.57 & 0.68 & -0.06 & -0.07 & $0.14^{\star \star}$ & 0.31. & $-0.11^{\star \star}$ & $0.43^{* \star}$ & (0.89) & \\
\hline Burnout & 2.31 & 1.16 & 0.06 & -0.01 & 0.01 & $-0.34^{\star \star}$ & $0.32^{\star \star}$ & $-0.45^{\star \star}$ & $-0.46^{\star \star}$ & $(0.95)$ \\
\hline
\end{tabular}

reliability estimated with Cronbach's alpha is presented in the diagonal between parentheses. ${ }^{*} p<0.05,{ }^{* \star} p<0.01$.

TABLE 2 | Descriptive statistics, aggregation indexes and bivariate correlations among the level 2 variables of the study (55 units/facilities).

\begin{tabular}{|c|c|c|c|c|c|c|c|c|}
\hline Variables & $M$ & $S D$ & ICC1 & ICC2 & TC & RC & PC & $\mathrm{CMC}$ \\
\hline Task conflict & 2.15 & 0.32 & 0.132 & 0.620 & - & & & \\
\hline Relationship conflict & 1.40 & 0.28 & 0.155 & 0.662 & $0.55^{\star \star}$ & - & & \\
\hline Process conflict & 1.87 & 0.40 & 0.170 & 0.686 & $0.82^{\star \star}$ & $0.50^{\star \star}$ & - & \\
\hline $\begin{array}{l}\text { Conflict management } \\
\text { climate }\end{array}$ & 2.85 & 0.31 & 0.152 & 0.543 & $-0.33^{\star \star}$ & $-0.29^{\star \star}$ & $-0.34^{\star \star}$ & - \\
\hline
\end{tabular}

${ }^{* \star} p<0.01$.

Climate first as a predictor (Step 1) and then (Step 2) its interaction with the different type of conflicts (relationship conflict for $\mathrm{H} 5 \mathrm{a}$, process conflict for $\mathrm{H} 5 \mathrm{~b}$, and task conflict for $\mathrm{H} 5 \mathrm{c})$. However, we did not find any empirical support for $\mathrm{H} 5 \mathrm{a}$, $\mathrm{H} 5 \mathrm{~b}$ and $\mathrm{H} 5 \mathrm{c}$. For reasons of space, results have not been reported but are available under request.

A similar data analysis strategy was used for testing hypotheses 2 , 4, and 6, which included quality of service as dependent variable or outcome. First, before estimating the 3 mentioned models in an HLM analysis using SPSS, we checked for the amount of variance of quality of service that is attributable to the between units/facilities differences and found a similar value as for burnout: $11.6 \%$.

As shown in Table 4, among the control variables, we did not find significant effects for sex, age, and role within the organization. Nevertheless, positive affect was positively related to quality of service $(r=0.50, p<0.01)$ while negative affect was negatively related $(r=-0.37, p<0.01)$. In support of hypothesis $\mathrm{H} 2$, which stated a positive relationship between psychological capital and quality of service, we found a significant and positive relationship $(r=0.28 ; p<0.01)$. Regarding hypothesis $\mathrm{H} 4 \mathrm{a}$, which stated a negative effect of relationship conflict on the quality of service, we found a weak but worthy to be mentioned relationship $(r=-0.21, p<0.10)$. Similarly, hypothesis H4b was supported as we found a significant negative relationship between process conflict and quality of service $(r=-0.29, p<$ $0.05)$. However, regarding hypothesis $\mathrm{H} 4 \mathrm{c}$, which stated a positive effect of task conflict on the quality of service, we did not found a significant relationship ( $r=0.09, p=\mathrm{ns}$ ).

To test hypothesis H6, we allowed the slope to vary for each type of conflict and we introduced the Conflict Management
TABLE 3 | HLM results to test main and cross-level effects on burnout (H1, H3).

\begin{tabular}{|c|c|c|c|}
\hline & $\begin{array}{c}\text { Model } 1 \\
\text { Estimation (SE) }\end{array}$ & $\begin{array}{l}\text { Model } 2 \\
\text { Estimation (SE) }\end{array}$ & $\begin{array}{c}\text { Model } 3 \\
\text { Estimation (SE) }\end{array}$ \\
\hline Intercept & $3.08^{\star \star}(0.38)$ & $5.13(0.46)$ & $2.45(0.36)$ \\
\hline \multicolumn{4}{|l|}{ WORKER LEVEL } \\
\hline Sex & $0.05(0.18)$ & $0.05(0.16)$ & $-0.00(0.13)$ \\
\hline Age & $0.00(0.01)$ & $0.00(0.01)$ & $0.00(0.01)$ \\
\hline Role & $-0.03(0.13)$ & $-0.01(0.13)$ & $-0.09(0.09)$ \\
\hline Positive affects & $-1.08^{\star \star}(0.09)$ & $-0.80^{\star \star}(0.09)$ & $-0.81^{\star \star}(0.06)$ \\
\hline Negative affects & $1.09^{\star *}(0.09)$ & $0.93^{\star *}(0.09)$ & $0.91^{* \star}(0.09)$ \\
\hline Psychological capital & & $-0.50^{\star \star}(0.07)$ & $-0.50^{\star \star}(0.07)$ \\
\hline \multicolumn{4}{|l|}{ UNIT LEVEL } \\
\hline Relationship conflict & & & $0.33^{\dagger}(0.20)$ \\
\hline Process conflict & & & $-0.00(0.36)$ \\
\hline Task conflict & & & $0.14(0.25)$ \\
\hline \multicolumn{4}{|c|}{ ADDITIONAL INFORMATION OF THE MODEL ESTIMATION } \\
\hline-2 log likelihood (FIML) & $1640.77^{\star \star}$ & $1591.16^{\star \star}$ & $1589.27^{\star \star}$ \\
\hline $\begin{array}{l}\text { Number of estimated } \\
\text { parameters }\end{array}$ & 9 & 10 & 13 \\
\hline
\end{tabular}

$N=798$ operators nested in 55 groups/facilities. Standard errors in parentheses. ${ }^{\dagger} p<0.10 ;{ }^{* *} p<0.01$.

Climate first as a predictor (Step 1) and then (Step 2) its interaction with the different type of conflicts (relationship conflict for $\mathrm{H} 6 \mathrm{a}$, process conflict for $\mathrm{H6b}$, and task conflict for H6c). As shown in Table 5, regarding H6a the interaction was close to be significant $(r=0.07, p<0.10)$ and its inclusion in the model (Step 2) reduced the negative impact of relationship conflict on quality of service (Step 1: $r=-0.20, p<0.10$; Step 2: $r=-0.16, p=n s)$. Given that both the effect of relationship conflict on quality of service as well as the interaction were significant only at $p<0.10$, we can only affirm that we found a weak moderating effect and consequently a poor empirical support for $\mathrm{H6a}$, but still worthy to be described as a tendency. Similarly, regarding $\mathrm{H} 6 \mathrm{~b}$, the interaction was significant $(r=0.09, p<0.05)$ and reduced the negative impact of process conflict on quality of service (Step 1: $r=-0.27, p<$ 0.05 ; Step 2: $r=-0.18, p=\mathrm{ns}$ ), so we can conclude that we found empirical support for H6b. Finally, regarding H6c, there was a non-significant main or interaction effect (Step 1: $r=0.10$, 
TABLE 4 | HLM results to test main and cross-level effects on quality of service (H2, H4).

\begin{tabular}{|c|c|c|c|}
\hline & \multicolumn{3}{|c|}{ MODELS } \\
\hline & $\begin{array}{c}\text { Model } 1 \\
\text { Estimation (SE) }\end{array}$ & $\begin{array}{c}\text { Model } 2 \\
\text { Estimation (SE) }\end{array}$ & $\begin{array}{c}\text { Model } 3 \\
\text { Estimation (SE) }\end{array}$ \\
\hline Intercept & $2.52^{\star \star}(0.12)$ & $1.82(0.31)$ & $2.45(0.36)$ \\
\hline \multicolumn{4}{|l|}{ WORKER LEVEL } \\
\hline Sex & $-0.07(0.14)$ & $-0.07(0.11)$ & $-0.03(0.11)$ \\
\hline Age (centered) & $0.00(0.01)$ & $0.00(0.01)$ & $0.00(0.01)$ \\
\hline Role & $-0.09(0.09)$ & $-0.10(0.09)$ & $-0.09(0.09)$ \\
\hline Positive affects & $0.50^{\star \star}(0.05)$ & $0.35^{\star \star}(0.06)$ & $0.35^{\star \star}(0.06)$ \\
\hline Negative affects & $-0.37^{\star \star}(0.05)$ & $-0.30^{\star \star}(0.04)$ & $-0.27^{\star \star}(0.06)$ \\
\hline Psychological capital & & $0.28^{\star *}(0.04)$ & $0.27^{\star \star}(0.05)$ \\
\hline \multicolumn{4}{|l|}{ UNIT LEVEL } \\
\hline Relationship conflict & & & $-0.21^{\dagger}(0.12)$ \\
\hline Process conflict & & & $-0.29^{\star}(0.12)$ \\
\hline Task conflict & & & $0.09(0.16)$ \\
\hline \multicolumn{4}{|c|}{ ADDITIONAL INFORMATION OF THE MODEL ESTIMATION } \\
\hline-2 log likelihood (FIML) & $1188.57^{\star \star}$ & $1176.07^{\star \star}$ & $1148.52^{* \star}$ \\
\hline $\begin{array}{l}\text { Number of estimated } \\
\text { parameters }\end{array}$ & 9 & 10 & 13 \\
\hline
\end{tabular}

$N=798$ operators nested in 55 units/facilities. Standard errors in parentheses. ${ }^{\dagger} p<0.10$; ${ }^{*} p<0.05 ;{ }^{* *} p<0.01$.

$p=\mathrm{ns}$; Step 2: $r=0.16, p=\mathrm{ns})$, concluding that we found no empirical support for $\mathrm{H} 6 \mathrm{c}$.

In sum, results supported the proposed main effects of psychological capital (PsyCap) on burnout (H1) and quality of service $(\mathrm{H} 2)$ as well as cross-level main effects of intragroup conflict on burnout (H3, only for relationship conflict: H3a) and quality of service ( $\mathrm{H} 4$, for both relationship conflict and process conflict: $\mathrm{H} 4 \mathrm{a}$ and $\mathrm{H} 4 \mathrm{~b}$ ). Additionally, our results revealed that the conflict management climate of the unit did not moderate the relationship between intragroup conflict and burnout (H5), whereas the units' conflict management climate buffers the negative association between both relationship (H6a) and process conflict (H6b) and quality of service.

\section{DISCUSSION AND CONCLUSION}

This study tries to integrate the traditional approach focusing on preventing resource-depleting (negative) experiences (i.e., intragroup conflict) and the more recent positive approach focusing on facilitating resource-building (positive) experiences (i.e., conflict management climate, psychological capital) in order to improve employees' well-being and performance (i.e., decreased burnout and increased quality of service), which are considered key outcomes for developing positive and healthy organizations (PHO). In doing so, a multilevel approach is taken into consideration because represents better the integration between traditional approaches focusing on working conditions and group processes (unit level) and the positive psychology framework which emphasizes personal strengths and resources (individual level).
TABLE 5 | The moderating effect of Conflict Management Climate on the relationship between relationship, process, and task conflict on quality of service.

\begin{tabular}{lccc}
\hline & \multicolumn{3}{c}{ Hypothesis tested } \\
\cline { 2 - 4 } & H6a Step 2 & H6b Step 2 & H6c Step 2 \\
\hline Intercept & $2.32(0.46)$ & $2.45(0.36)$ & $1.89^{* *}(0.48)$ \\
INDIVIDUAL LEVEL & & & \\
Sex & $0.01(0.11)$ & $-0.00(0.13)$ & $-0.02(0.11)$ \\
Age & $0.00(0.01)$ & $0.00(0.01)$ & $0.00(0.01)$ \\
Role & $-0.09(0.09)$ & $-0.09(0.09)$ & $-0.09(0.09)$ \\
Positive affects & $0.35^{* *}(0.06)$ & $-0.81^{* *}(0.06)$ & $0.34^{* *}(0.06)$ \\
Negative affects & $-0.26^{* *}(0.06)$ & $0.91^{* *}(0.09)$ & $-0.26^{* *}(0.06)$ \\
Psychological capital & $0.26^{* *}(05)$ & $-0.50^{* *}(0.07)$ & $0.26^{* *}(05)$ \\
GROUP LEVEL & & & \\
Task conflict (TC) & $0.10(0.14)$ & $0.14(0.25)$ & $0.10(0.15)$ \\
Relationship conflict & $-0.16(0.12)$ & $0.22^{\dagger}(0.20)$ & $-0.20^{\dagger}(0.12)$ \\
(RC) & & & \\
Process conflict (PC) & $-0.13^{* *}(0.12)$ & $-0.00(0.36)$ & $-0.27^{*}(0.12)$ \\
Conf. management & $0.14(0.09)$ & $0.16(.10)$ & $0.21^{\dagger}(0.09)$
\end{tabular}

climate (CMC)

Interaction $\mathrm{CMC}^{*} \mathrm{RC} \quad \mathrm{O}^{\dagger}(0.10)$

Interaction $\mathrm{CMC}^{*} \mathrm{PC} \quad 09^{*}(.08)$

Interaction CMC ${ }^{\star}$ TC $16^{\star}(0.28)$

ADDITIONAL INFORMATION OF THE MODEL ESTIMATION

$\begin{array}{lccc}-2 \text { log likelihood (FIML) } & 1151.26^{\star \star} & 1148.64^{\star \star} & 1291.77^{\star \star} \\ \text { Number of estimated } & 14 & 14 & 12 \\ \text { parameters } & & & \end{array}$

parameters

$N=798$ operators nested in 55 units/facilities. Standard errors in parentheses. ${ }^{\dagger} p<0.10$; ${ }^{\star} p<0.05 ;{ }^{* \star} p<0.01$.

In that sense, our results revealed that PsyCap is a relevant cognitive component that has great potential for explaining key workplace outcomes such as reduced burnout and increased quality of service. This is a particularly encouraging result given the fact that PsyCap can be trained (e.g., Luthans et al., 2010; Dello Russo and Stoykova, 2015), and has therefore the potential to further overcome limitations associated to other potential interventions focusing on cognitive resources such as selfregulation mechanisms, which are considered a limited resource and a weak predictor of performance (for a meta-analysis see Sitzmann and Yeo, 2013). Thus, developing employees PsyCap may lead them to a positive psychological state of development that is not only positively related to well-being and healthrelated outcomes (e.g., lower levels of cholesterol: Luthans et al., 2013) but can also prevent distress at work (i.e., reduced burnout). According to the stress appraisal theory (Lazarus and Folkman, 1984), the stressor-strain relationship is determined by individuals' evaluation of both the situation (primary appraisal: the significance of what is happening for their well-being) and their perception of having available coping resources to manage such situation (secondary appraisal: coping options). Drawing on such theory, PsyCap can help employees to perceive their working demands as challenging instead of potentially harmful (primary appraisal guided by their optimism and hope) as well as their self-efficacy and resilience may lead them to consider 
that they can effectively cope with such demands at work, experiencing more positive than negative emotions such as anxiety or fear and therefore reducing psychological distress.

In addition, PsyCap is associated to improved quality of service. This result can be related to the previous one: PsyCap is associated to reduced burnout. In that sense, in line with "the happy-productive worker hypothesis" (Wright et al., 2007), Taris and Schreurs (2009) argued that burnout impedes performance because "high levels of emotional fatigue result in being unable as well as being unwilling to perform well" ( $p$. 123). Thus, PsyCap can enhance performance because allow employees to experience positive emotions and reduced distress. Complementarily, Fredrickson (2001) suggests that positive emotions function to "broaden and build" skills and social capital, likely improving job performance and quality of service in social contexts such as work designs based on collaborative teams. Thus, employees with high PsyCap may deliver a higher quality of service because they experience more positive emotions, are more motivated and may expend more effort to perform well, which is in line with previous findings on the relationship between PsyCap and job performance at individual level (Avey et al., 2011).

Regarding the role of intragroup conflict, results revealed that only conflict about personal issues or relationship conflict is positively associated to burnout. This is in line with previous findings on conflict literature about the negative effects of relationship conflicts within the workplace. For example, Meier et al. (2013), in a daily diary study involving more than 4300 observations from 131 participants, found that daily relationship conflict predicted anger and well-being until the next day when task conflict was low, whereas task conflict was not related to anger and well-being. Similarly, from a conflict escalation perspective, several authors have found an association between relationship conflict and negative emotional reactions that lead to increased behaviors of mutual hostility that are part of conflict escalation (e.g., De Dreu and Van Vianen, 2001; Benítez et al., 2012; Arenas et al., 2015). Indeed, there is consensus about the negative effects of relationship conflict on employees' health and well-being since it usually implies more negative emotions such as anxiety, irritability, frustration, or tension compare to process and task-related conflict (for a meta-analysis see De Dreu and Weingart, 2003; de Wit et al., 2012). This can also explain why results did not reveal a moderation effect of conflict management climate on the association between relationship conflict and burnout: when conflict is about personal issues is more complex to manage and de-escalate to more productive levels (e.g., Arenas et al., 2015), resulting in impaired well-being. In contrast, neither task nor process conflict at team level was associated with burnout at individual level. Consequently, the existing conflict management climate did not show any moderation effect. A plausible explanation for these results is that such types of conflicts are usually associated with lower levels of tension and anxiety (i.e., are less stressful) compared to relationship conflicts, and therefore have non-significant associations with burnout, which can be considered as a long-term stress response.

On the other hand, as expected, results highlight that although relationship and process conflict can be detrimental to the quality of service that teams provide (de Wit et al., 2012), conflict management climate buffers the negative impact of both relationship and process conflict on such quality of service. Considering that positive psychology applied to organizational contexts "seek to identify the role of organizational climate and human resource practices (e.g., selection, socialization and norms, social capital, social contagion) in fostering authenticity, continuous self-improvement, and sustained performance" (Roberts, 2006, p. 293), these results open a new interesting research avenue by showing that fostering a positive climate of conflict management (i.e., open discussion of disagreements and effective resolution of conflict) can improve job performance (see also Chen et al., 2005; Greer et al., 2008; Leon-Perez et al., 2016). However, our results did not support that the existing conflict management climate in the team can enhance the positive association between task intragroup conflict and the quality of service they provide. Indeed, there was no association between task conflict and quality of service. Thus, future research should examine the role of team processes (e.g., collaboration, competition or openness: DeChurch et al., 2013; team cohesion and identity: Tekleab et al., 2009) in determining the positive or negative effects of task conflict for individual well-being and team performance. Moreover, following the positive resource caravans and gain spirals at work proposed in the Conservation of Resources (COR) theory, which assumes that various resources are salient factors in gaining new resources and enhancing well-being (Hobfoll, 1989, 2001, 2002), future research should test whether a constructive conflict management climate in the team can be considered as a team resource that not only prevents potential negative consequences of intragroup conflict on performance, but also improves relevant team processes that have potential positive consequences on team performance and viability.

Despite the above mentioned theoretical and practical implications, our study also presents some limitations. First, besides being a large and multilevel sample, we employed a cross-sectional research design; therefore future research should reply our results employing a longitudinal or cross-lagged research design. Second, regarding the measurement of conflict management climate (although we have several validity pieces of evidence; for example the bivariate correlations with the three types of conflict) we just employed a single item measure, which can explain the weak (or non-existing) moderation effect of conflict management climate. Future studies should use validated scales for measuring both conflict resolution and openness to discuss disagreements at team level. Third, like most survey-based study, our performance (quality of service) measure is perceptual in its nature and may be affected by social desirability. Further research may benefit from including objective performance indicators that combined with those perceptual will offer a more robust view of our findings.

In sum, although these results need caution since our study is not exempt from limitations, this study offers some insights into the interplay of individual resources and group dynamics, suggesting that interventions aimed both at developing individual psychological strengths and at improving group dynamics such as conflict resolution can have a 
positive impact on employees' well-being and performance, which are considered key indicators of positive and health organizations.

\section{AUTHOR CONTRIBUTIONS}

JMLP participated in the study design and wrote the first draft. MA conducted the data analysis and wrote the results section. JMLR designed the study and collected the data. All wrote and

\section{REFERENCES}

Aguinis, H., Gottfredson, R. K., and Culpepper, S. A. (2013). Best-practice recommendations for estimating cross-level interaction effects using multilevel modeling. J. Manage 39, 1490-1528. doi: 10.1177/0149206313478188

Alper, S., Tjosvold, D., and Law, K. S. (2000). Conflict management, efficacy, and performance in organizational teams. Pers. Psychol. 53, 625-642. doi: 10.1111/j.1744-6570.2000.tb00216.x

Arenas, A., Leon-Perez, J. M., Munduate, L., and Medina, F. J. (2015). Workplace bullying and interpersonal conflicts: the moderation effect of supervisor's power. Revista de Psicol. Soc. 30, 295-322. doi: 10.1080/21711976.2015. 1016753

Avey, J. B., Luthans, F., Smith, R. M., and Palmer, N. F. (2010). Impact of positive psychological capital on employee well-being over time. J. Occup. Health Psychol. 15, 17-28. doi: 10.1037/a0016998

Avey, J. B., Reichard, R. J., Luthans, F., and Mhatre, K. H. (2011). Meta-analysis of the impact of positive psychological capital on employee attitudes, behaviors, and performance. Hum. Resour. Dev. Q. 22, 127-152. doi: 10.1002/hrdq.20070

Avey, J. B., Wernsing, T. S., and Luthans, F. (2008). Can positive employees help positive organizational change? Impact of psychological capital and emotions on relevant attitudes and behaviors. J. Appl. Behav. Sci. 44, 48-70. doi: $10.1177 / 0021886307311470$

Bakker, A., and Schaufeli, W. B. (2008). Positive organizational behavior: engaged employees in flourishing organizations. J. Organ. Behav. 29, 147-154. doi: 10.1002/job.515

Baron, R. A., Franklin, R. J., and Hmieleski, K. M. (2016). Why entrepreneurs often experience low, not high, levels of stress. The joint effects of selection and psychological capital. J. Manag. 42, 742-768. doi: 10.1177/0149206313495411

Behfar, K. J., Peterson, R. S., Mannix, E. A., and Trochim, W. M. (2008). The critical role of conflict resolution in teams: a close look at the links between conflict type, conflict management strategies, and team outcomes. J. Appl. Psychol. 93, 170-188. doi: 10.1037/0021-9010.93.1.170

Benítez, M., Medina, F. J., and Munduate, L. (2012). La gestión de conflictos relacionales en las organizaciones de servicios [The management of relationship conflicts in service organizations]. Anales de Psicol. 28, 139-149.

Bono, J. E., Glomb, T. M., Shen, W., Kim, E., and Koch, A. J. (2013). Building positive resources: effects of positive events and positive reflection on work stress and health. Acad. Manag. J. 56, 1601-1627. doi: 10.5465/amj.2011.0272

Bradley, B. H., Postlethwaite, B. E., Klotz, A. C., Hamdani, M. R., and Brown, K. G. (2012). Reaping the benefits of task conflict in teams: the critical role of team psychological safety climate. J. Appl. Psychol. 97, 151-158. doi: $10.1037 / \mathrm{a} 0024200$

Carver, C. S., and Scheier, M. F. (2014). Dispositional optimism. Trends Cogn. Sci. (Regul. Ed). 18, 293-299. doi: 10.1016/j.tics.2014.02.003

Chen, G., Liu, C., and Tjosvold, D. (2005). Conflict management for effective top management teams and innovation in China. J. Manag. Stud. 42, 277-300. doi: 10.1111/j.1467-6486.2005.00497.x

Cheung, F., Tang, C. S., and Tang, S. (2011). Psychological capital as a moderator between emotional labor, burnout, and job satisfaction among school teachers in China. Int. J. Stress Manag. 18, 348-371. doi: 10.1037/a0025787

Cooper, C. L., and Cartwright, S. (1994). Healthy mind; healthy organization-A proactive approach to occupational stress. Hum. Relations 47, 455-471. doi: $10.1177 / 001872679404700405$ revised the manuscript and agreed on the final version submitted to the journal.

\section{FUNDING}

This research was funded through a research contract (Ref. 1768/0281). Authors would like to thank Mind Garden and Dr. Fred Luthans for their permission to use the PsyCap questionnaire, which is copyrighted material (see www. mindgarden.com).

Culbertson, S. S., Fullagar, C. J., and Mills, M. J. (2010). Feeling good and doing great: the relationship between psychological capital and well-being. J. Occup. Health Psychol. 15, 421-433. doi: 10.1037/a0020720

Day, A., and Randell, K. D. (2014). "Building a foundation for psychologically healthy workplaces and well-being," in Workplace Well-being: How to Build Psychologically Healthy Workplaces, eds A. Day, E. K. Kelloway, and J. J. Hurrell Jr. (New York, NY: Wiley-Blackwell), 3-26.

DeChurch, L. A., Mesmer-Magnus, J. R., and Doty, D. (2013). Moving beyond relationship and task conflict: toward a process-state perspective. J. Appl. Psychol. 98, 559-578. doi: 10.1037/a0032896

De Dreu, C. K., and Van Vianen, A. E. (2001). Managing relationship conflict and the effectiveness of organizational teams. J. Organ. Behav. 22, 309-328. doi: 10.1002/job.71

De Dreu, C. K., and Weingart, L. R. (2003). Task versus relationship conflict, team performance, and team member satisfaction: a meta-analysis. J. Appl. Psychol. 88, 741-749. doi: 10.1037/0021-9010.88.4.741

Dello Russo, S., and Stoykova, P. (2015). Psychological Capital Intervention (PCI): a replication and extension. Hum. Resour. Dev. Q. 26, 329-347. doi: 10.1002/hrdq. 21212

Deutsch, M., and Coleman, P. T. (2000). The Handbook of Conflict Resolution: Theory and Practice. San Francisco, CA: Jossey-Bass Publishers.

de Wit, F. R., Greer, L. L., and Jehn, K. A. (2012). The paradox of intragroup conflict: a meta-analysis. J. Appl. Psychol. 97, 360-390. doi: 10.1037/a0024844

Dijkstra, M. T., Beersma, B., and Evers, A. (2011). Reducing conflict-related employee strain: the benefits of an internal locus of control and a problem-solving conflict management strategy. Work Stress 25, 167-184. doi: 10.1080/02678373.2011.593344

Dijkstra, M. T., De Dreu, C. K., Evers, A., and van Dierendonck, D. (2009). Passive responses to interpersonal conflict at work amplify employee strain. Eur. J. Work Organ. Psychol. 18, 405-423. doi: 10.1080/13594320802 510880

Ding, Y., Yang, Y., Yang, X., Zhang, T., Qiu, X., and Sui, H., (2015). The Mediating Role of Coping Style in the Relationship between Psychological Capital and Burnout among Chinese Nurses. PLoS ONE 10:e0122128. doi: 10.1371/journal.pone.0122128

Einarsen, S., Skogstad, A., Rørvik, E., Lande, Å. B., and Nielsen, M. B. (2016). Climate for conflict management, exposure to workplace bullying and work engagement: a moderated mediation analysis. Int. J. Hum. Resour. Manag. 1-22. doi: 10.1080/09585192.2016.1164216

Fineman, S. (2006). On being positive: concerns and counterpoints. Acad. Manag. Rev. 31, 270-291. doi: 10.5465/AMR.2006.20208680

Folkman, S., and Moskowitz, J. T. (2000). Positive affect and the other side of coping. Am. Psychol. 55, 647-654. doi: 10.1037/0003-066X.55.6.647

Fredrickson, B. L. (2001). The role of positive emotions in positive psychology: the broaden-and-build theory of positive emotions. Am. Psychol. 56, 218-226. doi: 10.1037/0003-066X.56.3.218

Gamero, N., González-Romá, V., and Peiró, J. (2008). The influence of intrateam conflict on work teams' affective climate: a longitudinal study. J. Occup. Organ. Psychol. 81, 47-69. doi: 10.1348/096317907X180441

Gilbert, S., and Kelloway, E. K. (2014). "Positive psychology and the healthy workplace," in Workplace Well-being: How to Build Psychologically Healthy Workplaces, eds A. Day, E. K. Kelloway, and J. J. Hurrell Jr. (New York, NY: Wiley-Blackwell), 50-72. 
Grawitch, M. J., Gottschalk, M., and Munz, D. C. (2006). The path to a healthy workplace: a critical review linking healthy workplace practices, employee well-being, and organizational improvements. Consult. Psychol. J. 58, 129-147. doi: 10.1037/1065-9293.58.3.129

Greer, L. L., Jehn, K. A., and Mannix, E. A. (2008). Conflict transformation a longitudinal investigation of the relationships between different types of intragroup conflict and the moderating role of conflict resolution. Small Group Res. 39, 278-302. doi: 10.1177/1046496408317793

Griffith, J. A., Connelly, S., and Thiel, C. E. (2014). Emotion regulation and intragroup conflict: when more distracted minds prevail. Int. J. Confl. Manag. 25, 148-170. doi: 10.1108/IJCMA-04-2012-0036

Hackman, J. R. (2009). The perils of positivity. J. Organ. Behav. 30, 309-319. doi: $10.1002 /$ job.587

Hayes, A. F. (2006). A primer on multilevel modeling. Hum. Commun. Res. 32, 385-410. doi: 10.1111/j.1468-2958.2006.00281.x

Hobfoll, S. E. (1989). Conservation of resources: a new attempt at conceptualizing stress. Am. Psychol. 44, 513-524. doi: 10.1037/0003-066X.44.3.513

Hobfoll, S. E. (2001). The influence of culture, community, and the nested-self in the stress process: advancing conservation of resources theory. Appl. Psychol. 50, 337-370. doi: 10.1111/1464-0597.00062

Hobfoll, S. E. (2002). Social and psychological resources and adaptation. Rev. Gen. Psychol. 6, 307-324. doi: 10.1037/1089-2680.6.4.307

Jehn, K. A. (1997). A qualitative analysis of conflict types and dimensions in organizational groups. Adm. Sci. Q. 530-557. doi: 10.2307/2393737

Jehn, K. A., Greer, L., Levine, S., and Szulanski, G. (2008). The effects of conflict types, dimensions, and emergent states on group outcomes. Group Decis. Negot. 17, 465-495. doi: 10.1007/s10726-008-9107-0

Jehn, K. A., and Mannix, E. A. (2001). The dynamic nature of conflict: a longitudinal study of intragroup conflict and group performance. Acad. Manag. J .44, 238-251. doi: 10.2307/3069453

Joseph, D. L., and Newman, D. A. (2010). Emotional intelligence: an integrative meta-analysis and cascading model. J. Appl. Psychol. 95, 54-78. doi: $10.1037 / \mathrm{a} 0017286$

Keenan, A., and Newton, T. J. (1985). Stressful events, stressors and psychological strains in young professional engineers. J. Organ. Behav. 6, 151-156. doi: 10.1002/job.4030060206

Laschinger, H. K. S., and Fida R. (2014). A time-lagged analysis of the effect of authentic leadership on workplace bullying, burnout, and occupational turnover intentions. Eur. J. Work Organ. Psychol. 23, 739-753.

Lazarus, R. S., and Folkman, S. (1984). Stress, Appraisal, and Coping. New York, NY: Springer.

Leon-Perez, J. M., Antino, M., and Leon-Rubio, J. M. (in press). Adaptation of the short version of the Psychological Capital Questionnaire (PCQ-12) into Spanish. Revista de Psicol. Soc. 32.

Leon-Perez, J. M., Medina, F. J., Arenas, A., and Munduate, L. (2015). The relationship between interpersonal conflict and workplace bullying. J. Manag. Psychol. 30, 250-263. doi: 10.1108/JMP-01-2013-0034

Leon-Perez, J. M., Notelaers, G., and Leon-Rubio, J. M. (2016). Assessing the effectiveness of conflict management training in a health sector organisation: evidence from objective indicators. Eur. J. Work Organ. Psychol. 25, 1-12. doi: 10.1080/1359432X.2015.1010520

Li, X., Kan, D., Liu, L., Shi, M., Wang, Y., and Wu, H., (2015). The mediating role of psychological capital on the association between occupational stress and job burnout among bank employees in china. Int. J. Environ. Res. Public Health 12, 2984-3001. doi: 10.3390/ijerph120302984

Lu, J. F., Tjosvold, D., and Shi, K. (2010). Team training in china: testing and applying the theory of cooperation and competition. J. Appl. Soc. Psychol. 40, 101-134. doi: 10.1111/j.1559-1816.2009.00565.x

Luthans, F., Avey, J. B., Avolio, B. J., and Peterson, S. J. (2010). The development and resulting performance impact of positive psychological capital. Hum. Resour. Dev. Q. 21, 41-67. doi: 10.1002/hrdq.20034

Luthans, F., Avolio, B. J., Avey, J. B., and Norman, S. M. (2007). Psychological capital: measurement and relationship with performance and satisfaction. Pers. Psychol. 60, 541-572. doi: 10.1111/j.1744-6570.2007.00083.x

Luthans, F., Youssef, C. M., Sweetman, D. S., and Harms, P. D. (2013). Meeting the leadership challenge of employee well-being through relationship PsyCap and Health PsyCap. J. Leadersh. Organ. Stud. 20, 118-133. doi: $10.1177 / 1548051812465893$
Luthans, F., Youssef-Morgan, C. M., and Avolio, B. J. (2015). Psychological Capital and Beyond. New York, NY: Oxford University Press.

Lyubomirsky, S., King, L., and Diener, E. (2005). The benefits of frequent positive affect: does happiness lead to success? Psychol. Bull. 131, 803-855. doi: 10.1037/0033-2909.131.6.803

Meier, L. L., Gross, S., Spector, P. E., and Semmer, N. K. (2013). Relationship and task conflict at work: interactive short-term effects on angry mood and somatic complaints. J. Occup. Health Psychol. 18, 144-156. doi: 10.1037/a0032090

Meier, L. L., Semmer, N. K., and Gross, S. (2014). The effect of conflict at work on well-being: depressive symptoms as a vulnerability factor. Work Stress 28, 31-48. doi: 10.1080/02678373.2013.876691

Ong, A. D., Bergeman, C. S., Bisconti, T. L., and Wallace, K. A. (2006). Psychological resilience, positive emotions, and successful adaptation to stress in later life. J. Pers. Soc. Psychol. 91, 730-749. doi: 10.1037/0022-3514. 91.4.730

Peterson, S. J., Luthans, F., Avolio, B. J., Walumbwa, F. O., and Zhang, Z. (2011). Psychological capital and employee performance: a latent growth modeling approach. Pers. Psychol. 64, 427-450. doi: 10.1111/j.1744-6570.2011.01215.x

Roberts, L. M. (2006). Shifting the lens on organizational life: the added value of positive scholarship. Acad. Manag. Rev. 31, 292-305. doi: 10.5465/AMR.2006.20208681

Rust, R. T., Moorman, C., and Dickson, P. R. (2002). Getting return on quality: revenue expansion, cost reduction, or both? J. Mark. 66, 7-24. doi: 10.1509/jmkg.66.4.7.18515

Salanova, M., Agut, S., and Peiro, J. M. (2005). Linking organizational resources and work engagement to employee performance and customer loyalty: the mediation of service climate. J. Appl. Psychol. 90, 1217-1227. doi: 10.1037/00219010.90.6.1217

Sandín, B., Chorot, P., Lostao, L., Joiner, T. E., Santed, M. A., and Valiente, R. M. (1999). Escalas PANAS de afecto positivo y negativo: validación factorial $\mathrm{y}$ convergencia transcultural [The PANAS scales of positive and negative affect: factor analytic validation and cross-cultural convergence]. Psicothema 11, 37-51.

Seligman, M. E. P., and Csikszentmihalyi, M. (2000). Positive psychology: an introduction. Am. Psychol. 55, 5-14. doi: 10.1037/0003-066X.55.1.5

Shirom, A., and Melamed, S. (2006). A comparison of the construct validity of two burnout measures in two groups of professionals. Int. J. Stress Manag. 13, 176-200. doi: 10.1037/1072-5245.13.2.176

Sitzmann, T., and Yeo, G. (2013). A meta-analytic investigation of the withinperson self-efficacy domain: is self-efficacy a product of past performance or a driver of future performance? Pers. Psychol. 66, 531-568. doi: 10.1111/peps.12035

Somech, A., Desivilya, H. S., and Lidogoster, H. (2009). Team conflict management and team effectiveness: the effects of task interdependence and team identification. J. Organ. Behav. 30, 359-378. doi: 10.1002/job.537

Song, M., Dyer, B., and Thieme, R. J. (2006). Conflict management and innovation performance: an integrated contingency perspective. J. Acad. Market. Sci. 34, 341-356. doi: 10.1177/0092070306286705

Spector, P. E., and Jex, S. M. (1998). Development of four self-report measures of job stressors and strain: interpersonal conflict at work scale, organizational constraints scale, quantitative workload inventory, and physical symptoms inventory. J. Occup. Health Psychol. 3, 356-367. doi: 10.1037/1076-8998. 3.4 .356

Stajkovic, A. D., and Luthans, F. (1998). Self-efficacy and work-related performance: a meta-analysis. Psychol. Bull. 124, 240-261. doi: 10.1037/00332909.124.2.240

Taris, T. W., and Schreurs, P. J. (2009). Well-being and organizational performance: an organizational-level test of the happy-productive worker hypothesis. Work Stress 23, 120-136. doi: 10.1080/026783709030 72555

Tekleab, A. G., Quigley, N. R., and Tesluk, P. E. (2009). A longitudinal study of team conflict, conflict management, cohesion, and team effectiveness. Group Organ. Manag. 34, 170-205. doi: 10.1177/1059601108331218

Tjosvold, D. (2008). The conflict-positive organization: it depends upon us. J. Organ. Behav. 29, 19-28. doi: 10.1002/job.473

Tjosvold, D., Chen, N. Y., Huang, X., and Xu, D. (2014). Developing cooperative teams to support individual performance and well-being in a call center in China. Group Decis. Negot. 23, 325-348. doi: 10.1007/s10726-012-9314-6 
Watson, D., Clark, L. A., and Tellegen, A. (1988). Development and validation of brief measures of positive and negative affect: the PANAS scales. J. Pers. Soc. Psychol. 54, 1063-1070. doi: 10.1037/0022-3514.54.6.1063

Williams, P., Kern, M. L., and Waters, L. (2015). A longitudinal examination of the association between psychological capital, perception of organizational virtues and work happiness in school staff. Psychol. Well Being 5, 1-18. doi: 10.1186/s13612-015-0032-0

Wood, A. M., Linley, P. A., Maltby, J., Kashdan, T. B., and Hurling, R. (2011). Using personal and psychological strengths leads to increases in well-being over time: a longitudinal study and the development of the strengths use questionnaire. Pers. Individ. Dif. 50, 15-19. doi: 10.1016/j.paid.2010.08.004

Wright, T. A., Cropanzano, R., and Bonett, D. G. (2007). The moderating role of employee positive well being on the relation between job satisfaction and job performance. J. Occup. Health Psychol. 12, 93-104. doi: 10.1037/10768998.12.2.93

Conflict of Interest Statement: The authors declare that the research was conducted in the absence of any commercial or financial relationships that could be construed as a potential conflict of interest.

Copyright (C) 2016 Leon-Perez, Antino and Leon-Rubio. This is an open-access article distributed under the terms of the Creative Commons Attribution License (CC BY).

The use, distribution or reproduction in other forums is permitted, provided the original author(s) or licensor are credited and that the original publication in this journal is cited, in accordance with accepted academic practice. No use, distribution or reproduction is permitted which does not comply with these terms. 


\title{
The Challenge of Fostering Healthy Organizations: An Empirical Study on the Role of Workplace Relational Civility in Acceptance of Change and Well-Being
}

\author{
Annamaria Di Fabio ${ }^{1 *}$, Marco Giannini ${ }^{2}$, Yura Loscalzo ${ }^{2}$, Letizia Palazzeschi ${ }^{1}$, \\ Ornella Bucci ${ }^{1}$, Andrea Guazzini ${ }^{3}$ and Alessio Gori ${ }^{1}$
}

${ }^{1}$ Department of Education and Psychology (Psychology Section), University of Florence, Italy, ${ }^{2}$ Department of Health Science, University of Florence, Italy, ${ }^{3}$ Department of Education and Psychology (Psychology Section), Centre for the Study of Complex Dynamics, University of Florence, Florence, Italy

\section{OPEN ACCESS}

Edited by:

Radha R. Sharma,

Management Development Institute,

India

Reviewed by:

J. Goosby Goosby Smith,

Citadel, USA

Catherine S. Daus,

Southern Illinois University

Edwardsville, USA

*Correspondence:

Annamaria Di Fabio

adifabio@psico.unifi.it

Specialty section: This article was submitted to

Organizational Psychology,

a section of the journal

Frontiers in Psychology

Received: 30 May 2016 Accepted: 24 October 2016 Published: 21 November 2016

Citation:

Di Fabio A, Giannini M, Loscalzo Y, Palazzeschi L, Bucci O, Guazzini A and Gori $A$ (2016) The Challenge of Fostering Healthy Organizations: An

Empirical Study on the Role of

Workplace Relational Civility in

Acceptance of Change and

Well-Being. Front. Psychol. 7:1748.

doi: 10.3389/fpsyg.2016.01748
The world of work in the twenty-first century is characterized by globalization, instability, and unavoidable change. Organizations need to develop a positive relational environment in the workplace thereby enabling workers to enhance their personal resources in order to face with on-going changes in the sphere of work for promoting their well-being. Against this background, the aim of this research was to examine the relationship between workplace relational civility and both acceptance of change and well-being (hedonic well-being as well as eudaimonic well-being) beyond the effect of personality traits. The following instruments were administered to 261 Italian workers: the Ten Item Personality Inventory (TIPI), the Acceptance of Change Scale (ACS), the Satisfaction With Life Scale (SWLS), and the Meaningful Life Measure (MLM). The results of hierarchical regression analyses revealed that workplace relational civility explained a percentage of incremental variance beyond personality traits in relation to acceptance of change, life satisfaction, and meaning in life. These results underscore the positive relationship between workplace relational civility and acceptance of change, hedonic well-being, and eudaimonic wellbeing, offering new research and intervention opportunities to meet the challenge of fostering healthy organizations.

Keywords: positive healthy organizations, healthy business, workplace relational civility, acceptance of change, hedonic and eudaimonic well-being

\section{INTRODUCTION}

The world of work in the twenty-first century is characterized by globalization, instability, and unavoidable change (Savickas, 2011; Guichard, 2013). In this postmodern era, work and well-being play a key role in the health of individuals, and it is important to verify here the effect of a negative working place on the health and well-being of workers (Sparks et al., 2001; Arenas et al., 2015; Giorgi et al., 2015, 2016; Mucci et al., 2016). The insecurity of the current world of work highlights the need to promote "healthy organizations" from a primary prevention point of view (Hage et al., 2007; Kenny and Hage, 2009; Di Fabio and Kenny, 2015; Di Fabio and Gori, 2016b). The concept of healthy organizations is in line with the most recent definition of health of the World Health Organization (1998) that replaced the old definition that stated that health was simply the absence of disease. The most recent 
definition noted that "health is a state of complete physical, mental, spiritual and social well-being and not merely the absence of disease or infirmity" (World Health Organization, 1998). Starting from this definition, the World Health Organization (2007) underlined the importance for organizations of developing a culture of health in the world of work both for the well-being of workers and for the health of organizations starting from a primary prevention point of view.

A focus on healthy people and healthy organizations is introduced (Macik-Frey et al., 2007; World Health Organization, 2007). Healthy people deal with many challenges in the world of work and in general have satisfying and productive work and personal lives. Flourishing, resilience, and the ability to adapt themselves to environment, characterize healthy people. Starting from a point of view that initially characterized health as the absence of diseases (biomedical perspective), the concept of work has been broadening to examine positive work environment factors (humanistic perspective) for employee health, well-being and performance (Macik-Frey et al., 2007; Raya and Panneerselvam, 2013). Thus, attention to healthy people as flourishing and resilient workers is paid as well as the role of a positive work environment in promoting employee health, in terms of well-being and good performance within an organizational positive psychology perspective (Di Fabio, 2014a; Snyder et al., 2014; Di Fabio and Kenny, 2015; Di Fabio and Gori, 2016b). The positive psychology perspective (Seligman and Csikszentmihalyi, 2000; Seligman, 2002) is a recent framework characterized by emphasis on resources and on positive functioning rather than on negative functioning. This change of focus highlights the importance of gainful employment and life (Di Fabio, 2014a, 2015b; Snyder et al., 2014) for oneself and for the organization too, supporting one's own family, for a safe work environment, for job satisfaction, and for engagement with and creating a sense of belonging to the organization and healthy business. The following factors are essential in an organizational positive psychology framework: satisfaction with one's work, the development of talents and skills, and positive interpersonal relationships (Snyder et al., 2014; Di Fabio, 2014a). The value of such a framework (Seligman, 2002; Seligman and Csikszentmihalyi, 2000) is that it increases the quality of working life and organizational effectiveness and concentrates on the importance of enhancing individual resources (Boyatzis et al., 2002; Di Fabio, 2006, 2015a; Boyatzis and Saatcioglu, 2008; Boyatzis, 2009; Di Fabio and Kenny, 2012, 2015, 2016a,b; Di Fabio and Maree, 2012; Di Fabio and Palazzeschi, 2012a; Di Fabio et al., 2012, 2013; Sartori et al., 2013; Di Fabio and Saklofske, 2014a,b; Boyatzis et al., 2015; Di Fabio and Bucci, 2015 , 2016). The enhancement of individual resources impacts directly and indirectly on the professional life of individuals and the quality of work they produce. Furthermore, the quality of work seems to be associated with the quality of relationships in the workplace, highlighting the importance of such relationships in the overall life context (Blustein, 2011; Richardson, 2012). Positive organizational psychology thus underscores the need to develop positive and supportive relationships in the workplace (Blustein, 2011; Snyder et al., 2014; Di Fabio, 2015b).
The positive organizational psychology framework contains the idea of a healthy organization linked to the concept of "performance and health" (De Smet et al., 2007). Healthy organizations promote healthy business, relying on the importance of the health of individuals for organizational success in a framework characterized by a close connection between workers' well-being, organizational well-being and effective functioning (Di Fabio and Blustein, 2016a,b). A healthy organization can be defined as "one whose culture, climate and practices create an environment that promotes employee health and safety as well as organizational effectiveness" (Lowe, 2010; Ceschi et al., 2014). A healthy organization is conducive to healthy business, namely successful business (Grawitch and Ballard, 2016). Healthy business regards also the strong association between organizational profitability and workers' well-being (Raya and Panneerselvam, 2013; Arnoux-Nicolas et al., 2016). New ways of promoting good organizational relationships, including relationality (Blustein, 2011) and respectivity (Maree, 2012), can lead to healthy organizations (Di Fabio, 2014a, 2015b; Di Fabio and Kenny, 2016a). These relationships are fundamental aspects of people's lives with their focus on respect and care for oneself and for others (Di Fabio, 2014a, 2015b). This focus promotes flourishing relationships from a positive perspective and underscores the importance of a positive balance between "me," "us," "organization," "people," and "the world" (Snyder et al., 2014; Di Fabio, 2016a). This can be very useful in the construction of a new stage of social and human development marked by organizational and community maturity (Di Fabio, 2014a) characterized not simply by swinging between an egocentric position (centered on me) and an allocentric position (centered on others) but reaching a polycentric position (for mutually gain, for others and for myself) that asks for connectedness centered on reflexivity (Di Fabio, 2016a) and for the new paradigm of meaning (Di Fabio and Blustein, 2016a,b).

The following constructs are important in healthy organizations: prosocial organizational behavior (McNeely and Meglino, 1994), organizational citizenship behavior (Podsakoff et al., 1990), organizational support (Eisenberger et al., 1990), workplace civility (Di Fabio, 2015c), and workplace relational civility (WRC, Di Fabio and Gori, 2016b). This last construct refers to a new form of relational style in the workplace "characterized by respect and concern for oneself and others, interpersonal sensitivity, personal education, and kindness toward others. It also includes civil behaviors such as treating others with dignity and respecting social norms to facilitate peaceful and productive cohabitation" (Di Fabio and Gori, 2016b, p. 2). The workplace relational civility construct has three dimensions: Relational decency (RD) at work: decency-based relationships, characterized by respect for the self and others, assertiveness, ability to express convictions, and relational capacity; Relational culture $(\mathrm{RCu})$ at work: politeness, kindness, good education, courteousness; Relational readiness (RR) at work: sensibility toward others (speed in understanding the feelings of others and showing proactive sensibility), ability to read the emotions of others, concern for others, delicacy, attention to the reactions of others, empathy, and compassion. 
In particular, in comparison to the construct of emotional intelligence (EI), RR is a dimension of Workplace Relational Civility construct that refers to behavior in the workplace that is decent, prosocial, polite, careful, and that involves relational style patterns in line with one's involvement with others. RR in particular regards the understanding of the emotions of others quickly and easily, to demonstrate delicacy, empathy, compassion, and attention to their reactions. WRC thereby represents a larger construct that includes EI (Di Fabio and Gori, 2016b). Although, the academically accepted standard view of EI is as an ability model, we must acknowledge that there are other types of EI that are purported in the literature (Mayer et al., 2008; Stough et al., 2009). In the literature there are two main approaches to defining and measuring EI (Stough et al., 2009): EI as ability-based (Mayer and Salovey, 1997) and EI as trait-based self-report (Bar-On, 1997; Petrides and Furnham, 2000, 2001; Di Fabio et al., 2016).

The WRC can be assessed with a new "mirror" kind of measurement, the Workplace Relational Civility Scale (WRCS, Di Fabio and Gori, 2016b): the participants have to firstly describe their relationship with others, and then the relationship of others with them. This kind of measure allows a better evaluation of the interpersonal interactions helping to reduce bias and it recognizes the inconsistencies between how the person considers himself/herself during the interaction with others and how the person looks at others in their interaction with him/her. This kind of measurement enables individuals to reflect on his/her own actions and to examine the behavior of others, thereby making him/her more aware of the relational dynamics.

Organizations need to develop a positive relational environment in the workplace enabling workers to enhance their personal resources so that they can cope with the on-going changes in today's world of work and also improve their wellbeing (Di Fabio and Bernaud, 2008; Di Fabio and Palazzeschi, 2008, 2012b, 2015, 2016; Di Fabio, 2011, 2014a,b; Di Fabio et al., 2014; Snyder et al., 2014; Di Fabio and Gori, 2016a,b; Di Fabio and Kenny, 2016a,b).

In the present-day ever-changing and unstable world of work, acceptance of change is crucial (Di Fabio and Gori, 2016a). Acceptance of change (AC) is defined as "tendency to embrace rather than shy away from change." AC thus stems from the belief that, in their work and other activities, people who are able to accept change often find that the change has a positive impact on their working lives and their resource levels" (Di Fabio and Gori, 2016a, p. 2). Acceptance of change has the following dimensions: Predisposition to change: people's ability to learn from change and to use change to improve the quality of their lives; Support for change: social support perceived from others when the person is facing challenges; Change seeking: people's predisposition not only to seek change, but also to accept and integrate life and work changes; Positive reaction to change: experience of positive emotions able to predispose people to experience change positively and to benefit from it"; and Cognitive flexibility: the mental ability to go through between different concepts also adopting flexible cognitive processing strategies (Di Fabio and Gori, 2016a, p. 3).
From a positive psychology perspective and thus also from a healthy organizations perspective, promoting the well-being of workers is vital (Adkins, 1999; Danna and Griffin, 1999). In particular, from a positive psychology perspective (Seligman and Csikszentmihalyi, 2000; Seligman, 2002), it is possible to distinguish two forms of well-being: hedonic well-being and eudaimonic well-being. Hedonic well-being (Watson et al., 1988) has a cognitive component in terms of life satisfaction (Diener et al., 1985) and an affective component characterized by the ascendancy of positive emotions over negative emotions (Watson et al., 1988). Eudaimonic well-being concerns the full functioning of the person (Ryan and Deci, 2001) and relates to life meaning and purposefulness (Waterman et al., 2010; Gori et al., 2015). In previous research, important associations between positive relationships in the workplace, the tendency to accept changes, and both hedonic and eudaimonic well-being emerged (Di Fabio, 2014a, 2016a).

People who participate positively in the workplace, are generally able to communicate with others with kindness and to attune their expressions and behaviors to those of others to promote a climate of mutual respect, show also the tendency to accept change and respond easier to the current challenges of our society of complexity (Rehfuss and Di Fabio, 2012; Di Fabio, 2016a,b,c). Furthermore people can benefit from a work climate of decency, respect, and awareness between people, enhancing relational management (Di Fabio, 2015b), psychological strenghts (Di Fabio, 2014a; Di Fabio and Gori, 2016b), hedonic and eudaimonic wellbeing in terms respectively of life satisfaction, and flourishing, authenticity and life meaningfulness (Di Fabio, 2014a, 2016a,b). So, given the importance of the concepts of relationality and civility, the present study is related to the idea of promoting the acceptance of change and well-being at work, through relationality (Blustein, 2006; Di Fabio and Maree, 2012, 2016; Maree, 2013; Di Fabio, 2015b; Di Fabio and Gori, 2016a,b).

\section{Aim and Hypotheses}

The principal objective of this research was to assess the relationship among workplace relational civility, acceptance of change and well-being (hedonic well-being and eudaimonic well-being) controlling for the effects of personality traits.

The following three hypotheses were formulated.

H1: The workplace relational civility assessed by the WRCS will add a percentage of incremental variance beyond the variance explained by personality traits in relation to acceptance of change.

$\mathrm{H} 2$ : The workplace relational civility assessed by the WRCS will add a percentage of incremental variance beyond the variance explained by personality traits in relation to hedonic well-being (assessed by life satisfaction).

H3: The workplace relational civility assessed by the WRCS will add a percentage of incremental variance beyond the variance explained by personality traits in relation to eudaimonic well-being (assessed by meaning in life). 


\section{MATERIALS AND METHODS}

\section{Participants}

Two hundred and sixty-one Italian workers of different public and private organizations in central Italy participated in the study. The participants' ages ranged from 34 to 58 years $(M=$ $46.15, S D=8.642)$. 175 workers $(67.00 \%)$ of the participants were men with a mean age of 46.85 years, $S D=8.582$ and $86(33.00 \%)$ were women with a mean age of $44.73, S D=8.638$.

\section{Measures}

\section{Personality Traits}

The 10 Item Personality Inventory (TIPI, Gosling et al., 2003), in the Italian version by Di Fabio et al. (2016) was used to evaluate personality traits. The questionnaire was developed on the basis of descriptors of the Big Five instruments. Each item consists of two separated attributes with response options on a 7-point Likert scale ranging from 1 (strongly disagree) to 7 (strongly agree). The TIPI identifies five personality dimensions: Extraversion (E) (example of item: "I see myself as extraverted, enthusiastic"), Agreeableness (A) (example of item: "I see myself as sympathetic, warm"), Conscientiousness (C) (example of item: "I see myself as dependable, self-disciplined"), Neuroticism (N) (example of item: "I see myself as calm, emotionally stable"), Openness (O) (example of item: "I see myself open to new experiences, complex"). The Italian version of the TIPI indicated good values of reliability $(E=0.82 ; A=0.78 ; C=0.79 ; N=0.71$; $O=0.74$; Di Fabio et al., 2016).

\section{Workplace Relational Civility}

The Workplace Relational Civility Scale (WRCS, Di Fabio and Gori, 2016b) was used to evaluate relational civility in the workplace. It is a self-report mirror instrument consisting of 26 items to assess relational civility at work. The WRCS has three dimensions: Relational readiness (RR) at work, Relational culture $(\mathrm{RCu})$ at work, and Relational decency $(\mathrm{RD})$ at work. The sum of these dimensions gives an overall score for workplace relational civility for each part of the WRCS (Part A and Part B) and a total score. Part A concerns the analysis of an individual's perception of himself or herself regarding a particular issue (example of item: "I was able to express my values and my beliefs calmly to others) while Part B concerns the analysis of an individual's perception of others regarding the same issue (example of item: "Others were able to express their values and their beliefs calmly to me"). The participants in the present study were asked to describe their general relationship with others over the past 3 months, and then to describe their perception of the general relationship of others with them over the same time period. The response format was a Likert scale with five responses $(1=$ not at all; $2=$ a little; 3 = somewhat; $4=$ much; $5=$ a great deal). The Cronbach's alphas for the three dimensions for Part A were: Factor 1A = Relational readiness $(\alpha=0.83)$; Factor $2 \mathrm{~A}=$ Relational culture $(\alpha=0.76)$; Factor $3 \mathrm{~A}=$ Relational decency $(\alpha=0.75)$. The factors for Part $\mathrm{B}$ were: Factor $1 \mathrm{~B}=$ Relational readiness $(\alpha=0.86)$; Factor $2 \mathrm{~B}=$ Relational culture $(\alpha=0.88)$; Factor $3 \mathrm{~B}=$ Relational decency $(\alpha$ $=0.85$ ). The Cronbach's alpha coefficients for the total score for Part A and Part B of the WRC were, respectively, $\alpha=0.87$ and $\alpha=0.92$.

\section{Acceptance of Change}

The Acceptance of Change Scale (ACS, Di Fabio and Gori, 2016a) was used in the present study to evaluate the tendency of the participants to accept or move toward change. The ACS has 20 items with response options on a 5 -point Likert-type scale $(1=$ not at all, $2=$ a little, $3=$ somewhat, $4=$ much, $5=$ a great deal) . The scale enables five dimensions to be distinguished: Positive reaction to change (example of item: "I am able to give new meanings to the things that I have been doing for a long time," Change seeking (example of item: "I am looking for changes in my life, even when things are going well," Cognitive flexibility (example of item: "If necessary, it is not difficult for me to change my mind," Predisposition to change (example of item: "Thinking about new plans is easy for me," and Support for change (example of item: "I trust the people close to me when faced with change").

The Cronbach's alpha coefficients for the five dimensions were $\alpha=0.83$ for Predisposition to change; $\alpha=0.79$ for Support for change; $\alpha=0.80$ for Change seeking; $\alpha=0.75$ for Positive reaction to change, $\alpha=0.72$ for Cognitive flexibility, and $\alpha=$ 0.88 for the overall scale.

\section{Life Satisfaction}

The Satisfaction With Life Scale (SWLS, Diener et al., 1985) in the Italian version by Di Fabio and Gori (2015) was used to evaluate life satisfaction as hedonic well-being. The scale consists of five items (examples of items: "I am satisfied with my life," "The conditions of my life are excellent") on a 7-point Likert scale ranging from $1=$ strongly disagree to $7=$ strongly agree. The scale has a one-dimensional factorial structure. The Cronbach's alpha coefficient was 0.85 .

\section{Meaning in Life}

The Italian version (Di Fabio, 2014c) of the Meaningful Life Measure (MLM, Morgan and Farsides, 2009) was utilized to assess meaning in life as eudaimonic well-being. The questionnaire consists of 23 items on a 7 -point Likert scale ranging from $1=$ strongly disagree to $7=$ strongly agree. The MLM identifies five dimensions: Exciting life (e.g., "Life to me seems always exciting"), Accomplished life (e.g., "So far, I am pleased with what I have achieved in life"), Principled life (e.g., "I have a personal value system that makes my life worthwhile"), Purposeful life (e.g., "I have a clear idea of what my future goals and aims are"), Valued life (e.g., "My life is significant"). The Cronbach's alpha coefficients were 0.85 for Exciting life; 0.87 for Accomplished life; 0.86 for Principled life, 0.85 for Purposeful life; 0.84 for Valued life. The alpha value for the total score was 0.85 .

\section{Procedure and Data Analysis}

The administration procedure involved some trained research assistant psychologists who administered collectively the instruments to groups of workers in meeting room in their workplace.

The order of administration of the instruments was controlled to counterbalance the effects of the order of measures. Participants completed an informed consent form and the instruments were administered in line with the Italian Law (Law Decree DL-196/2003). The study adhered to the latest version of 
TABLE 1 | Means, standard deviations and correlations between TIPI, WRCS, ACS, SWLS, and MLM.

\begin{tabular}{|c|c|c|c|c|c|c|c|c|c|c|c|c|}
\hline & $M$ & $D S$ & 1 & 2 & 3 & 4 & 5 & 6 & 7 & 8 & 9 & 10 \\
\hline 1. Extraversion & 4.29 & 1.43 & - & & & & & & & & & \\
\hline 2. Agreeableness & 5.58 & 1.01 & $0.18^{\star \star}$ & - & & & & & & & & \\
\hline 3. Conscientiousness & 5.59 & 1.19 & $0.19^{\star \star}$ & $0.39^{\star \star}$ & - & & & & & & & \\
\hline 4. Emotional stability & 5.03 & 1.13 & $0.31^{\star \star}$ & $0.47^{\star \star}$ & $0.40^{\star \star}$ & - & & & & & & \\
\hline 5. Openness & 4.91 & 1.09 & $0.30^{\star \star}$ & $0.26^{\star \star}$ & $0.24^{\star \star}$ & $0.31^{\star \star}$ & - & & & & & \\
\hline 6. WRCS Part A & 52.58 & 5.95 & 0.09 & $0.32^{\star \star}$ & $0.22^{\star \star}$ & $0.19^{\star \star}$ & $0.19^{\star *}$ & - & & & & \\
\hline 7. WRCS Part B & 47.67 & 7.33 & $0.21^{\star \star}$ & $0.24^{\star *}$ & $0.23^{\star \star}$ & $0.31^{\star \star}$ & $0.21^{\star \star}$ & $0.40^{\star \star}$ & - & & & \\
\hline 8. ACS & 73.45 & 9.34 & $0.30^{\star *}$ & $0.29^{\star *}$ & $0.22^{\star *}$ & $0.41^{\star *}$ & $0.53^{\star *}$ & $0.46^{\star \star}$ & $0.43^{\star \star}$ & - & & \\
\hline 9. SWLS & 25.04 & 5.73 & $0.27^{\star \star}$ & $0.32^{\star \star}$ & $0.25^{\star \star}$ & $0.37^{\star \star}$ & $0.27^{\star \star}$ & $0.32^{\star \star}$ & $0.46^{\star \star}$ & $0.40^{\star \star}$ & - & \\
\hline 10. MLM & 123.18 & 20.71 & $0.24^{\star \star}$ & $0.41^{\star \star}$ & $0.48^{\star \star}$ & $0.48^{\star \star}$ & $0.37^{\star \star}$ & $0.39^{\star \star}$ & $0.50^{\star \star}$ & $0.42^{\star \star}$ & $0.41^{\star \star}$ & - \\
\hline
\end{tabular}

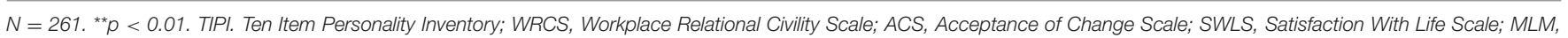
Meaningful Life Measure.

the Declaration of Helsinki revised in Fortaleza (World Medical Association [WMA], 2013) with regard to ethical standards for research. They were followed and approved by the Department of Education and Psychology of the University of Florence (Italy).

The participants were told that they could withdraw from the study at any time and that there would be no payment for participating. Firstly descriptive statistics and Pearson's $r$ correlations were carried out, and then hierarchical regressions were performed.

\section{RESULTS}

Means, standard deviations, and correlations between TIPI, WRCS, ACS, SWLS, and MLM are shown in Table $\mathbf{1 .}$

Regarding the differences between the gender groups and the age groups in respect to the three dependent variables, below there are the results of the generalized linear model analyses conducted adjusting for the unbalancing of gender factor within the sample, introducing such a factor as dummy variable. Moreover within the same models we considered the age as covariate variable.

The first model takes into account the ACS, reporting significant effects both for gender $F_{(1,257)}=6.538, p=0.05, \eta^{2}$ $=0.03$ and age $F_{(1,257)}=11.482, p=0.01, \eta^{2}=0.04$. For what concern the SWLS only the gender appears to play a significant effect $F_{(1,257)}=6.840, p=0.01, \eta^{2}=0.03$. The same happens for the MLM $F_{(1,257)}=5.733, p=0.05, \eta^{2}=0.02$. Despite their significance, all the previous effects appear to be characterized by a quite small magnitude in terms of effects dimensions, always ranging between 2 and $4 \%$ of the variance.

The results of three different hierarchical regression models are presented with acceptance of change, life satisfaction, and meaning in life as the criterion measures and with personality traits at the first step and workplace relational civility at the second step (Table 2).

As regard to acceptance of change, at the first step personality dimensions explained the $36 \%$ of the variance. At the second step, workplace relational civility added $12 \%$ of the
TABLE 2 | Hierarchical regression.

\begin{tabular}{llll}
\hline & ACS & SWLS & MLM \\
\hline & $\beta$ & $\beta$ & $\beta$ \\
\hline STEP 1 & & & \\
Extraversion & 0.08 & $0.10^{\star}$ & 0.01 \\
Agreeableness & 0.02 & $0.11^{\star}$ & $0.11^{\star}$ \\
Conscientiousness & 0.04 & 0.04 & $0.25^{\star \star \star}$ \\
Emotional stability & $0.20^{\star \star}$ & $0.14^{\star *}$ & $0.18^{\star \star}$ \\
Openness & $0.38^{\star \star \star}$ & 0.09 & $0.16^{\star \star}$ \\
STEP 2 & & & \\
WRCS Part A & $0.28^{\star \star \star}$ & $0.10^{\star}$ & $0.11^{\star}$ \\
WRCS Part B & $0.12^{\star}$ & $0.32^{\star \star \star}$ & $0.30^{\star \star \star}$ \\
$R^{2}$ step 1 & $0.36^{\star \star \star}$ & $0.20^{\star \star \star}$ & $0.38^{\star \star \star}$ \\
$\Delta R^{2}$ step 2 & $0.12^{\star \star \star}$ & $0.10^{\star \star \star}$ & $0.10^{\star \star \star}$ \\
$R^{2}$ total & $0.48^{\star \star \star}$ & $0.30^{* \star \star}$ & $0.48^{\star \star \star}$ \\
\hline
\end{tabular}

The contributions of personality traits (first step) and workplace relational civility (second step) to acceptance of change (AC), life satisfaction (LS), meaning in life (ML).

$N=261 .{ }^{*} p<0.05 .{ }^{* \star} p<0.01 .{ }^{* \star *} p<0.001$. WRCS, Workplace Relational Civility Scale; ACS, Acceptance of Change Scale; SWLS, Satisfaction with Life Scale; MLM, Meaningful Life Measure.

When WRCS Part A and WRCS Part B were examined separately in Step 3 and Step 4, the models didn't account for a percentage greater of variance in relation to ACS, SWLS, and MLM.

incremental variance. The model overall accounted for $48 \%$ of the variance.

For what concerns the analysis explaining hedonic well-being as assessed by life satisfaction, at the first step personality traits accounted for $20 \%$ of the variance. At the second step, workplace relational civility added $10 \%$ of the incremental variance. The model overall accounted for $30 \%$ of the variance.

For what refers to the analysis explaining eudaimonic well-being as assessed by meaning in life, at the first step personality traits explained the $38 \%$ of the variance. At the second step, workplace relational civility added $10 \%$ of the incremental variance. The model overall accounted for $48 \%$ of the variance. 


\section{DISCUSSION}

The aim of this research was to investigate the role of workplace relational civility in acceptance of change and in both hedonic and eudaimonic well-being beyond the effects of personality traits.

The first hypothesis was confirmed as workplace relational civility added a percentage of incremental variance beyond the variance explained by personality traits in relation to acceptance of change. A relational style characterized by respect and concern for oneself and others, interpersonal sensitivity, personal education, and kindness toward others (Di Fabio and Gori, 2016b) was related to acceptance of change (Di Fabio and Gori, 2016a). These results highlight the importance of developing a positive workplace relational environment so that workers can enhance their psychological strenghts (Di Fabio, 2014a; Di Fabio and Gori, 2016b) useful not only for managing their relationships but also for welcoming the ongoing changes in the workplace (Di Fabio, 2014a; Snyder et al., 2014; Di Fabio and Kenny, 2016a,b; Di Fabio and Gori, 2016a,b). People characterized by workplace relational civility in the workplace, can face adequately critical issues of change and achieve their organizational objectives coping with changes (Di Fabio and Gori, 2016b). The tendency to accept changes based on a positive relationality can help people to react better and to deal successfully with the complexity of the twenty-first century world of work (Di Fabio, 2016a).

The second hypothesis was also confirmed as workplace relational civility added a percentage of incremental variance beyond the variance explained by personality traits in relation to hedonic well-being (assessed by life satisfaction). The results of the present study showed that perceptions of civility in relationships in the workplace in terms of treating others and being treating by others with dignity and with respect in the interests of peaceful and productive cohabitation (Di Fabio and Gori, 2016a) correlated positively with greater satisfaction with one's own life (Diener et al., 1985). Thus, a relational style characterized by respect and caring for the self and the others in the relationships between people can foster relational well-being in the workplace (Di Fabio and Gori, 2016b). The construction of a positive workplace climate can affect also the overall evaluation of a person's life, contributing to hedonic well-being of individuals in their workplace.

Finally, the third hypothesis was also confirmed as workplace relational civility added a percentage of incremental variance beyond the variance explained by personality traits in relation to eudaimonic well-being (assessed by meaning in life). These results thus also supported the positive relationship between workplace relational civility (Di Fabio and Gori, 2016b) and eudaimonic well-being in terms of optimal functioning (Morgan and Farsides, 2009). Thus the perception of relational civility in an organizational environment seems to contribute to the identification of one's own meaning in work, encouraging the pursuing of meaningful goals in line with authentic aspects of the Self. The perception of good relationships in the workplace can thereby contribute to the efforts for self-realization of workers, fostering healthy individuals for healthy business and healthy organizations.

It is interesting to note that the Part A of the Workplace Relational Civility Scale regarding the evaluation of the perception of the self in relationships with others was linked closely to acceptance of change, while Part B of the WRC Scale regarding the evaluation of the perception of the relationship of others with oneself was linked closely to both hedonic and eudaimonic well-being. It seems thus that the perception of one's own workplace relational civility tends to be associated with a willingness and a readiness to face change effectively, relying on a deeper reflection on one's own possible relational actions. The perception of others' workplace relational civility tends to be associated with life satisfaction and optimal functioning, underlying the value of the behaviors of others and of the relational dynamics in the construction of own well-being. The awareness of one's own behavior and of the behaviors of other people in social relationships in the workplace, can help individuals to manage more effectively the ever-changing and unpredictable demands of their workplace, also developing new relational skills to overcome difficulties and find better solutions for themselves and the organizations.

Notwithstanding the present study showed the relationships between workplace relational civility, acceptance of change and both hedonic and eudaimonic well-being, the following limitations of the study should be noted. The research was conducted with a group of Italian workers who were not representative of the Italian population. Future research should therefore include workers from different geographical areas in Italy, from different types of organizations, and also incorporate samples from other countries. Furthermore future research could examine workplace relational civility in relation to other aspects of hedonic well-being such as positive affect (Watson et al., 1988) or other aspects of eudaimonic well-being like the subjective experience of eudaimonia (Waterman et al., 2010), the existential fulfillment (Längle et al., 2003), and the flourishing (Diener et al., 2010).

Despite the limitations of the study, the findings do add to the literature on the contribution of workplace relational civility to acceptance of change and to hedonic and eudaimonic well-being.

If the results of the present study are confirmed by future research, new interventions could be introduced to enhance workplace relational civility and thereby promote "healthy organizations," particularly from a primary prevention perspective (Hage et al., 2007; Kenny and Hage, 2009; Di Fabio and Saklofske, 2014a; Di Fabio and Kenny, 2015). The endeavor of improving relational resources in the workplace could foster strengths of workers and organizations, important for increasing the tendency to accept the on-going changes in the world of work (Di Fabio, 2016a,b), to anticipate critical aspects and to early intervene to decrease possible risks (Hage et al., 2007; Kenny and Hage, 2009). Building a positive relational environment can also promote individual hedonic and eudaimonic wellbeing of workers in terms respectively of life satisfaction and meaning in life, strongly associated with organizational well-being. 
Conceptualizing organizational relationality in terms of workplace relational civility in a preventive positive framework could thus strengthen healthy organizations, underlining the importance of developing positive and supportive relationships in the workplace (Blustein, 2011; Di Fabio, 2014a, 2015b; Snyder et al., 2014; Di Fabio and Gori, 2016b) for a safer and more decent relational work environment (Di Fabio and Blustein, 2016a,b).

\section{REFERENCES}

Adkins, J. A. (1999). Promoting organizational health: the evolving practice of occupational health psychology. Prof. Psychol. Res. Pract. 30, 129-137. doi: 10.1037/0735-7028.30.2.129

Arenas, A., Giorgi, G., Montani, F., Mancuso, S., Perez, J. F., Mucci, N., et al. (2015). Workplace bullying in a sample of Italian and Spanish employees and its relationship with job satisfaction, and psychological well-being. Front. Psychol. 6:1912. doi: 10.3389/fpsyg.2015.01912

Arnoux-Nicolas, C., Sovet, L., Lhotellier, L., Di Fabio, A., and Bernaud, J.-L. (2016). Perceived work conditions and turnover intentions: the mediating role of meaning of life and meaning of work. Front. Psychol. 7:704. doi: 10.3389/fpsyg.2016.00704

Bar-On, R. (1997). The Emotional Intelligence Inventory (EQ-i): Technical manual. Toronto, ON: Multi-Health Systems.

Blustein, D. L. (2006). The Psychology of Working: A New Perspective for Career Development, Counseling and Public Policy. New York, NY: Routledge.

Blustein, D. L. (2011). A relational theory of working. J. Vocat. Behav. 79, 1-17. doi: 10.1016/j.jvb.2010.10.004

Boyatzis, R. E. (2009). Competencies as a behavioral approach to emotional intelligence. J. Manag. Develop. 28, 749-770. doi: 10.1108/02621710910987647

Boyatzis, R. E., Batista-Foguet, J. M., Fernández-i-Marín, X., and Truninger, M. (2015). EI competencies as a related but different characteristic than intelligence. Front. Psychol. 6:72. doi: 10.3389/fpsyg.2015.00072

Boyatzis, R. E., and Saatcioglu, A. (2008). A twenty-year view of trying to develop emotional, social and cognitive intelligence competencies in graduate management education. J. Manag. Develop. 27, 92-108. doi: $10.1108 / 02621710810840785$

Boyatzis, R. E., Stubbs, E. C., and Taylor, S. N. (2002). Learning cognitive and emotional intelligence competencies through graduate management education. Acad. Manag. Learn. Educ. 1, 150-162. doi: 10.5465/AMLE.2002. 8509345

Ceschi, A., Dorofeeva, K., and Sartori, R. (2014). Studying teamwork and team climate by using a business simulation: how communication and innovation can improve group learning and decision-making performance. Eur. J. Train. Dev. 38, 211-230. doi: 10.1108/EJTD-01-2013-0004

Danna, K., and Griffin, R. W. (1999). Health and well-being in the workplace: a review and synthesis of the literature. J. Manage., 25, 357-384. doi: 10.1177/014920639902500305

De Smet, A., Loch, M., and Schaninger, B. (2007). Anatomy of a Healthy Corporation. Mckinsey Q. 2, 1-11. Available online at: https://solutions. mckinsey.com/catalog/media/AnatomyOfAHealthyCorporation.pdf

Diener, E., and Emmons, R. A., Larsen, R. J., and Griffin, S. (1985). The satisfaction with life scale. J. Pers. Assess. 49, 71-75. doi: 10.1207/s15327752jpa4901_13

Diener, E., Wirtz, D., Tov, W., Kim-Prieto, C., Choi, D. W., Oishi, S., et al. (2010). New well-being measures: short scales to assess flourishing and positive and negative feelings. Soc. Indic. Res. 97, 143-156. doi: 10.1007/s11205-009-9493-y

Di Fabio, A. (2006). Decisional procrastination correlates: Personality traits, selfesteem or perception of cognitive failure? Int. J. Educ. Vocat. Guid. 6, 109-122. doi: 10.1007/s10775-006-9000-9

Di Fabio, A. (2011). Intelligence émotionnelle et résistance au changement: Quelques résultats empiriques [Emotional intelligence and resistance to change: some empirical results]. Rev. Psychol. Travail Organ. 17, 91-106. doi: 10.1016/S1420-2530(16)30135-2

Di Fabio, A. (2014a). Career counseling and positive psychology in the 21st century: new constructs and measures for evaluating the effectiveness of intervention. J. Counsel. 1, 193-213.

\section{AUTHOR CONTRIBUTIONS}

ADF conceptualized the study, choose the theoretical framework, and chose measures. OB helped in the collection of the data. ADF, MG, YL, LP and OB analyzed the data and wrote the methods and results. Then all authors wrote the paper together and read and revised the manuscript several times.

Di Fabio, A. (2014b). Intrapreneurial self-capital: a new construct for the $21^{\text {st }}$ century. J. Employ. Counsel. 51, 98-111. doi: 10.1002/j.2161-1920.2014.00045.x

Di Fabio, A. (2014c). Meaningful life measure: primo contributo alla validazione della versione italiana [Meaningful life measure: first contribution to the validation of the Italian version]. Counsel. Giornale Italiano Ricerca Applic. 7, 307-315.

Di Fabio, A. (2015a). Beyond fluid intelligence and personality traits in social support: the role of ability-based emotional intelligence. Front. Psychol. 6:395. doi: 10.3389/fpsyg.2015.00395

Di Fabio, A. (2015b). Positive Relational Management Scale per Rilevare Positività e Complessità [Positive Relational Management Scale to Detect Positivity and Complexity]. Counseling. Giornale Italiano Ricerca Applic. 8. Available online at: http://rivistedigitali.erickson.it/counseling/archivio/vol-8-n-3/

Di Fabio, A. (2015c). Workplace Civility Scale: From Dark Side to Positive Side Nelle Organizzazioni [Workplace Civility Scale: From Dark Side to Positive Side in Organizations]. Counseling. Giornale Italiano di Ricerca e Applicazioni, 8. Available online at: http://rivistedigitali.erickson.it/counseling/ archivio/vol-8-n-2/

Di Fabio, A. (2016a). "The construction of personal project: the challenge of sustainability," in Career-Life Construction and Sustainability. Workshop at the World Conference of the UNESCO Chair "Lifelong Guidance and Counseling" in Wroclaw 2016, eds A. Di Fabio \& J. G. Maree (Moderators), D. L. Blustein (Discussant) (Wroclaw: University of Wroclaw (Poland)).

Di Fabio, A. (2016b). Positive Relational Management for Healthy Organizations: Psychometric Properties of a New Scale for Prevention for Workers. Front. Psychol. 7:1523. doi: 10.3389/fpsyg.2016.01523

Di Fabio, A. (2016c). Life design and career counseling innovative outcomes (CCIO): a case study. Career Dev. Q. 64, 35-48. doi: 10.1002/cdq.12039

Di Fabio, A., and Bernaud, J. (2008). The help-seeking in career counseling. J. Vocat. Behav., 72, 60-66. doi: 10.1016/j.jvb.2007.10.006

Di Fabio, A., Bernaud, J.-L., and Loarer, E. (2014). Emotional intelligence or personality in resistance to change? Empirical results in an Italian health care context. J. Employ. Counsel. 51, 146-157. doi: 10.1002/j.21611920.2014.00048.x

Di Fabio, A., and Blustein, D. L. (eds.) (2016a). Editorial ebook from meaning of working to meaningful lives: the challenges of expanding decent work. Front. Psychol. 7:1119 doi: 10.3389/fpsyg.2016.01119

Di Fabio, A., and Blustein, D. L. (eds.) (2016b). From Meaning of Working to Meaningful Lives: The Challenges of Expanding Decent Work. Lausanne: Frontiers Media. doi: 10.3389/978-2-88919-970-9 (Ebook)

Di Fabio, A., and Bucci, O. (2015). Affective profiles in Italian high school students: life satisfaction, psychological well-being, self-esteem, and optimism. Front. Psychol. 6:1310. doi: 10.3389/fpsyg.2015.01310

Di Fabio, A., and Bucci, O. (2016). Green positive guidance and green positive life counseling for decent work and decent lives: some empirical results. Front. Psychol. 7:261. doi: 10.3389/fpsyg.2016.00261

Di Fabio, A., and Gori, A. (2015). Measuring adolescent life satisfaction: psychometric properties of the Satisfaction With Life Scale in a sample of Italian adolescents and young adults. J. Psychoeduc. Assess. doi: $10.1177 / 0734282915621223$

Di Fabio, A., and Gori, A. (2016a). Developing a new instrument for assessing acceptance of change. Front. Psychol. 7: 802. doi: 10.3389/fpsyg.2016.00802

Di Fabio, A., and Gori, A. (2016b). Decent work and positive relational outcomes: Assessing Workplace Relational Civility (WRC) with a new multidimensional “mirror" measure. Front. Psychol. 7:890. doi: 10.3389/fpsyg.2016.00890

Di Fabio, A., Gori, A., and Giannini, M. (2016). Analizzare le Proprietà Psicometriche di Una Misura dei Big Five Con un Metodo Alternativo: L'esempio 
del Ten Item Personality Inventory (TIPI) [Analysing the Psychometric Properties of a Big Five Measurement Tool with an Alternative Method: The Example of the Ten Item Personality Inventory (TIPI)]. Counseling. Giornale Italiano di Ricerca e Applic. 9. doi: 10.14605/CS921618

Di Fabio, A., and Kenny, M. E. (2012). Emotional intelligence and perceived social support among Italian high school students. J. Career Dev. 39, 461-475. doi: $10.1177 / 0894845311421005$

Di Fabio, A., and Kenny, M. E. (2015). The contributions of emotional intelligence and social support to adaptive career progress among Italian youth. J. Career Dev. 42, 48-49. doi: 10.1177/0894845314533420

Di Fabio, A., and Kenny, M. E. (2016a). From decent work to decent lives: positive self and relational management (PS\&RM) in the twenty-first century. Front. Psychol. 7:361. doi: 10.3389/fpsyg.2016.00361

Di Fabio, A., and Kenny, M. E. (2016b). Promoting well-being: The contribution of emotional intelligence. Front. Psychol. 7:1182. doi: 10.3389/fpsyg.2016.01182

Di Fabio, A., and Maree, J. G. (2012). Group-based life design counseling in an Italian context. J. Vocat. Behav. 80, 100-107. doi: 10.1016/j.jvb.2011. 06.001

Di Fabio, A., and Maree, J. G. (2016). Using a transdisciplinary interpretive lens to broaden reflections on alleviating poverty and promoting decent work. Front. Psychol. 7:503. doi: 10.3389/fpsyg.2016.00503

Di Fabio, A., and Palazzeschi, L. (2008). Emotional intelligence and self-efficacy in a sample of Italian high school teachers. Soc. Behav. Pers. 36, 315-326. doi: 10.2224/sbp.2008.36.3.315

Di Fabio, A., and Palazzeschi, L. (2012a). Incremental variance of the core self-evaluation construct compared to fluid intelligence and personality traits in aspects of decision-making. Pers. Individ. Dif. 53, 196-201. doi: 10.1016/j.paid.2012.03.012

Di Fabio, A., and Palazzeschi, L. (2012b). Organizational justice: Personality traits or emotional intelligence? An empirical study in an Italian hospital context. J. Employ. Counsel. 49, 31-42. doi: 10.1002/j.2161-1920.2012.00004.x

Di Fabio, A., and Palazzeschi, L. (2015). Hedonic and eudaimonic well-being: the role of resilience beyond fluid intelligence and personality traits. Front. Psychol. 6:1367. doi: 10.3389/fpsyg.2015.01367

Di Fabio, A., and Palazzeschi, L. (2016). Marginalization and precariat: The challenge of intensifying life construction intervention. Front. Psychol. 7:444. doi: 10.3389/fpsyg.2016.00444

Di Fabio, A., Palazzeschi, L., Asulin-Peretz, L., and Gati, I. (2013). Career indecision versus indecisiveness: associations with personality traits and emotional intelligence. J. Career Assess. 21, 42-56. doi: $10.1177 / 1069072712454698$

Di Fabio, A., Palazzeschi, L., and Bar-On, R. (2012). The role of personality traits, core self-evaluation and emotional intelligence in career decisionmaking difficulties. J. Employ. Counsel. 49, 118-129. doi: 10.1002/j.21611920.2012.00012.x

Di Fabio, A., and Saklofske, D. H. (2014a). Promoting individual resources: the challenge of trait emotional intelligence. Pers. Individ. Dif. 65, 19-23. doi: 10.1016/j.paid.2014.01.026

Di Fabio, A., and Saklofske, D. H. (2014b). Comparing ability and self-report trait emotional intelligence, fluid intelligence, and personality traits in career decisions. Pers. Individ. Dif. 64, 174-178. doi: 10.1016/j.paid.2014.02.024

Di Fabio, A., Saklofske, D. H., and Tremblay,. P. F. (2016). Psychometric properties of the Italian trait emotional intelligence questionnaire (I-TEIQue). Pers. Indiv. Dif. 96, 198-201. doi: 10.1016/j.paid.2016.03.009

Eisenberger, R., Fasolo, P., and Davis-LaMastro, V. (1990). Perceived organizational support and employee diligence, commitment, and innovation. J. Appl. Psychol. 75, 51-59. doi: 10.1037/0021-9010.75.1.51

Giorgi, G., Mancuso, S., Fiz Perez, F., Castiello D’Antonio, A., Mucci, N., Cupelli, V., et al. (2016). Bullying among nurses and its relationship with burnout and organizational climate. Int. J. Nurs. Pract. 22, 160-168. doi: 10.1111/ijn.12376

Giorgi, G., Shoss, M. K., and Leon-Perez, J. M. (2015). Going beyond workplace stressors: Economic crisis and perceived employability in relation to psychological distress and job dissatisfaction. Int. J. Stress Manag. 22, 137. doi: $10.1037 / \mathrm{a} 0038900$

Gori, A., Craparo, G., Giannini, M., Loscalzo, Y., Caretti, V., La Barbera, D., et al. (2015). Development of a new measure for assessing insight: psychometric properties of the insight orientation scale (IOS). Schizophr. Res. 169, 298-302. doi: 10.1016/j.schres.2015.10.014
Gosling, S. D., Rentfrow, P. J., and Swann, W. B. Jr. (2003). A very brief measure of the Big Five personality domains. J. Res. Pers. 37, 504-528. doi: 10.1016/S00926566(03)00046-1

Grawitch, M. J., and Ballard, D. W. (2016). The Psychologically Healthy Workplace: Building a Win-Win Environment for Organizations and Employees. Washington, DC: American Psychological Association.

Guichard, J. (2013). "Career guidance, education, and dialogues for a fair and sustainable human development," in Inaugural Conference of the UNESCO Chair of Lifelong Guidance and Counselling (Wroclaw: University ofWroclaw).

Hage, S. M., Romano, J. L., Conyne, R. K., Kenny, M., Matthews, C., Schwartz, J. P., et al. (2007). Best practice guidelines on prevention practice, research, training, and social advocacy for psychologists. Couns. Psychol. 35, 493-566. doi: $10.1177 / 0011000006291411$

Kenny, M. E., and Hage, S. M. (2009). The next frontier: prevention as an instrument of social justice. J. Prim. Prev. 30, 1-10. doi: 10.1007/s10935-0080163-7

Längle, A., Orgler, C., and Kundi, M. (2003). The existence scale: a new approach to assess the ability to find personal meaning in life and to reach existential fulfillment. Euro. Psychother. 4, 135-146.

Lowe, G. (2010). Healthy Organizations: How Vibrant Workplaces Inspire Employees to Achieve Sustainable Success. Toronto, ON: University of Toronto Press.

Macik-Frey, M., Quick, J. C., and Nelson, D. L. (2007). Advances in occupational health: from a stressful beginning to a positive future. J. Manage. 33, 809-840. doi: $10.1177 / 0149206307307634$

Maree, J. G. (2012). Editorial. Promoting children's rights: rekindling respectivity. South Afr. J. Psychol. 42, 295-300. doi: 10.1177/008124631204200301

Maree, J. G. (2013). Counselling for Career Construction: Connecting Life Themes to Construct Life Portraits. Turning Pain into Hope. Rotterdam: Sense.

Mayer, J. D., Roberts, R. D., and Barsade, S. G. (2008). Human abilities: emotional intelligence. Ann. Rev. Psychol. 59, 507-536. doi: 10.1146/annurev. psych.59.103006.093646

Mayer, J. D., and Salovey, P. (1997). “What is emotional intelligence?", in Emotional Development and Emotional Intelligence: Educational Implications, eds P. Salovey and D. Sluyter (New York, NY: Basic Books), 3-31.

McNeely, B. L., and Meglino, B. M. (1994). The role of dispositional and situational antecedents in prosocial organizational behavior: an examination of the intended beneficiaries of prosocial behavior. J. Appl. Psychol. 79, 836-844. doi: 10.1037/0021-9010.79.6.836

Morgan, J., and Farsides, T. (2009). Measuring meaning in life. J. Happ. Stud. 10, 197-214. doi: 10.1007/s10902-007-9075-0

Mucci, N., Giorgi, G., Roncaioli, M., Perez, J. F., and Arcangeli, G. (2016). The correlation between stress and economic crisis: a systematic review. Neuropsychiatr. Dis. Treat. 12, 983-993. doi: 10.2147/NDT.S98525

Petrides, K. V., and Furnham, A. (2000). On the dimensional structure of emotional intelligence. Person. Individ. Differ. 29, 313-320. doi: 10.1016/S01918869(99)00195-6

Petrides, K. V., and Furnham, A. (2001). Trait emotional intelligence: psychometric investigation with reference to established trait taxonomies. Euro. J. Person. 15, 425-428. doi: 10.1002/per.416

Podsakoff, P. M., MacKenzie, S. B., Moorman, R. H., and Fetter, R. (1990). Transformational leader behaviors and their effects on followers' trust in leader, satisfaction, and organizational citizenship behaviors. Leadership Q. 1, 107-142. doi: 10.1016/1048-9843(90)90009-7

Raya, R. P., and Panneerselvam, S. (2013). The healthy organization construct: a review and research agenda. Indian J. Occupat. Environm. Med. 17, 89. doi: 10.4103/0019-5278.130835

Rehfuss, M., and Di Fabio, A. (2012). Validating the future career autobiography as a measure of narrative change. J. Career Assess. 20, 452-462. doi: 10.1177/1069 072712450005

Richardson, M. S. (2012). Counseling for work and relationship. Counsel. Psychol. 40, 190-242. doi: 10.1177/0011000011406452

Ryan, R. M., and Deci, E. L. (2001). "To be happy or to be self-fulfilled: a review of research on hedonic and eudaimonic well-being," in Annual Review of Psychology, Vol. 52, ed S. Fiske (Palo Alto, CA: Annual Reviews), 141-166.

Sartori, R., Favretto, G., and Ceschi, A. (2013). The relationships between innovation and human and psychological capital in organizations: a review. Innov. J. 18, 1-18. 
Savickas, M. L. (2011). Career Counseling. Washington, DC: American Psychological Association.

Seligman, M. E., and Csikszentmihalyi, M. (2000). Positive Psychology: An Introduction. Washington, DC: American Psychological Association.

Seligman, M. E. P. (2002). "Positive psychology, positive prevention, and positive therapy," in Handbook of Positive Psychology, eds C. R. Snyder and S. J. Lopez (New York, NY: Oxford University Press), 3-9.

Snyder, C. R., Lopez, S., and Teramoto Pedrotti, J. (2014). Positive Psychology: The Scientific and Practical Explorations of Human Strengths. London: Sage.

Sparks, K., Faragher, B., and Cooper, C. L. (2001). Well-being and occupational health in the 21st century workplace. J. Occupat. Organ. Psychol. 74, 489-509. doi: 10.1348/096317901167497

Stough, C., Saklofske, D., and Parker, J. (2009). Assessing Emotional Intelligence: Theory, Research, and Applications. New York, NY: Springer.

Waterman, A. S., Schwartz, S. J., Zamboanga, B. L., Ravert, R. D., Williams, M. K., Bede Agocha, V., et al. (2010). The questionnaire for eudaimonic well-being: psychometric properties, demographic comparisons, and evidence of validity. J. Posit. Psychol. 5, 41-61. doi: 10.1080/17439760903435208

Watson, D., Clark, L. A., and Tellegen, A. (1988). Development and validation of brief measures of positive and negative affect: the PANAS scales. J. Person. Soc. Psychol. 54, 1063-1070. doi: 10.1037/0022-3514.54.6.1063
World Health Organization (1998). World Health Organization Definition of Health. Available online at: http://www.who.ch/aboutwho/definition.htm

World Health Organization (2007). Workers' Health: Global Plan of Action. Sixtieth World Health Assembly. Available online at: http://www.who.int/ occupational_health/publications/global_plan/en/

World Medical Association [WMA] (2013). WMA Declaration of Helsinki-Ethical Principles for Medical Research Involving Human Subjects. Available online at : http://www.wma.net/en/30publications/10policies/b3/

Conflict of Interest Statement: The authors declare that the research was conducted in the absence of any commercial or financial relationships that could be construed as a potential conflict of interest.

Copyright (C) 2016 Di Fabio, Giannini, Loscalzo, Palazzeschi, Bucci, Guazzini and Gori. This is an open-access article distributed under the terms of the Creative Commons Attribution License (CC BY). The use, distribution or reproduction in other forums is permitted, provided the original author(s) or licensor are credited and that the original publication in this journal is cited, in accordance with accepted academic practice. No use, distribution or reproduction is permitted which does not comply with these terms. 


\section{OPEN ACCESS}

Edited by:

Gabriele Giorgi,

European University of Rome, Italy

Reviewed by:

Vincenzo Cupelli,

University of Florence, Italy

Milica Vukelic

University of Belgrade, Serbia

*Correspondence:

Silvia Pignata

silvia.pignata@unisa.edu.au

Specialty section:

This article was submitted to

Organizational Psychology,

a section of the journal

Frontiers in Psychology

Received: 13 May 2016 Accepted: 10 August 2016

Published: 25 August 2016

Citation:

Pignata S, Winefield AH, Provis $C$ and Boyd CM (2016) A Longitudinal Study of the Predictors of Perceived Procedural Justice in Australian University Staff.

Front. Psychol. 7:1271 doi: 10.3389/fpsyg.2016.01271

\section{A Longitudinal Study of the Predictors of Perceived Procedural Justice in Australian University Staff}

\author{
Silvia Pignata ${ }^{1,2 *}$, Anthony H. Winefield ${ }^{2,3}$, Chris Provis ${ }^{4}$ and Carolyn M. Boyd ${ }^{1}$ \\ ${ }^{1}$ School of Engineering, University of South Australia, Adelaide, SA, Australia, ${ }^{2}$ Asia Pacific Centre of Work Health and Safety, \\ School of Psychology, Social Work and Social Policy, University of South Australia, Adelaide, SA, Australia, ${ }^{3}$ School of \\ Psychology, University of Adelaide, Adelaide, SA, Australia, ${ }^{4}$ School of Management, University of South Australia, Adelaide, \\ SA, Australia
}

Purpose: This study examined the factors that predict employees' perceptions of procedural justice in university settings. The paper also reviews the ethical aspects of justice and psychological contracts within employment relationships.

Design/Methodology/Approach: The study examined the predictors of perceived procedural justice in a two-wave longitudinal sample of 945 employees from 13 universities by applying the Job Demands-Resources theoretical model of stress. The proposed predictors were classified into two categories: Job demands of work pressure and work-home conflict; and job resources of job security, autonomy, trust in senior management, and trust in supervisor. The predictor model also examined job satisfaction and affective organizational commitment, demographic (age, gender, tenure, role) and individual characteristics (negative affectivity, job involvement) as well as Time 1 (T1) perceptions of procedural justice to ensure that tests were rigorous.

Findings: A series of hierarchical multiple regression analyses found that job satisfaction at T1 was the strongest predictor of perceived procedural justice at Time 2. Employees' trust in senior management, and their length of tenure also positively predicted justice perceptions. There were also differences between academic and non-academic staff groups, as non-academic employees' level of job satisfaction, trust in senior management, and their length of organizational tenure predicted procedural justice perceptions, whereas for academics, only job satisfaction predicted perceived justice. For the "all staff" category, job satisfaction was a dominant and enduring predictor of justice, and employees' trust in senior management also predicted justice.

Research limitations/implications: Results highlight the importance of workplace factors in enhancing fair procedures to encourage reciprocity from employees. As perceived procedural justice is also conceptually linked to the psychological contract between employees-employers, it is possible that employees' levels of job satisfaction and perceptions of trust in senior management, relative to other work attitudinal outcomes, may be more effective for improving the broader working environment, and promoting staff morale. 
Originality/value: This study adds to research on applied business ethics as it focuses on the ethical aspects of perceived procedural justice and highlights the importance of workplace factors in enhancing fair procedures in organizational policy to encourage reciprocity and promote healthy organizational environments.

Keywords: procedural justice, psychological contract, reciprocity, job satisfaction, organizational policy

\section{INTRODUCTION}

Recent international research shows that the high global costs of work-related stress for employers due to absenteeism, presenteeism, and the loss of productivity, and the subsequent high health care costs for the community are a growing international concern (Giorgi et al., 2014; Mucci et al., 2015). In addition, work-related stress can influence the development of physical health problems with consequent negative repercussions on the productivity of human resources (Mucci et al., 2014; Bjørnstad et al., 2015). On the other hand, research on healthy organizational environments demonstrates that employees who are psychologically attached to an organization work more effectively and contribute to achieving organizational goals through higher levels of performance (Somech and DrachZahavy, 2004). Indeed, organizations rely upon “...acts of cooperation, altruism, and spontaneous unrewarded help" from employees to maintain a healthy organizational environment (O'Reilly and Chatman, 1986, p. 493). Justice is an important theme in effective organizational contexts, and an improved knowledge of employees' experiences of justice is needed to help understand the benefits of developing and maintaining a sense of justice within organizations. Employees perceive three main forms of justice: The fairness of the outcomes of a decision or allocation of goods (distributive justice); the fairness of the processes that are used to make decisions (procedural justice); and the fairness of the interactions and treatment that an individual receives from another (relational justice; Li and Cropanzano, 2009).

\section{Organizational Justice}

The justice literature emphasizes the importance of increasing justice via fair procedures both for reasons of intrinsic ethicality, and to encourage reciprocity from employees and the subsequent benefits for organizations in promoting commitment to the organization and encouraging employee trust (Ambrose and Cropanzano, 2003; Holtz and Harold, 2009). We argue that studying justice and pro-organizational behaviors helps guide research to improve our understanding of these behaviors. This paper focuses on examining the predictors of employees' perceptions of the procedural aspect of organizational justice and contributes to the literature in two ways. First, it examines the factors (workplace and individual) that predict employee perceptions of procedural justice in the university context. The paper also reviews the ethical aspects of justice and psychological contracts within employment relationships in order to understand what types of factors individuals perceive to be fair and just. Thus, the aim of the present study is to bridge gaps in the literature as an improved knowledge of these characteristics may produce healthier work environments within complex organizations such as universities, as well as other organizations.

Procedural justice refers to how decisions affecting staff are made and whether the outcomes from those decisions are correct and fair (Greenberg, 1994). The rights and responsibilities of employees and employers exceed economic issues such as productivity and competitiveness, since employment relationships also require fair treatment, equity, and voice for employees (Budd, 2004). Employers' recognition of employee voice may be seen as an acceptance of their rights at work as their voice is expected to be able to influence decisions (Thibaut and Walker, 1975). Procedural justice perceptions assist in shaping employees' relationships with their employers (Folger and Cropanzano, 1998) and thus affect attitudes such as job satisfaction (Masterson et al., 2000), organizational commitment, trust in management (Folger and Konovsky, 1989), organizational citizenship behavior (OCB), and turnover intentions (Ambrose and Cropanzano, 2003). Committed employees are prepared to engage in OCB (Organ and Konovsky, 1989), which is discretionary behavior directed at individuals or toward the organization as a whole that goes beyond the formal expectations of the work role, and which benefits, or is intended to benefit, the organization (Organ, 1988). Metaanalyses suggest that employees are more likely to engage in OCB when they are fairly treated, have a good relationship with their supervisor and have high levels of affective commitment to their organization (Hoffman et al., 2007). Rhoades and Eisenberger (2002) found that perceived procedural justice has a strong positive relationship with perceptions of organizational support and assert that employees may perceive that justice is regulated by management. Thus, an important focus for new research is to understand the factors that contribute to maintaining positive organizational behaviors and attitudes such as procedural justice.

In the procedural justice literature, Ambrose and Schminke (2003) propose that organizations may enhance employees' procedural justice perceptions by drafting formal policies that provide details of how outcomes are determined (Rhoades and Eisenberger, 2002), as this offers employees some control over decision-making processes, and provides reassurance about the fairness of the resulting outcomes (Thibaut and Walker, 1975). Coyle-Shapiro and Conway (2005) posit that the tenet of psychological contract theory in the employee-employer relationship is a mutual exchange of obligations, along with a perception of the level to which those obligations are fulfilled. According to the authors (p. 775) the exchange process includes "any item that might be exchanged between the organization 
and the employee (e.g., pay, training, support, in exchange for loyalty, performance, flexibility)." The literature shows that the fulfillment of a psychological contract is positively related to satisfaction with the organization, jobs and leaders; to commitment to the organization; to trust in the organization; and to $\mathrm{OCB}$, and is negatively related to turnover intentions (Coyle-Shapiro and Conway, 2005). Consistency between what is promised and provided by the organization establishes the basis of the reciprocal exchange (Pignata, 2011). Whilst perceived fairness is crucial for the relational psychological contract to continue (Rousseau and Parks, 1992), any violation of the contract and perception of unfulfilled obligations raises issues of procedural justice, and reduces the likelihood of employees engaging in civic virtue behaviors (see Robinson and Morrison, 1995). For example, assessments of organizational procedures, in terms of procedural justice, can influence an employee's trust (Folger and Konovsky, 1989; Saunders and Thornhill, 2003). In this way, perceptions of procedural justice can impact on the key determinants of trust: Integrity, ability, and benevolence. Thus, a perpetual sequence may exist amongst these constructs, where fair and beneficial organizational procedures encourage trust from employees, which then promotes pro-organizational behaviors that assist the organization to perform and achieve its goals. Some studies support this sequence as they show that perceptions of procedural justice promote trust, and that trust promotes affective organizational commitment (Bijlsma and Koopman, 2003).

\section{Justice and Reciprocity}

The tenet of Blau's (1964) social exchange theory is that people seek to reciprocate to those who benefit them. This state of reciprocal interdependence generates perceived obligations (Saks, 2006) as the voluntary action of providing something of value to another in a social exchange creates a perceived obligation on the other party to reciprocate. In the work setting, when employees see that fair procedures are implemented, they may feel valued by their organization and as a result, respond with increased feelings of commitment to the organization (Pignata et al., 2016). By contrast, perceptions of unfair procedures have been associated with decreased OCB and increased turnover intentions (Colquitt et al., 2001). Furthermore, Elovainio et al. (2001) assert that employees' perceptions of organizational injustice are associated with psychological strain at work. Siegrist's (1996) Effort-Reward Imbalance work stress model is based on the relationship between effort made at work and the reward obtained, and proposes that work strain is a consequence of an imbalance between the effort expended and the rewards gained. Effort is defined as the job demands and obligations that are imposed on the employee, with the premise of the model being that effort at work is reciprocated by adequate reward in the form of socio-emotional response (approval, respect, recognition, support), status, or money, as part of a social contract. A balance is achieved when the benefits received are what should be expected given the contribution at work. Work situations demanding high effort and offering little gain may have adverse effects on physical and emotional health due to the effort-reward imbalance (Marmot et al., 2002). For example, research on job satisfaction in Australian universities by Bentley et al. (2013b) highlighted key aspects of job dissatisfaction in the sector.

In the context of Australian universities, the negative impact of economic and management pressures on the wellbeing of university staff has been documented by Winefield et al. (2008) with a qualitative focus group study of 15 universities showing that university staff experienced high levels of stress, reporting insufficient funding and resources, fewer opportunities for career development, and reduced recognition and reward practices (Gillespie et al., 2001). According to Kinman and Jones (2008, p. 247), "...interventions restoring the balance between efforts expended and rewards received-thus improving employees' sense of fairness and reciprocity. In the university sector, such balance could be achieved by reducing extrinsic efforts and/or enhancing rewards such as esteem, promotion prospects, and job security," or both. Given that procedural justice perceptions can shape the employee-employer relationship, it is important to focus specifically on employees' perceptions of procedural justice in universities to investigate what types of workplace, demographic or individual characteristics predict procedural justice, so that intervention strategies can address the issues of control and uncertainty in employees' perceptions of procedural justice (Thibaut and Walker, 1975).

The importance of examining ethical issues in organizational interventions is noted by Dewe (1994, p. 23) who stated that the development and evaluation of such interventions "appears to be hampered by issues of power, control and ethics." Ethics is defined as "a system of moral principles, by which human actions and proposals may be judged good or bad, or right or wrong" (Delbridge, 2001, p. 378). Hence, ethics involves the application of certain principles to decide the right thing to do in the situation. Some of the key values in contemporary approaches to ethics are autonomy, responsibility, care, and justice (May et al., 1998). May and colleagues state that autonomy refers to individuals being true to their principles and acting in the way that they have chosen. Responsibility includes both a personal and social orientation as it concerns accountability for the consequences that individuals have explicitly and directly caused, and includes both the actions that they have explicitly performed and things they have failed to do. Care is oriented to those who cannot protect themselves, or to those individuals with whom they have interpersonal relationships. Like responsibility, justice has a personal and social orientation as it refers to giving each individual their due on the basis of that individual's legitimate rights. Those rights include contractual rights between two equal parties, and the fair distribution of goods and services in a society.

\section{Justice and Psychological Contracts}

The literature highlights: The positive relationships between fulfilled psychological contracts and satisfaction with the organization, jobs and leaders; the positive work-related outcomes of organizational commitment, trust, and OCB; and the negative relationship with turnover intentions (Masterson et al., 2000; Coyle-Shapiro and Conway, 2005). Thus, psychological contracts are clearly of importance to 
the employee-employer relationship. A meta-analysis by Zhao et al. (2007) showed that psychological contract breach impacts affective reactions, which in turn, affect important work behaviors and attitudes that result in employees being less likely to maintain their commitment to the organization. This leads into the deontological concerns of procedural justice that involve treating employees with respect and fairness.

Deontological theories view duty as the primary morally relevant feature, rather than consequences. Kant (cited in Cohen, 2004, p. 41) argued that "morality is a matter of doing one's duty, regardless of consequences, and that duty itself is determined not by reference to consequences but by reference to consistency and the requirements of rationality." For Kant, the pure moral law was related to duty and was independent of feelings and inclinations (Singer, 1994). An example of a deontological principle is the rule to treat others as we would like to be treated when it is used as a gauge for correct conduct that does not make reference to consequences (Cohen, 2004). Psychological contracts are linked to deontological concerns such as honesty and loyalty in that it is an employee's duty to carry out their work diligently, and it is an employer's duty to treat employees with respect. Fairness is another fundamental deontological principle, and so such ethical principles are tied into perceived procedural justice as that is the degree to which individuals perceive decisions to have been made according to fair procedures (Folger and Greenberg, 1985).

According to Brown et al. (2010, pp. 1589-90) procedurally just decisions are made with accuracy and without bias, and “Greenberg's (1994) conceptualization of procedural justice emphasized consistency, soliciting input, and the opportunity for two-way communication during implementation." Leventhal's (1980) seminal work established six principles of procedural justice: (1) consistency in applying just policies to all employees over a period of time; (2) no bias from those making the decisions; (3) ensuring the accuracy and completeness of information used to make the decision; (4) providing the opportunity to appeal outcomes; (5) the opportunity for those affected to voice their views regarding the outcome; and (6) upholding the ethical standards of those affected by the decision. For example, in deciding who should receive a promotion, a failure to apply the promotion policy correctly or to be biased in the decision may evoke procedural unfairness concerns in the employee(s) affected by the decision. Research on justice, trust, and work stress in the Australian university context has often occurred during difficult periods of enterprise bargaining when academic staff, in particular, were sensitive to justice issues regarding their pay, working conditions, and their opportunities for promotion, so it is not surprising that procedural justice was identified as a highly salient form of justice for academic staff (Gillespie et al., 2001). It is proposed that on the basis of socialexchange theory we can learn about employees' perceptions of justice by investigating the factors that may lead to their judgments of procedures and policies within highly formalized university settings. To this end, the present study examines the predictors of perceived procedural justice among a sample of university employees.

\section{Job Demands and Resources}

In order to address a need for a theoretically based organizing framework, the conceptual model for the study (see Figure 1) integrates the reciprocal relationships in social exchange theory with the dual factor Job Demand-Resources (JD-R) model of workplace stress and engagement (Demerouti et al., 2001; Bakker and Demerouti, 2007). The JD-R framework has been employed in the present study as it comprises the two classes of job demands and job resources which are broad in scope as they encompass physical, social, psychological, and organizational dimensions of the job. Consistent with the model, the current study classifies job demands as parts of the job that require sustained effort or skills and entail physiological or psychological costs (Bakker and Demerouti, 2007). By contrast, it categorizes job resources as parts of the job that reduce demands, assist in attaining goals, and enhance growth and development which are crucial for employee wellbeing (Demerouti et al., 2001; Schaufeli and Bakker, 2004). Based on the work stress literature, predictors of procedural justice can include work pressure and workhome conflict (job demands). Work pressure is the sense of having too much work to do in the time available, which is often treated as an indicator of job demands (Demerouti et al., 2004). Work-home conflict refers to the processes by which an individual's behavior at home is negatively influenced by the demands of their work role. Work-home conflict is a key source of occupational stress (DeFrank and Ivancevich, 1998) and a predictor of exhaustion, health complaints and depressive affect (Geurts et al., 2003).

Conversely, job resources comprise perceptions of job security, job autonomy, trust in senior management, and trust in supervisor which are particularly pertinent to perceptions of procedural justice. Job security refers to expectations about job continuity, whereas job insecurity indicates negative expectations about job continuity, and in the university setting has been shown to predict both psychological strain and lower job satisfaction for academic and non-academic staff (Winefield et al., 2002). Job autonomy is the degree to which employees can influence the pacing and timing of their work (Bakker and Demerouti, 2007), and, along with procedural justice, has been shown to influence psychological strain and commitment to the organization in academics (Boyd et al., 2011). Mayer et al. (1995, p. 712) define trust as "the willingness of a party to be vulnerable to the actions of another party based on the expectation that the other will perform a particular action important to the trustor, irrespective of the ability to monitor or control that other party." Trust in supervisor (in the university context typically a Head of Department) and trust in senior management refer to the extent to which supervisors or senior management are perceived by their subordinates to act with integrity, competence, and benevolence toward them. In their longitudinal study across three time-points, Holtz and Harold (2009, p. 1195) examined overall organizational and overall supervisory justice perceptions of 213 individuals, and found that "employees with higher levels of trust had more stable overall justice perceptions." They also found that overall justice perceptions changed over time as shown by within-person variance in organizational and supervisory justice. 


\section{T1 WORKPLACE PREDICTORS} Job Demands:

Work Pressure, Work-Home Conflict Job Resources:

Job Security, Workplace Autonomy, Trust in Senior Management, Trust in Supervisor

T1 INDIVIDUAL PREDICTORS

Job Satisfaction,

Affective Organizational Commitment, Negative Affectivity, Job Involvement

\section{T2 PERCEIVED PROCEDURAL JUSTICE}

FIGURE 1 | Conceptual model of the hypothesized Time 1 predictors of Time 2 perceived procedural justice (adapted from Winefield et al., 2008).

\section{Predictors}

In the present study, along with job demands and job resources, the attitudinal variables of job satisfaction and organizational commitment were included as predictors of procedural justice. Job satisfaction refers to the broad positive emotional reactions and attitudes individuals have toward their jobs (Locke, 1969). In their research on job satisfaction around the academic world, Bentley et al. (2013a) showed that academics are committed to their work and find it deeply satisfying. Other studies within university settings have found that academic staff reported intrinsic factors such as student interaction, relationships with fellow colleagues, the prestige of academic positions, autonomy and job variety, as their areas of greatest satisfaction (Kinman, 2001; Winefield et al., 2002). As the main predictors of job satisfaction include trust in management, autonomy, and procedural justice, we predict an association between perceptions of procedural justice and the job resources of autonomy, trust in supervisor, and trust in senior management.

Another key attitude is affective organizational commitment which refers to "the strength of an individual's identification with and involvement in a particular organization" (Porter et al., 1974, p. 604). As commitment develops from employees' work experiences and can be enhanced by positive experiences (Arnold et al., 1995), it can also be expected to predict procedural justice. The Time 1 (T1) level of procedural justice was included as an additional predictor to ensure that tests of the relationships between the hypothesized predictors and outcomes are rigorous.

The conceptual model for the study also contained the individual characteristics of negative affectivity and job involvement as the literature demonstrates their relationship to occupational stress and wellbeing (see Winefield et al., 2002). Negative affectivity and job involvement have been included in the analyses as possible predictors of procedural justice as they have been shown to exert an impact on strain, burnout, job satisfaction and organizational commitment (Landsbergis et al., 1992). Negative affectivity, refers to "the disposition to experience aversive emotional states" (Watson and Clark, 1984, p. 465), and as a stable personality characteristic may influence work attitudes over time. As employees with high levels of negative affectivity may be more likely to confront their supervisor due to their need to control the outcomes they experience and/or reduce their feelings of uncertainty in achieving fair and appropriate procedural outcomes (e.g., salary increases and promotional opportunities), it is predicted that there will be a negative association between negative affectivity and procedural justice perceptions. Furthermore, job involvement is a function of both individual differences and job characteristics and is the extent to which employees prioritize and become involved in their work (Lodahl and Kejner, 1965). Hallberg and Schaufeli (2006) showed that job involvement is an aspect of work attachment that relates to an intrinsic need for performance. As research in an Irish academic context by Kanungo (1982) found that Irish academics report high levels of job involvement and that their work relates to their core identity, it can be speculated that this focus on their work role and self-identity may translate to them caring for fair procedures and thus having positive perceptions of procedural justice within their work setting. Indeed, it has recently been suggested by Ruokolainen et al. (2016) that with regard to psychological contracts, and perhaps due to their higher levels of education, university employees expect more of themselves and their employer than those who work in less demanding work settings.

Due to the aforementioned justice research, and as the tenet of the JD-R model is that high job demands are associated with negative individual and workplace outcomes, and that abundant job resources are associated with achieving beneficial outcomes 
for individuals and workplaces, the present study incorporated the abovementioned variables in a two-wave longitudinal design to examine the effects of perceived procedural justice over time in order to investigate the following hypotheses:

Hypothesis 1: Job demands (work pressure, work-home conflict) at $\mathrm{T} 1$ will be negatively associated with perceptions of procedural justice at $\mathrm{T} 2$.

Hypothesis 2: Job resources (job security, autonomy, trust in supervisor, trust in senior management) at $\mathrm{T} 1$ will be positively associated with perceptions of procedural justice at $\mathrm{T} 2$.

Hypothesis 3: Work attitudes (job satisfaction and affective organizational commitment) at $\mathrm{T} 1$ will be positively associated with perceptions of procedural justice at T2.

Hypothesis 4: Negative affectivity at T1 will be negatively associated with perceptions of procedural justice at T2.

Hypothesis 5: Job involvement at T1 will be positively associated with perceptions of procedural justice at T2.

In Australia, academic work includes training professionals, conducting scholarly and applied research, building international networks, collaborating with business, mentoring individuals, and contributing to broader economic development (Coates and Goedegebuure, 2010). Thus, due to their different functional roles, and as prior research (see Winefield et al., 2008) indicated that academic and non-academic (professional) staff experience working conditions somewhat differently, with academic staff reporting more adverse work experiences than non-academic staff, we will explore the possibility that the predictors of perceived procedural justice will differ for academic (faculty) and non-academic staff.

\section{MATERIALS AND METHODS}

\section{Participants and Procedure}

A total sample of 4969 participants responded to both the 2000 (T1) and 2003/4 (T2) surveys at a representative sample of 13 Australian public universities (see Winefield et al., 2008 for more details and a broad analysis of the results of the survey). A three-year interval between the longitudinal surveys for 12 of the universities, and a four-year interval for one university was chosen in order to provide university management with adequate time to implement the researchers' recommendations for reducing occupational stress. Of the 4969 participants, this paper reports on the responses from the 945 matched tenured and contract staff (casual or hourly paid employees did not participate in the study) who participated in both waves of the survey and provided responses to the measure of perceived procedural justice. The mean age of the sample was 46.5 years with a standard deviation of 9.3 years. The sample comprised 345 men (37\%) and 600 women (63\%), and 399 (42\%) academic (faculty) staff and 546 (58\%) non-academic (professional) staff which is typical of the national Australian profile of academic and non-academic staff (Department of Education Science and Training, 2003). The longitudinal study received ethics approval from the University of South Australia's Human Research and Ethics Committee. As participation in both surveys was anonymous, code identifiers were used to match data across surveys.

\section{Measures}

Both the T1 and T2 questionnaires sought demographic information (age, university), and the following attitude and individual difference measures in the survey. The means shown for job satisfaction and negative affectivity are based on the total scores, whereas the measures of work pressure, workhome conflict, job security, autonomy, affective organizational commitment, trust in senior management, trust in supervisor, job involvement, and perceived procedural justice are based on the item means. The items for the procedural justice measure were developed from focus group discussions (see Gillespie et al., 2001), and the findings of the focus group study were used to inform the design of the questionnaire. The measures used in the survey were taken from well validated scales that have been published in the literature however, some measures were modified to ensure that the items were sensitive and relevant to the university context. For example, with regard to the job security measure, we retained three items: (1) Lose your job and be laid off; (2) Find your department or division's future uncertain; (3) Lose your job by being pressured to accept early retirement, as the other items were not judged to be as relevant to staff who were, by definition, in relatively secure long-term employment. The same criterion was used for other survey measures.

The measures of direct relevance had internal reliabilities between 67 and 96 (Cronbach's alpha coefficients) indicating acceptable reliability (see Table $\mathbf{1}$ ). It should be noted that work pressure was strongly associated with work-home conflict ( $r=$ 0.65 ) but none of the correlations suggest that any of the selfreport measures were assessing the same constructs (see DeVellis, 1991; Nunnally and Bernstein, 1994).

\section{Work Pressure}

Three items from Beehr et al.'s (1976) Work Pressure scale assessed work overload. An example item is "I don't have time to finish my job." Questions were rated on a 4-point scale $(1=$ definitely false, $4=$ definitely true).

\section{Work-Home Conflict}

Three items from Frone and Yardley's (1996) scale measured work-home conflict with an example item being, "My family dislikes how often I am preoccupied with my work while I am at home." Each item was rated on a 5 -point scale $(1=$ never, $5=$ very frequently).

\section{Job Security}

Three items drawn from Ashford et al.'s (1989) measure of job insecurity asked staff to rate the likelihood $(1=$ very unlikely, $5=$ likely) of items such as losing their job and being laid off; finding your department/division's future uncertain; being pressured to accept early retirement. The items were reverse scored to be consistent with the other job resource measures so that high scores meant high job security. 


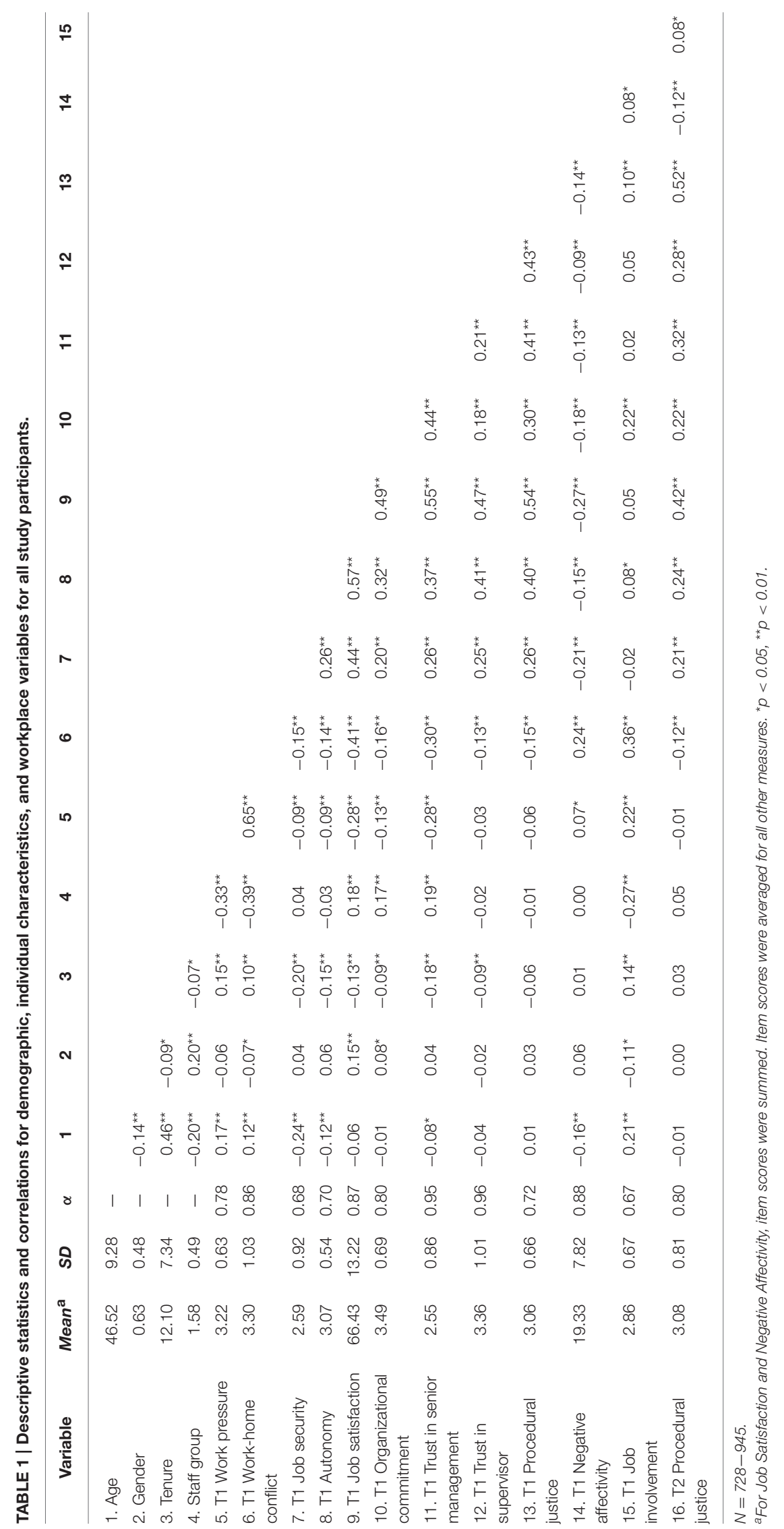




\section{Workplace Autonomy}

A 9-item measure, drawn from the Moos Work Environment Scale autonomy sub-scale (Moos and Insel, 1974), was used. An example item is "Staff are encouraged to make their own decisions," and responses are rated on a 5-point scale $(1=$ strongly disagree, $5=$ strongly agree).

\section{Job Satisfaction}

The 15-item scale developed by Warr et al. (1979) assessed job satisfaction (e.g., "How satisfied or dissatisfied do you feel with the amount of variety in your job?"), and each item was scored on a 7 -point Likert scale $(1=$ extremely dissatisfied; $7=$ extremely satisfied).

\section{Affective Organizational Commitment}

Five items from Porter et al.'s (1974) scale measured affective organizational commitment with each item scored on a 5-point scale $(1=$ strongly disagree; $5=$ strongly agree $)$. An example item is "I really care about the future of this university."

\section{Trust in Senior Management}

An 8-item scale developed from Mayer and Davis (1999) and Butler (1991) measured trust in senior management (e.g., "Senior Management of my University treat staff fairly"). Each item was scored on a 5 -point scale ( $1=$ strongly disagree; $5=$ strongly agree).

\section{Trust in Supervisor}

An 8-item scale adapted from Mayer and Davis (1999) and Butler (1991) measured trust in supervisor by assessing employees' perceptions of the level of integrity, competence, and concern for staff shown by their supervisor, school, or unit.

\section{Procedural Justice Perceptions}

A 4-item scale developed by Gillespie et al. (2001) measured perceptions of procedural justice (e.g., "Staff performance is fairly appraised") on a 5 -point scale $(1=$ strongly disagree; $5=$ strongly agree).

\section{Negative Affectivity}

The 12-item measure of Neuroticism from the NEO-Five Factory Inventory (NEO-FFI: Costa and McCrae, 1992) was used to measure negative affectivity, which assesses an individual's disposition to experience anxiety, depression and vulnerability. Each item was rated on a 5 -point scale $(0=$ strongly disagree, $4=$ strongly agree, with reverse scoring for positively phrased items).

\section{Job Involvement}

Four items from the scale developed by Lodahl and Kejner (1965) measured the extent to which staff are involved in their work. An example item is "The most important things that happen to me involve my work." Each item was rated on a 5-point scale $(1=$ strongly disagree, $5=$ strongly agree).

\section{Control Variables}

To reduce the possibility of spurious relationships with demographic characteristics, the control variables of age, gender ( $1=$ male, 2 = female $)$, length of organizational tenure, and staff group ( 1 =academic, $2=$ non-academic $)$ were entered in all the equations. The T1 level of procedural justice was also entered into each equation.

\section{Analyses}

Analyses were performed using Predictive Analytics Software (PASW) 18.0. Preliminary checks ensured that there was no violation of the assumptions of multicollinearity, normality, linearity, and homoscedasticity. As prior levels of procedural justice at $\mathrm{T} 1$ were included as additional predictors in the analysis, tests of the aforementioned relationships are more rigorous as they show that the predictors account for changes in the levels of the dependent variables (Zapf et al., 1996).

\section{RESULTS}

The means, standard deviations, internal reliability coefficients and bivariate correlations for the variables are displayed in Table 1.

The descriptive statistics for the variables for both academic and non-academic staff are displayed in Table 2.

The hierarchical regression analyses investigating the predictors of $\mathrm{T} 2$ procedural justice for both staff categories are displayed in Table 3.

As shown in Table 3, employee perceptions of procedural justice at $\mathrm{T} 2$ were predicted by workplace factors that predicted $31 \%$ of the variability in procedural justice. The individual characteristics did not account for the variance in justice. Excluding the effects of the T1 level of procedural justice, the strongest predictor of justice was job satisfaction which means that the more satisfied that employees are with their jobs,

TABLE 2 | Mean (SD) age, gender, and all measures for academic and non-academic (professional) staff categories.

\begin{tabular}{|c|c|c|c|c|}
\hline & \multicolumn{2}{|c|}{$\begin{array}{c}\text { Academic } \\
(n=249)\end{array}$} & \multicolumn{2}{|c|}{$\begin{array}{c}\text { Non-academic } \\
(n=324)\end{array}$} \\
\hline & $M$ & $S D$ & $M$ & $S D$ \\
\hline Age & 48.34 & 7.96 & 44.94 & 9.26 \\
\hline Gender & 0.51 & 0.50 & 0.69 & 0.46 \\
\hline Length of tenure & 13.09 & 7.59 & 11.90 & 7.07 \\
\hline Staff group & 1.02 & 0.15 & 1.98 & 0.15 \\
\hline T1 Work pressure & 3.46 & 0.56 & 3.06 & 0.61 \\
\hline T1 Work-home conflict & 3.82 & 0.98 & 2.93 & 0.91 \\
\hline T1 Job security & 2.69 & 0.94 & 2.60 & 0.88 \\
\hline T1 Autonomy & 3.04 & 0.53 & 3.06 & 0.55 \\
\hline T1 Job satisfaction & 62.71 & 13.73 & 67.89 & 13.00 \\
\hline T1 Organizational commitment & 3.36 & 0.74 & 3.55 & 0.63 \\
\hline T1 Trust in senior management & 2.32 & 0.90 & 2.65 & 0.78 \\
\hline T1 Trust in supervisor & 3.35 & 1.07 & 3.28 & 0.99 \\
\hline T1 Procedural justice & 3.06 & 0.68 & 3.04 & 0.70 \\
\hline T2 Procedural justice & 3.06 & 0.81 & 3.16 & 0.80 \\
\hline T1 Negative affectivity & 19.67 & 8.19 & 19.10 & 7.64 \\
\hline T1 Job involvement & 3.06 & 0.67 & 2.71 & 0.64 \\
\hline
\end{tabular}

Coding: Gender (Male =1, Female =2), Staff Group (Academic = 1, Non-academic =2). 
TABLE 3 | Multiple regression analyses of all predictors of T2 procedural justice for all study participants.

\begin{tabular}{|c|c|c|c|c|c|c|c|c|c|c|c|c|c|c|c|}
\hline Predictors & \multicolumn{4}{|c|}{ Step 1} & \multicolumn{5}{|c|}{ Step 2} & & \multicolumn{4}{|c|}{ Step 3} & \\
\hline Gender & -0.11 & 0.28 & -0.02 & -0.36 & & -0.25 & 0.24 & -0.04 & -1.03 & & -0.21 & 0.25 & -0.03 & -0.86 & \\
\hline Tenure & 0.02 & 0.02 & 0.05 & 1.06 & & 0.04 & 0.02 & 0.09 & $2.28^{\star}$ & & 0.04 & 0.02 & 0.09 & $2.30^{*}$ & \\
\hline Staff group & 0.35 & 0.28 & 0.05 & 1.27 & & 0.31 & 0.26 & 0.05 & 1.19 & & 0.34 & 0.27 & 0.05 & 1.28 & \\
\hline $\begin{array}{l}\text { T1 Work-home } \\
\text { Conflict }\end{array}$ & & & & & & 0.05 & 0.16 & 0.01 & 0.29 & & 0.06 & 0.17 & 0.02 & 0.34 & \\
\hline T1 Job security & & & & & & 0.05 & -0.15 & 0.01 & 0.35 & & 0.03 & -0.15 & 0.01 & 0.20 & \\
\hline T1 Autonomy & & & & & & -0.48 & 0.27 & -0.08 & -1.78 & & -0.49 & 0.27 & -0.08 & -1.82 & \\
\hline T1 Job satisfaction & & & & & & 0.05 & 0.02 & 0.22 & $3.58^{\star \star \star}$ & & 0.05 & 0.02 & 0.22 & $3.50^{\star \star}$ & \\
\hline T1 Org commitment & & & & & & -0.15 & 0.20 & -0.03 & -0.75 & & -0.20 & 0.20 & -0.04 & -0.97 & \\
\hline T1 Procedural justice & & & & & & 0.46 & 0.05 & 0.39 & $8.82^{\star \star \star}$ & & 0.46 & 0.05 & 0.39 & $8.79^{\star \star \star}$ & \\
\hline T1 Negative affectivity & & & & & & & & & & & -0.02 & 0.02 & -0.04 & -1.01 & \\
\hline T1 Job involvement & & & & & & & & & & & 0.10 & 0.20 & .02 & 0.049 & \\
\hline Adj. $R^{2}$ & & & & & -0.00 & & & & & & & & & & \\
\hline$F$ & & & & & 0.77 & & & & & & & & & & \\
\hline$\Delta R^{2}$ & & & & & & & & & & 0.31 & & & & & \\
\hline F change & & & & & & & & & & $28.98^{\star \star \star}$ & & & & & \\
\hline$\Delta R^{2}$ & & & & & & & & & & & & & & & 0.00 \\
\hline F change & & & & & & & & & & & & & & & 0.59 \\
\hline
\end{tabular}

$N=573 . \Delta R^{2}=$ change in $R^{2} .{ }^{*} p \leq 0.05 .{ }^{* *} p \leq 0.01 .{ }^{* * *} p \leq 0.001$.

the higher their perceptions of procedural justice. University employees' trust in their senior management, and their length of organizational tenure predicted justice as longer tenured employees perceived higher levels of justice. Of particular note, and unexpectedly, work pressure also positively predicted procedural justice.

The hierarchical regression analyses investigating the predictors of $\mathrm{T} 2$ procedural justice for academic staff are displayed in Table 4.

For academic staff, Table 4 shows that workplace factors predicted $36 \%$ of the variance in justice. After controlling for the T1 level of justice at Step 2, job satisfaction and work pressure were the strongest predictors of justice perceptions, however after the inclusion of the individual difference factors of negative affectivity and job involvement, the effects of work pressure did not endure and only job satisfaction remained a predictor of justice.

The hierarchical regression analyses investigating the predictors of perceived procedural justice for non-academic staff are displayed in Table 5.

Table 5 shows that for non-academic staff, workplace factors predicted $30 \%$ of the variance in justice perceptions. Consistent with the results for academic staff, job satisfaction was the strongest predictor of higher perceptions of procedural justice. However, there were differences between the two staff groups as non-academic employees' level of trust in their senior management and their length of organizational tenure also predicted perceived procedural justice. Indeed, in none of the three hierarchical regression analyses was negative affectivity nor job involvement related to employee perceptions of procedural justice. However, an unexpected finding was the negative relationship between non-academic employees' levels of organizational commitment and their justice perceptions. Whilst the effect of lower levels of commitment on justice did not endure when the individual characteristics were added to the analyses at Step 2, this unexpected result warrants further investigation.

\section{DISCUSSION}

This study employed workplace and individual difference characteristics through the theoretical frameworks of social exchange and the JD-R model to examine the factors that predicted employees' perceptions of procedural justice in the university setting. With regard to hypothesis 1 , and contrary to expectations, the job demand of work pressure positively predicted procedural justice for the "all staff" category which suggests that university employees who may feel under work or time pressure have higher perceptions of the fairness and justice of procedures than those who feel less pressured by work. While this result was not evident in the separate analyses for each of the two staff categories, it is of interest and warrants further investigation particularly in terms of the negative impact of job 
TABLE 4 | Multiple regression analyses of all predictors of T2 procedural justice for the academic staff category.

\begin{tabular}{|c|c|c|c|c|c|c|c|c|c|c|c|c|c|c|c|}
\hline Predictors & \multicolumn{4}{|c|}{ Step 1} & \multicolumn{5}{|c|}{ Step 2} & & \multicolumn{4}{|c|}{ Step 3} & \\
\hline Gender & 0.32 & 0.42 & 0.05 & 0.76 & & -0.12 & 0.36 & -0.02 & -0.34 & & 0.01 & 0.37 & 0.00 & 0.03 & \\
\hline Tenure & 0.02 & 0.03 & 0.06 & 0.72 & & 0.04 & 0.03 & 0.09 & 1.31 & & 0.04 & 0.03 & 0.09 & 1.40 & \\
\hline T1 Work pressure & & & & & & 0.85 & 0.39 & 0.14 & $2.18^{\star}$ & & 0.76 & 0.39 & 0.13 & 1.94 & \\
\hline T1 Autonomy & & & & & & -0.14 & 0.41 & -0.02 & -0.35 & & -0.14 & 0.41 & -0.02 & -0.33 & \\
\hline T1 Job satisfaction & & & & & & 0.05 & 0.02 & 0.22 & $2.37^{*}$ & & 0.05 & 0.02 & 0.20 & $2.10^{\star}$ & \\
\hline T1 Organizational commitment & & & & & & 0.03 & 0.27 & 0.01 & 0.10 & & -0.10 & 0.28 & -0.02 & -0.36 & \\
\hline T1 Trust in senior management & & & & & & -0.08 & 0.23 & -0.02 & -0.35 & & -0.05 & 0.23 & -0.01 & -0.21 & \\
\hline T1 Trust in supervisor & & & & & & -0.02 & 0.19 & -0.01 & -0.10 & & 0.02 & 0.20 & 0.01 & 0.12 & \\
\hline Adj. $R^{2}$ & & & & & -0.01 & & & & & & & & & & \\
\hline$F$ & & & & & 0.54 & & & & & & & & & & \\
\hline$\Delta R^{2}$ & & & & & & & & & & 0.36 & & & & & \\
\hline F change & & & & & & & & & & $14.92^{\star \star \star}$ & & & & & \\
\hline$\Delta R^{2}$ & & & & & & & & & & & & & & & 0.01 \\
\hline F change & & & & & & & & & & & & & & & 1.43 \\
\hline
\end{tabular}

$N=249 . \Delta R^{2}=$ change in $R^{2} .{ }^{*} p \leq 0.05 .{ }^{* *} p \leq 0.01 .{ }^{* * * *} p \leq 0.001$.

TABLE 5 | Multiple regression analyses of all predictors of T2 procedural justice for the non-academic (professional) staff category.

\begin{tabular}{|c|c|c|c|c|c|c|c|c|c|c|c|c|c|c|c|}
\hline Predictors & \multicolumn{4}{|c|}{ Step 1} & \multicolumn{5}{|c|}{ Step 2} & & \multicolumn{4}{|c|}{ Step 3} & \\
\hline Gender & -0.48 & 0.39 & -0.07 & -1.23 & & -0.48 & 0.34 & -0.07 & -1.41 & & -0.49 & 0.35 & -0.07 & -1.40 & \\
\hline Tenure & 0.03 & 0.03 & 0.07 & 1.08 & & 0.05 & 0.02 & 0.11 & $2.16^{\star}$ & & 0.05 & 0.02 & 0.11 & $2.20^{\star}$ & \\
\hline T1 Work pressure & & & & & & 0.36 & 0.31 & 0.07 & 1.17 & & 0.33 & 0.31 & 0.06 & 1.05 & \\
\hline T1 Job security & & & & & & 0.06 & -0.21 & 0.02 & 0.30 & & 0.06 & -0.21 & 0.02 & 0.29 & \\
\hline T1 Autonomy & & & & & & -0.67 & 0.37 & -0.12 & -1.9 & & -0.69 & 0.38 & -0.12 & -1.82 & \\
\hline T1 Job satisfaction & & & & & & 0.06 & 0.02 & 0.23 & $2.77^{\star \star}$ & & 0.06 & 0.02 & 0.23 & $2.76^{\star \star}$ & \\
\hline T1 Organizational commitment & & & & & & -0.58 & 0.29 & -0.12 & $-1.99^{\star}$ & & -0.55 & .31 & -0.11 & -1.78 & \\
\hline T1 Trust in senior management & & & & & & 0.89 & 0.25 & 0.22 & $3.58^{\star \star \star}$ & & 0.89 & 0.25 & 0.22 & $3.57^{\star \star \star}$ & \\
\hline Adj. $R^{2}$ & & & & & -0.00 & & & & & & & & & & \\
\hline$F$ & & & & & 0.88 & & & & & & & & & & \\
\hline$\Delta R^{2}$ & & & & & & & & & & 0.30 & & & & & \\
\hline F change & & & & & & & & & & $15.37^{\star \star \star}$ & & & & & \\
\hline$\Delta R^{2}$ & & & & & & & & & & & & & & & 0.00 \\
\hline F change & & & & & & & & & & & & & & & 0.27 \\
\hline
\end{tabular}

$N=324 . \Delta R^{2}=$ change in $R^{2} .{ }^{*} p \leq 0.05 .{ }^{* *} p \leq 0.01 .{ }^{* * *} p \leq 0.001$. 
demands on employee health and wellbeing as shown by the JD$\mathrm{R}$ research literature, and due to the negative effect of perceptions of unfair procedures in terms of decreased OCB, increased turnover intentions (Colquitt et al., 2001), and increased levels of psychological strain at work (Elovainio et al., 2001).

Hypothesis 2 was partially supported as employees' trust in senior management was positively associated with perceptions of justice which supports existing research (Folger and Konovsky, 1989; Saunders and Thornhill, 2003; Holtz and Harold, 2009). In addition, the demographic factor of an employees' length of organizational tenure predicted justice. The reason for this may be that as trust in senior management and perceptions of justice develop over time through the repeated interactions between employee-organization, it is likely that employees who trust senior management and perceive things to be done fairly are more likely to stay longer in the job. The results reveal the importance of workplace factors in enhancing fair procedures to encourage reciprocity from university employees. For the "all staff" category, and in partial support of hypothesis 3, job satisfaction was a dominant and enduring predictor of perceived procedural justice.

The two distinct staff categories (academic, non-academic) were analyzed separately in order to explore any occupation specific effects due to their different functional roles. There were differences in the predictors of procedural justice for academic and non-academic staff, as workplace factors for academics predicted $36 \%$ of the variance in justice perceptions, and job satisfaction and work pressure were the strongest predictors of perceived justice, however after the inclusion of the individual difference factors of negative affectivity and job involvement, only job satisfaction predicted perceived justice, partially supporting hypothesis 3 . As there have been long-term concerns about the low levels of job satisfaction in Australian academics (Bentley et al., 2013b), this study identifies the important link between job satisfaction and perceptions of justice. For nonacademic staff, workplace factors predicted $30 \%$ of the variance in justice perceptions, and consistent with the results for academic staff, and again in partial support of hypothesis 3, job satisfaction was the strongest predictor of higher perceptions of procedural justice. Nevertheless, there were differences between the two staff groups as non-academic employees' trust in their senior management (partially supporting hypothesis 2) and their length of organizational tenure predicted perceived justice. This result is supported by the organizational justice and trust literature and suggests that longer tenure employees have come to understand and appreciate the values represented by the organization (O'Reilly and Chatman, 1986). The findings are also consistent with prior research that academic employees report more adverse work experiences than non-academic employees (Winefield and Jarrett, 2001; Winefield et al., 2003, 2008).

With regard to hypotheses 4 and 5 , it is of interest that there were no associations between perceptions of procedural justice and the individual characteristics of negative affectivity and job involvement. The result for job involvement is particularly surprising given the strong association between an academics' work and their self-identity and that van Prooijen et al. (2002) found that social status was an important factor in procedural fairness concerns. Future research is needed in this area and there have been calls by Zhao et al. (2007) for research to also examine individual personality variables which may be particularly relevant in employees' affective reactions to breaches.

\section{Implications}

The strength of this study is its longitudinal design which provides results with practical implications for management. The results highlight the importance of workplace factors in enhancing the perceptions of fair procedures to encourage reciprocity from employees. Indeed, research has identified people's need to reduce uncertainty as the key component of why procedural justice is important to them (De Cremer and Blader, 2006). As procedural justice perceptions are also conceptually linked to the psychological contract between employees and employers, it is possible that employees' levels of job satisfaction and their perceptions of trust in senior management, relative to other work attitude outcomes, may be more effective for improving the broader working environment, and promoting staff wellbeing and morale. Given that prior psychological contract research has lacked "a theoretically based organizing framework” (Zhao et al., 2007, p. 649), the present study's integration of the JD-R theoretical framework demonstrates some progress in the area.

From an applied perspective, the importance of the workplace predictors identified in the study may assist university management to maintain or enhance current procedures and strategies. Organizations should look to ensure that processes are fair, transparent and just to increase justice perceptions. As noted in the literature (Bijlsma and Koopman, 2003), employee perceptions of trust in senior management and perceptions of procedural justice evolve over time through the repeated interactions between an employee and their employer, hence a strength of the study is the longitudinal approach that examines the effects of procedural justice perceptions across time.

The present study adds to research on applied business ethics as it focuses on the ethical aspects of procedural justice, psychological contracts, and the normative moral principles of autonomy, equality, and respect for individuals within employment relationships. Thibaut and Walker (1975, p. 212) posit that "the enactment of fair procedures is associated with the belief that one will be able to control one's own outcomes." By applying ethical principles consistent with Leventhal's (1980) principles of procedural justice, strategies for enhancing employee perceptions of procedural justice and thereby providing control, should include involving employees in the redesign of existing procedures, greater transparency and employee voice and participation in their implementation, consistency in applying the decisions, and clearer communication of the benefits of the procedures to employees.

\section{Limitations}

While the longitudinal design represents a methodological advantage, it is important to acknowledge that other uncontrolled characteristics of the sample may have influenced the results. The longitudinal analysis necessitated that participants remained 
employed at the same university for the period of the study, and that a sufficient number of employees were willing to respond to both waves of the data collection. It is possible that some participants, whose perceptions of justice may have declined significantly prior to the second wave, either left the university or failed to respond. Universities with high turnover, low response rates, or initially small staff numbers were thus probably under-represented in our sample. Though the study provides useful insights into the justice process, it has limitations. First, the data were collected by a self-report questionnaire that may be affected by social desirability. Second, the study was undertaken in the complex and hierarchical settings of universities with multiple faculties and tiers of management, and extensive numbers of employees so caution must be exercised in generalizing the findings to smaller and less structured organizations. Furthermore, and as asserted by Ruokolainen et al. (2016) universities are knowledge-based organizations in which employees may believe that it is their obligation to ensure their own wellbeing and to inform their employer about any concerns.

\section{Future Research}

Our findings provide an important insight into the specific workplace factors and processes that promote perceptions of justice in organizations. Given that Zhao et al. (2007) found that negative emotional reactions are a likely consequence of psychological contract breaches, future research is needed to investigate the role of procedural justice within organizations and, from an exchange perspective more broadly, how individual and workplace factors may function as resources to aid an organization to discharge its psychological contracts with employees by providing fair and just procedures. There is also a need to gain an important insight into the emotional reactions to procedural justice, specifically breaches of procedural justice.

\section{REFERENCES}

Ambrose, M. L., and Cropanzano, R. (2003). A longitudinal analysis of organizational fairness: an examination of reactions to tenure and promotion decisions. J. Appl. Psychol. 88, 266-275. doi: 10.1037/0021-9010.88.2.266

Ambrose, M. L., and Schminke, M. (2003). Organization structure as a moderator of the relationship between procedural justice, interactional justice, perceived organizational support, and supervisory trust. J. Appl. Psychol. 88, 295-305. doi: 10.1037/0021-9010.88.2.295

Arnold, J., Cooper, C. L., and Robertson, I. T. (1995). Work Psychology: Understanding Human Behaviour in the Workplace, 2nd Edn. London: Pitman Publishing.

Ashford, S. J., Lee, C., and Bobko, P. (1989). Content, causes, and consequences of job insecurity: a theory-based measure and substantive test. Acad. Manag. J. 32, 803-829.

Bakker, A. B., and Demerouti, E. (2007). The job demands-resources model: state of the art. J. Manag. Psychol. 22, 309-328. doi: 10.1108/02683940710733115

Beehr, T. A., Walsh, J. T., and Taber, T. D. (1976). Relationship of stress to individually and organizationally valued states: higher order needs as a moderator. J. Appl. Psychol. 61, 41-47.

Bentley, P., Coates, H., Dobson, I., Goedegebuure, L., and Meek, V. L. (2013a). "Academic job satisfaction from an international comparative perspective: factors associated with satisfaction across 12 countries," Job Satisfaction Around the Academic World (Dordrecht: Springer), 239-262
In conclusion, social exchange theory assumes that relationships are based on reciprocity, whereby a positive behavior is expected to be met with a positive response of equal benefit, followed by a continual exchange and interdependence between the two parties. This study adds to research on applied business ethics as it focuses on the ethical aspects of procedural justice and highlights the importance of workplace factors in enhancing fair procedures in organizational policy to encourage reciprocity from employees and the positive consequences of increasing employees' performance. An organization's employees are its most valuable resource and the effectiveness of organizations depends on healthy and engaged employees (Kinman, 1998). Hence, it is important that organizations focus their attention on implementing fair policies to enhance employees' prosocial and extra-role behaviors. Therefore, universities, as well as other organizations, need to continue to address the perceptions and experiences of staff in order to achieve long-term improvements in staff attitudes, and the corresponding benefits to organizational health and performance.

\section{AUTHOR CONTRIBUTIONS}

All four authors, SP, AW, CP, and CB contributed to the formulation and writing of this paper. SP also undertook the analyses.

\section{ACKNOWLEDGMENTS}

The research reported in this paper was supported by grants from the Australian Research Council and the National Tertiary Education Union, and contributions from the Vice Chancellors of the participating universities. The first author was supported by a Bellberry Limited PhD scholarship.

Bentley, P., Coates, H., Dobson, I., Goedegebuure, L., and Meek, V. L. (2013b). "Factors associated with job satisfaction amongst Australian university academics and future workforce implications," Job Satisfaction Around the Academic World (Dordrecht: Springer), $29-54$

Bijlsma, K., and Koopman, P. (2003). Introduction: trust within organisations. Pers. Rev. 32, 543-555. doi: 10.1108/00483480310488324

Bjørnstad, S., Patil, G. G., and Raanaas, R. K. (2015). Nature contact and organizational support during office working hours: benefits relating to stress reduction, subjective health complaints, and sick leave. Work 53, 9-20. doi: 10.3233/WOR-152211

Blau, P. M. (1964). Exchange and Power in Social Life. New York, NY: Wiley.

Boyd, C. M., Bakker, A. B., Pignata, S., Winefield, A. H., Gillespie, N., and Stough, C. (2011). A longitudinal test of the job demands-resources model among Australian university academics. Appl. Psychol. 60, 112-140. doi: 10.1111/j.1464-0597.2010.00429.x

Brown, G., Bemmels, B., and Barclay, L. J. (2010). The importance of policy in perceptions of organizational justice. Hum. Relat. 63, 1587-1609. doi: $10.1177 / 0018726710362273$

Budd, J. W. (2004). Employment with a Human Face: Balancing Efficiency, Equity, and Voice. Ithaca, NY: Cornell University Press.

Butler, J. K. (1991). Toward understanding and measuring conditions of trust: evolution of a conditions of trust inventory. J. Manag. 17, 643-663. doi: $10.1177 / 014920639101700307$ 
Coates, H., and Goedegebuure, L. (2010). The Real Academic Revolution: Why we Need to Reconceptualise Australia's Future Academic Workforce, and Eight Possible Strategies for How to Go About This. Research Briefing, LH Martin Institute.

Cohen, S. (2004). The Nature of Moral Reasoning. South Melbourne, VIC: Oxford University Press.

Colquitt, J. A., Conlon, D. E., Wesson, M. J., Porter, C. O. L. H., and Ng, K. Y. (2001). Justice at the millennium: a meta-analytic review of 25 years of organizational justice research. J. Appl. Psychol. 86, 425-445. doi: 10.1037// 0021-9010.86.3.425

Costa, P. T. Jr., and McCrae, R. R. (1992). Revised NEO Personality Inventory (NEO-PI-R) and NEO Five-Factor Inventory (NEO-FFI) Professional Manual. Odessa, FL: Psychological Assessment Resources.

Coyle-Shapiro, J. A. M., and Conway, N. (2005). Exchange relationships: examining psychological contracts and perceived organizational support. J. Appl. Psychol. 90, 774-781. doi: 10.1037/0021-9010.90.4.774

De Cremer, D., and Blader, S. (2006). Why do people care about procedural fairness? The importance of belongingness in responding and attending to procedures. Eur. J. Soc. Psychol. 36, 211-228. doi: 10.1002/ejsp. 290

DeFrank, R. S., and Ivancevich, J. M. (1998). Stress on the job: an executive update. Acad. Manag. Exec. 12, 55-66.

Delbridge, A., (ed.). (2001).The Macquarie dictionary. North Ryde, NSW: Macquarie Library.

Demerouti, E., Bakker, A. B., and Bulters, A. J. (2004). The loss spiral of work pressure, work-home interference and exhaustion: reciprocal relations in a three-wave study. J. Vocat. Behav. 64, 131-149. doi: 10.1016/S0001-8791(03) 00030-7

Demerouti, E., Bakker, A. B., Nachreiner, F., and Schaufeli, W. B. (2001). The job demands-resources model of burnout. J. Appl. Psychol. 86, 499-512. doi: 10.1037//0021-9010.86.3.499

Department of Education Science and Training [DEST] (2003). Staff 2003: Selected Higher Education Statistics. (Table 2). Canberra: DEST.

DeVellis, R. F. (1991). Scale Development: Theory and Applications (Applied Social Research Methods Series, Vol. 26). Newbury Park, CA: Sage.

Dewe, P. (1994). EAPs and stress management: from theory to practice to comprehensiveness. Pers. Rev. 23, 21-32.

Elovainio, M., Kivimäki, M., and Helkama, K. (2001). Organizational justice evaluations, job control, and occupational strain. J. Appl. Psychol. 86, 418-424. doi: 10.1037/0021-9010.86.3.418

Folger, R., and Cropanzano, R. (1998). Organizational Justice and Human Resource Management. Thousand Oaks, CA: Sage.

Folger, R., and Greenberg, J. (1985). "Procedural justice: an interpretive analysis of personnel systems," in Research in Personnel and Human Resource Management, eds K. M. Rowland and G. R. Ferris (Greenwich, CT: JAI Press), 141-183.

Folger, R., and Konovsky, M. A. (1989). Effects of procedural and distributive justice on reactions to pay raise decisions. Acad. Manag. J. 32, 115-130.

Frone, M. R., and Yardley, J. K. (1996). Workplace family-supportive programmes: predictors of employed parents' importance ratings. J. Occup. Organ. Psychol. 69, 351-366.

Geurts, S. A. E., Kompier, M. A. J., Roxburgh, S., and Houtman, I. L. D. (2003). Does work-home interference mediate the relationship between workload and well-being? J. Vocat. Behav. 63, 532-559. doi: 10.1016/S0001-8791(02)00025-8

Gillespie, N. A., Walsh, M., Winefield, A. H., Dua, J., and Stough, C. (2001). Occupational stress in universities: staff perceptions of the causes, consequences and moderators of stress. Work Stress 15, 53-72. doi: $10.1080 / 02678370117944$

Giorgi, G., Leon-Perez, J. M., Cupelli, V., Mucci, N., and Arcangeli, G. (2014). Do $\mathrm{i}$ just look stressed or am i stressed? work-related stress in a sample of Italian employees. Ind. Health 52, 43-53. doi: 10.2486/indhealth.2012-0164

Greenberg, J. (1994). Using socially fair treatment to promote acceptance of a work site smoking ban. J. Appl. Psychol. 79, 288-297. doi:10.1037/0021-9010.79.2.288

Hallberg, U. E., and Schaufeli, W. B. (2006). "Same Same" but different? Can work engagement be discriminated from job involvement, and organizational commitment? Eur. Psychol. 11, 119-127. doi: 10.1027/1016-9040.11.2.119

Hoffman, B. J., Blair, C. A., Meriac, J. P., and Woehr, D. J. (2007). Expanding the criterion domain? A quantitative review of the OCB literature. J. Appl. Psychol. 92, 555-566. doi: 10.1037/0021-9010.92.2.555
Holtz, B. C., and Harold, C. M. (2009). Fair today, fair tomorrow? A longitudinal investigation of overall justice perceptions. J. Appl. Psychol. 94, 1185-1199. doi: $10.1037 / \mathrm{a} 0015900$

Kanungo, R. N. (1982). Measurement of job and work involvement. J. Appl. Psychol. 67, 341-349.

Kinman, G. (1998). Pressure Points: A Survey into the Causes and Consequences of Occupational Stress in U. K. Academic and Related Staff. London: London Association of University Teachers.

Kinman, G. (2001). Pressure points: review of research on stressors and strains in UK academics. Educ. Psychol. 21, 473-492. doi: 10.1080/014434101200 90849

Kinman, G., and Jones, F. (2008). Effort-reward imbalance, over-commitment and work-life conflict:testing an expanded model. J. Manag. Psychol. 23, 236-251. doi: 10.1108/02683940810861365

Landsbergis, P. A., Schnall, P. L., Deitz, D., Friedman, R., and Pickering, T. (1992). The patterning of psychological attributes and distress by "job strain" and social support in a sample of working men. J. Behav. Med. 15, 379-405. doi: 10.1007/BF00844730

Leventhal, G. S. (1980). "What should be done with equity theory?, in Social Exchange: Advances in Theory and Research, eds K. J. Gergen, M. S. Greenberg, and R. H. Willis (New York, NY: Plenum Press), 27-55.

Li, A., and Cropanzano, R. (2009). Fairness at the group level: justice climate and intraunit justice climate. J. Manag. 35, 564-599. doi: $10.1177 / 0149206308330557$

Locke, E. A. (1969). What is job satisfaction? Organ. Behav. Hum. Perform. 4, 309-336.

Lodahl, T., and Kejner, M. (1965). The definition and measurement of job involvement. J. Appl. Psychol. 49, 24-33.

Marmot, M., Theorell, T., and Siegrist, J. (2002). "Work and coronary heart disease," in Stress and the Heart, eds S. Stansfeld and M. Marmot (London: BMJ Books), 50-71.

Masterson, S. S., Lewis, K., Goldman, B. M., and Taylor, M. S. (2000). Integrating justice and social exchange: the differing effects of fair procedures and treatment on work relationships. Acad. Manag. J. 43, 738-748. doi: $10.2307 / 1556364$

May, L., Collins-Chobanian, S., and Wong, K. (1998). Applied Ethics: A Multicultural Approach. Upper Saddle River, NJ.: Prentice Hall.

Mayer, R. C., and Davis, J. H. (1999). The effect of the performance appraisal system on trust for management: a field quasi-experiment. J. Appl. Psychol. 84, 123-136. doi: 10.1037/0021-9010.84.1.123

Mayer, R. C., Davis, J. H., and Schoorman, F. D. (1995). An integrative model of organizational trust. Acad. Manag. Rev. 20, 709-734.

Moos, R. H., and Insel, P. N. (1974). Work Environment Scale. Palo Alto, CA: Consulting Psychologists Press.

Mucci, N., Giorgi, G., Cupelli, V., and Arcangeli, G. (2014). Future health care workers-mental health problems and correlates. World Appl. Sci. J. 30, 710-715. doi: 10.5829/idosi.wasj.2014.30.06.8244

Mucci, N., Giorgi, G., Cupelli, V., Gioffrè, P. A., Rosati, M. V., Tomei, F., et al. (2015). Work-related stress assessment in a population of Italian workers. the stress questionnaire. Sci. Tot. Environ. 502, 673-679. doi: 10.1016/j.scitotenv.2014.09.069

Nunnally, J. C., and Bernstein, I. H. (1994). Psychometric Theory. New York, NY: McGraw-Hill.

O'Reilly, C., and Chatman, J. (1986). Organizational commitment and psychological attachment: the effects of compliance, identification, and internalization on prosocial behavior. J. Appl. Psychol. 71, 492-499.

Organ, D. W. (1988). Organizational Citizenship Behavior: The Good Soldier Syndrome. Lanham, MA: Lexington Books.

Organ, D. W., and Konovsky, M. (1989). Cognitive vs. affective determinants of organizational citizenship behavior. J. Appl. Psychol. 74, 157-164.

Pignata, S. (2011). Stress Interventions: Their Impact on Psychological Well-being and Work Attitudes in Australian University Staff. Unpublished $\mathrm{PhD}$ thesis, School of Psychology, Social Work and Social Policy, University of South Australia.

Pignata, S., Boyd, C. M., Gillespie, N., Provis, C., and Winefield, A. H. (2016). Awareness of stress-reduction interventions: the impact on employees' wellbeing and organizational attitudes. Stress Health 32, 231-243. doi: 10.1002/smi. 2597 
Porter, L. W., Steers, R. M., Mowday, R. T., and Boulian, P. V. (1974). Organizational commitment, job satisfaction, and turnover among psychiatric technicians. J. Appl. Psychol. 59, 603-609. doi: 10.1037/h0037335

Rhoades, L., and Eisenberger, R. (2002). Perceived organizational support: a review of the literature. J. Appl. Psychol. 87, 698-714. doi: 10.1037/0021-9010.87.4.698

Robinson, S. L., and Morrison, E. W. (1995). Psychological contracts and OCB: the effect of unfulfilled obligations on civic virtue behavior. J. Organ. Behav. 16, 289-298.

Rousseau, D. M., and Parks, J. M. (1992). The contracts of individuals and organizations. Res. Organ. Behav. 15, 1-43.

Ruokolainen, M., Mauno, S., Diehl, M., Tolvanen, A., Mäkikangas, A., and Kinnunen, U. (2016). Patterns of psychological contract and their relationships to employee well-being and in-role performance at work: longitudinal evidence from university employees. Int. J. Hum. Resour. Manag. 1-24. doi: 10.1080/ 09585192.2016.1166387

Saks, A. M. (2006). Antecedents and consequences of employee engagement. J. Manag. Psychol. 21, 600-619. doi: 10.1108/02683940610690169

Saunders, M., and Thornhill, A. (2003). Organisational justice, trust and the management of change: an exploration. Emer. Pers. Rev. 32, 360-374. doi: 10.1108/00483480310467660

Schaufeli, W. B., and Bakker, A. B. (2004). Job demands, job resources, and their relationship with burnout and engagement: a multi-sample study. J. Organ. Behav. 25, 293-315. doi: 10.1002/job.248

Siegrist, J. (1996). Adverse health effects of high-effort/low-reward conditions. J. Occup. Psychol. 1, 27-41.

Singer, P.(ed.). (1994). Ethics. Oxford; New York, NY: Oxford University Press.

Somech, A., and Drach-Zahavy, A. (2004). Exploring organizational citizenship behaviour from an organizational perspective: the relationship between organizational learning and organizational citizenship behaviour. J. Occup. Organ. Psychol. 77, 281-298. doi: 10.1348/0963179041752709

Thibaut, J., and Walker, L. (1975). Procedural Justice: A Psychological Analysis. Hillsdale, NJ: Lawrence Erlbaum.

van Prooijen, J., van den Bos, K., and Wilke, H. A. M. (2002). Procedural justice and status: status salience as antecedent of procedural fairness effects. J. Pers. Soc. Psychol. 83, 1353-1361. doi: 10.1037//0022-3514.83.6.1353
Warr, P. B., Cook, J., and Wall, T. D. (1979). Scales for the measurement of some work attitudes and aspects of psychological wellbeing. J. Occup. Psychol. 52, 129-148.

Watson, D., and Clark, L. A. (1984). Negative affectivity: the disposition to experience aversive emotional states. Psychol. Bull. 96, 465-490.

Winefield, A. H., Gillespie, N., Stough, C., Dua, J., and Hapuarachchi, J. (2002). Occupational Stress in Australian Universities: A National Survey [Report]. Melbourne, VIC: National Tertiary Education Union.

Winefield, A. H., Gillespie, N., Stough, C., Dua, J., Hapuarachchi, J. R., and Boyd, C. M. (2003). Occupational stress in Australian university staff: results from a national survey. Int. J. Stress Manag. 10, 51-63. doi: 10.1037/1072-5245. 10.1.51

Winefield, A. H., and Jarrett, R. J. (2001). Occupational stress in university staff. Int. J. Stress Manag. 8, 285-298. doi: 10.1023/A:101751 3615819

Winefield, T., Boyd, C., Saebel, J., and Pignata, S. (2008). Update on national university stress study. Aust. Univ. Rev. 50, 20-29.

Zapf, D., Dormann, C., and Frese, M. (1996). Longitudinal studies in organizational stress research: a review of the literature with reference to methodological issues. J. Occup. Health Psychol. 1, 145-169. doi: 10.1037/10768998.1.2.145

Zhao, H., Wayne, S. J., Glibkowski, B. C., and Bravo, J. (2007). The impact of psychological contract breach on work-related outcomes: a meta-analysis. Pers. Psychol. 60, 547-680. doi: 10.1111/j.1744-6570.2007.00087.x

Conflict of Interest Statement: The authors declare that the research was conducted in the absence of any commercial or financial relationships that could be construed as a potential conflict of interest.

Copyright (c) 2016 Pignata, Winefield, Provis and Boyd. This is an open-access article distributed under the terms of the Creative Commons Attribution License (CC BY). The use, distribution or reproduction in other forums is permitted, provided the original author(s) or licensor are credited and that the original publication in this journal is cited, in accordance with accepted academic practice. No use, distribution or reproduction is permitted which does not comply with these terms. 
OPEN ACCESS

Edited by: Pablo Fernández-Berrocal, University of Málaga, Spain

Reviewed by:

M. Teresa Anguera, University of Barcelona, Spain Dina Guglielmi,

University of Bologna, Italy

*Correspondence: Gabriele Giorg gabriele.giorgi@unier.it

Specialty section: This article was submitted to Organizational Psychology, a section of the journal Frontiers in Psychology

Received: 07 June 2016 Accepted: 28 October 2016 Published: 27 December 2016

Citation:

Giorgi G, Dubin D and Fiz Perez J (2016) Perceived Organizational Support for Enhancing Welfare at Work: A Regression Tree Model. Front. Psychol. 7:1770 doi: 10.3389/fpsyg.2016.01770

\section{Perceived Organizational Support for Enhancing Welfare at Work: A Regression Tree Model}

\author{
Gabriele Giorgi ${ }^{1 *}$, David Dubin ${ }^{2}$ and Javier Fiz Perez ${ }^{1}$ \\ ${ }^{1}$ Department of Psychology, European University of Rome, Rome, Italy, ${ }^{2}$ Psychological ARTS, Austin, TX, USA
}

When trying to examine outcomes such as welfare and well-being, research tends to focus on main effects and take into account limited numbers of variables at a time. There are a number of techniques that may help address this problem. For example, many statistical packages available in R provide easy-to-use methods of modeling complicated analysis such as classification and tree regression (i.e., recursive partitioning). The present research illustrates the value of recursive partitioning in the prediction of perceived organizational support in a sample of more than 6000 Italian bankers. Utilizing the tree function party package in $\mathrm{R}$, we estimated a regression tree model predicting perceived organizational support from a multitude of job characteristics including job demand, lack of job control, lack of supervisor support, training, etc. The resulting model appears particularly helpful in pointing out several interactions in the prediction of perceived organizational support. In particular, training is the dominant factor. Another dimension that seems to influence organizational support is reporting (perceived communication about safety and stress concerns). Results are discussed from a theoretical and methodological point of view.

Keywords: perceived organizational support, work-related stress, welfare, health promotion, workplace, organizational psychology

\section{INTRODUCTION}

Employee welfare is an "umbrella concept" including various services, benefits, and facilities offered to employees with the aim of fostering their working conditions and professional growth. Assessments of welfare measures are both objective and subjective. The former includes interventions regarding allowances, housing, transportation, medical insurance, wellness coverage, and so on (Schmitz and Schrader, 2015). The latter includes less tangible benefits such as perceived working conditions, the interpersonal environment in which work takes place, and organizational actions and support perceived by employees (Zhong et al., 2016).

Popular discourse suggests employees working under stressful conditions or experiencing problems in life-balance are increasing. As a result, it is important to examine factors that can foster personal well-being and professional growth with a potential return of investment in terms of higher productivity and greater loyalty. Indeed, employees who perceive that their organization is supportive show higher performance, proactive behaviors, reduced absenteeism, and a lessened intention of quitting their job (Eisenberger et al., 1997; Riggle et al., 2009; Arshadi and Hayavi, 2013; Caesens et al., 2016). 
Such an analysis is particularly important given that in some countries (e.g., Southern-Europe) the economic crisis is still ongoing with negative consequences for salaries and job stability (Mucci et al., 2016). In Italy, for instance, salaries have not increased significantly in the last 7 years, and salaries for public employees have remained frozen (Italian National Institute of Statistic-Istat, 2015). Consequently, as renumeration cannot be the first driver of employee motivation, non-economical reward is increasing with the aim of fostering perceived organizational support (see for instance the inter-ministries decree, 25 march, 2016 that introduce favorable taxation for welfare activities, Ministro del Lavoro e delle Politiche Sociali and Ministro dell'Economia e delle Finanze, 2016). Consequently, under economic turbulence, organizational support is crucial for developing employees' productivity and achieving business success (Choi and Lin, 2009).

The goal of the current paper is to present a recursive partitioning analysis in order to examine combinations of working conditions and organizational variables that contribute to employees' perceptions of organizational support.

\section{Perceived Organizational Support and Health}

Perceived organizational support (POS) is defined as the employees' "beliefs concerning the extent to which the organization values their contribution and cares about their well-being" (Eisenberger et al., 1986, p. 501).

Organizational support literature theorizes that a factor of business success is the extent employees develop beliefs concerning organization orientation to employees' welfare such as the organization valuing employees' contributions and caring about their well-being (Eisenberger and Stinglhamber, 2011). On one hand, employees develop an organization's identification evaluating the received treatment in the workplace. This perception is important both for business success and employee health (Eisenberger et al., 2002). On the other hand, social exchange theorists argue that receiving increased welfare activities from their organizations might contribute more to success. Specifically, employees compensate their employer with higher work performance (Eisenberger et al., 1986).

In a systematic review of 70 studies, Rhoades and Eisenberger (2002) found that positive organizational support is related to fair organizational procedures, supervisor support, and favorable rewards and job conditions, which in turn lead to positive outcomes for both the individual and the organization, such as increased affective commitment to the organization, increased performance, and reduced withdrawal behaviors.

In particular, Riggle et al. (2009) conducted an important meta-analytic study including 167 works. Results indicated that POS had a strong association with job satisfaction, organizational commitment, and intention to leave; whereas only moderate, positive effect on employee performance.

Research has pointed out that work organizations can be regarded as "employees' perceptions" as they represent contexts where people tend to assign the organization humanlike characteristics (Eisenberger et al., 1986) considering the company having its own unique capability, just like people do. Indeed POS seems characterized by specific psychological processes: the reciprocity norm, - the employee's felt obligation to care about the organization's welfare and to help the organization reach its mission-, the fulfillment of socio-emotional needsleading employees to identify positively in the organization-, the development of beliefs that the organization recognizes and rewards increased performance (i.e., performance-reward expectancies; Rhoades and Eisenberger, 2002; Eisenberger et al., 2014; Kurtessis et al., 2015).

In the first process, when employees trust their organization they develop a sense of obligation. They might work harder as well as increasing voluntary citizenship behaviors because the basis of social exchange is the norm of reciprocity (Eisenberger et al., 1986, 2001; Rhoades and Eisenberger, 2002).

In the second process, employees consider their organization a source of social and emotional resources and are dedicated to work because they feel valued, cared for, and esteemed. As a consequence emotional identification toward the organization (brand, costumers) may increase with a higher levels of teamwork satisfaction and an increased perception of the positive image of the company (Eisenberger et al., 1990; Edwards, 2009; Edwards and Peccei, 2010).

Finally, the belief that one is being rewarded fairly in the organization motivates employees to work well and engage in activities without tangible rewards (e.g., extra role behaviors) (Rhoades and Eisenberger, 2002).

An increasingly important aspect central to the psychological process of the perceived organizational support theory is the perceived consideration of employee well-being and welfare.

Accordingly, a systematic review on POS conducted by Baran et al. (2012) analyzed 249 studies and found that the primary theoretical theme in association with POS was employee wellbeing $(n=43)$.

In particular, employees who experience lower levels of welfare and wellbeing might deteriorate the reciprocation psychological process when they don't feel organizationally and emotionally supported (e.g., when employees experience organizational stress).

Accordingly, social exchange theory points out that POS is negatively associated with stress (Baran et al., 2012). For instance companies who care about their employees' well-being are more likely to improve working conditions and job design, such as reducing conflicting job requirements (Jawahar et al., 2007) or bullying and incivility in workplace (Miner et al., 2012).

Additionally, POS, fulfilling socio-emotional needs, increase employees organizational membership, and role status (Rhoades and Eisenberger, 2002) and this plays a central role in developing a healthy employee-employer relationship and in reducing stress. POS fulfills emotional needs, decreases strain and thus enhances well-being (Byrne and Hochwarter, 2006).

Furthermore, several researches found an association between POS with health-related variables such as sense of accomplishment (Jain and Sinha, 2005), organization-based self-esteem (Lee and Peccei, 2007), general health (Bradley and 
Cartwright, 2002), decreased burnout (Kang et al., 2010), and anger (O'Neill et al., 2009).

As far as POS antecedents is concerned, job conditions (such as aspects of training, job discretion, role stressors, relations in workplace), seem to have a impact. These job characteristics overlap with the concept of stress, especially if we consider recent expanded models that go beyond job demand and job control based models (see for instance Giorgi et al., 2013). Similarly, individual antecedent such as personality factors and sociodemographic variables seemed to have a weaker relationship with POS (Baran et al., 2012).

Our theoretical framework is based on the proposition that POS is associated with job characteristics of the working environment such as stress and welfare related factors.

\section{POS Organizational Antecedents}

Recently, a further systematic study and meta-analysis were conducted on POS pointing out its antecedents. Findings of the Ishfaq and Muhammad' (2015) review work, which included 170 studies, revealed that POS was mainly linked to justice, growth opportunities, supervisor support, and coworkers support.

Kurtessis et al. (2015) performed a meta-analysis, which included 492 papers containing 558 studies, grouped antecedents of POS into three categories: (a) treatment by organization members, (b) employee-organization relationship quality, (c) HR practices and job conditions.

In particular, job conditions played a substantial role in establishing POS, with employees being inclined to perceive organizational support as a way to reciprocate adequate working conditions (Shore et al., 2006; Kurtessis et al., 2015).

In addition, Kurtessis et al.'s study posited that POS is connected to favorable social interactions, both with colleagues and supervisors, with the latter more significant because leaders are perceived as representative of the organizations (Stinglhamber and Vandenberghe, 2003). Finally, contextual factors that convey the organization's regard for employees were associated with POS: common values shared with employee, psychological contracts, fairness of treatment, and perceived organizational politics (e.g., Eisenberger et al., 2001) An organizational factor not extensively investigated by the literature in connection with POS is training.

Conversely, high organizational concern with developing employees is linked with health and business success and might stimulate in workers a general felt obligation to reciprocate toward the organization in positive manner (Eisenberger et al., 1990; Kurtessis et al., 2015).

Instead, research has more recently looked at the relationship between low or high level of POS with safety perception. Safety climate seemed to play an important role in POS (Wallace et al., 2006). Similarly, as noted by Mearns and Reader (2008), the reporting of errors of unsafe situations was associated positively POS. On the other hand, the association of POS with safety seemed to be influenced by further variables (job demand, leadership, etc.) as previously noted.

Kath et al. study (2010) suggested that safety perception, as other stress related working conditions, have likely important associations with POS but do not represent exclusive antecedents (Kurtessis et al., 2015). To sum up, various stressors and strains need to be investigated in order to delineate more clearly the combination of interrelated processes that may occur in POS.

Accordingly, although meta-analysis exists in the field of POS (Kurtessis et al., 2015), current research offers limited empirical evidence of the work-related mechanisms and psychological processes potentially interacting in relation to perceived organizational support.

Given that multiple dimensions and distinguished categories have been suggested in studying POS, we expect specific combinations of antecedents (e.g., working conditions, social support, and work pressure) that interact with one another to impact worker's perceptions. This is also in accordance with theorists who advocate that the investigations of concurrent interconnected organizational variables for the prediction of several outcomes (Scott et al., 2011).

In doing so, we use regression tree analysis to explore main perceived organizational support relationships with correlated organizational and stress factors.

\section{Recursive Partitioning Models and Applications in the Health Field}

Of the parametric methods used in occupational health, regression is the most common. Regression carries with it a laundry list of requirements including linearity, normality, independence of error terms, and constant variance of error terms that need to be met in order to perform well (i.e., have unbiased parameter estimates). However, it is often the case in health research and practice that these conditions are not met or is overly restrictive. A particular limitation associated with parametric models is that it is challenging to estimate and interpret interactions occurring amongst more than two variables or to model the impact of variables with non-linear functional forms (Strobl et al., 2009a).

Yet, when trying to examine outcomes such as well-being, research tends to focus on main effects, and take into account limited numbers of variables at a time.

Regression tree models are based on graphs in which each circle in the diagram reflects a binary splitting point (i.e., a splitting node) in the model. Specifically, the application of graphical models on work related stress is motivated by the possibility to describe graphically the multitude of relations and dependencies among different variables. Recursive partitioning has been used in a variety of different fields to explain drug treatment retention (Hellemann et al., 2009) survival of cancer patients (Grossman and Ram, 2014); treatment effects in clinical trials (Doove et al., 2014); clusters in genomics (Nilsen et al., 2013); intimate partner violence (Salis et al., 2014); and to help detect problem gamblers (Markham et al., 2013), among others. 
The present research illustrates the value of recursive partitioning in the prediction of perceived organizational support in a sample of more than 6000 Italian bankers.

\section{MATERIALS AND METHODS}

\section{Procedure and Participants}

Data were collected by a team of researchers with the aim of measuring work-related stress and perceived organizational support. The survey was designed in accordance with privacy and anonymity regulations and was administered on-line through the company intranet. In particular, employees were informed of the purpose of the assessment and of the aggregate data analysis performed by qualified academic researchers. Information of data protection were presented in a precise manner, so the test-takers' security was enhanced.

The target population was an Italian national bank with multiple locations widespread in Italy. All the employees were invited to fill in the questionnaire on the bank intranet portal.

The participation for the study was considerable for on-line survey, as around $30 \%$ of employees filled in the questionnaire. Questionnaires with more than four missing items were deleted from the database in order to increase the validity of the research. The final sample consisted of 6588 bankers (of which $57.5 \%$ were males). In addition, $4.3 \%$ of the respondents were $<30$ years old, $26.5 \%$ were $31-40$ years old, $38.7 \%$ were $41-50$ years, $28.7 \%$, were between 51 and 60 years old; $1.7 \%$ of the respondents were over 60 years old. Regarding job seniority, $9.7 \%$ of the respondents had worked for up to 7 years in their current company; $25.1 \%$ for 8 15 years, $42.3 \%$ for, $16-30$ years $22.8 \%$ for more than 30 years. Finally, 91\% were office workers whereas $9 \%$ were managers or middle managers who co-ordinated a team.

\section{Measures}

The Stress Questionnaire (SQ) was chosen for this investigation because it is a validated Italian tool that measures not only work-related stress but also organizational perceptions. In brief, SQ has multiple scales which investigate classical stressors as well as emergent stressors and contextual variables. All the utilized scales are part of the SQ and detailed information can be found in the test validation study (Giorgi et al., 2013). The "Psychosocial risk scale of the Stress Questionnaire" (Giorgi et al., 2013) consists of 25 items and 5 subscales: job demand, lack of job control, role conflict, lack of supervisors' support, and lack of colleagues' support. A 5 point Likert scale ranging from 1 (absolutely agree) to 5 (absolutely disagree) was used: (a) role conflict, which measures the perception of lack of awareness in their roles and responsibilities (5 items: e.g., "I have a clear idea about what is expected of me at work," reverse scored) Alpha.84; (b) lack of colleagues' support or collaboration and support among employees (5 items: e.g., "I get the support I need from colleagues," reverse score it's difficult to assess whether my colleagues are competent") Alpha.79; (c) lack of supervisors' support or the extent to which employees don't experience support and understanding from their supervisors/leaders (5 items: e.g., "My supervisor energizes me at work," reverse scored "My supervisor is neither competent nor self-confident") Alpha.82; (d) job demands, which refers to quantitative, demanding aspects of the job (6 items: e.g., "I have unrealistic deadlines," "I'm under pressure at work"), Alpha.81; and e) lack job control or job resources that pertain to the task (5 items: e.g., "I can plan my work," reverse scored "I'm fully autonomous in choosing my working tools" reverse scored) Alpha.77. The factorial structure and the reliability of this scale have been supported in previous studies (Giorgi et al., 2013).

The scale "Perceived organizational support" comprises 4 items in a 5-point Likert-scale (from 1: "strongly disagree" to 5: "strongly agree") and measures the extent to which the organization values and cares for employees' welfare (e.g., "This organization pays little attention to the interests and well-being of its employees" reverse coded-; "This organization tries to take care of its employees' welfare"), Alpha.82. Consequently, after computing a total mean score, a higher score refers to higher perceived organizational support. This scale was included in the Stress Questionnaire (Giorgi et al., 2013).

The scale "Traning" consist of 3 items in a 5-points Likertscale (from 1: "strongly disagree" to 5: "strongly agree") and measures the perceived quality of training in workplace (e.g., "This organization trains adequately employees for performing job tasks" reverse scored; "employees are not well trained when they have to use a new tool/equipment"), Alpha.74.

Higher scores mean that employees perceived a lack of training or low quality training. This scale is part of the Stress Questionnaire (Giorgi et al., 2013).

The scale "Reporting" measures the employees' perception of an unsafe and unhealthy environment wherein procedures of safety and health are invisible or discouraged/under-reported ("workers are not trained neither informed about job related risks; "I can freely report stress and safety risks perceptions-for me and for others" (reverse coded) Alpha.52. It was measured using a four-item scale of the Stress Questionnaire (Giorgi et al., 2013).

\section{Analysis}

Descriptives, Alpha of Conbrach, and correlation were calculated.

Regression Tree analysis was used beginning with a generation of a root node. After, a splitting rule based on algorithm, determined cutoff points that minimize the within-group variance on the outcomes. Progressively further binary splits were performed in order to divide the sample into subsamples, called nodes that ended finally in terminal nodes at the bottom of the figure.

\section{RESULTS}

Descriptive statistics and correlations are displayed in Table 1. As expected, Stress questionnaire variables were related to POS.

Utilizing the ctree function party package in $\mathrm{R}$ (Hothorn et al., 2015; see also Strobl et al., 2009b), we estimated a regression tree model predicting perceived organizational support from the Stress Questionnaire. The optimal tree identified is displayed in Figure 1. 
TABLE 1 | Descriptive statistics and correlations.

\begin{tabular}{|c|c|c|c|c|c|c|c|c|c|c|}
\hline Variables & $M$ & $S D$ & 1 & 2 & 3 & 4 & 5 & 6 & 7 & 8 \\
\hline 1. Job demand & 3.21 & 0.75 & $(0.81)$ & & & & & & & \\
\hline 2. Lack of job control & 2.86 & 0.71 & $0.51^{* \star}$ & $(0.77)$ & & & & & & \\
\hline 4. Lack of supervisors support & 2.60 & 0.85 & $0.25^{\star \star}$ & $0.34^{* *}$ & $0.34^{* *}$ & $(0.82)$ & & & & \\
\hline 5. Lack of colleagues support & 2.48 & 0.69 & $0.34^{\star \star}$ & $0.38^{\star \star}$ & $0.29^{* *}$ & $0.51^{\star \star}$ & $(0.79)$ & & & \\
\hline 8. Reporting & 2.98 & 0.61 & $0.36^{\star \star}$ & $0.43^{\star *}$ & $0.33^{\star \star}$ & $0.36^{\star \star}$ & $0.38^{\star \star}$ & $0.49^{* \star}$ & $0.54^{\star \star}$ & $(0.52)$ \\
\hline
\end{tabular}

Internal Consistency coefficients (Cronbach's alphas, Cronbach, 1951) appear along the diagonal in parentheses. ${ }^{\star \star} p<0.01$.

The ctree function performs recursive partitioning using a conditional inference framework developed by Strasser and Weber (1999). For this study, recursive partitioning was carried out by first testing the global null hypothesis of independence between any of the job characteristics and POS. Based on this initial analysis, it was determined that several dependencies between POS and the job characteristics existed and, of these, splitting the training variable into two groups (above and below 2.667) had the strongest association to POS. The strength of the association is measured by the $p$-value corresponding to a test for the partial null hypothesis of the training variable and POS. Because this binary split on the training variable holds the strongest association with POS it appears at the top of the tree (i.e., node 1). Continuing on from node 1, the tree splits and recursively repeats the first step; i.e., searching for the strongest association between the remaining job characteristics or other splits of the variable that has already been split-in this case the training variable. Following the tree diagram in Figure 1 to node 2, the largest association occurs with the same variable (i.e., training), but this time at a binary split of 1.667. At this location of the tree, the data is again split into those employees below 1.667 on the training variable and those above 1.667 but $<2.667$, the split on node 1 . On the other side of the tree at node 21, the strongest association with POS for those employees who perceive a high degree of training (i.e., > 2.667) is with the variable of reporting split into groups at a score of 3 . The analysis ends when no additional associations meet the criteria for a meaningful association. In this study, the criterion was set where an association must have a $p<0.000000001$ in order to avoid capitalizing on effects due to chance. The bottom of the figure displays the terminal nodes and the distribution of perceived organizational support for individuals falling into each of the categories.

Overall, the figure illustrates a number of "pathways" to perceived organizational support. For example, particularly high levels of perceived organizational support occur amongst those who strongly feel they can report stress and safety risk perceptions (reporting) and among those workers who perceive they are trained (training; node 37). High levels of perceived organizational support also occur when individuals have lower levels of training (compared to node 37) but perceive more job control (node 32). POS is lowest amongst those who have low training, reporting, and job control (node 5). Note that variables not in the tree do not contribute significantly to the purity (i.e., homogeneity) of categories.

It's worthwhile to note that training is the primary splitter at the root node (Node 1) and appears again in several root nodes (Node 2, 7, 17, 27, 30,33) demonstrating that, the extent of perceived training in workplace, generates different profiles. Reporting also appears multiple times within the tree (Node 3, 10, 21, 22).

For those who report medium levels of supervisor support and reporting (Node 14 and 22), job demand further explains differences in overall level of perceived organizational support.

Finally, multiple pathways to perceived organizational support are evident in the terminal nodes, with the contribution of the majority of the tested variables.

Further results are found by following the pathways in the figure below.

\section{DISCUSSION AND CONCLUSIONS}

The field of organizational psychology has amassed numerous predictors of key outcomes (e.g., job performance, well-being), yet our standard regression methods prohibit modeling a large number of these predictors simultaneously, testing them against each other or, perhaps more importantly, examining how they function in conjunction.

It is precisely these challenges for which non-parametric data mining techniques are suited. In particular, techniques such as recursive partitioning can be fruitfully applied to high dimensionality problems (i.e., small $\mathrm{n}$, large $\mathrm{p}$ ), complex data structures, and problems with many predictor variables (Strobl et al., 2009b). These methods have the potential to greatly improve prediction.

In this study, we examined a diverse set of organizational variables, using the novel approach of Regression Tree, which identified combinations among predictors of POS. In particular we considered supportive welfare practices in the wellbeing/stress area relevant to determining employee POS.

Study aims linked to a recent meta-analytic literature emphasizing the simultaneous examination and the interactive nature of the causes of POS. It also resonates well with the 


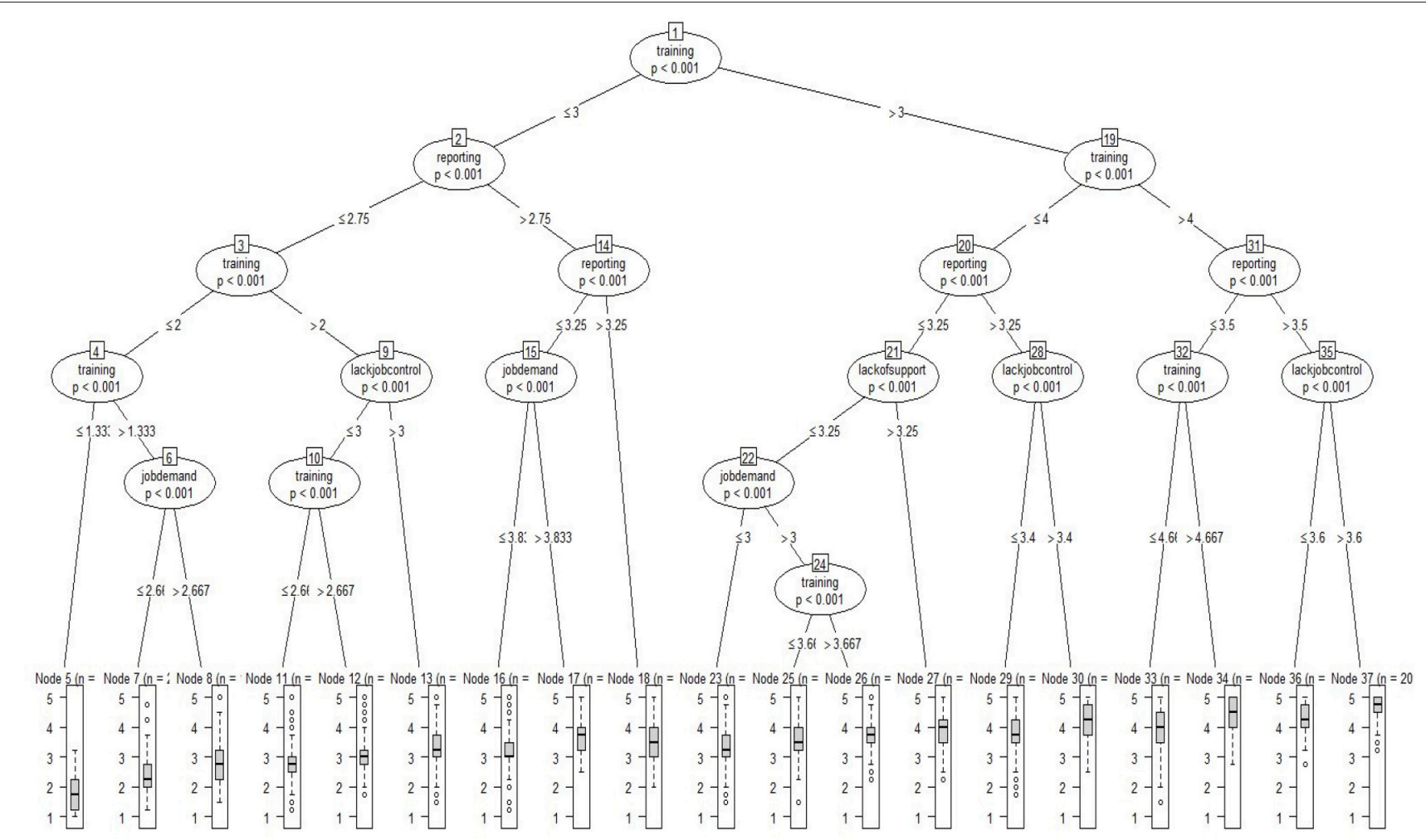

FIGURE 1 | Regression tree predicting perceived organizational support. All variables in tree are positively coded.

stress literature, as it demonstrates that significant organizational stressors rarely occur in isolation, but might generate interactive or combined effects (Ward, 2014).

As shown, the regression tree model contains five organizational variables (training, reporting, lack of job control, lack of support, and job demand), that sorted the sample into 19 groups through their interactions. Where a number of POS antecedents are present at the same time, synergetic effects seemed to occur.

In our study, the most dominant contributing factor on POS was training. This finding is consistent with the study of Eisenberger et al. (1997), and the recent met-analysis of Kurtessis et al. (2015) which indicated that "training (developmental) opportunity was the job condition most strongly viewed as under the discretionary control of organizations and, presumably, most indicative of POS." p. 11.

In addition, employees may simply have higher POS or become more attached to the organization because being well trained fulfills their socio-emotional needs (Di Fabio, 2014, 2015). Alternatively, consistent with organizational support theory, good training practice might be associated with POS because they are likely to be viewed as discretionary rather than compulsory and this aspect is theoretically fundamental for POS.

Training may also be considered a factor of protection from work instabilities that seems very widespread in the Italian context. This might be a promoting factor of POS (Di Fabio and Saklofske, 2014; Di Fabio and Kenny, 2015). For example, training practices might be perceived visible manifestations of invisible organizational characteristics (such as economical power). However, this issue should be investigated further.

Job control that considers resources, such as autonomy and discretionarily, confirmed its impact on POS in our study. Similarly, we pointed out the importance of supervisors' support on POS, and this finding is consistent with prior works (Shoss et al., 2013). Many studies described POS related to the leadership style and supervisory practices that play a key role in providing growth opportunities and organizational benefits to employees (Eisenberger and Stinglhamber, 2011).

In our study, tree analysis excluded colleagues' support and role ambiguity/role conflict, because they were not significant contributors to the model in comparison to the variables left in the tree diagram. Indeed, supervisors support has been highlighted as more important than colleagues's support (Kurtessis et al., 2015). Similarly, the impact of role conflict on determining POS is lower than intuitively expected. Eisenberger et al. (1997) pointed out that role stressors are less perceived to be under organizational control with respect to job enrichment elements and consequently marginally related to POS. Similarly, in our study the effect of job demand factors was limited and found only in the final nodes. According to Eisenberger and Stinglhamber (2011), job pressure is particularly due to the job characteristics rather than to the perceptions of employers and organizational support. 
While our study confirms the results of studies examining POS organizational antecedents, this research is one of the few to examine the factor called "reporting" in association with POS. People might be inclined to reciprocate less, or disengage because they can't feel secure about their own health and safety.

Our findings show that reporting in combination with other organizational variables might create lesser POS because such negative perceptions of health and safety conditions generate a greater concern for the individual's well-being (Rousseau and Aubé, 2010; Caricati et al., 2016). In addition, the role of reporting in the model seems particularly important as it interacts with the dominant factor training as well as with further elements. This result partially follows the literature, as the relationship of safety communication with POS was nonexclusive but related to several organizational factors such as leader-member exchange, job demands, etc. (Kath et al., 2010).

This study however presents some limitations that should be considered while interpreting our findings. A first limitation relates to the use of self-report measures, raising questions about common method bias. A second limitation is the lack of a longitudinal design. Hence, this study should be replicated with specific temporal design in order to fully understand how organizational perceptions lead to others. A third limitation is that the sample is not representative of the Italian bankers and was limited to a single organization. Further, the present study was conducted in an Italian setting. Socio-economical differences may impact POS (Eisenberger et al., 1986) across organizations and countries (Baran et al., 2012). The Italian banking sector, which is encountering a turbulent economical time (Quaglia and Royo, 2015), appears at risk of developing lesser POS.

Finally, contextual factors such as value congruence, (psychological contract and fairness), were not investigated, whereas in literature a strong association with POS was found (Cropanzano et al., 2001; Cropanzano and Mitchell, 2005).

\section{REFERENCES}

Arshadi, N., and Hayavi, G. (2013). The effect of perceived organizational support on affective commitment and job performance: mediating role of OBSE. Proc. Soc. Behav. Sci. 84, 739-743. doi: 10.1016/j.sbspro.2013. 06.637

Baran, B., Shanock, L., and Miller, L. (2012). Advancing organizational support theory into the twenty-first century world of work. J. Bus. Psychol. 27, 123-147. doi: 10.1007/s10869-011-9236-3

Bradley, J., and Cartwright, S. (2002). Social support, job stress, health, and job satisfaction among nurses in the United Kingdom. Int. J. Stress Manage. 9, 163-182. doi: 10.1023/A:1015567731248

Byrne, Z. S., and Hochwarter, W. A. (2006). I get by with a little help from my friends: the interaction of chronic pain and organizational support on performance. J. Occup. Health Psychol. 11, 215-227. doi: 10.1037/1076-8998. 11.3.215

Caesens, G., Marique, G., Hanin, D., and Stinglhamber, F. (2016). The relationship between perceived organizational support and proactive behaviour directed towards the organization. Eur. J. Work Organ. Psychol. 25, 398-411. doi: 10.1080/1359432X.2015.1092960

Caricati, L., Chiesa, R., Guglielmi, D., and Mariani, M. G. (2016). Real and perceived employability: a comparison among Italian graduates. J. Higher Educ. Policy Manage. 38, 490-502. doi: 10.1080/1360080X.2016.1182668
In conclusion the factor "reporting" is new in the literature and would benefit from refinement. The reliability of the scale in this study appeared also limited.

However, our study provides new research knowledge. The major strengths are the large sample of bankers (a difficult population to sample in psychology), the use of a new statistical method such as the regression tree model, and the fact that the study responds to the call of Italian regulation for welfare promotion.

Further, the study replies to a call of the literature to investigate (a) the association of POS with wellbeing, (b) the construct of POS in non-U.S. samples, (c) the measurement of POS in contexts with job instabilities. In addition, it is essential to emphasize that these findings can be used effectively to generate theoretical developments and organizational interventions. By having determined the interaction of antecedents that are predictive of POS, specific interventions can be implemented rather than be broadly focused.

The perceived organizational support experienced by employees as a result of a combination of working conditions (such as training and reporting) may cause important implications for generating a favorable orientation toward the organization stimulating welfare activities engagement. Indeed, as explained in the introduction, in Italy the government is promoting concrete welfare activities, however the choice of using these bonuses stand not only in the employer, but also in the employees and consequently, their perception of POS, might play a key role. These assumptions suggest the need for additional research to further refine the role of POS in the employee-organization relationship for practical and scientific purposes.

\section{AUTHOR CONTRIBUTIONS}

All authors listed, have made substantial, direct, and intellectual contribution to the work, and approved it for publication.

Choi, Y., and Lin, Y. (2009). Consumer response to crisis: exploring the concept of involvement in Mattel product recalls. Public Relat. Rev. 35, 18-22. doi: 10.1016/j.pubrev.2008.09.009

Cronbach, L. J. (1951). Coefficient alpha and the internal structure of tests. Psychometrika 16, 297-334. doi: 10.1007/bf02310555

Cropanzano, R., Byrne, Z. S., Bobocel, D., and Rupp, D. E. (2001). Moral virtues, fairness heuristics, social entities, and other denizens of organizational justice. J. Voc. Behav. 58, 164-209. doi: 10.1006/jvbe.2001.1791

Cropanzano, R., and Mitchell, M. S. (2005). Social exchange theory: an interdisciplinary review. J. Manage. 31, 874-900. doi: 10.1177/01492063052 79602

Di Fabio, A. (2014). Intrapreneurial Self-Capital: a new construct for the 21 st century. J. Employ. Counsel. 51, 98-111. doi: 10.1002/j.2161-1920.2014.00045.x

Di Fabio, A. (2015). Beyond fluid intelligence and personality traits in social support: the role of ability based emotional intelligence. Front. Psychol. 6:395. doi: $10.3389 /$ fpsyg. 2015.00395

Di Fabio, A., and Kenny, M. E. (2015). The contributions of emotional intelligence and social support for adaptive career progress among Italian youth. J. Career Dev. 42, 48-59. doi: 10.1177/0894845314 533420

Di Fabio, A., and Saklofske, D. H. (2014). Promoting individual resources: the challenge of trait emotional intelligence. Pers. Individ. Dif. 65, 19-23. doi: 10.1016/j.paid.2014.01.026 
Doove, L. L., Dusseldorp, E., Van Deun, K., and Van Mechelen, I. (2014). A comparison of five recursive partitioning methods to find person subgroups involved in meaningful treatment-subgroup interactions. Adv. Data Anal. Classif. 8, 403-425. doi: 10.1007/s11634-013-0159-x

Edwards, M. R. (2009). HR, perceived organisational support and organisational identification: an analysis after organizational formation. Hum. Resour. Manage. J. 19, 91-115. doi: 10.1111/j.1748-8583.2008.00083.x

Edwards, M. R., and Peccei, R. (2010). Perceived organizational support, organizational identification, and employee outcomes testing a simultaneous multifoci model. J. Pers. Psychol. 9, 17-26. doi: 10.1027/1866-5888/a000007

Eisenberger, R., Armeli, S., Rexwinkel, B., Lynch, P. D., and Rhoades, L. (2001). Reciprocation of perceived organizational support. J. Appl. Psychol. 86, 42-51. doi: 10.1037/0021-9010.86.1.42

Eisenberger, R., Cummings, J., Armeli, S., and Lynch, P. (1997). Perceived organizational support, discretionary treatment, and job satisfaction. J. Appl. Psychol. 82, 812-820. doi: 10.1037/0021-9010.82.5.812

Eisenberger, R., Fasolo, P., LaMastro, D. (1990). Perceived organizational support and employee diligence, commitment, and innovation. J. Appl. Psychol. 75, 51-59. doi: 10.1037/0021-9010.75.1.51

Eisenberger, R., Huntington, R., Hutchison, S., and Sowa, D. (1986). Perceived organizational support. J. Appl. Psychol. 71, 500-507. doi: 10.1037/0021-9010.71.3.500

Eisenberger, R., Shoss, M. K., Karagonlar, G., Gonzalez-Morales, M. G., Wickham, R., and Buffardi, L. C. (2014). The supervisor POS-LMX-subordinate POS chain: moderation by reciprocation wariness and supervisor's organizational embodiment. J. Organ. Behav. 35, 635-656. doi: 10.1002/job.1877

Eisenberger, R., and Stinglhamber, F. (2011). Perceived Organizational Support: Fostering Enthusiastic and Productive Employees. Washington, DC: American Psychological Association.

Eisenberger, R., Stinglhamber, F., Vandenberghe, C., Sucharski, I. L., and Rhoades, L. (2002). Perceived supervisor support: contributions to perceived organizational support and employee retention. J. Appl. Psychol. 87, 565-573. doi: 10.1037/0021-9010.87.3.565

Giorgi, G., Cupelli, V., and Arcangeli, G. (2013). Stress Questionnaire. Firenze: Hogrefe.

Grossman, R., and Ram, Z. (2014). Recursive Partitioning Analysis (RPA) classification predicts survival in patients with brain metastases from Sarcoma. World Neurosurg. 82, 1291-1294. doi: 10.1016/j.wneu.2014.07.039

Hellemann, G., Conner, B. T., Anglin, M. D., and Longshore, D. (2009). Seeing the trees despite the forest: applying recursive partitioning to the evaluation of drug treatment retention. J. Subst. Abuse Treat. 36, 59-64. doi: 10.1016/j.jsat.2008.03.005

Hothorn, T., Hornik, K., Strobl, C., and Zeileis, A. (2015). Party: A Laboratory for Recursive Partitioning. Available online at: http://cran.r-project.org/web/ packages/party/index.html

Ishfaq, A., and Muhammad, M. N. (2015). Antecedents and outcomes of perceived organizational support: a literature survey approach. J. Manage. Dev. 34, 867-880. doi: 10.1108/JMD-09-2013-0115

Istat (2015). Annuario Statistico Italiano. Istituto nazionale di statistica, Roma.

Jain, A., and Sinha, A. (2005). General health in organizations: relative relevance of emotional intelligence, trust, and organizational support. Int. J. Stress Manage. 12, 257-273. doi: 10.1037/1072-5245.12.3.257

Jawahar, I. M., Stone, T. H., and Kisamore, J. L. (2007). Role Conflict and burnout: the direct and moderating effects of political skill and perceived organizational support on burnout dimensions. Int. J. Stress Manage. 14, 142-159. doi: 10.1037/1072-5245.14.2.142

Kang, B., Twigg, N. W., and Hertzman, J. (2010). An examination of social support and social identity factors and their relationship to certified chefs' burnout. Int. J. Hosp. Manage. 29, 168-176. doi: 10.1016/j.ijhm.2009.08.004

Kath, L. M., Marks, K. M., and Ranney, J. (2010). Safety climate dimensions, leader-member exchange, and organizational support as predictors of upward safety communication in a sample of rail industry workers. Saf. Sci. 48, 643-650. doi: 10.1016/j.ssci.2010.01.016

Kurtessis, J., Eisenberger, R., Ford, M. T., Buffardi, L. C., Stewart, K. A., and Adis, C. S. (2015). Perceived organizational support: a meta-analytic evaluation of organizational support theory. J. Manage. doi: 10.1177/01492063155 75554
Lee, J., and Peccei, R. (2007). Perceived organizational support and affective commitment: the mediating role of organization-based self-esteem in the context of job insecurity. J. Organ. Behav. 28, 661-685. doi: 10.1002/job.431

Markham, F., Young, M., and Doran, B. (2013). Detection of problem gambler subgroups using recursive partitioning. Int. J. Ment. Health Addict. 11, 281-291. doi: $10.1007 /$ s1 1469-012-9408-z

Mearns, K., and Reader, J. T. (2008). Organizational support and safety outcomes: an un-investigated relationship? Saf. Sci. 46, 388-397. doi: 10.1016/j.ssci.2007.05.002

Miner, K. N., Settles, I. H., Pratt-Hyatt, J. S., and Brady, C. C. (2012). Experiencing incivility in organizations: the buffering effects of emotional and organizational support. J. Appl. Soc. Psychol. 42, 340-372. doi: 10.1111/j.1559-1816.2011.00891.x

Ministro del Lavoro e delle Politiche Sociali and Ministro dell'Economia e delle Finanze (2016). Ministro del Lavoro e delle Politiche Sociali and Ministro dell'Economia e delle Finanze. Available online at: http://www.diritto-lavoro. com/wp-content/uploads/2016/03/Decreto-Interministeriale.pdf

Mucci, N., Giorgi, G., Roncaioli, M., Fiz Perez, J., and Arcangeli, G. (2016). The correlation between stress and economic crisis: a systematic review. Neuropsychiatr. Dis. Treat. 12, 983-993. doi: 10.2147/ndt.s98525

Nilsen, G., Borgan, O., Liestøl, K., and Lingjaerde, C. (2013). Identifying clusters in genomics data by recursive. Stat. Appl. Genet. Mol. Biol. 637-652. doi: 10.1515/sagmb-2013-0016

O’Neill, O. A., Vandenberg, R. J., Dejoy, D. M., and Wilson, M. G. (2009). Exploring relationships among anger, perceived organizational support, and workplace outcomes. J. Occup. Health Psychol. 14, 318-333. doi: 10.1016/j.sbspro.2014.09.128

Quaglia, L., and Royo, S. (2015). Banks and the political economy of the sovereign debt crisis in Italy and Spain. Rev. Int. Polit. Econ. 22, 485-507. doi: 10.1080/09692290.2013.877059

Rhoades, L., and Eisenberger, R. (2002). Perceived organizational support: a review of the literature. J. Appl. Psychol. 87, 698-714. doi: 10.1037/0021-9010.87.4.698

Riggle, R. J., Edmondson, D. R., and Hansen, J. D. (2009). A meta-analysis of the relationship between perceived organizational support and job outcomes: 20 years of research. J. Bus. Res. 62, 1027-1030. doi: 10.1016/j.jbusres.2008.05.003

Rousseau, V., and Aubé, C. (2010). Social support at work and affective commitment to the organization: the moderating effect of job resource adequacy and ambient conditions. J. Soc. Psychol. 150, 321-340. doi: 10.1080/00224540903365380

Salis, K. L., Kliem, S., and O'Leary, K. D. (2014). Conditional inference trees: a method for predicting intimate partner violence. J. Martial Fam. Ther. 40, 430-441. doi: 10.1111/jmft.12089

Schmitz, J., and Schrader, J. (2015). Corporate social responsibility: a microeconomic review of the literature. J. Econ. Surv. 29, 27-45. doi: 10.1111/joes. 12043

Scott, S. B., Jackson, B. R., and Bergeman, C. S. (2011). What contributes to perceived stress in later life? A recursive partitioning approach. Psychol. Aging 26, 830-843. doi: 10.1037/a0023180

Shore, L. M., Tetrick, L. E., Lynch, P., and Barksdale, K. (2006). Social and economic exchange: construct development and validation. J. Appl. Soc. Psychol. 36, 837-867. doi: 10.1111/j.0021-9029.2006.00046.x

Shoss, M. K., Eisenberger, R., Restubog, S. L. D., and Zagenczyk, T. J. (2013). Blaming the organization for abusive supervision: the roles of perceived organizational support and supervisor's organizational embodiment. J. Appl. Psychol. 98, 158-168. doi: 10.1037/a0030687

Stinglhamber, F., and Vandenberghe, C. (2003). Organizations and supervisors as sources of support and targets of commitment: a longitudinal study. J. Organ. Behav. 24, 251-270. doi: 10.1002/job.192

Strasser, H., and Weber, C. (1999). On the asymptotic theory of permutation statistics. Math. Methods Stat. 8, 220-250.

Strobl, C., Hothorn, T., and Zeileis, A. (2009b). Party on! A new, conditional variable importance measure for random forests available in the party package. RJ. 1, 14-17.

Strobl, C., Malley, J., and Tutz, G. (2009a). An introduction to recursive partitioning: rationale, application, and characteristics of classification and regression trees, bagging, and random forests. Psychol. Methods 14, 323-248. doi: 10.1037/a0016973 
Wallace, J., Popp, E., and Mondore, S. (2006). Safety climate as a mediator between foundation climates and occupational accidents: a group-level investigation. J. Appl. Psychol. 91, 681-688. doi: 10.1037/0021-9010.91.3.681

Ward, B. W. (2014). "Stress proliferation," in The Wiley Blackwell Encyclopedia of Health, Illness, Behavior, and Society, eds W. C. Cockerham, R. Dingwall, and S. R. Quah (Birmingham, AL: University of Alabama at Birmingham; John Wiley \& Sons), 2346-2348.

Zhong, L., Wayne, S. J., and Liden, R. C. (2016). Job engagement, perceived organizational support, high-performance human resource practices, and cultural value orientations: a cross-level investigation. J. Organ. Behav. 37, 823-844. doi: 10.1002/job.2076
Conflict of Interest Statement: The authors declare that the research was conducted in the absence of any commercial or financial relationships that could be construed as a potential conflict of interest.

Copyright (c) 2016 Giorgi, Dubin and Fiz Perez. This is an open-access article distributed under the terms of the Creative Commons Attribution License (CC $B Y)$. The use, distribution or reproduction in other forums is permitted, provided the original author(s) or licensor are credited and that the original publication in this journal is cited, in accordance with accepted academic practice. No use, distribution or reproduction is permitted which does not comply with these terms. 


\section{OPEN ACCESS}

Edited by: Gabriele Giorgi,

European University of Rome, Italy

Reviewed by:

Francesco Montani, Montpellier Business School, France Giulio Arcangeli,

University of Florence, Italy

${ }^{*}$ Correspondence:

Dina Guglielmi

dina.guglielmi@unibo.it

Specialty section: This article was submitted to Organizational Psychology, a section of the journal

Frontiers in Psychology

Received: 11 May 2016 Accepted: 02 August 2016

Published: 15 August 2016

Citation:

Guglielmi D, Avanzi L, Chiesa $R$ Mariani MG, Bruni I and Depolo M (2016) Positive Aging in Demanding Workplaces: The Gain Cycle between Job Satisfaction and Work Engagement. Front. Psychol. 7:1224. doi: 10.3389/fpsyg.2016.01224

\section{Positive Aging in Demanding Workplaces: The Gain Cycle between Job Satisfaction and Work Engagement}

\author{
Dina Guglielmi ${ }^{*}$, Lorenzo Avanzi ${ }^{2}$, Rita Chiesa ${ }^{1}$, Marco G. Mariani ${ }^{1}$, Ilaria Bruni ${ }^{2}$ and \\ Marco Depolo ${ }^{3}$ \\ ${ }^{1}$ Department of Educational Science, University of Bologna, Bologna, Italy, ${ }^{2}$ Department of Psychology and Cognitive \\ Science, University of Trento, Trento, Italy, ${ }^{3}$ Department of Psychology, University of Bologna, Bologna, Italy
}

Nowadays organizations have to cope with two related challenges: maintaining an engaged and highly performing workforce and, at the same time, protecting and increasing employees' well-being and job satisfaction under conditions of a generalized increase of job demand, in an increasingly growing older population. According to the motivational process of the JD-R model, a work environment with many organizational resources will foster work engagement, which in turn will increase the likelihood of positive personal and organizational outcomes, such as job satisfaction, performance, and intention to stay. However, it is not clear how this motivational process could work in different age cohorts, as older workers may have different priorities to those of younger colleagues. Postulating the existence of a gain-cycle in the relationship between work engagement and outcomes, in this study we tested a longitudinal moderated mediation model in which job satisfaction increases over time through an increment in work engagement. We hypothesized that this process is moderated by job demand and aging. We collected data in public administrations in Northern Italy in order to measure work engagement and job satisfaction. 556 workers aged between 50 and 64 replied to the survey twice (the first time and 8 months later). The findings confirmed a moderated mediation model, in which job satisfaction at time 1 increased work engagement, which in turn fostered job satisfaction 8 months later, confirming the hypothesized gain-cycle. This relationship was shown to be moderated by the joint influence of job demand intensity and age: higher job demands and younger age are related to the maximum level of level gain cycle, while the same high level of job demands, when associated with older age, appears unable to stimulate a similar effect. The results confirm that, on one hand, older workers cannot be seen as a homogeneous group and, on the other hand, the importance of considering the role played by the gain cycle of resources. Our findings show that age matters, and that greater consideration should be devoted to age differences in order to design appropriate human resources practices that foster work engagement and satisfaction.

\footnotetext{
Keywords: engagement, aging, job satisfaction, gain cycle, job demands
} 


\section{INTRODUCTION}

The changing workforce configuration is one of the most important challenges for the organizations of the new Millennium (Kompier, 2006). In particular, the aging population is a very relevant demographic variation that will lead to older workers playing a prominent role in the workforce in the near future.

In European Union countries, also due to the impact of "recent pension reforms in many Member States aimed at increasing the retirement age," the employment rate of older workers (aged 55-64) is expected to increase continuously, shifting from $13.7 \%$ in 2013 to $18.3 \%$ in 2060 (European Commission, 2015, p. 65). As confirmed by the United Nations (2007, p. 24), by 2050 workers aged 50 years or over "are expected to make up almost one third (31.2\%) of the working-age population in developed countries." This scenario is complicated by other phenomena (i.e., internationalization, market deregulation, increased utilization of information and communication technology) that tend to change the nature of work, with the consequent increase in the percentage of workers experiencing high levels of stress (European Foundation for the Improvement of Living and Working Conditions, 2007). Although, work-related health problems also affect young employees (see Arcangeli and Mucci, 2009), this has become crucial as for elder workers.

This means that organizations have to cope with two related and important challenges: maintaining an engaged and highly performing workforce and, at the same time, protecting and increasing the employees' well-being and job satisfaction under conditions of a generalized increase of job demand in an increasingly aging working population. Consequently, more attention should be paid to understanding how to motivate and satisfy older employees. In the past, several studies found a positive relationship between age and job satisfaction (Kalleberg and Loscocco, 1983; Bedeian et al., 1992; Ng and Feldman, 2007). More recently, a research study by the Sloan Center on Aging and Work at Boston College (2011) examined the work experiences of employees in 11 countries, confirming that those 50 yearsold and older are the most engaged and satisfied with their jobs. However, little is known about the antecedents of older workers' job satisfaction.

The aim of this study is to test the relationship between job satisfaction and engagement of older workers measured over time, considering the mediation of work engagement and the moderation of job demands and age.

We based our research on two important theoretical contributions: the Job Demands-Resources Model (JD-R; Bakker and Demerouti, 2007) and the Conservation of Resources Theory (COR; Hobfoll, 1989, 2011). According to the motivational process of the JD-R model, a work environment with many organizational resources (i.e., control or support) will foster a positive attitude toward work (engagement), which in turn will increase the likelihood of positive personal and organizational outcomes, such as job satisfaction, performance, and intention to stay. The added value of our research is that in addition to the effect of work engagement on job satisfaction, we expect to find a positive effect of job satisfaction on work engagement (with the moderation of job demand). This assumption is in line with the COR theory (Hobfoll, 2002), which postulated that people seek to obtain and accumulate resources in order to tackle stressful conditions. On one hand, people tend to prevent the loss of existing resources; on the other hand, they try to increase new personal and social resources, thus creating the so-called "gain spiral." Gain spirals have been originally described as amplifying loops where cyclic relationships among constructs build on each other positively over time (Lindsley et al., 1995). More recently, this notion has been embedded in the motivational process of the Job Demands-Resources Model (JD-R; Bakker and Demerouti, 2007) in order to explain the reciprocal relationship between resources, work engagement and positive job outcomes, e.g., job satisfaction. In this regard, the interplay between these components is defined as highly dynamic: the motivational process unfolds across time, thus suggesting the occurrence of feedback and feed-forward loops (Salanova et al., 2010). Accordingly, such dynamic interplay may explain the reciprocal and self-perpetuating influence between job satisfaction and work engagement across time. In addition, the positive cycle between work engagement and job satisfaction could contribute to explaining the relative stability over time recorded by job satisfaction in previous research (e.g., Pulakos and Schmitt, 1983; Newton and Keenan, 1991; Schaubroeck et al., 1996; Dormann and Zapf, 2001; Kinicki et al., 2002). Moreover, it is important to highlight that past research has shown that the observed stability of job satisfaction decreases with length of time and as individuals change occupations or employers, suggesting that job satisfaction is influenced by situational factors (Dormann and Zapf, 2001). In line with these assumptions, Giorgi et al. (2015) found that job satisfaction is influenced by dimensions of work-related stress such as job demands and lack of job control, bullying and economic stressors, such as non-employability and fear of the crisis. For this reason, we hypothesized that job demands and age have a moderator effect on the relationship between job satisfaction and work engagement.

\section{Job Satisfaction and Work Engagement}

Job satisfaction is defined as "the extent to which people like (satisfaction) or dislike (dissatisfaction) their jobs" (Spector, 1997, p. 2). It is a result of individuals perception and evaluation of their job, influenced by their own unique needs, values and expectations, which they regard as being important to them. The consequences of job satisfaction include better performance and a reduction in withdrawal and counterproductive behavior (Morrison, 2008). According to the Job Demands-Resources Model (JD-R), job satisfaction is a job outcome of the motivational process that refers to the effect job resources have on positive outcomes such as job performance, employees' health, and job satisfaction, through the meditational role of work engagement (Schaufeli and Taris, 2013). Work engagement is considered "as a positive, fulfilling, work-related state of mind that is characterized by vigor, dedication, and absorption" (Schaufeli et al., 2002, p. 74). Engaged employees tend to be more resilient and able to cope effectively with problems, and they are characterized by high levels of energy and 
by the strong capability to invest effort in order to fulfill their jobs. They also show enthusiasm and pride in their work, and tend to be fully absorbed in and deeply concentrated on their tasks and duties (Schaufeli et al., 2002). Following Schaufeli and Bakker (2004), to achieve new resources people have to invest existing ones, and in this sense, engaged workers are in an ideal situation to amplify their resources and consequently produce positive outcomes (Simbula and Guglielmi, 2013). Although, there is strong empirical evidence of the mediation role played by engagement (Schaufeli and Taris, 2013), most research is cross-sectional in nature, and furthermore, the consequences of engagement have been less empirically studied (Halbesleben, 2010). Concerning the relationship between work engagement and job satisfaction, empirical research has found a moderate correlation among constructs, in both cross-sectional (Schaufeli et al., 2008b), and more recently, longitudinal studies (Simbula and Guglielmi, 2013). One possible explanation can be found in the nature of these two affective states. Job satisfaction represents "the positive emotional reactions and attitudes an individual has toward their job" (Faragher et al., 2005, p. 106). Although some authors tend to conceptualize job satisfaction only in terms of the cognitive component, such as the person's assessment of the job (i.e., Salanova and Schaufeli, 2009), it is actually more likely that some emotional components are also involved in its definition. Following the circumplex model of affect proposed by Russell and Carroll (1999), we can distinguish the affective states as a linear combination of two dimensions: activation/arousal and pleasure. In particular, job satisfaction represents an affective state reflecting a high level of pleasure and low level of arousal. On the contrary, job engagement is characterized by high levels of both pleasure and activation. Given these circumstances, it is not surprising that they are not highly related. Nevertheless, we expect that job satisfaction and work engagement reinforce each other. On one hand, in line with COR theory assumptions, given that job satisfaction is a function not only of the objective properties of a job but also of "the pleasurable emotional state resulting from the appraisal of one's job as achieving or facilitating one's job values" (Locke, 1969), we consider it a state which can boost work engagement. On the other hand, work engagement has been demonstrated to predict a variety of positive outcomes in all life domains. For instance, engaged employees show greater organizational commitment and enhanced job performance (Hakanen et al., 2008), they exhibit higher levels of proactivity (Salanova and Schaufeli, 2008) and are reported to demonstrate better in-role and extra-role behaviors (Bakker and Bal, 2010). Moreover, work engagement is related to higher life satisfaction and better mental and physical health (Shimazu et al., 2012). Surprisingly, the relationship between work engagement and job satisfaction is under-researched (Schaufeli et al., 2008a; Alarcon and Lyons, 2011), although some studies do confirm this relationship.

In other words, we expect that employees who are generally highly dedicated to their work most probably experience higher levels of job satisfaction. Equally, it is also possible that satisfied employees could be more prone to identifying with their job and be strongly committed to their tasks. Following the COR theory, therefore, we can postulate the existence of a gain cycle, in which work engagement and job satisfaction reinforce each other. In this regard, there is initial evidence about the reciprocity of the relationship between these two constructs (Simbula and Guglielmi, 2013).

\section{H1: Work engagement will mediate the relation between job satisfaction over time.}

As outlined in the introduction, stress is greatly increasing among employees. Workers have to cope with tight deadlines, processing and memorizing simultaneously different types of information, and many other cognitively exhausting tasks. However, job demand is not only a potentially draining stressor but also a challenging one. According to the differentiation between "challenge" and "hindrance" stressors (LePine et al., 2005), work characteristics can give rise to different reactions in employees. The authors maintain that some stressors, such as role conflict and ambiguity, called hindrance stressors, are related to fatigue and emotional exhaustion because they represent a threat for employees. Workers who face these types of stressors react in terms of greater anxiety and nervousness, and indeed they are related to job dissatisfaction and turnover (LePine et al., 2005; Podsakoff et al., 2007). On the contrary, challenge stressors (i.e., responsibility) are potentially able to promote personal achievement and future gain because employees see them as a "challenge" rather than a threat (Schaufeli and Taris, 2013). Furthermore, on one hand, following the COR theory, the gain cycle becomes more salient in a context of resource loss (i.e., when job demands are high; Hobfoll, 2002) and, on the other hand, following the JD-R model, "job resources gain their motivational potential particularly when employees are confronted with high job demands" (Bakker and Demerouti, 2007, p. 315).

In particular, workload and time pressure are job demands that represent an "overload of demands at work" (Alarcon, 2011, p. 550). Overload corresponds to a challenge stressor, that is potentially able "to promote personal gain or growth, trigger positive emotions and an active or problem-solving style of coping" (LePine et al., 2005, p. 765). Although, prolonged exposure to overload is associated with emotional exhaustion (Alarcon, 2011), this challenge stressor could be also associated with achievement, learning and work attainment. For these reasons, we expect that in workers exposed to a high level of job demands, the relationship between job satisfaction and work engagement will be stronger. Indeed, when employees are satisfied they are more motivated and committed to their jobs, and this increases the resources available for them; this in turn should increase their engagement and identification. This relationship should be particularly strong when workers have to cope with a high job demand, because they will perceive that they have the resources to face the task. Therefore, employees should show greater engagement and involvement when they are committed to mentally demanding jobs.

$\mathrm{H} 2$ : Job satisfaction $\mathrm{T} 1$ will be positively related to work engagement, above all when job demands are high. 
We further hypothesized an additional condition under which our mediation model should be established. We tested employees' age as a moderator of the relationship between work engagement and job satisfaction over time. As stated by McCarthy et al. (2014), there is no full agreement on how old an 'older' worker' is, but the most common choice is to use 50 years as a cut-off, and the main statistics on this topic use 50-55 to conceptualize older workers. Aging is a complex transition in which physical and psychosocial aspects interact and, in this sense, age is an umbrella-variable which captures various changes that take place when people become older (Bal, 2015). Although, a significant number of studies focus on the differences between "younger" and "older" workers (e.g., Bal and Kooij, 2010; James et al., 2011; Kooij et al., 2013), giving the idea that mature workers represent a homogenous group, our intent is to acknowledge that there may be no such a thing as a "typical older worker." As individuals age, their experiences and attitudes toward work tend to diverge rather than converge (Flynn, 2010; Nakai et al., 2011). Research has shown that some changes in specific personality traits, such as openness to experience or social vitality, could also be present in later years (Roberts et al., 2006). Furthermore, a recent study (von Bonsdorff et al., 2011) showed that mental and physical work strain differed according to the work ability trajectories identified. These results support the idea that older workers experience different conditions also in terms of health.

Moreover, older workers tend to identify more with and be more committed to their own organization, and tend to suppress negative information and events and experience more positive emotions at work ( $\mathrm{Ng}$ and Feldman, 2007). A strong sense of identification with a group satisfies very important human needs such as belonging and connectedness, which in turn are related to increased levels of job satisfaction and wellbeing (Ashforth et al., 2008; van Dick and Haslam, 2012). Consistently, there is meta-analytic evidence showing a positive relationship between age and overall job satisfaction $(\mathrm{Ng}$ and Feldman, 2007). However, little is known about the antecedents of older workers' job satisfaction. Recently, Drabe et al. (2015) analyzed the moderating role of age in the relationship between situational job characteristics and job satisfaction, focusing on income, advancement opportunities and security as extrinsic job characteristics, interesting job and independent work as intrinsic job characteristics and good relationships with management and colleagues as social job characteristics. They found that extrinsic and intrinsic job characteristics tend to be more predictive of younger workers' job satisfaction, while the good relationships with colleagues are more predictive of older workers' job satisfaction. Specifically, an interesting job, such as new challenges and new or further roles connected to the opportunity to qualify for new jobs or roles, was shown to be less important to older employees. We concentrated on workers aged 50 and older, and expect engagement to increase job satisfaction in the long run, particularly for relatively younger workers. In line with Expectancy Value theory, Kanfer and Ackerman (2004) assume that individuals allocate their resources based on three primary relationships: effort-performance, performance-utility, and effort-utility. First, with increasing age, more effort is needed to achieve high work performances in tasks based on fluid intelligence (i.e., abstract reasoning, attention). Moreover, high performance levels are associated with comparably lower utility levels, because older employees benefit less from an increase in work performance. Finally, higher effort levels are assumed to have lower utility for older employees, who tend to reallocate personal resources from growth goals (e.g., to learn new things) to maintenance and the regulation of loss (e.g., decline in health). In other words, the effect of work engagement on job satisfaction is expected to decline with age. Older workers will tend to be more engaged and more satisfied over time partially due to the intrinsic maturing of the personality during aging (Kanfer and Ackerman, 2004). Indeed, aging is associated with improvement in emotion regulation, particularly in terms of the use of cognitive emotion regulation strategies. Therefore, the effect of work engagement on job satisfaction over time will be greater for relatively younger employees, because older workers will be generally more satisfied also for reasons related to aging itself.

H3: Work engagement will be positively related to job satisfaction T2, above all for relatively younger workers.

To summarize, we tested a moderated mediation model (see Figure 1), in which job satisfaction will be related to work engagement, which in turn will be related to job satisfaction over time. We also hypothesize 2 moderations by job demands and age. In particular, we expect that this mediational model will be greater for high levels of job demands and for relatively younger employees.

H4: Job satisfaction T1 will be indirectly related to job satisfaction T2 through work engagement, and conditionally to the levels of job demands and age.

\section{MATERIALS AND METHODS}

\section{Procedure}

Prior to the distribution of the questionnaire, the management of a large local administration body posted a message on the news board of their website informing employees about the aims of the project. The research team then contacted all individuals aged 50 or more via e-mail. The e-mail contained information on the project and the link to an online questionnaire. The survey was designed in accordance with privacy and anonymity

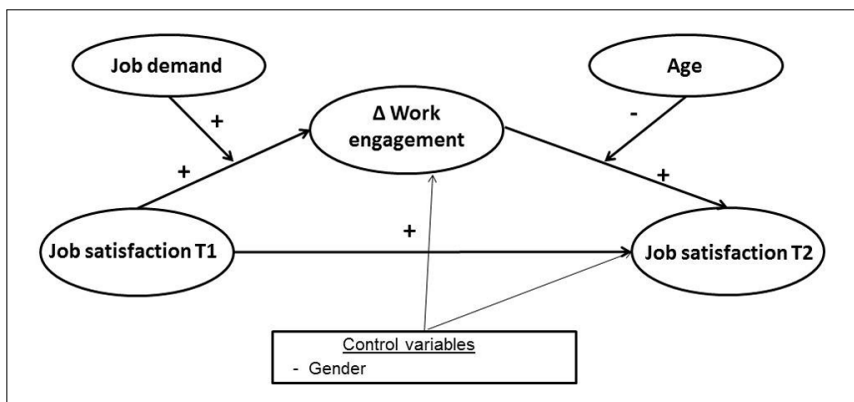

FIGURE 1 | Full Hypothesized model. 
regulations (as required by Italian law). The researchers assured the confidentiality of the employees' responses. 8 months later the research team contacted the participants again, asking them to fill in the questionnaire once more. Times 1 and 2 participants were paired, identifying them by the mean of anonymous codes.

With regard to ethical standards for research, the study adhered to the latest version of the Declaration of Helsinki revised in Fortaleza (World Medical Association [WMA], 2013).

\section{Participants}

The first questionnaire was completed by 1016 workers (64\% response rate), the second by 949 employees (60\% response rate). All participants were "white collar workers" with permanent and full time contracts. A total of 556 workers (63.5\% female) participated in both surveys. The participants' average age was 55.31 years $(S D=3.41)$, ranging from 50 to 64 years, and with an average organizational tenure of 22.38 years $(S D=9.44)$. After removing missing values at both times, the total sample consisted of 519 workers.

\section{Measures}

Work engagement was assessed through the Italian version of the nine-item Utrecht Work Engagement Scale (Italian validation: Schaufeli et al., 2006; Balducci et al., 2010). The items are grouped into three subscales (three for each dimension): vigor (e.g., "During my work, I feel bursting with energy"), dedication (e.g., "My job inspires me") and absorption (e.g., "I am immersed in my work"). We followed the recommendation of Schaufeli et al. (2006) and calculated an overall engagement score of the UWES, which we used in the analyses. All items related to dimensions of engagement were scored on a seven-point scale ranging from " 0 " (never) to " 6 " (always). The internal consistency reliability (Cronbach's $\alpha$ ) of this scale was 0.90 .

To measure Job demands we used eight psychological demands items taken from the Job Content Questionnaire (Karasek, 1985). An example of an item is "I have enough time to get the job done." The items were scored on a four-point scale ranging from " 1 " (strongly disagree) to " 4 " (strongly agree). Cronbach's alpha was 0.81 .

Job satisfaction was assessed with a single item (Wanous et al., 1997). The item was "Overall, how satisfied are you with your job?" and was scored on a five-point scale ranging from " 1 " (not satisfied at all) to " 5 " (completely satisfied).

\section{Data Analyses}

To test our hypotheses, we conducted hierarchical multiple regression analyses using the Process macro by Hayes (2013). In particular, we performed the model 21 , which makes it possible to test a moderated mediational model in which both the path from the independent variable to mediator and the path from the mediator to dependent variable are moderated by two different variables. To analyze conditional indirect effects, we calculated 95\% confidence intervals (CIs) based on bias-corrected bootstrap analyses with 10,000 repetitions.

\section{RESULTS}

Correlations, descriptive statistics, and scale reliabilities are given in Table 1.

We checked for non-random distribution of our sample following the analytic strategy suggested by Goodman and Blum (1996). In particular, we calculated a multiple logistic regression in order to ascertain the presence of non-random sampling in our longitudinal data. Since we found that some variables we couldn't exclude were not non-randomly distributed, we also checked for any differences among variables between participants who filled in both questionnaires (stayers) and those who filled in only the first questionnaire (leavers). We found only two statistical differences on the means and variances of the variables: (i) in particular, those who responded to both surveys (stayers) were relatively younger $(M=55.35)$ than leavers $(M=56.06)$; and (ii) the work engagement variance slightly decreased in stayers compared to whole sample. No differences were found concerning the relation among variables.

Table 2 presents the detailed results of our hypotheses tests. Variables were centered when necessary to calculate interaction terms. We followed the procedure suggested by Smith and Beaton (2008) ENREF_30, in which changes in the standardized residual scores were used to measure work engagement longitudinally. In particular, by regressing T2 scores of work engagement on the equivalent T1 scores, we obtained the T1-T2 changes in work engagement measured as the standardized residual scores. Positive residual scores indicated an increase in work engagement, while negative scores revealed a decrease. These scores were entered in the model as mediator variable of the relationship between job satisfaction $\mathrm{T} 1$ and job satisfaction T2.

TABLE 1 | Mean, standard deviation, reliabilities (in brackets), and correlations between variables.

\begin{tabular}{|c|c|c|c|c|c|c|c|}
\hline & $M$ & $S D$ & 1 & 2 & 3 & 4 & 5 \\
\hline (1) Age & 55.28 & 3.42 & - & & & & \\
\hline (2) Job demands T1 & 2.86 & 0.62 & $-0.11^{*}$ & $(0.81)$ & & & \\
\hline (3) Work engagement T1 & 4.53 & 1.25 & -0.01 & $0.18^{* * *}$ & $(0.90)$ & & \\
\hline (4) Work engagement T2 & 4.42 & 1.30 & -0.02 & $0.11^{*}$ & $0.70^{* * *}$ & $(0.90)$ & \\
\hline (5) Job satisfaction T1 & 3.23 & 0.99 & 0.03 & $0.09 *$ & $0.55^{* * *}$ & $0.55^{* * *}$ & - \\
\hline (6) Job satisfaction T2 & 3.34 & 1.16 & $-0.09 *$ & 0.02 & $0.43^{* * *}$ & $0.58^{* * *}$ & $0.65^{* * *}$ \\
\hline
\end{tabular}

$N=519 .{ }^{*} p<0.05 ; * * * p<0.001$ (two-tailed). 
TABLE 2 | Direct and indirect effects of hypothesized model.

\begin{tabular}{|c|c|c|}
\hline & $\begin{array}{l}\Delta \text { Engagement (M) } \\
\qquad \begin{array}{c}R^{2}=0.07^{* * *} \\
b(S E)\end{array}\end{array}$ & $\begin{array}{l}\text { Job satisfaction T2 (Y) } \\
\qquad \begin{array}{c}R^{2}=0.49^{* * *} \\
b(S E)\end{array}\end{array}$ \\
\hline Gender $^{\mathrm{a}}$ & $-0.03(0.09)$ & $-0.04(0.08)$ \\
\hline Age & - & $0.02 *(0.01)$ \\
\hline Job satisfaction T1 (JS) & $0.24^{* * *}(0.04)$ & $0.68^{* * *}(0.04)$ \\
\hline Job demand T1 (JD) & $-0.03(0.07)$ & - \\
\hline Interaction 1 (JS X JD) & $0.13^{*}(0.06)$ & - \\
\hline$\Delta$ Engagement (M) & - & $0.30 * * *(0.04)$ \\
\hline Interaction 2 (Age X M) & & $-0.03 *(0.01)$ \\
\hline
\end{tabular}

Conditional indirect effects of job satisfaction T1

through $\Delta$ Engagement

Job satisfaction T2

Low job demands and younger workers

Point estimate (95\% Cl)

Low job demands and older workers

$0.06(0.01,0.12)$

$0.04(0.01,0.09)$

$0.12(0.08,0.19)$

$0.07(0.03,0.12)$

High job demands and older workers $N=519$ (listwise). ${ }^{a} 0=$ male, $1=$ female; ${ }^{*} p<0.05 ;{ }^{* *} p<0.001 . M=$ mediator
variable, $Y=$ dependent variable. Confidence intervals $(\mathrm{Cls})$ of indirect effects variable, $Y=$ dependent variable. Confidence intervals $(\mathrm{Cls})$ of indirect effects
based on 10,000 bias corrected bootstrap samples. Unstandardized coefficients are reported.

As shown in the upper part of the table, first of all we computed the model for the mediator (M) work engagement ( $\Delta=$ standardized residual scores). After checking for gender and in support of hypothesis 1, job satisfaction T1 was significantly related to work engagement $(b=0.24, p<0.001)$. More importantly, and in line with hypothesis 2 , the interaction term (computed as the product of job demands $\mathrm{T} 1$ and job satisfaction $\mathrm{T} 1$ variables) also had a positive and significant relationship to work engagement $(b=0.13, p<0.01)$, over and above the direct effect of job demands itself. This means that job satisfaction T1 increases work engagement particularly for employees who perceived relatively high job demands.

We then calculated the model for the dependent variable (Y) job satisfaction T2. Again, after checking for gender and consistent with hypothesis 3, job satisfaction T1 was a strong predictor of the satisfaction over time both directly $(b=0.68$, $p<0.001)$ and indirectly through the mediation of work engagement $(b=0.30, p<0.001)$. Finally, and in line with hypothesis 4 , after checking for a direct effect of age, also the interaction term, computed as the product of work engagement and age, was negatively and significantly related to job satisfaction T2 $(b=-0.03, p<0.05)$, meaning that work engagement increases job satisfaction T2 particularly for younger workers.

We then computed the conditional indirect effects and related bootstrap analyses (see lower part of Table 2). In particular, we calculated the indirect effect of job satisfaction T1 on job satisfaction T2 through work engagement, conditionally to the levels of both moderators: job demands and age. As can be seen, all the conditional indirect effects were significant, ranging from 0.04 to 0.12 . The sizes of the specific indirect effects at the specific levels of the two moderators and with respective bootstrap CIs are

also shown in Figure 2. The largest indirect effect size was found for younger employees with relatively high levels of job demands ( $b=0.12,95 \%$ CI $[0.08,0.19])$, while the lowest effect was found for older workers with low levels of job demands $(b=0.04,95 \%$ CI $[0.01,0.09])$.

\section{DISCUSSION}

A great challenge for the future, as well as for current management, is how to obtain and keep employees motivated and well-performing without jeopardizing their health. This challenge is increased by the great changes that have occurred in the last decades, in particular the constant and predictable aging of the workforce and the increase in job workload (Kompier, 2006; Toossi, 2012). In our study we tested a longitudinal moderated mediation model in which job satisfaction increases over time through an increment in work engagement. Furthermore, we hypothesized that this process was moderated by job demand, and hypothesis 1 was built on the mediating role of engagement in a gain circle of job satisfaction, in this sense examining the mechanism ("how") on the basis of satisfied employees. However, at the same time it is also important to address the conditions ("when") under which this mechanism works (hypotheses 23 ). Thus, in this study we tried to answer both how and when questions (Hayes and Preacher, 2013).

The findings confirm our hypotheses. In particular, our results showed that the higher their satisfaction, the more engaged and committed to their job the workers were, which in turn should increase job satisfaction over time, as stated in hypothesis 1 . This result, as over mentioned, is in line with the main idea of the COR theory (Hobfoll, 2002) and give reason of a self-perpetuating influence between job satisfaction and work engagement across time. Furthermore, hypothesis 2 stated that such a longitudinal mediation model is moderated by job demands, as confirmed by data. Based on the differentiation between hindrance and challenge stressors proposed by LePine et al. (2005), job

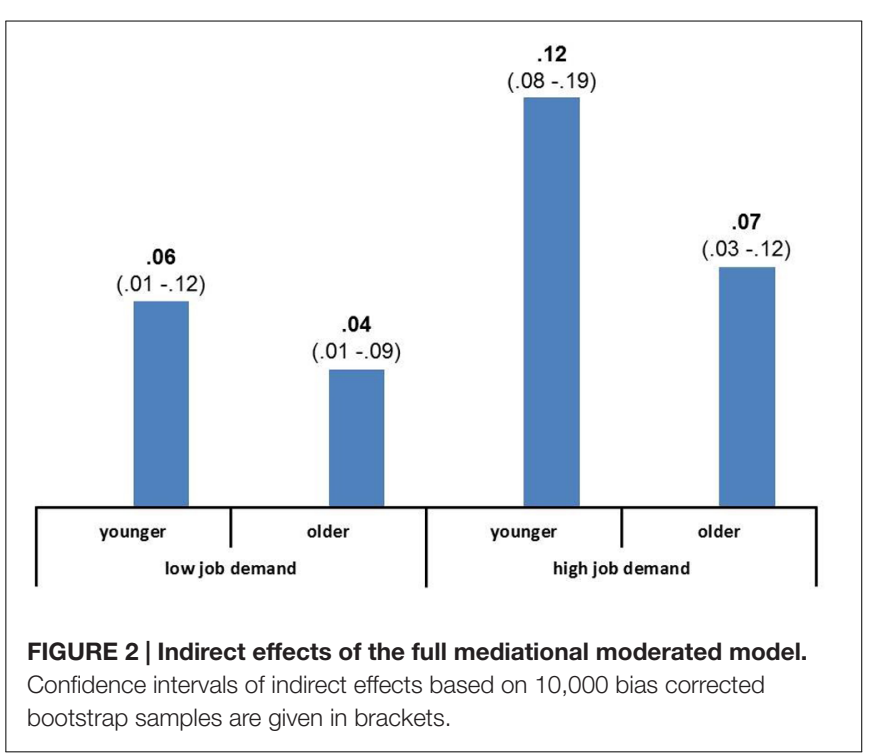


demands were considered a challenge stressor, able to increase the relationship between job satisfaction and engagement. Our results showed that satisfied employees are more engaged in their jobs, particularly under the condition of high job demand. In line with the challenge stress approach, they feel able to cope with their demanding job, using such a challenge as an opportunity for growth. Similarly, to previous research that showed how positive affective states, in particular optimism, may foster the capacity to cope with threatening situations (Luthans and Youssef, 2007) and increase work engagement (Xanthopoulou et al., 2009), our findings confirmed that job satisfaction may foster the gain cycle in a challenging workplace. As hypothesized in $\mathrm{H} 3$, we also found that age moderates the relationship between work engagement and job satisfaction. As age increases, the effect of work engagement on job satisfaction weakens. Relatively older workers are more satisfied in general, for reasons related to the aging process itself (i.e., maturation, change in personality, etc.), and less attracted by a high level of effort (Kanfer and Ackerman, 2004). In this sense the motivational pattern (engagement job satisfaction) plays a prominent role especially for relatively younger people. This is important as it suggests that both younger and older workers should be offered more challenge stressors (such as job demands), which could stimulate them, but that the expected effect could be more prominent for relatively younger workers. Our results confirmed that a gain cycle may be found in older workers, although with different trends according to age and job demands. The moderating role of age, which has been confirmed by our research, appears an added value, since understanding the relationship between age, motivation, and engagement is crucial when and where the workforce is growing older (cf. Pitt-Catsouphes and Matz-Costa, 2008). Although this aspect has not been widely investigated, some studies (e.g., James et al., 2011; Guglielmi et al., 2016) underlined an impact of age on employment engagement, though comparing younger vs. older workers. Instead, our study points out that age makes the difference and influences motivation, also within the same group of older workers.

Currently most research on the aging workforce focuses on the difference between older and younger workers, assuming demographic thresholds that usually use cut-off ages between 40 and 50 years. The improvement in health conditions of the population, a shift toward mental rather than physical job demands, and the general increase in the retirement age will probably make future 50-years-old similar to today's 40 -yearsold. In general, research showed that important changes occur between age cohorts, even among so-called 'older' workers (cf. James et al., 2011; von Bonsdorff et al., 2011), therefore it is important to understand the differences in motivational patterns occurring after the age of 50, as older workers may not be such a homogeneous group. In our sample we decided to use employees aged 50 and over. As seen in the previous references, in developed countries currently the majority of statistics on aging produced by international institutions define 'older workers' as those aged from 50 to 55 years and over.

Our results confirm the importance, on one hand, of not considering older workers as a uniform group and, on the other, of taking into account the role played by the gain cycle of resources. As reported by Gorgievski and Hobfoll (2008, p. 5), people "with greater resources are less vulnerable to resource loss and more capable of orchestrating resource gain." This means that workers with high engagement will not only be more satisfied but will also tend to increase their resources over time, becoming more resilient against stress and adverse job conditions. In our study we observed that this cycle also works in employees over the age of 50 .

\section{Practical Implications}

Our findings show that age matters, and that greater consideration should be devoted to age differences in order to design appropriate human resource practices that foster work engagement and satisfaction.

Gain cycle was shown to be moderated by the combined influence of job demand intensity and age: higher job demands and younger age are related to the maximum level of gain cycle, while the same high level of job demands, when associated with older age, appears not to be able to stimulate a similar effect. In terms of managerial implications, job demands represents a potential leverage to increase work engagement, though human resource practices aiming to use this feature should be designed bearing in mind that such a positive and stimulating effect does not impact "younger" and "older" old workers in the same way. Should employers be interested in modifying job design, they could consider increasing job demands (within functional limits) mainly for younger workers: indeed, in principle every worker may be stimulated by a challenging job, although our findings showed that the gain cycle is more likely to be maximized among younger workers. On the other hand, given the role of engagement shown in this study, if employers are unable to make changes in job design, they should bear in mind that other types of interventions are available to improve engagement, such as opportunities for learning and personal development. In fact, training and development activities aimed at developing new skills are important to prevent obsolescence and improve engagement. This is also confirmed in our results by the role of high job demands in work engagement. Stereotypes against older workers should be definitively challenged, and older workers should be offered opportunities to expand their knowledge, as studies show that opportunity for development is related to job satisfaction (Kooij et al., 2010) and the stereotypes held by supervisors on older workers' avoidance of learning lessen their willingness to train and develop (Van Vianen et al., 2011). Furthermore, it should also be taken into consideration that aging employees are increasingly motivated by intrinsic reasons, so helping others, and the chance to act as mentors could reciprocate in terms of higher engagement.

The current state of studies offers limited evidence on the specific and differential effects of different HRM practices, following different age cohorts within the older workers population (Kooij et al., 2010, 2013). However, our study suggests that age matters as far as the gain cycle of work engagement and positive work outcomes are concerned, therefore it is possible to hypothesize that different practices can be used to motivate middle-aged and older workers. This field of research appears promising and deserves further investigation. 


\section{Limitations}

While conducting a longitudinal study increases the power of our inferences, some problems may relate to the sample mortality. This is important because, as outlined by Goodman and Blum (1996, p. 628), "Particular groups of people may be lost in subsequent data collection, resulting in a biased sample or lack of generalizability." In order to establish the presence or otherwise of non-random sampling, we conducted an attrition analysis. This revealed only two differences between those who participated in both surveys and those who dropped out of the research. Since no differences were found concerning the strength of the relationships among variables, we are confident that subject attrition did not seriously affect our results. In addition to this, our study has several limitations. Firstly, our sample was certainly not representative, and for this reason the generalization of our findings is limited. Future research could replicate our results in different organizations (i.e., private organizations) and in different countries. Another limitation of our study is that only self-reported data were

\section{REFERENCES}

Alarcon, G. M. (2011). A meta-analysis of burnout with job demands, resources, and attitudes. J. Vocat. Behav. 79, 549-562. doi: 10.1016/j.jvb.2011.03.007

Alarcon, G. M., and Lyons, J. B. (2011). The relationship of engagement and job satisfaction in working samples. J. Psychol. 145, 463-480. doi: 10.1080/00223980.2011.584083

Arcangeli, G., and Mucci, N. (2009). Health problems in the working occupation of young people in handicraft factories. G. Ital. Med. Lav. Ergon. 31, 303-306.

Ashforth, B. E., Harrison, S. H., and Corley, K. G. (2008). Identification in organizations: an examination of four fundamental questions. J. Manage. 34, 325-374. doi: 10.1177/0149206308316059

Bakker, A. B., and Bal, P. M. (2010). Weekly work engagement and performance: a study among starting teachers. J. Occup. Organ. Psych. 83, 189-206. doi: 10.1348/096317909X402596

Bakker, A. B., and Demerouti, E. (2007). The job demands-resources model: state of the art. J. Manage. Psychol. 22, 309-328. doi: 10.1108/02683940710733115

Bal, M. P. (2015). “Sustainable careers: enabling older workers to continue working through individualized work arrangements," in Handbook of Research on Sustainable Careers, eds A. De Vos and B. Van der Heijden (Cheltenham: Edward Elgar), 304-318.

Bal, P. M., and Kooij, D. (2010). The relations between work centrality, psychological contracts, and job attitudes: the influence of age. Eur. J. Work Organ. Psychol. 20, 497-523. doi: 10.1080/13594321003669079

Balducci, C., Fraccaroli, F., and Schaufeli, W. B. (2010). Psychometric properties of the Italian version of the Utrecht Work Engagement Scale (UWES-9): a cross-cultural analysis. Eur. J. Psychol. Assess. 26, 143-149. doi: 10.1027/10155759/a000020

Bedeian, A. G., Ferris, G. R., and Kacmar, K. M. (1992). Age, tenure, and job satisfaction: a tale of two perspectives. J. Vocat. Behav. 40, 33-48. doi: 10.1016/0001-8791(92)90045-2

Dormann, C., and Zapf, D. (2001). Job satisfaction: a meta-analysis of stabilities. J. Organ. Behav. 22, 483-504. doi: 10.1002/job.98

Drabe, D., Hauff, S., and Richter, N. F. (2015). Job satisfaction in agin workforces: an analysis of the USA, Japan and Germany. Int. J. Hum. Resour. Man. 26, 783-805. doi: 10.1080/09585192.2014.939101

European Commission (2015). The 2015 Ageing Report Underlying Assumptions and Projection Methodologies. Brussels: European Commission.

European Foundation for the Improvement of Living and Working Conditions (2007). Fourth European Working Conditions Survey. Dublin: European Foundation for the Improvement of Living, and Working Conditions.

Faragher, E. B., Cass, M., and Cooper, C. L. (2005). The relationship between job satisfaction and health: a meta-analysis. Occup. Eviron. Med. 62, 105-112. doi: 10.1136/oem.2002.006734 used; future studies could use objective measures to evaluate, for example, job demands (i.e., supervisors' evaluations). A further limitation concerns the time lag used in this study (8 months). This time lag was chosen for practical convenience. Although, other studies using the same lag time in similar research (see for e.g., Salanova et al., 2011) future studies could select more theoretically grounded intervals, and above all use more measurement points in order to better measure the hypothesized gain cycle.

\section{AUTHOR CONTRIBUTIONS}

DG, IB, and RC conceptualized the study and chose the theoretical framework. The first version of the introduction was written by LA and RC. LA and MM analyzed the data and wrote the methods and results. DG and MD wrote the discussion and practical implications. All the authors then revised and improved the manuscript several times.

Flynn, M. (2010). The United Kingdom government's "business case" approach to the regulation of retirement. Ageing Soc. 30, 421-443. doi: 10.1017/S0144686X09990705

Giorgi, G., Shoss, M. K., and Leon-Perez, J. M. (2015). Going beyond workplace stressors: economic crisis and perceived employability in relation to psychological distress and job dissatisfaction. Int. J. Stress Manag. 22, 137-158. doi: $10.1037 / \mathrm{a} 0038900$

Goodman, J. S., and Blum, T. C. (1996). Assessing the non-random sampling effects of subject attrition in longitudinal research. J. Manag. 22, 627-652. doi: $10.1177 / 014920639602200405$

Gorgievski, M. J., and Hobfoll, S. E. (2008). "Work can burn us out or fire us up: conservation of resources in burnout and engagement," in Handbook of Stress and Burnout in Health Care, ed. J. R. B. Halbesleben (Hauppauge, NY: Nova Science Publishers), 1-22.

Guglielmi, D., Bruni, I., Simbula, S., Fraccaroli, F., and Depolo, M. (2016). What drives teacher engagement: a study of different age cohorts. Eur. J. Psychol. Educ. 31, 323-340. doi: 10.1007/s10212-015-0263-8

Hakanen, J. J., Schaufeli, W. B., and Ahola, K. (2008). The Job DemandsResources model: a three-year cross-lagged study of burnout, depression, commitment, and work engagement. Work Stress 22, 224-241. doi: $10.1080 / 02678370802379432$

Halbesleben, J. R. B. (2010). “A meta-analysis of work engagement: relationships with burnout, demands, resources, and consequences," in Work Engagement: A Handbook Of Essential Theory and Research, eds B. Bakker Arnold and P. Leiter Michael (New York, NY: Psychology Press).

Hayes, A. F. (2013). Data from: PROCESS: A Versatile Computational Tool for Observed Variable Mediation, Moderation, and Conditional Process Modeling. Available at: http://afhayes.com/public/process2012.pdf

Hayes, A. F., and Preacher, K. J. (2013). "Conditional process modeling: using structural equation modeling to examine contingent causal processes,"in Structural Equation Modeling: A Second Course, eds G. R. Hancock and R. O. Mueller (Charlotte, NC: Information Age Publishing).

Hobfoll, S. E. (1989). Conservation of resources: a new attempt at conceptualizing stress. Am. Psychol. 44, 513-524. doi: 10.1037/0003-066X.44.3.513

Hobfoll, S. E. (2002). Social and psychological resources and adaptation. Rev. Gen. Psychol. 6, 307-324. doi: 10.1037/1089-2680.6.4.307

Hobfoll, S. E. (2011). Conservation of resource caravans and engaged settings. J. Occup. Organ. Psych. 84, 116-122. doi: 10.1111/j.2044-8325.2010.02016.x

James, J. B., McKechnie, S., and Swanberg, J. (2011). Predicting employee engagement in an age-diverse retail workforce. J. Organ. Behav. 32, 173-196. doi: $10.1002 /$ job.681

Kalleberg, A. L., and Loscocco, K. A. (1983). Aging, values, and rewards: explaining age differences in job satisfaction. Am. Sociol. Rev. 48, 78-90. doi: $10.2307 / 2095146$ 
Kanfer, R., and Ackerman, P. L. (2004). Aging, adult development, and work motivation. Acad. Manag. Rev. 29, 440-458. doi: 10.5465/AMR.2004.1367 0969

Karasek, R. A. (1985). Job Content Questionnaire and User's Guide. Lowell, MA: University of Massachusetts.

Kinicki, A. J., McKee-Ryan, F. M., Schriesheim, C. A., and Carson, K. P. (2002). Assessing the construct validity of the job descriptive index: a review and meta-analysis. J. Appl. Psychol. 87, 14-32. doi: 10.1037//0021-9010.87. 1.14

Kompier, M. A. (2006). New systems of work organization and workers' health. Scand. J. Work Env. Health 32, 421-430. doi: 10.5271/sjweh.1048

Kooij, D. T., Guest, D. E., Clinton, M., Knight, T., Jansen, P. G., and Dikkers, J. S. (2013). How the impact of HR practices on employee well-being and performance changes with age. Hum. Resour. Manag. J. 23, 18-35. doi: 10.1111/1748-8583.12000

Kooij, D. T., Jansen, P. G., Dikkers, J. S., and De Lange, A. H. (2010). The influence of age on the associations between HR practices and both affective commitment and job satisfaction: a meta analysis. J. Organ. Behav. 31, 1111-1136. doi: 10.1002/job.666

LePine, J. A., Podsakoff, N. P., and LePine, M. A. (2005). A meta-analytic test of the challenge stressor hindrance stressor framework: an explanation for inconsistent relationships among stressors and performance. Acad. Manag. Rev. 48, 764-775. doi: 10.5465/AMJ.2005.18803921

Lindsley, D. H., Brass, D. J., and Thomas, J. B. (1995). Efficacy-performing spirals: a multilevel perspective. Acad. Manag. Rev. 20, 645-678. doi: 10.2307/ 258790

Locke, E. A. (1969). What is job satisfaction? Organ. Behav. Hum. Perf. 4, 309-336. doi: 10.1016/0030-5073(69)90013-0

Luthans, F., and Youssef, C. M. (2007). Emerging positive organizational behavior. J. Manag. 33, 321-349. doi: 10.1177/0149206307300814

McCarthy, J., Heraty, N., Cross, C., and Cleveland, J. N. (2014). Who is considered an "older worker"? Extending our conceptualization of "older" from an organizational decision maker perspective. Hum. Resour. Manag. J. 24, 374-393. doi: 10.1111/1748-8583.12041

Morrison, R. (2008). Negative relationships in the workplace: associations with organizational commitment, cohesion, job satisfaction and intention turnover. J. Manage. Organ. 14, 330-344. doi: 10.1017/S1833367200003126

Nakai, Y., Chang, B., Snell, A., and Fluckinger, C. (2011). Profiles of mature job seekers: connecting needs and desires to work characteristics. J. Organ. Behav. 32, 155-172. doi: 10.1002/job.697

Newton, T., and Keenan, T. (1991). Further analyses of the dispositional argument in organizational behavior. J. Appl. Psychol. 76:781. doi: 10.1037/a00 30939

Ng, T. W., and Feldman, D. C. (2007). Organizational embeddedness and occupational embeddedness across career stages. J. Vocat. Behav. 70, 336-351. doi: 10.1016/j.jvb.2006.10.002

Pitt-Catsouphes, M., and Matz-Costa, C. (2008). The Multi-Generational Workforce: Findings from the Age \& Generations Study. Chestnut Hill, MA: Sloan Center on Aging \& Work at Boston College.

Podsakoff, N. P., LePine, J. A., and LePine, M. A. (2007). Differential challenge stressor-hindrance stressor relationships with job attitudes, turnover intentions, turnover, and withdrawal behavior: a meta-analysis. J. Appl. Psychol. 92, 438454. doi: $10.1037 / 0021-9010.92 .2 .438$

Pulakos, E. D., and Schmitt, N. (1983). A longitudinal study of a valence model approach for the prediction of job satisfaction of new employees. J. Appl. Psychol. 68, 307-312. doi: 10.1037/0021-9010.68.2.307

Roberts, B. W., Walton, K. E., and Viechtbauer, W. (2006). Patterns of meanlevel change in personality traits across the life course: a meta_analysis of longitudinal studies. Psychol. Bull. 132, 3-27. doi: 10.1037/0033-2909. 132.1.1

Russell, J. A., and Carroll, J. M. (1999). On the bipolarity of positive and negative affect. Psychol. Bull. 125, 3-30. doi: 10.1037/0033-2909.125.1.3

Salanova, M., Llorens, S., and Schaufeli, W. B. (2011). Yes, I can, I feel good, and I just do it! On gain cycles and spirals of efficacy beliefs, affect, and engagement. Appl. Pyschol. Int. Rev. 60, 255-285. doi: 10.1111/j.1464-0597.2010. 00435.x

Salanova, M., and Schaufeli, W. (2009). El Engagement en el Trabajo: Cuando el Trabajo se Convierte en Pasión. Madrid: Alianza Editorial.
Salanova, M., and Schaufeli, W. B. (2008). A cross-national study of work engagement as a mediator between job resources and proactive behaviour. Int. J. Hum. Resour. Manag. 19, 116-131. doi: 10.1080/095851907017 63982

Salanova, M., Schaufeli, W. B., Xanthopoulou, D., and Bakker, A. B. (2010). "The gain spiral of resources and work engagement: sustaining a positive worklife," in Work Engagement: A Handbook of Essential Theory and Research, eds A. B. Bakker and M. P. Leiter (New York, NY: Psychology Press), 118-131.

Schaubroeck, J., Ganster, D. C., and Kemmerer, B. (1996). Research Does trait affect promote job attitude note stability? J. Organ. Behav. 17, 191-196. doi: 10.1002/(SICI)1099-1379(199603)17:2 < 191::AID-JOB777> 3.3.CO;2-O

Schaufeli, W. B., and Bakker, A. B. (2004). Job demands, job resources, and their relationship with burnout and engagement: a multi-sample study. J. Organ. Behav. 25, 293-315. doi: 10.1002/job.248

Schaufeli, W. B., Bakker, A. B., and Salanova, M. (2006). The measurement of work engagement with a short questionnaire a cross-national study. Educ. Psychol. Meas. 66, 701-716. doi: 10.1177/0013164405282471

Schaufeli, W. B., Salanova, M., González-Romá, V., and Bakker, A. B. (2002). The measurement of engagement and burnout: a two sample confirmatory factor analytic approach. J. Happiness Stud. 3, 71-92. doi: 10.1023/A:10156309 30326

Schaufeli, W. B., and Taris, T. W. (2013). "A critical review of the job demandsresources model: implications for improving work and health," in Bridging Occupational, Organizational and Public Health: A Transdisciplinary Approach, eds G. F. Bauer and O. Hämmig (Dordrecht: The Netherlands: Springer), 43-68.

Schaufeli, W. B., Taris, T. W., and Bakker, A. B. (2008a). "It takes two to tango: workaholism is working excessively and working compulsively," in The long Work Hours Culture. Causes, Consequences and Choices, eds R. J. Burke and C. L. Cooper (Bingley: Emerald), 203-226.

Schaufeli, W. B., Taris, T. W., and van Rhenen, W. (2008b). Workaholism, burnout, and work engagement: three of a kind or three different kinds of employee well-being? Appl. Psychol. 57, 173-203. doi: 10.1111/j.1464-0597.2007. 00285. $\mathrm{x}$

Shimazu, A., Schaufeli, W. B., Kubota, K., and Kawakami, N. (2012). Do workaholism and work engagement predict employee well-being and performance in opposite directions? Ind. Health 50, 316-321. doi: 10.2486/ indhealth.MS1355

Simbula, S., and Guglielmi, D. (2013). I am engaged, I feel good, and I go the extramile: reciprocal relationships between work engagement and consequences. Rev. Psicol. Trab. Organ. 29, 117-125. doi: 10.5093/tr2013a17

Sloan Center on Aging and Work at Boston College (2011). Data from: Effects of "Old-Developed" versus "Young Developing" Country Type and Age-Related Factors on Work Engagement, Job Satisfaction, \& Organizational Commitment. (2011) Available at http://www.bc.edu/content/dam/files/research_sites/ agingandwork/pdf/publications/GOT_CR_Sumary.pdf

Smith, P., and Beaton, D. (2008). Measuring change in psychosocial working conditions: methodological issues to consider when data are collected at baseline and one follow-up time point. Occup. Environ. Med. 65, 288-296. doi: 10.1136/oem.2006.032144

Spector, P. E. (1997). Job Satisfaction: Application, Assessment, Causes, and Consequences. Thousand Oaks, CA: Sage.

Toossi, M. (2012). Projections of the labor force to 2050: a visual essay. Mon. Labor Rev. 135, 3-16.

United Nations (2007). World Economic and Social Survey 2007. New York, NY: Development in an Ageing World, United Nations Publication.

van Dick, R., and Haslam, S. A. (2012). "Stress and well-being in the workplace: support for key propositions from the social identity approach," in The Social cure: Identity, Health, and Well-Being, eds J. Jetten, C. Haslam, and S. A. Haslam (London: Psychology Press), 1-27.

Van Vianen, A. E., Dalhoeven, B. A., and De Pater, I. E. (2011). Aging and training and development willingness: employee and supervisor mindsets. J. Organ. Behav. 32, 226-247. doi: 10.1002/job.685

von Bonsdorff, M. E., Kokko, K., Seitsamo, J., von Bonsdorff, M. B., Nygård, C. H., Ilmarinen, J., et al. (2011). Work strain in midlife and 28-year work ability trajectories. Scand. J. Work. Env. Health 37, 455-463. doi: 10.5271/sjweh. 3177 
Wanous, J. P., Reichers, A. E., and Hudy, M. J. (1997). Overall job satisfaction: how good are single item measures? J. Appl. Psychol. 82, 247-252. doi: 10.1037/00219010.82.2.247

World Medical Association [WMA] (2013). World Medical Association Declaration of Helsinki ethical principles for medical research involving human subjects. J. Amr. Med. Assoc. 310, 2191-2194. doi: 10.1001/jama.2013. 281053

Xanthopoulou, D., Bakker, A. B., Demerouti, E., and Schaufeli, W. B. (2009). How job and personal resources influence work engagement and financial returns: a diary study in a Greek fast-food company. J. Occup. Organ. Psych. 82, 183-200. doi: 10.1348/096317908X285633
Conflict of Interest Statement: The authors declare that the research was conducted in the absence of any commercial or financial relationships that could be construed as a potential conflict of interest.

Copyright (c) 2016 Guglielmi, Avanzi, Chiesa, Mariani, Bruni and Depolo. This is an open-access article distributed under the terms of the Creative Commons Attribution License (CC BY). The use, distribution or reproduction in other forums is permitted, provided the original author(s) or licensor are credited and that the original publication in this journal is cited, in accordance with accepted academic practice. No use, distribution or reproduction is permitted which does not comply with these terms. 
OPEN ACCESS

Edited by: Gabriele Giorgi,

European University of Rome, Italy

Reviewed by:

Joann Farrell Quinn,

University of South Florida Morsan

College of Medicine, USA

Giulio Arcangeli,

University of Florence, Italy

${ }^{*}$ Correspondence:

Nadine C. Page

nadine.page@ashridge.hult.edu

Specialty section:

This article was submitted to Organizational Psychology,

a section of the journal

Frontiers in Psychology

Received: 13 July 2016 Accepted: 08 December 2016 Published: 10 January 2017

Citation:

Page NC and Nilsson VO (2017) Active Commuting: Workplace Health Promotion for Improved Employee Well-Being and Organizational Behavior. Front. Psychol. 7:1994 doi: 10.3389/fpsyg.2016.01994

\section{Active Commuting: Workplace Health Promotion for Improved Employee Well-Being and Organizational Behavior}

\author{
Nadine C. Page* and Viktor O. Nilsson \\ Hult International Business School, Berkhamsted, UK
}

Objective: This paper describes a behavior change intervention that encourages active commuting using electrically assisted bikes (e-bikes) for health promotion in the workplace. This paper presents the preliminary findings of the intervention's impact on improving employee well-being and organizational behavior, as an indicator of potential business success.

Method: Employees of a UK-based organization participated in a workplace travel behavior change intervention and used e-bikes as an active commuting mode; this was a change to their usual passive commuting behavior. The purpose of the intervention was to develop employee well-being and organizational behavior for improved business success. We explored the personal benefits and organizational co-benefits of active commuting and compared these to a travel-as-usual group of employees who did not change their behavior and continued taking non-active commutes.

Results: Employees who changed their behavior to active commuting reported more positive affect, better physical health and more productive organizational behavior outcomes compared with passive commuters. In addition, there was an interactive effect of commuting mode and commuting distance: a more frequent active commute was positively associated with more productive organizational behavior and stronger overall positive employee well-being whereas a longer passive commute was associated with poorer well-being, although there was no impact on organizational behavior.

Conclusion: This research provides emerging evidence of the value of an innovative workplace health promotion initiative focused on active commuting in protecting and improving employee well-being and organizational behavior for stronger business performance. It considers the significant opportunities for organizations pursuing improved workforce well-being, both in terms of employee health, and for improved organizational behavior and business success.

Keywords: workplace health promotion, active commuting, electric bikes, employee well-being, organizational behavior, business success 


\section{INTRODUCTION}

\section{Workplace Health Promotion}

A healthy and productive workforce is critical for economic success and population health (Cancelliere et al., 2011). Unhealthy working adults contribute to a substantial economic burden of health-related productivity loss (Burton et al., 2004; Goetzel and Pronk, 2010; Eng et al., 2016). With regards to health, physical (in)activity directly contributes to one in six deaths and costs $£ 7.4$ billion to business and wider society (Petrokofsky and Davis, 2016). According to the World Health Organization (WHO), non-communicable diseases are estimated to have reduced the Gross Domestic Product by one percent in most low- and middle-income countries by 2015 (Abegun and Stanciole, 2006). Due to the expansion of sedentary occupations and an aging population, over a quarter of adults in England report to have less than $30 \mathrm{~min}$ of physical activity a week (Public Health England, 2014); this is significantly lower than the recommended amount (Department of Health, 2011). In light of this, the WHO has identified the workplace as one of the priority settings for health promotion in the 21 st Century.

The workplace presents an ideal setting to promote and deliver health-promotion activities; overcoming barriers such as a lack of time and providing access to a large intersection of society (Malik et al., 2014). Workplace health promotion is important in the prevention of non-communicable diseases among employees. For example, workplace health promotion programs have shown to offer benefits by improving employees' blood pressure levels (Eng et al., 2016), lowering disease prevalence (Boshtam et al., 2010; Jung et al., 2012), reducing stress (Jarman et al., 2015), lowering sickness absence (Loeppke et al., 2008; Goetzel et al., 2009), and improving presenteeism (Cancelliere et al., 2011). They have also been shown to produce happier, healthier, more loyal and productive employees (Fitzgerald and Danner, 2012). However, despite long-standing advocacy for comprehensive worksite programs, there needs to be more empirical evidence that links these strategies to improvements in health and productivity (Terry et al., 2008), and further consideration to the types of intervention that encourage behavior change and maintenance (Hunter et al., 2016). In essence, further implementation research is needed.

Recent National Institute for Health and Clinical Excellence (NICE) guidelines recommend the promotion of physical activity in and around the workplace, particularly through walking and cycling (National Institute for Health and Clinical Excellence [NICE], 2008). One way employees might be encouraged to be more active at work is by integrating active commuting modes such as walking and cycling into daily routines. This has been recommended as the best way of encouraging physical activity (Petrokofsky and Davis, 2016), and will be explored further in this study.

\section{Commuting Behavior}

There is increasing interest in commuting behaviors for health and environmental benefits, especially against the backdrop of climate change and the global physical activity 'pandemic' (Kohl et al., 2012; Shaw et al., 2014). However, it seems that passive commuting modes remain the preferred option. Car use accounts for $76 \%$ of commuting behavior for journeys greater than two miles and active commuting modes such as walking and cycling account for just 3\% (Department for Transport, 2007). As such, commuting behavior is one target area for health promotion; it presents an opportunity to shift, where appropriate, passive travel behavior (e.g., car use) to more active modes (e.g., walking, cycling) for improved environmental and personal well-being. A workplace health program focused on active commuting might help to change employee behavior and bring about broader benefits for the organization.

\section{Active Travel and Health}

Active travel modes include walking or cycling as an alternative to motorized transport for the purpose of making everyday journeys. Encouraging people to switch their journeys to active travel modes can improve health, quality of life, and the environment (Woodcock et al., 2009), and will directly benefit individuals and communities as a whole. Integrating active commuting modes such as walking and cycling into daily routines is recommended as the best way of encouraging physical activity (Petrokofsky and Davis, 2016). Indeed, people who cycle for travel purposes, as opposed to leisure, are four times more likely to meet physical activity guidelines than those who don't (Stewart et al., 2015). Cycling to work is very good exercise that is relatively easy to incorporate in normal daily routines (Vuori et al., 1994). Furthermore, the workplace setting is a logical place to promote active travel since in many countries the majority of adults work (OECD , 2014) and as stated above, a large proportion of journeys to work are made by private motor vehicles (Enoch and Rye, 2006; Goodman, 2013). Following on, this study describes a workplace behavior change intervention for encouraging active commuting.

\section{The Impact of Commuting}

Commuting is an integral part of the workday routine; it is the connection between home- and work-life. Commute mode and commuting experience can have an impact on who we are, not just in terms of physical health, but with regards to our overall well-being and behavior (Santhosh, 2015). Further, these effects can manifest both at home and in the workplace, and in a bidirectional way: work and home life can seep into the commute in many ways and the commuting experience can seep back into work and home life (Bissell, 2015). Commuting to and from work has been found to create subtle but significant transformations in people over time, in relation to the way they interact, what they desire from work and home life, personal tolerance and coping levels, and habits in thinking and feeling (Bissell, 2015). In sum, an employee's mode of commute and the commuting experience can have both a positive and negative effect.

\section{Commuting Experience}

Experiences during the commuting journey can change what people are capable and willing to do at work. Indeed, as Leiter and Durup (1996) suggest, workplace attitudes and behaviors can be influenced significantly by non-work factors. Furthermore, unresolved daily hassles, such as those that might be experienced 
during the commute to work, can persist even when they are no longer in the conscious awareness and they can add to hassles in other life contexts (Kohn and Macdonald, 1992). Put differently, an employee's commuting experience can spillover and influence their behavior and performance at work, and this might lead to decreases in productivity (see Regus International, 2012).

Research exploring the impact of commuting has focused in two areas: studies that have explored the negative impacts that are largely associated with long and stressful commutes and studies that have explored the positive impacts of an active commuting mode. Dealing with the former first, experiencing stress as a result of commuting is fairly commonplace. For example, the majority of Australian commuters are stressed as a result of their daily trips to and from work (IBM, 2011) and in the UK, traffic congestion was the most commonly reported source of daily stress among employees (BBC News, 2000). Longer commuting times and greater commuting distances have been associated with negative psychological and behavioral outcomes (Koslowsky et al., 1996), and poorer well-being (Stutzer and Frey, 2008). Women seem especially susceptible to the impact of long commutes (Evans et al., 2002).

A stressful commute to work can potentially lead to poorer cognitive, behavioral, and emotional performance at work (Schaeffer et al., 1988), and also associate with a range of physical and emotional health problems (Crabtree, 2010). For example, Hennessy (2008) found a negative spillover of the traffic environment on workplace behavior. The results of this study suggest that dealing with traffic stress on the commute to work might deplete coping resources and thereby make employees less able to deal with workplace stress (see also Leiter and Durup, 1996).

The same resource-based hypothesis could also explain poorer cognitive and behavioral performance. In sum, it seems that negative experiences on the journey to work can spillover and have a negative impact on employees' emotional well-being and, in turn, broader workplace performance, and viz. business success.

\section{Commuting Mode}

With regards to commuting mode, an active commute can associate with positive outcomes, especially those related to physical health (Petrunoff et al., 2016a,b). Research on the associations between active travel and health has focused on physical health outcomes (Amlani and Munir, 2010) including major diseases and mortality (Jarrett et al., 2012; Laverty et al., 2013) and overall well-being (Martin et al., 2014). Specifically, cycling as a means of active travel is associated with reduced absence at work due to any form of sickness (Hendriksen et al., 2010). The more often people cycle to work and the longer the distance traveled, the lower the absenteeism. In other words, cycling to work not only contributes to employee health, it may also result in a financial benefit for the employer (Hendriksen et al., 2010).

As Hendriksen et al.'s (2010) study suggests, empirical research in this area is moving toward a broader scope and recent findings have suggested that there might be broader benefits of an active commute for both individuals and organizations, including greater overall well-being (Gómez et al., 2013) and social inclusion (Woodcock et al., 2009). Specifically, Mytton et al. (2016) found positive associations of active commuting with physical and mental well-being and lower sickness absence for employees who maintained cycling to work. These associations warrant further exploration. The aim of this paper, therefore, is to describe the implementation of a workplace health program that encourages active commuting, and further explore the associations of active and passive commuting modes with employee well-being and the broader co-benefits on organizational behavior.

Specifically, one organizational behavior that might be negatively impacted by commuting experience and commuting mode is Organizational Citizenship Behavior (Organ, 1988). Organizational Citizenship Behavior, defined as "individual behavior that is discretionary, not directly or explicitly recognized by the formal reward system, and that is aggregate, promotes the effective functioning of the organization. ...the behavior is rather a matter of personal choice, such that its omission is not generally understood as punishable" (Organ and Ryan, 1995). Organizational Citizenship Behavior has been described as one prominent variable that indicates the significant manpower in organizational effectiveness. Williams and Anderson (1991) identified two dimensions of OCB; behavior exhibited toward individuals (OCBI) and behavior toward organizations (OCBO). Luthans (2005) describes the dispositional traits of employees with OCB to be cooperative, helpful, caring and conscientious. Despite the theoretical association between workplace commuting experience and OCB, the empirical research has not consistently identified the existence or nature of the relationship (Santhosh, 2015). In light of these findings, this study explores the relationship between commuting mode - an active compared with a passive commute - and Organizational Citizenship Behavior as an organizational co-benefit.

\section{Electrical Assisted Bikes for Active Commuting}

Active commuting using a conventional bicycle might not be a viable alternative to passive commuting for some employees. This might be because of the increasing distances between home and work - a maximum distance of $10 \mathrm{~km}$ to the workplace was found to be a feasible commuter cycling distance using a conventional bike (Iacono et al., 2010) - or because of the topography of certain urban environments and roads that are not adapted for cyclists. As well as these physical constrains, people also commonly cite a lack of time; a lack of bicycle facilities at the workplace; and poor physical fitness and age as factors that deter them from choosing the conventional bicycle for transport (de Geus and Hendriksen, 2015).

Electrical assisted bikes (e-bikes), also called pedelecs, are becoming an increasingly popular mode of transport for leisure and active commuting (Papoutsi et al., 2014; Peterman et al., 2016) and their use might help to challenge some of the barriers associated with cycling. E-bikes provide electric assistance only when a rider is pedaling. They have a sensor to detect the pedaling speed, pedaling force, or both, and are typically limited to a 
maximum speed of $25 \mathrm{~km} / \mathrm{h}$. They are more environmentally sustainable than using a car - they produce no emissions, no noise and they use very little energy at very low cost (Intelligent Energy Europe, 2012). They also make active travel a more viable alternative to using a conventional bicycle and reduce the problems associated with cycling on hilly terrains and longer distances (Sperlich et al., 2012). The commuting distance with an e-bike is 1.5 times longer than with a conventional bicycle (Hendriksen et al., 2008). The additional 'assistance' provided by the e-bike also provides new motivation for novice cyclists and increases the likelihood that those users will continue cycling in the future (de Geus and Hendriksen, 2015).

The desire for increased speed and reduced physical exertion is reported to be the main motivation for the increasing popularity of e-bikes (MacArthur et al., 2014; Johnson and Rose, 2015). There is growing interest in the role that e-bikes can play in promoting health, and despite some concerns that electrically assisted cycling might not contribute sufficiently to minimum physical activity requirements (Simons et al., 2009; Sperlich et al., 2012), there is mounting empirical evidence to suggest that cycling with assistance can confer positive health benefits (Gojanovic et al., 2011; Louis et al., 2012). There are direct positive physical health outcomes. Peterman et al. (2016) found that using an e-bike helped participants meet their physical activity recommendations and improve their cardiometabolic risk factors within only 4 weeks. Following their assessment of the physiological demands of pedaling an e-bike, Louis et al. (2012) concluded that electrically assisted cycling has great potential to promote physical activity in industrialized societies.

Evidence on the broader psychological and behavioral impacts of e-cycling is less clear, although some studies have reported an increased sense of enjoyment of the user (Popovich et al., 2014; Fyhri and Fearnley, 2015). Furthermore, Theurel et al. (2012) found that postmen performed better on a mail-sorting test after delivering mail on an e-bike compared with a bicycle without assistance. These positive results were probably due to the fact that participants using the e-bike were less exhausted and could concentrate better. Research on the use of e-bikes is growing and there is certainly scope for further research that explores the feasibility and benefits of using e-bikes for active commuting as part of a workplace health program.

\section{Changing Travel Behavior}

There are clear health benefits of active travel for individuals and co-benefits for organizations. However, the cycling culture in the UK is small ( $1 \%$ of all trips per year; Jones et al., 2016) and there has been limited effectiveness of physical activity behavior change interventions (Abraham and Graham-Rowe, 2009; Conn et al., 2009; Rongen et al., 2013). Behavior change approaches can be broadly categorized as structural or psychological (Fujii and Kitamura, 2003). More specifically, their design can be grouped into four broad categories: (1) economic policies focused on changing the finance system; (2) physical policies focused on changing the infrastructure; (3) soft policies, which are focused on behavior change; and (4) knowledge policies that support research and development (Shaw et al., 2014). There is ongoing development in the UK to improve the infrastructure that supports active travel (e.g., Cycling Delivery Plan and the Cycling and Walking Investment Strategy) and this is supported by significant investment in electrically assisted cycle sharing schemes. However, for these schemes to be effective, people need to change their behavior toward active travel modes and this requires effective behavior change interventions.

Studies on travel behavior have suggested that multicomponent interventions are often more effective in creating behavior change (Ferdowsian et al., 2010), and for inducing longterm change (Goetzel and Pronk, 2010). Furthermore, when encouraging walking and cycling behaviors as alternatives to using the car, Ogilvie et al. (2004) found that those interventions that were participatory, as opposed to informational, were found to be the most effective. Intensive interventions with individuals have also been shown as an effective method to increase walking and cycling (Yang et al., 2010).

Wider social and economic concerns with health and well-being have led to an increased number of workplace health interventions, and a related increase in research on their effectiveness. However, previous research has shown modest and short-term results of interventions to date (National Institute for Health and Clinical Excellence [NICE], 2008; Conn et al., 2009; Foster et al., 2012). There is a recognized need for more innovative approaches and interventions that purposefully encourage physical activity behavior change maintenance (Hunter et al., 2016) and more high-quality research to inform policy and practice in the UK and elsewhere (Carmichael et al., 2016). Therefore, this paper focuses on describing a workplace health behavior change intervention for encouraging active commuting using e-bikes, and reports on the preliminary findings of the intervention's impact on employee and organizational well-being.

This study addresses the following research questions: Are there differences in personal well-being and organizational behavior according to active and passive travel modes? What is the impact of active and passive commuting mode on personal well-being (physical and psychological health) and organizational behavior? What is the relationship between frequency and distance of commute and personal well-being and organizational behavior, and does this differ according to commuting mode? What are the perceived barriers to active commuting and do perceptions of these change following a change in commuting behavior?

\section{MATERIALS AND METHODS}

\section{Research Design}

The study is designed as a quasi-experimental longitudinal intervention designed to change workplace travel behavior, and adopts a mixed method approach. Both quantitative and qualitative data were collected from baseline (pre-intervention), throughout the intervention phase, and are planned postintervention. This paper focuses on the quantitative data that were collected online via monthly questionnaires and weekly diaries. All data were self-reported. At the time of writing, the 
data collection was mid-way through the intervention phase, approximately 8 weeks into the intervention.

\section{Organization Location}

This research was conducted at the UK campus of a global education provider. The campus is rurally located approximately $5 \mathrm{~km}$ from the nearest town and public transport links. This makes car-use the default travel mode for the majority of employees and because of the hilly terrain, e-cycling is a more viable alternative compared with conventional cycling.

\section{Participants}

All employees of the case organization were eligible to participate. Participants formed a self-selecting sample and were naturally assigned, through self-selection, to either the active travel group (Active Travel) or the non-active (Passive Travel) group. At the start of the research, 12 participants were included in the Active Travel group and 19 participants affiliated with the Passive Travel group. Due to the longitudinal nature of the research, there was a degree of participation withdrawal/non-compliance over time. The size of the participant groups therefore varied at different time points (see Table 1). The majority of participants were female $(80 \%)$ and were aged between 21 and 55 years. The age distribution was similar for the active and passive travel groups (21-25 years: $n=3,5 ; 26-30$ years: $n=2,2 ; 31-35$ years: $n=1$, 3; 36-40 years: $n=1,1$; 41-45 years: $n=2,5$; 46-50 years: $n=0,0 ; 51-55$ years: $n=2,2$; 56-60 years: $n=1,1$, for active and passive travel groups, respectively). All participants were day-shift workers although their start time was specific to their role.

\section{The Workplace Travel Intervention}

The workplace behavior change intervention was multicomponent. The initiative started with an e-bike taster session that was delivered during a lunchtime at the case organization approximately 1 month prior to the start of the intervention. The taster session offered all employees from across the organization the opportunity to trial a power-assisted electric bike (e-bike) for a 10-min guided cycle ride. Participants were

TABLE 1 | Data collection throughout the workplace intervention.

\begin{tabular}{lcc}
\hline & Active travel & Passive travel \\
\hline Week 1 & 12 & 19 \\
Week 2 & 11 & 11 \\
Week 3 & 8 & 10 \\
Week 4 & 7 & 8 \\
Week 5 & 6 & 8 \\
Week 6 & 6 & 6 \\
Week 7 & 4 & 5 \\
Week 8 & 2 & 2 \\
Monthly pre survey & 13 & 8 \\
Monthly 1 month & 9 & 7
\end{tabular}

The active travel group also includes employees who cycled to work not using an e-bike. These participants were not included in the inferential analyses. introduced to the e-bikes, their functionality including the maximum mileage range and speed that was possible with a fully charged battery, and to how remove and charge the battery. During this session, the researchers were available to answer any questions about the e-bikes and provide further information about the intervention. As follow-up to this, all employees across the organization received an information email detailing the workplace travel intervention and were invited to participate.

Participants in the intervention (Active Travel) group were given the opportunity to borrow an e-bike, free of charge, for up to 5-months duration (from May to September). The timing of the research was selected intentionally to encourage behavior change; it was hoped that the milder weather would be less of a deterrent. There were 10 Giant Prime E+3 W e-bikes available for loan and these were allocated to employees on a first come, first serve basis following the e-bike lunchtime taster session and follow-up email invitation. The intervention started with an e-bike induction, which informed participants about the functionality of the e-bike and ensured they had sufficient cycling proficiency.

Participants in the Active Travel group were loaned the e-bike for as long as they requested. Rather than imposing a minimum or maximum loan period, we decided to leave this open-ended to enable participants to have complete control over how long they borrowed the e-bike. We hoped that having this flexible approach would encourage a broad range of employees to borrow an e-bike and try active commuting even if this was for just a few days or a week. The median loan period at the time for this paper was 6 weeks (minimum $=3$ weeks; maximum $=8$ weeks). This suggested that participants did in fact continue with their behavior change for a sustained period of time. In addition, we did not insist that participants used the e-bike every day for their commute; again, employees were in complete control of how often they used the e-bike to commute; this was determined by their personal schedule. Lastly, we did not restrict participants to only using the e-bike for their commute; they were able to use the e-bike for any journey they wanted to. In essence, we gave participants complete control over where, when, and for how long they used the e-bikes.

The e-bikes were supplied with a battery, battery charger and lock, and were delivered to participants' home addresses or to their workplace, as requested. A similar process was followed when participants wanted to return the e-bikes; we arranged a convenient location and time to collect the e-bike.

During the e-bike loan period participants were provided with fully comprehensive roadside assistance. This enabled them to be 'rescued' if their e-bike broke-down. Fortunately, this service was not used. Furthermore, we also serviced each e-bike midway through each loan period to ensure its running efficiency and safety.

The e-bikes were re-distributed to participants throughout the duration of the intervention on a rotational basis. Once an e-bike was returned, it was serviced and then re-issued to another employee, again for an open-ended duration. This approach ensured that the maximum number of employees were able to use an e-bike and participate in the intervention. 
Participants in the control (Passive Travel) group continued with their usual car travel behavior for the duration of the study.

\section{Measures and Data Collection}

Data were collected at the individual (employee) level preintervention, during the intervention phase, and will be collected post-intervention, via online monthly questionnaires and weekly diaries. A link to the questionnaires was sent individually to participants via email on a weekly/monthly basis. If participants had not completed these surveys within 2 days, a follow-up reminder email was sent. Participants in both the intervention and control groups completed near identical questionnaires, at the same time points, using the same data collection method.

The monthly questionnaire consisted of three major parts: (1) demographic variables including gender and age, (2) information on organizational behavior and (3) information on personal well-being. We measured positive and negative organizational behavior using the Organizational Citizenship Behavior (OCB) and Counterproductive Workplace Behavior (CWB) scales, respectively, developed by Dalal et al. (2009). The items from both scales were randomized and presented as one scale containing 14 items. Participants were asked to consider how frequently ( $1=$ not at all; $5=$ a great deal) they had performed the behavior stated in each item (e.g., "Went out of my way to be a good employee"; "Talked badly about people behind their back") in the last 4 weeks.

We measured personal well-being using the Flourishing scale (Diener et al., 2009) and the short General Health Questionnaire (GHQ12; Goldberg et al., 1997). The Flourishing scale contained eight items. Participants were asked to consider how strongly ( 1 = strongly disagree; $5=$ strongly agree $)$ they had felt a particular way over the past month (e.g., "I have been a good person and have lived a good life"). The GHQ was used to measure participants' general physical health in the previous month (e.g., "Been able to concentrate on what you are doing?"). Participants rated each item according to whether they had felt that way more or less than normal $(1=$ not at all; $4=$ more so than usual).

The weekly diary also consisted of three major components: (1) information on workplace commute (e.g., frequency, duration of journey), (2) barriers to active commuting (e.g., what factors stopped e-bike users/deterred car users cycling in future weeks), and (3) impact of the commute on personal affect (e.g., feeling energized, tired) and organizational behavior (e.g., ability to connect with other people at work, willingness to help others). The analysis presented here focuses mainly on the quantitative data collected from the weekly diaries.

The research was conducted in accordance with the recommendations of the Organization's Research Ethics Protocol, and the Organization's Research Ethics Committee. All participants gave written informed consent in accordance with the Declaration of Helsinki to confirm their agreement to participate in the research. Furthermore, all participants were comprehensively insured to cover personal injury for the duration of the study.

\section{RESULTS}

\section{Commuter Journeys}

The median frequency of the bike usage was 1-2 days per week. The median loan period at the time of writing this paper was 6weeks, ranging from 3 to 8 weeks. The median length (in time) of the commute was similar between both travel groups indicating that both active and passive travel groups spent an equal amount of time commuting each day. The average commuting distance (in $\mathrm{kms}$ ) was longer for the Passive Travel group compared with the Active Travel group, indicating that the control group had a longer distance to commute to work (see Table 2 for a summary).

\section{Active vs. Passive Commuting}

A MANOVA was conducted to analyze the differences between the Active and Passive commuting groups on the outcome measures collected in the weekly diaries - changes in Organizational Behavior, Positive Feelings and Negative Feelings - over time. Using Pillai's Trace, the was an overall moderate main effect of commuting group on the reported behaviors and the feelings, $V=0.30, F(3,100)=14, p<0.01$, $\eta_{\mathrm{p}}^{2}=0.30$. However, there was no significant effect of time, $V=0.22, F(21,306)=1.14, p=0.30, \eta_{\mathrm{p}}^{2}=0.08$, and no significant interaction of group and time, $V=0.15$, $F(21,306)=0.74, p=0.74, \eta_{\mathrm{p}}^{2}=0.05$.

Separate Univariate ANOVAS were used to follow up the main effect of travel group from the MANOVA; the ANOVA $_{S}$ were conducted with Travel Group as the independent variable with two groups (Active vs. Passive) and Organizational Behavior, Positive Feelings and Negative Feelings as separate dependent variables. A Bonferroni correction was used due to the multiple-comparisons and the new suggested $p$-value was $0.017(0.05 / 3)$. The $\mathrm{ANOVA}_{S}$ revealed significant main effects of commuting group (Active vs. Passive) on Organizational Behavior, $F(1,102)=26.08, p<0.01, \eta_{\mathrm{p}}^{2}=0.20$ and Positive Feelings, $F(1,102)=32.33, p<0.01, \eta_{p}^{2}=0.24$. The Active Travel group indicated both more positive organizational behavior and positive feelings compared to the Passive Travel group (see Table 3 for descriptive statistics). There was no statistically significant difference between the commuting groups (Active vs. Passive) on Negative Feelings at the Bonferroni-corrected $p$-value, $F(1,102)=4.89, p=0.029, \eta_{\mathrm{p}}^{2}=0.05$, although the difference in means was in the expected direction.

TABLE 2 | Workplace commute descriptive statistics for travel groups.

\begin{tabular}{lll}
\hline & Active travel & Passive travel \\
\hline Usage (Median days/week) & $1-2$ & 5 \\
Loan period (Median weeks) & 6 & N/A \\
& (Minimum & \\
Distance (Mean in km) & 10.31 & 17.08 \\
& (Minimum 5.63- & (Minimum 5.63- \\
Travel time (Median in min) & Maximum 20.92) & Maximum 29.12) \\
& $21-30$ & $21-30$
\end{tabular}


TABLE 3 | Descriptive statistics on the outcome measures according to travel group.

\begin{tabular}{|c|c|c|c|}
\hline & & \multicolumn{2}{|c|}{ Travel mode } \\
\hline & & Active & Passive \\
\hline \multirow[t]{3}{*}{ Weekly measures } & Organizational behavior & $17.10(2.95)$ & $14.82(1.63)$ \\
\hline & Positive affect & $22.32(4.74)$ & $16.71(3.57)$ \\
\hline & Negative affect & $9.17(3.17)$ & $10.43(3.36)$ \\
\hline \multirow[t]{4}{*}{ Monthly measures } & $\begin{array}{l}\text { Organizational Citizenship } \\
\text { Behavior }\end{array}$ & $21.65(4.53)$ & $22.38(3.76)$ \\
\hline & $\begin{array}{l}\text { Counter-productive } \\
\text { Workplace Behavior }\end{array}$ & $34.16(3.87)$ & $34.31(2.03)$ \\
\hline & Flourishing & $44.38(4.72)$ & 43.80 (4.79) \\
\hline & GHQ12 & $38.84(4.16)$ & $32.67(6.08)$ \\
\hline
\end{tabular}

A further MANOVA was conducted to analyze the differences between the Active and Passive commuting groups on the outcome measures collected in the monthly survey Organizational Citizenship Behavior (OCB), Counterproductive Workplace Behavior (CWB), Flourishing, and general physical health as measured by GHQ12. Using Pillai's Trace, there was a significant main effect of Travel Group on physical health, as measured by GHQ12, $V=0.37, F(4,29)=4.24, p<0.01$, $\eta_{\mathrm{p}}^{2}=0.37$. A follow up ANOVA indicated that the Active Travel group reported statistically significantly higher GHQ12 scores compared with the Passive Travel group, $F(1,32)=12.65$, $p<0.01, \eta_{\mathrm{p}}^{2}=0.28$. There were no additional statistically significant effects of group, time or interaction (see Table 3 for descriptive statistics).

These results suggest that active commuting associates with more positive organizational outcomes and that employees who use an e-bike for their commute also perceive greater personal well-being with more positive feelings and better physical health according to GHQ12. At this stage of the intervention, the differences in organizational behavior and well-being do not seem to differ according to commuting mode.

\section{The Impact of Commuting Mode}

As well as exploring the differences between active and passive commuting groups, we also explored the changes within travel groups (Active and Passive) over the course of the intervention to discover the impact of commuting mode on personal well-being and organizational behavior (see Table 4). Pairedsamples $t$-test were conducted to compare the pre-intervention score to the most recently reported score on Organizational Behavior and Affect separately for the Active Travel and Passive Travel groups. The alpha level was Bonferroni corrected to account for multiple comparisons; the new $p$-value $=0.025$ $(0.05 / 2)$.

For the Active Travel group, those employees who participated in the intervention and changed their behavior from passive to active commuting, there was a statistically significant increase, equating to a large effect, in reported Organizational Behavior, $t(8)=-4.14, p<0.01, d=1.44$. Participants in the Active Travel group reported more positive Organizational Behavior at this stage (mid-intervention) compared with pre-intervention.
TABLE 4 | Descriptive statistics on the outcome measures according to travel group pre- and mid-intervention.

\begin{tabular}{|c|c|c|c|}
\hline & & Pre-intervention & Mid-intervention \\
\hline \multirow[t]{6}{*}{$\begin{array}{l}\text { Active } \\
\text { travel group }\end{array}$} & $\begin{array}{l}\text { Organizational } \\
\text { behavior }\end{array}$ & $14.63(1.68)$ & 17.05 (1.57) \\
\hline & Total affect & $32.22(4.67)$ & $36.49(5.76)$ \\
\hline & $\begin{array}{l}\text { Organizational } \\
\text { Citizenship Behavior }\end{array}$ & $21.75(3.31)$ & $21.56(5.76)$ \\
\hline & $\begin{array}{l}\text { Counter-productive } \\
\text { Workplace Behavior }\end{array}$ & $34.42(4.27)$ & $33.89(3.48)$ \\
\hline & Flourishing & 44.08 (3.92) & $44.67(5.52)$ \\
\hline & GHQ12 & $38.00(3.86)$ & $39.67(4.47)$ \\
\hline \multirow[t]{6}{*}{$\begin{array}{l}\text { Passive } \\
\text { travel group }\end{array}$} & $\begin{array}{l}\text { Organizational } \\
\text { behavior }\end{array}$ & $14.00(1.60)$ & $14.86(0.84)$ \\
\hline & Total affect & $29.13(7.06)$ & $29.54(4.52)$ \\
\hline & $\begin{array}{l}\text { Organizational } \\
\text { Citizenship Behavior }\end{array}$ & $22.75(4.20)$ & $22.00(3.32)$ \\
\hline & $\begin{array}{l}\text { Counter-productive } \\
\text { Workplace Behavior }\end{array}$ & 33.63 (1.69) & $35.00(2.38)$ \\
\hline & Flourishing & $44.88(4.16)$ & $42.71(5.41)$ \\
\hline & GHQ12 & $29.63(6.57)$ & $35.71(5.59)$ \\
\hline
\end{tabular}

Furthermore, the Active Travel group also reported a significant increase in Affect from pre-intervention, $t(8)=-2.4, p=0.04$, $d=0.92$, although this did not remain statistically significant according the Bonferroni $p$-value. However, it is worth noting that the magnitude of the effect was large according to Cohen's $d$ conventions. There was not, however, a statistically significant difference between the pre- and mid/intervention scores on Organizational Behavior or Affect for the Passive Travel group, $t(7)=-1.51, p=0.17, d=0.05 ; t(7)=-0.28, p=0.79, d=0.06$, respectively.

Paired samples $t$-test were also conducted on the pre- and mid-intervention scores on the OCB, CWB, Flourishing, and GHQ12 scales. However, these did not identify any statistically significant differences over time for either of the travel groups. It is worth noting that these data were collected monthly and therefore we had fewer associated data points at this stage of the research.

Overall, the results from the paired sample $t$-tests of the weekly diaries indicated that there was a positive change in reported Organizational Behavior and Affect from pre-intervention to mid-intervention among the Active Travel group, and this was associated with a change in behavior from passive to active commuting.

Pearson correlations were conducted to analyze the relationship between e-cycling frequency and Organizational Behavior and Personal Well-being. The Pearson's correlation indicated a moderate positive relationship between e-bike use and Organizational Behavior, $r=0.59, p<0.01$, and Positive Affect, $r=0.64, p<0.01$. Furthermore, a Pearson's correlation analysis indicated a moderate significant negative correlation between e-bike use and Negative Affect, $r=-0.55, p<0.01$. In sum, the more frequently participants cycled to work, the better they felt. Put differently, greater behavior change was associated with more positive outcomes. 
The length of time spent commuting did not tend to have any significant correlation with the behavioral or affective outcome measures among the Active Travel group. However, interestingly, the time spent on commuting was weakly correlated with negative feelings among the Passive Travel group, $r=0.28$, $p<0.05$.

Furthermore, for both travel groups, positive and negative affect was significantly associated with organizational behavior. Pearson's correlations indicated a significant moderate positive correlation between Positive Affect and Organizational Behavior for the Active Travel group, $r=0.69, p<0.01$, and a low correlation for the Passive Travel group, $r=0.39$, $p<0.01$. Furthermore, there was a significant moderate negative correlation between Negative Affect and Organizational Behavior for the Active Travel group, $r=-0.62, p<0.01$, and a low significant negative relationship for the Passive Travel group, $r=-0.38, p<0.01$.

The results of the Pearson's correlations highlight the relationships between commuting experience and well-being. A more frequent active commute is associated with more productive organizational behavior, positive affect, whilst a longer car commute is associated with more negative and affect.

\section{Perceived Barriers to Active Commuting}

The participants in the Active Travel group reported on the factors that had previously deterred them from changing their behavior and cycling to work. Prior to using the e-bike, the most frequently reported concerns were road safety (68\%), poor weather $(89 \%)$, and poor road conditions (53\%). We explored whether perceptions of these concerns changed as a result of changing behavior and cycling to work. Of these three reported concerns, the behavior change intervention was significantly associated with reducing concerns about road safety, $x^{2}(1)=22.38, p<0.01$, with an odds ratio of 0.04 , and road condition, $x^{2}(1)=4.49, p<0.05$, odds ratio $=0.29$. However, poor weather still remained the biggest concern after the intervention. Furthermore, the effect of using an e-bike decreased the frequency of reported concerns with hills from 28 to $0 \%$, which was significantly associated according to Fisher's Exact Test, $x^{2}(1)=11.02, p<0.01$, Cramer's $V=0.45$.

\section{DISCUSSION}

The purpose of this study was to describe a workplace behavior change intervention that encourages active commuting using e-bikes, and to explore the associations of active vs. passive commuting on personal well-being (psychological and physical) and organizational behavior. Based on these preliminary data, we report three main findings, which are broadly in line with our expectations.

First, we found that there were both direct personal benefits and organizational co-benefits of an active commute compared with passive commuting. Employees who changed their behavior and undertook an active commute reported more positive affect and more productive organizational behavior compared with employees who continued with a passive commute, and this was attributable to their behavior change from a passive to active travel mode (as indicated by the pre- and midintervention comparisons). Indeed, these results, which concur with previous research that compares active travel using a conventional bike with car travel (Hendriksen et al., 2010; Martin et al., 2014; Mytton et al., 2016; Petrunoff et al., 2016a,b), suggest that there are multiple co-benefits of an active commute beyond those associated with improved physical health and carbon reduction. Further, these findings concur with previous researchers who have explored the impact of workplace health programs (e.g., Jarman et al., 2015) but additionally, they suggest that encouraging active commuting is a viable way to get employees to be more physically active with associated benefits for employees and their employing organization.

The use of electric bikes to encourage active commuting amongst employees was novel and offers a new approach to workplace health promotion that brings together the expertise of transport and health researchers and organizational psychologists who have, historically, often worked in siloes (Ogilvie et al., 2004). Future research should harness together the expertise from these disciplines.

Second, we found a positive relationship between e-cycling frequency and the outcome measures; more frequent use of the e-bike was associated with more positive affect, and more positive organizational behavior. In contrast, a longer passive commute was associated with more negative outcomes. These findings demonstrate the cumulative positive effects of active commuting and suggest that workplace health programs should encourage and support employees to develop habitual patterns of active commuting behavior so that this travel mode becomes the default and embedded within daily routines. As the results of this study show, there are progressive positive effects of e-cycling both for individuals and their organization.

These results also have implications for human resource management (HRM) practices and the recruitment of employees for a healthy workplace and business success. The employees in our sample lived relatively close to their place of work (between 5 and $30 \mathrm{~km}$ ), which was located in rural and secluded location. Active commuting was a feasible alternative to passive commuting, although perhaps not perceived this way with a conventional bike (see next paragraph). However, even with a relatively short commute, there were still emergent differences between the active and passive travel groups in this study. These differences are likely to be magnified for longer (and more stressful) commutes. HR managers should consider the potential implications of these findings for not only controlling the organization's environmental impact (Deming, 1986), but for also ensuring a healthy workforce for improved business success. An employee's commuting distance to work should, perhaps, be considered as part of the recruitment process of the employee lifecycle. Organizations should consider how their recruitment practices can cultivate a 'greener', healthier, and more productive workforce. 
Although the distance of our employees' commutes was manageable using a conventional bike, employees had strong perceptions about the barriers of cycling to work, and these had deterred them from undertaking an active commute using a conventional bike. Previous research (see Page and Page, 2014) suggests that people often have inaccurate perceptions about their behavior and the factors that influence it, and this can determine their efforts toward behavior change and the associated success of behavior change interventions, especially if these are designed around the perspective of bounded rationality choice models and the subject utility model of behavior (e.g., the majority of 'soft' psychological interventions; Page, 2015). The results of this study suggest that a participatory approach to behavior change challenges these inaccurate assumptions and reduces their inertial effects.

The results of this study also suggest that priori to cycling to work, the active travel group reported many concerns about an active commute and these were barriers to behavior change. However, following a change in commuting behavior, many of these concerns had reduced or diminished completely despite there being no physical change in many of these factors; active commuters simply changed their perceptions about cycling to work. These results suggest that behavior change interventions that are participatory, address behavior directly, and get people to try new behaviors rather than encouraging people to think about changing their behavior, might be more effective (see Page and Page, 2014; Page, 2015). Indeed, this approach has been effective in this workplace intervention. It appears that the performance of different behaviors has challenged thinking and weakened some of the cognitive barriers that had previously prevented behavior change.

Lastly, based on the findings of this study we have learnt something about changing employees' behavior as part of workplace health programs. We suggest that workplace health interventions that encourage physical activity as part of an employee's existing daily routine might result in greater behavior change maintenance, as desired (see Hunter et al., 2016), compared with approaches that seek to develop novel behaviors. Further, we found that our approach to behavior change, which was innovative in terms of offering employees the use of e-bikes free of charge and allowing employees complete control over their behavior change, worked really well. We found that not imposing any specific rules about usage encouraged engagement and allowed employees complete control over their approach to behavior change. Lastly, the use of a multi-component intervention involving both informational and participatory behavior change approaches was also successful and concurs with previous research (Ferdowsian et al., 2010; Goetzel and Pronk, 2010).

\section{Summary}

This study, as far as the authors are aware, is the first to explore the effectiveness of a behavior change intervention that encourages active commuting using e-bikes for health promotion in the workplace. Previous studies exploring the differences between active and passive commuting have focused on conventional cycling (see Petrunoff et al., 2016a,b). Furthermore, those studies exploring the benefits of e-cycling have focused on the physical health benefits to the individual (e.g., Louis et al., 2012; de Geus and Hendriksen, 2015; Jones et al., 2016). No studies, as far as the authors are aware, have explored the broader benefits to the individual's psychological health or the co-benefits for the organization. In light of the positive preliminary findings of this study, there is certainly much scope for future research to further explore the use of e-bikes to encourage behavior change as part of workplace health promotion programs.

\section{Strengths and Weaknesses}

Limitations of the current results are noted. This study evaluated a workplace behavior change intervention to promote active travel behavior within a real world setting, which is both a strength and a limitation. The research design was quasi-experimental. It did include a control group but assignment to commuting groups was by self-selection. This automatically introduces a degree of bias to the research design. The offering of e-bikes to encourage active commuting is novel, was popular, and offers a new dimension and greater flexibility to active commuting.

While the data in this study are self-reported, this is entirely appropriate for well-being (which depends on selfreport) and appears unlikely to have resulted in important biases for other measures. Previous research has shown good agreement between self-reported and objective estimates of commuting behavior (Panter et al., 2014) and health indices (Ferrie et al., 2005). The sample size was small and biased toward affluent, educated and predominately whitecollar, and the workplace location was also rather unique so the findings may not be readily generalizable to other populations and workplace settings. Furthermore, the low response rate of employees during the latter stages of the intervention has a negative impact on the representativeness of the sample.

\section{CONCLUSION}

Whilst acknowledging that the results presented in this article are preliminary - the research is still live and a work in progress - and based on a small sample, the results of this innovative workplace behavior change intervention study are promising and potentially powerful. Overall, the findings concur with previous researchers (e.g., Hennessy, 2008; Petrunoff et al., 2016a,b) and assert to the direct benefits and co-benefits of an active commuting experience. Furthermore, they suggest that active commuting using an e-bike is a viable alternative to passive commuting, and is an innovative way of encouraging behavior change and developing the health and well-being of employees and their organizations for improved business success. 


\section{ETHICS STATEMENT}

This research was approved by Ashridge/Hult Research Ethics Committee. All participants gave informed consent to participate. All participants were fully insured for the duration of the trial. They received training and were issued with safety equipment.

\section{REFERENCES}

Abegun, D., and Stanciole, A. (2006). An Estimation of the Economic Impact of Chronic Noncommunicable Diseases in Selected Countries. Geneva: World Health Organization.

Abraham, C., and Graham-Rowe, E. (2009). Are worksite interventions effective in increasing physical activity? A systematic review and meta-analysis. Health Psychol. Rev. 3, 108-144. doi: 10.1080/17437190903151096

Amlani, N. M., and Munir, F. (2010). Does physical activity have an impact on sickness absence? A review. Sports Med. 44, 887-907. doi: 10.1007/s40279-0140171-0

BBC News (2000). Commuting is Biggest Stress. BBC News. Available at: http://news.bbc.co.uk/1/hi/health/999961.stm [accessed September 19, 2016].

Bissell, D. (2015). Understanding the Impacts of Commuting: Research Report for Stakeholders. Canberra: The Australian National University.

Boshtam, M., Sarafzadegan, N., Zare, K., Sadeghi, S., Sajjadi, F., Rabiei, K., et al. (2010). Effects of 5-year interventions on cardiovascular risk factors of factories and office employees of isfahan and najafabad: worksite intervention projectisfahan healthy heart program. ARYA Atheroscler. 6, 94-101. doi: 10.1016/ s0167-5273(12)70315-7

Burton, W. N., Pransky, G., Conti, D. J., Chen, C. Y., and Edington, D. W. (2004). The association of medical conditions and presenteeism. J. Occup. Environ. Med. 46(Suppl. 6), S38-S45. doi: 10.1097/01.jom.0000126687. 49652.44

Cancelliere, C., Cassidy, J. D., Ammendolia, C., and Côté, P. (2011). Are workplace health promotion programs effective at improving presenteeism in workers? A systematic review and best evidence synthesis of the literature. BMC Public Health 11:395. doi: 10.1186/1471-2458-11-395

Carmichael, F., Fenton, S. J., Pinilla Roncancio, M., Sadhra, S., and Sing, M. (2016). Workplace Wellbeing Programmes and Their Impact on Employees and Their Employing Organisations: A Scoping Review of the Evidence Base. Birmingham: University of Birmingham.

Conn, V. S., Hafdahl, A. R., Cooper, P. S., Brown, L. M., and Lusk, S. L. (2009). Meta-analysis of workplace physical activity interventions. Am. J. Prev. Med. 37, 330-339. doi: 10.1016/j.amepre.2009.06.008

Crabtree, S. (2010). Wellbeing Lower Among Workers with Long Commutes, GallupNews Service. Available at: http://www.gallup.com/poll/142142/ wellbeing-lower-among-workers-long-commutes.aspx

Dalal, R. S., Lam, H., Weiss, H. M., Welch, E., and Hulin, C. L. (2009). A dynamic approach to organisational citizenship behavior and counterproductive work behavior: behavioral co-occurrence and switching, and dynamic relationships with mood and overall job performance. Acad. Manag. J. 52, 1051-1066. doi: 10.5465/AMJ.2009.44636148

de Geus, B., and Hendriksen, I. (2015). "Cycling for transport, physical activity and health: what about Pedelecs?", in Cycling Futures: From Research into Practice, Vol. 28, eds R. Gerike and J. Parkin (Farnham: Ashgate), 17-31.

Deming, W. (1986). Out of the Crisis. Cambridge, MA: MIT Press.

Department for Transport (2007). Annual Report. London: Department for Transport.

Department of Health (2011). Start Active, Stay Active. A Report on Physical Activity from the Four Home Countries' Chief Medical Officers. London: Department of Health.

Diener, E., Wirtz, D., Biswas-Diener, R., Tov, W., Kim-Prieto, C., Choi, D. W., et al. (2009). "New measures of well-being," in Assessing well-being, ed. E. Diener (Dordrecht: Springer), 247-266.

Eng, J. Y., Moy, F. M., and Bulgiba, A. (2016). Impact of a workplace health promotion program on employees' blood pressure in a public university. PLoS ONE 11:e0148307. doi: 10.1371/journal.pone.0148307

\section{AUTHOR CONTRIBUTIONS}

NP: wrote/edited all sections of the paper. VN conducted the data analysis and drafted the Results section of the paper, which was edited and finalized by NP.

Enoch, M., and Rye, T. (2006). “Travel plans: using good practice to inform future policy," in Towards Better Performing Transport Networks, eds B. Jourquin, P. Rietveld, and K. Westin (London: Routledge), 157.

Evans, G. W., Wener, R. E., and Phillips, D. (2002). The morning rush hour predictability and commuter stress. Environ. Behav. 34, 521-530. doi: 10.1177/ 00116502034004007

Ferdowsian, H. R., Barnard, N. D., Hoover, V. J., Katcher, H. I., Levin, S. M., Green, A. A., et al. (2010). A multicomponent intervention reduces body weight and cardiovascular risk at a GEICO corporate site. Am. J. Health Promot. 24, 384-387. doi: 10.4278/ajhp.081027-QUAN-255

Ferrie, J. E., Kivimäki, M., Head, J., Shipley, M. J., Vahtera, J., and Marmot, M. G. (2005). A comparison of self-reported sickness absence with absences recorded in employers' registers: evidence from the Whitehall II study. Occup. Environ. Med. 62, 74-79. doi: 10.1136/oem.2004.013896

Fitzgerald, C. J., and Danner, K. M. (2012). Evolution in the office: how evolutionary psychology can increase employee health, happiness, and productivity. Evol. Psychol. 10, 770-781. doi: 10.1177/147470491201000502

Foster, C., Hillsdon, M., Thorogood, M., Kaur, A., and Wedatilake, T. (2012). Interventions for promoting physical activity. Syst. Rev. 1:CD003180.

Fujii, S., and Kitamura, R. (2003). What does a one-month free bus ticket do to habitual drivers? An experimental analysis of habit and attitude change. Transportation 30, 81-95. doi: 10.1023/A:1021234607980

Fyhri, A., and Fearnley, N. (2015). Effects of e-bikes on bicycle use and mode share. Transport Research Part D: transport and Environment. Inst. Transp. Econ. 36, 45-52. doi: 10.1016/j.trd.2015.02.005

Goetzel, R. Z., Carls, G. S., Wang, S., Kelly, E., Mauceri, E., Columbus, D., et al. (2009). The relationship between modifiable health risk factors and medical expenditures, absenteeism, short-term disability, and presenteeism among employees at novartis. J. Occup. Environ. Med. 51, 487-499. doi: 10. 1097/JOM.0b013e31819eb902

Goetzel, R. Z., and Pronk, N. P. (2010). Worksite health promotion: How much do we really know about what works? Am. J. Prev. Med. 38, S223-S225. doi: 10.1016/j.amepre.2009.10.032

Gojanovic, B., Welker, J., Iglesias, K., Daucourt, C., and Gremion, G. (2011). Electric bicycles as a new active transportation modality to promote health. Med. Sci. Sports Exerc. 43, 2204-2210. doi: 10.1249/MSS.0b013e31821cbdc8

Goldberg, D. P., Gater, R., Sartorius, N., Ustun, T., Piccinelli, M., Gureje, O., et al. (1997). The validity of two versions of the GHQ in the WHO study of mental illness in general health care. Psychol. Med. 27, 191-197. doi: 10.1017/ S0033291796004242

Gómez, L. F., Moreno, J., Gómez, O. L., Carvajal, R., and Parra, D. C. (2013). Physical activity and health-related quality of life among adult women in Cali, Colombia: a cross-sectional study. Qual. Life Res. 22, 2351-2358. doi: 10.1007/ s11136-013-0378-9

Goodman, A. (2013). Walking, cycling and driving to work in the English and Welsh 2011 census: trends, socio-economic patterning and relevance to travel behaviour in general. PLOS ONE 8:e0071790. doi: 10.1371/journal.pone. 0071790

Hendriksen, I., Engbers, L., Schrijver, J., van Gijlswijk, R., Weltevreden, J., and Wilting, J. (2008). Elektrisch fietsen: Marktonderzoek en verkenning toekomstmogelijkheden. Report KvL/B\&G/2008.067. Leiden: TNO Kwaliteit van Leven.

Hendriksen, I. J., Simons, M., Garre, F. G., and Hildebrandt, V. H. (2010). The association between commuter cycling and sickness absence. Prev. Med. 51, 132-135. doi: 10.1016/j.ypmed.2010.05.007

Hennessy, D. A. (2008). The impact of commuter stress on workplace aggression. J. Appl. Soc. Psychol. 38, 2315-2335. doi: 10.1111/j.1559-1816.2008.00393.x

Hunter, R. F., Brennan, S. F., Tang, J., Smith, O. J., Murray, J., Tully, M. A., et al., (2016). Effectiveness and cost-effectiveness of a physical activity loyalty scheme 
for behaviour change maintenance: a cluster randomised controlled trial. $B M C$ Public Health 16:618. doi: 10.1186/s12889-016-3244-1

Iacono, M., Krizek, K. J., and El-Geneidy, A. (2010). Measuring non-motorized accessibility: issues, alternatives, and execution. J. Transp. Geogr. 18, 133-140. doi: $10.1016 /$ j.jtrangeo.2009.02.002

IBM (2011). Australian Cities not Keeping Up with Commuter Needs: IBM Commuter Pain Study. Available at: https://www-03.ibm.com/press/au/en/ pressrelease/33560.wss [accessed September 19, 2016].

Intelligent Energy Europe (2012). To Cycle Electric or Not to Cycle. Available at: http://www.rupprecht-consult.eu/uploads/tx_rupprecht/Presto_Pedelecs_ brochure.pdf [accessed September 19, 2016].

Jarman, L., Martin, A., Venn, A., Otahal, P., and Sanderson, K. (2015). Does workplace health promotion contribute to job stress reduction? Three-year findings from Partnering Healthy@ Work. BMC Public Health 15:1293. doi: 10.1186/S12889-015-2625-1

Jarrett, J., Woodcock, J., Griffiths, U. K., Chalabi, Z., Edwards, P., Roberts, I., et al. (2012). Effect of increasing active travel in urban England and Wales on costs to the National Health Service. Lancet 379, 2198-2205. doi: 10.1016/S01406736(12)60766-1

Johnson, M., and Rose, G. (2015). Extending life on the bike: electric bike use by older Australians. J. Transp. Health 2, 276-283. doi: 10.1016/j.jth.2015.03.001

Jones, T., Harms, L., and Heinen, E. (2016). Motives, perceptions and experiences of electric bicycle owners and implications for health, wellbeing and mobility. J. Transp. Geogr. 53, 41-49. doi: 10.1016/j.jtrangeo.2016.04.006

Jung, H., Lee, B., Lee, J. E., Kwon, Y. H., and Song, H. (2012). Efficacy of a programme for workers with metabolic syndrome based on an e-health system in the workplace: a pilot study. J. Telemed. Telecare 18, 339-343. doi: 10.1258/ jtt.2012.120318

Kohl, H. W., Craig, C. L., Lambert, E. V., Inoue, S., Alkandari, J. R., and Leetongin, G. (2012). The pandemic of physical inactivity: global action for public health. Lancet 380, 294-305. doi: 10.1016/S0140-6736(12)60898-8

Kohn, P. M., and Macdonald, J. E. (1992). The survey of recent life experiences: a decontaminated hassles scale for adults. J. Behav. Med. 15, 221-236. doi: $10.1007 / \mathrm{BF} 00848327$

Koslowsky, M., Aizer, A., and Krausz, M. (1996). Stressor and personal variables in the commuting experience. Int. J. Manpow. 17, 4-14. doi: 10.1108/ 01437729610119478

Laverty, A. A., Mindell, J. S., Webb, E. A., and Millett, C. (2013). Active travel to work and cardiovascular risk factors in the United Kingdom. Am. J. Prev. Med. 45, 283-288. doi: 10.1016/j.amepre.2013.04.012

Leiter, M. P., and Durup, M. J. (1996). Work, home, and in-between: a longitudinal study of spillover. J. Appl. Behav. Sci. 32, 29-47. doi: 10.1177/002188639632 1002

Loeppke, R., Nicholson, S., Taitel, M., Sweeney, M., Haufle, V., and Kessler, R. C. (2008). The impact of an integrated population health enhancement and disease management program on employee health risk, health conditions, and productivity. Popul. Health Manag. 11, 287-296. doi: 10.1089/pop.2008. 0006

Louis, J., Brisswalter, J., Morio, C., Barla, C., and Temprado, J. J. (2012). The electrically assisted bicycle: an alternative way to promote physical activity. Am. J. Phys. Med. Rehabil. 91, 931-940. doi: 10.1097/PHM.0b013e318269d9bb

Luthans, F. (2005). Organisational Behavior. New York, NY: McGrawhill International Edition.

MacArthur, J., Dill, J., and Person, M. (2014). Electric bikes in North America: results of an online survey. J. Transp. Res. 2468, 123-130. doi: 10.3141/2468-14

Malik, S. H., Blake, H., and Suggs, L. S. (2014). A systematic review of workplace health promotion interventions for increasing physical activity. Br. J. Health Psychol. 19, 149-180. doi: 10.1111/bjhp. 12052

Martin, A., Goryakin, Y., and Suhrcke, M. (2014). Does active commuting improve psychological wellbeing? Longitudinal evidence from eighteen waves of the British Household Panel Survey. Prev. Med. 69, 296-303. doi: 10.1016/j.ypmed. 2014.08.023

Mytton, O. T., Panter, J., and Ogilvie, D. (2016). Longitudinal associations of active commuting with wellbeing and sickness absence. Prev. Med. 84, 19-26. doi: 10.1016/j.ypmed.2015.12.010

National Institute for Health and Clinical Excellence [NICE] (2008). Physical Activity in the Workplace. 2008. Available at: https://www.nice.org.uk/guidance/ ph13/chapter/1-Recommendations [accessed October 26, 2016].
OECD (2014). OECD Labour Force Statistics. Paris: OECD Publishing.

Ogilvie, D., Egan, M., Hamilton, V., and Petticrew, M. (2004). Promoting walking and cycling as an alternative to using cars: systematic review. BMJ 329:763. doi: $10.1136 /$ bmj.38216.714560.55

Organ, D. W. (1988). Organisational Citizenship Behavior: The Good Soldier Syndrome. Lexington, MA: Lexington Books.

Organ, D. W., and Ryan, K. (1995). A meta-analytic review of attitudinal and dispositional predictors of organisational citizenship behavior. Pers. Psychol. 48, 775-802. doi: 10.1111/j.1744-6570.1995.tb01781.x

Page, N., and Page, M. (2014). Climate change: time to do something different. Front. Psychol. 5:1294. doi: 10.3389/fpsyg.2014.01294

Page, N. C. (2015). The Influence of Habits, Opportunities and Thoughts on Environmentally Sustainable Lifestyles. Ph.D. dissertation, University of Hertfordshire, Hatfield.

Panter, J., Costa, S., Dalton, A., Jones, A., and Ogilvie, D. (2014). Development of methods to objectively identify time spent using active and motorised modes of travel to work: how do self-reported measures compare? Int. J. Behav. Nutr. Phys. Act. 11:116. doi: 10.1186/s12966-014-0116-x

Papoutsi, S., Martinolli, L., Braun, C. T., and Exadaktylos, A. K. (2014). E-bike injuries: experience from an urban emergency department. A retrospective study from Switzerland. Emerg. Med. Int. 2014:850236. doi: 10.1155/2014/ 850236

Peterman, J. E., Morris, K. L., Kram, R., and Byrnes, W. C. (2016). Pedelecs as a physically active transportation mode. Eur. J. Appl. Physiol. 116, 1565-1573. doi: 10.1007/s00421-016-3408-9

Petrokofsky, C., and Davis, A. (2016). Working Together to Promote Active Travel. A Briefing Document for Local Authorities. London: Public Health England.

Petrunoff, N., Rissel, C., and Wen, L. M. (2016a). The effect of active travel interventions conducted in work settings on driving to work: a systematic review. J. Transp. Health 3, 61-76. doi: 10.1016/j.jth.2015.12.001

Petrunoff, N., Wen, L. M., and Rissel, C. (2016b). Effects of a workplace travel plan intervention encouraging active travel to work: outcomes from a three-year time-series. Public Health 135, 38-47. doi: 10.1016/j.puhe.2016. 02.012

Popovich, N., Gordon, E., Shao, Z., Xing, Y., Wang, Y., and Handy, S. (2014). Experiences of electric bicycle users in the Sacramento, California area. Travel Behav. Soc. 1, 37-44. doi: 10.1016/j.tbs.2013.10.006

Public Health England (2014). Active People Survey. London: Public Health England.

Regus International (2012). Indian Employees Prefer Family and Fitness. Mumbai. Available at: http://www.regus.presscentre.com/Press-Releases/ Indian-employees-prefer-family-and-fitness-finds-survey-3b99aspx [accessed September 19, 2016].

Rongen, A., Robroek, S. J., van Lenthe, F. J., and Burdorf, A. (2013). Workplace health promotion: a meta-analysis of effectiveness. Am. J. Prev. Med. 44, 404-415. doi: 10.1016/j.amepre.2012.12.007

Santhosh, V. A. (2015). A study of the impact of workplace commuting on citizenship behaviour of employees working with public and private sector organisations. Vision 19, 13-24. doi: 10.1177/0972262914564043

Schaeffer, M. H., Street, S. W., Singer, J. E., and Baum, A. (1988). Effects of control on the stress reactions of commuters. J. Appl. Soc. Psychol. 18, 944-957. doi: 10.1111/j.1559-1816.1988.tb01185.x

Shaw, C., Hales, S., Howden-Chapman, P., and Edwards, R. (2014). Health cobenefits of climate change mitigation policies in the transport sector. Nat. Clim. Change 4, 427-433. doi: 10.1038/nclimate2247

Simons, M., van Es, E., and Hendriksen, I. (2009). Electrically assisted cycling: a new mode for meeting physical activity guidelines? Med. Sci. Sports Exerc. 41, 2097-2102. doi: 10.1249/MSS.0b013e3181a6aaa4

Sperlich, B., Zinner, C., Hébert-Losier, K., Born, D. P., and Holmberg, H. C. (2012). Biomechanical, cardiorespiratory, metabolic and perceived responses to electrically assisted cycling. Eur. J. Appl. Physiol. 112, 4215-4225. doi: 10.1007/ s00421-012-2382-0

Stewart, G., Anokye, N. K., and Pokhrel, S. (2015). Quantifying the contribution of utility cycling to population levels of physical activity: an analysis of the Active People Survey. J. Public Health doi: 10.1093/pubmed/fdv182 [Epub ahead of print].

Stutzer, A., and Frey, B. S. (2008). Stress that doesn't pay: the commuting paradox. Scand. J. Econ. 111, 339-366. doi: 10.1111/j.1467-9442.2008.00542.x 
Terry, P. E., Seaverson, E. L., Grossmeier, J., and Anderson, D. R. (2008). Association between nine quality components and superior worksite health management program results. J. Occup. Environ. Med. 50, 633-641. doi: 10. 1097/JOM.0b013e31817e7c1c

Theurel, J., Theurel, A., and Lepers, R. (2012). Physiological and cognitive responses when riding an electrically assisted bicycle versus a classical bicycle. Ergonomics 55, 773-781. doi: 10.1080/00140139.2012.671964

Vuori, I. M., Oja, P. E. K. K. A., and Paronen, O. L. A. V. I. (1994). Physically active commuting to work: testing its potential for exercise promotion. Med. Sci. Sports Exerc. 26, 844-850. doi: 10.1249/00005768-19940700 0-00006

Williams, L. J., and Anderson, S. E. (1991). Job satisfaction and organisational commitment as predictors of organisational citizenship and in-role behaviors. J. Manage. 17, 601-617. doi: 10.1177/014920639101700305

Woodcock, J., Edwards, P., Tonne, C., Armstrong, B. G., Ashiru, O., Banister, D., et al. (2009). Public health benefits of strategies to reduce greenhouse-gas emissions: urban land transport. Lancet 374, 1930-1943. doi: 10.1016/S01406736(09)61714- 1

Yang, L., Sahlqvist, S., McMinn, A., Griffin, S. J., and Ogilvie, D. (2010). Interventions to promote cycling: systematic review. BMJ 341:c5293. doi: 10. 1136/bmj.c5293

Conflict of Interest Statement: The authors declare that the research was conducted in the absence of any commercial or financial relationships that could be construed as a potential conflict of interest.

Copyright (C) 2017 Page and Nilsson. This is an open-access article distributed under the terms of the Creative Commons Attribution License (CC BY). The use, distribution or reproduction in other forums is permitted, provided the original author(s) or licensor are credited and that the original publication in this journal is cited, in accordance with accepted academic practice. No use, distribution or reproduction is permitted which does not comply with these terms. 
OPEN ACCESS

Edited by: Gabriele Giorgi, European University of Rome, Italy

Reviewed by:

Javier Fiz Pérez,

Università Europea di Roma, Italy

Alicia Arenas,

University of Seville, Spain

*Correspondence:

Silvia Pignata

silvia.pignata@unisa.edu.au

Specialty section:

This article was submitted to

Organizational Psychology,

a section of the journal

Frontiers in Psychology

Received: 20 May 2016 Accepted: 02 August 2016 Published: 18 August 2016

Citation:

Pignata S, Winefield AH, Provis $C$ and Boyd CM (2016) Awareness of

Stress-Reduction Interventions on Work Attitudes: The Impact of Tenure and Staff Group in Australian

Universities. Front. Psychol. 7:1225.

doi: 10.3389/fpsyg.2016.01225

\section{Awareness of Stress-Reduction Interventions on Work Attitudes: The Impact of Tenure and Staff Group in Australian Universities}

\author{
Silvia Pignata ${ }^{1,2 *}$, Anthony H. Winefield ${ }^{2}$, Chris Provis $^{3}$ and Carolyn M. Boyd ${ }^{1}$ \\ ${ }^{1}$ School of Engineering, University of South Australia, Adelaide, SA, Australia, ${ }^{2}$ Asia Pacific Centre for Work Health and \\ Safety, School of Psychology, Social Work and Social Policy, University of South Australia, Adelaide, SA, Australia, ${ }^{3}$ School of \\ Management, University of South Australia, Adelaide, SA, Australia
}

This study explored the impact of staff group role and length of organizational tenure in the relationship between the awareness of stress interventions (termed intervention awareness: IA) and the work-related attitudinal outcomes of university employees. A two-wave longitudinal study of a sample of 869 employees from 13 universities completed a psychosocial work factors and health questionnaire. Hierarchical regression analyses examined the contribution of staff role and different lengths of organizational tenure with IA and employees' reports of job satisfaction, affective organizational commitment, trust in senior management, and perceived procedural justice. Employees' length of tenure affected the relation between IA and work attitudes, and there were also differences between academic and non-academic staff groups. For non-academic employees, IA predicted job satisfaction, affective organizational commitment, trust in senior management, and perceived procedural justice. However, for academics, IA only predicted job satisfaction and trust which identifies a need to increase the visibility of organizational interventions. Across the tenure groups, IA predicted: (1) perceived procedural justice for employees with five or less years of tenure; (2) job satisfaction for employees with 0-19 years of tenure; (3) trust in senior management for employees with 6-19 years of tenure; and (4) affective organizational commitment for employees with a tenure length of 6-10 years. Employees working at the university for an intermediate period had the most positive perceptions of their organization in terms of IA, job satisfaction, trust in senior management, and affective organizational commitment, whereas employees with 20-38 years of tenure had the least positive perceptions. Results suggest that employees in the middle of their careers report the most positive perceptions of their university. The findings highlight the need to attend to contextual issues in organizational stress and wellbeing interventions and suggest that management may need to implement new strategies and/or promote existing stress-management and reduction strategies to academics, and employees whom are either new to the university or those who have been working for the organization for longer periods of time to ensure that they are aware of organizational strategies to promote employee wellbeing and morale within their work environments.

Keywords: organizational tenure, intervention awareness, universities, organizational attitudes, job satisfaction 


\section{INTRODUCTION}

A body of international research shows that due to economic pressures, the incidence, and severity of work-related stress in organizations is increasing (Mucci et al., 2016). In many countries, the university sector, and the working culture in universities has experienced intense change over recent decades and this has had negative impacts on the health of staff. Kinman and Court (2010) assert that workload, the pace of work, managerial, and collegial support, and levels of interpersonal conflict are of growing concern in tertiary institutions in the United Kingdom (UK). Moreover, in a review of the occupational health needs of universities in the UK, Venables and Allender (2006) indicated that academics are likely to experience particular problems with mental health. The authors found "a notably wide range of occupational hazards, and other significant factors which must be considered in planning occupational health provision for individual universities or for the sector as a whole" (p. 159). They posit that their findings in UK universities are comparable to those in other developed countries as there are broad similarities between universities in different countries. There is also research evidence that the changing and diverse work roles of academics which involve teaching, thesis supervision, research/scholarship, administration, consultancy, and community service (McInnis, 1999) are negatively impacting their wellbeing. These increasing demands have resulted in longer working hours, which have had damaging effects on the work-life balance and physical and psychological health of academics (Kinman and Jones, 2003). The international stress literature demonstrates that the situation is similar in many countries including Australia (Winefield et al., 2008), Canada (Catano et al., 2010), South Africa (Coetzee and Rothmann, 2005), the UK (Kinman and Wray, 2014), and the United States (Liu et al., 2008) showing that occupational stress has increased due to increased work demands and reduced government funding. In Canadian universities, for example, Catano et al. (2010) examined stress and its impact on health and work-related outcomes in a sample of 1440 staff from 56 universities. The authors found that with regard to strain, $13 \%$ reported high levels of psychological distress and $22 \%$ reported increased physical health symptoms. They also found that job insecurity and work-life imbalance were strong predictors of job dissatisfaction and increased levels of psychological distress.

In the context of Australian universities, a national twowave longitudinal study of occupational stress by Winefield and colleagues found that reduced staff numbers, increased student numbers, the introduction of forced redundancies and contract appointments contributed to high levels of strain and low levels of autonomy in university staff (Winefield et al., 2008). A qualitative focus group study of work-related stress in 15 Australian universities found that university staff experienced high levels of work-related stress, with reduced funding and resources, increased workloads, fewer opportunities for career development, and reduced reward practices and recognition of staff being identified as key stressors (see Gillespie et al., 2001). The identified stressors should be considered in planning for the provision of occupational health services (Venables and Allender, 2006) and may assist university management to develop and implement stress intervention strategies. A study by Pignata and Winefield (2015) in one Australian university of the effects of the awareness of stress-reduction interventions (termed intervention awareness: IA) on employee wellbeing and work attitudes found that employees who reported IA reported higher levels of job satisfaction, affective organizational commitment, perceptions of procedural justice, and trust in senior management than those who were not aware of the interventions. Thus, it is also necessary to promote the university's stress management and wellbeing initiatives to staff.

Academics have previously reported intrinsic work role factors such as student interaction, relationships with fellow colleagues, the prestige of academic positions, autonomy, and job variety as their areas of greatest satisfaction (Kinman, 2001; Winefield et al., 2008) however, reductions in tenure, autonomy, and the collegiality inherent in academic work have affected their levels of wellbeing. In a report on the attractiveness of the academic profession in Australia, Coates et al. (2009) note that in comparison to international colleagues, Australian academics report lower levels of job satisfaction, have greater propensity for job change, and work among the longest hours per week with senior faculty working the highest of any group internationally. Venables and Allender (2006) report that a high percentage of the UK university workforce work on fixed-term teaching or research contracts which, due to their short-term commitment to the university, has implications for the way that employees work, and how they are managed. The ease of access to smart phones and other devices has allowed digital work to intrude into the non-work domain with email and other online technologies contributing towards work-life conflict and work stress. A study in one Australian university (Pignata et al., 2015) examining email volume and email management strategies found that staff associated the unnecessary use of emails by staff and students, expectations of quick responses, and high levels of email traffic with increases in work-related stress. Thus, there is a clear need for organizational initiatives to reduce stress and enhance employees' health and wellbeing.

The key aims of the present study are to examine whether employees' length of organizational tenure and/or their membership of a staff group (academic or non-academic) is related to their awareness of stress intervention strategies implemented at their university and if this has an influence on their job satisfaction, affective organizational commitment, trust in senior management, and perceptions of procedural justice (see Figure 1). Thus, the present study's focus on tenure and staff group within a longitudinal sample of university staff extends the work by Pignata et al. (2016) who examined IA and the employee level consequences on psychological strain, affective organizational commitment, and job satisfaction. As Pignata and colleagues found that the category of staff group status predicted employee levels of affective commitment to the organization, further research was undertaken to delve deeper into the two distinct occupational groups and to also examine the effect of employees' length of organizational tenure.

Research has shown that individuals differ in what they find satisfying in their jobs. Whilst non-academic employees work in diverse roles that include professional (e.g., accountant), clerical, 


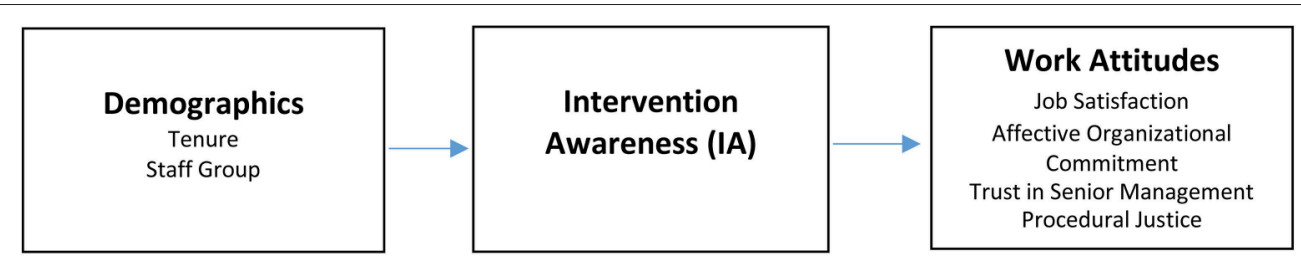

FIGURE 1 | Model for the study.

technical, and service work, there are marked differences in the mainly administrative roles of non-academic staff and the functional roles of academics who are engaged in teaching and research. Evidence of the differences between staff populations in the university context (see Winefield et al., 2003) show that in terms of job satisfaction, $74 \%$ of non-academic staff expressed overall job satisfaction, whereas only $61 \%$ of academic staff expressed overall job satisfaction. Indeed, research by Winefield and colleagues showed that academic staff reported less affective organizational commitment, job satisfaction, and trust in senior management compared to non-academic staff (Winefield et al., 2008). Given the functional differences in staff groupings within universities, and as Pignata et al. (2016) have proposed that IA is a form of perceived organizational support which is positively associated with job satisfaction, organizational commitment, and trust in management (Rhoades and Eisenberger, 2002), we predict that in relation to IA, non-academic staff will report more positive associations with job satisfaction, affective commitment to the organization, and trust in senior management than academics (Hypothesis 1).

Stress and psychological risk at work can be conceptualized as an imbalance of job demands and job resources. For example, the theoretical framework of the Job Demands-Resources model (Demerouti et al., 2001) proposes that high job demands (i.e., work overload, interpersonal conflict, job insecurity) lead to strain and health impairment (via the health impairment process), whereas high resources (i.e., feedback, job control, social support) lead to improved motivation, and productivity (via the motivational process; Schaufeli and Taris, 2014). Thus, in psychologically healthy workplaces, work demands, and available job resources are in balance. Conversely, in unhealthy workplaces, high job demands may lead to exhaustion, whilst low job resources may lead to disengagement which are both symptoms of burnout. In an examination of the management of academics in terms of balancing job demands and job resources, Barkhuizen et al. (2014) showed that academics experienced high job demands compared to the availability of job resources. Given this imbalance in demands and resources, and on the basis of the social-exchange reciprocity norm that suggests that academics may perceive this imbalance in the organization's processes of allocating resources as unjust, we propose that in relation to IA, non-academic staff will report more positive associations with perceived procedural justice than academics (Hypothesis 2).

The present study also investigates length of organizational tenure in relation to work-related outcomes such as job satisfaction as they may be explained by Herzberg's two-factor theory (see Herzberg et al., 1957) which considers job satisfaction (a function of motivating factors e.g., achievement, advancement) and dissatisfaction (a function of hygiene factors e.g., supervision, company policy, and administration) as distinct constructs. The model posits that workers in the early stages of their careers usually experienced low job satisfaction due to unfulfilled work expectations. However, when those workers advanced in their careers they gained maturity and work experience which in turn, led to higher levels of job satisfaction. It is clear that gaining experience at work is an outcome of tenure, and that work experience is a requirement for promotion opportunities and the inherent reward and salary benefits. Work experience may also lead to a sense of mastery, which would be related to the motivating factors inherent in job satisfaction. Furthermore, research has shown that employees who have been with the organization for longer periods may have developed a favorable view of their treatment by the organization (Rhoades and Eisenberger, 2002) and this may be associated with increased morale and wellbeing outcomes. Indeed, the long-term development of employee wellbeing was examined by Mäkikangas et al. (2015) over a 10-year period and the development of favorable affective wellbeing was found to be eight times more probable than the development of unfavorable affective wellbeing. In a systematic review of the findings of 40 studies on the long-term development of affective employee wellbeing (accounting for the effects of time lag, age, and job change Mäkikangas et al., 2016) found that age and change of job were the major factors influencing stability, with younger employees and job changers tending to display greater acrosstime changes in wellbeing than older employees and those who have stayed in the job. As Bentley et al. (2013) report that levels of job satisfaction are higher amongst recently promoted academics and lower amongst mid-career academics, we propose that longer tenured employees will have greater maturity, experience, and mastery of their job and will perceive that their organization supports them by offering stress intervention strategies. Thus, we predict that longer lengths of organizational tenure will positively affect the relationship between IA and employees' levels of job satisfaction (Hypothesis 3).

As trustworthiness, perceived procedural justice, and affective commitment to the organization are attitudes that develop over time and can be enhanced by positive experiences (Arnold et al., 1995; Holtz and Harold, 2009) they highlight the reciprocal social-exchange process between employee and their employer and suggest that when employees feel valued and supported by their employing organization, they may perceive 
senior management as being trustworthy, or perceive that organizational policies and practices are just (Pignata et al., 2016). As longer term employees are likely to have had more opportunities for positive exchanges with their organization, and as assessments of organizational procedures (in terms of procedural justice) can influence employee's levels of trust (Folger and Konovsky, 1989; Saunders and Thornhill, 2003), we predict that there will be a positive association with organizational tenure in that longer lengths of organizational tenure will positively affect the relationship between IA and employees' level of trust in senior management, procedural justice, and affective organizational commitment (Hypothesis 4).

\section{METHOD}

\section{Participants and Procedure}

Of the 969 participants who responded to both the 2000 (Time 1:T1) and 2003/4 (Time 2:T2) waves of a study of occupational stress at a representative sample of 13 Australian public universities (see Winefield et al., 2008 for characteristics of the universities), the present study focused on the 869 participants who remained employed at the same university for the period of the two-wave study and responded to the measure of IA. Like the sample examined in Pignata et al. (2016), this sample of 869 salaried staff (casual or hourly paid staff did not participate in the study) comprised 327 men (38\%) and 542 women $(62 \%)$. The average age in 2003 was 46.5 years $(S D=9.24)$ while the average length of tenure was 12.1 years $(S D=7.34)$. The composition of the sample was $372(43 \%)$ academic and 497 (57\%) non-academic staff which is broadly representative of the 2003 national profile of $42 \%$ academic and $58 \%$ non-academic staff (Department of Education Science and Training, 2003). The majority of the sample were non-academic staff who worked in clerical / administrative $(n=237,27 \%)$, non-academic $(n=$ $147,17 \%)$, technical $(n=91,10 \%)$, general service $(n=7,1 \%)$, or other classifications $(n=7,1 \%)$. The sample of academics comprised tutors/ research assistants $(n=61,7 \%)$, lecturers $(n=$ $124,14 \%)$, senior lecturers $(n=114,13 \%)$, Associate Professors /Professors ( $n=61,7 \%$ ), and other classifications (e.g., Deans; $n=7,1 \%)$. No job classification was reported by $13(2 \%)$ respondents.

Participation in both survey waves was anonymous but data were matched across surveys using code identifiers as staff were asked to provide the first three letters of their mother's maiden name (if unknown, the first three letters of their mother's first name), the first three letters of their father's first name, and their date of birth and gender. Thirteen of the 17 universities that participated in the first survey took part in the second. The surveys were completed by 6756 participants at T1, giving a response rate of $25 \%$. At $\mathrm{T} 2$, the surveys were completed by 6321 participants, a response rate of $26 \%$. The longitudinal sample of 869 participants represent approximately $13 \%$ of the $\mathrm{T} 1$ respondents. In contrast to the use of a paper survey at T1, the T2 survey was administered electronically and was conducted between October and December 2003 at 12 of the universities, and 1 year later at the remaining university. It should be noted that the measurement equivalence of paper-and-pencil and organizational internet surveys was demonstrated in a largescale examination by De Beuckelaer and Lievens (2009). The longitudinal study received ethics approval from the University of South Australia's Human Research and Ethics Committee. All non-casual staff at each university were emailed an invitation letter providing details of the nature and purpose of the survey and how to access the survey website. Reminder notices were emailed to staff 2, 4, and 6 weeks thereafter.

\section{Measures}

Both the T1 and T2 survey questionnaires sought demographic details (i.e., age, gender). The following work attitude measures were used in the survey, and each had internal reliabilities of between 0.69 and 0.96 (Cronbach's alpha coefficients).

The mean for job satisfaction is based on the total scores, whereas the measures of affective organizational commitment, perceived procedural justice and trust in senior management are based on the item means. It should be noted that the following five measures (job satisfaction, affective organizational commitment, trust in senior management, procedural justice, and IA) were also employed in the study by Pignata et al. (2016).

\section{Job Satisfaction}

The 15-item scale developed by Warr et al. (1979) measured job satisfaction. The scale assessed the intrinsic (i.e., "How satisfied or dissatisfied do you feel with your opportunity to use your abilities?") and the extrinsic aspect of job satisfaction, for example, "How satisfied or dissatisfied do you feel with your job security? Each item was scored on a 7 -point Likert scale $(1=$ extremely dissatisfied; 7 = extremely satisfied).

\section{Affective Organizational Commitment}

Five items from Porter et al.'s (1974) scale measured affective organizational commitment. An example item is "I really care about the future of this university." Each item was scored on a 5 -point scale ( $1=$ strongly disagree; $5=$ strongly agree $)$.

\section{Trust in Senior Management}

An 8-item scale developed from Mayer and Davis (1999) and Butler (1991) measured trust in senior management (e.g., "Senior Management of my University treat staff fairly"). Each item was scored on a 5 -point scale $(1=$ strongly disagree; $5=$ strongly agree).

\section{Procedural Justice}

A 4-item scale developed by Gillespie et al. (2001) measured perceptions of procedural justice (e.g., "Staff performance is fairly appraised"). Each item was scored on a 5 -point scale ( $1=$ strongly disagree; 5 = strongly agree).

\section{IA}

We used an intervention evaluation component in the T2 survey in which university staff were asked: "During the past 3 years has your university undertaken any measures to reduce stress among its employees?" Response options were $(1=$ Yes, $2=$ No, $3=$ Don't Know). These options were then coded in a binary format $(0=$ No/Don't Know, $1=$ Yes $)$ to distinguish between those with 
a positive awareness of stress-reduction measures and those with negative or neutral perceptions.

\section{Length of Organizational Tenure}

Respondents were asked to complete the number of years that they had worked at the university. The responses were recoded into four tenure groups (0-5 years, 6-10 years, 11-19 years, 20-38 years).

\section{Staff Group}

Respondents were asked to state whether they were a member of academic or non-academic staff $(1=$ academic, $2=$ nonacademic).

\section{Control Variables}

To reduce the possibility of spurious relationships introduced by demographic characteristics, two control variables were entered in all the equations: age, and gender $(1=$ male, $2=$ female $)$.

\section{Analyses}

Hierarchical regression analyses were performed using SPSS Statistics 17.0 software. Preliminary checks were conducted to ensure that there was no violation of the assumptions of multicollinearity, normality, linearity, and homoscedasticity. Two multivariate outliers were identified through Mahalanobis distance with $p<0.001$, and were deleted. Listwise deletion of missing data was used in all analyses. As prior levels of the dependent variable (i.e., T1 levels of job satisfaction, affective organizational commitment, trust in senior management, perceived procedural justice) were included as additional predictors in the analysis, tests of the abovementioned relationships are rigorous as they show that the predictors account for changes over time in the levels of the dependent variables (Zapf et al., 1996).

\section{RESULTS}

The means, standard deviations, internal reliability coefficients (Cronbach's alpha), and bivariate correlations are displayed in Table 1. Although none of the bivariate correlations was high enough to suggest that any of the self-report measures were assessing the same constructs (see Nunnally and Bernstein, 1994), job satisfaction at T2 was strongly associated with the T2 variables of perceived procedural justice $(r=0.67)$ and trust in senior management $(r=0.57)$. Affective organizational commitment at T2 was also strongly associated with the T2 variable of trust in senior management $(r=0.56)$.

\section{Analysis of Interaction Effects}

Analyses assessed the contribution of staff group and tenure on IA controlling for age, gender, tenure, staff group, the interaction between length of organizational tenure, and staff group, and T1 variable differences. Thus, age, gender, tenure, and staff group were entered into the analyses. In addition, to examine possible interactions between tenure and staff group, a product term was calculated in accordance with the method suggested by Cohen and Cohen (1983) and Jaccard et al. (1990). This method involved three steps. First, tenure scores were "centered" (i.e., mean $=0$ ) to reduce the problem of multicollinearity in the subsequent analysis. Secondly, the centered tenure scores were multiplied by the dummy variable scores for staff group to obtain a product term. Third, this product term was entered into the regression analysis following tenure and staff group. A significant interaction was deemed to have occurred if the addition of this term produced (or resulted in) a significant increase in $R^{2}$.

The regression tables display the unstandardized regression coefficients (B) and their standard errors, the standardized regression coefficients, $(\beta)$ and adjusted $R^{2}$ for each step.

As can be observed in Table 2, the T1 levels of the attitudinal outcome variables were predictors of the T2 outcomes.

TABLE 1 | Descriptive statistics and variable inter-correlations.

\begin{tabular}{|c|c|c|c|c|c|c|c|c|c|c|c|c|c|c|c|c|}
\hline \multicolumn{2}{|c|}{ Variable } & \multirow{2}{*}{$\begin{array}{c}\mathbf{M}^{\mathbf{a}} \\
46.50\end{array}$} & \multirow{2}{*}{$\begin{array}{l}\text { SD } \\
9.24\end{array}$} & \multirow{2}{*}{$\begin{array}{c}\alpha \\
-\end{array}$} & \multirow[t]{2}{*}{1} & \multirow[t]{2}{*}{2} & \multirow[t]{2}{*}{3} & \multirow[t]{2}{*}{4} & \multirow[t]{2}{*}{5} & \multirow[t]{2}{*}{6} & \multirow[t]{2}{*}{7} & \multirow[t]{2}{*}{8} & \multirow[t]{2}{*}{9} & \multirow[t]{2}{*}{10} & \multirow[t]{2}{*}{11} & \multirow[t]{2}{*}{12} \\
\hline 1. & Age & & & & & & & & & & & & & & & \\
\hline 3. & Tenure & 12.08 & 7.34 & - & $0.46^{\star \star}$ & $-0.09^{\star}$ & & & & & & & & & & \\
\hline 4. & Group & - & - & - & $-0.19^{\star \star}$ & $0.20^{\star \star}$ & -0.07 & & & & & & & & & \\
\hline 5. & JS T1 & 66.26 & 13.39 & 0.87 & -0.06 & $0.13^{\star \star}$ & $-0.13^{\star \star}$ & $0.18^{\star *}$ & & & & & & & & \\
\hline 7. & AC T1 & 3.49 & 0.69 & 0.79 & -0.01 & $0.08^{\star}$ & $-0.09^{\star \star}$ & $0.18^{\star \star}$ & $0.49^{\star \star}$ & $0.34^{\star \star}$ & & & & & & \\
\hline 8. & AC T2 & 3.51 & 0.79 & 0.84 & -0.04 & $0.10^{\star \star}$ & -0.03 & $0.19^{\star *}$ & $0.41^{\star \star}$ & $0.53^{\star \star}$ & $0.62^{\star \star}$ & & & & & \\
\hline 9. & TM T1 & 2.53 & 0.86 & 0.95 & $-0.08^{\star}$ & 0.03 & $-0.18^{\star *}$ & $0.19^{* \star}$ & $0.55^{\star \star}$ & $0.40^{* \star}$ & $0.45^{\star \star}$ & $0.40^{\star \star}$ & & & & \\
\hline 10. & TM T2 & 2.64 & 0.93 & 0.96 & $-0.12^{\star \star}$ & 0.05 & $-0.14^{\star \star}$ & $0.18^{\star \star}$ & $0.44^{\star \star}$ & $0.57^{\star \star}$ & $0.38^{\star \star}$ & $0.56^{\star \star}$ & $0.59^{* \star}$ & & & \\
\hline 11. & PJ T1 & 3.06 & 0.67 & 0.69 & 0.00 & 0.03 & $-0.07^{\star}$ & -0.02 & $0.54^{\star \star}$ & $0.42^{\star \star}$ & $0.31^{\star \star}$ & $0.29^{\star \star}$ & $0.41^{\star \star}$ & $0.36^{\star \star}$ & & \\
\hline
\end{tabular}

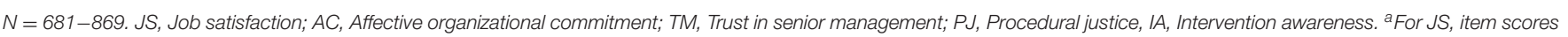
were summed. Item scores were averaged for AC, TM, and PJ.

${ }^{*} p<0.05 .{ }^{* \star} p<0.01 .{ }^{* \star *} p<0.001$. 
TABLE 2 | Hierarchical regression analyses for relations between IA and T2 work attitudes controlling for age, gender, tenure, staff group, the interaction between tenure and staff group, and T1 variables.

\begin{tabular}{|c|c|c|c|c|c|c|c|c|c|c|}
\hline Measure & \multicolumn{5}{|c|}{ Step 1} & \multicolumn{5}{|c|}{ Step 2} \\
\hline Age & 0.02 & 0.05 & 0.02 & 0.46 & & 0.02 & 0.05 & 0.01 & 0.30 & \\
\hline Gender & 0.83 & 0.85 & 0.03 & 0.97 & & 0.79 & 0.84 & 0.03 & 0.95 & \\
\hline Tenure & -0.06 & 0.18 & -0.03 & -0.30 & & -0.04 & 0.18 & -0.02 & -0.24 & \\
\hline Tenure $\times$ Staff Group & 0.11 & 0.11 & 0.08 & 0.96 & & 0.10 & 0.11 & 0.08 & 0.95 & \\
\hline T1 Satisfaction & 0.68 & 0.03 & 0.62 & $22.15^{\star \star \star}$ & & 0.66 & 0.03 & 0.60 & $21.66^{\star \star \star}$ & \\
\hline IA & & & & & & 4.50 & 1.00 & 0.14 & $5.00^{\star \star \star}$ & \\
\hline $\operatorname{Adj} . R^{2}$ & & & & & 0.40 & & & & & \\
\hline$F$ & & & & & $91.03^{\star \star \star}$ & & & & & \\
\hline$\Delta R^{2}$ & & & & & & & & & & 0.02 \\
\hline Gender & 0.28 & 0.22 & 0.04 & 1.27 & & 0.27 & 0.22 & 0.03 & 1.23 & \\
\hline Tenure & -0.03 & 0.05 & -0.05 & -0.55 & & -0.02 & 0.05 & -0.05 & -0.52 & \\
\hline Staff Group & 0.59 & 0.22 & 0.07 & $2.67^{\star \star}$ & & 0.49 & 0.22 & 0.06 & $2.19^{\star}$ & \\
\hline Tenure $\times$ Staff Group & 0.03 & 0.03 & 0.10 & 1.19 & & 0.03 & 0.03 & 0.10 & 1.20 & \\
\hline T1 Commitment & 0.70 & 0.03 & 0.61 & $22.49^{\star \star \star}$ & & 0.68 & 0.03 & 0.60 & $22.10^{\star \star \star}$ & \\
\hline IA & & & & & & 0.78 & 0.26 & 0.08 & $2.98^{\star \star}$ & \\
\hline $\operatorname{Adj} . R^{2}$ & & & & & 0.40 & & & & & \\
\hline$F$ & & & & & $95.36^{\star \star \star}$ & & & & & \\
\hline$\Delta R^{2}$ & & & & & & & & & & 0.01 \\
\hline$F$ change & & & & & & & & & & $8.85^{\star \star}$ \\
\hline IA & & & & & & 2.09 & 0.52 & 0.11 & $4.02^{\star \star \star}$ & \\
\hline Adj. $R^{2}$ & & & & & 0.35 & & & & & \\
\hline$F$ & & & & & $77.55^{\star \star \star}$ & & & & & \\
\hline$\Delta R^{2}$ & & & & & & & & & & 0.01 \\
\hline$F$ change & & & & & & & & & & $16.12^{\star \star \star}$ \\
\hline \multicolumn{11}{|c|}{ PROCEDURAL JUSTICE } \\
\hline Age & -0.01 & 0.01 & -0.03 & -0.86 & & -0.01 & 0.01 & -0.03 & -0.86 & \\
\hline Gender & -0.24 & 0.23 & -0.04 & -1.04 & & -0.26 & 0.23 & -0.04 & -1.13 & \\
\hline Tenure & -0.06 & 0.05 & -0.14 & -1.31 & & -0.06 & 0.05 & -0.13 & -1.18 & \\
\hline Staff Group & 0.48 & 0.22 & 0.07 & $2.16^{*}$ & & 0.38 & 0.23 & 0.06 & 1.68 & \\
\hline Tenure $\times$ Staff Group & 0.06 & 0.03 & 0.21 & $1.99^{*}$ & & 0.06 & 0.03 & 0.20 & 1.91 & \\
\hline T1 Justice & 0.63 & 0.04 & 0.53 & $16.24^{\star \star \star}$ & & 0.63 & 0.04 & 0.53 & $16.12^{\star \star \star}$ & \\
\hline IA & & & & & & 0.84 & 0.27 & 0.10 & $3.13^{\star \star}$ & \\
\hline $\operatorname{Adj} . R^{2}$ & & & & & 0.28 & & & & & \\
\hline$F$ & & & & & $45.19^{\star \star \star}$ & & & & & \\
\hline$\Delta R^{2}$ & & & & & & & & & & 0.01 \\
\hline$F$ change & & & & & & & & & & $9.77^{\star \star}$ \\
\hline
\end{tabular}

$N=673-869 . \Delta R^{2}$, change in $R^{2}$. IA, Intervention awareness.

${ }^{*} p \leq 0.05 .{ }^{* *} p \leq 0.01 .{ }^{* * *} p \leq 0.001$. 
Staff group remained a predictor of affective organizational commitment after the addition of IA in Step 2, whereas staff group was only a significant predictor of trust in senior management at Step 1. With regard to perceived procedural justice, it should be noted that staff group and the interaction between staff group and tenure, predicted procedural justice prior to the addition of IA. In view of these findings, further regression analyses were undertaken to examine differences between academic and non-academic staff in the effect of IA on affective organizational commitment, and other work attitudinal outcomes.

\section{Analyses Examining Staff Group Differences}

Hierarchical regression analyses examined differences between academic and non-academic staff in terms of the impact of IA on job satisfaction, affective organizational commitment, trust in senior management, and perceived procedural justice. In all cases, IA was the independent variable with two levels (No/Don't Know, and Yes). Respondents' age, gender, tenure, and their scores on the relevant $\mathrm{T} 1$ variables were included in the analyses as control variables at Step 1.

As shown in Table 3, the T1 level variables of job satisfaction, affective organizational commitment, trust in senior management, and perceived procedural justice were predictors of job satisfaction, affective organizational commitment, trust, and justice, respectively, for academic staff. In addition, tenure was a predictor of affective organizational commitment at Step 1 only. When IA was added to the analyses at Step 2, its effect was significant for job satisfaction, and trust in senior management, but not for affective organizational commitment and perceived procedural justice.

For non-academic staff, Table 4 shows that the T1 levels of job satisfaction, affective commitment to the organization, trust and procedural justice were predictors of the T2 levels of job satisfaction, affective organizational commitment, trust in senior management, and procedural justice, respectively. Furthermore, tenure remained a predictor of procedural justice for nonacademic staff. However, unlike the results for academic staff, the effect of IA was significant for all four attitudinal outcomes.

\section{Analyses Examining Different Lengths of Tenure}

Hierarchical regression analyses examined differing lengths of tenure in the inter-relationships between IA and employee levels of job satisfaction, affective organizational commitment, trust in senior management, and perceptions of procedural justice. In all cases, IA was the independent variable with two levels (No/Don't Know, and Yes). Age, gender, staff group, and respondents' scores on the relevant $\mathrm{T} 1$ variables were included in analyses as control variables at Step 1.

Respondents reported the number of years that they had worked at the university and their responses were recoded into four tenure groups (0-5 years, 6-10 years, 11-19 years, and 20-38 years). Each of these samples met the sample size criteria recommended by Tabachnick and Fidell (2001, p. 117) for multiple regression analyses. According to Tabachnick and Fidell's formula $(N>50+8 \mathrm{~m}$ where $m=$ the number of independent variables), and taking into account the five independent variables used in the analyses, 90 cases were required for a reliable equation.

Table 5 shows the relation of IA to work attitudes for each of the four tenure groups. For university staff with 5 or fewer years of organizational tenure, there were significant positive relationships (albeit small) between IA and job satisfaction and perceived procedural justice when prior levels of job satisfaction and justice, respectively, were included as additional predictors in the hierarchical regression analyses. For all attitudinal outcomes, the T1 level of the dependent variable was a predictor of the T2 attitudinal outcome.

For employees with 6-10 years length of tenure, IA was a predictor of higher levels of job satisfaction, affective commitment to the organization and trust in senior management when prior levels of those respective variables were included as additional predictors in the analyses. For all attitudinal outcomes, the T1 level of the dependent variable was a predictor of the T2 outcome. Of particular note, staff group (i.e., being a member of non-academic staff) predicted affective commitment to the organization and remained a predictor of higher levels of commitment when both IA and prior levels of commitment were included as additional predictors in the analyses.

For employees with 11-19 years of tenure, IA predicted higher levels of job satisfaction and perceptions of trust in senior management when prior levels of those respective variables were included as additional predictors in the analyses. For all work-attitude outcomes, the T1 level of the dependent variable predicted the T2 outcome.

With regard to university employees with 20-38 years of organizational tenure, there were no relationships between the awareness of stress-reduction interventions, and job satisfaction, commitment to the organization, trust in senior management, or perceived procedural justice. However, T1 levels of the dependent variables predicted their corresponding $\mathrm{T} 2$ attitudinal outcomes.

\section{DISCUSSION}

The present study examined the inter-relationships between staff group role, length of organizational tenure, IA (in the positive awareness of intervention strategies), and job satisfaction and other positive work attitudinal outcomes. First, the study looked at academic and non-academic staff separately to examine the contribution of IA on the attitudinal outcomes controlling for age, gender, and $\mathrm{T} 1$ variable differences. With regard to hypothesis 1 , the study found that for academics, IA predicted both job satisfaction and trust in senior management. The results for non-academic staff were more positive as IA predicted job satisfaction, affective organizational commitment, and trust in senior management supporting hypothesis 1 . Thus, in terms of job satisfaction for both staff groups, IA may be considered an aspect of perceived organizational support (POS) as this 
TABLE 3 | Relationships between IA and T2 work attitudes: academic staff.

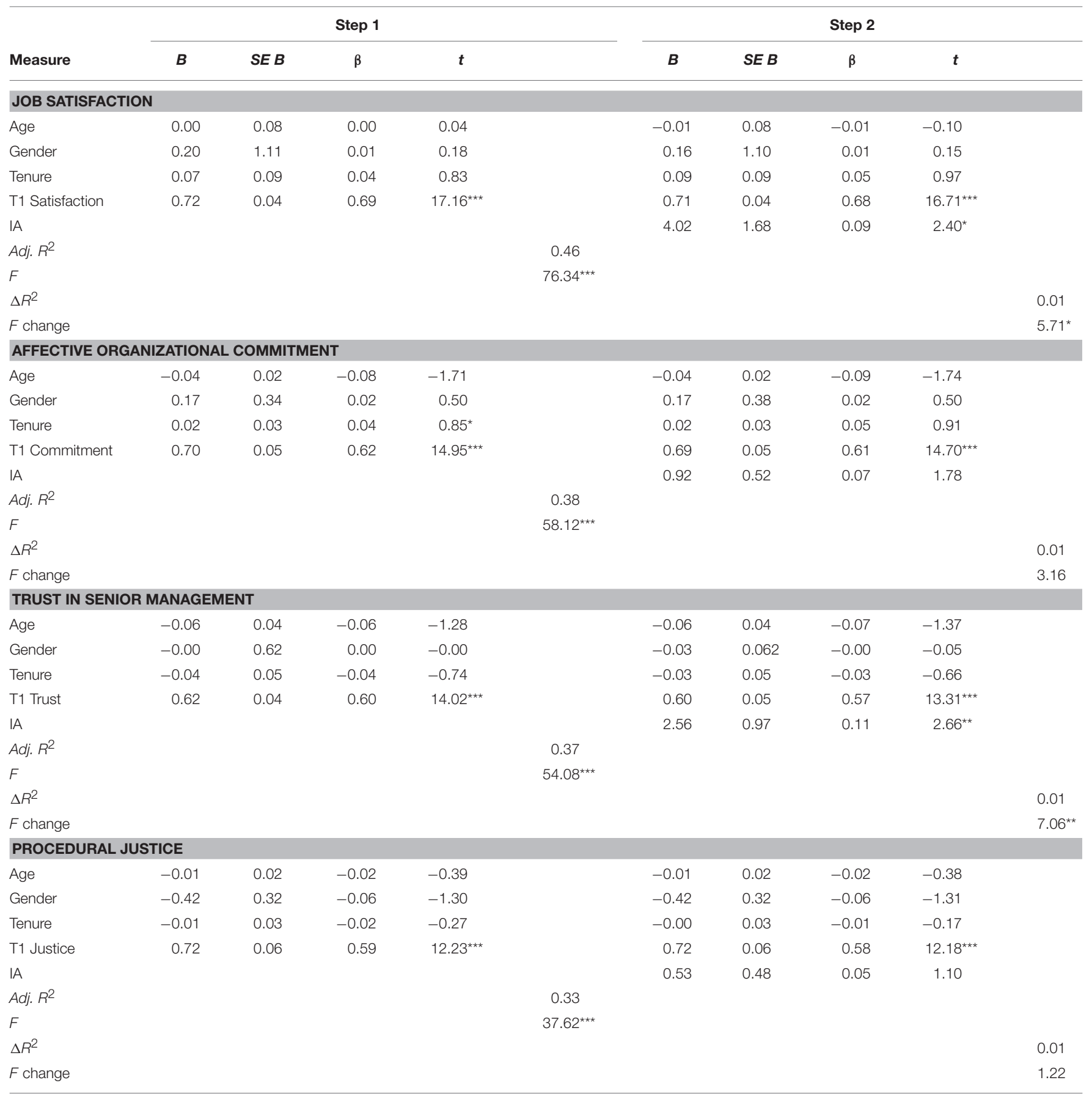

$N=294-372 . \Delta R^{2}$, change in $R^{2}$. IA, Intervention awareness.

${ }^{*} p \leq 0.05 .{ }^{* *} p \leq 0.01$. ${ }^{* * *} p \leq 0.001$.

finding is in line with the literature on social-exchange theory, as a body of job satisfaction research including a metaanalytic review by Riggle et al. (2009) found that POS has a strong, positive effect on job satisfaction. Indeed, Rhoades and Eisenberger (2002, p. 701) propose that "POS should contribute to overall job satisfaction by meeting socio-emotional needs, increasing performance-reward expectancies, and signaling the availability of aid when needed." Furthermore, as trust evolves over time through the repeated interactions of values and attitudes within the exchange relationship between employee and organization (Jones and George, 1998), this result is consistent with research by Whitener (2001) that POS was related to trust in management. Given that there was no association between IA and affective organizational commitment for the academic 
TABLE 4 | Relationships between IA and T2 work attitudes: non-academic staff.

\begin{tabular}{|c|c|c|c|c|c|c|c|c|c|c|}
\hline Measure & \multicolumn{5}{|c|}{ Step 1} & \multicolumn{5}{|c|}{ Step 2} \\
\hline Age & 0.04 & 0.07 & 0.03 & 0.59 & & 0.03 & 0.07 & 0.02 & 0.50 & \\
\hline Gender & 1.45 & 1.26 & 0.04 & 1.15 & & 1.43 & 1.24 & 0.04 & 1.15 & \\
\hline Tenure & 0.16 & 0.09 & 0.07 & 1.78 & & 0.16 & 0.09 & 0.07 & 1.78 & \\
\hline IA & & & & & & 5.41 & 1.26 & 0.16 & $4.28^{\star \star \star}$ & \\
\hline Adj. $R^{2}$ & & & & & 0.33 & & & & & \\
\hline$F$ & & & & & $58.23^{\star \star \star}$ & & & & & \\
\hline$\Delta R^{2}$ & & & & & & & & & & 0.03 \\
\hline$F$ change & & & & & & & & & & $18.30^{\star \star \star}$ \\
\hline Tenure & 0.04 & 0.02 & 0.07 & 1.77 & & 0.04 & 0.02 & 0.07 & 1.83 & \\
\hline T1 Commitment & 0.69 & 0.04 & 0.60 & $16.74^{\star \star \star}$ & & 0.68 & 0.04 & 0.59 & $16.44^{\star \star \star}$ & \\
\hline IA & & & & & & 0.72 & 0.30 & 0.09 & $2.42^{\star}$ & \\
\hline $\operatorname{Adj} . R^{2}$ & & & & & 0.36 & & & & & \\
\hline$F$ & & & & & $71.27^{\star \star \star}$ & & & & & \\
\hline$\Delta R^{2}$ & & & & & & & & & & 0.01 \\
\hline$F$ change & & & & & & & & & & $5.86^{\star \star \star}$ \\
\hline \multicolumn{11}{|c|}{ TRUST IN SENIOR MANAGEMENT } \\
\hline Age & -0.04 & 0.03 & -0.05 & -1.15 & & -0.04 & 0.03 & -0.05 & -1.25 & \\
\hline Gender & 0.43 & 0.62 & 0.03 & 0.69 & & 0.35 & 0.62 & 0.02 & 0.57 & \\
\hline$F$ change & & & & & & & & & & $9.32^{\star \star}$ \\
\hline \multicolumn{11}{|c|}{ PROCEDURAL JUSTICE } \\
\hline Age & -0.01 & 0.02 & -0.03 & -0.63 & & -0.01 & 0.02 & -0.03 & -0.64 & \\
\hline Gender & -0.11 & 0.32 & -0.02 & -0.34 & & -0.15 & 0.32 & -0.02 & -0.48 & \\
\hline Tenure & 0.05 & 0.02 & 0.12 & $2.37^{\star}$ & & 0.05 & 0.02 & 0.12 & $2.46^{\star}$ & \\
\hline T1 Justice & 0.57 & 0.05 & 0.49 & $10.99^{\star \star \star}$ & & 0.56 & 0.05 & 0.48 & $10.83^{\star \star \star}$ & \\
\hline IA & & & & & & 1.00 & 0.33 & 0.14 & $3.04^{\star \star}$ & \\
\hline Adj. $R^{2}$ & & & & & 0.24 & & & & & \\
\hline$F$ & & & & & $31.07^{\star \star \star}$ & & & & & \\
\hline$\Delta R^{2}$ & & & & & & & & & & 0.02 \\
\hline$F$ change & & & & & & & & & & $9.24^{\star *}$ \\
\hline
\end{tabular}

$N=379-497 . \Delta R^{2}$, change in $R^{2}$. IA, Intervention awareness.

${ }^{*} p \leq 0.05 .{ }^{* *} p \leq 0.01 .{ }^{* \star *} p \leq 0.001$.

group, this suggests that organizational grouping impacts on employees' emotional attachment to their organization. This may require university management to build the cohesiveness of employees within the organization as research has demonstrated the organizational benefits of a strongly committed workforce in terms of enhancing job performance and organizational citizenship behaviors (Meyer et al., 2002; Riketta, 2002). The finding is also in line with previous research that has indicated 
TABLE 5 | Relation of IA to T2 work attitudes by length of tenure.

\begin{tabular}{|c|c|c|c|c|c|c|c|c|c|}
\hline \multirow[b]{2}{*}{ Step } & \multirow[t]{2}{*}{ rk Attitude } & \multicolumn{8}{|c|}{ Length of Tenure } \\
\hline & & $\beta$ & $\Delta R^{2}$ & $\beta$ & $\Delta R^{2}$ & $\beta$ & $\Delta R^{2}$ & $\beta$ & $\Delta R^{2}$ \\
\hline \multicolumn{10}{|c|}{ JOB SATISFACTION } \\
\hline & Staff Group & -0.10 & & $0.12^{*}$ & & 0.07 & & 0.07 & \\
\hline & T1 Satisfaction & $0.44^{\star \star \star}$ & & $0.62^{\star \star \star}$ & & $0.65^{\star \star \star}$ & & $0.73^{\star \star \star}$ & \\
\hline \multirow[t]{2}{*}{2} & IA & $0.16^{\star}$ & $0.03^{*}$ & $0.17^{\star *}$ & $0.03^{\star *}$ & $0.12^{\star \star}$ & $0.01^{\star \star}$ & 0.05 & 0.00 \\
\hline & Total $R^{2}$ & & $0.22^{\star \star \star}$ & & $0.45^{\star \star \star}$ & & $.45^{\star \star \star}$ & & $0.54^{\star \star \star}$ \\
\hline 1 & T1 Commitment & $0.53^{\star \star \star}$ & & $0.51^{\star \star *}$ & & $0.66^{\star \star \star}$ & & $0.70^{\star \star \star}$ & \\
\hline \multirow[t]{2}{*}{2} & IA & 0.06 & 0.00 & $0.14^{\star \star}$ & $0.02^{\star \star}$ & 0.05 & 0.00 & 0.02 & 0.00 \\
\hline & Total $R^{2}$ & & $0.26^{\star \star \star}$ & & $0.36^{\star \star *}$ & & $0.45^{\star \star \star}$ & & $0.55^{\star \star \star}$ \\
\hline \multicolumn{10}{|c|}{ TRUST IN SENIOR MANAGEMENT } \\
\hline \multirow[t]{4}{*}{1} & Age & -0.04 & $0.25^{\star \star \star}$ & -0.08 & $0.35^{\star \star \star}$ & -0.04 & $0.34^{\star \star \star}$ & -0.09 & $0.43^{\star \star \star}$ \\
\hline & Gender & -0.04 & & -0.02 & & 0.05 & & 0.05 & \\
\hline & Staff Group & -0.03 & & 0.11 & & 0.04 & & 0.11 & \\
\hline & T1 Trust & $0.51^{\star \star \star}$ & & $0.56^{\star \star \star}$ & & $0.58^{\star \star \star}$ & & $0.62^{\star \star \star}$ & . \\
\hline \multirow[t]{2}{*}{2} & IA & 0.06 & 0.00 & $0.24^{\star \star \star}$ & $0.05^{\star \star \star}$ & $0.12^{\star}$ & $0.01^{*}$ & -0.05 & 0.00 \\
\hline & Total $R^{2}$ & & $0.25^{\star \star \star}$ & & $0.40^{\star \star \star}$ & & $0.35^{\star \star \star}$ & & $0.43^{\star \star \star}$ \\
\hline 2 & Total $R^{2}$ & & $0.19^{\star \star \star}$ & & $0.25^{\star \star \star}$ & & $0.29^{\star \star \star}$ & & $0.47^{\star \star \star}$ \\
\hline
\end{tabular}

$\Delta R^{2}=R^{2}$ change.

${ }^{\star} p \leq 0.05 .{ }^{* \star} p \leq 0.01$. ${ }^{\star \star *} p \leq 0.001$.

that academics reported more adverse work experiences than non-academic respondents (Winefield et al., 2008) so there is a clear need to focus on the talent management of academics to enhance the mutual exchange processes between them and their organization.

The second hypothesis that non-academic staff would report more positive associations with IA and perceived procedural justice than academics, was also supported as there was no effect of IA on justice for academic staff whereas for nonacademic staff, IA predicted perceived procedural justice. In addition, tenure also predicted procedural justice which is not surprising given that the social exchange processes between employee-employer are shaped over time. There was partial support for hypothesis 3 that longer lengths of organizational tenure would positively affect the relationship between IA and employees' levels of job satisfaction. However, this assertion only applied for employees with up to 19 years of tenure and not those holding 20-38 years of tenure. The adverse result for longer tenured employees is of particular interest and requires further investigation as research has shown that positive work experiences enhance employees' perceptions of trust, justice and commitment (Arnold et al., 1995; Holtz and Harold, 2009) and that the perception of fair treatment is critical to the continuation of relational psychological contracts (Rousseau and Parks, 1992).

There was partial support for the fourth hypothesis that longer lengths of organizational tenure will positively affect the relationship between IA and employees' level of trust in senior management, procedural justice, and affective organizational commitment. However, this was only for staff with tenure 
lengths of 6-10 years for the outcomes of affective organizational commitment and 6-19 years tenure for trust in senior management. With regard to university staff with five or less years of tenure, IA only predicted higher levels of perceptions of procedural justice even when prior levels of justice was included as additional predictors in the hierarchical regression analyses. For employees with 6-10 years of tenure, IA predicted higher levels of affective organizational commitment and perceptions of trust in senior management. Of particular note, being a member of non-academic staff with between 6-10 years of tenure predicted affective commitment to the organization and remained a predictor of higher levels of commitment when both IA and prior levels of commitment were included as additional predictors. With regard to employees with 1119 years of tenure, IA only predicted higher levels of trust in senior management. However, for employees with 20-38 years of organizational tenure, there were no relationships between IA and affective commitment to the organization, trust in senior management, or perceptions of procedural justice.

In sum, employees' length of organizational tenure did affect the relation between IA and some attitudinal outcomes. Across the tenure groups, IA predicted: (1) job satisfaction for employees with 0-19 years of tenure; (2) trust in senior management for employees with 6-19 years of tenure; (3) affective organizational commitment for employees with tenure for 6-10 years; and (4) perceived procedural justice for employees with five or less years of tenure. These results suggest that employees working at the university for an intermediate period of time such as $6-10$ years had the most positive perceptions of their organization in terms of the awareness of stressreduction interventions, job satisfaction, trust, and affective commitment, whereas employees with 20-38 years of tenure had the least positive perceptions which may reflect the need to better manage and communicate organizational change initiatives to longstanding employees. Nonetheless, this finding warrants further investigation as it is intuitively appealing that a sense of mastery at work is related to having seniority and/or a longer length of organizational tenure which, in turn, is associated with greater job satisfaction and other positive work attitudes. Thus, it would be valuable, particularly in terms of employee wellbeing and supporting effective performance, to determine what factors are causing longer term employees to develop unfavorable perceptions.

Research by Winefield et al. (2008), for example, has shown that in the Australian university context, workplace factors (i.e., trust in senior management, perceived procedural justice, autonomy) were the best predictors of academics' affective commitment to their university as they accounted for $21 \%$ of the variance, whereas demographic factors (i.e., occupational level) and individual difference variables (i.e., job involvement, extraversion, negative affectivity, hardiness) accounted only for $3 \%$ and $14 \%$ of the variance, respectively. On the other hand, for non-academic staff, the individual difference variables of job involvement, extraversion, conscientiousness, hardiness, and maladaptive coping were more predictive of affective commitment than the workplace factors of trust, justice, and autonomy (Winefield et al., 2008). These results suggest that the roles played by perceived work conditions and individual variables in predicting commitment differ between academic and non-academic employees. As a result, Human Resource practices (i.e., reward, promotion, incentive practices) and interventions may need to be tailored to take account of these group differences. Future research should also focus more on trust in management (both senior and line managers) and perceptions of procedural justice as key mechanisms to develop affective organizational commitment and job satisfaction during the professional career.

\section{Limitations}

The results suggest that the positive perception of stressreduction intervention strategies implemented within university workplaces appear to enhance employee job satisfaction, trust in senior management, affective commitment to the organization and perceptions of procedural justice for some staff groups. The results of this study emphasize the importance of using a longitudinal design and multiple regression analyses that incorporate the T1 levels of the dependent variables in order to examine the links from demographic characteristics such as staff group and length of tenure, and organizational resources such as IA, to work-related attitudes. Although the effect sizes for the aforementioned relationships were small, it is reasonable to assume that the positive effects of IA on these attitudes were statistically reliable. Whilst causation is not conclusive, these findings suggest a link that warrants further investigation. It is important to acknowledge the limitation of common method bias of the measurement method as only self-report questionnaire data on health and psychosocial factors were collected from the same participants in both waves of the study.

There is a need for future research in this specific area to take steps to control for the number of stress interventions implemented prior to the study period. The authors were not able to collect data regarding the number of stress-reduction initiatives implemented at each of the thirteen universities prior to the study. However, a forthcoming study by Pignata and colleagues will report on the data collected from management at five of the 13 universities that details the stress interventions implemented between the two waves of the longitudinal study.

\section{Implications and Conclusion}

The present study identifies the potential target groups for the promotion of organizational stress-reduction strategies and thus, adds to the stress intervention literature in two ways. First, it compared academic and non-academic university staff to explore potential occupation-specific associations between IA, tenure, and work-related outcomes; and secondly, it compared groups with differing lengths of tenure to examine specific associations between IA and work-related attitudes. As no previous research has examined those relationships the study fills a gap in the stress intervention literature. By examining the two distinct staff groups separately, as well as investigating employees in differing stages of their careers, the study's results have practical implications for organizations and management, particularly university management as they identify potential target groups or areas for the promotion of stress-reduction strategies. Management at 
each of the individual universities may benefit from conducting independent assessments in order to identify specific areas that require attention. Given the need to attend to contextual and process issues in organizational stress and wellbeing interventions (Biron and Karanika-Murray, 2014), the findings suggest that university management may need to implement new strategies and promote existing stress-management and reduction strategies to academic staff, and employees whom are either new to the university or those who have been working for the organization for longer periods of time, to ensure that those employees are aware of organizational strategies to promote and enhance employee wellbeing and morale within university environments.

\section{REFERENCES}

Arnold, J., Cooper, C. L., and Robertson, I. T. (1995). Work Psychology: Understanding Human Behaviour in the Workplace, 2nd Edn. London: Pitman Publishing.

Barkhuizen, N., Roodt, E., and Schutte, N. (2014). Talent management of academics: balancing job demands and job resources. Med. J. Soc. Sci. 5, 69-77. doi: 10.5901/mjss.2014.v5n20p2033

Bentley, P., Coates, H., Dobson, I., Goedegebuure, L., and Meek, V. L. (eds.). (2013). "Factors associated with job satisfaction amongst Australian university academics and future workforce implications," in Job Satisfaction around the Academic World, Chapter 3 (Dordrecht: Springer), 29-53.

Biron, C., and Karanika-Murray, M. (2014). Process evaluation for organizational stress and well-being interventions: implications for theory, method, and practice. Int. J. Stress Manage. 21, 85-111. doi: 10.1037/a0033227

Butler, J. K. (1991). Toward understanding and measuring conditions of trust: evolution of a conditions of trust inventory. J. Manage. 17, 643-663. doi: $10.1177 / 014920639101700307$

Catano, V., Francis, L., Haines, T., Kirpalani, H., Shannon, H., Stringer, B., et al. (2010). Occupational stress in Canadian Universities: a national survey. Int. J. Stress Man. 17, 232-258. doi: 10.1037/a0018582

Coates, H., Dobson, I., Edwards, D., Friedman, T., Goedegebuure, L., and Meek, L. (2009). The Attractiveness of the Australian Academic Profession: a Comparative Analysis. Melbourne, LH: Martin Institute EPI and ACER.

Coetzee, S. E., and Rothmann, S. (2005). Occupational stress, organisational commitment and ill-health of employees at a higher education institution in South Africa. J. Ind. Psychol. 31, 47-54. doi: 10.4102/sajip.v31i1.179

Cohen, J., and Cohen, P. (1983). Applied Multiple Regression/Correlation analysis for the Behavioral Sciences. Hillsdale, NJ: Erlbaum.

De Beuckelaer, A., and Lievens, F. (2009). Measurement equivalence of paperand-pencil and online organizational surveys: a large scale examination in 16 countries. Appl. Psychol. 58, 336-361. doi: 10.1111/j.1464-0597.2008.00350

Demerouti, E., Bakker, A. B., Nachreiner, F., and Schaufeli, W. B. (2001). The job demands-resources model of burnout. J. Appl. Psychol. 86, 499-512. doi: 10.1037/0021-9010.86.3.499

Department of Education Science and Training (2003). Staff 2003: Selected Higher Education Statistics. (Table 2). Canberra, CA: DEST.

Folger, R., and Konovsky, M. A. (1989). Effects of procedural and distributive justice on reactions to pay raise decisions. Acad. Manage. J. 32, 115-130.

Gillespie, N. A., Walsh, M., Winefield, A. H., Dua, J., and Stough, C. (2001). Occupational stress in universities: staff perceptions of the causes, consequences and moderators of stress. Work Stress 15, 53-72. doi: 10.1080/ 02678370117944

Herzberg, F., Mausner, B., Peterson, R. D., and Capwell, D. F. (1957). Job Attitudes: Review of Research and Opinions. Pittsburgh: Psychological Service of Pittsburgh.

Holtz, B. C., and Harold, C. M. (2009). Fair today, fair tomorrow? A longitudinal investigation of overall justice perceptions. J. Appl. Psychol. 94, 1185-1199. doi: $10.1037 / \mathrm{a} 0015900$

\section{AUTHOR CONTRIBUTIONS}

All four authors, SP, AW, CP, and $\mathrm{CB}$ contributed to the formulation and writing of this paper. SP also undertook the analyses.

\section{FUNDING}

The research reported in this paper was supported by grants from the Australian Research Council and the National Tertiary Education Union, and contributions from the Vice Chancellors of the participating universities. The first author was supported by a Bellberry PhD Scholarship.

Jaccard, J., Turrisi, R., and Wan, C. K. (1990). Interaction Effects in Multiple Regression. Newbury Park; California, CA: Sage.

Jones, G. R., and George, J. M. (1998). The experience and evolution of trust: implications for cooperation and teamwork. Acad. Manage. Rev. 23, 531-546.

Kinman, G. (2001). Pressure points: review of research on stressors and strains in UK academics. Educat. Psychol. 21, 473-492. doi: 10.1080/01443410120090849

Kinman, G., and Court, S. (2010). Psychosocial hazards in UK universities: adopting a risk assessment approach. High. Educat. Q. 64, 413-428. doi: 10.1111/j.1468-2273.2009.00447.x

Kinman, G., and Jones, F. (2003). Running up the down escalator: stressors and strains in UK academics. Qual. High. Educat. 9, 21-38. doi: $10.1080 / 13538320308162$

Kinman, G., and Wray, S. (2014). Taking its Toll: Rising Stress Levels in Further Education. UCU Publications. Available online at: http://www.ucu.org.uk/ media/pdf/q/b/ucu_festressreport14.pdf?CFID=22923281\&CFTOKEN=47794 b65a042a5a-A97173F8-AEFD-756C-7658D963909FB278

Liu, C., Spector, P. E., and Shi, L. (2008). Use of both qualitative and quantitative approaches to study job stress in different gender and occupational groups. J. Occup. Health. Psychol. 13, 357-370. doi: 10.1037/1076-8998.13. 4.357

Mäkikangas, A., Kinnunen, U., Feldt, T., and Schaufeli, W. (2016). The longitudinal development of employee well-being: a systematic review. Work Stress 30, 46-70. doi: 10.1080/02678373.2015.1126870

Mäkikangas, A., Schaufeli, W., Leskinen, E., Kinnunen, U., Hyvönen, K., and Feldt, T. (2015). Long-term development of employee well-being: a latent transition approach. J. Happ. Stud. doi: 10.1007/s10902-015-9696-7. [Epub ahead of print].

Mayer, R. C., and Davis, J. H. (1999). The effect of the performance appraisal system on trust for management: a field quasi-experiment. J. App. Psych. 84, 123-136. doi: 10.1037/0021-9010.84.1.123

McInnis, C. (1999). The Work Roles of Academics in Australian Universities. (Evaluations and Investigations Programme, EIP00/05). [Electronic version]. Commonwealth of Australia, Department of Education, Training and Youth Affairs (DETYA). Available online at: http://pandora.nla.gov.au/pan/ 24685/20020426-0000/www.detya.gov.au/archive/highered/eippubs/eip00_5/ fullcopy.pdf

Meyer, J. P., Stanley, D. J., Herscovitch, L., and Topolnytsky, L. (2002). Affective, continuance, and normative commitment to the organization: a meta-analysis of antecedents, correlates, and consequences. J. Vocat. Behav. 61, 20-52. doi: 10.1006/jvbe.2001.1842

Mucci, N., Giorgi, G., Roncaioli, M., Fiz Perez, J., and Arcangeli, G. (2016). The correlation between stress and economic crisis: a systematic review. Neuropsychiatr. Dis. Treat. 12, 983-993. doi: 10.2147/NDT.S98525

Nunnally, J. C., and Bernstein, I. H. (1994). Psychometric Theory. New York, NY: McGraw-Hill.

Pignata, S., Boyd, C., Gillespie, N., Provis, C., and Winefield, A. H. (2016). Awareness of stress-reduction interventions: the impact on employees' wellbeing and organizational attitudes. Stress Health 32, 231-243. doi: 10.1002/smi. 2597 
Pignata, S., Lushington, K., Sloan, J., and Buchanan, F. (2015). Employees' perceptions of email communication, volume and management strategies in an Australian university. J. High. Educ. Policy Manage. 37, 159-171. doi: 10.1080/ 1360080X.2015.1019121

Pignata, S., and Winefield, A. H. (2015). Stress-reduction interventions in an Australian university: a case study. Stress Health 31, 24-34. doi: 10.1002/smi.2517

Porter, L. W., Steers, R. M., Mowday, R. T., and Boulian, P. V. (1974). Organizational commitment, job satisfaction, and turnover among psychiatric technicians. J. Appl. Psychol. 59, 603-609. doi: 10.1037/ h0037335

Rhoades, L., and Eisenberger, R. (2002). Perceived organizational support: a review of the literature. J. Appl. Psychol. 87, 698-714. doi: 10.1037/0021-9010.87.4.698

Riggle, R. J., Edmondson, D. R., and Hansen, J. D., (2009). A metaanalysis of the relationship between perceived organizational support and job outcomes: 20 years of research. J. Business Res. 62, 1027-1030. doi: 10.1016/j.jbusres.2008.05.003

Riketta, M. (2002). Attitudinal organizational commitment and job performance: a meta-analysis. J. Organ. Behav. 23, 257-266. doi: 10.1002/job.141

Rousseau, D. M., and Parks, J. M. (1992). The contracts of individuals and organizations. Res. Organ. Behav. 15, 1-43.

Saunders, M., and Thornhill, A. (2003). Organisational justice, trust and the management of change: an exploration. Emerg. Per. Rev. 32, 360-374. doi: $10.1108 / 00483480310467660$

Schaufeli, W. B., and Taris, T. W. (2014). "A critical review of the job demandsresources model: implications for improving work and health," in Bridging Occupational, Organizational and Public Health: A Transdisciplinary Approach, eds G. F. Bauer and O. Hämmig (Dordrecht: Springer Science), 43-68.

Tabachnick, B. G., and Fidell, L. S. (2001). Using Multivariate Statistics. New York, NY: HarperCollins.
Venables, K. M., and Allender, S. (2006). Occupational health needs of universities: a review with an emphasis on the United Kingdom. Occup. Environ. Med. 63, 159-167. doi: 10.1136/oem.2005.022145

Warr, P. B., Cook, J., and Wall, T. D. (1979). Scales for the measurement of some work attitudes and aspects of psychological wellbeing. J. Occup. Organ. Psychol. $52,129-148$.

Whitener, E. M. (2001). Do high commitment human resource practices affect employee commitment? A cross-level analysis using hierarchical linear modelling. J. Manage. 27, 515-535. doi: 10.1177/014920630102700502

Winefield, A. H., Boyd, C., Saebel, J., and Pignata, S. (2008). Job Stress in University Staff: An Australian Research Study. Bowen Hills, QL: Australian Academic Press.

Winefield, A. H., Gillespie, N., Stough, C., Dua, J., Hapuarachchi, J. R., and Boyd, C. M. (2003). Occupational stress in Australian university staff: results from a national survey. Int. J. Stress Manage. 10, 51-63. doi: 10.1037/1072-5245.10.1.51

Zapf, D., Dormann, C., and Frese, M. (1996). Longitudinal studies in organizational stress research: a review of the literature with reference to methodological issues. J. Occup. Health. Psychol. 1, 145-169. doi: 10.1037/10768998.1.2.145

Conflict of Interest Statement: The authors declare that the research was conducted in the absence of any commercial or financial relationships that could be construed as a potential conflict of interest.

Copyright () 2016 Pignata, Winefield, Provis and Boyd. This is an open-access article distributed under the terms of the Creative Commons Attribution License (CC BY). The use, distribution or reproduction in other forums is permitted, provided the original author(s) or licensor are credited and that the original publication in this journal is cited, in accordance with accepted academic practice. No use, distribution or reproduction is permitted which does not comply with these terms. 


\title{
Learning Climate and Job Performance among Health Workers. A Pilot Study
}

\author{
Michela Cortini $^{1 *}$, Monica Pivetti ${ }^{*}$ and Sara Cervai ${ }^{2}$ \\ ${ }^{1}$ Dipartimento di Scienze Psicologiche, della Salute e del Territorio, Università degli Studi "G. d'Annunzio" Chieti - Pescara, \\ Chieti, Italy, ${ }^{2}$ Dipartimento di Studi Umanistici, Università degli Studi di Trieste, Trieste, Italy
}

This paper will explore if and how psychological strain plays a mediator role between the learning climate and job performance in a group of health workers. Although the relationship between learning climate and job performance has already been explored in the international literature, the role of psychological strain, which may hamper or deepen this relationship, has yet to be investigated. The research hypothesis is that psychological strain mediates the relationship between the climate toward learning (including also the error avoidance climate) and job performance. Data were gathered in a Public hospital in Italy. Participants $(N=61)$ were health professionals (nurses and obstetricians). Considering the relatively small sample size, a mediation analysis with the aid of the SPSS macro PROCESS was performed. The results show that the relationship between the learning climate (specifically its dimension of organizational appreciation toward learning) and job performance is mediated by psychological strain. The future research agenda and practical implications are discussed in the paper.

Keywords: learning climate, job performance, psychological strain, health professions, mediation analysis

\section{INTRODUCTION}

The relationship between soft constructs (i.e., Perceived Organizational Support, Job Satisfaction, Commitment, Engagement...) and performance has received growing attention from scholars in particular, work psychology researchers - working to show the link between subjective items (perception, motivation, satisfaction) and measurable outcomes (Riggle et al., 2009).

The dimensions that refer to the psychological side of the organization are - in the common experience of any practitioner - clearly related to personal behaviors and performance, although the scientific literature still struggles to demonstrate it. International contests (e.g., Great Place To Work) are receiving more and more attention from companies, motivated first of all by the need to attract human resources (Employer Branding), and to consider the possibility of a close link between organizational wellbeing and performance.

One open question is about how to demonstrate the relationship between the performance of a whole organization and psychological dimensions such as organizational culture, climate, stress. . . Managerial studies propose considering economic indicators as proxies for soft constructs: i.e., funds dedicated to training and budget results. Moreover, there is an increasing need to focus on how psychological organizational dimensions can impact on performance.

Organizational performance is usually measured in terms of financial indicators; productivity and performance are often considered good proxies. Furthermore, specific markets and sectors required a specific focus. For instance, in education, where the proposal to measure performance 
by monitoring the salary of former students, or even by means of financial indicators (ROI), is not well accepted yet, and may not be very appropriate, either.

In the healthcare sector, budget indicators are seen in terms of performance linked to health indicators: healthy people do not require treatment, so they do not cost to the community anything; recovery rates, cure rates, surgery rates, pertinence of prescription are only some examples of how the healthcare sector is used to consider costs and quantitative indicators to measure organizational performance. In this context, incidents and errors may become one of the most appropriate dimensions to analyze the link between organizational dynamics and performance in healthcare. Each incident or error in medicine contains a potential cost in terms of patient health, additional therapies, legal costs, damaged reputation, which can have a direct impact on organizational performance. On the other hand, each incident contains information regarding how to improve procedures to avoid a similar error in the future, so that it constitutes a precious source of information for the continuous improvement process. Generally speaking, errors trigger learning because negative and informative events have the potential to highlight what still needs to be changed, becoming a step in a wide organizational development (Argyris and Schön, 1978). If something changes following an error, it means the organization has learnt from it (Frese and Keith, 2015). Putz et al. (2013, p. 516) proposed a classification in four factors influencing such error- related learning processes at work, underlining that: "While members act and learn as their organization's agents, the organization itself affects the learning processes of individuals with its routines, processes, structures and its culture." They consist in supervisor's behavior, colleagues' behavior, task structure and procedures, principles and values. Following this rationale, Putz et al. (2013) focus their research on the climate conducive for learning from errors, seen as a multifaceted construct.

Since the error rate can be seen as performance indicator in the healthcare sector (because any error potentially causes a failure), we argue that the way errors trigger an improvement indicates, in a clear way, the organizational learning process, and its effectiveness.

To investigate which dimensions encourage or discourage this process is one of the major challenges for practitioners and researchers.

The link between HR practices and strategies, and in particular training policies, with healthcare organizations' performance has been reported by Michie et al. (2014). Moreover, the relationship between organizational support for training and performance has been well highlighted in the meta-analytic review conducted by Arthur et al. (2003).

More recently, Nikolova et al. (2014) have reviewed the organizational learning literature, and have underlined three different dimensions that occur in different studies and different contexts; the facilitation dimension (all the forms of support for learning that organizations guarantee to their employees); the dimension of rewarding and appreciation for learning, such as incentives; the dimension of error management. These dimensions have been included in the Learning Climate Scale (LCS).
To contribute to this field of research, the present study focuses on the relationship between learning climate and performance, seeking to understand the influence played by an individual dimension, particularly challenging nowadays, that is psychological strain.

In other studies (Cervai et al., 2013; Cervai and Polo, 2015) we have stressed the fact that learning is crucial for the health context, stressing the need to evaluate its outcome. In line with this attention toward learning outcome evaluation, we propose to investigate the role of the internal evaluation of learning. In particular, the research aims to explore the role played by the organizational learning climate, which can become a proxy to evaluate workplace learning.

In particular, following the work of Motowidlo et al. (1986), our attention focuses on the mediator role of psychological strain between learning climate and performance, putting forward the following hypothesis:

$\mathrm{H} 1$ : Perceived organizational support for training and learning positively affects job performance.

$\mathrm{H} 2$ : Appreciation from the organization for training and learning activities positively affects job performance.

H3: Error avoidance negatively affects job performance.

H4: Psychological strain mediates the relationship between support for training and learning and job performance.

H5: Psychological strain mediates the relationship between appreciation for training and learning and job performance.

H6: Psychological strain mediates the relationship between error management and job performance.

\section{MATERIALS AND METHODS}

\section{Sample}

Data were gathered in a Public hospital in Italy. Participants ( $N=61)$ were full-time health professionals (nurses and obstetricians); most of them (51 participants) were female, their average age was 47.9 years (SD. 9,6), with a range between 31 and 68 years of age.

\section{Measures and Data Collection}

A cross-sectional survey was adopted with a self-administered and anonymous questionnaire, with a first part on sociodemographic information (age, sex, contract type) and a core part related to the variables being analyzed whose description follows.

\section{Learning Climate}

The original scales developed by Nikolova et al. (2014) were used to assess the following dimensions of the learning climate: organizational support for training (ex. "My organization provides sufficient resources to develop my competences"), appreciation for training (e.g., "In my organization, employees who make effort to learn new things, earn appreciation and respect") and error avoidance (e.g., "In my organization, one is afraid to admit mistakes"). These measures showed high Cronbach alpha reliability levels (indexes vary from 0.81 to 0.91 ). All the scales consist of three items where respondents express 
TABLE 1 | Descriptive statistics and correlations.

\begin{tabular}{|c|c|c|c|c|c|c|c|c|}
\hline & NI & $M$ & $S D$ & Alpha & 2 & 3 & 4 & 5 \\
\hline (1) Psychological strain & 1 & 2.26 & 1.04 & - & $-0.429^{* *}$ & $-0.266^{*}$ & 0.110 & $-0.375^{* *}$ \\
\hline $\begin{array}{l}\text { (2) Organizational } \\
\text { support for training }\end{array}$ & 3 & 2.75 & 1.15 & 0.91 & & $0.569^{* *}$ & 0.120 & $0.550^{* *}$ \\
\hline $\begin{array}{l}\text { (3) Appreciation for } \\
\text { training }\end{array}$ & 3 & 2.17 & 0.94 & 0.83 & & & -0.043 & $0.600^{* *}$ \\
\hline (4) Error avoidance & 3 & 3.51 & 0.86 & 0.86 & & & & 0.077 \\
\hline (5) Performance & 2 & 4.80 & 1.85 & 0.76 & & & & \\
\hline
\end{tabular}

$n=61 ;$ NI, number of items; ${ }^{*} p<0.05 ; * * p<0.01$.

an opinion by means of a seven-point Likert scale, representing an increasing level of agreement (from 1, "strongly disagree" to 7, “strongly agree").

\section{Psychological Strain}

Job strain was measured with a single item of the General Health Questionnaire (GHQ) focused on feelings of stress. The GHQ has a long tradition within nursing studies (e.g., Hunter and Houghton, 1993; Fagin et al., 1995; Jones and Johnston, 1997; Tully, 2004; Gomes et al., 2013). Furthermore, in the past, the GHQ was used as a simple tool for detecting the prevalence of psychological stress within general medical practice (Werneke et al., 2000). Several versions of the GHQ exist: 60-, 30-, 28-, and 12 -item scales. GHQ-12 is perhaps the most popular version of the questionnaire, very often used in large social surveys (Banks and Jackson, 1982; Winefield et al., 1989) or applied contexts (Tully, 2004), owing to its brevity.

The choice of the single item was driven by a cost and time rationale, especially in view of the fact that we had collected data inside the working context, in the time between shifts. The choice to replace longer measurement scales with a single measure is not a novelty in the international literature and it seems to be particularly efficient for the working environment, showing a satisfactory content validity (see, Elo et al., 2003). We have preferred the single item taken from the GHQ ("Have you experienced stress during the past 2 weeks?", measured by a fourpoint scale, ranging from 1, "better than usual," to 4, "Much less than usual"), instead of the one derived from the Occupational Stress Questionnaire (Elo and Leppänen, 1999), because the latter includes an introduction ("Stress means a situation in which a person feels tense, restless, nervous or anxious or is unable to sleep at night because his/her mind is troubled all the time. Do you feel this kind of stress these days?") that might, in our opinion, risk confusing the respondents. We believe that nowadays people are so used to talking about stress that they do not need any kind of detailed explanation to understand whether they are experiencing stress or not.

\section{Job Performance}

Finally, in line with the most recent research in work and organizational psychology (e.g., Demerouti et al., 2005), we have decided to use a self-rated job performance measure, adopting two items from Chirumbolo and Areni (2005). The first item was "I have achieved all my job goals in the last 6 months" to which participants had to declare their agreement/disagreement
TABLE 2 | Summary of simple regression analysis for learning climate dimensions predicting job satisfaction $(N=86)$; ${ }^{*} p<0.05$; ${ }^{* * *} p<0.001$.

\begin{tabular}{lccc}
\hline & $\boldsymbol{B}$ & $\boldsymbol{S E} \boldsymbol{B}$ & $\boldsymbol{\beta}$ \\
\hline $\begin{array}{l}\text { Organizational support } \\
\text { for training }\end{array}$ & 0.507 & 0.212 & $0.295^{*}$ \\
Appreciation for training & 0.789 & 0.223 & $0.435^{* * *}$ \\
Error Avoidance & 0.119 & 0.203 & 0.060 \\
$F=14.22^{* * *}$ & & & \\
$R^{2}=0.42$ & & & \\
\hline
\end{tabular}

( 1 = strongly disagree; $9=$ strongly agree). The second item was "In the last 6 months, your job performance was:" to which participants had to answer using a five-point scale ranging from $1=$ particularly low, to $9=$ particularly high .

We have decided to use self-reported measures of the main study dimensions, since we focused on perceived job characteristics (job satisfaction, as well as learning climate), as many other researchers have done (Chan, 2009; Judge et al., 2000), "making self-reports the theoretically most relevant measure method" (Conway and Lance, 2010, p. 329).

\section{RESULTS}

None of the demographic variables related to any of the study variables so they were excluded from further analysis. Table $\mathbf{1}$ presents the preliminary analysis of the dataset: the means, standard deviations and inter-correlations of the main study variables.

Firstly, scaled variables achieved good reliability, with Cronbach's alpha coefficients between 0.76 and 0.91 .

\section{Test Hypotheses}

In order to test $\mathrm{H} 1, \mathrm{H} 2$, and $\mathrm{H} 3$ we performed a multiple linear regression, to predict job performance based on the three different dimensions of the Learning Climate: organizational support for training, appreciation for training and error avoidance. Preliminary analysis was performed to ensure there was no violation of the assumption of normality, linearity and multicollinearity.

A significant regression equation was found: $F(1,59)=14,22$; $p<0.001$, with an $R^{2}=0.42$. 


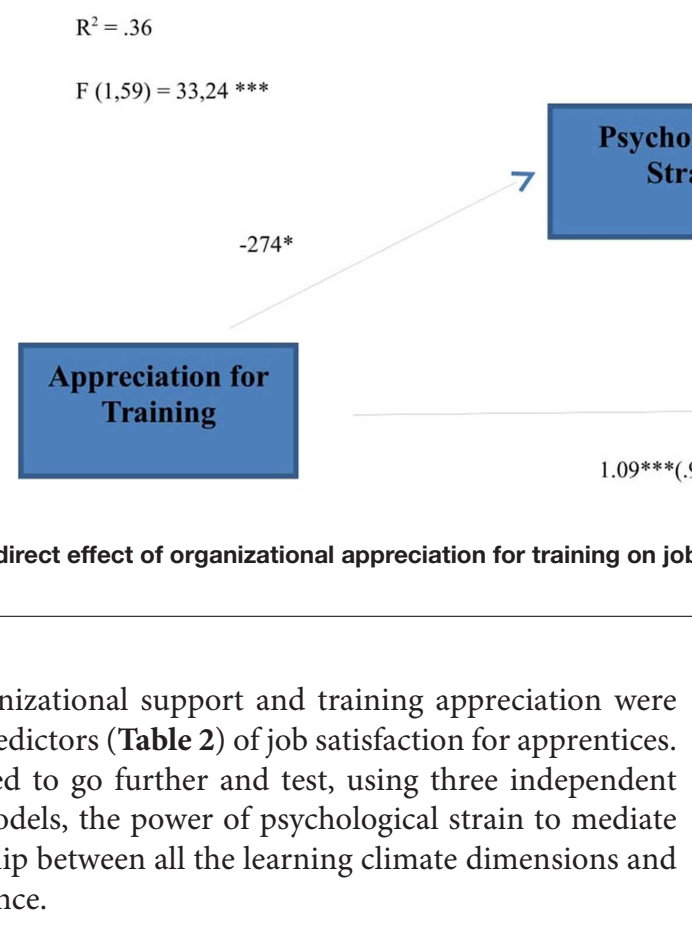

\section{Mediation Analysis}

There are two different methods for performing mediation analyses: Multiple Regression and Structural Equations Models (SEM). Although some researchers (Baron and Kenny, 1986; Hoyle and Smith, 1994; Kenny et al., 1998) suggest adopting SEM because it allows for a better control of measurement error and gives good information about the fit of the model, we follow the guidelines of those (Holmbeck, 1997; Frazier et al., 2004) who suggest using Multiple Regression in case of a small sample size, as in the present study.

We tested the hypotheses following the guidelines described by Preacher and Hayes (2004), who developed an SPSS macro, called PROCESS, that triangulates the normal theory approach (i.e., the Sobel test), a bootstrap approach, and Baron and Kenny's (1986) approach to measure the indirect effects of the predictor on the dependent variable. In particular, the use of bootstrapped confidence intervals was necessary in order to avoid problems related to our limited sample size (MacKinnon et al., 2004; Preacher et al., 2007) and to take into consideration also the potential mediation for the dimension of error avoidance, which definitely seems interesting for this research, and it is not among the significant predictors of job performance in the present regression analysis.

We performed three different mediation analyses for each of the dimensions of the Learning Climate, with the aid of the macro PROCESS, using model n. 4.

First, it was found that psychological strain significantly mediated the relation between appreciation for training and job satisfaction (Figure 1) (indirect effect $=0.112, S E=0.108,95 \%$ CI $[0.0109,0.2840])$; since zero is not in the $95 \%$ confidence interval we can conclude that the indirect effect is significantly different from zero at $p<0.05$, and that, as predicted, change in psychological strain mediates the relationship between training support and job satisfaction.

The mediator could account for an almost $10 \%$ of the effect; $P \mathrm{M}=0.11 ; K^{2}=0.07$, CI $\left.[0.0110,0.1875]\right)$.

Even if the role of mediator is not crucial as it would be in a totally mediated output, the interactive force between stress and valorization of learning and training is worth underlining, which suggests to HR managers the importance of taking into account nurses' training needs.

It was also found that psychological strain did not significantly mediate the relationship between organizational support for training and job performance or the relationship between error avoidance and job performance.

\section{DISCUSSION}

First of all, the regression analysis clearly underlined the dimension of learning as being crucial in terms of performance. Learning, in this sense, has to be understood not only as something that happens at an individual level but rather as something involving employer responsibilities. In particular, the Climate for Learning underlines that, on the one hand, giving support for training and learning and, on the other hand, valuing the learning activities and efforts made by every single worker, is something vital (we suppose in both instrumental and motivational terms) for performance development.

In addition, the significant mediation model provides support for the prediction that nurses experience differences in job performance due to their different levels of psychological stress and the valorization they perceive they receive from their organization. Consequently, these results suggest a series of guidelines for HR managers, who should develop specific training plans and seek to appreciate every single learning outcome, with relentless attention paid to the wellbeing and stress of their employees: in line with other scholars (Montani et al., 2015; Giorgi et al., 2015) we claim for a supervisors' empowering management practices

In terms of additional practical implications, notwithstanding the importance of both learning and training, on the one hand, 
and stress and well-being, on the other one, we trust the potential of learning and training activities focused on stress management. Stress management, generally being paid for by the employees is not sufficiently promoted within organizations. In terms of primary prevention, we wonder about the role of specific devices and tools (think to the organizational gym) to prevent psychological strain; something that could play a role on performance.

Finally, our results may corroborate the proposals for HR managers we have put forward in other studies (Cortini, 2016), stressing the role of organizational support in order to develop a sense of self as worker; in such a sense, employers ought to provide participatory practices to discuss work-related issues together along with proper error management that allow errors to become a form of learning.

\section{LIMITATIONS AND FUTURE RESEARCH}

The results of the present study should be seen in the light of some limitations. First of all, our study has a cross-sectional design, which limits our capability to extrapolate the causal relationship between the variables under investigation. Especially in view of the recent criticism cross-sectional mediation analysis has received (e.g., Maxwell and Cole, 2007; Mitchell and Maxwell, 2013), we plan to collect longitudinal data to be analyzed by a Continuous Time Mediation, as suggested by Deboeck and Preacher (2016) in order to respond to the limit of mediation models in terms of time-lag analysis.

\section{REFERENCES}

Argyris, C., and Schön, D. A. (1978). Organizational Learning: A Theory of Action Perspective. Reading, MA: Addison-Wesley.

Arthur, W. Jr., Bennett, W. Jr., Edens, P. S., and Bell, S. T. (2003). Effectiveness of training in organizations: a meta-analysis of design and evaluation features. J. Appl. Psychol. 88, 234-245. doi: 10.1037/0021-9010.88.2.234

Banks, M. H., and Jackson, P. R. (1982). Unemployment and risk of minor psychiatric disorder in young people: cross-sectional and longitudinal evidence. Psychol. Med. 12, 789-798. doi: 10.1017/S0033291700049096

Baron, R. M., and Kenny, D. A. (1986). The moderator-mediator variable distinction in social psychological research: conceptual, strategic, and statistical considerations. J. Pers. Soc. Psychol. 51, 1173-1182. doi: 10.1037/00223514.51.6.1173

Cervai, S., Cian, L., Berlanga, A., Borelli, M., and Kekäle, T. (2013). Assessing the quality of the learning outcome in vocational education: the Expero model. J. Workplace Learn. 25, 198-210. doi: 10.1108/13665621311306565

Cervai, S., and Polo, F. (2015). Evaluating the quality of the learning outcome in healthcare sector: the Expero4care model. J. Workplace Learn. 27, 611-626. doi: 10.1108/JWL-09-2015-0063

Chan, D. (2009). "So why ask me? Are self-report data really that bad," in Statistical \& Methodological Myths and Urban Legends: Doctrine, verity and fable in the organizational and social sciences, eds C. E. Lance and R. J. Vandenberg (Hillsdale, NJ: Erlbaum), 309-336.

Chirumbolo, A., and Areni, A. (2005). The influence of job insecurity on job performance and absenteeism: the moderating effect of work attitudes. SA J. Ind. Psychol. 31, 65-71. doi: 10.4102/sajip.v31i4.213

Conway, J. M., and Lance, C. E. (2010). What reviewers should expect from authors regarding common method bias in organizational research. J. Bus. Psychol. 25, 325-334. doi: 10.1007/s10869-010-9181-6
Furthermore, we have used a small sample size, which should definitely be enlarged. Specifically, our data were collected in a single Italian hospital; it would be necessary to collect additional data, also qualitative in nature, so as to deepen both the relationships we did find significant as well as those we did not find to be significant (but still showing a trend in the hypothesized direction). In addition, with a larger sample it may be easier to check for differences in formal and informal learning, as done by other scholars (Kyndt et al., 2009; Manuti et al., 2015).

We have decided to focus on self-rated performance; it would be interesting in the upcoming future to detail performance and to distinguish between adaptive performance and task performance, in line with recent literature trends (Shoss et al., 2012; Jundt et al., 2015).

Finally, taking into consideration our results, we suggest a venue for future studies that will allow for a greater understanding of the processes of workplace learning in the health context. In particular, these recommendations include further investigation of the different roles the managers and the organizational climate may play, as well as assessing the potential outcomes at both organizational and patient levels.

\section{AUTHOR CONTRIBUTIONS}

SC and MC designed the pilot study. SC and MC reviewed literature. MP collected data. MC analysed data. Together, MC, SC, and MP wrote discussion, limitations and future research agenda.

Cortini, M. (2016). Workplace identity as a mediator in the relationship between learning climate and job satisfaction during apprenticeship: suggestions for HR practitioners. J. Workplace Learn. 28, 54-65. doi: 10.1108/JWL-12-20150093

Deboeck, P. R., and Preacher, K. J. (2016). No need to be discrete: A method for continuous time mediation analysis. Struct. Equ. Modeling 23, 61-75. doi: 10.1080/10705511.2014.973960

Demerouti, E., Verbeke, W. J., and Bakker, A. B. (2005). Exploring the relationship between a multidimensional and multifaceted burnout concept and self-rated performance. J. Manag. 31, 186-209. doi: 10.1177/0149206304271602

Elo, A. L., and Leppänen, A. (1999). Efforts of health promotion teams to improve the psychosocial work environment. J. Occup. Health Psychol. 4, 87-94. doi: 10.1037/1076-8998.4.2.87

Elo, A. L., Leppänen, A., and Jahkola, A. (2003). Validity of a single-item measure of stress symptoms. Scand. J. Work Environ. Health 29, 444-451. doi: 10.5271/sjweh.752

Fagin, L., Brown, D., Bartlett, H., Leary, J., and Carson, J. (1995). The Claybury community psychiatric nurse stress study: is it more stressful to work in hospital or the community? J. Adv. Nurs. 22, 347-358. doi: 10.1046/j.13652648.1995.22020347.x

Frazier, P. A., Tix, A. P., and Barron, K. E. (2004). Testing moderator and mediator effects in counseling psychology research. J. Couns. Psychol. 51, 115-134. doi: 10.1037/0022-0167.51.1.115

Frese, M., and Keith, N. (2015). Action errors, error management, and learning in organizations. Annu. Rev. Psychol. 66, 661-687. doi: 10.1146/annurev-psych010814-015205

Giorgi, G., Mancuso, S., Perez, F. J. F., Montani, F., Courcy, F., and Arcangeli, G. (2015). Does leaders' health (and work-related experiences) affect their evaluation of followers' stress? Saf. Health Work 6, 249-255. doi: 10.1016/j.shaw.2015.07.005 
Gomes, S. F. S., Santos, M. M. M., and Carolino, E. T. D. M. (2013). Psycho-social risks at work: Stress and coping strategies in oncology nurses. Lat. Am. J. Nurs. 21, 1282-1289.

Holmbeck, G. N. (1997). Toward terminological, conceptual, and statistical clarity in the study of mediators and moderators: examples from the child-clinical and pediatric psychology literatures. J. Consult. Clin. Psychol. 65, 599-610. doi: 10.1037/0022-006X.65.4.599

Hoyle, R. H., and Smith, G. T. (1994). Formulating clinical research hypotheses as structural equation models: a conceptual overview. J.Consult. Clin. Psychol. 62, 429-440. doi: 10.1037/0022-006X.62.3.429

Hunter, P., and Houghton, D. M. (1993). Nurse teacher stress in northern Ireland. J. Adv. Nurs. 18, 1315-1323. doi: 10.1046/j.1365-2648.1993.180 81315.x

Jones, M. C., and Johnston, D. W. (1997). Distress, stress and coping in first-year student nurses. J. Adv. Nurs. 26, 475-482. doi: 10.1046/j.1365-2648.1997.t01-500999.x

Judge, T. A., Bono, J. E., and Locke, E. A. (2000). Personality and job satisfaction: the mediating role of job characteristics. J. Appl. Psychol. 85, 237-249. doi: 10.1037/0021-9010.85.2.237

Jundt, D. K., Shoss, M. K., and Huang, J. L. (2015). Individual adaptive performance in organizations: a review. J. Organ. Behav. 36, S53-S71. doi: 10.1002/job. 1955

Kenny, D. A., Kashy, D. A., and Bolger, N. (1998). "Data analysis in social psychology," in Handbook of Social Psychology, 4th Edn, eds D. Gilbert, S. T. Fiske, and G. Lindzey (New York, NY: McGraw-Hill), 233-265.

Kyndt, E., Dochy, F., and Nijs, H. (2009). Learning conditions for non-formal and informal workplace learning. J. Workplace Learn. 21, 369-383. doi: $10.1108 / 13665620910966785$

MacKinnon, D. P., Lockwood, C. M., and Williams, J. (2004). Confidence limits for the indirect effect: Distribution of the product and resampling methods. Multivariate Behav. Res. 39, 99-128. doi: 10.1207/s15327906mbr 3901_4

Manuti, A., Pastore, S., Scardigno, A. F., Giancaspro, M. L., and Morciano, D. (2015). Formal and informal learning in the workplace: a research review. Int. J. Train. Dev. 19, 1-17. doi: 10.1111/ijtd.12044

Maxwell, S. E., and Cole, D. A. (2007). Bias in cross-sectional analyses of longitudinal mediation. Psychol. Methods 12, 23-44. doi: 10.1037/1082989X.12.1.23

Michie, S., Atkins, L., and West, R. (2014). The Behaviour Change Wheel: A Guide to Designing Interventions. London: Silverback Publishing.

Mitchell, M. A., and Maxwell, S. E. (2013). A comparison of the cross-sectional and sequential designs when assessing longitudinal mediation. Multivariate Behav. Res. 48, 301-339. doi: 10.1080/00273171.2013.784696

Montani, F., Courcy, F., Giorgi, G., and Boilard, A. (2015). Enhancing nurses' empowerment: the role of supervisors' empowering management practice. J. Adv. Nurs. 71, 2129-2141. doi: 10.1111/jan.12665
Motowidlo, S. J., Packard, J. S., and Manning, M. R. (1986). Occupational stress: its causes and consequences for job performance. J. Appl. Psychol. 71, 618-629. doi: 10.1037/0021-9010.71.4.618

Nikolova, I., Van Ruysseveldt, J., De Witte, H., and Van Dam, K. (2014). Learning climate scale: construction, reliability and initial validity evidence. J. Vocat. Behav. 85, 258-265. doi: 10.1016/j.jvb.2014.07.007

Preacher, K. J., and Hayes, A. F. (2004). SPSS and SAS procedures for estimating indirect effects in simple mediation models. Behav. Res. Methods Instrum. Comput. 36, 717-731. doi: 10.3758/BF03206553

Preacher, K. J., Rucker, D. D., and Hayes, A. F. (2007). Addressing Moderated Mediation Hypotheses: theory, methods, and prescriptions. Multivariate Behav. Res. 42, 185-227. doi: 10.1080/00273170701341316

Putz, D., Schilling, J., Kluge, A., and Stangenberg, C. (2013). Measuring organizational learning from errors: development and validation of an integrated model and questionnaire. Manag. Learn. 44, 511-536. doi: $10.1177 / 1350507612444391$

Riggle, R. J., Edmondson, D. R., and Hansen, J. D. (2009). A meta-analysis of the relationship between perceived organizational support and job outcomes: 20 years of research. J. Bus. Res. 62, 1027-1030. doi: 10.1016/j.jbusres.2008.05.003

Shoss, M. K., Witt, L. A., and Vera, D. (2012). When does adaptive performance lead to higher task performance? J. Organ. Behav. 33, 910-924. doi: 10.1002/job.780

Tully, A. (2004). Stress, sources of stress and ways of coping among psychiatric nursing students. J. Psychiatr. Ment. Health Nurs. 11, 43-47. doi: 10.1111/j.13652850.2004.00682.x

Werneke, U., Goldberg, D. P., Yalcin, I., and Üstün, B. T. (2000). The stability of the factor structure of the General Health Questionnaire. Psychol. Med. 30, 823-829. doi: 10.1017/S0033291799002287

Winefield, H. R., Goldney, R. D., Winefield, A. H., and Tiggemann, M. (1989). The General Health Questionnaire: reliability and validity for Australian youth. Aust. N. Z. J. Psychiatry 23, 53-58. doi: 10.3109/00048678909062592

Conflict of Interest Statement: The authors declare that the research was conducted in the absence of any commercial or financial relationships that could be construed as a potential conflict of interest.

The reviewer JP and the handling Editor declared their shared affiliation, and the handling Editor states that the process nevertheless met the standards of a fair and objective review.

Copyright (c) 2016 Cortini, Pivetti and Cervai. This is an open-access article distributed under the terms of the Creative Commons Attribution License (CC BY). The use, distribution or reproduction in other forums is permitted, provided the original author(s) or licensor are credited and that the original publication in this journal is cited, in accordance with accepted academic practice. No use, distribution or reproduction is permitted which does not comply with these terms. 


\title{
Rocking at 81 and Rolling at 34: ROC Cut-Off Scores for the Negative Acts Questionnaire-Revised in Serbia
}

\author{
Ivana B. Petrović, Milica Vukelić* and Svetlana Čizmić \\ Department of Psychology, Faculty of Philosophy, University of Belgrade, Belgrade, Serbia
}

Researchers are still searching for the ways to identify different categories of employees according to their exposure to negative acts and psychological experience of workplace bullying. We followed Notelaers and Einarsen's application of the ROC analysis to determine the NAQ-R cut-off scores applying a "lower" and "higher" threshold. The main goal of this research was to develop and test different gold standards of personal and organizational relevance in determining the NAQ-R cut-off scores in a specific cultural and economic context of Serbia. Apart from combining self-labeling as a victim with self-perceived health, the objectives were to test the gold standards developed as a combination of self-labeling with life satisfaction, self-labeling with intention to leave and

OPEN ACCESS

Edited by: Mindy Shoss, University of Central Florida, USA

Reviewed by:

Nicola Mucci,

University of Florence, Italy Clair Reynolds Kueny, Missouri University of Science and Technology, USA

${ }^{*}$ Correspondence: Milica Vukelic mbvukeli@f.bg.ac.rs

Specialty section: This article was submitted to Organizational Psychology, a section of the journal

Frontiers in Psychology

Received: 31 August 2016 Accepted: 20 December 2016 Published: 09 January 2017

Citation:

Petrović IB, Vukelić M and Čizmić S (2017) Rocking at 81 and Rolling at 34: ROC Cut-Off Scores for the Negative Acts Questionnaire-Revised in Serbia. Front. Psychol. 7:2058. doi: 10.3389/fpsyg.2016.02058 a complex gold standard based on self-labeling, self-perceived health, life satisfaction and intention to leave taken together. The ROC analysis on Serbian workforce data supports applying of different gold standards. For identifying employees in a preliminary stage of bullying, the most applicable was the gold standard based on self-labeling and intention to leave (score 34 and higher). The most accurate identification of victims could be based on the most complex gold standard (score 81 and higher). This research encourages further investigation of gold standards in different cultures.

\footnotetext{
Keywords: workplace bullying, Negative Acts Questionnaire-Revised (NAQ-R), receiver operating characteristic (ROC), cut-off points, Serbia
}

\section{INTRODUCTION}

Workplace bullying is characterized by persistent and systematic negative acts that are directed toward one or more employees by one or more of their colleagues (Einarsen et al., 2009). There are numerous studies that deal with the negative impact of workplace bullying on health and wellbeing of employees (e.g., Leymann and Gustafsson, 1996; Mikkelsen and Einarsen, 2001, 2002; Matthiesen and Einarsen, 2004; Nielsen et al., 2014; Di Marco et al., 2016; Giorgi et al., 2016b). It can also have negative impact on organizations, leading to a plethora of counterproductive behaviors (Ayoko et al., 2003; Djurkovic et al., 2008; Hoel et al., 2011). Both the personal and organizational outcomes of workplace bullying are of high importance to individual employees, organizations and society at large (Leymann, 1990; Hoel et al., 2001; Giga et al., 2008).

Researchers and practitioners need ways of detecting different categories of employees according to their exposure to negative acts and psychological experience of bullying. Introducing the ROC analysis to identify the victims in different stages of workplace bullying, Notelaers and Einarsen (2013) opened a new chapter in workplace bullying research. In composing gold standard for identifying victims, Notelaers and Einarsen (2013) combined self-labeling with perceived 
health. In order to enrich this new "chapter" of research, in this research we aimed to explore, develop and test different gold standards of personal and organizational relevance in a specific cultural and economic context of Serbia.

When dealing with workplace bullying, both researchers and practitioners are first confronted with striking individual outcomes. According to Leymann (1990), the first phase of workplace bullying is linked to conflict and stigmatization, while the last phase is seen as a significant disruption of employee's personal resources, which leads to endangering his/her health. Some studies have confirmed that workplace bullying was related to subsequent health and, mostly, mental health problems (Nielsen et al., 2014). In majority of studies mental health and subjective health were measured by using depression, anxiety and somatic symptoms as indicators. Searching for workplace bullying studies dealing with well-being, we found that most of them operationalized well-being as subjective mental and somatic health. There are only a few studies that included broader subjective well-being indicators, such as life satisfaction (Bowling and Beehr, 2006; Trépanier et al., 2016).

Having in mind a rich body of literature pointing out various negative individual outcomes of workplace bullying, we propose adopting a broader operationalization of wellbeing. We see life satisfaction as a measure of well-being that incorporates all aspects of subjective mental and somatic health. Moreover, such measure includes more nuances of psychological experiences and emotional states as an expression of the quality of life. Life satisfaction could also be a relevant and sensitive measure of well-being for studying reactions to workplace bullying. It can finely portray all the sequences of bullying, from an isolated critical incident to severe victimization. In that vein, the model of Erdogan et al. (2012) considered life satisfaction as a key indicator of subjective well-being in the work context. After analyzing numerous research studies of life satisfaction, Erdogan et al. (2012) proposed that the level of life satisfaction could be the consequence of the quality of work life. In Bowling and Beehr's (2006) research it was shown that workplace bullying was positively correlated with depression, anxiety, burnout, frustration, negative emotions at work, and physical symptoms as 'negative' psychological indicators of health and well-being. On the other side, it was negatively correlated with positive emotions at work, life satisfaction, self-esteem, job satisfaction and organizational commitment as 'positive' psychological indicators of well-being (Trépanier et al., 2016).

Along with individual outcomes, workplace bullying also negatively affects organizational functioning through behaviors that lead to lower productivity, absenteeism and higher turnover rate (Hoel et al., 2011). We consider that the organizationally relevant outcomes are less highlighted in understanding workplace bullying in an individualistic cultural context in which persons are primarily expected to take care of themselves and their close relatives (Hofstede, 2001). As noted by Giorgi (2010), in collectivistic cultures, feeling stronger identification with their organization, employees might perceive negative acts as less harmful than in individualistic cultures and they might be better in coping with negative acts. In support with this thesis, exploring employees' reactions to severe economic downturn in Serbia it was found that employees were coming to work regularly without receiving salaries for months, as they were strongly attached to their organizations (Čizmić et al., 2004). Both from the theoretical and practical perspective it is important for an organization to explore in depth organizationally relevant outcomes that are crucial for understanding and prevention of bullying.

Embedded in Leymann's (1990) writings, the atmosphere of exclusion from work could be regarded as ingrained in negative acts such as ignoring and socially isolating the victim that directly signal to an employee that he/she should quit the job. If an organization fails to intervene adequately, the employer loses the employee either by having a detached, dissatisfied, disengaged and an employee of ill-health or having a higher turnover rate since a victimized employee could actually leave the organization (Glambek et al., 2014). Indeed, some authors agree that leaving the organization could be the most effective strategy of coping with severe workplace bullying (Berthelsen et al., 2011).

There is evidence that throughout the entire bullying process employees feel insecure about their jobs and often (re)think themselves to leave the job voluntarily due to unmanageable pressure (Glambek et al., 2014). The results of the cross-sectional research of Glambek et al. (2014) on Norwegian offshore workers showed that exposure to bullying behavior in two different time points was significantly related to job insecurity and employees' intention to leave the job.

Intention to leave, as any other "intention to..." type of variables, does not indicate actual turnover (Dalton et al., 1999). Based on meta-analysis of 29 research studies carried out in the USA, the mean correlation between intention to leave and turnover rate weighted by the sample size and adjusted for unreliability was -0.32 (Carsten and Spector, 1987). Berthelsen et al. (2011) actually explored turnover as a response to exposure to workplace bullying behaviors. Berthelsen et al. (2011) found that employees that were exposed to bullying behaviors at one point of time reported actually changing the job at a later point in time.

Meta-analyzing correlations between intention to leave and actual leaving the organization, Carsten and Spector (1987) found that this relation was moderated by economic alternatives, i.e., unemployment rate in the society. This is a highly relevant issue for the present study based on research data from Serbia, a country with a very high unemployment rate. Thus, this study puts forward that intention to leave is a persistent outcome of the bullying process and a solid indicator of previous "shock" (Glambek et al., 2014) caused by workplace bullying.

In conclusion, we point out two major outcomes of workplace bullying - intention to leave and well-being. By using these two groups of indicators, in this research we aimed to cover both individual (well-being measured by subjective health and life satisfaction) and organizationally relevant outcomes (intention to leave) of workplace bullying.

\section{Workplace Bullying in Serbia}

Since workplace bullying research has been initiated and welldeveloped in the Scandinavian cultural context (Einarsen, 2000), there is limited empirical evidence on workplace bullying in 
other cultural contexts, especially in 'post-transitional countries' in Europe (Tambur and Vadi, 2012). Scarce research confirms that bullying may differ from country to country (Jiménez et al., 2007; Lutgen-Sandvik et al., 2007; Baillien and De Witte, 2009; Tambur and Vadi, 2009; Tsuno et al., 2010; Öcel and Aydin, 2012; Seo et al., 2012; Giorgi et al., 2013; Vukelić et al., 2015). Since workplace bullying is a sensitive social phenomenon it is always useful to understand specific national, cultural and economic research context.

Serbia is a country characterized by deep, long-lasting socioeconomic crisis that has been progressing since the 1990s as a consequence of economic sanctions and inner political and economic turmoil (Simić et al., 2013). Serbian economy is characterized by low economic activity. According to the 2010 Gallup Wellbeing survey (Gallup, 2010), in terms of life evaluation estimates Serbia was among the top four European countries labeled as the most "struggling" (other two categories being "thriving" and "suffering"). At the time of gathering data for the Negative Acts Questionnaire-Revised (NAQ-R) research presented in this paper, the unemployment rate in Serbia was 22.4\% (Statistical Office of the Republic of Serbia, 2012), while GDP per capita was among the bottom $5 \%$ of European countries (Eurostat, ND). Apart from being already torn down by inner political and economic situation, Serbia was confronted with the consequences of a deep global financial crisis that begun between 2007 and 2008. Affecting the strongest economies, the financial crisis had a negative impact on labor market across the world (Mucci et al., 2016), and consequently, hampered employees' well-being (Giorgi et al., 2015a).

In 2010 Serbia adopted the first anti-bullying law that gave the legal and practical reinforcement to the practitioners and researchers of workplace bullying. The law, above all, encourages organizations to work on prevention of workplace bullying. Thus, it is of high importance to constantly follow this phenomenon and identify both organizations and individuals at the risk of being targets of workplace bullying. In the context of direct legal and psychological aid to victims and organizations, it is also important to recognize those severely hurt by workplace bullying.

Workplace bullying has been studied in Serbia since 2009 using The Negative Acts Questionnaire-Revised (Einarsen et al., 2009). Approximately 3,000 employees from different sectors of economy in Serbia took part in several studies of workplace bullying that used the NAQ-R. The overall prevalence of workplace bullying in Serbia, based on the NAQ-R and operationalized as at least two negative acts experienced on a weekly basis is $16 \%$ (Petrović et al., 2014). The most frequent negative acts in Serbia are gossiping and rumors, whereas threats of violence and physical abuse or actual abuse are the least frequent. Altogether, person-related bullying is more frequent than the work-related bullying. There were no identified risk groups based on gender, education and hierarchical level. Even though those self-labeled as bullied were significantly older than those self-labeled as non-bullied, the size of the effect was small. Correlating the NAQ-R scores with work related behaviors (Vukelić et al., 2015), the highest correlations were with intention to leave $(r=0.457)$ and perceived organizational support $(r=-0.497)$. Correlating the NAQ-R with health and well-being indicators, the highest correlations were with self-rating of health $(r=-0.315)$ and satisfaction with life $(r=-0.273)$.

\section{Measuring Workplace Bullying}

There are two distinctive ways of measuring workplace bullying (Nielsen et al., 2011): the first one is based on employees' estimations of the general feeling of being bullied, usually after reading the definition of workplace bullying (the socalled "self-labeling method"), and the second one is based on employees' ratings of exposure to a range of negative acts that are representative for workplace bullying (the so-called "behavioral experience method"). A significant, but not a complete overlap between the "subjective" and "objective" measures (e.g., LutgenSandvik et al., 2007; Petrović et al., 2014), implies that it is beneficial to apply them both in research of workplace bullying.

Both the Negative Acts Questionnaire (NAQ), and its newest version the Negative Acts Questionnaire-Revised, are probably the most internationally used and most thoroughly psychometrically explored workplace bullying inventories based on behavioral experience (e.g., McCormack et al., 2006; Jiménez et al., 2007; Lutgen-Sandvik et al., 2007; Baillien and De Witte, 2009; Einarsen et al., 2009; Tambur and Vadi, 2009; Tsuno et al., 2010; Öcel and Aydin, 2012; Seo et al., 2012; Giorgi et al., 2013; Notelaers and Einarsen, 2013; Arenas et al., 2015; Vukelić et al., 2015). The NAQ-R was developed based on previous versions of the NAQ scale that went through several quantitative and qualitative research analyses (Einarsen et al., 2009).

Even though the NAQ-R is a very comprehensive measure of workplace bullying with good psychometric properties, there are still plenty of methodological 'challenges' (Nielsen et al., 2011). One of the prominent challenges concerns separating victims from non-victims of workplace-bullying. Reviewing published research, we could single out three approaches currently applied in separating workplace bullying victims from non-victims - approach based on the number and frequency of acts, Latent Class Cluster (LCC) approach and Receiver Operating Characteristic (ROC) approach. One approach separates them based on an operational criterion that determines the cutoff point by taking into account the number and frequency of negative acts (Nielsen et al., 2011). However, there is no consensus among researchers about the number and frequency of acts that are critical for separating the victims from non-victims. For example, Leymann (1990) claimed that at least one negative act on a weekly basis could separate the victims from non-victims, Mikkelsen and Einarsen (2001) claimed there should be at least two and Agervold (2007) advocated for at least three negative acts on a weekly bases as a criterion for identifying a victim. Obviously, a relatively arbitrary operational criterion consistent with the reasoning "more negative acts, more often" and treating all bullying behaviors as equally jeopardizing, wasn't "satisfying" and led researchers to keep on searching for a better solution.

In order to address the limitation of arbitrary cut-off scores, the LCC approach was proposed (Notelaers et al., 2006) as a technique for classifying subgroups of related cases based on experience of different negative acts (Nielsen et al., 2011). A large validation study of the NAQ-R in the UK (Einarsen et al., 2009) found seven emerging clusters based on 
different levels of exposure to bullying. The clusters varied from "no bullying" to exposure to "severe bullying" and "physical intimidation." Similar clusters emerged in a study of employees from different Belgian organizations (Notelaers et al., 2006; Einarsen et al., 2009). The Belgian research identified groups from "not bullied," to groups of those exposed to "limited work criticism," "work related bulling" and "victims," with the exception of physical intimidation that has not emerged. In comparison with traditional operational classification method, the LCC demonstrated higher construct and higher predictive validity regarding indicators of stress and well-being (Notelaers et al., 2006). Surpassing the traditional "target-not target" approach, the LCC method offered a variety of target groups based on exposure to negative behaviors (Nielsen et al., 2011). Nevertheless, it did not consider sensitivity or specificity, the basic measures of accuracy in differentiating different clusters (Notelaers and Einarsen, 2013).

\section{ROC as a Method for Fine-Tuning the Cut-Off Scores}

The ROC is often used in medicine for diagnosing the disease (true positive) and correctly rejecting the disease when it is truly absent (Obuchowski, 2003). The ROC is a plot of the sensitivity of a test versus its false-positive rate ( 1 - Specificity) for all possible cut points. Thus, the area under the ROC curve (AUC) is an indicator of test accuracy or, more precisely, it shows the ability of the test to discriminate between the persons with a certain state or complaint and the persons without it (Hajian-Tilaki, 2013). The impeccable differentiation is reached when the AUC is 1 , which means that sensitivity is 1.0 , and false positive rate is 0.0 (Obuchowski, 2003). In line with that, the AUC close to 1 indicates high accuracy of the test, while the AUC about 0.5 indicates low accuracy of the test which is almost in line with "chance discrimination" (Hajian-Tilaki, 2013) or close to "chance diagonal” (Obuchowski, 2003).

The ROC analysis is based on an independent criterion of whether or not the individual has some state or disease, the socalled "gold standard" (Streiner and Cairney, 2007). Established on the gold standard, in a process of delineating victims from non-victims, the ROC analysis calculates cut scores on some measure/test under investigation. Logically, it is expected that a gold standard is of an objective nature. However, in the field of organizational psychology, specifically in the area of workplace bullying, it is reasonable to rely upon employees' subjective perceptions, as an independent criterion (Notelaers and Einarsen, 2013).

Applying the ROC analysis in distinguishing workplace bullying victims from non-victims, Notelaers and Einarsen (2013) operationalized the gold standard based on two indicators-labeling oneself as being subjected to bullying and the personal report of presence of psychiatric symptoms of anxiety and depression. Notelaers and Einarsen (2013) proposed two gold standards: "higher" and "lower." The lower standard detects employees "in a preliminary stage of bullying" and the higher detects "targets of severe bullying." More precisely, the lower cut-off point was based on labeling oneself as being bullied at least "now and then" and being a probable "psychiatric case." On the other hand, the higher cut-off point was based on labeling oneself as being bullied once a week or more often and being a "case in need of treatment." The precise cut-off NAQ-R points were determined by using the AUC and the highest sum value of sensitivity and specificity as indicators (Sensitivity + Specificity). They calculated the scores on the NAQ-R in two ways: by adding frequency ratings on all negative acts and by adding previously dichotomized frequency ratings. The frequency ratings were dichotomized as "0," including the answers "never," "now and then," and "monthly," and "1," including answers "weekly" and "daily." Notelaers and Einarsen (2013) determined that the NAQ-R score lower than 33 identifies employees that are not bullied, the score between 33 and 44 identifies those in a preliminary stage of bullying, and the score 45 and higher identifies employees that are victims of workplace bullying. Based on dichotomized frequency ratings they determined the cut score both for lower and higher gold standard, as one negative act that happens once a week or more often.

Departing from Notelaers and Einarsen's (2013) research, the aim of this study was twofold. First, the broader aim was to propose and test various models of defining the "gold standard" in defining victims in different stages of workplace bullying. In composing gold standards we introduced both personally and organizationally relevant criteria. Apart from combining selflabeling with perceived health status indicator (Notelaers and Einarsen, 2013), we also tested the gold standards constructed based on combining self-labeling with life satisfaction and intention to leave. On one side, we focused on self-rating of health status and satisfaction with life as a broader approach to personal well-being. On the other side, we explored intention to leave as an outcome of workplace bullying that is highly relevant both for the individual employee and for the organization.

The second aim was to answer to Notelaers and Einarsen's (2013) call for enriching the NAQ-R body of knowledge by determining the cut-off scores for distinguishing the victims of workplace bullying in specific cultural settings. Thus, we wanted to determine the cut-off scores in the Serbian social and cultural context. This research question is interesting as, based on previous research, workplace bullying is more prominent in Serbia than in the Norwegian context analyzed in Notelaers and Einarsen's (2013) research (Vukelić et al., 2015). In our analysis we followed Notelaers and Einarsen (2013) in determining cutoff scores for both dichotomous and the raw sum NAQ-R scores. We applied a "lower" threshold that could distinguish employees in a preliminary stage of suffering from workplace bullying and a "higher" threshold that could distinguish those that could be regarded as victims of severe bullying.

\section{MATERIALS AND METHODS}

\section{Design and Sample}

The research is based on re-analyzing the data obtained from a large national workplace bullying survey (Petrović et al., 2014; Vukelić et al., 2015). The data were gathered in cooperation with the Confederation of Autonomous Trade Unions of Serbia that 
comprises almost one-third of employees in Serbia. Respondents were randomly chosen, regardless of their union membership. Information about participants' union membership was not collected. The participation in the study was anonymous and voluntary and participants were not rewarded in any way. The study was carried out in accordance with the Code of Ethics (Serbian Psychological Society, 2000).

The sample involved 1,998 employees ( $54.4 \%$ women) from 44 municipalities in Serbia. The mean age of employees was $44.40(S D=10.23)$. More than half of respondents completed secondary education (55.5\%), almost one quarter had a university diploma (24.3\%), 16.2\% had trade school/college and $4 \%$ had primary education. The majority of employees held subordinate positions $(84.7 \%)$, while $15.3 \%$ were at supervisory positions. More than half of respondents $(61.3 \%)$ worked in public organizations and 35\% were from private organizations. The average length of service with their present organizations was 15.4 years $(S D=10.64)$. Classification of educational attainment applied in this research is somewhat different from the official statistics (Statistical Office of the Republic of Serbia, 2012), but we could conclude that the sample represents population quite well with exception of employees with university education somewhat overrepresented and unskilled employees under represented. Women were slightly overrepresented and age of respondents corresponds with the age structure of the population.

\section{Instruments and Measures}

The NAQ-R (Einarsen et al., 2009) was used to assess the exposure to workplace bullying. The scale consists of 22 items in the form of statements that are rated on a five-point rating scale that denotes the frequency of each negative act within the past 6 months $(1$ - never; 2 - now and then; 3 monthly; 4 - weekly, and 5 - daily). The statements cover both direct and indirect negative acts that represent workplacebullying, without explicitly mentioning the terms "bullying" or "harassment." The NAQ-R was translated into Serbian using the committee technique in three iterations (Brislin et al., 1973). The psychometric analysis of the NAQ-R in the Serbian population (Vukelić et al., 2015) showed exceptional internal consistency (Cronbach's alpha of 0.96 ), as well as satisfactory criterion validity (Vukelić et al., 2015).

The NAQ-R scores were calculated in two ways - as a raw sum of scores on 22 items, and as a sum of dichotomized scores (Notelaers and Einarsen, 2013). The mean of the raw sum scores was 33.67 , with a standard deviation of 13.85 , and median was at 30.00. Dichotomized scores were determined in line with previous research that counted as bullying at least weekly exposure to negative acts (Leymann, 1996; Notelaers and Einarsen, 2013). The frequency of ratings of negative acts "never," "now and then," and "monthly" (ratings 1, 2, and 3) were coded as 0 , and "weekly" and "daily" (ratings 4 and 5) were coded as 1 . Thus, the mean of sum of the NAQ-R dichotomized scores was 0.99 with a standard deviation of 2.94 , and median of 0.00 .

We also used the so-called "self-labeling approach," which is a single item measure of overall victimization from workplace bullying (Einarsen et al., 2009). As a reference, respondents were first presented with the definition of workplace bullying. They rated whether and how much they had been bullied in the past 6 months on the six-point rating scale (No; Yes, very rarely; Yes, now and then; Yes, several times a month; Yes, several times a week, and Yes, almost daily). The mean was 1.49 with a standard deviation of 1.00 .

Intention to leave was assessed by the frequency of considering quitting the present job in the past 6 months. It was estimated by one-item on a five-point scale $(1$ - never, 2 - rarely, 3 - from time to time, 4 - often, 5 - very often). The mean was 1.55 with the standard deviation of 1.03. Health status was also estimated by one item on a five-point scale (1 - very bad, 2 - bad, 3 neither good nor bad, 4 - good, very good -5$)$. The mean was 3.62 with standard deviation of 0.84 . The ratings for health status were reverse scored for calculating gold standards so that higher score means worse health status.

General satisfaction with life was measured by Diener's Satisfaction with Life Scale (SWLS, Diener et al., 1985). The scale has five items followed by a seven-point Likert-type scale. Previous research (Vukelić et al., 2015) has shown that the Serbian translation of The Satisfaction with Life Scale had high internal consistency, with Cronbach's alpha of 0.91 . The mean was 17.93 with standard deviation of 7.01. Scores on the SWLS could be interpreted in terms of six categories of life satisfaction: highly satisfied (scores 30-35), high score (scores 25-29), average scores (scores 20-24), slightly below average (15-19), dissatisfied (10-14) and extremely dissatisfied (scores 59) (Pavot and Diener, 1993). According to Pavot and Diener's (1993) classification, the satisfaction with life average score falls in the category "slightly below the average."

\section{Operationalizing the "Gold" Standards}

Staying in line with the research of Notelaers and Einarsen (2013), for each of the four defined gold standards we performed ROC analyses for higher and lower values of defined variables for both dichotomized and raw scores.

The standards and their lower and higher levels were operationalized as:

(1) Self-labeling and health status

(a) Lower - Self-labeling as being bullied at least "now and then" and estimating health status as at least "neither good nor bad."

(b) Higher - Self-labeling as being bullied at least "several times a week" and estimating health status at least "bad."

(2) Self-labeling and satisfaction with life

(a) Lower - Self-labeling as being bullied at least "now and then" and having the satisfaction with life scores that could be classified as "slightly below the average" and less satisfied (i.e., categories: slightly below average, dissatisfied and extremely dissatisfied).

(b) Higher - Self-labeling as being bullied at least "several times a week" and having the satisfaction with life scores that could be classified as "dissatisfied" and "extremely dissatisfied." 
(3) Self-labeling and intention to leave

(a) Lower - Self-labeling as being bullied at least "now and then" and declaring thinking of intention to leave from time to time and more frequently.

(b) Higher - Self-labeling as being bullied at least "several times a week" and declaring intention to leave at least "often."

(4) Self-labeling, self-perceived health, satisfaction with life and potential intention to leave

(a) Lower - Self-labeling as being bullied at least "now and then," estimating health status "neither good nor bad" or worse, having the satisfaction with life scores that could be classified as "slightly below average" or lower, and declaring intention to leave from time to time.

(b) Higher - Self-labeling as being bullied at least "several times a week," estimating health status as at least "bad," having the satisfaction with life scores that could be classified as "dissatisfied" or lower, and declaring intention to leave at least "often."

In order to perform ROC analyses, first we dichotomized the combination of listed standards that were used as ROC outcome variables so that ' 0 ' meant "not at-risk" in respect of the above defined values for each gold standard, and '1' meant "at-risk."

\section{RESULTS}

In order to test the proposed models of gold standard and determine the cut points that differentiate employees in the preliminary stage of workplace bullying and those that are victims of severe bullying, we performed altogether sixteen ROC analyses. The golden standards and cut-off scores were evaluated and selected by considering two main indicators: AUC (Table 1) and the values of sensitivity and specificity and their sum (Tables 2-5).

As can be seen from Table 1, the area under the curve (AUC) values are close to 1 , which indicates satisfying differentiation, for both raw and dichotomized NAQ-R scores, as well as for lower and higher threshold approaches. The AUCs were altogether higher for raw sum NAQ-R scores than for dichotomized sum NAQ-R scores indicating the higher accuracy of raw scores, especially for the lower threshold. These findings are in accordance with results from Notelaers and Einarsen's (2013) study. Also, there was a tendency for the AUCs to be higher for higher thresholds, meaning that higher thresholds produced more accurate classifications.

For the lower threshold, the raw sum score approach produced scores between 34 and 40 (Table 2) and the dichotomized score approach produced one-act score (Table 3). Based on values of sensitivity, the sum of raw scores approach is more acceptable than the sum of dichotomized scores. On the other hand, specificity values are higher for the sum of dichotomized scores. It means that raw scores identify more accurately true positive cases, while dichotomized scores identify more accurately true negative cases.

Among the tested models of the gold standard, for the lower threshold, the combination of self-labeling (at least now and then) and intention to leave (at least from time to time) produced the highest sum of sensitivity and specificity both for the raw and dichotomized scores approaches (Tables 2 and 3 ). The raw score of 34 produced $0 \%$ false negatives and $30.6 \%$ false positives for self-labeling and intention to leave as a composite criterion. One negative act on a weekly basis produces $28.8 \%$ false negatives and $11.1 \%$ false positives for the same criterion.

Concerning the indicators based on the personal perspective that integrate self-perceived health ("neither good nor bad" or worse) or satisfaction with life ("slightly below average" or lower) with self-labeling, the results have shown that the sum of dichotomized scores gives unsatisfying sensitivity. Regarding the sum of raw scores, satisfaction with life combined with selflabeling gives more true positives, while self-labeling combined with self-perceived health gives slightly more true negatives.

For the higher threshold, the raw sum score approach produced scores between 50 and 81 and the dichotomized score approach produced between five and 12 acts score (Tables 4 and 5). It is interesting that based on values of sensitivity; both raw and dichotomized scores produced equal proportions of true positives.

As for the specificity, there is no clear difference between the raw sum and dichotomized approaches. Both in case of raw and dichotomized scores approaches, the gold standard that produced the most accurate classifications was the most complex one, a combination of self-labeling (at least "several times a week"), satisfaction with life ("dissatisfied" and "extremely dissatisfied"), self-perceived health (health status as "bad" or worse), and intention to leave (at least "often"). Based on this gold standard, the raw sum score of 81 yielded no false negatives and only $1 \%$ false positives. For the same gold standard, the sum of dichotomized scores of 12 negative acts also produced no false negatives and only $1.5 \%$ of false positives.

TABLE 1 | Area under the ROC curve (AUC) scores for tested gold standard models.

\begin{tabular}{|c|c|c|c|c|}
\hline \multirow[b]{2}{*}{ Gold standard } & \multicolumn{2}{|c|}{ AUC Based on sum of raw NAQ-R scores } & \multicolumn{2}{|c|}{ AUC Based on sum of dichotomized scores } \\
\hline & Lower threshold & Higher threshold & Lower threshold & Higher threshold \\
\hline Self-labeling and self-perceived health & 0.900 & 0.962 & 0.799 & 0.944 \\
\hline Self-labeling and satisfaction with life & 0.887 & 0.957 & 0.773 & 0.937 \\
\hline Self-labeling and intention to leave & 0.919 & 0.990 & 0.859 & 0.991 \\
\hline Self-labeling, self-perceived health, satisfaction & 0.917 & 0.996 & 0.848 & 0.995 \\
\hline
\end{tabular}

with life and intention to leave 
TABLE 2 | Lower threshold (sum of raw scores): cut-off scores for tested gold standard models.

\begin{tabular}{|c|c|c|c|c|c|c|}
\hline Gold standards & Score & Sensitivity & Specificity & Sens.+Spec. & PPV \% & NPV \% \\
\hline Self-labeling and self-perceived health & 36 & 0.902 & 0.767 & 1.669 & 28.17 & 98.72 \\
\hline Self-labeling and satisfaction with life & 34 & 0.936 & 0.721 & 1.657 & 30.92 & 98.69 \\
\hline Self-labeling and intention to leave & 34 & 1 & 0.700 & 1.694 & 17.28 & 100 \\
\hline $\begin{array}{l}\text { Self-labeling, self-perceived health, satisfaction } \\
\text { with life and intention to leave }\end{array}$ & 40 & 0.870 & 0.819 & 1.689 & 19.29 & 99.28 \\
\hline
\end{tabular}

Sens., sensitivity; Spec., specificity; PPV, positive predictive value; NPV, negative predictive value.

TABLE 3 | Lower threshold (sum of dichotomized scores): cut-off scores for tested gold standard models.

\begin{tabular}{lcccc}
\hline Gold standards & Score & Sensitivity & Specificity & Sens. + Spec. \\
\hline $\begin{array}{l}\text { Self-labeling and } \\
\text { self-perceived health }\end{array}$ & 1 & 0.580 & 0.894 & 1.474 \\
$\begin{array}{l}\text { Self-labeling and } \\
\text { satisfaction with life }\end{array}$ & 1 & 0.532 & 0.899 & 1.431 \\
$\begin{array}{l}\text { Self-labeling and } \\
\text { intention to leave }\end{array}$ & 1 & 0.712 & 0.889 & 1.601 \\
$\begin{array}{l}\text { Self-labeling, } \\
\text { self-perceived health, } \\
\text { satisfaction with life } \\
\text { and intention to leave }\end{array}$ & 1 & 0.710 & 0.879 & 1.589 \\
\hline
\end{tabular}

Among the tested gold standards composed of a combination of self-labeling (several times a week or more often) and one more criterion, the combination with intention to leave (i.e., thinking of leaving the organization at least "often") gave the most accurate classification, as shown by the highest sum of sensitivity and specificity (Tables 4 and 5). Comparing the gold standards based on personal perspective that combined self-labeling either with self-perceived health or with satisfaction with life, it is visible that the combination of self-labeling and self-perceived health produced a more accurate classification. For the gold standard defined in terms of self-labeling as being bullied at least "several times a week" and estimating health status as "bad" or worse, the NAQ-R raw sum of 50 and five negative acts on a weekly basis produced less false negatives classifications than the gold standard based on self-labeling and satisfaction with life.

Based on the selected gold standards and selected cutoff scores, we have presented the classification of employees in relation to lower threshold, i.e., being or not being in a preliminary stage of workplace bullying (Table 6), as well as in relation to higher threshold, i.e., being or not being a serious victim of workplace bullying (Table 7 ). We can see that based on the lower threshold (Table 6), we have almost two thirds of total employees in the true negative category, but almost onethird in the false positive category. It is evident that the cut-off score of 34 for the lower threshold does not miss the employees in a preliminary stage of WPB (Tables 2 and 6 ).

Based on the selected gold standard for the higher threshold (Table 7), the presented classification is almost impeccable, with only $1.3 \%$ of employees that are wrongly classified as victims. Clearly, the low prevalence of workplace bullying needs to be considered and including positive and negative predictive values (NPV) might be useful as they are dependent on the prevalence rate (Tables 2 and 4). Positive predictive value (PPV) indicates the likelihood that the employee with the specified NAQ-R raw sum score has been suffering from WPB, and the NPV indicates the likelihood that the employee with the specific score has not been suffering from WPB. It is evident that PPVs for both lower and higher threshold are low (Tables 2 and 4). On the other hand, based on NPVs, the selected NAQ-R raw sum scores all give almost $100 \%$ likelihood that the employee has not been suffering from workplace bullying, either in the preliminary or severe stage.

\section{DISCUSSION}

Workplace bullying is mostly addressed in the literature for its personal consequences (Hoel et al., 2011). Causing depression, anxiety, burnout, frustration and physical illness, it affects the overall physical and psychological health and well-being (Nielsen

TABLE 4 | Higher threshold (sum of raw scores): cut-off scores for tested gold standard models.

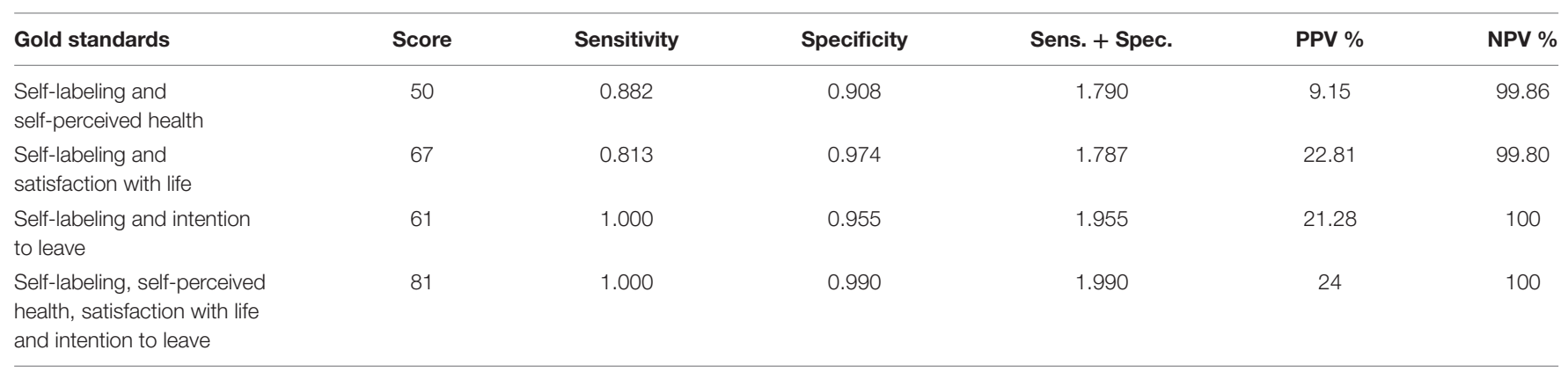

Sens., sensitivity; Spec., specificity; PPV, positive predictive value; NPV, negative predictive value. 
TABLE 5 | Higher threshold (sum of dichotomized scores): cut-off scores for tested gold standard models.

\begin{tabular}{lcccc}
\hline Gold standards & Score & Sensitivity & Specificity & Sens. + Spec. \\
\hline $\begin{array}{l}\text { Self-labeling and } \\
\text { self-perceived health }\end{array}$ & 5 & 0.882 & 0.943 & 1.826 \\
$\begin{array}{l}\text { Self-labeling and } \\
\text { satisfaction with life }\end{array}$ & 7 & 0.813 & 0.962 & 1.775 \\
$\begin{array}{l}\text { Self-labeling and } \\
\text { intention to leave }\end{array}$ & 7 & 1.000 & 0.966 & 1.966 \\
$\begin{array}{l}\text { Self-labeling, } \\
\text { self-perceived health, } \\
\text { satisfaction with life } \\
\text { and intention to leave }\end{array}$ & 12 & 1.000 & 0.985 & 1.985 \\
\hline
\end{tabular}

TABLE 6 | Classification of employees based on the lower threshold for the self-labeling and intention to leave gold standard.

\begin{tabular}{lcc}
\hline Gold standard & $\begin{array}{c}\text { NAQ-R Raw } \\
\text { sum <33 }\end{array}$ & $\begin{array}{c}\text { NAQ-R Raw } \\
\text { sum 34 > }\end{array}$ \\
\hline $\begin{array}{l}\text { Self-labeling as being bullied at least } \\
\text { "now and then" (ratings 3-6) and }\end{array}$ & $0.0 \%$ & $6.6 \%$ \\
$\begin{array}{l}\text { declaring thinking of intention to leave } \\
\text { at least from time to time (ratings 3-5) }\end{array}$ & \\
$\begin{array}{l}\text { Self-labeling as being bullied up to "very } \\
\text { rarely" (ratings 1-2, reversed) and } \\
\text { declaring thinking of intention to leave } \\
\text { rarely or never (ratings 1-2) }\end{array}$ & $61.6 \%$ & $31.8 \%$ \\
\hline
\end{tabular}

TABLE 7 | Classification of employees based on the higher threshold for the composite gold standard.

\begin{tabular}{|c|c|c|}
\hline Gold standard & $\begin{array}{c}\text { NAQ-R Raw } \\
\text { sum }<80\end{array}$ & $\begin{array}{c}\text { NAQ-R Raw } \\
\text { sum } 81>\end{array}$ \\
\hline $\begin{array}{l}\text { Self-labeling as being bullied at least several } \\
\text { times a week (ratings } 5-6 \text { ), estimating } \\
\text { health status as bad or very bad (ratings } \\
1-2 \text { ), having the satisfaction with life scores } \\
\text { that could be classified as dissatisfied and } \\
\text { extremely dissatisfied, and thinking of } \\
\text { intention to leave at least often (ratings } 4-5 \text { ) }\end{array}$ & $0.0 \%$ & $0.4 \%$ \\
\hline $\begin{array}{l}\text { Self-labeling as being bullied from no to } \\
\text { several times a month (ratings } 1-4 \text { ), } \\
\text { estimating health status as neither good nor } \\
\text { bad or better (ratings } 3-5) \text {, having the } \\
\text { satisfaction with life scores that could be } \\
\text { classified from slightly below average to } \\
\text { highly satisfied, and thinking of intention to } \\
\text { leave up to from time to time (ratings } 1-3 \text { ) }\end{array}$ & $98.3 \%$ & $1.3 \%$ \\
\hline
\end{tabular}

et al., 2014). Additionally, it affects organizations in many ways by hampering organizational climate, job satisfaction, work engagement, organizational commitment, organizational and employee well-being, as well as productivity and a number of other aspects of organizational functioning (McCormack et al., 2006; Lutgen-Sandvik et al., 2007; Hoel et al., 2011; Nielsen et al., 2014; Giorgi et al., 2016a; Trépanier et al., 2016). Thus, both from the employee and organizational perspectives, it is vital to detect both the extent of workplace bullying in an organization and the employees that are differently affected by workplace bullying.
From the organizational standpoint, the identification of a category of employees in the preliminary stage of being bullied is very important as the organization could make some changes that could prevent further bulling and subsequent negative feelings. Furthermore, this is an opportunity for the organization to influence the voluntary turnover. The most appropriate gold standard for the lower threshold is the combination of selflabeling and intention to leave (Table 1). The NAQ-R score of 34 and higher is the first sign that employees are in the preliminary stage of being bullied. It points to the employees' overall feeling of being bullied occasionally and considering quitting an organization at least from time to time. Based on the dichotomized scores, the cut value for the lower threshold is the same for all the tested gold standards (one negative act).

For the higher threshold, different gold standards produce more diverse cut scores than for the lower threshold, both for the raw sum and dichotomized sum approaches. The most complex gold standard that entails self-labeling, self-perceived health, satisfaction with life and intention to leave gives the most accurate classifications and the highest cut values for both approaches (Table 1). Considering the gold standards that have self-labeling in combination with one more criterion, the NAQ-R sum cut scores are in the range 50-67, while the most complex and composite gold standard gives the highest cut-off value of 81 .

Though it is logical to expect that the more criteria the researcher includes, the higher cut value is to be expected, the question is how complex a gold standard should be for the higher threshold. In the composing and subsequent choosing of the gold standard, it is of utmost importance to consider the wider social, economic and cultural context. Keeping in mind that workplace bullying is a complex phenomenon that provokes varied psychological and behavioral responses, it is reasonable to use more criteria to identify victims in a severe stage. Based on small differences in the AUC, sensitivity and specificity values, it could be called into question whether the most complex gold standard gives an adequate return in identifying different categories of employees. We believe that for the higher threshold it is better to apply a more complex gold standard. It gives finer grounds and precision for identifying employees that respond to workplace-bullying in different ways. For the selected most complex gold standard, the higher threshold suggests that the organization should examine all the relevant aspects of the situation at the microscopic level and identify employees that are involved in the situation as well as the particular negative acts.

Considering the classifications of employees based on the lower and higher thresholds, it is evident that the higher threshold for the selected most accurate and at the same time most composite criterion produces the largest proportion of correct classifications with only $1.3 \%$ of false positives. The lower threshold also produces $0 \%$ of false negative classifications, but it classifies more employees as false positives (31.8\%). At the same time, PPVs for the higher threshold indicate that only between 9 and $24 \%$ of the time an employee can be accurately classified as being the victim of workplace bullying, whereas there is a 91-76\% chance for making a false positive identification. For the lower threshold, PPV indicate that only between 17 and $31 \%$ of the time someone identified as being bullied based on a 
specified NAQ-R score is actually being bullied (the other 83$69 \%$ are false positives). Contrary to PPV, the NPVs paint a more precise picture indicating neither of explored thresholds would inappropriately identify someone as being bullied. Taking all together, it should be noted that at the organizational level the lower threshold suggests wider preventive interventions that could not hurt anyone. On the other hand, in-depth exploring the bullying knot and searching for the victims under the microscope could be threatening both for those falsely classified and those affected by false classifications.

Low prevalence rate of workplace bullying makes limited use of identified cut-offs as a predictive tool to identify preliminary and severe workplace bullying victims. Low prevalence rate makes it very hard to positively detect victims of workplace bullying based on any measure (whereas ruling them out is quite precise based on all tested measures). Indeed, low prevalence of workplace bullying was found in a majority of countries where NAQ was used (Zapf et al., 2011; Petrović et al., 2014). However, it should be noted that the aim of using the chosen cut-off scores was not to identify specific victims, but rather to assess the situation in the organization. Thinking in that direction, the proposed cut-off scores can be useful.

Comparing the NAQ-R raw sum and dichotomized sum approaches, our results have indicated that applying raw sum scores in determining cut-off points is superior. It stresses the nature of workplace bullying as not being an either-or phenomenon. The raw sum score approach produces more accurate classifications. As for the lower threshold, the raw sum identifies more accurately the cases that are truly in a preliminary stage of workplace bullying, whereas the dichotomized sum identifies more accurately the cases that are truly not in a preliminary stage of bullying. On the other hand, when it comes to the higher threshold, both raw and dichotomized sums produced equal proportions of true positive classifications. The dichotomized approach may be too rough in identifying employees in a preliminary stage of workplace bullying but more appropriate for identifying severe victims of workplace bullying. Both for the raw and dichotomized sums, the gold standards that rely solely on the personal perspective (self-labeling with selfperceived health and self-labeling with satisfaction with life) gave less accurate classifications, whereas gold standards that included both personally and organizationally relevant perspectives gave more accurate classifications.

Concerning the findings from Serbia and Norway (Notelaers and Einarsen, 2013), the proposed cut-off NAQ-R scores proved to be higher for employees in Serbia. Whereas, based on dichotomized scores, one negative act differentiates Norwegian employees affected with workplace bullying both for the lower and higher thresholds, for the employees in Serbia the cut score for the higher threshold is much higher (from 5 to 12, based on the applied gold standard) than the cut score for the lower threshold. The gold standard tested in this research that is closest to the gold standard applied in Notelaers and Einarsen's research, i.e., the combination of self-labeling and self-perceived health, still points to five negative acts as a cut-off score. Comparing raw sum data from Serbia and Norway, cut-off scores for the lower thresholds are very close (34 vs. 33$)$, whereas there is a large difference between the cut-off scores for the higher threshold (81 vs. 45 ). As assessed applying self-labeling and self-perceived health as a gold standard, to affect health it takes more negative acts on a more frequent basis for employees in Serbia than for those in Norway. Of course, comparing the data from Serbia and Norway, we should keep in mind that the applied gold standards were of a different nature, even the closest one that was related to health. What is more important, we should keep in mind that exposure to workplace bullying is more prominent in Serbia than in the Norwegian context (Vukelić et al., 2015). Even though the comparison is not justifiable, it inspires some possible explanations about higher upper threshold scores in Serbia. Since Serbia is highly collectivistic culture, it is possible that colleagues at work could act as a protective social shield from negative acts and thus, more negative acts are needed to provoke more severe consequences. The other possible explanation is tolerance of workplace bulling (Power et al., 2013; Giorgi et al., 2015b). Namely, in some cultures the workplace bullying could be more tolerated than in others. Also, higher upper threshold could be explained by the lower salience of negative acts in comparison with more salient work-related events or events from employees' personal life. Serbian context is strongly defined by a long lasting economic and social crisis that could easily make existence issues more salient (worrying about satisfying basic needs, etc.) than hardships at work. Deep crisis makes employees more aware and vulnerable to existential stressors putting workplace bullying in the less salient position on the ladder of life stressors.

To sum up, it is once again important to emphasize that this research contributed to Notelaers and Einarsen's (2013) standpoint of the usefulness of the ROC analysis in defining the cut-off points for the NAQ-R. Unlike other approaches (e.g., LCC, operational criterion), the ROC analysis gives more precise thresholds for separating the victims from non-victims and those in the preliminary stage of being bullied from those that are not. In future developing and investigating of different gold standards it would be useful to find one that could enable a direct comparison of the NAQ-R cut-off points in different cultural settings.

\section{Strengths and Limitations}

In this research, we have answered Notelaers and Einarsen's (2013) call to explore the ROC in determining the NAQ-R cut-off scores for separating employees in different stages of workplace bullying in a specific socio-economic and cultural context. Presented analyses, notably PPVs and NPVs, clearly indicate that the thresholds found in the current study may not predict victims in different stages of workplace bullying as accurately as one would hope. The presented findings support the need for further research efforts in exploring workplace bullying gold standard.

The findings have also contributed the evidence about the NAQ-R capacity for application in different cultural settings. Additionally, it has been confirmed that it is possible to broaden the NAQ-R application for precisely categorizing employees based on responding to workplace bullying. In this study, we went a step further in testing Notelaers and Einarsen's (2013) idea by proposing the testing of several gold standard models. In defining 
the gold standards, we introduced intention to leave as an organizationally relevant criterion since leaving the organization could be one of the most severe consequences of workplace bullying. We have also tried to approach employees' health from a broader well-being perspective by integrating self-perceived health status and satisfaction with life.

The analysis was performed on a large, well-explored database that was previously used for analyzing psychometric properties of the NAQ-R (Vukelić et al., 2015). The fact that we could not generalize the findings to the Serbian working population, as the sample was not recruited as a representative, could be listed as a potential limitation. However, based on the sampling frame and sample size we expect that it enabled reliable testing of different criteria in determining NAQ-R cut-off scores. Certainly, future longitudinal study could help in unfolding some of the questions posed by this research.

It should be noted that our aim was not to test exactly the same gold standard as Notelaers and Einarsen (2013). For direct comparison purposes, it could be regarded as a limitation of this research. The health status was operationalized as a one-item measure of self-perceived health since some objective measure of employees' health was not available. Future research could include different indicators of employees' health.

As for intention to leave as a criterion, it could be observed that different operationalizations are available. In our study, the measure was the frequency of thinking of leaving the organization, whereas in some studies it was the measure of the strength of intention (Carsten and Spector, 1987). In future workplace bullying research, intention to leave could be operationalized both by the frequency of thinking of leaving the organization and by the strength of intention. It is also possible that using different methods, i.e., including objectively measured organizational outcomes (such as actual turnover, employees' absence from work and productivity loss data) could be useful in objectively specifying the gold standard and further strengthening the organizational perspective in determining NAQ-R cut-off scores. Triangulation could enable determining more robust cut-off scores and also point which of the applied subjective criteria better fitted with the objective indicators of workplace bullying.

Last, but not the least, the nature of explored gold standards can be regarded as a limitation of the study. For the chosen outcome variables (e.g., well-being, intention to leave) we do not have the data that show that these variables are undoubtedly the outcomes of workplace bullying. Even though the indicators of well-being and intention to leave are sensitive to exposure to workplace bullying (e.g., Glambek et al., 2014; Giorgi et al., 2016a), they could also be the indicators of many other processes that happen in organizations. Thus, mix-method and longitudinal studies could help in clearing these questions.

\section{Implications for Practice and Future Research}

Both practitioners and researchers agree on the importance of developing the so-called workplace bullying zero-tolerance organizational climate (Vartia and Tehrani, 2012). Still, before organizations manage to attain this goal, they should successfully deal with workplace bullying on a day-to-day basis. For the purpose of preventing workplace bullying and/or dealing with its consequences it would be beneficial to come up with a cutoff score that would help in detecting not only employees that are under the risk of suffering from workplace bullying (as identified by the lower threshold), but also those that have been severely affected by workplace bullying (as identified by the higher threshold).

Based on our findings we propose organizational interventions at two levels. Departing from the lower threshold, it is advisable to strengthen and introduce more prominent and effective prevention measures. Keeping in mind the severe consequences detected at and above the higher threshold, both from the individual and organizational perspectives, we suggest developing red-alarm, in-depth exploration of the situation and all the involved parties. In published research, the NAQ-R is mostly applied anonymously. The advantages of anonymous organizational surveys are widely accepted. Undoubtedly, in the context of workplace bullying research, anonymity can be regarded as essential both for research participation rate and for employees' openness and sincerity in answering the survey. However, it is questionable what to do with the survey results if we apply the higher cut-off score and identify severe but anonymous victims of workplace bullying.

The NAQ-R is a widely used workplace bullying instrument with good psychometric characteristics yielded in different cultural settings. It gives solid grounds for comparing countries concerning the rate and different types of workplace bullying acts. Nevertheless, for further cross-cultural exploration it could be useful to check employees' understanding of rating scale as it is time anchored. As it is known, different cultures have different perception of a time (e.g., Graham, 1981; Wearden, 2016). It is possible that employees from different cultures differently perceive the same frequency of negative acts. To further strengthen golden standards, it would be useful to explore the connections of exposure to negative acts with specific consequences. The researchers should explore whether the health indicators, attitudes and feelings that constitute different golden standards are the consequence of workplace bullying or something else.

At the organizational level NAQ-R can give data about employees' exposure to specific negative acts and overall intensity of workplace bullying. One of the possible directions for further developing of the NAQ-R could be establishing the proper criterion for identifying victims on a personal level. Yielded results suggest exploring the NAQ-R application as a diagnostic instrument with known participants.

\section{CONCLUSION}

In this research we wanted to test different gold standards in determining the NAQ-R cut-off scores in Serbia. Workplace bullying as a complex work phenomenon provokes complex experiences and reactions. Exploration of presented different gold standards clearly highlights how difficult it is to identify 
and detect workplace bullying. The complexity of trying to truly detect and predict possible workplace bullying victims, in the preliminary and especially in the severe stages of bullying, highlights the importance of the current study as well as the importance of continued efforts in this area of research and practice. Seemingly unsatisfactory, the low PPVs call for further efforts in searching for better ways of identifying workplace bullying.

In order to fully grasp the nature of workplace bullying, it is valuable to define and test more gold standards, both from the theoretical and practical standpoints. Our findings confirm that, in addition to Notelaers and Einarsen's (2013) gold standard based on two criteria - perceived victimization and psychological health, it is reasonable to include more gold standards composed of more criteria and criteria of a different nature. Moreover, the results have confirmed that it was justifiable to compose complex gold standards based on personally and organizationally relevant criteria at the same time. In addition to self-labeling, personal well-being indicators (self-perceived health and satisfaction with life) and intention to leave proved to be important criteria for defining the gold standard.

The cut-off scores determined for employees in Serbia, based on explored gold standards, show that employees in Serbia get into the preliminary stage of feeling bullied based on an almost identical exposure to negative acts at work as employees in Norway, but to feel seriously victimized they need to be much more exposed to negative acts.

The research has presented the application of the ROC analysis in identifying the NAQ-R cut-off scores in Serbia, a specific social, economic and cultural context. The data have confirmed Notelaers and Einarsen's (2013) proposed approach for exploring the cut-off scores for the NAQ-R, both for the raw sum approach and dichotomized approach, by using

\section{REFERENCES}

Agervold, M. (2007). Bullying at work: a discussion of definitions and prevalence, based on an empirical study. Scand. J. Psychol. 48, 161-172. doi: 10.1111/j.14679450.2007.00585.x

Arenas, A., Giorgi, G., Montani, F., Mancuso, S., Perez, J. F., Mucci, N., et al. (2015). Workplace bullying in a sample of Italian and Spanish employees and its relationship with job satisfaction, and psychological well-being. Front. Psychol. 6:1912. doi: 10.3389/fpsyg.2015. 01912

Ayoko, O. B., Callan, V. J., and Härtel, C. E. (2003). Workplace conflict, bullying, and counterproductive behaviors. Int. J. Organ. Anal. 11, 283-301. doi: 10.1108/ eb028976

Baillien, E., and De Witte, H. (2009). Why is organizational change related to workplace bullying? Role conflict and job insecurity as mediators. Econ. Ind. Democracy 30, 348-371. doi: 10.1177/0143831x093 36557

Berthelsen, M., Skogstad, A., Lau, B., and Einarsen, S. (2011). Do they stay or do they go? A longitudinal study of intentions to leave and exclusion from working life among targets of workplace bullying. Int. J. Manpow. 32, 178-193. doi: 10.1108/01437721111130198

Bowling, N. A., and Beehr, T. A. (2006). Workplace harassment from the victim's perspective: a theoretical model and meta-analysis. J. Appl. Psychol. 91, 9981012. doi: 10.1037/0021-9010.91.5.998

Brislin, R. W., Lonner, W. J., and Thorndike, R. M. (1973). Cross-Cultural Research Methods. New York, NY: Wiley. the ROC analysis. The results speak in favor of applying the NAQ-R raw sum score approach as superior to the dichotomized sum score approach. As for exploring the lower and higher threshold, our data have confirmed Notelaers and Einarsen's (2013) reasoning and applications in identifying probable victims in a preliminary stage of workplace bullying as well as severe victims. Presented results strongly point out the difficulties in correctly identifying victims and precision in identifying non-victims of workplace bullying. In closing, this research highlights the need for further exploration of workplace bullying phenomenon in general and gold standard in particular.

\section{AUTHOR CONTRIBUTIONS}

All three authors, IP, MV, and SČ contributed equally to the research design and writing of this paper. MV conducted the analyses. IP, MV, and SČ are equally accountable for the content of the paper.

\section{FUNDING}

Research was carried out with the support of the Ministry of Education, Science and Technological Development of the Republic of Serbia.

\section{ACKNOWLEDGMENT}

The authors thank Mara Đordević and Gradimir Ivanić for their support in field research.

Carsten, J. M., and Spector, P. E. (1987). Unemployment, job satisfaction, and employee turnover: a meta-analytic test of the Muchinsky model. J. Appl. Psychol. 72, 374-381. doi: 10.1037/0021-9010.72.3.374

Čizmić, S., Petrović, I. B., and Cvetičanin, S. (2004). Angažovanje u traženju novog posla bankarskih službenika koji su stečajem banaka ostali bez posla [Bank clerks that lost jobs at liquidated banks: engagement in searching for a new job]. in Paper Presented at Sabor Psihologa Srbije. Book of Abstracts, (Belgrade: Serbian Psychological Society), 58.

Dalton, D. R., Johnson, J. L., and Daily, C. M. (1999). On the use of "intent to." variables in organizational research: an empirical and cautionary assessment. Hum. Relat. 52, 1337-1350. doi: 10.1177/001872679905201006

Di Marco, D., López-Cabrera, R., Arenas, A., Giorgi, G., Arcangeli, G., and Mucci, N. (2016). Approaching the discriminatory work environment as stressor: the protective role of job satisfaction on health. Front. Psychol. 7:1313. doi: $10.3389 /$ fpsyg.2016.01313

Diener, E., Emmons, R. A., Larsen, R. J., and Griffin, S. (1985). The satisfaction with life scale. J. Pers. Assess. 49, 71-75. doi: 10.1207/s15327752jpa4901_13

Djurkovic, N., McCormack, D., and Casimir, G. (2008). Workplace bullying and intention to leave: the moderating effect of perceived organisational support. Hum. Resour. Manage. J. 18, 405-422. doi: 10.1111/j.1748-8583.2008. 00081.x

Einarsen, S. (2000). Harassment and bullying at work: a review of the scandinavian approach. Aggress. Violent Behav. 5, 379-401. doi: 10.1016/S1359-1789(98) 00043-3

Einarsen, S., Hoel, H., and Notelaers, G. (2009). Measuring exposure to bullying and harassment at work: validity, factor structure and psychometric properties 
of the negative acts questionnaire-revised. Work. Stress 23, 24-44. doi: 10.1080/ 02678370902815673

Erdogan, B., Bauer, T. N., Truxillo, D. M., and Mansfield, L. R. (2012). Whistle while you work a review of the life satisfaction literature. J. Manage. 38, 1038-1083. doi: 10.1177/0149206311429379

Eurostat (ND). National Accounts and GDP. Luxembourg: Eurostat.

Gallup (2010). Gallup Global Wellbeing: The Behavioral Economics of GDP Growth. Washington, DC: Gallup.

Giga, S. I., Hoel, H., and Lewis, D. (2008). The Costs of Workplace Bullying. Manchester: University of Manchester Institute of Science and Technology.

Giorgi, G. (2010). Workplace bullying partially mediates the climate-health relationship. J. Manag. Psychol. 25, 727-740. doi: 10.1108/02683941011075274

Giorgi, G., Ando, M., Arenas, A., Shoss, M. K., and Leon-Perez, J. M. (2013). Exploring personal and organizational determinants of workplace bullying and its prevalence in a Japanese sample. Psychol. Violence 3, 185-197. doi: 10.1037/ a0028049

Giorgi, G., Arcangeli, G., Mucci, N., and Cupelli, V. (2015a). Economic stress in workplace: the impact of fear the crisis on mental health. Work. 51, 135-142. doi: 10.3233/WOR-141844

Giorgi, G., Leon-Perez, J. M., and Arenas, A. (2015b). Are bullying behaviors tolerated in some cultures? Evidence for a curvilinear relationship between workplace bullying and job satisfaction among Italian workers. J. Bus. Ethics 131, 227-237. doi: 10.1007/s10551-014-2266-9

Giorgi, G., Mancuso, S., Fiz Perez, F., Castiello, D., Antonio, A., Mucci, N., et al. (2016a). Bullying among nurses and its relationship with burnout and organizational climate. Int. J. Nurs. Pract. 22, 160-168. doi: 10.1111/ijn.12376

Giorgi, G., Perminienë, M., Montani, F., Fiz-Perez, F. J., Mucci, N., and Arcangeli, G. (2016b). Detrimental effects of workplace bullying: impediment of self-management competence via psychological distress. Front. Psychol. 7:60. doi: 10.3389/fpsyg.2016.00060

Glambek, M., Matthiesen, S. B., Hetland, J., and Einarsen, S. (2014). Workplace bullying as an antecedent to job insecurity and intention to leave: a 6-month prospective study. Hum. Resour. Manage. J. 24, 255-268. doi: 10.1111/17488583.12035

Graham, R. J. (1981). The role of perception of time in consumer research. J. Cons. Res. 7, 335-342. doi: 10.1086/208823

Hajian-Tilaki, K. (2013). Receiver operating characteristic (ROC) curve analysis for medical diagnostic test evaluation. Caspian. J. Intern. Med. 4, 627-635. doi: 10.1016/j.ebobgyn.2006.01.016

Hoel, H., Sheehan, M. J., Cooper, C. L., and Einarsen, S. (2011). "Organisational effects of workplace bullying," in Bullying and Harassment in the Workplace: Developments in Theory, Research, and Practice, 2nd Edn, eds S. Einarsen, H. Hoel, D. Zapf, and C. L. Cooper (Boca Raton, FL: CRC Press), 129-148.

Hoel, H., Sparks, K., and Cooper, C. L. (2001). The cost of Violence/Stress at Work and the Benefits of a Violence/Stress-Free Working Environment. Geneva: International Labour Organization.

Hofstede, G. (2001). Culture's Consequences: Comparing Values, Behaviors, Institutions, and Organizations across Nations, 2nd Edn. Thousand Oaks, CA: Sage.

Jiménez, B. M., Muñoz, A. R., Gamarra, M. M., and Herrer, M. G. (2007). Assessing workplace bullying. Span. J. Psychol. 10, 449-457. doi: 10.1017/ S1138741600006715

Leymann, H. (1990). Mobbing and psychological terror at workplaces. Violence Vict. 5, 119-126.

Leymann, H. (1996). The content and development of mobbing at work. Eur. J. Work Organ. Psychol. 5, 165-184. doi: 10.1080/13594329608414853

Leymann, H., and Gustafsson, A. (1996). Mobbing at work and the development of post-traumatic stress disorders. Eur. J. Work. Organ. Psychol. 5, 251-275. doi: 10.1080/13594329608414858

Lutgen-Sandvik, P., Tracy, S. J., and Alberts, J. K. (2007). Burned by bullying in the American workplace: Prevalence, perception, degree and impact. J. Manage. Stud. 44, 837-862. doi: 10.1111/j.1467-6486.2007.00715.x

Matthiesen, S. B., and Einarsen, S. (2004). Psychiatric distress and symptoms of PTSD among victims of bullying at work. Br. J. Guid. Counc. 32, 335-356. doi: 10.1007/s00420-008-0370-9

McCormack, D., Casimir, G., Djurkovic, N., and Yang, L. (2006). The concurrent effects of workplace bullying, satisfaction with supervisor, and satisfaction with coworkers on affective commitment among schoolteachers in China. Int. J. Confl. Manage. 17, 316-331. doi: 10.1108/10444060610749473

Mikkelsen, E. G., and Einarsen, S. (2001). Bullying in Danish work-life: prevalence and health correlates. Eur. J. Work. Organ. Psychol. 10, 393-413. doi: 10.1080/ 13594320143000816

Mikkelsen, E. G., and Einarsen, S. (2002). Basic assumptions and symptoms of post-traumatic stress among victims of bullying at work. Eur. J. Work. Organ. Psychol. 11, 87-111. doi: 10.1080/13594320143000861

Mucci, N., Giorgi, G., Roncaioli, M., Fiz Perez, J., and Arcangeli, G. (2016). The correlation between stress and economic crisis: a systematic review. Neuropsychiatr. Dis. Treat. 12, 983-993. doi: 10.2147/NDT.S98525

Nielsen, M. B., Magerøy, N., Gjerstad, J., and Einarsen, S. (2014). Workplace bullying and subsequent health problems. Tidsskr. Nor. Laegeforen. 134, 12331238. doi: 10.4045/tidsskr.13.0880

Nielsen, M. B., Notelaers, G., and Einarsen, S. (2011). "Measuring exposure to workplace bullying," in Bullying and Harassment in the Workplace: Developments in Theory, Research, and Practice, 2nd Edn, eds S. Einarsen, H. Hoel, D. Zapf, and C. L. Cooper (Boca Raton, FL: CRC Press), 149-174.

Notelaers, G., and Einarsen, S. (2013). The world turns at 33 and 45: defining simple cutoff scores for the negative acts questionnaire-revised in a representative sample. Eur. J. Work. Organ. Psychol. 22, 670-682. doi: 10.1080/1359432X.2012. 690558

Notelaers, G., Einarsen, S., De Witte, H., and Vermunt, J. K. (2006). Measuring exposure to bullying at work: the validity and advantages of the latent class cluster approach. Work. Stress 20, 289-302. doi: 10.1080/02678370601071594

Obuchowski, N. A. (2003). Receiver operating characteristic curves and their use in radiology. Radiology 229, 3-8. doi: 10.1148/radiol.2291010898

Öcel, H., and Aydin, O. (2012). Workplace bullying and turnover intention: the moderating role of belief in a just world. Int. J. Bus. Soc. Sci. 3, 248-258.

Pavot, W., and Diener, E. (1993). Review of the satisfaction with life scale. Psychol. Assess. 5, 164-172. doi: 10.1037/1040-3590.5.2.164

Petrović, I. B., Čizmić, S., and Vukelić, M. (2014). Workplace bullying in Serbia: the relation of self-labeling and behavioral experience with job-related behaviors. Psihologija 47, 185-199. doi: 10.2298/PSI1402185P

Power, J. L., Brotheridge, C. M., Blenkinsopp, J., Bowes-Sperry, L., Bozionelos, N., Buzády, Z., et al. (2013). Acceptability of workplace bullying: a comparative study on six continents. J. Bus. Res. 66, 374-380. doi: 10.1016/j.jbusres.2011. 08.018

Seo, Y. N., Leather, P., and Coyne, I. (2012). South Korean culture and history: the implications for workplace bullying. Aggress. Violent. Beh. 17, 419-422. doi: 10.1016/j.avb.2012.05.003

Serbian Psychological Society (2000). Code of Ethics. Available at: http://www. dps.org.rs/images/stories/pdf/DPS/Code\%20of\%20Ethics.pdf?phpMyAdmin= 4700dc1d4e4bcd06a0448c38edf6f98b

Simić, N., Vukelić, M., and Đordević, V. (2013). Self-presentation in "unsuitable" resumes: a case from Serbia. Sociologija. 55, 503-518. doi: 10.2298/ SOC1304503S

Statistical Office of the Republic of Serbia (2012). Labour Force Survey. Belgrade: Statistical Office of the Republic of Serbia.

Streiner, D. L., and Cairney, J. (2007). What's under the ROC? An introduction to Receiver Operating Characteristics curves. Can. J. Psychol. 52, 121-128.

Tambur, M., and Vadi, M. (2009). Bullying at work: research in Estonia using the Negative Acts Questionnaire Revised (NAQ-R). Rev. Int. Comp. Manag. 10, 791-805.

Tambur, M., and Vadi, M. (2012). Workplace bullying and organizational culture in a post-transitional country. Int. J. Manpow. 33, 754-768. doi: 10.1108/ 01437721211268302

Trépanier, S. G., Fernet, C., and Austin, S. (2016). Longitudinal relationships between workplace bullying, basic psychological needs, and employee functioning: a simultaneous investigation of psychological need satisfaction and frustration. Eur. J. Work Organ. Psychol. 25, 1-17. doi: 10.1080/1359432X.2015. 1132200

Tsuno, K., Kawakami, N., Inoue, A., and Abe, K. (2010). Measuring workplace bullying: reliability and validity of the Japanese version of the Negative Acts Questionnaire. J. Occup. Health 52, 216-226. doi: 10.1539/joh.L10036

Vartia, M., and Tehrani, N. (2012). “Addressing bullying in the workplace," in Workplace Bullying: Symptoms and Solutions, ed. N. Tehrani (London: Routledge), 213-229. 
Vukelić, M., Čizmić, S., Petrović, I. B., Tenjović, L., and Giorgi, G. (2015). Psychometric properties of the Serbian version of the Negative acts questionnaire-revised. Psihologija 48, 19-33. doi: 10.2298/PSI1402185P

Wearden, J. (2016). The Psychology of Time Perception. London: Palgrave Macmillan.

Zapf, D., Escartín, J., Einarsen, S., Hoel, H., and Vartia, M. (2011). "Empirical findings on prevalence and risk groups of bullying in the workplace," in Bullying and Harassment in the workplace: Developments in Theory, Research, and Practice, 2nd Edn, eds S. Einarsen, H. Hoel, D. Zapf, and C. L. Cooper (Boca Raton, FL: CRC Press), 75-105.
Conflict of Interest Statement: The authors declare that the research was conducted in the absence of any commercial or financial relationships that could be construed as a potential conflict of interest.

Copyright (c) 2017 Petrović, Vukelić and Čizmić. This is an open-access article distributed under the terms of the Creative Commons Attribution License (CC BY). The use, distribution or reproduction in other forums is permitted, provided the original author(s) or licensor are credited and that the original publication in this journal is cited, in accordance with accepted academic practice. No use, distribution or reproduction is permitted which does not comply with these terms. 


\section{OPEN ACCESS}

Edited by:

Fabrizio Gerli,

Ca' Foscari University of Venice, Italy

Reviewed by:

Babis Mainemelis,

ALBA Graduate Business School,

Greece

Leonidas A. Zampetakis,

Technical University of Crete, Greece

*Correspondence:

Annamaria Di Fabio

adifabio@psico.unifi.it

Specialty section

This article was submitted to

Organizational Psychology,

a section of the journal

Frontiers in Psychology

Received: 13 July 2016 Accepted: 07 November 2016 Published: 25 November 2016

Citation:

Di Fabio A, Bucci O and Gori A (2016) High Entrepreneurship,

Leadership, and Professionalism (HELP): Toward an Integrated, Empirically Based Perspective.

Front. Psychol. 7:1842 doi: 10.3389/fpsyg.2016.01842

\section{High Entrepreneurship, Leadership, and Professionalism (HELP): Toward an Integrated, Empirically Based Perspective}

\author{
Annamaria Di Fabio*, Ornella Bucci and Alessio Gori \\ Department of Education and Psychology (Psychology Section), University of Florence, Florence, Italy
}

This article evaluates the psychometric properties of a new measure for assessing the constructs of entrepreneurship, leadership, and professionalism, from an integrated point of view, the High Entrepreneurship, Leadership and Professionalism Questionnaire (HELP-Q). Exploratory factor analysis indicated a factor structure with three principal dimensions, and confirmatory factor analysis and goodness of fit indices indicated a good fit of the model to the data. All the dimensions showed good values of internal consistency. The results of the study thus indicate that the HELP-Q is a short and easily administered instrument with good psychometric properties that can promote entrepreneurship, leadership, and professionalism in workers as well as in those who are preparing to enter the turbulent 21st century labor market.

Keywords: entrepreneurship, leadership, professionalism, psychometric properties, healthy business, healthy organization

\section{INTRODUCTION}

In today's rapidly changing world of work, a career is more than just a vocation or occupation-it is about creating meaning from an unfolding set of experiences and the lessons of a lifetime (Super, 1957, 1980; Savickas, 2002; Chan et al., 2012). People need specific personality characteristics and talents to achieve their career goals (Di Fabio and Maree, 2012; Di Fabio and Saklofske, 2014a,b; Di Fabio and Kenny, 2015, 2016a,b; Di Fabio, 2016a; Di Fabio et al., 2016b), and three constructs considered crucial in career management are entrepreneurship, leadership, and professionalism (Shane and Venkataraman, 2000; Kuratko, 2005; Chan et al., 2012).

These constructs have been studied separately in the past, and only recently attention has been given to studying them together (Chan et al., 2012; Renko et al., 2012). The major focus has been on the construct entrepreneurial leadership (Renko et al., 2012) while attempts to integrate it with the construct professionalism have only just begun.

This article sets out to review existing research on entrepreneurial leadership and professionalism and to present the key elements of these constructs. After describing the domains of entrepreneurship, leadership, and professionalism, we analyze the construct entrepreneurial leadership and suggest how it too can be integrated with the construct professionalism. We then propose and empirically test a scale to measure entrepreneurship, leadership, and professionalism from an integrated point of view in terms of career construction and conclude with the implications for future research and managerial practice. 


\section{Entrepreneurship}

Entrepreneurial behaviors are becoming increasingly important in a variety of contexts. In organizations, these behaviors foster innovation and adaptation to changing environments (Renko et al., 2015). Entrepreneurial behavior is described as the processes, practices, and decision-making activities that lead to entrepreneurship (Lumpkin and Dess, 1996). According to Lumpkin and Dess (1996), key entrepreneurial processes are autonomy, innovativeness, risk-taking, proactiveness, and competitive aggressiveness.

Autonomy refers to the independent action of a person in carrying an idea or a vision through to completion. Innovativeness is the tendency to engage with new ideas and to conduct experimentation that may result in new products. Proactiveness implies acting in anticipation of future problems, needs, or changes. Competitive aggressiveness involves directly and intensely challenging competitors. Effective entrepreneurial education should facilitate and promote these entrepreneurial behaviors (Okudana and Rzasa, 2006).

Regarding entrepreneurship, two different academic approaches can be seen in the literature: the study of "entrepreneurial traits" and the study of "entrepreneurial rates." Entrepreneurial traits research (a major division of the empirical work in the field) focuses on the individual differences between entrepreneurs while entrepreneurial rates research examines environmental influences (often economic conditions) on the propensity to start a business or to innovate. By and large, the rates approach ignores the constructs used by traits researchers, and the traits approach does not incorporate the constructs used by rates researchers. Rates researchers are more likely to be interested in studying changes in the rate of the establishment of new businesses over time and consequently more commonly make use of longitudinal research designs (Shane, 1996; Vecchio, 2003). Traits researchers, while acknowledging longitudinal research, more typically adopt cross-sectional designs as part of a survey-based approach. Because of these differences in focus and preferred study design, the two approaches are not particularly supplementary to one another. Instead, each approach fosters a knowledge base that is cumulative within itself and is not amenable to integration with other approaches. The distinction between the traits and rates approaches can be best understood as a distinction between a supply side approach and a demand-side approach (Thornton, 1999). The supply side approach focuses on the propensity and availability of individuals for entrepreneurial roles while the demand-side approach focuses on the number and nature of entrepreneurial roles that need to be filled. While entrepreneurship requires an attitude toward risk taking that includes using one's instinctive feelings, many aspects of entrepreneurship can also be taught (Garavan and O'Cinneide, 1994).

\section{Leadership}

Leadership, in general, involves influencing the activities of an organized group toward goal achievement (Rauch and Behling, 1984, p. 46; House et al., 1999, p. 184; Boyatzis, 2006). It differs from management, which tends to be focused on coordination and planning (Zaleznik, 1977; Michael et al., 2002; Renko et al., 2015).

Academic authors have presented a range of views on gender differences and similarities in different leadership styles (e.g., Eagly and Johnson, 1990) such as transformational, transactional, and laissez-faire leadership styles (Eagly et al., 2003). Burns (1978) introduced transformational leadership theory, which was further developed by Bass and Avolio (1994). According to these authors, transformational leadership has four components: charismatic role modeling, individualized consideration, inspirational motivation, and intellectual stimulation. Using charisma, the leader inspires admiration, respect, and loyalty and emphasizes the importance of having a collective sense of mission. Through individualized consideration, the leader builds a one-on-one relationship with his or her followers and understands and takes into consideration their differing needs, skills, and aspirations (Gumusluoglu and Ilsev, 2009). Through inspirational motivation, the leader articulates an exciting vision of the future, shows his or her followers how to achieve the particular goals, and expresses his or her belief that they can achieve the goals (Gumusluoglu and Ilsev, 2009). Through intellectual stimulation, the leader broadens and elevates the interests of his or her followers (Bass, 1990) and encourages them to think about old problems in new ways (Bass, 1985).

Transformational leadership behaviors closely match the determinants of innovation and creativity in the workplace, some of which are vision, support for innovation, autonomy, encouragement, recognition, and challenge (Elkins and Keller, 2003; Gumusluoglu and Ilsev, 2009). Burns (1978) and other researchers (see Bass, 1998; Avolio, 1999) compare transformational leaders to transactional leaders, who appeal to followers' self-interest by establishing exchange relationships with them (i.e., where ideas and resources are exchanged between leaders and followers) (Eagly et al., 2003). This type of leadership involves managing in the more conventional sense of clarifying subordinates' responsibilities, rewarding them for meeting objectives, and correcting them for failing to meet objectives. Although there are thus two different styles of leadership-transformational and transactional-both are displayed by effective leaders. In addition to these two styles, the above authors distinguish a laissez-faire style marked by a general failure to take responsibility for managing (Eagly et al., 2003).

The new approaches to the study of leadership acknowledge several styles of leadership: sustainable leadership, servant leadership, authentic leadership, ethical leadership, mindful leadership, benevolent leadership, and decent leadership (Di Fabio, in press), each of which has peculiar characteristics. For example, sustainable leadership refers to the shared responsibility not to deplete human or financial resources unduly and not to cause social or environmental damage (Hargreaves et al., 2003; Hargreaves and Fink, 2004); servant leadership considers the personal growth of subordinates as paramount and more important than achieving the objectives of the company or of the leaders (Ehrhart, 2004); authentic leadership refers to a style of leadership and ethics where the emphasis is more 
on subordinates' strengths rather than their weaknesses (Avolio et al., 2009); ethical leadership refers to the pursuit of ethical goals and the empowerment of an organization's members (Gallagher and Tschudin, 2010); mindful leadership refers to a leadership style that focuses on the present moment, acknowledging feelings and emotions and keeping them under control, especially in times of stress; mindful leadership refers to full awareness of people's presence and your (the leader's) effect on them (George, 2012; Herold, 2013); benevolent leadership refers to leaders who consider subordinates family members and show an interest in their welfare in their working as well as their private lives (Wang and Cheng, 2010); and decent leadership refers to the previous integrated concepts of leadership (sustainable, servant, authentic, ethical, mindful leadership, and benevolent) and includes also diversity management leadership related to the asset of different resources in an organization (Di Fabio, in press).

\section{Entrepreneurial Leadership}

Entrepreneurial leadership is a distinctive style of leadership that can be present in organizations of any size, type, or age. The literature review revealed that entrepreneurial leadership has been studied by many authors. According to Cunningham and Lischeron (1991), entrepreneurial leadership involves setting clear goals, creating opportunities, empowering people, promoting mutual awareness, and awareness of the organization, and developing a sound human resource system. Ireland et al. (2003) maintain that entrepreneurial leadership is the ability to influence others to manage resources strategically in order to promote opportunity-seeking and advantage-seeking behaviors. Gupta et al. (2004) define entrepreneurial leadership as leadership that creates visionary scenarios that can be used to mobilize and commit subordinates to the discovery and exploitation of strategic value creation. According to Thornberry (2006), leadership in general requires passion, vision, focus, and the ability to inspire others. Entrepreneurial leadership requires all these qualities plus a mindset and skill set that can help entrepreneurial leaders identify, develop, and exploit new business opportunities. Surie and Ashley (2008) define good leadership as the ability to sustain innovation and adaptation in rapidly changing and uncertain environments.

A more recent definition is that entrepreneurial leadership entails influencing and directing the performance of group members toward the achievement of organizational goals that involve recognizing and exploiting entrepreneurial opportunities (Renko et al., 2015). With its explicit focus on the achievement of entrepreneurial goals, this definition can be seen as similar to, yet different from, previous definitions of entrepreneurial leadership.

\section{Professionalism}

Ducheny et al. (1997, p. 89) define professional development as "an ongoing process through which an individual derives a cohesive sense of professional identity by integrating the broadbased knowledge, skills, and attitudes within psychology with one's values and interests."

Psychology is not alone in its attempt to explain professional development and professionalism. Epstein and Hundert (2002) considered comparable issues in the training of physicians (e.g., interpersonal functioning and critical thinking; Elman et al., 2005). They focused on "the habitual and judicious use of communication, knowledge, technical skills, clinical reasoning, emotions, values, and reflection in daily practice for the benefit of the individual and community being served" (p. 226). They also considered the acquisition and use of knowledge, integrative aspects of care, building therapeutic relationships, context, development, and "habits of mind." This last concept encompasses observation of one's own thinking, emotions, and techniques; attentiveness; critical curiosity; recognition of and response to cognitive and emotional biases; and a willingness to acknowledge and correct errors (p. 230). Attention to professionalism in medicine has burgeoned, and, according to Lundberg (2004), the essential elements of professionalism are self-governance and self-regulation (Elman et al., 2005).

The development of professionalism is the process of acquiring, expanding, refining, and sustaining knowledge, proficiency, skill, and qualifications for competent professional functioning that result in professionalism. This process comprises (a) the internal tasks of clarifying professional objectives, crystallizing professional identity, increasing self-awareness and confidence, and sharpening reasoning, thinking, reflecting, and judgment, and (b) the social/contextual dimension of enhancing interpersonal aspects of professional functioning and broadening professional autonomy (Elman et al., 2005). Professionalism is a necessary component of all aspects of psychologists' functioning, but it is not a substitute for other factors that contribute to specific competencies (e.g., technical training and clinical and research experience). Professionalism may be conceptualized more as an underlying capacity or capability than a specific skill or competency; some key components of professionalism are self-knowledge, self-assessment, and self-care (Elman et al., 2005).

\section{Toward a Unified Theoretical and Empirically Based Integrated Framework for Studying High Entrepreneurship, Leadership, and Professionalism}

Because flexibility is increasingly required in the world of work, and workers are increasingly called on to deal with challenges and to have more complex skills (Di Fabio, 2016b; Di Fabio and Blustein, 2016a,b; Di Fabio et al., 2016a), it is important to look at entrepreneurship, leadership, and professionalism as three integrated aspects of the successful worker.

In the development of this model, we first started focusing our attention on the construct of entrepreneurial leadership (Renko et al., 2012) that can be conceptualized as the ability to influence others to manage resources strategically in order to promote opportunity-seeking and advantage-seeking behaviors (Ireland et al., 2003) and that involves setting clear goals, creating opportunities, empowering people, promoting mutual awareness and awareness of the organization (Cunningham and Lischeron, 1991). In this integrated background, already existing in the literature, we attempted to enrich this model with the construct of professionalism; because in our point of view, a successful worker 
need, not only the ability of creating visionary scenarios helpful for the discovery and exploitation of strategic value creation (Gupta et al., 2004), but also a professional identity based on knowledge, skills, and attitudes.

We also considered Kanter's (1989) theory on the connection between careers and economic, social, and political issues, and also Chan et al.'s (2012) proposal of a person-centered framework for conceptualizing subjective careers. In an increasingly boundaryless work environment, these authors recognized entrepreneurship, leadership, and professionalism (ELP) as three key dimensions of subjective career space.

Because Kanter (1989) conceptualizes the constructs of entrepreneurship, leadership, and professionalism separately, we concentrated more on the work of Chan et al. (2012), which conceptualizes these three variables with the focus on motivation, intentions, and efficacy. In Chan et al.'s (2012) scale, the ELP career aspiration questionnaire, these variables are conceptualized separately; indeed, in our proposed model too, motivation, intentions, and efficacy are conceptualized as three aspects of each dimension analyzed. Entrepreneurship, leadership, and professionalism are thus three integrated variables, and each includes the three aspects of motivation, intentions, and efficacy.

In our point of view we consider the importance of developing a brief and easily administered measure that assesses entrepreneurship, leadership, and professionalism in a complex manner that entertains these three crucial aspects for career success as three integrated parts of a career success model and that can be used both in organizational contexts and with students samples. In this paper we propose a new, self-report instrument for measuring these three variables, considering them in a integrative way, because of the links of motivation, intentions, and efficacy that are present in each of these constructs. The main novelty of this study primarily refers to motivation, intentions, and efficacy that are considered together in each dimension of entrepreneurship, leadership, and professionalism; besides this new scale, directly inspired by the criteria of briefness, capability of being used with different kinds of populations (workers, students, trainers, and trainees) and usefulness for building one's own personal and professional path, could be something important for training and practice.

\section{Rationale for the Study}

The importance of the following three competencies needed to help people construct careers, shape their identities, and design successful careers and lives was stressed: leadership, entrepreneurship, and professionalism.

This article supports the idea that greater flexibility and an integrated entrepreneurship leadership and professionalism model are needed by people to help them face the challenges and precariousness in the contemporary world of work. In fact, in today's rapidly changing world of work, a career is more than just a job (Savickas, 2011; Guichard, 2013); it is analogous to a vocation, and it is becoming increasingly important to develop the competences needed to deal with career-life related transitions in the 21st century (Boyatzis et al., 2002, 2015; Boyatzis, 2008; Boyatzis and Saatcioglu, 2008; Boyatzis, 2009; Camuffo et al., 2012; Gerli et al., 2015). The main aim of this study was to support career constructing and life design/life meaning-related interventions and preventive actions (Di Fabio and Bernaud, 2008; Di Fabio and Kenny, 2012; Bernaud, 2013; Bernaud et al., 2015; Di Fabio, 2015; Di Fabio and Palazzeschi, 2015). More particularly, it is hoped that the new measure presented here will increase people's awareness of key competencies such as entrepreneurship, leadership, and professionalism. The results should help them reflect on the level of these competencies in themselves and also help them deal with life work challenges as these challenges manifest in their career-life stories.

The present study thus examined the psychometric properties of a new measure for assessing these important career dimensions in the HELP questionnaire (HELP-Q). Particularly, we expect significant correlations of the HELP-Q constructs with the other constructs analyzed in the present study because we hypothesize a link between constructs related to self-competencies, selfawareness, and positive attitudes, particularly between scales that intend to assess similar constructs.

\section{MATERIALS AND METHODS}

\section{Preliminary Study}

A measure consisting of 54 items was developed. In the first phase of the study, we tested the factor structure of the preliminary version of the HELP-Q scale. A convenience sample of 97 students ( 81 women, 16 men) with a mean age of 24,31 $(S D=2.70)$ enrolled in various psychology courses at the University of Florence and 107 employees (61 women, 46 men) with a mean age of $48,75(S D=9,66)$ completed this preliminary version. Exploratory factor analysis (EFA) was used to verify the factor structure of the scale. Velicer's minimum average partial (MAP) criterion and the inspection of the scree plot suggested a three-factor solution for the measure. In order to obtain a clear, robust factor solution-and on the basis of the theoretical principles and the factor analysis criteria-we eliminated the items with commonalities under 0.30 and duly reached a version with nine items.

\section{Participants and Procedure}

The study participants were 65 workers (36.9\% male, $63.1 \%$ female) with a mean age of 29.78 years $(S D=9.03)$ and 66 students (34.8\% male, $65.2 \%$ female) with a mean age of 23.08 years $(S D=3.19)$. The total sample thus numbered 131 subjects (35.9\% male, $64.1 \%$ female with a mean age of 26.51 years $)(S D=7.15)$.

Significant differences emerged with respect to gender in the Entrepreneurship (E) subscale $\left(\chi^{2}=32.45, p=0.01\right)$, in the Leadership (L) subscale $\left(\chi^{2}=24.89, p=0.01\right)$, and in the HELP-Q total score $\left(\chi^{2}=49.53, p=0.01\right)$, but not in the Professionalism $(\mathrm{P})$ subscale $\left(\chi^{2}=10.91, p=0.282\right)$.

The participants first completed the HELP-Q and then, in order to assess aspects of the concurrent validity of this new 
mirror measure, completed other instruments that assessed similar as well as different constructs. All the instruments were administered in accordance with the norms regarding the privacy and anonymity of participants.

The questionnaires were administered according to the laws of privacy and informed consent of the Italian law (Law Decree DL-196/2003). The participants were told also that they could withdraw from the study at any time and that there would be no payment for participating. Regarding ethical standards for research, the study followed procedures consistent with the latest version of the Declaration of Helsinki revised in Fortaleza (World Medical Association [WMA], 2013).

\section{Instruments}

High Entrepreneurship, Leadership, Professionalism Questionnaire (HELP-Q; Di Fabio, Bucci and Gori, 2016)

The HELP-Q is a short, integrated scale that assesses the principal dimensions of entrepreneurship (E), leadership (L), and professionalism (P) in terms of the areas of motivations, intentions, and efficacies. This scale consists of nine items, three for each area, on a 5-point Likert-type scale $(1=$ not at all, $2=\mathrm{a}$ little, $3=$ somewhat, $4=$ much, $5=$ a great deal) that helps build a profile of ELP in relation to the three areas.

\section{Intrapreneurial Self-Capital Scale (ISCS; Di Fabio, 2014b)}

Intrapreneurial self-capital is defined as a core of individual intrapreneurial resources used to cope with career and life construction challenges and includes dimensions of core selfevaluation, hardiness, creative self-efficacy, resilience, goal mastery, decisiveness, and vigilance (Di Fabio, 2014b). The ISCS was developed by Di Fabio (2014b) to measure this new construct of intrapreneurial self-capital. It uses a 5-point Likert-type scale ( $1=$ strongly disagree, $2=$ disagree, $3=$ neither agree nor disagree, $4=$ agree, $5=$ strongly agree) and consists of 28 items (e.g., "I am able to deal with most of my problems," "I am able to improve the ideas produced by others," "I am able to achieve objectives despite obstacles," "One of my goals in training is to learn as much as I can"). In the present study, we used the Italian version of the ISCS, which showed good internal consistency $(\alpha=0.86)$.

\section{Psychological Capital Questionnaire (PCQ; Luthans et al., 2007)}

Psychological capital is a new construct measured with the Psychological Capital Questionnaire (PCQ). This measure consists of 12 items with four subscales: (1) hope (e.g., "I feel confident contributing to discussions about the organization's management"); (2) efficacy (e.g., "I can think of many ways to reach my current work goals"); (3) optimism (e.g., "I'm optimistic about what will happen to me in the future pertaining to work"); and (4) resilience (e.g., "I usually take stressful things at work in stride"). Each of these subscales consists of six items with response options on a six-point Likert scale ranging from 1 (strongly disagree) to 6 (strongly agree). The PCQ has good psychometric properties also in its Italian version, which was used in the present study (hope $=0.75$; efficacy $=0.78$; resilience $=0.70$; optimism $=0.77$; the overall scale $=0.81$; Alessandri et al., 2015).

\section{Proactive Personality Scale (PPS; Bateman and Crant, 1993)}

This scale consists of 17 items on a seven-point Likert scale ranging from 1 (strongly disagree) to 7 (strongly agree). Such items include: "I excel at identifying opportunities" and "No matter what the odds, if I believe in something, I will make it happen." The items are summed to arrive at a proactive personality score. The unidimensionality of the scale is supported by factor analysis and reliability across three samples (ranging from 0.87 to 0.89) (Bateman and Crant, 1993). The PPS has good psychometric properties also in its Italian version, which was used in the present study $(a=0.81)$ (Di Fabio and Gori, 2016c).

\section{Rosenberg Self-Esteem Scale (RSES; Rosenberg, 1965)}

The Rosenberg Self-Esteem Scale (RSES) is a 10-item scale for assessing global self-esteem with the items answered on a 4 point Likert scale ranging from strongly agree to strongly disagree. Examples of the items: "On the whole, I am satisfied with myself," "I have a positive attitude toward myself." The psychometric properties of the RSES have been reported as good in several studies (Corwyn, 2000). In this study, the Italian version of the scale was used ( $a=0.84$ ) (Prezza et al., 1997).

\section{Satisfaction With Life Scale (SWLS; Diener et al., 1985)}

The Satisfaction With Life Scale (SWLS) is a self-report instrument that measures global life satisfaction. It consists of five items with responses on a 7-point Likert scale with higher values corresponding to a higher degree of life satisfaction. Examples of the items: "I am satisfied with my life," "The conditions of my life are excellent." The psychometric properties of the SWLS are good, with different studies reporting a unidimensional structure of the measure (Diener et al., 1985). In this study, the Italian version of the scale was used $(a=0.85)$ (Di Fabio and Gori, 2015).

\section{Data Analysis}

Factor analysis was used to identify the underlying dimensions of the HELP career construction questionnaire using various criteria for item selection according to the number of selected factors and item factor loadings. In order to verify some assumptions, we used Bartlett's Test of Sphericity and KaiserMeyer-Olkin's (KMO) Measure of Sampling Adequacy to determine whether the items were significantly correlated and shared sufficient variance to justify factor extraction. Principal axis factoring was selected as the method of factor extraction with oblique rotation (promax criterion) to obtain a simple structure as there was no theoretical assumption to suggest that the factors were independent of each other. Eigenvalues greater than 1, the Kaiser criterion, and the scree test were checked for agreement (Giannini et al., 2011), and their 
salience was determined by applying the following criteria: a) a factor loading of at least 0.3 on the primary factor, ensuring a high degree of association between the item and the factor; (b) a difference of 0.3 between loading on the primary factor and loading on other factors, ensuring that each item could be considered salient to one factor when an item was loading simultaneously on two factors; (c) a minimum of three items for each factor thus ensuring meaningful interpretation of stable factors (Craparo et al., 2015). The standard Pearson correlation coefficient was used to investigate to what extent the factor scores were intercorrelated. The reliability of the scales of the questionnaire was calculated by means of the alpha coefficient. A confirmatory factor analysis (CFA) was performed using maximum likelihood (ML) estimation procedures. To assess the closeness of the hypothetical model to the empirical data statistically, multiple goodness-of-fit indices were used, including the ratio of the chi-square to degrees of freedom $\left(\chi_{2} / d f\right)$, the Non-Normed Fit Index (NNFI), the Comparative Fit Index (CFI), the Standardized Root Mean Square Residual (SRMR), and the Root Mean Square Error of Approximation (RMSEA). Bentler and Bonnet (1980) contend that values greater than 0.90 indicate acceptable fit for the NNFI while values below 0.90 indicate a need to respecify the model; Hu and Bentler (1999) contend that CFI values greater than 0.90 are needed; and Byrne (1994) contends that a cutoff of 0.93 should indicate a good fit. SRMR and RMSEA values less than 0.08 (Browne and Cudeck, 1993), and ideally equal to or less than 0.05 , are interpreted as indicating models that fit well (Steiger, 1990; Schermelleh-Engel et al., 2003; Giannini et al., 2011; Gori et al., 2015). Several aspects of concurrent validity were verified using Pearson's $r$ coefficient.

\section{RESULTS}

An examination of the scree plot (Cattell, 1966), and the percentage of variance accounted for, revealed that as many as three factors should be retained for rotation. The adequacy of the sample was measured as $0.72, p=0.001$ in terms of the KaiserMeyer-Olkin test (KMO) (Field, 2009). The exploratory factor analysis (EFA) (promax rotation) showed a factor structure with three principal dimensions (eigenvalues $>1 ; 3.41,2.73,1.33$ ) with $83.01 \%$ of total variance explained.

Factor 1 (Leadership), with three items loading above 0.80 , had an eigenvalue of 4.41 and accounted for $37.88 \%$ of the total variance explained. Factor 2 (Entrepreneurial), with three items loading above 0.80, had an eigenvalue of 2.73 and accounted for $30.32 \%$ of the total variance explained. Factor 3 (Professionalism), with three items loading above 0.60 , had an eigenvalue of 1.33 and accounted for $14.81 \%$ of the total variance explained. The factor structure matrix shows the three independent factors of the questionnaire (Table 1).

The goodness-of-fit indices of the three factor model showed a good fit of the model to the data. Although the chi-square was significant, the other goodness-of-fit indices showed satisfactory
TABLE 1 | Exploratory factor analysis (EFA) results (principal axis factoring method, promax rotation).

\begin{tabular}{lccc}
\hline Original item number & \multicolumn{3}{c}{ Factor } \\
\cline { 2 - 4 } & Leadership & Entrepreneurship & Professionalism \\
\hline HELP item 5 & 0.940 & & \\
HELP item 8 & 0.932 & & \\
HELP item 2 & 0.928 & & \\
HELP item 6 & & 0.956 & \\
HELP item 9 & 0.870 & 0.937 \\
HELP item 3 & 0.827 & 0.848 \\
HELP item 1 & & 0.840 \\
HELP item 4 & & & \\
HELP item 7 & & & \\
\hline
\end{tabular}

Extraction method: principal axis factoring. Rotation method: promax with Kaiser normalization.

and good values $\left(x^{2} / \mathrm{df}=3.13, p<0.001 ; \mathrm{CFI}=0.95\right.$; $\mathrm{NNFI}=0.93$; SRMR $=0.06$; RMSEA $=0.11$ ) (Table 2).

The reliability of the scales, calculated using Cronbach's alpha coefficient, indicated good values of internal consistency (Leadership, $a=0.92$; Entrepreneurship, $a=0.92$; Professionalism, $a=0.90$; and the overall scale $=0.77)$.

The HELP career construction questionnaire (HELP-Q; see Appendix) showed strong correlations with the measures used to assess aspects of concurrent validity (Table 3 ). In particular, the relationship between the HELP-Q and these measures indicates that the HELP-Q is a measure strictly related to individual intrapreneurial resources (Intrapreneurial SelfCapital Scale), to self-capital (Psychological Self-Capital Scale),

TABLE 2 | Fit indexes for the three-factorial models.

\begin{tabular}{lccccc}
\hline Sample & $\chi \mathbf{2} / \boldsymbol{d f}$ & CFI & NNFI & SRMR & RMSEA \\
\hline One factor model & 18.29 & 0.67 & 0.65 & 0.21 & 0.24 \\
Two factors model & 11.7 & 0.77 & 0.74 & 0.15 & 0.19 \\
Three factors model & 3.13 & 0.95 & 0.93 & 0.06 & 0.11 \\
\hline
\end{tabular}

CFI, Comparative Fit Index; NNFI, Non-Normed Fit Index; SRMR, Standardized Root Mean Square Residual; RMSEA, Root Mean Square Error of Approximation.

TABLE 3 | Summary of the correlation between the two parts of the ACS and ISC, PSC, F, IOS, PSR, MSPSS.

\begin{tabular}{lllllll}
\hline & ISCS & PSCS & PPS & RSES & SWLS & $\begin{array}{c}\text { ELP } \\
\text { CAQ }\end{array}$ \\
\hline (1) Leadership & & & & & & \\
(2) Entrepreneurship & $0.445^{* *}$ & $0.399^{* *}$ & $0.573^{* *}$ & 0.163 & 0.109 & $0.546^{* *}$ \\
(3) Professionalism & $0.467^{* *}$ & $0.484^{* *}$ & $0.636^{* *}$ & $0.351^{*}$ & 0.005 & $0.539^{* *}$ \\
HELP total score & $0.598^{* *}$ & $0.518^{* *}$ & $0.680^{* *}$ & $0.360^{* *}$ & 0.113 & $0.672^{* *}$ \\
\hline
\end{tabular}

${ }^{*} p<0.05,{ }^{* *} p<0.01$. ISCS, Intrapreneurial Self-Capital Scale; PSCS, Psychological Self-Capital Scale; PPS, Proactive Personality Scale; RSES, Rosenberg Self-Esteem Scale; SWLS, Satisfaction With Life Scale; ELP, Entrepreneurship, Leadership, and Professionalism Career Aspiration Questionnaire. 
to proactivity (Proactivity Scale), to self-esteem (Rosenberg SelfEsteem Scale), and to entrepreneurship, professionalism, and leadership (Entrepreneurship, Leadership, and Professionalism Career Aspiration Questionnaire), while it seems not to be significantly related to life satisfaction (Satisfaction With Life Scale).

\section{DISCUSSION}

In the contemporary world of work, because of the financial crisis and as consequences the use of new policies, workers need to develop specific characteristics to help them adapt to the new, complex scenarios characterized by high degrees of uncertainty (Di Fabio et al., 2013; Di Fabio and Bucci, 2015, 2016; Di Fabio and Gori, 2016a,b; Di Fabio and Palazzeschi, 2016). Personal characteristics such as entrepreneurship, leadership, and professionalism can help make people more flexible and help them evolve in their careers and in their lives.

In this article, along with the further issue of integrating entrepreneurship research and theory into the more established traditions of leadership and management and with the integration of professionalism, we have discussed a new integrated model of entrepreneurship, leadership, and professionalism. It is hoped that the model will assist the design of future research in these areas by highlighting the common trends and common threads of thought that underlie them. A comprehensive model of these constructs may also help people grow in their careers.

The study also set out to develop a new measure for assessing entrepreneurship, leadership, and professionalism, as well as the psychometric properties of the measure. The exploratory factor analysis revealed a good structure with three principal dimensions: entrepreneurship, leadership, and professionalism. Despite the reduced number of items, each dimension yielded a good Cronbach's alpha (Nunnally and Bernstein, 1994).

Confirmatory factor analysis also revealed a good fit of the three factor model to the empirical data, as indicated by the fit indices. In particular, for the three factor model, the CFA results showed that the SRMS were 0.06 indicating a good fit (Browne and Cudeck, 1993; MacCallum et al., 1996). The NNFI index indicated an acceptable fit (Byrne, 1994) and the TLI index a satisfactory fit (Bentler and Bonnet, 1980). Regarding the RMSEA result, while some researchers (Browne and Cudeck, 1993; MacCallum et al., 1996) have used 0.01, 0.05, and 0.08 to indicate excellent, good, and mediocre fit, respectively, other researchers consider 0.10 a reasonable cutoff for good vs. poor fitting models if the other indices used to verify the model fit are good or acceptable, which was the case in this study (Kenny et al., 2014).

Correlations between the HELP-Q and the measures used to verify aspects of concurrent validity showed good values: all the relationships between the variables under investigation were in the right direction and with the right significance.

Regarding the limitations of the study, the major limitation was the small number of participants, although this number met the sufficient criterion (Winter et al., 2009). Future studies on this topic should nevertheless use larger samples to provide information about potential gender differences and also take advantage of cross-cultural studies. An additional limitation of this study concerns the absence of an appropriate evaluation of nomological validity; future research should examine various aspects of the nomological associations of the constructs in the HELP-Q.

Despite these limitations, the results of the study are promising and indicate that the HELP-Q model can be of use to those working in guidance, career counseling, career planning, career life construction, human resources, and organizational development. Those who use the model to identify preventive individual resources in terms of high entrepreneurship, leadership, and professionalism will be better able to handle and succeed in a constantly changing labor market. The model can also be of help in designing one's own future, in creating one's own opportunities, in reinforcing adaptability skills, in maintaining employability and proactivity, and in constructing one's self, identity, and life (Savickas, 2011; Guichard, 2013). The integrated HELP model thus underlines the value of personal entrepreneurship, leadership, and professionalism as an integrated preventive core of competencies that can flexibly, adaptively, and proactively build one's own personal and professional path (Di Fabio, 2014a; Di Fabio et al., 2016a) and ensure success (Akhouri and Sharma, 2009). It can also help people cope with the new reality of the world of work (Arenas et al., 2015; Giorgi et al., 2015, 2016; Mucci et al., 2016) and preserve their individual potentialities and talents (Di Fabio, 2006, 2011; Di Fabio and Palazzeschi, 2008; Kenny and Hage, 2009; Blustein, 2011; Guichard, 2013). The value of the HELP model is that it helps prevent potential career decision-making problems or failures (Sartori et al., 2013, 2015; Ceschi et al., 2014) rather than focusing just on remediation (Di Fabio and Palazzeschi, 2012; Di Fabio et al., 2012, 2013). This new model calls for timeous actions to enhance the mentioned set of competencies at school or at university from a primary preventive perspective. The model calls also for a high level of continuing education as the study results suggest that the HELP-Q can help people prevent future lifelong career problems. Assessing the level of these competencies can also help people develop these competences when they are low. The HELP model can be used also to devise career services, career counseling goals, and new managerial practices in organizational and community contexts to help people cope with the complex career issues of the 21st century.

\section{CONCLUSION}

The study showed that the HELP-Q is a model that can be profitably used to help people adjust to change and manage their life and work opportunities.

\section{ETHICS STATEMENT}

The administration adhered to the requirements of privacy and informed consent in Italian law (Law Decree DL-196/2003) and 
the ethical standards for research of the Declaration of Helsinki revised in Fortaleza (World Medical Association [WMA], 2013), followed and approved by the Department of Education and Psychology of the University of Florence (Italy).

The administration adhered to the requirements of privacy in Italian law (Law Decree DL-196/2003) and informed consent was recollected for each participant.

\section{REFERENCES}

Akhouri, N., and Sharma, R. (2009). HR determinants of organizational success amongst small and medium enterprises in the Indian automobile sector. Glob. Bus. Rev. 10, 173-186. doi: 10.1177/097215090901000203

Alessandri, G., Borgogni, L., Consiglio, C., and Mitidieri, G. (2015). Psychometric properties of the Italian version of the psychological capital questionnaire. Int. J. Sel. Assess. 23, 149-159. doi: 10.1111/ijsa.12103

Arenas, A., Giorgi, G., Montani, F., Mancuso, S., Perez, J. F., Mucci, N., et al. (2015). Workplace bullying in a sample of Italian and Spanish employees and its relationship with job satisfaction, and psychological well-being. Front. Psychol. 6:1912. doi: 10.3389/fpsyg.2015.01912

Avolio, B. J. (1999). Full Leadership Development. Thousand Oaks, CA: Sage.

Avolio, B. J., Walumbwa, F. O., and Weber, T. J. (2009). Leadership: current theories, research, and future directions. Annu. Rev. Psychol. 60, 421-449. doi: 10.1146/annurev.psych.60.110707.163621

Bass, B. M. (1985). Leadership and Performance beyond Expectations. New York, NY: Free Press.

Bass, B. M. (1990). From transactional to transformational leadership: learning to share the vision. Organ. Dyn. 18, 19-32. doi: 10.1016/0090-2616(90)90061-S

Bass, B. M. (1998). Transformational Leadership: Industry, Military, and Educational Impact. Mahwah, NJ: Erlbaum.

Bass, B. M., and Avolio, B. J. (1994). Improving Organizational Effectiveness through Transformational Leadership. Thousand Oaks, CA: Sage.

Bateman, T. S., and Crant, J. M. (1993). The proactive component of organizational behavior. J. Organ. Behav. 14, 103-118. doi: 10.1002/job.4030140202

Bentler, P. M., and Bonnet, D. C. (1980). Significance tests and goodness of fit in the analysis of covariance structures. Psychol. Bull. 88, 588-606. doi: 10.1037/ 0033-2909.88.3.588

Bernaud, J. L. (2013). "Career counseling and life meaning: a new perspective life designing for research and applications," in Psychology of Career Counseling: New Challenges for a New era, eds A. Di Fabio and K. Maree (New-York, NY: Nova Science Publishers).

Bernaud, J. L., Lhotellier, L., Sovet, L., Arnoux-Nicolas, C., and Pelayo, F. (2015). Psychologie de Laccompagnement: Concepts et Outils pour Développer le Sens de la vie et du Travail. Paris: Dunod.

Blustein, D. L. (2011). A relational theory of working. J. Vocat. Behav. 79, 1-17. doi: $10.1016 /$ j.jvb.2010.10.004

Boyatzis, R. E. (2006). Using tipping points of emotional intelligence and cognitive competencies to predict financial performance of leaders. Psicothema 18, $124-131$.

Boyatzis, R. E. (2008). Competencies in the 21st century. J. Manag. Dev. 27, 5-12. doi: $10.1108 / 02621710810840730$

Boyatzis, R. E. (2009). Competencies as a behavioral approach to emotional intelligence. J. Manag. Dev. 28, 749-770. doi: 10.1108/026217109109 87647

Boyatzis, R. E., Batista-Foguet, J. M., Fernández-i-Marín, X., and Truninger, M. (2015). EI competencies as a related but different characteristic than intelligence. Front. Psychol. 6:72. doi: 10.3389/fpsyg.2015.00072

Boyatzis, R. E., and Saatcioglu, A. (2008). A twenty-year view of trying to develop emotional, social and cognitive intelligence competencies in graduate management education. J. Manag. Dev. 27, 92-108. doi: 10.1108/ 02621710810840785

Boyatzis, R. E., Stubbs, E. C., and Taylor, S. N. (2002). Learning cognitive and emotional intelligence competencies through graduate management education. Acad. Manag. Learn. Educ. 1, 150-162. doi: 10.5465/AMLE.2002.85 09345

\section{AUTHOR CONTRIBUTIONS}

$\mathrm{AD}$ and $\mathrm{AG}$ conceptualized the study, chose measures, designed the scale. OB helped in the collection of the data. AD and AG analyzed the data and wrote the methods and results. Then all authors wrote the paper together and read and revised the manuscript several times.

Browne, M. W., and Cudeck, R. (1993). “Alternative ways of assessing model fit," in Testing Structural Equation Models, eds K. A. Bollen and J. S. Long (Newsbury Park, CA: Sage), 136-162.

Burns, J. M. (1978). Leadership. New York, NY: Harper \& Row.

Byrne, B. M. (1994). Structural Equation Modeling with EQS and EQS/Windows. Thousand Oaks, CA: Sage Publications.

Camuffo, A., Gerli, F., and Gubitta, P. (2012). Competencies matter: modeling effective entrepreneurship in northeast of Italy small firms. Cross Cult. Manag. Int. J. 19, 48-66. doi: 10.1108/13527601211195628

Cattell, R. B. (1966). The scree test for the number of factors. Multivar. Behav. Res. 1, 245-276. doi: 10.1207/s15327906mbr0102_10

Ceschi, A., Dorofeeva, K., and Sartori, R. (2014). Studying teamwork and team climate by using a business simulation: how communication and innovation can improve group learning and decision-making performance. Eur. J. Train. Dev. 38, 211-230. doi: 10.1108/EJTD-01-2013-0004

Chan, K. Y., Ho, M.-H. R., Chernyshenko, O., Bedford, O. A., Uy, M. A., Gomulya, D. A., et al. (2012). Entrepreneurship, professionalism, leadership: a framework and measure for understanding boundaryless careers. J. Vocat. Behav. 81, 73-88. doi: 10.1016/j.jvb.2012.05.001

Corwyn, R. F. (2000). The factor structure of global self-esteem among adolescents and adults. J. Res. Personal. 34, 357-379. doi: 10.1006/jrpe.2000. 2291

Craparo, G., Faraci, P., and Gori, A. (2015). Psychometric properties of the 20-item Toronto Alexithymia Scale in a group of Italian younger adolescents. Psychiatry Investig. 12, 500-507. doi: 10.4306/pi.2015.12.4.500

Cunningham, J. B., and Lischeron, J. (1991). Defining entrepreneurship. J. Small Bus. Manag. 29, 45-61.

Di Fabio, A. (2006). Decisional procrastination correlates: personality traits, selfesteem or perception of cognitive failure? Int. J. Educ. Vocat. Guid. 6, 109-122. doi: 10.1007/s10775-006-9000-9

Di Fabio, A. (2011). Intelligence émotionnelle et résistance au changement: quelques résultats empiriques [Emotional intelligence and resistance to change: some empirical results]. Rev. Psychol. Travail Organ. 17, 91-106. doi: 10.1016/ S1420-2530(16)30135-2

Di Fabio, A. (2014a). Career counseling and positive psychology in the 21 st century: new constructs and measures for evaluating the effectiveness of intervention. J. Couns. 1, 193-213.

Di Fabio, A. (2014b). Intrapreneurial Self-Capital: a new construct for the 21st century. J. Employ. Couns. 51, 98-111. doi: 10.1002/j.2161-1920.2014.00045.x

Di Fabio, A. (2015). Beyond fluid intelligence and personality traits in social support: the role of ability-based emotional intelligence. Front. Psychol. 6:395. doi: 10.3389/fpsyg.2015.00395

Di Fabio, A. (2016a). Life design and career counseling innovative outcomes (CCIO): a case study. Career Dev. Q. 64, 35-48. doi: 10.1002/cdq.12039

Di Fabio, A. (2016b). Positive relational management for healthy organizations: psychometric properties of a new scale for prevention for workers. Front. Psychol. 7:1523. doi: 10.3389/fpsyg.2016.01523

Di Fabio, A. (in press). Decent Leadership: Primo Studio delle proprietà psicometriche. Counseling. Giornale Italiano di Ricerca e Applicazioni.

Di Fabio, A., and Bernaud, J. (2008). The help-seeking in career counseling. J. Vocat. Behav. 72, 60-66. doi: 10.1016/j.jvb.2007.10.006

Di Fabio, A., and Blustein, D. L. (2016a). Editorial: from meaning of working to meaningful lives: the challenges of expanding decent work. Front. Psychol. 7:1119 doi: $10.3389 /$ fpsyg.2016.01119

Di Fabio, A., and Blustein, D. L. (eds). (2016b). From Meaning of Working to Meaningful Lives: The Challenges of Expanding Decent Work. Lausanne: Frontiers Media. doi: 10.3389/978-2-88919-970-9 
Di Fabio, A., and Bucci, O. (2015). Affective profiles in Italian high school students: life satisfaction, psychological well-being, self-esteem, and optimism. Front. Psychol. 6:1310. doi: 10.3389/fpsyg.2015.01310

Di Fabio, A., and Bucci, O. (2016). Green positive guidance and green positive life counseling for decent work and decent lives: some empirical results. Front. Psychol. 7:261. doi: 10.3389/fpsyg.2016.00261

Di Fabio, A., Giannini, M., Loscalzo, Y., Palazzeschi, L., Bucci, O., Guazzini, A., et al. (2016a). The challenge of fostering healthy organizations: an empirical study on the role of workplace relational civility in acceptance of change and well-being. Front. Psychol. 7:1748. doi: 10.3389/fpsyg.2016.01748

Di Fabio, A., and Gori, A. (2015). Measuring adolescent life satisfaction: psychometric properties of the satisfaction with life scale in a sample of Italian adolescents and young adults. J. Psychoeduc. Assess. 34, 501-506. doi: 10.1177/ 0734282915621223

Di Fabio, A., and Gori, A. (2016a). Developing a new instrument for assessing acceptance of change. Front. Psychol. 7:802. doi: 10.3389/fpsyg.2016.00802

Di Fabio, A., and Gori, A. (2016b). Assessing Workplace Relational Civility (WRC) with a new multidimensional "mirror" measure. Front. Psychol. 7:890. doi: 10.3389/fpsyg.2016.00890

Di Fabio, A., and Gori, A. (2016c). Proactive Personality Scale: Uno studio sulle propriet Ȧ psicometriche della versione italiana [Proactive Personality Scale: first study on the psychometric properties of the Italian version]. Counseling. Giornale Italiano di Ricerca e Applicazioni 9. doi: 10.14605/CS911608

Di Fabio, A., and Kenny, M. E. (2012). Emotional intelligence and perceived social support among Italian high school students. J. Career Dev. 39, 461-475. doi: $10.1177 / 0894845311421005$

Di Fabio, A., and Kenny, M. E. (2015). The contributions of emotional intelligence and social support to adaptive career progress among Italian youth. J. Career Dev. 42, 48-49. doi: 10.1177/0894845314533420

Di Fabio, A., and Kenny, M. E. (2016a). From decent work to decent lives: positive self and relational management (PS\&RM) in the twenty-first century. Front. Psychol. 7:361. doi: 10.3389/fpsyg.2016.00361

Di Fabio, A., and Kenny, M. E. (2016b). Promoting well-being: the contribution of emotional intelligence. Front. Psychol. 7:1182. doi: 10.3389/fpsyg.2016.01182

Di Fabio, A., and Maree, J. G. (2012). Group-based life design counseling in an Italian context. J. Vocat. Behav. 80, 100-107. doi: 10.1016/j.jvb.2011.06.001

Di Fabio, A., and Palazzeschi, L. (2008). Emotional intelligence and self-efficacy in a sample of Italian high school teachers. Soc. Behav. Pers. 36, 315-326. doi: 10.2224/sbp.2008.36.3.315

Di Fabio, A., and Palazzeschi, L. (2012). Incremental variance of the core selfevaluation construct compared to fluid intelligence and personality traits in aspects of decision-making. Pers. Individ. Dif. 53, 196-201. doi: 10.1016/j.paid. 2012.03.012

Di Fabio, A., and Palazzeschi, L. (2015). Hedonic and eudaimonic well-being: the role of resilience beyond fluid intelligence and personality traits. Front. Psychol. 6:1367. doi: 10.3389/fpsyg.2015.01367

Di Fabio, A., and Palazzeschi, L. (2016). Marginalization and precariat: the challenge of intensifying life construction intervention. Front. Psychol. 7:444. doi: 10.3389/fpsyg.2016.00444

Di Fabio, A., Palazzeschi, L., Asulin-Peretz, L., and Gati, I. (2013). Career indecision versus indecisiveness: associations with personality traits and emotional intelligence. J. Career Assess. 21, 42-56. doi: $10.1177 / 1069072712454698$

Di Fabio, A., Palazzeschi, L., and Bar-On, R. (2012). The role of personality traits, core self-evaluation and emotional intelligence in career decisionmaking difficulties. J. Employ. Couns. 49, 118-129. doi: 10.1002/j.2161-1920.2012. 00012.x

Di Fabio, A., and Saklofske, D. H. (2014a). Promoting individual resources: the challenge of trait emotional intelligence. Pers. Individ. Dif. 65, 19-23. doi: 10. 1016/j.paid.2014.01.026

Di Fabio, A., and Saklofske, D. H. (2014b). Comparing ability and self-report trait emotional intelligence, fluid intelligence, and personality traits in career decisions. Pers. Individ. Dif. 64, 174-178. doi: 10.1016/j.paid.2014.02.024

Di Fabio, A., Saklofske, D. H., and Tremblay, P. F. (2016b). Psychometric properties of the Italian Trait Emotional Intelligence Questionnaire (I-TEIQue). Pers. Individ. Dif. 96, 198-201. doi: 10.1016/j.paid.2016.03.009

Diener, E., Emmons, R. A., Larsen, R. J., and Griffin, S. (1985). The satisfaction with life scale. J. Pers. Assess. 49, 71-75. doi: 10.1207/s15327752jpa4901_13
Ducheny, K., Alletzhauser, H. L., Crandell, D., and Schneider, T. R. (1997). Graduate student professional development. Prof. Psychol. Res. Pract. 28, 87-91. doi: $10.1037 / 0735-7028.28 .1 .87$

Eagly, A. H., Johannesen-Schmidt, M. C., and van Engen, M. (2003). Transformational, transactional, and laissez faire leadership styles: a metaanalysis comparing women and men. Psychol. Bull. 129, 569-591. doi: 10.1037/ 0033-2909.129.4.569

Eagly, A. H., and Johnson, B. T. (1990). Gender and leadership style: a metaanalysis. Psychol. Bull. 108, 233-256. doi: 10.1037/0033-2909.108.2.233

Ehrhart, M. G. (2004). Leadership and procedural justice climate as antecedents of unit-level organizational citizenship behavior. Pers. Psychol. 57, 61-94. doi: 10.1111/j.1744-6570.2004.tb02484.x

Elkins, T., and Keller, R. T. (2003). Leadership in research and development organizations: a literature review and conceptual framework. Leadersh. Q. 14, 587-606. doi: 10.1016/S1048-9843(03)00053-5

Elman, N. S., Illfelder-Kaye, J., and Robiner, W. N. (2005). Professional development: training for professionalism as a foundation for competent practice in psychology. Prof. Psychol. Res. Prac. 36, 367-375. doi: 10.1037/07357028.36.4.367

Epstein, R. M., and Hundert, E. M. (2002). Defining and assessing professional competence. J. Am. Med. Assoc. 287, 226-235. doi: 10.1001/jama.287.2.226

Field, A. (2009). Discovering Statistics using SPSS. London: Sage.

Gallagher, A., and Tschudin, V. (2010). Educating for ethical leadership. Nurse Educ. Today 30, 224-227. doi: 10.1016/j.nedt.2009.11.003

Garavan, T. N., and O'Cinneide, B. (1994). Entrepreneurship education and training programmes: a review and evaluation. J. Eur. Ind. Train. 18, 3-12. doi: 10.1108/03090599410068024

George, B. (2012). Mindfulness Helps You Become a Better Leader. Available at: http://gsg.students.mtu.edu/wordpress/wp-content/uploads/ 2015/11/Mindfulness-Helps-You-Become-a-Better-Leader-article-2.pdf

Gerli, F., Bonesso, S., and Pizzi, C. (2015). Boundaryless career and career success: the impact of emotional and social competencies. Front. Psychol. 6:1304. doi: 10.3389/fpsyg.2015.01304

Giannini, M., Gori, A., De Sanctis, E., and Schuldberg, D. (2011). A comparative analysis of attachment: psychometric properties of the PTI Attachment Styles Scale (ASS). J. Psychother. Integr. 21, 363-381. doi: 10.1037/a00 25461

Giorgi, G., Mancuso, S., Fiz Perez, F., Castiello, D., Antonio, A., Mucci, N., et al. (2016). Bullying among nurses and its relationship with burnout and organizational climate. Int. J. Nurs. Pract. 22, 160-168. doi: 10.1111/ijn. 12376

Giorgi, G., Shoss, M. K., and Leon-Perez, J. M. (2015). Going beyond workplace stressors: economic crisis and perceived employability in relation to psychological distress and job dissatisfaction. Int. J. Stress Manag. 22, 137-158. doi: $10.1037 / \mathrm{a} 0038900$

Gori, A., Craparo, G., Giannini, M., Loscalzo, Y., Caretti, V., La Barbera, D., et al. (2015). Development of a new measure for assessing insight: psychometric properties of the insight orientation scale (IOS). Schizophr. Res. 169, 298-302. doi: $10.1016 /$ j.schres.2015.10.014

Guichard, J. (2013). "Career guidance, education, and dialogues for a fair and sustainable human development," in Proceedings of the Inaugural Conference of the UNESCO Chair of Lifelong Guidance and Counselling, Poland.

Gumusluoglu, L., and Ilsev, A. (2009). Transformational leadership and organizational innovation: the roles of internal and external support for innovation. J. Prod. Innov. Manag. 264-274. doi: 10.1111/j.1540-5885.2009. 00657.x

Gupta, V., MacMillan, I., and Surie, G. (2004). Entrepreneurial leadership: developing a cross-cultural construct. J. Bus. Ventur. 19, 241-260. doi: 10.1016/ S0883-9026(03)00040-5

Hargreaves, A., and Fink, D. (2004). The seven principles of sustainable leadership. Educ. Leadersh. 61, 8-13. doi: 10.1111/j.1753-6405.2010.00534.x

Hargreaves, A., Moore, S., Fink, D., Brayman, C., and White, R. (2003). Succeeding Leaders? - A Study of Principal Rotation and Succession, Report to the Ontario Principals' Council. Toronto, ON: Ontario Principals' Council.

Herold, I. M. (2013). The mindful library leader. Libr. Issues 33, 1-4.

House, R. J., Hanges, P. J., Ruiz-Quintanilla, S. A., Dorfman, P. W., Javidan, M., Dickson, M., et al. (1999). Cultural influences on leadership and organizations: Project GLOBE. Adv. Glob. Leadersh. 1, 171-233. 
Hu, L., and Bentler, P. M. (1999). Cut-off criteria for fit indexes in covariance structure analysis: conventional criteria versus new alternatives. Struct. Equ. Model. 6, 1-55. doi: 10.1080/10705519909540118

Ireland, R. D., Hitt, M. A., and Sirmon, D. G. (2003). A model of strategic entrepreneurship: the construct and its dimensions. J. Manag. 29, 963-989. doi: 10.1016/S0149-2063_03_00086-2

Kanter, R. M. (1989). "Careers and the wealth of nations: a macro-perspective on the structure and implications of career forms," in Handbook of Career Theory, eds M. Arthur, D. Hall, and B. Lawrence (Cambridge: Cambridge University Press), 506-522.

Kenny, D. A., Kaniskan, B., and McCoach, D. B. (2014). The performance of RMSEA in models with small degrees of freedom. Sociol. Methods Res. 24, 1-22. doi: 10.1177/0049124114543236

Kenny, M. E., and Hage, S. M. (2009). The next frontier: prevention as an instrument of social justice. J. Prim. Prev. 30, 1-10. doi: 10.1007/s10935-0080163-7

Kuratko, D. F. (2005). The emergence of entrepreneurship education: development, trends, and challenges. Entrep. Theory Pract. 29, 577-597. doi: 10.1111/j.1540-6520.2005.00099.x

Lumpkin, G. T., and Dess, G. G. (1996). Clarifying the entrepreneurial orientation construct and linking it to performance. Acad. Manag. Rev. 21, 135-172. doi: 10.5465/AMR.1996.9602161568

Lundberg, G. D. (2004). Professionalism in Medicine is the Basis for all that Follows. Available at: http://www.medscape.com/viewarticle/490035

Luthans, F., Avolio, B. J., Avey, J. B., and Norman, S. M. (2007). Positive psychological capital: measurement and relationship with performance and satisfaction. Pers. Psychol. 60, 541-572. doi: 10.1111/j.1744-6570.2007. 00083.x

MacCallum, R. C., Browne, M. W., and Sugawara, H. M. (1996). Power analysis and determination of sample size for covariance structure modeling. Psychol. Methods 1, 130-149. doi: 10.1037/1082-989X.1.2.130

Michael, S., Storey, D., and Thomas, H. (2002). "Discovery and coordination in strategic management and entrepreneurship," in Strategic Entrepreneurship, Creating a New Mindset, eds M. A. Hitt, R. D. Ireland, S. M. Camp, and D. L. Sexton (Oxford: Blackwell Publishers), 45-65.

Mucci, N., Giorgi, G., Roncaioli, M., Perez, J. F., and Arcangeli, G. (2016). The correlation between stress and economic crisis: a systematic review. Neuropsychiatr. Dis. Treat. 12, 983-993. doi: 10.2147/NDT.S98525

Nunnally, J. C., and Bernstein, I. H. (1994). Psychometric Theory, 3rd Edn. New York, NY: McGraw-Hill.

Okudana, G. E., and Rzasa, S. E. (2006). A project-based approach to entrepreneurial leadership education. Technovation 26, 195-210. doi: 10.1016/ j.technovation.2004.10.012

Prezza, M., Trombaccia, F. R., and Armento, L. (1997). The Rosenberg Self-Esteem Scale: Italian translation and validation [La scala dell'Autostima di Rosenberg: traduzione e validazione Italiana]. Appl. Psychol. Bull. 223, 34-44.

Rauch, C. F., and Behling, O. (1984). "Functionalism: basis for an alternate approach to the study of leadership," in Leaders and Managers: International Perspectives on Managerial Behavior and Leadership, eds J. G. Hunt, D. Hosking, C. Schriesheim, and R. Stewart (Elmsford, NY: Pergamon), 45-62.

Renko, M., El Tarabishy, A., Carsrud, A. L., and Brännback, M. (2015). Understanding and measuring entrepreneurial leadership style. J. Small Bus. Manag. 53, 54-74. doi: 10.1111/jsbm.12086

Renko, M., Kroeck, K. G., and Bullough, A. (2012). Expectancy theory and nascent entrepreneurship. Small Bus. Econ. 39, 667-684. doi: 10.1007/s11187-0119354-3
Rosenberg, M. (1965). Society and the Adolescent Self-Image. Princeton, NJ: Princeton University Press.

Sartori, R., Ceschi, A., and Costantini, A. (2015). On decision processes in businesses, companies and organizations computed through a generative approach: the case of the agent-based modeling. Int. J. Bus. Res. 15, 25-38. doi: 10.18374/IJBR-15-2.3

Sartori, R., Favretto, G., and Ceschi, A. (2013). The relationships between innovation and human and psychological capital in organizations: a review. Innov. J. 18, 2.

Savickas, M. L. (2002). Reinvigorating the study of careers. J. Vocat. Behav. 61, 381-385. doi: 10.1006/jvbe.2002.1880

Savickas, M. L. (2011). Career Counseling. Washington, DC: American Psychological Association.

Schermelleh-Engel, K., Moosbrugger, H., and Muller, H. (2003). Evaluating the fit of structural equation models: tests of significance and goodness-of-fit models. Methods Psychol. Res. Online 8, 23-74.

Shane, S. (1996). Explaining variation in rates of entrepreneurship in the United States: 1899-1988. J. Manag. 22, 747-781. doi: 10.1016/S0149-2063(96)90021-5

Shane, S., and Venkataraman, S. (2000). The promise of entrepreneurship as a field of research. Acad. Manag. Rev. 25, 217-226. doi: 10.5465/AMR.2000.2791611

Steiger, J. H. (1990). Structural model evaluation and modification: an interval estimation approach. Multivar. Behav. Res. 25, 173-180.

Super, D. E. (1957). The Psychology of Careers. New York, NY: Harper and Row.

Super, D. E. (1980). A life-span, life space approach to career development. J. Vocat. Behav. 16, 282-298. doi: 10.1016/0001-8791(80)90056-1

Surie, G., and Ashley, A. (2008). Integrating pragmatism and ethics in entrepreneurial leadership for sustainable value creation. J. Bus. Ethics 81, $235-246$.

Thornberry, N. (2006). Lead Like an Entrepreneur. Blacklick, OH: McGraw-Hill.

Thornton, P. H. (1999). The sociology of entrepreneurship. Annu. Rev. Sociol. 25, 19-46. doi: 10.1146/annurev.soc.25.1.19

Vecchio, R. P. (2003). Entrepreneurship and leadership: common trends and common threads. Hum. Resour. Manag. Rev. 13, 303-328. doi: 10.1016/S10534822(03)00019-6

Wang, A. C., and Cheng, B. S. (2010). When does benevolent leadership lead to creativity? The moderating role of creative role identity and job autonomy. J. Organ. Behav. 31, 106-121. doi: 10.1002/job.634

Winter, J. C. F., Dodou, D., and Wieringa, P. A. (2009). Exploratory factor analysis with small sample sizes. Multivar. Behav. Res. 44, 147-181. doi: 10.1080/ 00273170902794206

World Medical Association [WMA] (2013). WMA Declaration of Helsinki Ethical Principles for Medical Research Involving Human Subjects. Available at: http://www.wma.net/en/30publications/10policies/b3/

Zaleznik, A. (1977). Managers and leaders: are they different? Harv. Bus. Rev. 55, $67-78$.

Conflict of Interest Statement: The authors declare that the research was conducted in the absence of any commercial or financial relationships that could be construed as a potential conflict of interest.

Copyright (c) 2016 Di Fabio, Bucci and Gori. This is an open-access article distributed under the terms of the Creative Commons Attribution License (CC BY). The use, distribution or reproduction in other forums is permitted, provided the original author(s) or licensor are credited and that the original publication in this journal is cited, in accordance with accepted academic practice. No use, distribution or reproduction is permitted which does not comply with these terms. 


\section{APPENDIX}

\section{High Entrepreneurship, Leadership, Professionalism - Questionnaire (HELP-Q) Annamaria Di Fabio, Ornella Bucci, and Alessio Gori}

Please read each statement carefully and indicate the degree to which you recognize yourself in it by choosing the appropriate number based on the following scale.

\begin{tabular}{|c|c|c|c|c|}
\hline 1 & 2 & 3 & 4 & 5 \\
\hline Not at all & A little & Somewhat & A lot & A great deal \\
\hline
\end{tabular}

(1) To what extent it is important for me: (Quanto è importante per me)

\begin{tabular}{|c|c|c|c|c|c|}
\hline (1) To excel in my chosen area of study/work (Eccellere nella mia area di studi e/o di lavoro) & 1 & 2 & 3 & 4 & 5 \\
\hline (2) To become a leader or a manager (Diventare un leader o un manager ) & 1 & 2 & 3 & 4 & 5 \\
\hline (3) Look for new ideas on how to make a profit (Cercare nuove idee su come realizzare guadagni) & 1 & 2 & 3 & 4 & 5 \\
\hline
\end{tabular}

(2) My main professional goal is to: (Il mio principale obiettivo professionale è quello di)

\begin{tabular}{|c|c|c|c|c|c|}
\hline $\begin{array}{l}\text { (4) Be an expert, a specialist, or a professional in my field of study/work (Essere un esperto, uno } \\
\text { specialista o un professionista nel mio campo di studi/lavoro) }\end{array}$ & 1 & 2 & 3 & 4 & 5 \\
\hline $\begin{array}{l}\text { (5) Know how a leader or a manager can inspire/valorize the people who work with him/her } \\
\text { (Saper essere un leader o un manager in grado di ispirare/valorizzare le persone che lavorano con } \\
\text { lui/lei) }\end{array}$ & 1 & 2 & 3 & 4 & 5 \\
\hline $\begin{array}{l}\text { (6) Be an entrepreneur by starting my own company soon after graduation or in the near future } \\
\text { (Essere un imprenditore avviando presto la mia azienda dopo la laurea o nel mio prossimo } \\
\text { futuro) }\end{array}$ & 1 & 2 & 3 & 4 & 5 \\
\hline
\end{tabular}

(3) To what extent do I feel able to: (In che misura mi sento in grado di):

(7) Become a specialist or a professional in my field of study and/or work (Diventare uno dei migliori esperti o professionisti nel mio campo di studi e/o lavoro)

(8) Create and/or build a vision of leadership and/or management style to inspire/valorize others (Creare e/o costruire una visione di leadership e/o di stile manageriale in grado di ispirare/valorizzare gli altri)

(9) Find opportunities to start an efficient and successful business project (Trovare opportunità per avviare un progetto imprenditoriale efficiente e di successo) 


\title{
Positive Relational Management for Healthy Organizations: Psychometric Properties of a New Scale for Prevention for Workers
}

\author{
Annamaria Di Fabio* \\ Department of Education and Psychology (Psychology Section), University of Florence, Florence, Italy
}

This contribution aims at evaluating the psychometric properties of the Positive Relational Management Scale (PRMS) in a sample of 251 Italian workers. The dimensionality, reliability, and concurrent validity of the scale were investigated. Confirmatory factor analysis supported a correlated three-dimensional version of the scale, comprising Respect, Caring, and Connectedness. Latent correlations among the dimensions were moderate-to-strong (0.44-0.57), but suggestive of the multidimensionality of the scores. In addition, good internal consistency was confirmed. The concurrent validity is good as the Pearson's correlations between PRMS and measure for social support, life satisfaction, life meaningfulness, and flourishing range

\section{OPEN ACCESS}

Edited by:

Margaret M. Hopkins,

University of Toledo, USA

Reviewed by:

Tommaso Fabbri,

Università di Reggio Emilia, Italy Harsha Perera,

University of Nevada, Las Vegas, USA

*Correspondence: Annamaria Di Fabio

adifabio@psico.unifi.it

Specialty section:

This article was submitted to

Organizational Psychology,

a section of the journal

Frontiers in Psychology

Received: 30 May 2016 Accepted: 20 September 2016

Published: 13 October 2016

Citation:

Di Fabio A (2016) Positive Relational Management for Healthy

Organizations: Psychometric

Properties of a New Scale

for Prevention for Workers.

Front. Psychol. 7:1523.

doi: 10.3389/fpsyg.2016.01523 from 0.39 to 0.52 . The results indicate that the PRMS is a valid instrument for measuring positive relational management at work in the Italian context within a positive preventive perspective.

Keywords: positive relational management, psychometric properties, positive relational management scale, positive psychology, inclusive psychology of working, inclusive relational perspective, relational theory of working

\section{INTRODUCTION}

\section{The Importance of Relationships}

Interpersonal relationships and relational experiences are of primary importance for work success (Blustein et al., 1995; Schultheiss et al., 2001; Kenny et al., 2003; Blustein, 2006). In the field of work and organizational psychology, Blustein (2006) in his inclusive psychology of working states that relationships are an important need of people and that working can be coupled with three basic needs: the need for survival and power, the need for social relationships, and the need for self-determination. Within a relational perspective Blustein (2011) later maintains that the work is an inherently relational act: relationships influence and shape every decision, experience, and interaction of individuals in the world of work (Blustein, 2011; Di Fabio, 2014a). Relationships can thus be considered fundamental resources for workers, highlighting the importance of creating optimal conditions to support adaptive relationships in organizational contexts from a positive psychology perspective (Seligman and Csikszentmihalyi, 2000; Seligman, 2002) in terms of flourishing relationships (Di Fabio, 2014a; Snyder et al., 2014). The focus should therefore be on helping people build lives through work and relationships (Blustein, 2011; Richardson, 2012). This calls for a positive organizational psychology approach that underlines the importance of developing positive and supportive relationships in the workplace (Snyder et al., 2014; Di Fabio, 2015a,b; Di Fabio and Gori, 2016b). 


\section{Healthy Organization and Healthy Business}

The positive organizational psychology framework (Snyder et al., 2014; Di Fabio, 2015b) also involves the concept of the healthy organization (De Smet et al., 2007) implying the relevance of the health and well-being of workers for business and organizational health (Danna and Griffin, 1999; Di Fabio et al., 2014; Grawitch and Ballard, 2016). The focus on the concept of health in organizations is in line with the definition of health by World Health Organization [WHO] (1998). Indeed health is not merely the absence of disease: "it is a state of complete physical, mental, spiritual and social well-being and not merely the absence of disease or infirmity" (World Health Organization [WHO], 1998). Thus healthy people in organizations are flourishing and resilient workers on the one side; on the other side positive work environment focuses on workers' health, well-being and joint performance for healthy organizations (Di Fabio and Busoni, 2007; Di Fabio, 2014a; Snyder et al., 2014; Di Fabio and Gori, 2016b; Di Fabio and Kenny, 2016a). Substantially healthy organizations promote healthy businesses (Grawitch and Ballard, 2016) by taking into account not only performance but at the same time workers' as well as organizations' well-being (Di Fabio and Kenny, 2016a; Di Fabio and Maree, 2016). The concept of healthy organization (De Smet et al., 2007) highlights the importance of health and performance of individuals for organizational success and business, effectiveness and functioning (Danna and Griffin, 1999) and underlines the sound relationships between workers and organizational well-being. A healthy organization is characterized by both good profit and health business (Grawitch and Ballard, 2016) and the well-being of workers.

In order to promote healthy organizations and healthy businesses, the concepts of gainful employment and life (Di Fabio, 2014a, 2015b) and new ways of conceptualizing organizational relationality require urgent attention (Di Fabio, 2015b).

\section{Relationships and Well-Being in Organizations}

In the current unstable and insecure world of work, the wellbeing of individuals in organizations is under threat (Di Fabio, 2014a,b, 2015b; Di Fabio et al., 2016a). Because relationships are a key factor in people's well-being (Gallagher and VellaBrodrick, 2008; Suldo et al., 2009; Ferguson and Goodwin, 2010; Blustein, 2011; Kalpana Rani, 2016), fostering positive relationships can promote well-being in the workplace (Di Fabio, 2014a, 2015b; Snyder et al., 2014; Di Fabio and Gori, 2016b). The attention to a condition of well-being can also improve the opportunities of workers to adapt themselves to changes and uncertainty of the postmodern world of work (Di Fabio and Kenny, 2016a).

Particularly from a positive preventive perspective (Hage et al., 2007; Kenny and Hage, 2009; Di Fabio and Kenny, 2011, 2012, 2015, 2016b; Kenny et al., 2014; Di Fabio et al., 2016a), it is crucial to anticipate critical situations in order to intervene early as well as identify promptly resources that can promote people's well-being (Di Fabio and Bucci, 2015; Di Fabio and Palazzeschi, 2015a, 2016) and optimal functioning (Di Fabio et al., 2016a). In line with American Psychological Guidelines (Hage et al., 2007) early interventions are more effective when efforts to increase resources and competencies (Boyatzis et al., 2002, 2015; Di Fabio, 2006; Boyatzis and Saatcioglu, 2008; Di Fabio and Bernaud, 2008; Boyatzis, 2009) are combined with efforts to decrease risks (Di Fabio and Kenny, 2011; Di Fabio, 2014a; Di Fabio and Saklofske, 2014a,b; Di Fabio et al., 2014). The availability of instruments able to detect relational resources in different contexts and in particular in the workplace, is important for early interventions to promote well-being focusing on individual and organizational strengths (Di Fabio, 2014a). A positive workplace relational environment needs to be created to enable workers to increase their personal resources to face the ever-changing word of work, to accept the inevitability of change (Di Fabio and Gori, 2016a), and to promote their well-being (Di Fabio, 2014a; Snyder et al., 2014; Di Fabio and Gori, 2016a; Di Fabio and Kenny, 2016a).

In a positive preventive perspective (Di Fabio and Kenny, 2016a) the focus of interventions aiming at promoting wellbeing in order to gain balance between oneself and other individuals and context, asks for the detection and promotion of the following aspects: respects for me and others, take care of me and of others, the connection and strong relationships with me and with others (Di Fabio, 2014a, 2015b). Positive preventive perspective (Hage et al., 2007; Kenny and Hage, 2009; Di Fabio et al., 2016a) highlights the need for individuals to enhance and manage positive relationships (Di Fabio and Palazzeschi, 2008, 2012a,b; Di Fabio et al., 2012, 2013b, 2015; Di Fabio, 2014a,b, 2015b) and to improve respectivity (Maree, 2012) and relationality (Blustein, 2011). For individuals taking care of self and others is important for flourishing in the construction of new chapters of their personal and professional lives (Di Fabio, 2014a).

\section{Positive Self and Relational Management}

Positive relational management is central in the Positive Self and Relational Management (PS\&RM, Di Fabio and Kenny, 2016a) model. PS\&RM (Di Fabio and Kenny, 2016a) draw upon the career and life management through self and relational management (Di Fabio, 2014a; Di Fabio and Kenny, 2016a) integrating work and relationship in a dialectical manner across the lifespan (Di Fabio, 2014a), and strengthening many aspects of the self in a relational context. PS\&RM (Di Fabio and Kenny, 2016a) defines lifelong development as "the development of individuals' strengths, potentials and varied talents from a lifespan perspective and the positive dialectic of the self in relationship" (Guichard, 2004, 2005, 2009, 2013; Blustein, 2011; Savickas, 2011; Di Fabio, 2014a, 2015b). In PS\&RM (Di Fabio and Kenny, 2016a) the construct of positive lifelong relational management is fundamental, including relational and social skills, such as emotional intelligence and social support, and competencies useful to manage the current challenges. In this model the construct of Positive relational management emerges, relying on the ideas of respect and caring for the 
self and others and the relationships between people (Blustein, 2006; Di Fabio and Maree, 2012, 2016; Maree, 2013; Di Fabio, 2015b).

Moving from the importance of the concepts of relationality, respectivity and caring toward oneself and others in the relationships (Blustein, 2006; Di Fabio and Maree, 2012, 2016; Maree, 2013; Di Fabio, 2015b; Di Fabio and Bucci, 2016), central in the positive relational management construct, a new instrument was developed, the Positive Relational Management Scale (PRMS; Di Fabio, 2015b).

The scale consists of 12 items, four for each dimension: Respect (my respect for others, the respect of others for me, my respect for myself), Caring (my care for others, the care of others for me, my care for myself), and Connectedness (my connectedness with family members, with friends, with significant others).

These aspects are not comprised by other construct and relative measure, such as perceived social support received by others (Zimet et al., 1988) or flourishing (Diener et al., 2010), a process of growth in which social relationships are one of the main aspects for individual.

A pilot study (Di Fabio, 2015b) with Italian university students empirically confirmed the theoretical three-dimensional structure of the scale. In this study an exploratory factor analysis (EFA) was firstly conducted and then a confirmatory factor analysis (CFA) was used to analyze the three-dimensional structure of the PRMS. The goodness-of-fit indices were good for the ratio of the chi-square to degrees of freedom $(\chi / \mathrm{gdl}=1.64)$ acceptable for the Comparative fit Index $(\mathrm{CFI}=0.92)$ and the Non-Normed Fit Index (NNFI $=0.94)$, and acceptable for the Root Mean Square Error of Approximation (RMSEA = 0.07) (Browne and Cudeck, 1993; Marsh et al., 2004). The scale presented also a good reliability (Cronbach's alpha coefficient are 0.79 for Caring, 0.80 for Connection, 0.81 for Respect, and 0.84 for PRMS total).

Because positive relational management is a resource in university students, in line with previous studies (Di Fabio, 2015b; Di Fabio and Kenny, 2016a) it is expected as a resource also for relational productive and positive adaptation in the workplace (Di Fabio and Kenny, 2016a). In Italian university students associations between positive relational management and social support emerged (Di Fabio, 2015b; Di Fabio and Kenny, 2016a), showing the importance to nurture sound relationships (Di Fabio et al., 2013a; Kozan et al., 2014). Some studies reported also the positive association between positive relational management and hedonic well-being in terms of life satisfaction (Di Fabio and Kenny, 2016a), and eudaimonic wellbeing in terms of life meaningfulness and flourishing (Di Fabio and Kenny, 2016a), indicating that positive relationships can promote individual well-being (Arnoux-Nicolas et al., 2016). The value of positive relational management was also underlined in an organizational context regarding workplace relational civility (Di Fabio and Gori, 2016b).

Against this theoretical background, and on the basis of the good results of the pilot study (Di Fabio, 2015b) with regard to Italian university students, the aim of the present study was to evaluate the psychometric properties of the PRMS by Di Fabio (2015b) also in Italian workers.

\section{MATERIALS AND METHODS}

\section{Participants}

Two hundred and fifty-one workers of different public and private organizations in central Italy participated in the study. Regarding gender, 158 were men $(62.95 \%)$ and 93 were women $(37.05 \%)$, with a mean age of $38.75(D S=10.02)$. Regarding occupations, 143 (57.97\%) were white collars and $108(42.03 \%)$ were blue collars.

\section{Measures}

\section{Positive Relational Management Scale (PRMS) for Workers}

The PRMS is a measure consisting of 12 items on a five-point Likert scale ranging from 1 (strongly disagree) to 5 (strongly agree). The PRMS detects three dimensions (Respect, Caring, Connectedness) and also has a total score (e.g., Respect: "I keep a balance between respect toward others and toward myself"; Caring: "I often take care of others"; Connectedness: "I have good relationships with my family"). The Cronbach's alpha coefficients in the previous study with Italian university students (Di Fabio, 2015b) were the following: for Respect 0.81; for Caring 0.79; for Connection 0.80. Regarding the concurrent validity, the correlations between the PRMS and perceived social support were 0.36 for Respect, 0.38 for Caring, 0.42 for Connectedness, and 0.41 for the total (Di Fabio, 2015b).

The psychometric properties of the PRMS for workers were analyzed in the present study. The items of the PRMS are shown in the Appendix at the end of this article.

\section{Multidimensional Scale for Perceived Social Support (MSPSS)}

The Multidimensional Scale for Perceived Social Support (MSPSS; Zimet et al., 1988) in the Italian version by Di Fabio and Palazzeschi (2015a) was used to evaluate perceived social support. The scale consists of 12 items with response options on a seven-point Likert scale ranging from $1=$ strongly disagree to 7 = strongly agree. The MSPSS detects perceived support from family members (example of item: "My family works very hard to help me"), friends (example of item: "I can speak about my problems with my friends"), significant others (example of item: "When I need someone, there is always a special person who stands by me"). Cronbach's alpha coefficients were 0.92 for the Family dimension, 0.90 for the Friends dimension, 0.93 for the Significant others dimension, and 0.91 for the total score. Regarding the concurrent validity, the correlations between the MSPSS and the Italian version of SWLS (Di Fabio and Gori, 2015) were 0.49 for Perceived support from family; 0.42 for Perceived support from friends; 0.39 for Significant others dimension; and 0.51 for the total score.

\section{Satisfaction With Life Scale (SWLS)}

Life satisfaction was assessed using the Italian version (Di Fabio and Gori, 2015) of the Satisfaction With Life Scale (SWLS, Diener et al., 1985). The questionnaire consists of five items, which are rated using a seven-point Likert scale that ranges from $1=$ Strongly disagree to $7=$ Strongly agree. 
The Cronbach's alpha coefficient reported by Di Fabio and Gori (2015) was 0.85. Regarding the concurrent validity, the correlations between the SWLS were 0.57 with the Italian version of Rosenberg Self-Esteem Scale (Prezza et al., 1997); 0.51 with the Italian version of MSPSS (Di Fabio and Palazzeschi, 2015a); and 0.65 with the Italian version of TEIQue (Di Fabio et al., 2016b).

\section{Meaningful Life Measure (MLM)}

The Meaningful Life Measure (MLM, Morgan and Farsides, 2009) in the Italian version by Di Fabio (2014d) was used to evaluate meaning in life. The questionnaire consists of 23 items with response options on a seven-point Likert scale ranging from $1=$ strongly disagree to $7=$ strongly agree. The MLM detects five dimensions: Exciting life, Accomplished life, Principled life, Purposeful life, Valued life. Cronbach's alpha coefficient for the total score was 0.82 . Regarding the concurrent validity, the correlations between the MLM were 0.58 with the Italian version of Meaning in Life Questionnaire (MLQ, Di Fabio, 2014e); 0.43 with the Italian version of SWLS (Di Fabio and Gori, 2015); 0.49 with Positive Affect and -0.20 with Negative Affect of the Italian version of Positive and Negative Affect Schedule (PANAS, Terraciano et al., 2003).

\section{Flourishing Scale}

The Flourishing Scale (Diener et al., 2010) in the Italian version by Di Fabio (2016a) was used to evaluate flourishing. This measure consists of eight items with response options on a seven-point Likert scale ranging from $1=$ strongly disagree to $7=$ strongly agree. Examples of items are "My social relationships are supportive and rewarding," "I lead a purposeful and meaningful life," "I am optimistic about my future." Cronbach's alpha coefficient was 0.88 . Regarding the concurrent validity, the correlations between the Flourishing Scale were 0.69 with the Italian version of MLM (Di Fabio, 2014d); 0.48 with the Italian version of the Authenticity Scale (Di Fabio, 2014c); 0.48 with the Italian version of SWLS (Di Fabio and Gori, 2015); 0.54 with Positive Affect and -0.33 with Negative Affect of the Italian version of Positive and Negative Affect Schedule (PANAS, Terraciano et al., 2003).

\section{Procedure}

The instruments/questionnaires were administered to groups of respondents by trained psychologists. The administration sequence was alternated to counter the possible effects of a set presentation of the instruments. The instruments were administered according to the requirements of privacy and informed consent of Italian law (Law Decree DL-196/2003). Regarding ethical standards for research, the study adhered to the latest version of the Declaration of Helsinki revised in Fortaleza (World Medical Association [WMA], 2013). They were followed and approved by the Department of Education and Psychology of the University of Florence (Italy).

\section{Data Analysis}

Confirmatory factor analysis, conducted through the maximum likelihood estimation using Mplus version 7 (Muthén and Muthén, 1998-2015), was used to analyze the factor structure of the PRMS for workers, and multiple goodness-of-fit indices were used to assess statistically the closeness of the hypothetical

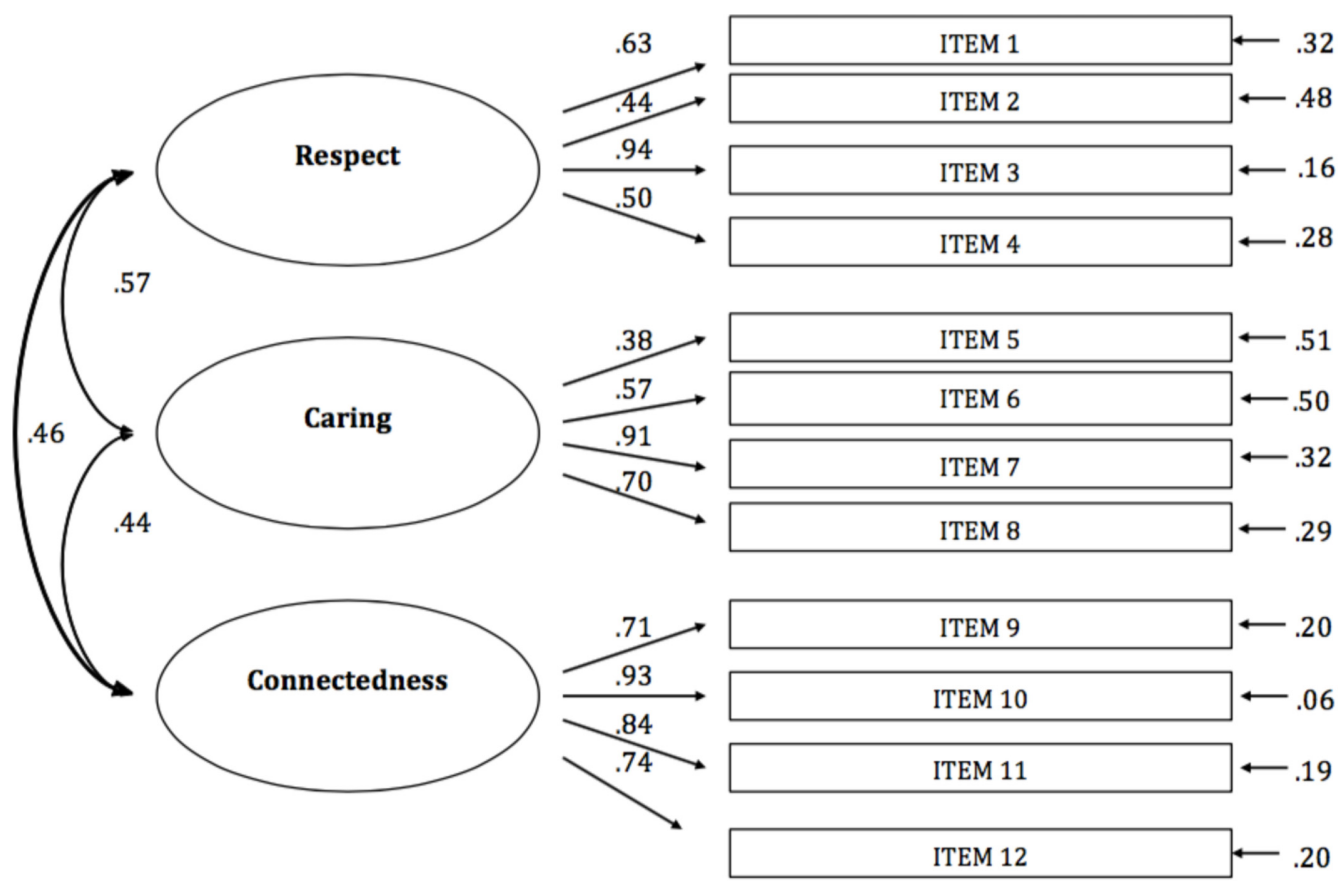

FIGURE 1 | Confirmatory factor analysis (CFA) of the theoretical three-factor structure of the Positive Relational Management Scale (PRMS). 
model to the empirical data. The reliance on fit indices, as opposed to statistical tests of fit like the chi-square, to determine model fit emerges from limitations with the chi-square. Standard goodness-of-fit indexes were used including the chi-square $(\chi 2)$, the Tucker-Lewis Index (TLI), the Comparative Fit Index (CFI), the Standardized Root Mean Square Residual (SRMR), and the Root Mean Square Error of Approximation (RMSEA). Values greater than 0.90 and 0.95 of CFI and TLI are indicative of acceptable and excellent fit, respectively; and SRMR and RMSEA values lower than 0.05 and 0.08 are suggestive of close and reasonable fit, respectively (Browne and Cudeck, 1993; Marsh et al., 2004), and ideally equal to or less than 0.05 , are indices of good fit (Steiger, 1990; Schermelleh-Engel et al., 2003; Giannini et al., 2011). The reliability of the PRMS was confirmed through Cronbach's alpha coefficient and corrected item-total correlations. Pearson's correlations between the PRMS and the MSPSS, SWLS, MLM, and FS were used to verify several aspects of concurrent validity.

\section{RESULTS}

A CFA was carried out to confirm the structure of the PRMS for workers (Figure 1).

The goodness of fit indices are acceptable for the threedimensional structure of the PRSM. The chi-square, degree of freedom, and probability values for the three-dimensional model are $\chi^{2}(51)=135.42(p<0.001)$. The other goodness-of-fit indices showed acceptable and reasonable values $(\mathrm{CFI}=0.93$; $\mathrm{TLI}=0.91$; SRMR $=0.07$; RMSEA $=0.05$ ).

The goodness of fit indices of the bi-dimensional model $(\mathrm{TLI}=0.83 ; \mathrm{CFI}=0.87 ; \mathrm{RMSEA}=0.11 ; \mathrm{SRMR}=0.06$; $\mathrm{BIC}=5975.927)$ and of the uni-dimensional model tested $(\mathrm{TLI}=0.60 ; \mathrm{CFI}=0.67$; $\mathrm{RMSEA}=0.18$; $\mathrm{SRMR}=0.12)$ were lower than the three-factor model.

According to the literature (Raftery, 1995; Muthén and Muthén, 1998-2015) the three examined structures of the PRMS were compared, using the Mplus Bayesian Information Criterion (BIC) as a suitable statistical comparison. Comparison between BIC of two-factor model and three-factor model was 5975.927$5901.758=74.169$; comparison between uni-dimensional model and three-factor model was 6220.609-5901.758 $=318.851$. A value of comparison greater than 10 highlights a strong evidence that the model with the lower BIC fits better data, in this case the three-factor model of the PRMS.

Relating to the issue of gender invariance it was conducted MIMIC modeling analysis using Mplus 7. The results of the MIMIC model showed that gender had no significant effect regarding the dimensions of Caring and Connectedness; gender had a significant effect regarding the dimension of Respect.

Cronbach's alpha coefficients for the three dimensions of the PRMS and for the total score were calculated to verify the internal consistency of the scale (Table 1).

The corrected item total correlations were also calculated (Table 2).

The correlations between the PRMS and the MSPSS, SWLS, MLM, and FL are shown in Table 3.
TABLE 1 | Cronbach's alpha for the three dimensions and for the total score of the Positive Relational Management Scale for workers.

\begin{tabular}{lc}
\hline & Cronbach's alpha \\
\hline Respect & 0.82 \\
Caring & 0.80 \\
Connectedness & 0.81 \\
Positive Relational Management Scale total & 0.85
\end{tabular}

$N=251$.

TABLE 2 | Correlations item-total score of the Positive Relational Management Scale (PRMS).

\begin{tabular}{lcccc}
\hline & $\begin{array}{c}\text { PRMS total } \\
\text { score }\end{array}$ & $\begin{array}{c}\text { PRMS } \\
\text { respect }\end{array}$ & $\begin{array}{c}\text { PRMS } \\
\text { caring }\end{array}$ & $\begin{array}{c}\text { PRMS } \\
\text { connectedness }\end{array}$ \\
\hline PRMS1 & 0.46 & 0.60 & & \\
PRMS2 & 0.55 & 0.66 & & \\
PRMS3 & 0.63 & 0.79 & & \\
PRMS4 & 0.65 & 0.68 & & \\
PRMS5 & 0.43 & & 0.53 & \\
PRMS6 & 0.49 & & 0.62 & \\
PRMS7 & 0.62 & & 0.76 & \\
PRMS8 & 0.65 & & 0.72 & \\
PRMS9 & 0.57 & & & 0.76 \\
PRMS10 & 0.70 & & & 0.89 \\
PRMS11 & 0.57 & & & 0.81 \\
PRMS12 & 0.70 & & & \\
\hline
\end{tabular}

$N=251$.

TABLE 3 | Correlations of the Positive Relational Management Scale for workers with the MSPSS, SWLS, MLM, and FS.

\begin{tabular}{lllll}
\hline & MSPSS & SWLS & MLM & FS \\
\hline Respect & $0.41^{* *}$ & $0.49^{* *}$ & $0.41^{* *}$ & $0.43^{* *}$ \\
Caring & $0.44^{* *}$ & $0.52^{* *}$ & $0.39^{* *}$ & $0.41^{* *}$ \\
Connectedness & $0.46^{* *}$ & $0.50^{* *}$ & $0.42^{* *}$ & $0.47^{* *}$ \\
Total & $0.45^{* *}$ & $0.51^{* *}$ & $0.43^{* *}$ & $0.45^{* *}$ \\
\hline
\end{tabular}

$N=251 .{ }^{* *} p<0.01$. MSPSS, Multidimensional Scale for Perceived Social Support; SWLS, Satisfaction With Life Scale; MLM, Meaningful Life Measure; FS, Flourishing Scale.

\section{DISCUSSION}

The aim of the present study was to evaluate the psychometric properties of the PRMS (Di Fabio, 2015b) also for Italian workers. In line with the results of the pilot study carried out on Italian university students (Di Fabio, 2015b), the espoused three-factor model with its three dimensions was confirmed also in the present study with Italian workers, via CFA, as indicated by good indices of fit to the empirical data. Latent correlations of the three factors (Respect, Caring, Connectedness) indicate moderate relationships between the three factors (ranging from 0.44 to 0.57 ) supporting a three-factor structure of the PRMS. The reliability of the three dimensions and of the total score of the scale (verified through Cronbach's alpha coefficient and corrected item-total correlations) was good. 
Correlations between the PRSM and the measures used to verify aspects of concurrent validity showed good values, in line with previous studies. In particular, the positive correlation between the PRMS and the MSPSS, that emerged in the pilot study of the PRMS in Italian university students (Di Fabio, 2015b), indicated also the positive association between positive relational management at work and perceived social support, underlining the importance of developing positive and supportive relationships in different individual life contexts and particularly in the workplace, as reported in literature (Di Fabio, 2014a, 2015b; Snyder et al., 2014; Di Fabio and Kenny, 2016a). The quality of relationships at work can thus also enhance the quality of work produced and thereby promote healthy organizations (De Smet et al., 2007; Di Fabio, 2014a, 2015b; Di Fabio and Kenny, 2016a; Di Fabio and Maree, 2016).

Furthermore, the positive correlations between the PRMS and the SWLS, MLM (Di Fabio and Kenny, 2016a) and FS (Di Fabio and Gori, 2016b) indicated a positive association between positive relational management and both hedonic (SWLS) and eudaimonic well-being (MLM, FS) thus showing that positive relationships are a key factor in individual well-being in the workplace (Gallagher and Vella-Brodrick, 2008; Suldo et al., 2009; Ferguson and Goodwin, 2010; Blustein, 2011; Kalpana Rani, 2016). From a positive preventive point of view, positive relationships can promote well-being in the workplace (Di Fabio, 2014a, 2015b; Snyder et al., 2014; Di Fabio and Gori, 2016b), helping workers to positively live in the complexity of the current world of work (Di Fabio and Kenny, 2016a).

The results of the present study indicate that the PRMS can be considered a reliable and valid instrument for detecting the positive relational management construct at work. Nevertheless, some limitations of the study need mentioning. The psychometric properties of the PRMS for workers were investigated in a small group of Italian workers from different public and private organizations in central Italy who were not necessarily representative of all Italian workers. Future research should therefore include workers from other geographical areas in Italy and also from different types of organizations. It would also be interesting to compare the PRMS results for Italian workers with those for workers in other countries.

Furthermore, the use of Pearson's correlations for verifying aspect of concurrent validity could be a limitation of the present study by virtue of their failure to controls for

\section{REFERENCES}

Arnoux-Nicolas, C., Sovet, L., Lhotellier, L., Di Fabio, A., and Bernaud, J.-L. (2016). Perceived work conditions and turnover intentions: the mediating role of meaning of life and meaning of work. Front. Psychol. 7:704. doi: 10.3389/fpsyg.2016.00704

Blustein, D. L. (2006). The Psychology of Working: A New Perspective for Counseling, Career Development, and Public Policy. Mahway, NJ: Lawrence Erlbaum Associates.

Blustein, D. L. (2011). A relational theory of working. J. Vocat. Behav. 79, 1-17. doi: 10.1016/j.jvb.2010.10.004

Blustein, D. L., Prezioso, M. S., and Schultheiss, D. P. (1995). Attachment theory and career development: current status and future directions. Counsel. Psychol. 23, 416-432. doi: 10.1177/0011000095233002 errors of measurement and partial out common method variance that may lead to upwardly biased relationships. In future studies it would be interesting to conduct these analyses in a latent framework, controlling for errors of measurements and report concomitant fit indices for separate models with each model containing a different criterion latent construct.

Despite the indicated limitations, the PRMS is an instrument that can be used confidently to detect positive relational management in the Italian workplace. This instrument can open new perspectives for research and intervention in organizational contexts, particularly from a positive preventive perspective (Hage et al., 2007; Kenny and Hage, 2009; Di Fabio and Kenny, 2012; Di Fabio et al., 2014, 2016a). On the basis of this framework (Hage et al., 2007; Kenny and Hage, 2009; Di Fabio and Saklofske, 2014a,b; Kenny et al., 2014; Di Fabio et al., 2016a), positive relational management needs to be promoted to enhance relational strengths also in the workplace (Blustein, 2011; Di Fabio and Kenny, 2012, 2015), improving the quality of work and lives of workers (Di Fabio and Blustein, 2016) and thereby fostering healthy organizations.

It is therefore important to create a positive workplace relational environment to enable workers to increase their personal resources (Boyatzis et al., 2002, 2015; Boyatzis and Saatcioglu, 2008; Di Fabio and Bernaud, 2008; Boyatzis, 2009; Di Fabio and Maree, 2012; Rehfuss and Di Fabio, 2012; Di Fabio, 2014a, 2016b; Giorgi et al., 2014, 2015a,b, 2016; Di Fabio and Palazzeschi, 2015b; Di Fabio and Gori, 2016a,b) so that they can enhance their well-being (Snyder et al., 2014; Di Fabio and Kenny, 2016a). This study presents new ways to conceptualize organizational relationality (Di Fabio, 2015b; Di Fabio and Gori, 2016a,b) to promote gainful employment and life (Di Fabio, $2014 a, 2015 b)$, as well as to create healthy organizations and healthy businesses.

\section{AUTHOR CONTRIBUTIONS}

ADF conceptualized the study, chose the theoretical framework, conceptualized the items of the new scale and realized it. ADF collected and analyzed the data, wrote the methods and results. Then ADF wrote the paper, read and revised the manuscript several times.

Boyatzis, R. E. (2009). Competencies as a behavioral approach to emotional intelligence. J. Manag. Dev. 28, 749-770. doi: 10.1108/026217109109 87647

Boyatzis, R. E., Batista-Foguet, J. M., Fernández-i-Marín, X., and Truninger, M. (2015). EI competencies as a related but different characteristic than intelligence. Front. Psychol. 6:72. doi: 10.3389/fpsyg.2015.00072

Boyatzis, R. E., and Saatcioglu, A. (2008). A twenty-year view of trying to develop emotional, social and cognitive intelligence competencies in graduate management education. J. Manag. Dev. 27, 92-108. doi: $10.1108 / 02621710810840785$

Boyatzis, R. E., Stubbs, E. C., and Taylor, S. N. (2002). Learning cognitive and emotional intelligence competencies through graduate management education. Acad. Manag. Learn. Educ. 1, 150-162. doi: 10.5465/AMLE.2002. 8509345 
Browne, M. W., and Cudeck, R. (1993). "Alternative ways of assessing model fit," in Testing Structural Equation Models, eds K. A. Bollen and J. S. Long (Newsbury Park, CA: Sage), 136-162.

Danna, K., and Griffin, R. W. (1999). Health and well-being in the workplace: a review and synthesis of the literature. J. Manag. 25, 357-384. doi: $10.1177 / 014920639902500305$

De Smet, A., Loch, M., and Schaninger, B. (2007). Anatomy of a healthy corporation. Mckinsey Q. 2, 1-11.

Di Fabio, A. (2006). Decisional procrastination correlates: personality traits, selfesteem or perception of cognitive failure? Int. J. Educ. Vocat. Guid. 6, 109-122. doi: 10.1007/s10775-006-9000-9

Di Fabio, A. (2014a). Career counseling and positive psychology in the 21st century: new constructs and measures for evaluating the effectiveness of intervention. J. Counsell. 1, 193-213.

Di Fabio, A. (2014b). Intrapreneurial self-capital: a new construct for the 21st century. J. Employ. Couns. 51, 98-111. doi: 10.1002/j.2161-1920.2014. 00045.x

Di Fabio, A. (2014c). Authenticity scale: un primo contributo alla validazione della versione italiana [Authenticity Scale: A first contribution to validation of the Italian version]. Counsel. Giornale Ital. Ric. Appl. 7, 231-238.

Di Fabio, A. (2014d). Meaningful life measure: primo contributo alla validazione della versione italiana [Meaningful life measure: first contribution to the validation of the italian version]. Counsel. Giornale Ital. Ric. Appl. 7, 307-315.

Di Fabio, A. (2014e). Meaning in Life Questionnaire: un contributo alla validazione della versione italiana con studenti di scuola superiore [Meaning in life questionnaire: a contribution to the validation of the Italian version with high school students]. Counsel. Giornale Ital. Ric. Appl. 7, 317-325.

Di Fabio, A. (2015a). Beyond fluid intelligence and personality traits in social support: the role of ability-based emotional intelligence. Front. Psychol. 6:395. doi: $10.3389 /$ fpsyg. 2015.00395

Di Fabio, A. (2015b). Positive Relational Management Scale per rilevare positività e complessità [Positive Relational Management Scale to detect positivity and complexity]. Counsel. Giornale Ital. Ric. Appl. 8.

Di Fabio, A. (2016a). Flourishing Scale: Primo contributo alla validazione della versione italiana [Flourishing Scale: First contribution to the validation of the Italian version]. Counsel. Giornale Ital. Ric. Appl. 9.

Di Fabio, A. (2016b). Life design and career counseling innovative outcomes. Career Dev. Quart. 64, 35-48. doi: 10.1002/cdq.12039

Di Fabio, A., and Bernaud, J. (2008). Help-seeking in career counseling. J. Vocat. Behav. 72, 60-66. doi: 10.1016/j.jvb.2007.10.006

Di Fabio, A., Bernaud, J.-L., and Kenny, M. E. (2013a). Perceived career counselor relational and technical behaviors and outcomes among Italian university students. J. Career Assess. 21, 190-199. doi: 10.1177/1069072712 466721

Di Fabio, A., Bernaud, J.-L., and Loarer, E. (2014). Emotional intelligence or personality in resistance to change? Empirical results in an Italian health care context. J. Empl. Counsel. 51, 146-157.

Di Fabio, A., and Blustein, D. L. (eds). (2016). From Meaning of Working to Meaningful Lives: The Challenges of Expanding Decent Work. Lausanne: Frontiers Media. doi: 10.3389/978-2-88919-970-9

Di Fabio, A., and Bucci, O. (2015). Affective profiles in Italian high school students: life satisfaction, psychological well-being, self-esteem, and optimism. Front. Psychol. 6:1310. doi: 10.3389/fpsyg.2015.01310

Di Fabio, A., and Bucci, O. (2016). "Green positive guidance and green positive life counseling for decent work and decent lives: some empirical results," in From Meaning of Working to Meaningful Lives: The Challenges of Expanding Decent Work, Vol. 7, eds A. Di Fabio and D. L. Blustein (Lausanne: Frontiers), 261.

Di Fabio, A., and Busoni, L. (2007). Fluid intelligence, personality traits and scholastic success: empirical evidence in a sample of Italian high school students. Pers. Individ. Dif. 43, 2095-2104. doi: 10.1016/j.paid.2007.06.025

Di Fabio, A., and Gori, A. (2015). Measuring adolescent life satisfaction: psychometric properties of the Satisfaction With Life Scale in a sample of Italian adolescents and young adults. J. Psychoeduc. Assessment. 34, 501-506. doi: $10.1177 / 0734282915621223$

Di Fabio, A., and Gori, A. (2016a). Developing a new instrument for assessing acceptance of change. Front. Psychol. 7:802. doi: 10.3389/fpsyg.2016.00802

Di Fabio, A., and Gori, A. (2016b). "Decent work and positive relational outcomes: assessing workplace relational civility (WRC) with a new multidimensional "mirror" measure," in "From Meaning of Working to Meaningful Lives: The Challenges of Expanding Decent Work, eds A. Di Fabio and D. L. Blustein (Lausanne: Frontiers).

Di Fabio, A., and Kenny, M. E. (2011). Promoting emotional intelligence and career decision making among Italian high school students. J. Career Assess. 19, 21-34. doi: $10.1177 / 1069072710382530$

Di Fabio, A., and Kenny, M. E. (2012). Emotional intelligence and perceived social support among Italian high school students. J. Career Dev. 39, 461-475. doi: $10.1177 / 0894845311421005$

Di Fabio, A., and Kenny, M. E. (2015). The contributions of emotional intelligence and social support for adaptive career progress among Italian youth. J. Career Dev. 42, 48-49. doi: 10.1177/0894845314533420

Di Fabio, A., and Kenny, M. E. (2016a). From decent work to decent lives: positive self and relational management (PS\&RM) in the twenty-first century. Front. Psychol. 7:361. doi: 10.3389/fpsyg.2016.00361

Di Fabio, A., and Kenny, M. E. (2016b). Promoting well-being: the contribution of emotional intelligence. Front. Psychol. 7:1182. doi: 10.3389/fpsyg.2016. 01182

Di Fabio, A., Kenny, M. E., and Claudius, M. (2016a). "Preventing distress and promoting psychological well-being in uncertain times through career management intervention," in Cambridge Handbook of International Prevention Science, eds M. Israelashvili and J. L. Romano (Cambridge: Cambridge University Press).

Di Fabio, A., and Maree, J. G. (2012). Group-based life design counseling in an Italian context. J. Vocat. Behav. 80, 100-107. doi: 10.1016/j.jvb.2011. 06.001

Di Fabio, A., and Maree, J. G. (2016). "Using a transdisciplinary interpretive lens to broaden reflections on alleviating poverty and promoting decent work," in From Meaning of Working to Meaningful Lives: The Challenges of Expanding Decent Work, Vol. 7, eds A. Di Fabio and D. L. Blustein (Lausanne: Frontiers), 503.

Di Fabio, A., and Palazzeschi, L. (2008). Emotional intelligence and self-efficacy in a sample of Italian high school teachers. Soc. Behav. Pers. 36, 315-326. doi: 10.2224/sbp.2008.36.3.315

Di Fabio, A., and Palazzeschi, L. (2012a). Incremental variance of the core self-evaluation construct compared to fluid intelligence and personality traits in aspects of decision-making. Pers. Ind. Differ. 53, 196-201. doi: 10.1016/j.paid.2012.03.012

Di Fabio, A., and Palazzeschi, L. (2012b). Organizational justice: personality traits or emotional intelligence? An empirical study in an Italian hospital context. J. Employ. Counsel. 49, 31-42.

Di Fabio, A., and Palazzeschi, L. (2015a). Multidimensional Scale of Perceived Social Support (MSPSS): Un contributo alla validazione italiana [Multidimensional Scale of Perceived Social Support (MSPSS): A contribution to Italian validation]. Counsel. Giornale Ital. Ric. Appl. 8.

Di Fabio, A., and Palazzeschi, L. (2015b). Hedonic and eudaimonic well-being: the role of resilience beyond fluid intelligence and personality traits. Front. Psychol. 6:1367. doi: 10.3389/fpsyg.2015.01367

Di Fabio, A., and Palazzeschi, L. (2016). "Marginalization and precariat: the challenge of intensifying life construction intervention," in From Meaning of Working to Meaningful Lives: The Challenges of Expanding Decent Work, Vol. 7, eds A. Di Fabio and D. L. Blustein (Lausanne: Frontiers), 444.

Di Fabio, A., Palazzeschi, L., Asulin-Peretz, L., and Gati, I. (2013b). Career indecision versus indecisiveness: associations with personality traits and emotional intelligence. J. Career Assess. 21, 42-56. doi: $10.1177 / 1069072712454698$

Di Fabio, A., Palazzeschi, L., and Bar-On, R. (2012). The role of personality traits, core self-evaluation and emotional intelligence in career decisionmaking difficulties. J. Employ. Counsel. 49, 118-129. doi: 10.1002/j.21611920.2012.00012.x

Di Fabio, A., Palazzeschi, L., Levin, N., and Gati, I. (2015). The role of personality in the career decision-making difficulties of Italian young adults. J. Career Assess. 23, 281-293. doi: 10.1177/1069072714535031

Di Fabio, A., and Saklofske, D. H. (2014a). Promoting individual resources: the challenge of trait emotional intelligence. Pers. Ind. Diff. 65, 19-23. doi: 10.1016/j.paid.2014.01.026

Di Fabio, A., and Saklofske, D. H. (2014b). Comparing ability and self-report trait emotional intelligence, fluid intelligence, and personality traits in career decision. Pers. Ind. Diff. 64, 174-178. doi: 10.1016/j.paid.2014.02.024 
Di Fabio, A., Saklofske, D. H., and Tremblay, P. F. (2016b). Psychometric properties of the italian trait emotional intelligence questionnaire (I-TEIQue). Pers. Ind. Diff. 96, 198-201. doi: 10.1016/j.paid.2016.03.009

Diener, E., Wirtz, D., Tov, W., Kim-Prieto, C., Choi, D. W., Oishi, S., et al. (2010). New well-being measures: short scales to assess flourishing and positive and negative feelings. Soc. Indic. Res. 97, 143-156. doi: 10.1007/s11205-0099493-y

Diener, E. D., Emmons, R. A., Larsen, R. J., and Griffin, S. (1985). The satisfaction with life scale. J. Pers. Assess. 49, 71-75. doi: 10.1207/s15327752jpa4901_13

Ferguson, S. J., and Goodwin, A. D. (2010). Optimism and well-being in older adults: the mediating role of social support and perceived control. Int. J. Aging Hum. Dev. 71, 43-68. doi: 10.2190/AG.71.1.c

Gallagher, E. N., and Vella-Brodrick, D. A. (2008). Social support and emotional intelligence as predictors of subjective well-being. Pers. Ind. Diff. 44, 1551-1561. doi: $10.1016 /$ j.paid.2008.01.011

Giannini, M., Gori, A., De Sanctis, E., and Schuldberg, D. (2011). A comparative analysis of attachment: psychometric properties of the PTI attachment styles scale (ASS). J. Psychother. Integr. 21, 363-381. doi: 10.1037/a0025461

Giorgi, G., Mancuso, S., and Perez, F. J. F. (2014). Organizational emotional intelligence and top selling. Eur. J. Psychol. 10, 712-725. doi: 10.5964/ejop.v10i4.755

Giorgi, G., Perez, J. M. L., Montani, F., Courcy, F., and Arcangeli, G. (2015a). Distress and job satisfaction after robbery assaults: a longitudinal study. Occup. Med. 65, 290-295. doi: 10.1093/occmed/kqv051

Giorgi, G., Perminiene, M., Montani, F., Fiz-Perez, J., Mucci, N., and Arcangeli, G. (2016). Detrimental effects of workplace bullying: impediment of selfmanagement competence via psychological distress. Front. Psychol. 7:60. doi: 10.3389/fpsyg.2016.00060

Giorgi, G., Shoss, M. K., and Leon-Perez, J. M. (2015b). Going beyond workplace stressors: economic crisis and perceived employability in relation to psychological distress and job dissatisfaction. Int. J. Stress Manag. 22, 137-158. doi: $10.1037 / \mathrm{a} 0038900$

Grawitch, M. J., and Ballard, D. W. (2016). The Psychologically Healthy Workplace: Building a Win-Win Environment for Organizations and Employees. Washington, DC: American Psychological Association.

Guichard, J. (2004). Se faire soi. L"Orientat. Scol. Prof. 33, 499-534. doi: 10.1007/s10775-005-8789-y

Guichard, J. (2005). Life-long self-construction. Int. J. Educ. Vocat. Guid. 5, 111-124.

Guichard, J. (2009). Self-constructing. J. Vocat. Behav. 75, 251-258. doi: 10.1016/j.jvb.2009.03.004

Guichard, J. (2013). Which paradigm for career and life designing interventions contributing to the development of a fairer world during the 21 st century. Lecture Presented at the IAEVG International Conference, Montpellier.

Hage, S. M., Romano, J. L., Conyne, R. K., Kenny, M., Matthews, C., Schwartz, J. P., et al. (2007). Best practice guidelines on prevention practice, research, training, and social advocacy for psychologists. Counsel. Psychol. 35, 493-566. doi: $10.1177 / 0011000006291411$

Kalpana Rani, E. (2016). Perceived social support and psychological well-being: testing the unique association and gender differences among young working adults. Int. J. Indian Psychol. 3, 99-113.

Kenny, M. E., Blustein, D. L., Chaves, A., Grossman, J. M., and Gallagher, L. A. (2003). The role of perceived barriers and relational support in the educational and vocational lives of urban high school students. J. Counsel. Psychol. 50, 142-155. doi: 10.1037/0022-0167.50.2.142

Kenny, M. E., Di Fabio, A., and Minor, K. (2014). "School-based research and practice in Italy," in Handbook of Positive Psychology in the Schools, 2nd Edn, eds M. J. Furlong, R. Gilman, and E. S. Huebner (New York, NY: Routledge), 450-464.

Kenny, M. E., and Hage, S. M. (2009). The next frontier: prevention as an instrument of social justice. J. Primary Prevent. 30, 1-10. doi: 10.1007/s10935008-0163-7

Kozan, S., Di Fabio, A., Blustein, D. L., and Kenny, M. E. (2014). The role of social support and work-related factors on the school engagement of Italian high school students. J. Career Assess. 22, 345-354. doi: 10.1177/10690727134 93988
Maree, J. G. (2012). Editorial. Promoting children's rights: rekindling respectivity. S. Afr. J. Psychol. 42, 295-300. doi: 10.1177/008124631204200301

Maree, J. G. (2013). Counselling for Career Construction: Connecting life Themes to Construct Life Portraits. Turning Pain into Hope. Rotterdam: Sense.

Marsh, H. W., Hau, K. T., and Wen, Z. (2004). In search of golden rules: comment on hypothesis-testing approaches to setting cutoff values for fit indexes and dangers in overgeneralizing $\mathrm{Hu}$ and Bentler's (1999) findings. Struct. Equ. Model. 11, 320-341. doi: 10.1207/s15328007sem1103_2

Morgan, J., and Farsides, T. (2009). Measuring meaning in life. J. Happiness Stud. 10, 197-214. doi: 10.1007/s10902-008-9093-6

Muthén, L. K., and Muthén, B. O. (1998-2015). Mplus User's Guide. 7th Edn. Los Angeles, CA: Muthén \& Muthén.

Prezza, M., Trombaccia, F., and Armento, L. (1997). The rosenberg self-esteem scale: Italian translation and validation. Boll. Psicol. Appl. 223, 35-44.

Raftery, A. E. (1995). Bayesian model selection in social research. Sociol. Methodol. 25, 111-163. doi: $10.2307 / 271063$

Rehfuss, M., and Di Fabio, A. (2012). Validating the Future Career Autobiography as a measure of narrative change. J. Career Assess. 20, 452-462. doi: $10.1177 / 1069072712450005$

Richardson, M. S. (2012). Counseling for work and relationship. Counsel. Psychol. 40, 190-242. doi: 10.1177/0011000011406452

Savickas, M. L. (2011). Career Counseling. Washington, DC: American Psychological Association.

Schermelleh-Engel, K., Moosbrugger, H., and Muller, H. (2003). Evaluating the fit of structural equation models: tests of significance and goodness-of-fit models. Methods Psychol. Res. Online 8, 23-74.

Schultheiss, D. E. P., Kress, H. M., Manzi, A. J., and Glasscock, J. M. J. (2001). Relational influences in career development: a qualitative inquiry. Counsel. Psychol. 29, 216-241. doi: 10.1177/0011000001292003

Seligman, M. E., and Csikszentmihalyi, M. (2000). Positive Psychology: An Introduction. Washington, DC: American Psychological Association.

Seligman, M. E. P. (2002). "Positive psychology, positive prevention, and positive therapy," in Handbook of Positive Psychology, eds C. R. Snyder and S. J. Lopez (New York, NY: Oxford University Press), 3-9.

Snyder, C. R., Lopez, S., and Teramoto Pedrotti, J. (2014). "Wisdom and courage: two universal virtues," in Positive Psychology: The Scientific and Practical Explorations of Human Strengths, eds C. R. Snyder, S. Lopez, and J. Teramoto Pedrotti (London: Sage), 205-242.

Steiger, J. H. (1990). Structural model evaluation and modification: an interval estimation approach. Multivar. Behav. Res. 25, 173-180. doi: $10.1207 / \mathrm{s} 15327906 \mathrm{mbr} 2502 \_4$

Suldo, S. M., Friedrich, A. A., White, T., Farmer, J., Minch, D., and Michalowski, J. (2009). Teacher support and adolescents' subjective well-being: a mixedmethods investigation. Sch. Psychol. Rev. 38, 67-85.

Terraciano, A., McCrae, R. R., and Costa, P. T. Jr. (2003). Factorial and construct validity of the Italian positive and negative affect schedule (PANAS). Euro. J. Psychol. Assess. 19, 131. doi: 10.1027//1015-5759.19.2.131

World Health Organization [WHO] (1998). World Health Organization Definition of Health. Available at: http://www.who.ch/aboutwho/definition.htm

World Medical Association [WMA] (2013). WMA Declaration of Helsinki-Ethical Principles for Medical Research Involving Human Subjects. Available at: http: //www.wma.net/en/30publications/10policies/b3/

Zimet, G. D., Dahlem, N. W., Zimet, S. G., and Farley, G. K. (1988). The multidimensional scale of perceived social support. J. Pers. Assess. 52, 30-41. doi: 10.1207/s15327752jpa5201_2

Conflict of Interest Statement: The author declares that the research was conducted in the absence of any commercial or financial relationships that could be construed as a potential conflict of interest.

Copyright (C) 2016 Di Fabio. This is an open-access article distributed under the terms of the Creative Commons Attribution License (CC BY). The use, distribution or reproduction in other forums is permitted, provided the original author(s) or licensor are credited and that the original publication in this journal is cited, in accordance with accepted academic practice. No use, distribution or reproduction is permitted which does not comply with these terms. 


\section{APPENDIX}

Instructions. Please indicate with a tick the box that best describes you from $1=$ strongly disagree to $5=$ strongly agree.

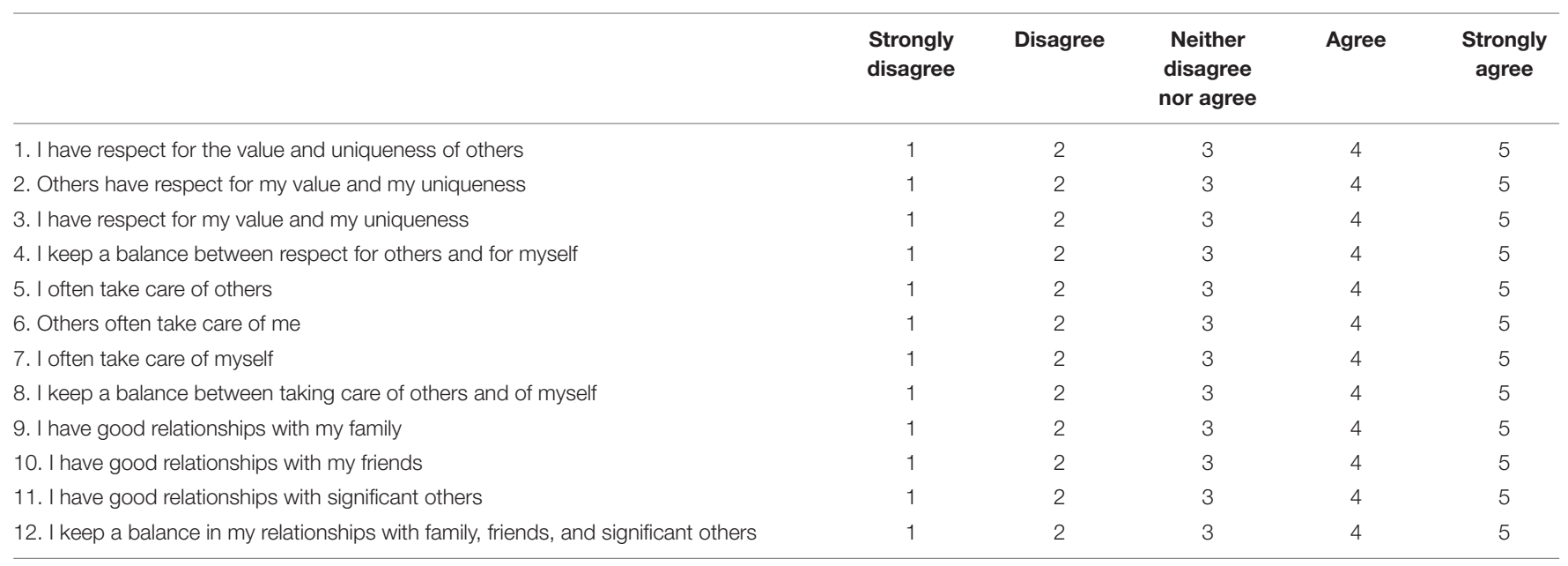


OPEN ACCESS

Edited by:

Gabriele Giorgi,

European University of Rome, Italy

Reviewed by:

Rita Berger:

University of Barcelona, Spain

Nicola Mucci,

University of Florence, Italy

*Correspondence:

Mara Martin

mara.martini@unito.it

Specialty section: This article was submitted to

Organizational Psychology, a section of the journal

Frontiers in Psychology

Received: 13 May 2016 Accepted: 05 August 2016 Published: 23 August 2016

Citation:

Loera B, Martini M, Viotti S and Converso D (2016) Users' Support as a Social Resource in Educational

Services: Construct Validity and Measurement Invariance of the User-Initiated Support Scale (UISS).

Front. Psychol. 7:1248.

doi: 10.3389/fpsyg.2016.01248

\section{Users' Support as a Social Resource in Educational Services: Construct Validity and Measurement Invariance of the User-Initiated Support Scale (UISS)}

\author{
Barbara Loera, Mara Martini *, Sara Viotti and Daniela Converso \\ Department of Psychology, University of Turin, Turin, Italy
}

Social support is an important resource for reducing the risks of stress and burnout at work. It seems to be particularly helpful for educational and social professionals. The constant and intense relationships with users that characterize this kind of service can be very demanding, increasing stress and leading to burnout. While significant attention has been paid to supervisors and colleagues in the literature, users have rarely been considered as possible sources of social support. The only exception is the Zimmermann et al.'s (2011) research, focused on customer support as a resource for workers' well-being. This paper proposes the validation of the customer-initiated support scale developed by Zimmermann et al. (2011), translated into Italian and focused on educational services users (children's parents), to measure the user support perceived by workers: the User-Initiated Support Scale (UISS). In Study 1 (105 teachers), which specifically involved educators and kindergarten teachers, the items and scale properties were preliminarily examined using descriptive analyses and exploratory factor analysis (EFA). In Study 2 (304 teachers), the construct and criterion validity and scale dimensionality were analyzed using confirmatory factor analysis (CFA). In Study 3 (304 teachers from Study 2 and 296 educators), measurement invariance (MI) was tested. The EFA results from Study 1 showed a one-factor solution (explained variance, $67.2 \%$ ). The scale showed good internal coherence (alpha $=0.88$ ). The CFA in Study 2 validated the one-factor solution (comparative fit index $=0.987$; standardized root mean square residual $=0.054$ ). Bivariate correlations confirmed construct validity; the UISS was positively associated (convergent) with user gratitude, and not associated (divergent) with disproportionate customer expectations. Regarding the criterion validity test, the UISS was strongly correlated with burnout and job satisfaction. The analysis of $\mathrm{Ml}$ performed on the Study 3 data confirmed the equality of the parameters of the covariance structure model between the two samples of kindergarten teachers and educators. This research study offers a useful version of a tool for measuring a crucial, but often ignored, protective resource for all professionals working directly with people (patients, students, and service users) that can represent important sources of well-being, directly or indirectly lessening the negative impacts of job demands.

Keywords: JD-R model, user support, social resources, educational services, confirmatory factor analysis, measurement invariance, UISS 


\section{INTRODUCTION}

The renowned job demand-resources (JD-R) model (Bakker et al., 2003) describes the complex interactions that take place in the "dual process" induced by both requests and resources. Due to excessive demands, the first process results in the progressive exhaustion of workers, while the second process-the consequence of resource availability-may improve the ability to cope with demands, thus increasing motivation, satisfaction, and general participation at work. With the conservation of resources (COR) theory, Hobfoll (1989) explains how people strive to obtain, foster, and protect resources that can be delineated into four main categories-material, condition, personal, and energy resources. To better introduce the present research, it is useful to mention the social exchange theory (Foa and Foa, 1980), which underlines the resource exchange process that is activated during interpersonal relationships. From this perspective, every social exchange consists of taking and/or giving resources (money, goods, status, information, services, and love). Both resources theories have been widely considered in recent work and organization studies in the literature related to stress and burnout or to social support by co-workers and superiors, among other topics.

In all the models that are dedicated to the determinants of work-related stress, support from colleagues and/or supervisors is an important resource for protecting workers; conversely, when this support is absent or poor or when, on the contrary, colleagues and supervisors are bullying, workers' psychological malaise can be worsened (Caplan, 1974; Johnson and Hall, 1988; Karasek and Theorell, 1990; Demerouti et al., 2001; Bakker et al., 2007; Arenas et al., 2015; Giorgi et al., 2016). In the literature, supervisors and colleagues are examined as possible sources both of support and of aggression. In service-sector organizations, conversely, users have rarely been considered as possible sources of support: the focus has been almost exclusively on the negative side of the relationship with "others." Thus, disproportionate requests (Dormann and Zapf, 2004; Dudenhöffer and Dormann, 2013, 2015), customer mistreatment (Koopmann et al., 2015), or aggressive behaviors (LeBlanc and Kelloway, 2002; Viotti et al., 2015) have been considered to be factors that decrease job satisfaction and psychological wellbeing, contribute to developing stress, burnout, and the spiraling of negative exchanges between employees and customers (Groth and Grandey, 2012), and directly or indirectly enhance an employee's intention to leave an organization (Lee and Ashforth, 1996; Jourdain and Chênevert, 2010). However, when service workers are asked why they have chosen their jobs (Maslach, 1982), they often declare their interest in "dealing with people" (Zimmermann et al., 2011, p. 31), thus implying that the motivational processes among service workers is often based on their interest in building a positive relationship with customers (users, patients, students, etc.). Contrary to the widely studied "negative side," the relationship between service workers and users may then activate a positive gain spiral (Ferrara et al., 2013) and represent a resource, not just a request, for employees.

Consistent with the social exchange theory (Foa and Foa, 1980), in recent years some scholars have innovatively considered the hypothesis that service recipients can be important sources of support, and they have analyzed the direct and indirect effects of positive customer behavior on the positive affect of employees. For example, Converso et al. (2015a) and Martini et al. (2015) have shown that the perception of gratitude expressed by patients/customers was a relational resource useful to relieve the fatigue of daily commitment and to return significance to a professional's work for healthcare workers and teachers, while Zimmermann et al. (2011) pointed out how sales workers' behavior and customers' behavior may activate reciprocal positive affective states. Thus, customerinitiated support is an "instrumental and emotional behavior that customers direct toward employees during the customer contact, making it easier to cope with service demands" (Zimmermann et al., 2011, p. 37). If different kinds of social support, such as material, behavioral, emotional, and informational support (Cohen and Wills, 1985), can be distinguished through feedback or attachment/integration, similar support can be offered by customers, too. According to the hypothesis posited by Zimmermann et al. (2011), customers may support employees in several ways: behaviorally by adapting their behaviors and expectations to the work process, emotionally by expressing appreciation for the employees' work and becoming attached to them, and informationally by providing information and knowledge that can simplify the process.

In other words, customer support is a specific resource that can be considered for service organizations (Bakker et al., 2003). When it is derived from positive social exchanges (Foa and Foa, 1980), the COR theory (Hobfoll, 1989) indicates that it may counteract the loss of personal resources during the service interaction or promote a gain spiral through the positive climate of the relationship.

Zimmermann et al.'s (2011) customer-initiated support scale was developed in the retail sector. However, their suggestions may be even more important in the services sector where the social exchange between workers and the others occurs in an educational or healthcare relationship. On the one hand, employees are very motivated by "dealing with people" (Zimmermann et al., 2011, p. 31); on the other hand, the caring or educational process lasts longer than the customer/employee exchange. Preventing the loss of a personal resource from the users' social support can be particularly useful because of the emotional and cognitively demanding nature of these types of occupations.

The present study was undertaken to investigate the impact of employee support in the early childhood education service sector. This sector has scarcely been considered in the stress or well-being literature (Hall-Kenyon et al., 2014) that has mainly studied teachers in primary school, secondary school, and college settings (Duncan, 1980; Byrne, 1991; Kelly and Berthelsen, 1995; Guidetti et al., 2015). Nonetheless, the early childhood education profession has specific features (Ohi, 2014) due to the very young age of the children whom the teachers care for (Converso et al., 2015b; Viotti et al., 2015). In the Italian context, based on the children's age, further specificities exist between pre-school teachers (of 3- to 6-year-old children) and educators (of 0- to 3year-old babies and toddlers). Educators have to care for infants 
and toddlers who are often not yet able to walk or talk, so these professionals are expected to engage in the physical work of lifting and the emotional work of cheering up children who suffer from their parents' absence. Pre-school teachers have to support the children's physical and cognitive development and autonomy, by playing and by developing school preparatory activities (e.g., painting, listening, or reading). Older children are able to speak clearly, walk, and provide for their own simple personal needs. Thus, pre-school teachers exert less physical effort than those who take care for babies and toddlers, and they also engage in more cognitive work with the children they teach, as part of applying the principles of child psychology.

Despite these differences, both the pre-school teachers' and the educators' educational work is perceived as being very demanding (cognitively, emotionally, and physically) because it requires playing a complex mixture of roles (Ohi, 2014; Nislin et al., 2016). As educators, they are responsible for sustaining the children's overall development. As communicators, they should have the ability to interact effectively both with very young children and with parents. As care providers, they have to lift and carry children or bend, risking musculoskeletal disorders, as well as burnout (Koch et al., 2015). They also perceive themselves to be "pastoral care providers" (Ohi, 2014, p. 1013) as they have to support parents in their relationships with their children and in their personal crises. Thus, they may have to perform some nonteaching tasks (e.g., paperwork) that educators generally define as annoying and onerous. In addition to all these issues, pre-school teachers and educators perceive that they lack the resources they need and they are under hectic time pressures (Hall-Kenyon et al., 2014; Ohi, 2014).

To handle these requests, early childhood teachers can count on support from their colleagues and supervisors but, primarily, their relationship with the children is "the[ir] strongest source of satisfaction" (Jorde-Bloom, 1988, p. 118; Hall-Kenyon et al., 2014 , p. 158). Thus, the relationship with users can enhance teachers' well-being and reduce stress. Nevertheless, due to the specific nature of the users and the service, parents must be considered to be users as well. Ohi (2014) affirmed that, for teachers, developing a positive relationship with parents is "an enjoyable part of their work, even if it is also a daily challenge" (p. 1015). A positive relationship with parents can be defined as an alliance to support each child's development; it is based on empathy, sharing educational objectives, frequent and honest exchange of information, reciprocal trust, and recognition of their roles, which are the dimensions of user support mentioned by Zimmermann et al. (2011).

The original scale developed by Zimmermann et al. (2011) measured the support from customers in market services. In this regard, our work aimed to measure the user support perceived in a helping-profession context by proposing a refined and validated version of the instrument developed by Zimmermann et al. (2011), which we renamed the User-Initiated Support Scale (UISS). We expected the UISS to adequately measure a single construct and to produce a valid measure, thus correlating with the only other available measure in our knowledge related to positive relational resources from users, the P-Grate scale, which considers the workers' perceived gratitude (Martini et al., 2015).
We anticipated that the measurement of user support would not be consistently correlated with the operators' beliefs that users could be over-demanding and could make unrealistic requests beyond the professional role (Dormann and Zapf, 2004). Based on the hypothesis that user support would be a positive resource that would sustain well-being at work, we also expected that the presence of high support would be correlated with high work satisfaction and weak burnout symptoms.

Finally, since the meanings of the items might vary in terms of the function of the work's content and its characteristics, even if the service offerings would remain the same, we decided to test the measurement invariance (MI) of the UISS between two different groups of professionals (kindergarten teachers and educators) operating in the same socio-educational service.

\section{MATERIALS AND METHODS}

\section{Procedure}

The research was conducted at the Educational Service of the Municipality of Turin, Italy, between June 2013 and February 2014. The educational service includes both kindergarten and nursery schools for 0 - to 6-year-old children that are residents of the city. The research design included a preliminary qualitative phase, consisting of 70 in-depth individual interviews with the more experienced kindergarten teachers and educators, as well as a quantitative phase using a questionnaire distributed to all kindergarten teachers and educators working in the Educational Service. The questionnaire was administered during work hours to all kindergarten teachers and educators who voluntarily agreed to participate in the research project. The subjects were asked to sign informed consent forms for the data analysis process. Anonymity of the data and the findings was ensured. The completed questionnaires were enclosed in blank envelopes and collected by researchers from the Department of Psychology, University of Turin.

\section{Ethics Statement}

The present research study involved human beings in a data collection process in which participants were required to provide personal data concerning health information, personal opinions, and socio-demographical data. The research procedure was designed to conform to the provisions of the 1995 Declaration of Helsinki (as revised in Edinburgh in 2000), the Charter of Fundamental Rights of the European Union, the European Data Protection Directive (95/46/EC and following updates), and Italian laws on privacy and data protection (L. 196/2003). More specifically, data was collected and processed anonymously. The participants volunteered to participate in the research, and they were asked to sign an informed consent form in which they agreed to anonymously complete a questionnaire and allow the researchers to use the data for scientific purposes. No individuals unable to give informed content, vulnerable individuals or groups, or patients or minors were involved in the survey. The questionnaire used for data collection included a cover sheet that clearly explained the research aim, the voluntary nature of 
participation, the anonymity of the data, and the elaboration of the findings.

\section{Participants}

In the first study (Study 1), 119 kindergarten teachers filled out the questionnaires; of these, 105 of the questionnaires were correctly completed and considered for the analysis. The 105 kindergarten teachers were all women, with an average age of 51.02 years $(S D=7.34)$.

Study 2 involved 320 kindergarten teachers; of these, 304 completely filled out the questionnaires, which were considered for the analysis. All of the 304 valid cases were women, with an average age of 51.92 years $(S D=7.25)$.

In Study 3, 308 educators in nursery schools filled out the questionnaire; 12 of the respondents returned incomplete questionnaires, which were discarded from the sample. The remaining valid questionnaires were from 296 educators, all women, with an average age of 47.59 years $(S D=7.59)$; most of the respondents were parents $(77.5 \%)$ and $28.7 \%$ provided care for other people. On average, they worked $31.85 \mathrm{~h}$ per week $(S D=4.18)$. In this study, the 296 educators were compared with the 304 kindergarten teachers of the Study 2.

\section{Measures}

Each participant filled out a self-report questionnaire. The introductory part consisted of socio-demographic and professional indicators. This was followed by a section that used scales to measure user-initiated support, the perceived gratitude of users, customer-related social stressors (CSS), and burnout. In addition, there was a single item on work satisfaction.

\section{User-Initiated Support Scale}

The UISS measures the support perceived by operators as a result of the users' positive behavior. It applies the user-operator dyad to educational services. It is a modified version of the customer-initiated support scale that was initially developed for the employee-customer dyad (Zimmermann et al., 2011; original Cronbach's $\alpha$ 0.82), which considered behavioral, informational, feedback, and emotional support. Following the International Guidelines on Test Adaptation (International Test Commission [ITC], 2005) the adaptation process has taken into full account the linguistic and the cultural differences among the populations for whom the adapted versions of the instrument are intended. The original scale (one item for each kind of support) was translated into Italian using the double-blind method, and an accurate translation was produced. The Italian version was backtranslated by an individual whose native tongue is English; the original English scale and the back-translated scale were compared and the differences were discussed until a consensus was reached. The translated scale was then adapted for social operators, replacing "customer" with "user" in each item of the scale (Table 1). The five items on a 5-point Likert-response scale ranged from $1=$ "I completely disagree" to $5=$ "I completely agree." The score of the scale was computed using the mean of the five items. A preliminary validation of the UISS involving health operators was proposed by Converso et al. (2015a). For the questionnaire intended for educational operators, the "users" referred to in the item formulations were the children's parents. Because of the very young age of the direct users (children), parents (indirect users) should be considered as a possible source of support in the relationship with kindergarten teachers and educators. Before inserting the scale into the data collection tool, its adapted version was proposed to 27 kindergarten teachers and educators for a comprehension pretext; the items were considered enough clear by the subjects.

\section{P-Grate Scale}

The P-Grate scale (Martini et al., 2015) measures the perception of user gratitude and the support function that user gratitude offers social operators. It consists of the two subscales of gratitude expression (three items, e.g., "Several users express gratitude for the care we offer them") and gratitude as a source of support (five items, e.g., "Some users' gratitude compensates for the efforts you make at work"). On a 5-point Likert answering scale, the items ranged from $1=$ "I completely disagree" to $5=$ "I completely agree." The scores of the two subscales were obtained by calculating the respective mean scores of the three items and the five items. The original Cronbach's $\alpha$ for each was 0.88 and 0.82 , respectively.

\section{Disproportionate Customer Expectations}

The broader scale of CSS (Dormann and Zapf, 2004; Taddei and Vanni, 2008; Guglielmetti et al., 2014) represents the opposite construct of customer support. It includes the following four subdimensions: disproportionate customer expectations, customer verbal aggression, disliked customers, and ambiguous customer expectations. Only the disproportionate customer expectations subscale (eight items) was included in this present research study (original Cronbach's $\alpha$ 0.86). This subscale aimed to measure the users' excessive requests to operators as possible sources of stress. An example of an item is: "Our customers do not recognize the fact that we are very busy." The items on the Likert response scale ranged from $1=$ "not at all true" to $4=$ "completely true." To compute the score of the scale, we calculated the mean of the eight items.

\section{Maslach Burnout Inventory}

The Maslach Burnout Inventory-Educational Survey (Maslach and Jackson, 1986; Sirigatti and Stefanile, 1993; Loera et al., 2014) measures operators' perceptions of burnout using three subscales: Emotional Exhaustion (EE; eight items, e.g., "I feel used up at the end of the workday"), Depersonalization (DP; five items, e.g., "I feel I treat some recipients as if they were impersonal objects"), and Personal Accomplishment (PA; seven items, e.g., "I can easily understand how my recipients feel about things"). The original (Sirigatti and Stefanile, 1993) Cronbach's $\alpha$ for each of these subscales was $0.87,0.68$, and 0.76 , respectively. The responses were given on a Likert scale ranging from $0=$ "never" to $6=$ "every day." The scores of the subscales were obtained by computing the mean scores of the eight, five, and seven items, respectively.

\section{Job Satisfaction}

To measure work satisfaction, we used a single item from the Organizational Health Questionnaire (OHQ; Avallone and 
TABLE 1 | Italian item translation.

\author{
User-Initiated Support Scale \\ 1. The users adapted my working process \\ 2. The users facilitated the service conversation through his/her previous \\ knowledge \\ 3. The users trusted in my competencies \\ 4. The users explicitly valued my work effort \\ 5. The users and I were on the same wave length
}

Scala di Supporto offerto dagli utenti

1. Gli utenti trovano adeguato il mio modo di lavorare

2. Gli utenti facilitano la comunicazione relativa al servizio di cura con le loro conoscenze precedenti

3. Gli utenti si fidano delle mie competenze

4. Gli utenti riconoscono esplicitamente l'impegno che metto nel lavoro

5. Gli utenti ed io siamo sulla stessa lunghezza d'onda
Paplomatas, 2005): "How much do you feel satisfied about your work [referring to the last three months?]." The responses were given on a Likert scale ranging from $1=$ "not at all" to $10=$ "completely." For its brevity, a single item is particularly suitable in a study that takes negative (EE and DP) and positive (PA) variables into account.

\section{Data Analysis}

The items and scale properties were preliminarily explored using a descriptive analysis of the sample of 105 kindergarten teachers who participated in Study 1. Scale reliability was assessed with Cronbach's coefficient, while the contribution to internal consistency at the item level was evaluated by the item-total correlations. Exploratory factor analysis (EFA) was used to check the factorability of the items correlation matrix.

The confirmatory factor analysis (CFA) model was specified in the data collected in Study 2 for testing item validity and scale dimensionality. CFA is a theory driven technique; it is applied to test hypotheses about the factor structure of the measurement instrument (Kline, 2011). It is recommended over EFA when there is an a priori hypothesis regarding dimensionality, as it allows testing of whether the empirical data fit an assumed structure (Floyd and Widaman, 1995). In this case, we assumed that UISS adequately measured a single latent dimension of support from service users.

Since data generally do not have univariate normal distributions let alone multivariate normal distribution, as requested in CFA models, it is dangerous to apply a normal theory-based estimation method on Pearson's correlations. In trying to solve this problem, Jöreskog and Sörbom (1996a) found that, regardless of sample size and population correlation, polychoric correlations were the most consistent and robust estimator. Moreover, it has been demonstrated that the use of polychoric correlations provides a more accurate reproduction of the measurement model (Holgado-Tello et al., 2010). Following Jöreskog and Sörbom (1996b), after the normality of the items distributions was assessed, the model estimation was produced by applying the maximum likelihood method to the polychoric correlation matrix to correct the non-normal distribution of the UISS items in the sample by using the corresponding asymptotic covariance matrix.

Model fit was assessed by considering the goodness-offit index (GFI), the comparative fit index (CFI), and the standardized root mean square residual (SRMR). The GFI measures the amount of variance explained by the model, while the CFI indicates the relative amount of variation accounted for by the model by comparing its fit with a baseline model (null model). Both indices range from 0 to 1 , and values higher than 0.90 are considered to be indicators of a good model fit (Bentler, 1995; Hoyle, 1995). The SRMR is a measure of the mean absolute correlation residual, that is, the overall difference between the observed and predicted correlations. An SRMR value less than 0.05 indicates a good fit (Byrne, 1998; Diamantopoulos and Siguaw, 2000); an SRMR value less than 0.08 is considered acceptable ( $\mathrm{Hu}$ and Bentler, 1999).

The construct and criterion validity of the UISS were assessed using bivariate correlations. Specifically, the correlation with a similar construct (user gratitude) was analyzed to test the convergent validity of the UISS, and the correlation with a different construct (disproportionate customer expectations) was observed for divergent validity. The criterion validity of the UISS was evaluated by relating the user support score with well-being at work (work satisfaction and burnout). To improve immediacy and to compare the results, the mean of individuals' answers was calculated for each scale, in order to maintain the same short range of the items response scale and the same range of scores regardless of the specific length of each instrument.

Finally, a multigroup confirmatory factor model was estimated to test the MI in the samples of kindergarten teachers and educators collected in Study 2 and Study 3. MI tests enable one to assess whether a scale is measuring the same latent variable in all of the significant population subgroups because comparisons and analyses of scores can be acceptable and meaningful only if the assumption of invariance is confirmed (Meredith, 1993; Reise et al., 1993; Widaman and Reise, 1997; Vandenberg and Lance, 2000). Toward that end, six hypotheses were tested using an equal number of structural equation models:

(1) The construct operationalization is valid in each group (configural invariance: equal number of latent factors and the same pattern of factors loadings);

(2) The respondents attribute the same meaning to the items, i.e., to the measured latent construct (metric invariance: factor loadings restricted to be invariant across groups);

(3) The respondents attribute the same meaning to the latent construct, as well the same meaning to the levels of the underlying items (scalar invariance: factor loadings and items intercepts restricted to be equal across groups);

(4) The latent construct is measured identically across groups, i.e., the explained variance of each item is the same in both groups (uniqueness invariance: factor loadings, items 
intercepts, and residual variances restricted to be equal across groups);

(5) The groups have the same mean for the latent construct (structural invariance in terms of factor means: factors means restricted to be equal across groups);

(6) The groups have the same range of scores for the latent factor (structural invariance in terms of factor variances: factor variances restricted to be equal across groups).

Testing for measurement (item loadings, intercepts, and uniqueness) and structural invariances (factors means and variance) was conducted using the scaled chi-squared difference test for nested models (Satorra and Bentler, 1994, 2001). The analyses were performed using PRELIS, LISREL 8.72, and IBM SPSS Statistics 22.0 software programs.

\section{RESULTS}

\section{Study 1: Descriptive Analysis, Reliability, and Exploratory Factor Analysis}

The five items of the UISS did not have a normal distribution (see Table 2). Even if the values for items 2 and 5 were not very sharp, all the item distributions showed negative skewness and had positive kurtosis, particularly items 1 and 3. Both the Kolmogorov-Smirnov (KS) and the Shapiro-Wilk (SW) normality tests consistently suggested rejecting the hypothesis of normality of the distributions for all items.

Since the items of the scale did not have normal distribution, the EFA model was estimated using the generalized least squares extraction method. The mono-factorial solution explained the $67.18 \%$ variance. As shown in Table 3, Cronbach's alpha on the UISS highlighted a satisfying internal coherence $(0.88)$ that was quite close to the 0.82 Cronbach's alpha noted by Zimmermann et al. (2011). Moreover, the item-scale correlation values were between 0.60 (item 2) and 0.75 (item 1), which was definitely above the cutoff value of 0.40 indicated by Nunnally (1967).

\section{Study 2: Confirmatory Factor Analysis and Construct Validity UISS Measurement Model}

Because the UISS was built to measure one construct, the estimated CFA model was congeneric, with all items loaded on one factor. This model, illustrated in Figure 1, had a good fit and it performed satisfactorily. Moreover, if the minimum fit function chi-square was significant $\left(\chi^{2}=30.26, p<0.000\right)$, all the fit indices achieved the preselected cutoff values $(\mathrm{GFI}=0.96$; $\mathrm{CFI}=0.98$; SRMR $=0.05$ ).

The item loadings were also all significant if item 2 seemed not quite efficient in measuring user support; its loading value was above 0.3 , but its $r$-squared value was just 0.22 , indicating the small amount of variance of this item when explained from the factor. In other words, for item 2, the amount of variance in common with the other items in the scale was 0.47. For comparison, the best scale item, in terms of loading and r-square, was item 4 , which had at least $83 \%$ of variance in common with the other items.

\section{Convergent and Discriminant Validity}

The UISS had a strong positive correlation with the users' expression of gratitude and with gratitude as a source of support. Both of these constructs were similar to user-initiated support since they represented different kinds of relational resources or different intentions of the meaning of user support. On the other hand, there was no correlation between disproportionate customer expectations and the expression of users' negative behavior toward operators (Table 4). Therefore, the hypothesis about construct validity, both convergent and discriminant, was confirmed.

\section{Criterion-Related Validity}

Several authors (among the others: Etzion, 1984) have provided evidence showing that social support can reduce burnout (by reducing emotional exhaustion and depersonalization and increasing personal accomplishment) and enhance job satisfaction. Therefore, as a kind of social support at work, user support can, theoretically, be considered to be related to burnout and satisfaction at work. We used these constructs to test criterion-related validity. The UISS showed strong positive correlations with personal accomplishment and job satisfaction and a negative correlation with depersonalization (Table 5), confirming the hypothesis about criterion-related validity.

\section{Study 3: Measurement Invariance}

The socio-educational service examined in the present research study included two groups of workers that were in contact with the same users but that were involved in different tasks and relationships. These differences led to testing whether the UISS could have the same psychometric performance in the two workers' subpopulations, that is, whether the measurement model estimated in the kindergarten teachers' subsample might be valid and useful for the educators subsample, too. The fit for the model that was estimated by using the educators' sample was very satisfactory $(\mathrm{GFI}=0.96$; $\mathrm{CFI}=0.97$; $\mathrm{SRMR}=0.04$; $\left.\chi^{2}=32.70, p<0.000\right)$, apart from root mean square error of approximation (RMSEA; 0.10), and apparently the model fit seemed very close to the one previously estimated for kindergarten teachers (Figure 2).

The invariance of the UISS was tested by imposing the same measurement model on samples of kindergarten teachers (Study $2, N=304$ ) and educators (Study 3, $N=296$ ). The data had passed the more severe test of population invariance, which, in turn, might imply the equality of the parameters of the covariance structure model (factor loadings, unique variances, and factor variance). The chi-square test value for equality of covariance was 23.245 , with a probability value of 0.08 . Thus, we accepted the null hypothesis of invariance of the two observed covariance matrices. This might mean that the two subsamples of kindergarten teachers and educators had the same covariance matrix, namely, that they belonged to the same population of socio-educational workers, at least when considering the perception of user support of this service.

However, since the population equality might be considered only to be a preliminary indication that some MI existed between the groups (Vandenberg and Self, 1993; 
TABLE 2 | Descriptive analysis of the User-Initiated Support Scale items.

\begin{tabular}{|c|c|c|c|c|c|c|c|}
\hline User-Initiated Support Scale & $M$ & $S D$ & Skewness & Kurtosis & KS & $p$ & sw \\
\hline 1. The users adapted my working process & 3.80 & 0.90 & -0.87 & 1.21 & 0.30 & 0.000 & 0.83 \\
\hline $\begin{array}{l}\text { 2. The users facilitated the service conversation through his/her } \\
\text { previous knowledge }\end{array}$ & 3.20 & 0.96 & -0.28 & 0.15 & 0.24 & 0.000 & 0.89 \\
\hline 3. The users trusted in my competencies & 3.96 & 0.83 & -0.95 & 1.84 & 0.30 & 0.000 & 0.80 \\
\hline 4. The users explicitly valued my work effort & 3.83 & 0.99 & -0.88 & 0.84 & 0.25 & 0.000 & 0.85 \\
\hline 5. The users and I were on the same wave length & 3.26 & 0.93 & -0.17 & 0.06 & 0.22 & 0.000 & 0.90 \\
\hline
\end{tabular}

TABLE 3 | EFA solution and reliability analysis of the User-Initiated Support Scale.

\begin{tabular}{|c|c|c|c|c|}
\hline User-Initiated Support Scale & $\begin{array}{l}\text { Factor } \\
\text { loading }\end{array}$ & $\begin{array}{l}\text { Corrected item-total } \\
\text { correlations }\end{array}$ & $\begin{array}{l}\text { Squared-multiple } \\
\text { correlations }\end{array}$ & $\begin{array}{l}\text { Cronbach's alpha if } \\
\text { item deleted }\end{array}$ \\
\hline 1. The users adapted my working process & 0.850 & 0.750 & 0.644 & 0.837 \\
\hline 3. The users trusted in my competencies & 0.828 & 0.742 & 0.620 & 0.841 \\
\hline 4. The users explicitly valued my work effort & 0.797 & 0.724 & 0.583 & 0.844 \\
\hline 5. The users and I were on the same wave length & 0.763 & 0.715 & 0.562 & 0.846 \\
\hline $\begin{array}{l}\text { 2. The users facilitated the service conversation through his/her } \\
\text { previous knowledge }\end{array}$ & 0.641 & 0.602 & 0.395 & 0.873 \\
\hline Cronbach's alpha & 0.88 & & & \\
\hline
\end{tabular}

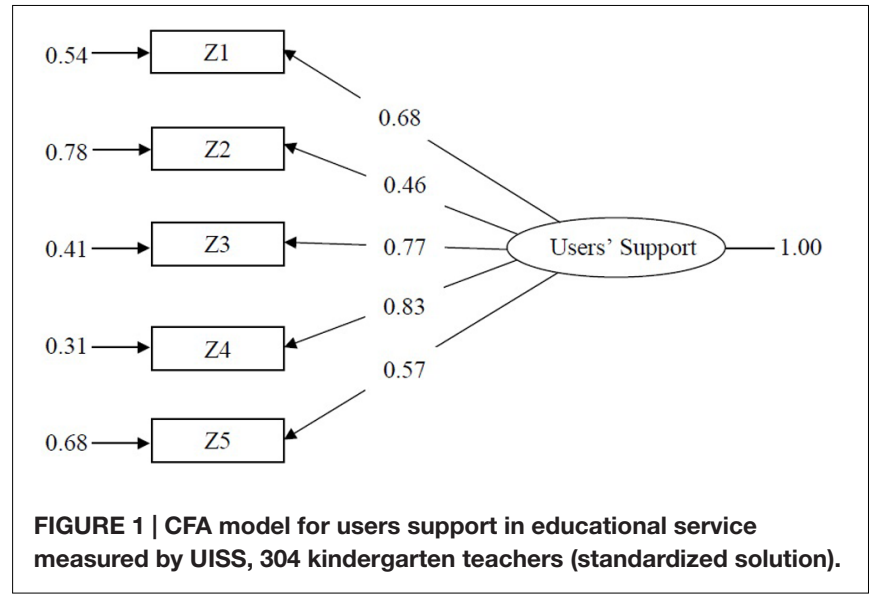

TABLE 4 | Convergent and divergent validity: bivariate correlations with convergent and divergent constructs.

\begin{tabular}{lcccc}
\hline & $\mathbf{1}$ & $\mathbf{2}$ & $\mathbf{3}$ & $\mathbf{4}$ \\
\hline $\begin{array}{l}\text { 1. User-initiated support } \\
\text { 2. Disproportionate customer } \\
\quad \text { expectations }\end{array}$ & -0.09 & - & & \\
3. Gratitude users' expression & & & & \\
4. Gratitude as source of support & $0.51^{* *}$ & -0.04 & - & \\
Mean & $0.44^{* *}$ & 0.03 & $0.41^{* *}$ & - \\
Standard deviation & 3.79 & 2.91 & 4.13 & 4.08 \\
Alpha & 0.62 & 0.93 & 0.81 & 0.76 \\
\hline
\end{tabular}

$* * p<0.001$.

Vandenberg and Lance, 2000), we decided to consider four nested models (M1, M2, M3, and M4), with increasingly restrictive specifications, in order to identify the eventual sources of non-equivalence in the measurement. Moreover, because population equality might be a clue for MI, but is uninformative with respect to structural invariance (Byrne et al., 1989), we added two models (M5 and M6) to test the equality of the factor means and variances across the two groups of kindergarten teachers and educators.

The results (Table 6) showed that consistent with the tenability of the population equality hypothesis, MI was perfectly achieved. The differences among the nested models, calculated using the Satorra-Bentler scaled difference chi-square $\left(\Delta \chi^{2}\right)$, were all insignificant, thus confirming that the measurement model had the same loadings, intercepts, and unique item variances between the two professional subgroups. The same conclusion was supported by the CFI that was substantially stable in the first five models; all the CFI differences were positive or had a maximum value of 0.01 , indicating better fits or a minimal decrease in the CFI (Cheung and Rensvold, 2002).

In examining the structure of the latent variable, the sixth model (M6) enabled us to determine that the factor measured by the UISS had the same variance in the two professional groups. In comparison to its more general model (M3), M6 produced an irrelevant increment of chi-square $\left(\Delta \chi^{2} \mathrm{M} 6-\mathrm{M} 3=5.18\right.$, $p=0.521$ ). Conversely, M5 assessed significant differences between the mean scores of the latent factor measured in the two groups $\left(\Delta \chi^{2} \mathrm{M} 5-\mathrm{M} 4=5.18, p<0.001\right)$, but these results were expected since the hypothesis about the equality of the item intercepts was confirmed, implying that the items' mean scores were different only because of differences in the latent mean scores, and they were not due to the items' specific factors.

In the end, all the estimated models performed well in terms of the CFI and the local (within groups) SRMR. However, the models fitted badly in terms of the RMSEA; in general, the RMSEA values were acceptable $(<0.8)$, but never appreciable $(<0.5)$. 
TABLE 5 | Criterion-related validity: bivariate correlations with concurrent constructs.

\begin{tabular}{lccccc}
\hline & $\mathbf{1}$ & $\mathbf{2}$ & $\mathbf{3}$ & $\mathbf{4}$ & $\mathbf{5}$ \\
\hline $\begin{array}{l}\text { 1. User-initiated } \\
\text { support }\end{array}$ & - & & & & \\
$\begin{array}{l}\text { 2. Emotional } \\
\quad \text { exhaustion }\end{array}$ & -0.03 & - & & & \\
$\begin{array}{l}\text { 3. Depersonalization } \\
\text { 4. Personal }\end{array}$ & $-0.15^{*}$ & $0.36^{* *}$ & - & & \\
$\quad$ accomplishment & $0.34^{* *}$ & -0.08 & $-0.18^{* *}$ & - & \\
$\begin{array}{l}\text { 5. Job satisfaction } \\
\text { Mean }\end{array}$ & $0.31^{* *}$ & $0.53^{* *}$ & $-0.23^{* *}$ & $0.26^{* *}$ & - \\
$\begin{array}{l}\text { Standard deviation } \\
\text { Alpha }\end{array}$ & 3.79 & 2.31 & 0.51 & 4.65 & 7.10 \\
\hline
\end{tabular}

$* p<0.05 ; * p<0.001$.

\section{DISCUSSION}

Scholars have rarely examined the positive side of the relationship between service workers and service users. Consistent with the COR theory (Hobfoll, 1989) and with the social exchange theory (Foa and Foa, 1980), this side of the relationship may represent an important social resource, may contribute to supporting service workers, and may activate positive gain spirals. Zimmermann et al. (2011) developed the customerinitiated support scale, which, to our knowledge, is the only scale specifically devoted to measuring users' cognitive and emotional support, but they only referred to the retail sector. In the social/healthcare service sector previous studies have highlighted the importance of the perceived gratitude expressed, for example, by patients to enhance job satisfaction or to buffer burnout (Converso et al., 2015a). Gratitude may be considered to be a source of emotional support, while Zimmermann et al. (2011) also considered behavioral, informational, and feedback support. Thus, this present work aimed to validate UISS, a revised version of the scale developed by Zimmermann et al. (2011), to evaluate the impact of support for workers in the social (educational) services. Three studies involving kindergarten teachers were presented in this paper to verify the mono-factorial

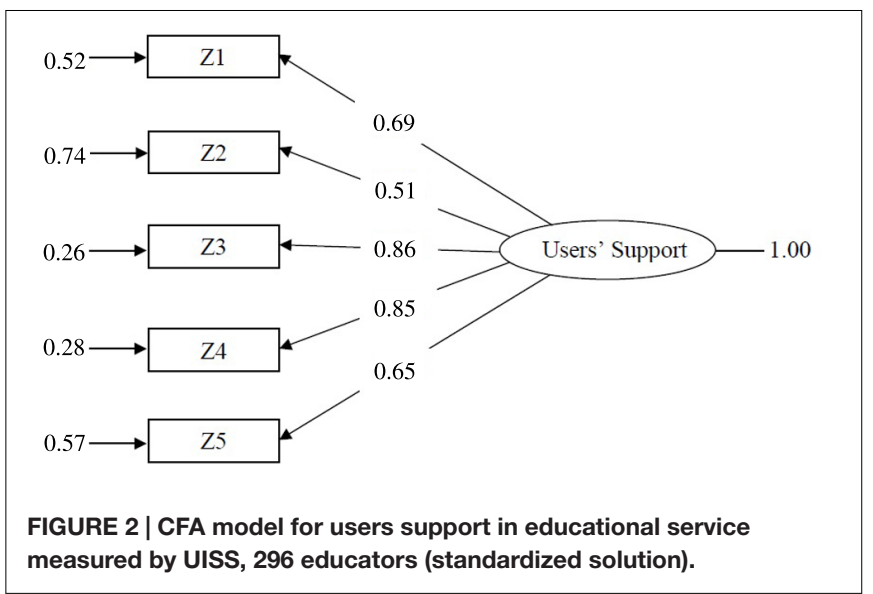

structure of the instrument via EFA and CFA. UISS showed a satisfactory percentage of explained variance and internal coherence, very close to that of Zimmermann et al.'s (2011) original scale.

Moreover, both the construct and criterion validity were confirmed for UISS. Indeed, convergent validity was verified because other positive dimensions of the relationship with users (user gratitude) strongly correlated with user-initiated support, even if they were clearly distinct. Divergent validity was verified by the absence of any significant correlation with the perception that users' requests exceeded the operators' roles, which could be defined as a relational demand in the educational profession. Correlations with both the supposed positive and negative consequences of social support were then analyzed. Although, to the best of our knowledge, few studies have examined the protective role that user support plays in the risk of burnout and its enhancing role in job satisfaction, many studies have confirmed this function of social support (from supervisors and colleagues). Our research results confirmed the criterion validity hypothesis.

Based on these results, we can affirm that this study (and the resulting paper) provides a scale to measure a crucial, but

TABLE 6 | Tests of UISS measurement and structural invariance across teachers and educators.

\begin{tabular}{|c|c|c|c|c|c|c|c|c|c|c|c|c|}
\hline $\begin{array}{l}\text { Model and } \\
\text { invariance }\end{array}$ & CFI & df & $x^{2}$ & $p$ & $\mathrm{SB} \chi^{2}$ & $p$ & $\Delta \chi^{2}$ & df & $p$ & SRMR & RMSEA & RMSEA Cl \\
\hline $\begin{array}{l}\text { M1. } \\
\text { Configural }\end{array}$ & 0.98 & 10 & 62.96 & 0.000 & 35.09 & 0.000 & & & & $\begin{array}{l}g 1=0.04 \\
g 2=0.04\end{array}$ & 0.081 & $0.05 ; 0.09$ \\
\hline $\begin{array}{l}\text { M2. } \\
\text { Metric }\end{array}$ & 0.98 & 14 & 66.81 & 0.000 & 40.15 & 0.000 & $\begin{array}{c}\mathrm{M}_{2}-\mathrm{M}_{1} \\
2.88\end{array}$ & 4 & 0.579 & $\begin{array}{l}g 1=0.05 \\
g 2=0.05\end{array}$ & 0.079 & $0.05 ; 0.09$ \\
\hline $\begin{array}{l}\text { M3. } \\
\text { Scalar }\end{array}$ & 0.97 & 18 & 72.32 & 0.000 & 47.64 & 0.000 & $\begin{array}{c}\mathrm{M}_{3}-\mathrm{M}_{2} \\
5.47\end{array}$ & 4 & 0.242 & $\begin{array}{l}g 1=0.06 \\
g 2=0.05\end{array}$ & 0.074 & $0.05 ; 0.10$ \\
\hline $\begin{array}{l}\text { M4. } \\
\text { Uniquenesses }\end{array}$ & 0.98 & 23 & 80.26 & 0.000 & 49.79 & 0.000 & $\begin{array}{c}\mathrm{M}_{4}-\mathrm{M}_{3} \\
4.07\end{array}$ & 5 & 0.539 & $\begin{array}{l}g 1=0.05 \\
g 2=0.05\end{array}$ & 0.062 & $0.04 ; 0.09$ \\
\hline $\begin{array}{l}\text { M5. } \\
\text { Factor means }\end{array}$ & 0.97 & 24 & 105.61 & 0.000 & 67.08 & 0.000 & $\begin{array}{c}\mathrm{M}_{5}-\mathrm{M}_{4} \\
35.37\end{array}$ & 1 & 0.000 & $\begin{array}{l}g 1=0.05 \\
g 2=0.05\end{array}$ & 0.077 & $0.06 ; 0.09$ \\
\hline $\begin{array}{l}\text { M6. } \\
\text { Factor variances }\end{array}$ & 0.98 & 24 & 81.77 & 0.000 & 51.27 & 0.000 & $\begin{array}{c}\mathrm{M}_{6}-\mathrm{M}_{3} \\
5.18\end{array}$ & 6 & 0.521 & $\begin{array}{l}g 1=0.07 \\
g 2=0.07\end{array}$ & 0.062 & $0.04 ; 0.09$ \\
\hline
\end{tabular}


largely under-explored, concept for research in the educational context-social support from users. Educational professionals have defined that support as the core and most important source of strain as well as a source of motivation and satisfaction (Ohi, 2014).

Thus, it was important to analyze whether there were differences between two groups of professionals. The UISS showed strict MI (metric, scalar, and uniqueness), as well as latent factor invariance, between kindergarten teachers and educators. These findings imply that the instrument was found to be equally valid and reliable for these two professional groups (Lance and Vandenberg, 2009). Moreover, the groups could be compared at the level of their respective, latent mean scores (Meredith, 1993).

\section{Limitations and Future Directions}

The present study has some limitations. In primis, the sample size is quite limited, and the participants were from the same geographical area and organizational context. Future studies should involve a larger sample of educators and kindergarten teachers. Another drawback of this research is its cross-sectional design; a longitudinal design could more effectively verify the importance of a supportive relationship between service workers and service users and identify the possible consequences of the user-initiated support. The study, moreover, is focused on educational services professionals. In order to test the invariance of the scale using different kinds of social operators, further research can hypothesize about the inclusion of other groups of social professionals (e.g., healthcare-sector workers). The aim is to consider this specific, and not yet deeply studied, source of support in

\section{REFERENCES}

Arenas, A., Giorgi, G., Montani, F., Mancuso, S., Perez, J. F., Mucci, N., et al. (2015). Workplace bullying in a sample of Italian and Spanish employees and its relationship with job satisfaction, and psychological well-being. Front. Psychol. 6:1912. doi: 10.3389/fpsyg.2015.01912

Avallone, F., and Paplomatas, A. (2005). Salute Organizzativa, Psicologia Del Benessere Nei Contesti Lavorativi. Milano: Raffaello Cortina Editore.

Bakker, A. B., Demerouti, E., and Schaufeli, W. B. (2003). Dual processes at work in a call centre: an application of the job demands a resources model. Eur. J. Work Organ. Psychol. 12, 393-417. doi: 10.1080/13594320344000165

Bakker, A. B., Hakanen, J. J., Demerouti, E., and Xanthopoulou, D. (2007). Job resources boost work engagement, particularly when job demands are high. J. Educ. Psychol. 99, 274-284. doi: 10.1037/0022-0663.99.2.274

Bentler, P. M. (1995). EQS Structural Equations Program Manual. Encino, CA: Multivariate Software.

Byrne, B. M. (1991). Burnout: investigating the impact of background variables for elementary, intermediate, secondary, and university educators. Teach. Teach. Educ. 7, 197-209. doi: 10.1016/0742-051X(91)90027-M

Byrne, B. M. (1998). Structural Equation Modeling with LISREL, PRELIS and SIMPLIS: Basic Concepts, Applications and Programming. Mahwah, NJ: Lawrence Erlbaum Associates.

Byrne, B. M., Shavelson, R. J., and Muthen, B. (1989). Testing for the equivalence of factor covariance and mean structures: the issue of partial measurement invariance. Psychol. Bull. 105, 456-466. doi: 10.1037/0033-2909.105. 3.456

Caplan, G. (1974). Support Systems and Community Mental Health: Lectures on Concept Development. New York, NY: Behavioral Publications. other working populations that deal with people, in order to verify the similarities and differences. Future research should also simultaneously involve workers and service users. In doing so, it will contribute to the analysis of the reciprocity between employees' health/well-being and users' perceptions of the quality of services (Dormann and Kaiser, 2002; Ferrara et al., 2013; Converso et al., 2015a), as well as the affective crossover process as originally hypothesized by Zimmermann et al. (2011).

Despite these limitations, the UISS scale proposed in this paper was found to be a simple, yet valid and reliable, instrument to measure user support in educational and social services. Thus, it is a useful scale for evaluating the type of relational resources that promote employee well-being. Further advantages of the UISS scale are its concise form and it ability to explore several facets of user support. Therefore, it is particularly suitable both for complex research designs that take into account numerous dimensions and for applied research in organizations that need brief and simple instruments.

\section{AUTHOR CONTRIBUTIONS}

$\mathrm{BL}, \mathrm{MM}, \mathrm{SV}$, and DC equally contributed at the: conception and design of the work; the analysis of data for the work; acquisition and interpretation of data for the work; drafting the work and critically revising it; final approval of the version to be published; agreement to be accountable for all aspects of the work in ensuring that questions related to the accuracy or integrity of any part of the work are appropriately investigated and resolved.

Cheung, G. W., and Rensvold, R. B. (2002). Evaluating goodness-of-fit indexes for testing measurement invariance. Struct. Equ. Modeling 9, 233-255. doi: 10.1207/S15328007SEM0902_5

Cohen, S., and Wills, T. A. (1985). Stress, social support, and the buffering hypothesis. Psychol. Bull. 98, 310-357. doi: 10.1037/0033-2909. 98.2.310

Converso, D., Loera, B., Viotti, S., and Martini, M. (2015a). Do positive relations with patients play a protective role for healthcare employees? Effects of patients' gratitude and support on nurses' burnout. Front. Psychol. 6:470. doi: 10.3389/fpsyg.2015.00470

Converso, D., Viotti, S., Sottimano, I., Cascio, V., and Guidetti, G. (2015b). Capacità lavorativa, salute psico-fisica, burnout ed età, tra insegnanti d'infanzia ed educatori di asilo nido: uno studio trasversale. Med. Lav. 106, 91-108.

Demerouti, E., Bakker, A. B., Nachreiner, F., and Schaufeli, W. B. (2001). The job demand-resources model of Burnout. J. Appl. Psychol. 86, 499-512. doi: 10.1037/0021-9010.86.3.499

Diamantopoulos, A., and Siguaw, J. A. (2000). Introducing LISREL. London: Sage Publications.

Dormann, C., and Kaiser, D. (2002). Job conditions and customer satisfaction. Eur. J. Work Organ. Psychol. 11, 257-283. doi: 10.1080/13594320244000166

Dormann, C., and Zapf, D. (2004). Customer-related social stressors and burnout. J. Occup. Health Psychol. 9, 61-82. doi: 10.1080/13594320344000183

Dudenhöffer, S., and Dormann, C. (2013). Customer-related social stressors and service providers' affective reactions. J. Organ. Behav. 34, 520-539. doi: 10.1002/job.1826

Dudenhöffer, S., and Dormann, C. (2015). Customer-related social stressors: meaning and consequences across service jobs. J. Pers. Psychol. 14, 165-181. doi: 10.1027/1866-5888/a000132 
Duncan, C. W. (1980). Coping with stress. Day Care Early Educ. 7, 18-21. doi: 10.1007/BF01617489

Etzion, D. (1984). Moderating effect of social support on the stress-burnout relationship. J. Appl. Psychol. 69, 615-622. doi: 10.1037/0021-9010.69.4.615

Ferrara, M., Converso, D., and Viotti, S. (2013). Patient satisfaction and occupational health of workers in hospital care setting: associations and reciprocity. Health 5, 1622-1628. doi: 10.4236/health.2013.510218

Floyd, F. J., and Widaman, K. F. (1995). Factor analysis in the development and refinement of clinical assessment instruments. Psychol. Assess. 7, 286-299. doi: 10.1037/1040-3590.7.3.286

Foa, U. G., and Foa, E. B. (1980). "Resource theory: interpersonal behavior as exchange," in Social Exchange: Advances in Theory and Research, eds K. J. Gergen, M. S. Greenberg, and R. H. Willis (New York, NY: Plenum).

Giorgi, G., Perminienë, M., Montani, F., Fiz-Perez, F. J., Mucci, N., and Arcangeli, G. (2016). Detrimental effects of workplace bullying: impediment of self-management competence via psychological distress. Front. Psychol. 7:60. doi: $10.3389 /$ fpsyg. 2016.00060

Groth, M., and Grandey, A. (2012). From bad to worse: negative exchange spirals in employee-customer service interactions. Organ. Psychol. Rev. 2, 208-233. doi: $10.1177 / 2041386612441735$

Guglielmetti, C., Gilardi, S., Accorsi, L., and Converso, D. (2014). La relazione con i pazienti in sanità: quali risorse lavorative per attenuare l'impatto degli stressor sociali? [The relationship with patients in healthcare: which workplace resources can lessen the impact of social stressors]. Psicol. Della Salute 2, 121-137. doi: 10.3280/PDS2014-002008

Guidetti, G., Viotti, S., Badagliacca, R., and Converso, D. (2015). Looking for a specific measure for assessing sources of stress among teachers: a proposal for an Italian context. Turk. Online J. Educ. Technol. 330-337. Available at: https://www.researchgate.net/publication/283010398_Looking_For_A_Specific _Measure_For_Assessing_Sources_Of_Stress_Among_Teachers_A_Proposal_ For_An_Italian_Context

Hall-Kenyon, K. M., Bullough, R. V., MacKay, K. L., and Marshall, E. E. (2014). Preschool teacher well-being: a review of the literature. Early Child. Educ. J. 42, 153-162. doi: 10.1007/s10643-013-0595-4

Hobfoll, S. E. (1989). Conservation of resources: a new attempt at conceptualizing stress. Am. Psychol. 44, 513-524. doi: 10.1037/0003-066X.44.3.513

Holgado-Tello, F. P., Chacón-Moscoso, S., Barbero-García, I., and VilaAbad, E. (2010). Polychoric versus pearson correlations in exploratory and confirmatory factor analysis of ordinal variables. Qual. Quant. 44, 153-166. doi: 10.1007/s11135-008-9190-y

Hoyle, R. H. (ed.) (1995). Structural Equation Modeling. Thousand Oaks, CA: SAGE Publications Inc.

Hu, L., and Bentler, P. M. (1999). Cutoff criteria for fit indexes in covariance structure analysis: conventional criteria versus new alternatives. Struct. Equ. Modeling 6, 1-55. doi: 10.1080/10705519909540118

International Test Commission [ITC] (2005). International Guidelines on Test Adaptation. www.intestcom.org

Johnson, J. V., and Hall, E. M. (1988). Job strain, work place social support and cardiovascular disease: a cross sectional study of a random sample of the Swedish working population. Am. J. Public Health 78, 1336-1342. doi: 10.2105/AJPH.78.10.1336

Jorde-Bloom, P. (1988). Factors influencing overall job satisfaction and organizational commitment in early childhood work environments. J. Res. Child. Educ. 3, 107-122. doi: 10.1080/02568548809594933

Jöreskog, K. G., and Sörbom, D. (1996a). PRELIS 2: User's Reference Guide. Chicago, IL: Scientific Software International.

Jöreskog, K. G., and Sörbom, D. (1996b). LISREL 8: User's Reference Guide. Chicago: Scientific Software International.

Jourdain, G., and Chênevert, D. (2010). Job demands-resources, burnout and intention to leave the nursing profession: a questionnaire survey. Int. J. Nurs. Stud. 47, 709-722. doi: 10.1016/j.ijnurstu.2009.11.007

Karasek, R., and Theorell, T. (1990). Healthy Work: Stress, Productivity, and the Reconstruction of Working Life. New York, NY: Basic Books.

Kelly, A. L., and Berthelsen, D. C. (1995). Preschool teachers' experiences of stress. Teach. Teach. Educ. 11, 345-357. doi: 10.1016/0742-051X(94) 00038-8

Kline, R. B. (2011). Principles and Practice of Structural Equation Modeling. New York, NY: Guilford press.
Koch, P., Stranzinger, J., Nienhaus, A., and Kozak, A. (2015). Musculoskeletal symptoms and risk of burnout in child care workers - A crosssectional study. PLoS ONE 21:e0140980. doi: 10.1371/journal.pone. 0140980

Koopmann, J., Wang, M., Liu, Y., and Song, Y. (2015). "Customer mistreatment: a review of conceptualizations and a multilevel theoretical model," in Mistreatment in Organizations, Vol. 3. eds P. L. Perrewe, J. R. B. Halbesleben, and C. C. Rosen (Bingley: Emerald Group Publishing), 33-79.

Lance, C. E., and Vandenberg, R. J. (2009). Statistical and Methodological Myths and Urban. London: Routledge.

LeBlanc, M. M., and Kelloway, E. K. (2002). Predictors and outcomes of workplace violence and aggression. J. Appl. Psychol. 87, 444-453. doi: 10.1037/00219010.87.3.444

Lee, R. T., and Ashforth, B. E. (1996). A meta-analytic examination of the correlates of the three dimensions of job burnout. J. Appl. Psychol. 81, 123-133. doi: 10.1037/0021-9010.81.2.123

Loera, B., Converso, D., and Viotti, S. (2014). Evaluating the psychometric properties of the Maslach Burnout Inventory-Human Service Survey (MBI-HSS) among italian nurses: how many factors must a research consider? PLOS ONE 9:e114987. doi: 10.1371/journal.pone.01 14987

Martini, M., Loera, B., and Converso, D. (2015). Users' gratitude as a source of support for Social-Health Operators first validation of the Perceived Gratitude Scale (PGrate). Boll. Di Psicol. Appl. 274, 23-33.

Maslach, C. (1982). Burnout: The cost of caring. Englewood. Cliffs, NJ: Prentice Hall. Maslach, C., and Jackson, S. E. (1986). Maslach Burnout Inventory, 2nd Edn. Palo Alto: Consulting Psychologists Press.

Meredith, W. (1993). Measurement invariance, factor analysis, and factorial invariance. Psychometrika 58, 525-542. doi: 10.1007/BF022 94825

Nislin, M. A., Sajaniemi, N. K., Sims, M., Suhonen, E., Maldonado Montero, E. F., Hirvonen, A., et al. (2016). Pedagogical work, stress regulation and work-related well-being among early childhood professionals in integrated special day-care groups. Eur. J. Spec. Needs Educ. 31, 27-43. doi: $10.1080 / 08856257.2015 .1087127$

Nunnally, J. (1967). Psychometric Methods. New York, NY: McGraw-Hill Book Co. Ohi, S. (2014). A day in the life of an early childhood teacher: identifying the confronting issues and challenges that arise. Creat. Educ. 5, 1008-1018. doi: $10.4236 /$ ce.2014.511115

Reise, S. P., Widaman, K. F., and Pugh, R. H. (1993). Confirmatory factor analysis and item response theory: two approaches for exploring measurement invariance. Psychol. Bull. 114, 552-566. doi: 10.1037/0033-2909.114. 3.552

Satorra, A., and Bentler, P. M. (1994). "Corrections to test statistics and standard errors in covariance structure analysis," in Latent Variables Analysis: Applications for Developmental Research, eds A. von Eye and C. C. Clogg (Thousand Oaks, CA: Sage), 399-419.

Satorra, A., and Bentler, P. M. (2001). A scaled difference chi-square test statistic for moment structure analysis. Psychometrika 66, 507-514. doi: 10.1007/BF02296192

Sirigatti, S., and Stefanile, C. (1993). Adattamento Italiano Del Mbi-Maslach Burnout Inventory. [Italian Adaptation of the Mbi-Maslach Burnout Inventory]. Firenze: Organizzazioni Speciali.

Taddei, S., and Vanni, D. (2008). Customer-related social stress and burnout. A contribution to the Italian adaptation of the customer-related social stress scale. Boll. Di Psicol. Appl. 256, 41-53.

Vandenberg, R. J., and Lance, C. E. (2000). A review and synthesis of the measurement invariance literature: suggestions, practices, and recommendations for organizational research. Organ. Res. Methods 3, 4-70. doi: $10.1177 / 109442810031002$

Vandenberg, R. J., and Self, R. M. (1993). Assessing newcomers' changing commitments to the organization during the first 6 months of work. J. Appl. Psychol. 78, 557-568. doi: 10.1037/0021-9010.78.4.557

Viotti, S., Gilardi, S., Guglielmetti, C., and Converso, D. (2015). Verbal aggression from care recipients as a risk factor among nursing staff: a study on burnout in the JD-R model perspective. BioMed. Res. Int. 2015:215267. doi: $10.1155 / 2015 / 215267$ 
Widaman, K. F., and Reise, S. P. (1997). "Exploring the measurement invariance of psychological instruments: applications in the substance use domain," in The science of Prevention: Methodological Advances from Alcohol and Substance Abuse Research, eds K. J. Bryant, M. Windle, and S. G. West (Washington, DC: American Psychological Assocation), 281-324.

Zimmermann, B. K., Dormann, C., and Dollard, M. F. (2011). On the positive aspects of customers: customer-initiated support and affective crossover in employee-customer dyads. J. Occup. Health Psychol. 84, 31-57. doi: 10.1111/j.2044-8325.2010.02011.x
Conflict of Interest Statement: The authors declare that the research was conducted in the absence of any commercial or financial relationships that could be construed as a potential conflict of interest.

Copyright (c) 2016 Loera, Martini, Viotti and Converso. This is an open-access article distributed under the terms of the Creative Commons Attribution License (CC BY). The use, distribution or reproduction in other forums is permitted, provided the original author(s) or licensor are credited and that the original publication in this journal is cited, in accordance with accepted academic practice. No use, distribution or reproduction is permitted which does not comply with these terms. 


\section{OPEN ACCESS}

Edited by:

Gabriele Giorgi,

European University of Rome, Italy

Reviewed by:

Nicola Mucci,

University of Florence, Italy

Marco Giovanni Mariani,

University of Bologna, Italy

*Correspondence: Monica Pedrazza monica.pedrazza@univr.it

Specialty section This article was submitted to Organizational Psychology, a section of the journal Frontiers in Psychology

Received: 12 May 2016 Accepted: 03 August 2016 Published: 18 August 2016

Citation:

Pedrazza M, Berlanda S, Trifiletti E and Bressan F (2016) Exploring

Physicians' Dissatisfaction and Work-Related Stress: Development of the PhyDis Scale. Front. Psychol. 7:1238 doi: 10.3389/fpsyg.2016.01238

\section{Exploring Physicians' Dissatisfaction and Work-Related Stress: Development of the PhyDis Scale}

\author{
Monica Pedrazza $^{1 *}$, Sabrina Berlanda ${ }^{1}$, Elena Trifiletti ${ }^{1}$ and Franco Bressan ${ }^{2}$ \\ ${ }^{1}$ Department of Human Sciences, University of Verona, Verona, Italy, ${ }^{2}$ Department of Economics, University of Verona, \\ Verona, Italy
}

Research, all over the world, is starting to recognize the potential impact of physicians' dissatisfaction and burnout on their productivity, that is, on their intent to leave the job, on their work ability, on the amount of sick leave days, on their intent to continue practicing, and last but not least, on the quality of the services provided, which is an essential part of the general medical care system. It was interest of the provincial medical board's ethical committee to acquire information about physician's work-related stress and dissatisfaction. The research group was committed to define the indicators of dissatisfaction and work-related stressors. Focus groups were carried out, 21 stressful experience's indicators were identified; we developed an online questionnaire to assess the amount of perceived stress relating to each indicator at work (3070 physicians were contacted by e-mail); quantitative and qualitative data analysis were carried out. The grounded theory perspective was applied in order to assure the most reliable procedure to investigate the concepts' structure of "work-related stress." We tested the five dimensions' model of the stressful experience with a confirmatory factor analysis: Personal Costs; Decline in Public Image and Role Uncertainty; Physician's Responsibility toward hopelessly ill Patients; Relationship with Staff and Colleagues; Bureaucracy. We split the sample according to attachment style (secure and insecure -anxious and avoidant-). Results show the complex representation of physicians' dissatisfaction at work also with references to the variable of individual difference of attachment security/insecurity. The discriminant validity of the scale was tested. The original contribution of this paper lies on the one hand in the qualitative in depth inductive analysis of physicians' dissatisfaction starting from physicians' perception, on the other hand, it represents the first attempt to analyze the physicians' dissatisfaction with reference to attachment styles, which is recognized as being a central variable of individual difference supporting caregiving practices. This study represents an original and innovative attempt to address physicians' dissatisfaction and job satisfaction. The PhyDis scale has been developed and, in line with international findings, our results indicate that role uncertainty and loss of social esteem are the most dissatisfying factors.

Keywords: physicians, job satisfaction, dissatisfaction, attachment style, scale development, mix method design 


\section{INTRODUCTION}

Research all over the world, is starting to recognize the potential impact of physicians' dissatisfaction and burnout on their productivity, that is on their intent to leave the job, on their work ability, on the amount of sick leave days, on their intent to continue practicing, and last but not least, on the quality of the services provided which is an essential part of the general medical care system (Dewa et al., 2014). Physicians' burnout rates range between 30 and $65 \%$ across medical specialties with particular reference to those working at the front line of clinical care, in general internal medicine and emergency medicine (Linzer et al., 2014, 2015; Schrijver, 2016). During the last decades, starting approximately about the late seventies, the practice of medicine begins to change, very rapidly, at a global level, most importantly, in all developed countries (Landon et al., 2002). Physicians, who once practiced primarily alone, are now asked to learn and adapt to work in larger groups, and begin to be subject to evaluation and approval regarding to their choice of treatments and procedures. Their autonomy shrinks sometimes consistently (Landon et al., 2002) also because of the widespread adoption of "evidence based practice" protocols and guidelines.

Economical issues, related above all to liability insurances costs, are increasingly affecting physicians' perceived job satisfaction. In fact there are different contextual factors which have contributed to the development of this last issue: the general growth of the patient-centered care, the consequent shareddecision making model, which enhances physicians engagement with patients in interactive discussions for treatment and, finally, the development of the judicialization of care (Schaad et al., 2015). Fear of crisis seems to be an important construct for organizational wellbeing (Giorgi et al., 2015) scholars demonstrate that job stress and poor social support mediate the relationship between fear of the crisis and health. In addition self-perceived poor health status, cardiovascular diseases, the development of mental illness and depression seem all to increase and to be related to the rate of unemployment (Astell-Burt and Feng, 2013; Mucci et al., 2016).

Even though hospital managers tend to shift physicianpatient litigation toward conciliation, the number of complaints, regarding patients' dissatisfaction and procedural factors is exponentially increasing (Kynes et al., 2013). Moreover, a number of administrative new strategies of the health management are strongly reducing physicians' time available for deepening interpersonal relationships with patients.

Up to date literature shows that the interest toward those issues increases. A large number of in-depth analysis is available, regarding the consequences of job dissatisfaction in physicians with particular reference to burnout and its consequences: contextual ones as replacement rates and turn over intentions, those affecting the relationship with patients such as compassion, professionalism and clinical errors, and those which contribute to determine physicians' personal costs such as chronic fatigue, substance abuse, psychiatric morbidity, and suicidal ideation (Shanafelt et al., 2003; Wallace et al., 2009; Schrijver, 2016). Although, there is an increasing availability of different measures to monitor physicians' job satisfaction with their career and general wellbeing (Landon et al., 2002, 2003; Gong et al., 2014), there is a lack of instruments to assess physicians' dissatisfaction to get a $360^{\circ}$ vision. The original contribution of this paper focuses on the priority to identify the roots of physician dissatisfaction applying a mix-method research strategy.

Therefore, aim of our research was to investigate construct and the validity of physicians' dissatisfaction (Grimm and Widaman, 2012). Moreover, since attachment style is recognized as one of the most relevant variables of individual difference affecting social competences, we assessed it in our sample in order to give a glance into the process which allows variables of individual difference to affect self-perception relating to satisfaction and dissatisfaction at work.

\section{Old Problems and Recent Changes Affecting Negatively Physicians' General Work Conditions}

A large number of old and new problems enhance nowadays the normal burden on physicians' general conditions. Physicians and other health workers are distributed in a very uneven manner: countries with the lowest relative need have the highest number of health workers. Health care is anyway the world's largest single industry employing in excess of 59 million staff (Gottret and Schieber, 2006; WHO, 2006). In addition, even developed countries are experiencing an important shrinking of the domestic resources attributable to the welfare services. Moreover, health systems are often vulnerable during times of crisis, such as the last one, which is still ongoing. Many health systems are functioning on limited budgets and are currently understaffed. The current need for sustainable health services is increasingly dealing with issues such as the need to reduce bureaucracy, increasing cost-effectiveness, improving efficiency, decentralizing services and allocating resources to address the needs of the population (Johnson and Stoskopf, 2010). In this context, the government of the country where this study was carried out attempted during the last decade to transfer management techniques and economic/organizational models from the private sector as a basis to reorganize and "reform" public services, which are often portrayed as monolithic, inflexible, inefficient and unable to innovate. It also recently proposed to reduce significantly physicians' autonomy in their clinical practice.

Additional problems, exacerbating physicians general conditions, are related to the exponential growth of malpractice costs, related both to liability insurance and defensive medicine costs. Premium's costs for physicians are growing relating also to the increasing number of patients' complaints. Today medicine is much more complex than 50 years ago, it often requires teams instead of a single professional and very expensive drugs and technologies, moreover the exponential growth of medical knowledge is often coupled with additional relational competences which have to be reached within fields such as inter-professional team work, physicians/patient relationship, quality of care and safety (Dyrbye and Shanafelt, 2016). Patients are nowadays much more informed and therefore willing to protect and defend their right to health. 
Since the economic downturn of 2008 the trend rates of complaints increased across medical specialities (Kynes et al., 2013) and across services (consumer complaints increased also during the same period from 7 to $10 \%$ ). Different ergonomic and environmental conditions such as insurances' costs, healthcare institutions in general, technical aspects of care and access to information, may be correlated to a number of complaint risk factors for physicians. Despite this, interesting findings are pointing at analyzing complaints by their type, including thereby physicians' variable of individual difference. Recent studies, in fact, (Kynes et al., 2013; Zengin et al., 2014; Schaad et al., 2015) agree on pointing out that the main reason which motivates patient to consult a complaints center, or to take legal action in order to restore their safety, are converging toward "the quality of interpersonal relationship with health care professionals" (Schaad et al., 2015) and communication (Kynes et al., 2013).

\section{Dissatisfaction Scales and Studies}

Despite the large number of studies on physicians' job satisfaction (Lichtenstein, 1984; Cooper et al., 1989; Konrad et al., 1999; Williams et al., 1999; Lavanchy et al., 2004; Bell et al., 2006; Etchegaray et al., 2010; Mcintyre and Mcintyre, 2010; Hann et al., 2011; Mohr and Burgess, 2011; Jönsson, 2012; BouwkampMemmer et al., 2013) and well-being (Firth-Cozens, 2001; Arnetz et al., 2002; Wallace and Lemaire, 2007; Janisse, 2008; Fang et al., 2011; Hills et al., 2012; Rockey, 2012; Alsuwaida et al., 2013; Bell, 2013; Aalto et al., 2014; Heponiemi et al., 2014; Simon and Durand-Bush, 2014; Min et al., 2015; Scheepers et al., 2015; Tucker et al., 2015), there is apparently little interest in physicians' dissatisfaction and its roots.

During the early' 80 physicians dissatisfaction gained social and academic attention. The first study was carried out in 1984 (Lichtenstein). Even though this first attempt allowed researcher to develop an instrument for physicians' satisfaction and dissatisfaction which was found to have both convergent and discriminant validity it is totally out of date. Previous studies (Nathanson and Becker, 1973; Lichtenstein, 1984) don't help us to understand the multifaceted and complex nature of physicians dissatisfaction because researchers used either a single overall question or multiple question derived from literature, that simply were summed and reported as a single general level of physicians dissatisfaction. Various job satisfaction scales, including single-item, and multi-item scales have been employed during the last decades. The 10-item mono-factorial scale (Hills et al., 2012) used to assess job satisfaction in Europe, UK, North America and Australasia does not allow an indepth, multifaceted approach to physician's dissatisfaction, thus preventing the differentiation between intrinsic and extrinsic factors.

The first systematic longitudinal survey on physicians' dissatisfaction was carried out in the US in the period from 1996 to 2001 (Landon et al., 2003). Findings demonstrate that physicians' dissatisfaction ranges did not change dramatically. Major driving forces of dissatisfaction are those related to threat of physicians' autonomy, to their ability to manage their daytoday patient interactions and to their ability to provide highquality care.
A recent study on dissatisfaction included a comparative assessment of results on Indian physicians' dissatisfaction with those of developed countries (Sharma et al., 2014). Dissatisfaction magnitude and its causes are similar, working environment and rates of pay were identified as major satisfaction/dissatisfaction factors. Work-overload and deprivation of autonomy associated to management outcome/ efficacy and efficiency evaluations are also reported as important dissatisfaction's factors. A study in Europe (Janus et al., 2008) is congruent with those findings. According to the AA. non-monetary factors are important determinant of physicians dissatisfaction, even more than monetary incentives. Seven principal factors were identified: decision making and social recognition, continuous education and job security and the increasing amount of administrative tasks.

The above-mentioned studies were carried out using measures mainly based on previous studies and on literature; their approach is therefore quantitative and focused on confirming previous results and already tested frameworks of reference. Because of the global need for enhancing integration of health systems all over the world (Lister and Labonté, 2009) and the widespread lack of economic resources, health systems constantly undergo a large number of changes. In addition research so far, largely failed to analyze the potential impact of different service systems within and between countries on physicians' well-being/dissatisfaction and performance (Linzer et al., 2002; Siegrist et al., 2010) We assume therefore there is an urgent need of accurate data on physicians' dissatisfaction addressing a $360^{\circ}$ view of their perception relating to individual, environmental, and social causes.

\section{Consequences of Dissatisfaction}

According to the 2015 Medscape Physician Compensation Report physicians' dissatisfaction is increasing. Results of several studies (Reschovsky et al., 1998; Barnard and Tong, 2000; Landon et al., 2006) show that dissatisfied physicians are 2-3 times more likely to leave medicine than satisfied physicians. AA. demonstrate that dissatisfied physicians are also more likely to retire and to take that step at an early age. Women physician during their childbearing years and high-paying specialties, such as surgery, compared with lower-paid specialties, such as internal medicine, are more likely to reduce their clinical practice or retire. These finding account for a lack of relationship of this decision with income. Previous research demonstrate that unhappy physicians provide lower quality care (Linn et al., 1985; Grembowsky et al., 2005) and are unable to cope with increased physical demands and stress related to surgical specialties. Physicians' job satisfaction affects positively patients' adherence to treatment and different actions in managing their disease (Williams and Skinner, 2003) in fact dissatisfied physician have a riskier prescribing profile, less satisfied patients, less adherent patients and thus their global performance drops to a reduced quality of care (Wallace et al., 2009). In addition physicians' job satisfaction is related to patients' satisfaction rates (Haas et al., 2000; Williams and Skinner, 2003; Stelfox et al., 2005). Comparative analysis (Siegrist et al., 2010) of physicians' dissatisfaction between countries, ruled by different health-care 
provision systems, highlights that the highest levels of work stress is reported by physicians in Germany and the lowest level by physicians in the UK, with US physicians reporting intermediate levels. Differences are largely due to the reward component. Moreover, lower levels of administrative and clinical autonomy are associated with higher work stress in all countries. A wide range of factors may potentially raise physicians' risks of work stress (Dyrbye and Shanafelt, 2016) and dissatisfaction: frequent organizational changes, worldwide lasting crisis and subsequent lack of resources, the health system management's need for stringent outcome evaluation, increasing frequency of patients complaints, the strengthening of parameters to assess services' quality (Lister and Labonté, 2009), the growing amount of evidence based strict protocols implementation and the increasing lack of professional autonomy. Long-term exposure to stressful experiences at work and lasting job dissatisfaction can often result in burnout. Scholars (Dewa et al., 2014) show that both burnout dimensions, that is emotional exhaustion and depersonalization, are significantly associated with more use of sick leave days and with the intention to leave a current position. Moreover, physicians who have high scores for both EE and DP dimensions of burnout incur significantly greater odds of having self-perceived "insufficient” work ability (Ruitenburg et al., 2012).

\section{MATERIALS AND METHODS}

Ethical approval was obtained from the ethics committee of the provincial medical board's (Ordine dei Medici Chirurghi e degli Odontoiatri della Provincia di Verona). The study was carried out between November 2013 and January 2015. Informed consent was obtained from each participant, after having explained the nature and purpose of the study. Participation was entirely voluntary; participants were informed about their right to withdraw from the study at any time without incurring any penalties. The anonymity and confidentiality of answers were guaranteed. Questionnaire included an information sheet that briefly described the study's purpose and a consent form.

The research was articulated into two studies: instrument development (item generation and content validity) and test of psychometric properties. The latter examined the construct validity (factor analysis and reliability) and the discriminant validity of the PhyDis scale (Physicians' Dissatisfaction Scale), that is, its correlation with the Global Job Satisfaction dimension of the Physicians' Job Satisfaction Scale (Konrad et al., 1999; Williams et al., 1999).

\section{Study 1: Development of the PhyDis Scale (Physicians' Dissatisfaction Scale) Item Generation}

The items for the PhyDis scale were generated through 4 focus group including 35 physicians, representatives of all specialties. Focus groups were low structured and their participants underwent a theoretical sampling procedure (Strauss and Corbin, 2008; Pedrazza and Berlanda, 2014). Participants represented both genders, and were selected having more than 10 years of clinical experience.
Participants were asked to list all potential sources of physicians' dissatisfaction. Participants were therefore free to express whatever they could perceive as root of their unease and dissatisfaction at work. They were encouraged to generate as many statements as possible. The transcripts of the focus groups were submitted to a content analysis (with NVivo 8). The qualitative analysis was structured around three conceptually progressive coding operations: open coding, axial coding and selective coding. Reliability in this type of research is construed as the degree of consistency with which cases are assigned to the same category by different observers or by the same observer on different occasions (Hammersley, 1992). Categories were used consistently. Units of meaning were included in the categories on the basis of decisions made by four different judges, who worked independently and compared their results only when they had finished their work, in order to exclude the possibility of their influencing each other. The final comparison process brought to the final issues' number through a continuous and generative re-interpretation, toward agreement- process between judges (Strauss and Corbin, 2008; Pedrazza and Berlanda, 2014). The open coding (Strauss and Corbin, 2008) allowed us to identify 276 responses. This initial set of statements was refined by removing redundant answers. Axial coding defined as a set of procedures whereby data are put back together in new ways, by making connections between categories (Kelle, 2005; Strauss and Corbin, 2008), brought researchers to identify 21 issues. A content validity index (CVI; Polit and Beck, 2006) was computed by considering the percentage of items deemed to be relevant. A CVI of 0.91 was obtained, which indicated an acceptable agreement among the experts about the validity of the measure.

The final qualitative exploration of data, performed through selective coding, enabled us to gather those items in 5 distinct dissatisfaction's areas: economical issues; lost of social recognition and public image; relationship with staff and colleagues; patient/physician relationship and physician's responsibility; and bureaucracy. Personal Costs: includes items related to social security and liability insurance costs. Role Uncertainty: this factor is associated to the following issues: negative feelings caused by the health systems' frequent negative media exposure, dealing with confronting and stressful patient's complaints, the ongoing decline in public image because of the lost of status physicians were used to enjoy. Relationship with colleagues and staff is referred to poor communication with colleagues and staff, rudeness, delays and inattentiveness as also the physicians' often perceived professional solitude. Responsibility toward patients, this factor includes items referring to patients' and their families' anxiety and worry, to discomfort in discussing and communicating a poor prognosis associated to the responsibility physicians feel to provide safe and effective care. Bureaucracy: Health organizations as also medical facilities are nowadays increasingly heavy in procedural documentation, in addition the high documentation demand (e.g., computerbased patient record CPR, Rahimi et al., 2008) is associated with high caseload. We used Krippendorff's alpha (Geertzen, 2012; Krippendorff, 2012) to assess the inter-rater agreement achieved among the four judges in the selective coding $(\alpha=0.779)$. 
At this stage we proceeded to the development of a questionnaire, about all potential sources of physicians' dissatisfaction gathered from axial coding (21 items, see Table 1), to investigate more deeply the structure and mutual relation of the five identified factors.

In addition, given that the largest number of studies on physicians' dissatisfaction refer the importance of relational issues regarding both colleagues, teams and patients, we decided to include a self-report attachment style measure.

According to literature (Mikulincer and Shaver, 2007) individuals' attachment style is relevant within the present study for at least 4 reasons: (1) it represents the most important variable involved in the occurrence of relationships' issues, it supports and regulates intra and interpersonal psychological processes, which are needed in order to manage dyadic relationships regarding to any social domain: familial, social, peers' and professional's domain; (2) up to date literature states that attachment is a variable of individual difference which affects a consistent number of organizational processes (Declercq and Willemsen, 2006; Mikulincer and Shaver, 2007; Richards and Schat, 2011; Falvo et al., 2012; Pedrazza and Boccato, 2012); (3) furthermore
(Mikulincer and Shaver, 2007; Adshead, 2010) care-giving or care-eliciting relationships are attachment relationships, where secure subjects are able to recognize others' need, providing responsive answers and care; avoidant subjects tend to avoid negative emotion and provide a rather dismissive caregiving and anxious subjects engage often in a rather compulsive caregiving (Dozier and Tyrrell, 1998; Leiper and Casares, 2000). Insecure attachment style is likely to be one of several individual risk factors that affect professionals' psychological well-being in helping professions and thereby it affects professionals ability to cope with threatening events at work and relational issues with patients; (4) finally attachment style affects the individual's ability to cope with threatening events of any type. Secure attached people, unlike insecure ones, are more likely to perceive as less threatening any type of negative event such as long-lasting stress, death of relatives, poor prognosis, job loss, and severe economical issues. Despite the evidence of the importance of attachment style in shaping the manner professionals manage their relationships with clients, patients, and users (Dozier and Tyrrell, 1998), only one study assessed attachment style in a convenience sample of medical students (Ciechanowski et al., 2004).

TABLE 1 | Item loadings of confirmatory factor analysis (CFA) with 20 items $(N=853)$.

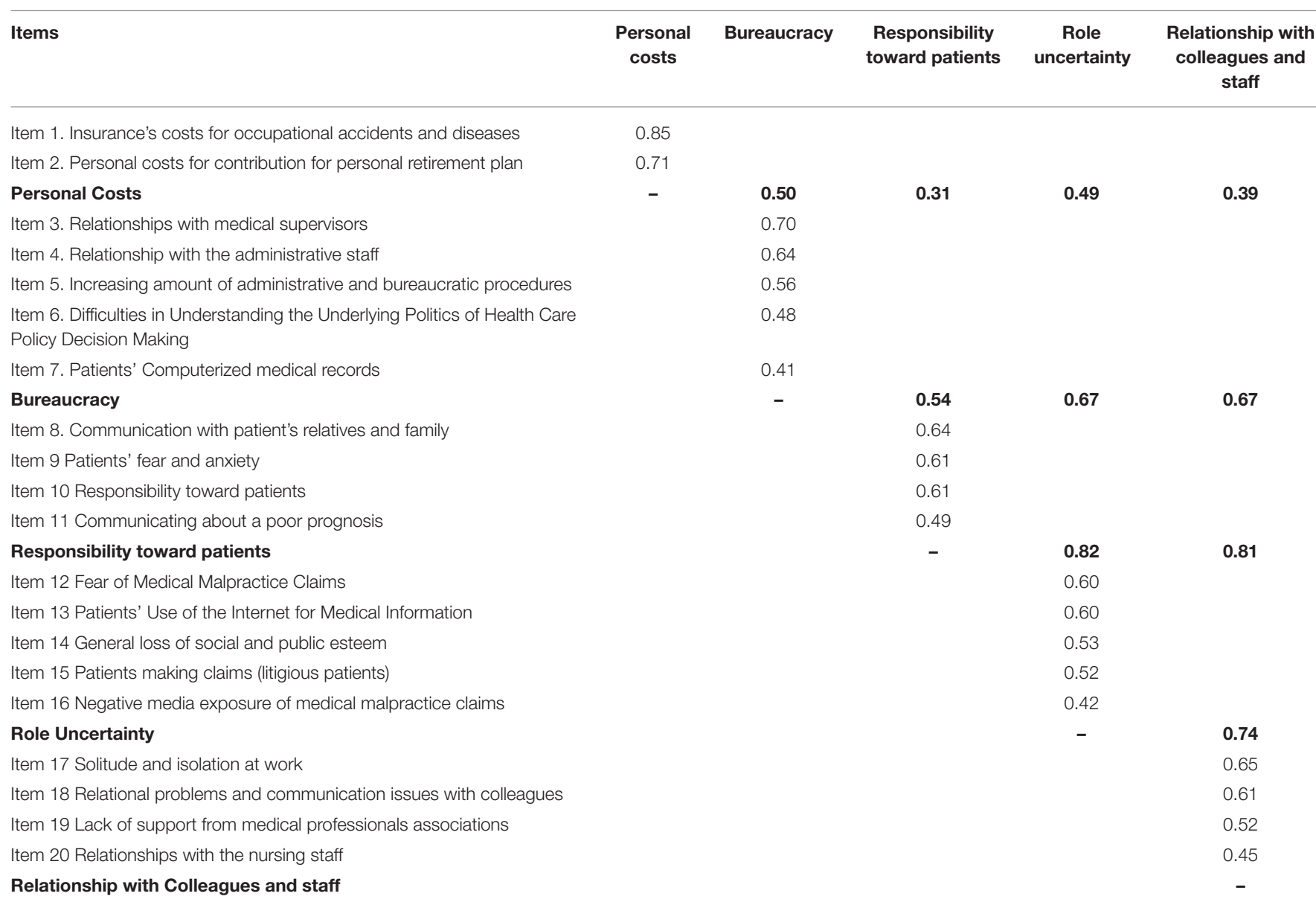

All loadings were significant, $p<0.001$. Bold value indicates the standardized relationship among $\xi$ (ksi -Latent Variables). 


\section{Study 2: Psychometric Test}

The PhyDis scale consisted of 21 items. Participants were asked to indicate to which extent each item indicates a perceived subjective source of dissatisfaction. Each item was answered on a 6-point Likert scale, ranging from 1 (not at all) to 6 (extremely). On line questionnaire reached 3070 physicians of the province. The study was presented as research on physicians' dissatisfaction.

The survey was administered to all physicians of the Verona province in Northern Italy. Three thousand and seventy physicians were contacted by e-mail. A total of 1251 questionnaires were completed, with a response rate of $40.75 \%$. We eliminated 398 questionnaires because they had more than $20 \%$ of missing responses in the PhyDis Scale and in the Global Job Satisfaction Scale (311 questionnaires), and/or they had all missing answers in the Global Job Satisfaction Scale (88 questionnaires). The final sample consisted of 853 physicians. The gender distribution was 510 males (59.8\%) and 323 females (37.9\%); 20 participants have not indicated the gender $(2.3 \%)$. The mean age was 51.38 years $(S D=11.71$; range $=24-83 ; 120$ missing data, $14.07 \%$ ), and the mean length of service was 17.94 years $(S D=12.20$; range $=0-55 ; 101$ missing data, $11.84 \%)$.

\section{Measures}

The instrument included the so developed PhyDis Scale, questions on demographic and occupational characteristics, the Global Job Satisfaction dimension of the Physicians' Job Satisfaction Scale (Konrad et al., 1999; Williams et al., 1999) in order to test external validity of the proposed new scale, and Adult Attachment Types (Hazan and Shaver, 1987, 1990).

Global Job Satisfaction (Konrad et al., 1999; Williams et al., 1999). This dimension refers to a factor of the validated Physicians' Job Satisfaction Scale. It includes 5 items (e.g., Overall I am satisfied in my current practice) regarding pleasure with work practices, perceived level of general satisfaction at work, level of perceived frustration in the clinical practice (reverse item), the extent to which work practices meet physicians' expectations, the consistency in time of their career choice (the extent to which they would choose again their job). Responses were given on a 6-point Likert scale ranging from 1 (complete disagreement) to 6 (complete agreement). The reliability of the scale in the present study was $\alpha=0.80$.

Adult Attachment Types (Hazan and Shaver, 1987, 1990). This measure of attachment type offered physicians three answer alternatives (the avoidant type, the anxious type, and the secure type), of which they were to choose the one that best described how they typically felt in relationships.

\section{Data Analysis}

All of the data were analyzed using the IBM SPSS Statistics 21.0 and LISREL 8.8 (Jöreskog and Sörbom, 2006). PRELIS (LISREL 8.7) was used for the imputation of missing data with the Expectation-maximization (EM) algorithm. Following Schafer and Graham's (2002) recommendations, maximum likelihood imputation (EM algorithm) was used to estimate values for missing scores. Maximum likelihood procedures provide more accurate estimates of population parameters than list-wise deletion or mean substitution (Schafer and Graham, 2002; see also Pedrazza et al., 2015). The validity of the PhyDis scale was tested by applying CFA (LISREL 8.8). A five-factor model was tested, in which observed variables corresponded to the 21 items and latent variables to the five dimensions identified in the qualitative analysis. The first loading of each factor was fixed to one for model identification. The goodness of fit was evaluated using the $\chi^{2}$ test, the comparative fit index (CFI), the root mean square error of approximation (RMSEA), and the standardized root mean square residual (SRMR). The fit of a model can be considered acceptable when $\chi^{2}$ is non-significant, CFI is $\geq 0.95$, RMSEA is $\leq 0.06$, and SRMR is $\leq 0.08$ ( $\mathrm{Hu}$ and Bentler, 1999). The Shapiro-Wilk test revealed that responses to the 21 items were not normally distributed ( $p s<0.001$ ). Therefore, robust maximum likelihood (RML) estimation was used. Compared to other estimators, such as generalized least squares (GLS) or weighted least squares (WLS), RML generally performs better under non-normality conditions in large models (Boomsma and Hoogland, 2001). The chi-square difference test (Satorra and Bentler, 2001) was applied to correlations $\geq 0.80$ to test whether highly correlated factors were distinct from each other. For each of these correlations, the five-factor model was compared with a nested model, in which the correlation between the two latent variables was fixed to 1 (i.e., the perfect correlation) and the two factors were constrained to have equal correlations with the remaining factors (see Miyake et al., 2000; Trifiletti et al., 2009; for a different method see Trifiletti et al., 2007). Subsequently, the five factor model was compared to a one-factor solution, in which all the items loaded onto one latent variable. The two models were compared using the Akaike information criterion (AIC). Values of AIC closer to zero indicate a better model fit (Hair et al., 1998).

As a measure of reliability, the internal consistency was examined by computing Cronbach's alphas (SPSS 21.0) for the five dimensions. Reliability is generally considered satisfactory when alpha is $\geq 0.70$ (Kline, 2000), however many authors consider an alpha values between 0.60 and 0.70 acceptable (Loewenthal, 2004). Descriptive statistics were obtained with SPSS 21.0. For each variable, a composite score was computed by averaging the respective items. Pearson correlation (SPSS 21.0) was used to examine the relationship between the five PhyDis subscales and Global Job Satisfaction. Finally, multiple linear regression analyses were conducted.

\section{RESULTS}

\section{Factor Structure, Reliability, and Validity of PhyDis Scale}

The five-factor model with 21 items showed an acceptable fit: $\left[\chi_{(179)}^{2}=789.36, p \cong 0.00\right.$; CFI $=0.99$; $\mathrm{RMSEA}=0.03$; $\mathrm{SRMR}=0.05]$. Although, the $\chi^{2}$ was significant, all the other indices met the respective criterion. However, the inspection of loadings revealed that one item of the factor Responsibility toward patients ("Patients' suffering and pain") showed a low loading (0.30, completely standardized coefficient). After dropping it, the fit indices for the model were: $\left[\chi_{(160)}^{2}=683.79\right.$, $p \cong 0.00 ; \mathrm{CFI}=0.99 ; \mathrm{RMSEA}=0.03 ; \mathrm{SRMR}=0.05]$. The 
loadings were all significant (see Table 1). Correlations between the five factors (Table 2) were moderate to large (range $=0.31-$ 0.82 ). The chi-square difference test showed that the correlations $>0.80$ were significantly different from 1 (i.e., the latent construct were distinct factors): all $\left[\chi_{d(4)}^{2} \geq 58.37\right.$, $\left.p s \leq 0.00\right]$. The onefactor model showed an acceptable fit: $\left[\chi_{(170)}^{2}=1318.90, p \cong\right.$ 0.00; CFI $=0.96$; RMSEA $=0.05$; SRMR $=0.07$ ], although worse than the five-factor model. AIC values confirmed that the fivefactor solution (AIC $=369.30)$ was preferable compared to the one-factor model (AIC $=639.88)$.

The reliability of each dimension was examined by computing Cronbach's alphas for the five dimensions. Cronbach's alphas were 0.75 for Personal Costs, 0.69 for Bureaucracy, 0.68 for Physician's responsibility toward hopelessly ill patients, 0.67 for Decline in Public Image and Role Uncertainty, and 0.63 for Relationship with colleagues and staff.

\section{Descriptive Statistics and Correlations}

The means, standard deviations, and correlations of study variables are presented in Table 2. As shown in the table, the Role Uncertainty was rated as the most dissatisfying factor, Bureaucracy immediately following. Relationship with colleagues and staff was the aspect that generated less dissatisfaction.

The correlations reveal that the five sources of dissatisfaction were positively related. Global Job Satisfaction was negatively correlated with each of the five identified sources of dissatisfaction. These results support that the two sets of measures are discriminated from each other.

Age and Length of Service were positively correlated with Global Job Satisfaction and with the dissatisfaction due to the Bureaucracy. Moreover, Age and Length of Service were negatively correlated with dissatisfaction about Personal Costs and Role Uncertainty.

\section{The Roles of Gender, Age, and Attachment Style}

There were few sex differences (Table 3). Women reported higher levels of dissatisfaction than men, with specific reference to decline in public image and role uncertainty $(p=0.001)$, physician's responsibility toward patients $(p<0.001)$; and relationship with colleagues and staff $(p=0.002)$; and on average, women were less satisfied ( $p=0.041)$. There weren't differences regarding Personal Costs, and Bureaucracy.

We divided participants into two groups on the basis of their age, using the median split method. We split the sample in two groups relating to the average of age (from 24 to 53 years and from 55 to 83 years).

Younger subjects and senior ones rated differently relating to personal costs $(p<0.001)$; Decline in Public Image and Role Uncertainty ( $p=0.007)$; Bureaucracy $(p=0.039)$; Relationship with colleagues and staff $(p=0.044)$; and Global Job Satisfaction $(p<0.001)$. The younger population perceived lower levels of job satisfaction and higher levels of dissatisfaction; but they suffered less than senior to the bureaucratization. There weren't differences regarding physician's Responsibility toward patients.

One hundred and twenty-two physicians did not complete this question. $41.6 \%$ of the subjects classified themselves as secure, $13.3 \%$ as anxious, and $45.1 \%$ as avoidant.

In line with up to date literature, in our sample the attachment assessment allowed us to identified differences between secure and insecure subjects when confronted with relational issues: insecure subjects feel more uncomfortable than secure ones when charged with the responsibility of severely ill patients $(p=$ 0.006), and when in trouble because of relational problems with colleagues and staff $(p=0.013)$. Moreover, insecure subjects feel less satisfied than secure physicians $(p=0.037)$. No differences emerged relating to Personal costs, Bureaucracy, and Role Uncertainty.

To examine invariance of factor structure between women and men subgroups, and between senior and young subgroups, and between secure and insecure subgroups, the multi-sample procedure was applied. In four models, we tested: (a) the configural invariance (i.e., the same number of factors across the groups; Baseline model); (b) the invariance of factor loadings $\left(\lambda_{\mathrm{x}}\right.$; Model 1); (c) the invariance of error variances $\left(\theta_{\delta}\right.$; Model 2$)$; (d) the invariance of correlations and variances $(\Phi$; Model 3; see Bobbio and Manganelli, 2011). The chi-square difference test was used to compare nested models.

Fit indices and chi-square differences are summarized in Tables 4-6.

As can be seen, the invariance of factor loadings and of error variances was not confirmed for the women-men comparison. We then constrained each factor loading, one at time, to be equal across the two groups (with the exception of the first

TABLE 2 | Descriptive statistics and intercorrelations among variables.

\begin{tabular}{|c|c|c|c|c|c|c|c|c|c|c|c|}
\hline & & $\mathbf{N}$ & Mean & SD & 1 & 2 & 3 & 4 & 5 & 6 & 7 \\
\hline 1 & Personal costs & 853 & 3.78 & 1.47 & - & & & & & & \\
\hline 2 & Bureaucracy & 853 & 4.36 & 0.95 & $0.344^{\star * *}$ & - & & & & & \\
\hline 3 & Responsibility toward patients & 853 & 3.37 & 1.03 & $0.221^{\star \star \star}$ & $0.539^{\star \star \star}$ & - & & & & \\
\hline 4 & Role uncertainty & 853 & 3.30 & 1.03 & $0.302^{\star \star \star \star}$ & $0.489^{\star \star \star}$ & $0.541^{\star \star \star}$ & - & & & \\
\hline 5 & Relationship with colleagues and staff & 853 & 4.07 & 0.96 & $0.380^{\star \star \star}$ & $0.473^{\star \star \star}$ & $0.369^{\star \star \star}$ & $0.474^{\star \star \star}$ & - & & \\
\hline 6 & Global Job satisfaction & 853 & 4.48 & 1.12 & $-0.233^{\star \star \star}$ & $-0.208^{\star \star \star}$ & $-0.165^{\star \star \star}$ & $-0.269^{\star \star \star}$ & $-0.263^{\star \star \star}$ & - & \\
\hline 7 & Age & 733 & 51.38 & 11.71 & $-0.183^{\star \star \star}$ & $-0.086^{\star}$ & -0.062 & -0.049 & $0.107^{* \star}$ & $0.147^{\star \star \star}$ & - \\
\hline 8 & Length of service & 752 & 17.94 & 12.20 & $-0.225^{\star \star \star}$ & $-0.105^{\star \star}$ & -0.039 & -0.056 & $0.084^{*}$ & $0.092^{\star}$ & $0.802^{\star \star \star}$ \\
\hline
\end{tabular}

${ }^{*} p<0.05,{ }^{* *} p<0.01,{ }^{* \star *} p<0.001$. 
TABLE 3 | Differences in the sample means.

\begin{tabular}{|c|c|c|c|c|c|c|c|c|c|c|}
\hline & & $\begin{array}{c}\text { Men } \\
N=510\end{array}$ & $\begin{array}{l}\text { Women } \\
N=323\end{array}$ & $t$ & $\begin{array}{l}\text { Younger } \\
N=347\end{array}$ & $\begin{array}{l}\text { Senior } \\
N=366\end{array}$ & $T$ & $\begin{array}{l}\text { Secure } \\
N=304\end{array}$ & $\begin{array}{l}\text { Insecure } \\
N=427\end{array}$ & $t$ \\
\hline 1 & Personal Costs & $\begin{array}{c}3.76 \\
(1.50)\end{array}$ & $\begin{array}{c}3.78 \\
(1.43)\end{array}$ & -0.18 & $\begin{array}{c}4.02 \\
(1.43)\end{array}$ & $\begin{array}{c}3.41 \\
(1.49)\end{array}$ & $5.57^{\star \star \star}$ & $\begin{array}{c}3.83 \\
(1.48)\end{array}$ & $\begin{array}{c}3.77 \\
(1.48)\end{array}$ & -0.51 \\
\hline 2 & Bureaucracy & $\begin{array}{l}4.11 \\
(0.97)\end{array}$ & $\begin{array}{c}4.02 \\
(0.93)\end{array}$ & 1.33 & $\begin{array}{c}3.99 \\
(0.94)\end{array}$ & $\begin{array}{c}4.14 \\
(0.98)\end{array}$ & $-2.07^{\star}$ & $\begin{array}{c}4.03 \\
(0.99)\end{array}$ & $\begin{array}{l}4.09 \\
(0.93)\end{array}$ & 0.81 \\
\hline 3 & Responsibility toward patients & $\begin{array}{c}3.25 \\
(0.99)\end{array}$ & $\begin{array}{c}3.55 \\
(1.06)\end{array}$ & $-4.24^{\star \star \star}$ & $\begin{array}{c}3.43 \\
(1.04)\end{array}$ & $\begin{array}{c}3.33 \\
(1.07)\end{array}$ & 1.19 & $\begin{array}{c}3.24 \\
(1.09)\end{array}$ & $\begin{array}{c}3.45 \\
(0.96)\end{array}$ & $2.78^{\star \star}$ \\
\hline 4 & Role Uncertainty & $\begin{array}{c}4.28 \\
(0.96)\end{array}$ & $\begin{array}{c}4.50 \\
(0.92)\end{array}$ & $-3.20^{\star \star}$ & $\begin{array}{l}4.45 \\
(0.93)\end{array}$ & $\begin{array}{c}4.26 \\
(1.00)\end{array}$ & $2.64^{\star *}$ & $\begin{array}{c}4.29 \\
(0.99)\end{array}$ & $\begin{array}{c}4.42 \\
(0.91)\end{array}$ & 1.78 \\
\hline 5 & Relationship with Colleagues and staff & $\begin{array}{l}3.21 \\
(0.98)\end{array}$ & $\begin{array}{c}3.44 \\
(1.07)\end{array}$ & $-3.12^{\star *}$ & $\begin{array}{c}3.36 \\
(1.03)\end{array}$ & $\begin{array}{c}3.21 \\
(1.04)\end{array}$ & $2.02^{*}$ & $\begin{array}{c}3.17 \\
(1.05)\end{array}$ & $\begin{array}{c}3.36 \\
(1.00)\end{array}$ & $2.48^{\star}$ \\
\hline 6 & Global Job Satisfaction & $\begin{array}{c}4.55 \\
(1.07)\end{array}$ & $\begin{array}{c}4.38 \\
(1.18)\end{array}$ & $2.05^{\star}$ & $\begin{array}{c}4.39 \\
(1.11)\end{array}$ & $\begin{array}{c}4.58 \\
(1.15)\end{array}$ & $-2.24^{\star \star}$ & $\begin{array}{c}4.56 \\
(1.11)\end{array}$ & $\begin{array}{c}4.39 \\
(1.13)\end{array}$ & $-2.09^{\star}$ \\
\hline
\end{tabular}

${ }^{*} p<0.05,{ }^{* \star} p<0.01,{ }^{* \star *} p<0.001$.

TABLE 4 | Fit indices and chi-square differences for the multi-sample analysis (men vs. women).

\begin{tabular}{lcccc}
\hline \multirow{2}{*}{ Fit indices } & \multicolumn{4}{c}{ Model } \\
\cline { 2 - 5 } & Baseline model & Model 1 & Model 2 & Model 3 \\
\hline$\chi_{(d f)}^{2}$ & $885.21(320)$ & $915.28(335)$ & $958.81(355)$ & $978.07(370)$ \\
$P$ & 0.00 & 0.00 & 0.00 & 0.00 \\
CFI & 1.00 & 1.00 & 1.00 & 1.00 \\
RMSEA & 0.00 & 0.01 & 0.01 & 0.01 \\
SRMR & 0.06 & 0.07 & 0.07 & 0.08 \\
$\chi_{\Delta(d f)}^{2}$ & - & $30.07(15)$ & $43.53(20)$ & $19.26(15)$ \\
$P$ & - & 0.012 & 0.002 & 0.20
\end{tabular}

Baseline model tested configural invariance; model 1 tested invariance of factor loadings; model 2 tested invariance of error variances; model 3 tested invariance of correlations; $d$, degrees of freedom; CFI, Comparative Fit Index; RMSEA, Root Mean Square Error of Approximation; SRMR, Standardized Root Mean Square Residual.

factor loading of each factor, which was fixed to one for model identification). Each model was compared to the baseline model using the chi-square difference test. Results showed significant differences across the two groups on the loadings items Item 3 ( 0.66 and $0.74, p s<0.001$ for men and women, respectively), Item 4 (0.61 and $0.72, p s<0.001$ for men and women, respectively), Item 11 ( 0.50 and $0.45, p s<0.001$ for men and women, respectively), Item 20 ( 0.35 and 0.56 , $p s<0.001$ for men and women, respectively; see Table 1). All $\left[\chi_{\Delta(1)}^{2} \geq 3.71, p s \leq\right.$ 0.054].

The same procedure was applied to error variances; the model including the equality constraint was compared to the model testing the invariance of factor loadings (Model 1); significant differences were found between men and women on the error variance of items Item16 (0.84 and 0.81 , for men and women, respectively, $p s<0.001)$, Item 15 (0.77 and 0.66 , for men and women, respectively, $p s<0.001$ ), Item 13 ( 0.64 and 0.63 , for men and women, respectively, $p s<0.001)$, Item 19 (0.79 and 0.65 , for men and women, respectively, $p s<0.001)$, all $\chi_{\Delta(1)}^{2} \geq 7.12$, ps $\leq 0.01$.
TABLE 5 | Fit indices and chi-square differences for the multi-sample analysis (senior vs. young).

\begin{tabular}{lcccc}
\hline \multirow{2}{*}{ Fit indices } & \multicolumn{4}{c}{ Model } \\
\cline { 2 - 5 } & Baseline model & Model 1 & Model 2 & Model 3 \\
\hline$\chi_{(d f)}^{2}$ & $793.49(320)$ & $812.37(335)$ & $840.50(355)$ & $854.44(370)$ \\
$P$ & 0.00 & 0.00 & 0.00 & 0.00 \\
CFI & 1.00 & 1.00 & 1.00 & 1.00 \\
RMSEA & 0.00 & 0.00 & 0.00 & 0.00 \\
SRMR & 0.06 & 0.06 & 0.07 & 0.07 \\
$\chi_{\Delta(d f)}^{2}$ & - & $18.88(15)$ & $28.13(20)$ & $13.94(15)$ \\
$p$ & - & 0.22 & 0.11 & 0.53 \\
\hline
\end{tabular}

Baseline model tested configural invariance; model 1 tested invariance of factor loadings; model 2 tested invariance of error variances; model 3 tested invariance of correlations; df, degrees of freedom; CFI, Comparative Fit Index; RMSEA, Root Mean Square Error of Approximation; SRMR, Standardized Root Mean Square Residual.

Invariance of factor loadings, error variances and correlations was confirmed for the senior-young comparison (see Table 5), and for the secure-insecure comparison (see Table 6).

\section{Regression Analysis}

Multiple regression analyses were used to explore the effects of physicians' dissatisfaction on Global Job Satisfaction.

There was a constant effect of age, ranging from $\beta=0.12$, $S E=0.01, p=0.046$, to $\beta=0.17, S E=0.01, p=0.004)$.

The regression analysis $\left[F_{(6,732)}=19.63, p<0.001, R^{2}=\right.$ $0.14]$, showed that high levels of dissatisfaction relating to personal cost $(\beta=-0.09, S E=0.03, p=0.030)$, bureaucracy $(\beta=-0.19, S E=0.05, p<0.001)$, and problems with the staff $(\beta=-0.14, S E=0.05, p=0.001)$, predict low job satisfaction.

The regression analysis showed some sex differences. Whereas males' low job satisfaction is predicted by increasing bureaucratic procedures $\left[F_{(6,441)}=13.20, p<0.001, R^{2}=0.15 ; \beta=-0.27\right.$, $S E=0.06, p<0.001]$; relational problems with colleagues and staff $(\beta=-0.24, S E=0.08, p=0.002)$, predict females' low rates of job satisfaction $\left[F_{(6,271)}=6.77, p<0.001, R^{2}=0.13\right]$. 
TABLE 6 | Fit indices and chi-square differences for the multi-sample analysis (secure vs. insecure).

\begin{tabular}{lcccc}
\hline \multirow{2}{*}{ Fit indices } & \multicolumn{4}{c}{ Model } \\
\cline { 2 - 5 } & Baseline model & Model 1 & Model 2 & Model 3 \\
\hline$\chi_{(d f)}^{2}$ & $818.08(320)$ & $830.92(335)$ & $853.87(355)$ & $876.35(370)$ \\
$p$ & 0.00 & 0.00 & 0.00 & 0.00 \\
CFI & 1.00 & 1.00 & 1.00 & 1.00 \\
RMSEA & 0.00 & 0.00 & 0.00 & 0.00 \\
SRMR & 0.07 & 0.07 & 0.07 & 0.08 \\
$\chi_{\Delta(d f)}^{2}$ & - & $12.84(15)$ & $22.95(20)$ & $22.48(15)$ \\
$p$ & - & 0.61 & 0.29 & 0.10 \\
\hline
\end{tabular}

Baseline model tested configural invariance; model 1 tested invariance of factor loadings; model 2 tested invariance of error variances; model 3 tested invariance of correlations; df, degrees of freedom; CFI, Comparative Fit Index; RMSEA, Root Mean Square Error of Approximation; SRMR, Standardized Root Mean Square Residual.

The variable which predicts low job satisfaction in insecure attached physicians is bureaucracy $\left[F_{(6,361)}=8.39, p<\right.$ $\left.0.001, R^{2}=0.12 ; \beta=-0.19, S E=0.08, p=0.006\right]$; whereas secure attached physicians' low job satisfaction is foremost due to difficulties and relational problems with colleagues/staff $(\beta=-0.17, S E=0.08, p=0.027)$, and bureaucracy $\left[F_{(6,263)}\right.$ $\left.=8.61, p<0.001, R^{2}=0.17 ; \beta=-0.19, S E=0.08, p=0.006\right]$. Secure attached physicians are more sensitive to emotional and relational issues and therefore more prone to the risk of feeling uncomfortable when confronted with uncooperative staff's and colleagues' attitudes.

\section{DISCUSSION}

This study represents an original and innovative attempt to address physicians' dissatisfaction and job satisfaction. We developed the PhyDis Scale to measure physicians' dissatisfaction applying a mixed-method research design in order to capture the different and quickly changing sources of physicians' dissatisfaction. This study reports the development of a new measurement instrument to assess physicians' work-related stressors (PhyDis Scale), starting from their roots, that is from physicians' perception and subjective experience. We identified different, complex and probably inter-related sources of distress and dissatisfaction reported by physicians. Perceived increasing responsibility for patients, associated to augmented frequency of patients' complaints, brings physicians to pay often escalating liability insurance's costs. The almost widespread use of technology and the surge in competency maintenance requirements (Williams and Skinner, 2003; Bodenheimer and Sinsky, 2014; Schrijver, 2016) must be considered as additional stressors. The explosion of medical knowledge and of the therapeutic choices available to physicians causes an increased perception of responsibility toward patients. (Crosson and Casalino, 2015) In line with the above mentioned studies, the exploratory qualitative study and the subsequent confirmatory factor analysis of the 21 identified items of the PhyDis Scale revealed a five-dimensional factor structure: Personal costs; Role uncertainty; Physician's Responsibility toward patients; Relationship with colleagues and staff and Bureaucracy. The final version of the scale includes 20 items. Results indicated an adequate fit of the five-factor structure. The PhyDis subscales appear to be internally reliable. The external validity of the scale was confirmed, given that each source of dissatisfaction relates negatively to Job Satisfaction.

Since job satisfaction has a positive effect on patients' adherence to treatment and since it is associated with the quality of medical care, we point out that an integrated approach is crucial. The multifaceted feature of physicians' dissatisfaction has been recognized and we assume that one cannot longer rely on single-factor or even single-item scales to assess physicians' dissatisfaction. Even though international comparative studies carried out across different health care systems (Siegrist et al., 2010) reveal that effort-reward imbalance, economic issues and esteem/recognition determine a substantial part of the variation in physicians' stress levels, other studies (Quinn et al., 2009; Sinsky, 2015) identify also work-life issues and psychosocial work conditions such as esteem, social support, social conflicts with staff (Angerer and Weigl, 2015) as important sources of physicians' dissatisfaction. In line with those findings participants identified Role Uncertainty associated to loss of social esteem as the most dissatisfying factor. In line with up to date literature (Bovier and Perneger, 2003; French et al., 2004; Bogue et al., 2006; Davenport et al., 2008; McNearney et al., 2008; Hills et al., 2012) increasing age consistently shows to be associated with higher job satisfaction. Since attachment style is recognized as one of the most relevant variable of individual difference affecting social competences we assessed it in our convenience sample. Moreover, this is the first time attachment style's assessment in physicians is introduced in a cross-sectional study concerning the issues of dissatisfaction and job satisfaction.

According to literature on management and organizational studies (Richards and Schat, 2011) attachment insecurity predicts both job burnout (Mucci et al., 2015), and low rates of job satisfaction. Nevertheless, with the exception of Ciechanowski et al.'s (2004) study, attachment style in physicians has not yet been studied. In our study secure subjects were less dissatisfied than insecure ones, in fact, according to literature (Mikulincer and Shaver, 2007) secure subject perceive negative events as less threatening than insecure subjects. Moreover, $70 \%$ of insecure physicians was represented by avoidant subjects; their low job satisfaction rates were predicted by Bureaucracy. Avoidant subjects typically distrust others' goodwill and pursue autonomy and emotional distance from others, they can therefore rarely be affected by negative relational stances such as conflicts with colleagues and staff.

It is necessary to acknowledge some limitations of this study. The first limitation is inherent to the fact that it is based entirely on self-report measures. Secondly the exclusive reliance on cross-sectional data prevents us from making causal inferences. Even though our data support the initial validation of the multi-factorial scale, future research should compare physicians' dissatisfaction rates from the three major different systems of health care provision: private insurance-based system (US); government-supported, tax-based system (UK); and mixed system (Europe) (Siegrist et al., 2010); a comparison should also be made between countries with low/middle incomes and 
those with high incomes. Further limitations refer to the fact that participants are employed in a mixed health system and future research should be devoted to identify differences in the variety and range of dissatisfaction sources between private and mixed systems. Item's wording could not be pre-tested in order reduce possible slight differences in the understanding of items' meaning. Future longitudinal studies could explore the variability of dissatisfaction sources over time. Last but not least, further exploration is needed in the testing of the model within the women and men subgroups.

\section{CONCLUSION}

The final version of the PhyDis scale includes 20 items. Results indicated an adequate fit of the five-factor structure. The PhyDis subscales appear to be internally reliable. The external validity of the scale was confirmed, given that each source of dissatisfaction relates negatively to Job Satisfaction.

Invariance of correlations was confirmed for each considered subgroup: for the senior-young, the women-men and for the insecure-secure attached subgroups. The invariance of factor loadings and error variance was confirmed for the senior-young and for the insecure-secure attached populations. These last were not confirmed for the women-men groups.

Role Uncertainty associated to loss of social esteem is the most dissatisfying factor. Increasing age consistently shows to be associated with higher job satisfaction and with higher dissatisfaction relating to Bureaucracy.

Attachment style is recognized as important variable of individual difference affecting social competence and coping strategies in interpersonal relational contexts, with special regard to health/and helping-professions' organizations. For the first time attachment style's assessment in physicians is introduced in a cross-sectional study concerning the issues of dissatisfaction and job satisfaction. The insecure sub-sample (58.4\%) of our population is represented by physicians, whose low job satisfaction rates are predicted by Bureaucracy. By contrast secure attached physicians' (41.6\%) low job satisfaction is paramount due to difficulties in relational problems with staff and colleagues.

\section{REFERENCES}

Aalto, A.-M., Heponiemi, T., Väänänen, A., Bergbom, B., Sinervo, T., and Elovinio, M. (2014). Is working in culturally diverse working environment associated with physicians' work-related well-being? A cross-sectional survey study among Finnish physicians. Health Policy 117, 187-194. doi: 10.1016/j.healthpol.2014.02.006

Adshead, G. (2010). Becoming a caregiver: attachment theory and poorly performing doctors. Med. Educ. 44, 125-131. doi: 10.1111/j.1365-2923. 2009.03556.x

Alsuwaida, A., Alsharidi, A., Alanazi, N., Alghamdi, M., Almeshal, M., Aljaser, R., et al. (2013). Health and well being among physicians. Intern. Med. J. 43, 1310-1315. doi: 10.1111/imj.12249

Angerer, P., and Weigl, M. (2015). Physicians' psychosocial work conditions and quality of care: a literature review. Profess. Profession, 5, 1-5. doi: $10.7577 /$ pp. 960

Arnetz, B., Petersson, O., and Prag, M. (2002). Physicians' well being is deteriorating. Results from a prospective intervention study. The mental energy decreases as workload increases. Lakartidningen 99, 2496-2504.
Whilst addressing factors that may trigger dissatisfaction such as collegial support and work demands may have a tangible positive effect on the quality of care, physicians' attachment style assessment may be useful to offer appropriate and differentiated training opportunities to secure and insecure healthcare professionals allowing them to contribute to improving the quality of care. In addition lower levels of dissatisfaction due to Bureaucracy in the younger physicians' population could be associated to their higher computer literacy which allows them to cope easily with various tasks connected to the CPR (computer-based patient record). Whereas the older population could benefit from computertraining (Rahimi et al., 2008), the younger sub-group could benefit from conflict-resolution training courses in order to increase the number of coping strategies they rely on managing the physician/patient and the physician/staff relationships.

\section{AUTHOR CONTRIBUTIONS}

All authors listed, have made substantial, direct and intellectual contribution to the work, and approved it for publication.

\section{FUNDING}

The authors received no financial support for the research, authorship, and/or publication of this article.

\section{ACKNOWLEDGMENTS}

We gratefully acknowledge the assistance of Arianna Motteran and Claudio Capiluppi. We acknowledge support for the research by the provincial medical board's ethical committee: Arnaldo Petterlini, Franco Alberton, M. Antonietta Bassetto, Giovanni Bonadonna, Elisa Bertazzoni, FB, Giorgio Carrara, Pasquale D’Ascola, Fabio De Nardi, Roberto Fostini, Andrea Gaino, Maria Gabriella Landuzzi, Sabrina Lovato, Ezio Padovani, Marina Repola, Bianca Rosa, Mario Giulio Schinaia, Gaetano Trabucco, Luciano Vettore.
Astell-Burt, T., and Feng, X. (2013). Health and the 2008 economic recession: evidence from the United Kingdom. PLOS ONE 8:e56674. doi: 10.1371/journal.pone.0056674

Barnard, A., and Tong, K. (2000). The doctor is out-more and more physicians, frustrated with managed care, are trying new professions and finding life less stressful. Boston Globe 9, A1.

Bell, D. J., Bringman, J., Bush, A., and Phillips, O. P. (2006). Job satisfaction among obstetrician-gynecologists: a comparison between private practice physicians and academic physicians. Am. J. Obstet. Gynecol. 195, 1474-1478. doi: 10.1016/j.ajog.2006.05.039

Bell, H. (2013). The burn out busters: how three Mayo Clinic physicians became experts on physician well-being. Minn. Med. 96, 14-18.

Bobbio, A., and Manganelli, A. M. (2011). Measuring social desirability responding: a short version of Paulhus' BIDR 6. Tesing Psychomet. Methodol. Appl. Psychol. 18, 117-135. doi: 10.4473/TPM. 18.2.4

Bodenheimer, T., and Sinsky, C. A. (2014). From triple to quadruple aim: care of the patient requires care of the provider. Ann. Fam. Med. 12, 573-576. doi: $10.1370 /$ afm.1713 
Bogue, R. J., Guarneri, J. G., Reed, M., Bradley, K., and Hughes, J. (2006). Secrets of physician satisfaction: Study identifies pressure points and reveals life practices of highly satisfied doctors. Physician Exec. 32, 30-39.

Boomsma, A., and Hoogland, J. J. (2001). "The robustness of LISREL modeling revisited," in Structural Equation Models: Present and Future. A Festschrift in Honor of Karl Jöreskog, eds R. Cudeck, S. du Toit, and D. Sörbom (Lincolnwood, IL: Scientific Software International), 139-168.

Bouwkamp-Memmer, J. C., Whiston, S. C., and Hartung, P. J. (2013). Work values and job satisfaction of family physicians. J. Vocat. Behav. 82, 248-255. doi: 10.1016/jvb.2013.02.0001

Bovier, P. A., and Perneger, T. V. (2003). Predictors of work satisfaction among physicians. Eur. J. Public Health 13, 299-305. doi: 10.1093/eurpub/13.4.299

Ciechanowski, P., Russo, J. E., Katon, W., and Walker, E. (2004). Attachment theory in health care: the influence of relationship style on medical students' speciality choice. Med. Educ. 38, 262-270. doi: 10.1046/j.13652923.2004.01767.x

Cooper, C. L., Rout, U., and Faragher, B. (1989). Mental health, job satisfaction, and job stress among general practitioners. Br. Med. J. 298, 366-370. doi: 10.1136/bmj.298.6670.366

Crosson, F. J., and Casalino, L. P. (2015). Physician dissatisfaction in the United States: an examination. Professions Professionalism 5, 1-12. doi: 10.7577/pp.926

Davenport, D. L., Henderson, W. G., Hogan, S., Mentzer, R. M. Jr., and Zwischenberger, J. B. (2008). Surgery resident working conditions and job satisfaction. Surgery 144, 332.e5-338.e5. doi: 10.1016/j.surg.2008.03.038

Declercq, F., and Willemsen, J. (2006). Distress and post traumatic stress disorders in high risk professionals: adult attachment style and the dimensions of anxiety and avoidance. Clin. Psychol. Psychother. 13, 256-263. doi: 10.1002/cpp.492

Dewa, C. S., Loong, D., Bonato, S., Thanh, N. X., and Jacobs, P. (2014). How does burnout affect physician productivity? A systematic literature review. BMC Health Services Res. 14:325. doi: 10.1186/1472-6963-14-325

Dozier, M., and Tyrrell, C. (1998). "The role of attachment in therapeutic relationships," in Attachment Theory and Close Relationships, eds J. A. Simpson and W. S. Rholes (New York, NY: The Guilford Press), 221-248.

Dyrbye, L., and Shanafelt, T. (2016). A narrative review on burnout experienced by medical students and residents. Med. Educ. 50, 132-149. doi: $10.1111 /$ medu. 12927

Etchegaray, J. M., Sexton, J. B., Helmreich, R. L., and Thomas, E. J. (2010). Job satisfaction ratings: measurement equivalence across nurses and physicians. West. J. Nurs. Res. 32, 530-539. doi: 10.1177/0193945909355148

Falvo, R., Favara, I., Di Bernardo, G. A., Boccato, G., and Capozza, D. (2012). Attachment styles in organizations: a study performed in a hospital. Test. Psychomet. Methodol. Appl. Psychol. 19, 263-279. doi: 10.4473/TPM19.4.2

Fang, C. K., Li, P. Y., Lai, M. L., Lin, M. H., Bridge, D. T., and Chen, H. W. (2011). Establishing a 'Physician's Spiritual Well-being Scale' and testing its reliability and validity. J. Med. Ethics 37, 6-12. doi: 10.1136/jme.2010.037200

Firth-Cozens, J. (2001). Interventions to improve physicians' well-being and patient care. Soc. Sci. Med. 52, 215-222. doi: 10.1016/S0277-9536(00)00221-5

French, F. H., Andrew, J. E., Awramenko, M., Coutts, H., Leighton-Beck, L., Mollison, J., et al. (2004). Consultants in NHS scotland: a survey of work commitments, remuneration, job satisfaction and retirement plans. Scott. Med. J. 49, 47-52. doi: 10.1177/003693300404900205

Geertzen, J. (2012). Inter-Rater Agreement with Multiple Raters and Variables. Available online at: https://nlp-ml.io/jg/software/ira/

Giorgi, G., Arcangeli, G., Mucci, N., and Cupelli, V. (2015). Economic stress in workplace: the impact of fear the crisis on mental health. Work 51, 135-142. doi: 10.3233/WOR-141844

Gong, Y., Han, T., Chen, W., Dib, H. H., Yang, G., Zhauang, R., et al. (2014). Prevalence of anxiety and depressive symptoms and related risk factors among physicians in china: a cross-sectional study. PLOS ONE 9:e103242. doi: 10.1371/journal.pone.0103242

Gottret, P., and Schieber, G. (2006). Health Financing Revisited: A Practitioner's Guide. Washington, DC: World Bank.

Grembowsky, D., Paschane, D., Diehr, P., Katon, W., Martin, D., and Patrick, D. L. (2005). Managed care, physician job satisfaction, and the quality of primary care. J. Gen. Intern. Med. 20, 271-277. doi: 10.1111/j.1525-1497.2005.32127.x

Grimm, K. J., and Widaman, K. F. (2012). “Construct validity,” in APA Handbook of Research Methods in Psychology, Vol 1, Foundations, Planning, Measures, and Psychometrics, eds H. Cooper, P. M. Camic, D. L. Long, A. T. Panter,
D. Rindskopf, and K. J. Sher (Washington, DC: American Psychological Association), 621-642.

Haas, J. S., Cook, E. F., Puopolo, A. L., Burstin, H. R., Cleary, P. D., and Brennan, T. A. (2000). Is the professional satisfaction of general internists associated with patient satisfaction? J. Gen. Intern. Med. 15, 122-128. doi: 10.1046/j.15251497.2000.02219.x

Hair, J. F., Anderson, R. E., Tatham, R. L., and Black, W. C. (1998). Multivariate Data Analysis. Upper Saddle River, NJ: Prentice-Hall, Inc.

Hammersley, M. (1992). What's Wrong with Ethnography: Methodological Explorations. London: Routledge.

Hann, M., Reeves, D., and Sibbald, B. (2011). Relationships between job satisfaction, intentions to leave family practice and actually leaving among family physicians in England. Eur. J. Public Health 21, 499-503. doi: 10.1093/eurpub/ckq005

Hazan, C., and Shaver, P. (1987). Romantic love conceptualized as an attachment process. J. Pers. Soc. Psychol. 52, 511-524. doi: 10.1037/0022-3514.52.3.511

Hazan, C., and Shaver, P. (1990). Love and work: an attachment-theoretical perspective. J. Pers. Soc. Psychol. 59, 270-280. doi: 10.1037/0022-3514.59.2.270

Heponiemi, T., Puttonen, S., and Elovainio, M. (2014). On-call work and physicians' well-being: testing the potential mediators. Occup. Med. (Lond). 64, 352-357. doi: 10.1093/occmed/kqu036

Hills, D., Joyce, C., and Humphreys, J. (2012). Validation of a job satisfaction scale in the Australian clinical medical workforce. Eval. Health Prof. 35, 47-76. doi: $10.1177 / 0163278710397339$

Hu, L. T., and Bentler, P. M. (1999). Cutoff criteria for fit indexes in covariance structure analysis: conventional criteria versus new alternatives. Struct. Equ. Model. 6, 1-55. doi: 10.1080/10705519909540118

Janisse, T. (2008). Relationship of a physician's wellbeing to interactions with Patients: practices of the highest performing physicians on the art of medicine patient survey. Perm. J. 12, 70-76. doi: 10.7812/TPP/08-041

Janus, K., Amelung, V. E., Baker, L. C., Gaitanides, M., Schwartz, F. W., and Rundall, T. G. (2008). Job satisfaction and motivation among physicians in academic medical centers: insights from a cross-national study. J. Health Polit. Policy Law 33, 1133-1167. doi: 10.1215/03616878-2008-035

Johnson, J. A., and Stoskopf, C. (2010). Comparative Health Systems: Global Perspectives. Sudbury, MA: Jones and Bartlett Publishers.

Jönsson, S. (2012). Psychological work environment and prediction of job satisfaction among Swedish registered nurses and physicians - a follow-up study. Scand. J. Caring Sci. 26, 236-244. doi: 10.1111/j.1471-6712.2011.00924.x

Jöreskog, K. G., and Sörbom, D. (2006). LISREL 8.80 for Windows [Computer Software]. Lincolnwood, IL: Scientific Software International, Inc.

Kelle, U. (2005). "Emergence" vs. "Forcing” of empirical data? A crucial problem of “Grounded Theory” reconsidered. Forum Qual. Soc. Res. 6, 1-23.

Kline, P. (2000). The Handbook of Psychological Testing. Florence, KY: Psychology Press.

Konrad, T. R., Williams, E. S., Linzer, M., McMurray, J., Pathman, D. E., Gerrity, M., et al. (1999). Measuring physician job satisfaction in a changing workplace and a challenging environment. Med. Care 37, 1174-1182. doi: 10.1097/00005650-199911000-00010

Krippendorff, K. (2012). Content Analysis, An Introduction to Its Methodology, 3rd Edn. Thousand Oaks, CA: Sage Publications.

Kynes, J. M., Schildcrout, J. S., Hickson, G. B., Pichert, J. W., Han, X., Ehrenfeld, J. M., et al. (2013). An Analysis of Risk Factors for Patient Complaints about ambulatory anesthesiology care. Anesth. Analg. 116, 1325-1332. doi: 10.1213/ANE.0b013e31827aef83

Landon, B. E., Aseltine, R. Jr., Shaul, J. A., Miller, Y., Auerbach, B. A., and Cleary, P. D. (2002). Evolving dissatisfaction among primary care physicians. Am. J. Manag. Care 8, 890-901.

Landon, B. E., Reschovsky, J., and Blumenthal, D. (2003). Changes in career satisfaction among primary care and specialist physicians, 1997-2001. J. Am. Med. Assoc. 289, 442-449. doi: 10.1001/jama.289.4.442

Landon, B. E., Reschovsky, J. D., Pham, H. H., and Blumenthal, D. (2006). Leaving medicine. The consequence of physician dissatisfaction. Med. Care 44, 234-242. doi: 10.1097/01.mlr.0000199848.17133.9b

Lavanchy, M., Connelly, I., Grzybowski, S., Michalos, A. C., Berkowitz, J., and Thommasen, H. V. (2004). Determinants of rural physicians' life and job satisfaction. Soc. Indic. Res. 69, 93-101. doi: 10.1023/B:SOCI.0000032662.79752.e8 
Leiper, R., and Casares, P. (2000). An investigation of the attachment organization of clinical psychologists and its relationship to clinical practice. $\mathrm{Br}$. J. Med. Psychol. 73, 449-464. doi: 10.1348/000711200160651

Lichtenstein, R. (1984). Measuring the job satisfaction of physicians in organized settings. Med. Care 22, 56-68. doi: 10.1097/00005650-198401000-00005

Linn, L. S., Yager, J., Cope, D., and Leake, B. (1985). Health status, job satisfaction, job stress, and life satisfaction among academic and clinical faculty. JAMA 254, 2775-2782. doi: 10.1001/jama.1985.03360190081029

Linzer, M., Levine, R., Meltzer, D., Poplau, S., Warde, C., and West, C. P. (2014). 10 bold steps to prevent burnout in general internal medicine. J. Gen. Inter. Med. 29, 18-20. doi: 10.1007/s11606-013-2597-8

Linzer, M., McMurray, J. E., Visser, M. R., Oort, F. J., Smets, E., and de Haes, H. C. (2002). Sex differences in physician burnout in the United States and the Netherlands. J. Am. Med. Womens 57, 191-193.

Linzer, M., Poplau, S., Grossman, E., Varkey, A., Yale, S., Williams, E., et al. (2015). A cluster randomized trial of interventions to improve work conditions and clinician burnout in primary care: results from the Healthy Work Place (HWP). J. Gen. Intern. Med. 30, 1105-1111. doi: 10.1007/s11606-0153235-4

Lister, J., and Labonté, R. (2009). "Globalization and health system change," in Globalization and Health, Pathways, Evidence and Policy, eds R. Labonté, T. Schrecker, C. Packer, and V. Runnels (New York, NY: Routledge), 181-212.

Loewenthal, K. M. (2004). An Introduction to Psychological Tests and Scales, 2 Edn. Hove, UK: Psychology Press.

Mcintyre, S. E., and Mcintyre, T. M. (2010). Measuring Job Satisfaction in Portuguese Health Professionals: correlates and validation of the job descriptive index and the job in general scale. Int. J. Select. Assess. 18, 425-431. doi: 10.1111/j.1468-2389.2010.00524.x

McNearney, T. A., Hunnicutt, S. E., Maganti, R., and Rice, J. (2008). What factors relate to job satisfaction among rheumatologists? J. Clin. Rheumatol. 14, 133-137. doi: 10.1097/RHU.0b013e318177274d

Mikulincer, M., and Shaver, P. R. (2007). Attachment in Adulthood: Structure, Dynamics, and Change. New York, NY: Guilford Press.

Min, A. A., Sbarra, D. A., and Keim, S. M. (2015). Sleep disturbances predict prospective declines in resident physicians' psychological well-being. Med. Educ. Online 20:28530. doi: 10.3402/meo.v20.28530

Miyake, A., Friedman, N., Emerson, M. J., Witzki, A. H., Howerter, A., and Wager, T. D. (2000). The unity and diversity of executive functions and their contribution to complex "frontal lobe" tasks: a latent variable analysis. Cogn. Psychol. 41, 49-100. doi: 10.1006/cogp.1999.0734

Mohr, D. C., and Burgess, J. F. (2011). Job characteristics and job satisfaction among physicians involved with research in the veterans health administration. Acad. Med. 86, 938-945. doi: 10.1097/ACM.0b013e3182223b76

Mucci, N., Giorgi, G., Cupelli, V., Gioffrè, P. A., Rosati, M. V., Tomei, F., et al. (2015). Work-related stress assessment in a population of Italian workers. The Stress Questionnaire. Sci. Total Environ. 502, 673-679. doi: 10.1016/j.scitotenv.2014.09.069

Mucci, N., Giorgi, G., Roncaioli, M., Fiz Perez, J., and Arcangeli, G. (2016). The correlation between stress and economic crisis: a systematic review. Neuropsychiatr. Dis. Treat. 12, 983-993. doi: 10.2147/NDT.S98525

Nathanson, C. A., and Becker, M. H. (1973). Job satisfaction and job performance: an empirical test of some theoretical propositions. Organ. Behav. Hum. Perform. 9, 267-279. doi: 10.1016/0030-5073(73)90051-2

Pedrazza, M., and Berlanda, S. (2014). Intergroup conflict and co-construction of identity in the primary school: multi-method research in an interethnic context. Test. Psychomet. Methodol. Appl. Psychol. 21, 21-36. doi: 10.4473/TPM21.1.2

Pedrazza, M., and Boccato, G. (2012). Training on attachment styles increases secure adult's attributions of control. Test. Psychomet. Methodol. Appl. Psychol. 19, 69-79. doi: 10.4473/TPM19.2.1

Pedrazza, M., Minuzzo, S., Berlanda, S., and Trifiletti, E. (2015). Nurses' comfort with touch and workplace well-being. West. J. Nurs. Res. 37, 781-798. doi: 10.1177/0193945914527356

Polit, D. F., and Beck, C. T. (2006). The content validity index: are you sure you know what's being reported? Critique and recommendations. Res. Nurs. Health 29, 489-497. doi: 10.1002/nur.20147

Quinn, M. A., Wilcox, A., Orav, J., Bates, D. W., and Simon, S. R. (2009). The relationship between perceived practice quality and quality improvement activities and physician practice dissatisfaction, professional isolation, and work-life stress. Med. Care 47, 924-928. doi: 10.1097/MLR.0b013e3181a393e4

Rahimi, B., Moberg, A., Timpka, T., and Vimarlund, V. (2008). "Implementing an integrated computerized patient record system: towards an evidence-based information system implementation practice in healthcare," in AIMA Annual Symposium Proceedings (Washington, DC), 616-620.

Reschovsky, J. D., Edson, D., and Sewall, A. (1998). Community Tracking Study Physician Survey Public Use File: Users' Guide (Round One, Release 1). Washington, DC: Center for Studying Health System Change.

Richards, D. A., and Schat, A. C. (2011). Attachment at (Not to) work: applying attachment theory to explain individual behavior in organizations. J. Appl. Psychol. 96, 169-182. doi: 10.1037/a0020372

Rockey, P. H. (2012). Physicians' well-being and safety: it's not all about sleep. Mayo Clin. Proc. 87, 1135-1136. doi: 10.1016/j.mayocp.2012.10.001

Ruitenburg, M. M., Frings-Dresen, M. H., and Sluiter, J. K. (2012). The prevalence of common mental disorders among hospital physicians and their association with self-reported work ability: a cross-sectional study. BMC Health Serv. Res. 12, 292-298. doi: 10.1186/1472-6963-12-292

Satorra, A., and Bentler, P. M. (2001). A scaled difference chi-square test statistic for moment structure analysis. Psychometrika 66, 507-514. doi: 10.1007/BF02296192

Schaad, B., Bourquin, C., Bornet, F., Currat, T., Saraga, M., Panese, F., et al. (2015). Dissatisfaction of hospital patients, their relatives, and friends: analysis of accounts collected in a complaints center. Patient Educ. Couns. 98, 771-776. doi: 10.1016/j.pec.2015.02.019

Schafer, J. L., and Graham, J. W. (2002). Missing data: our view of the state of the art. Psychol. Methods 7, 147-177. doi: 10.1037/1082-989X.7.2.147

Scheepers, R. A., Boerebach, B. C., Arah, O. A., Heineman, M. J., and Lombarts, K. M. (2015). A systematic review of the impact of Physicians' occupational well-being on the quality of patient care. Int. J. Behav. Med. 22, 683-698. doi: 10.1007/s12529-015-9473-3

Schrijver, I. (2016). Pathology in the Medical Profession? Taking the pulse of Physician wellness and burnout. Arch. Pathol. Lab. Med. doi: 10.5858/arpa.2015-0524-RA. [Epub ahead of print].

Shanafelt, T. D., Sloan, J. A., and Habermann, T. M. (2003). The well-being of physicians. Am. J. Med. 114, 513-519. doi: 10.1016/S0002-9343(03)00117-7

Sharma, M., Goel, S., Singh, S. K., Sharma, R., and Gupta, P. K. (2014). Determinants of Indian physicians' satisfaction \& dissatisfaction from their job. Indian J. Med. Res. 139, 409-417.

Siegrist, J., Shackelton, R., Link, C., Marceau, L., von dem Knesebeck, O., and McKinlay, J. (2010). Work stress of primary care physicians in the US, UK and German health care systems. Soc. Sci. Med. 71, 298-304. doi: 10.1016/j.socscimed.2010.03.043

Simon, C. R., and Durand-Bush, M. (2014). Differences in psychological and affective well-being between physicians and resident physicians: does high and low self-regulation capacity matter? Psychol. Well Being 4, 1-19. doi: 10.1186/s13612-014-0019-2

Sinsky, C. A. (2015). Dissatisfaction among Wisconsin Physicians is part of serious national trend. WMJ 114, 132-133.

Stelfox, H. T., Gandhi, T. K., Orav, E. J., and Gutsafson, M. L. (2005). The relation of patient satisfaction with complaints against physicians and malpractice lawsuits. Am. J. Med. 118, 1126-1133. doi: 10.1016/j.amjmed.2005.01.060

Strauss, A., and Corbin, J. (2008). Basics of Qualitative Research: Grounded Theory Procedures and Techniques, 3rd Edn. Newbury Park, CA: Sage.

Trifiletti, E., Capozza, D., Pasin, A., and Falvo, R. (2009). A validation of the proactive personality scale. Test. Psychomet. Methodol. Appl. Psychol. 16, 77-93. doi: 10.4473/TPM.16.2.2

Trifiletti, E., Dazzi, C., Hichy, Z., and Capozza, D. (2007). A validation of HCAS: The host community acculturation scale. Test. Psychomet. Methodol. Appl. Psychol. 14, 135-149. doi: 10.4473/TPM.14.3-4.2

Tucker, P., Bejerot, E., Kecklund, G., Aronsson, G., and Åkerstedt, T. (2015). The impact of work time control on physicians' sleep and well-being. Appl. Ergon. 47, 109-116. doi: 10.1016/j.apergo.2014.09.001

Wallace, J. E., and Lemaire, J. (2007). On physician well being - Wou'll get by with a little halp from your friends. Soc. Sci. Med. 64, 2565-2577. doi: 10.1016/j.socscimed.2007.03.016

Wallace, J. E., Lemaire, J. B., and Ghali, W. A. (2009). Physician wellness: a missing quality indicator. Lancet 374, 1714-1721. doi: 10.1016/S0140-6736(09)61424-0 
WHO (2006). Public Health, Innovation and Intellectual Property Rights: Report of the Commission on Intellectual Property Rights. Innovation and Public Health. Geneva: WHO.

Williams, E. S., Konrad, T. R., Linzer, M., McMurray, J., Pathman, D. E., Gerrity, M., et al. (1999). Refining the measurement of physician job satisfaction: results from the physician worklife survey. Med. Care 37, 1140-1154. doi: 10.1097/00005650-199911000-00006

Williams, E. S., and Skinner, A. C. (2003). Outcomes of physician job satisfaction: a narrative review, implications, and directions for future research. Health Care Manage. Rev. 28, 119-139. doi: 10.1097/00004010-20030400000004

Zengin, S., Al, B., Yavuz, E., Kursunköseler, G., Guzel, R., Sabak, M., et al. (2014). Analysis of complaints lodged by patients attending a university hospital: a 4-year analysis. J. Forens. Leg. Med. 22, 121-124. doi: 10.1016/j.jflm.2013. 12.008

Conflict of Interest Statement: The authors declare that the research was conducted in the absence of any commercial or financial relationships that could be construed as a potential conflict of interest.

Copyright (c) 2016 Pedrazza, Berlanda, Trifiletti and Bressan. This is an open-access article distributed under the terms of the Creative Commons Attribution License (CC $B Y$ ). The use, distribution or reproduction in other forums is permitted, provided the original author(s) or licensor are credited and that the original publication in this journal is cited, in accordance with accepted academic practice. No use, distribution or reproduction is permitted which does not comply with these terms. 


\section{OPEN ACCESS}

Edited by:

Gabriele Giorgi,

European University of Rome, Italy

Reviewed by:

Chiara Ghislieri,

University of Turin, Italy Javier Fiz Pérez,

Università Europea di Roma, Italy

*Correspondence: Andreina Bruno andreina.bruno@unige.it Fabrizio Bracco

fabrizio.bracco@unige.it

Specialty section: This article was submitted to Organizational Psychology, a section of the journal Frontiers in Psychology

Received: 13 May 2016 Accepted: 02 August 2016 Published: 12 August 2016

Citation:

Bruno A and Bracco F (2016) Promoting Safety through Well-Being:

An Experience in Healthcare.

Front. Psychol. 7:1208.

doi: 10.3389/fpsyg.2016.01208

\section{Promoting Safety through Well-Being: An Experience in Healthcare}

\author{
Andreina Bruno* and Fabrizio Bracco* \\ Department of Educational Sciences, University of Genoa, Genoa, Italy
}

Practitioners' well-being and clinical risk management are two interrelated concepts in healthcare. Patient safety, workers' safety and practitioners well-being have often been managed and measured with different methods, even though they are tightly linked. In this paper we propose a method that is suitable to increase organizational health. The action-research project aims to increase the commitment of healthcare managers and practitioners toward the development of an organizational culture which is oriented to patient and practitioner safety and well-being. These are crucial organizational resource for an effective process management. The project lasted 18 months and involved 60 nurses and physicians working in the operating room of six hospitals in the North of Italy. The project aimed to develop an inter-organizational methodology for noticing and monitoring critical threats to safety and well-being. The tool consisted of a report form in which practitioners could describe possible threats, solutions and personal contributions to the solutions. The participants designed it according to their practice and it was considered suitable and usable in their current work activities. Its added value is to overcome the habitual bottleneck between anomalies investigation and action planning, by identifying a specific role in the learning process to take care of the transition from data gathering to data use. The tool aims to enable individuals and teams to monitor and share ideas about critical aspects that affect their safety and well-being, collect contributions to solve them, sustain dissemination of good practices and frame health promotion as a crucial organizational resource.

Keywords: healthcare, safety, well-being, human error, reporting, surgery, participatory action-research

\section{INTRODUCTION}

Since the publication of the famous report "To Err is Human" (Kohn et al., 2000), the issue of medical error has gained increasing attention and has been widely investigated. The report demonstrated the incidence of human error as a main root cause of patients injuries and deaths, recording that every year, in the United States, between 44.000 to 98.000 people lose their lives because of factors concerning preventable errors in clinical treatment. All western countries share the same statistics, thus leading researchers in clinical risk management to argue that the problem resides in how complex organizations deal with likewise complex issues as those concerning healthcare (Hollnagel et al., 2013). The category of "human error" is extremely vague and misleading, since it can comprise almost everything (Dekker, 2007). A closer look inside this category reveals that doctors and nurses do not make mistakes because they are unprepared, 
unprofessional, or they do not care about patient's health. Rather, they make mistakes because they often lack proper coordination, communication, and leadership in diagnosis and treatment (Leape et al., 1993; Hollnagel, 2014). Recent evidence demonstrates the link between workers' well-being and patient safety, since burnout, workload, miscommunication, and dysfunctional organizational climate could be the factors leading to poor performance in complex environments like healthcare (Yassy and Hancock, 2005; Henriksen and Dayton, 2006; Hoffman and Mark, 2006; Laschinger et al., 2006; Elfering et al., 2007; Reader et al., 2008). According to the Joint Commission (2016) report about sentinel event data, the top-three root causes for patients' harm, between 2013 and 2015, are human factors, leadership, and communication. These factors have been recently framed as non-technical skills (Flinn et al., 2008), since they do not strictly concern the technical expertise but, rather, they are based on social and cognitive abilities that help the team to cooperate and perform safely and effectively (Gordon et al., 2012). In addition, a close relationship between nontechnical skills and performance has been demonstrated (Bower et al., 2003; West, 2004), since stress, organizational malaise, miscommunication, and workers' isolation are connected to dysfunctional resource management, poor coordination and underperformance (Arenas et al., 2015). This relation can be framed according to the well-known pyramid of accidents, where for each fatality (the tip of the pyramid) there could be hundreds of near-misses and thousands of at risk behaviors (the larger base; Heinrich, 1931). Within an organization, the sharp-end workers (practitioners at the front-line) are the only one able to notice and report information pertaining the lower part of the pyramid, while managers will be aware only of the tip of the pyramid, when the injury or the loss is impossible to hide (Wreathall, 2006). Therefore, safety culture is possible only when there is a clear commitment toward workers' well-being, since they will have the resources and motivation to report data in the lower part of the pyramid (i.e., the weak signals concerning risky situations and near misses).

The most widely used method for sharing information about errors and threats is incident reporting. It is based on a free and often anonymous description of what happened and the event's supposed contributing factors. The document is then analyzed by risk managers in order to act on the factors that led to the unwanted outcome. Notwithstanding its potential for safety, the rate of reporting is often lower than expected (Whitaker and Ibrahim, 2016). The reasons could be the need for anonymity, the lack of feedback, a poor reporting culture, the complexity of procedures, the confusion about what and how to report, the lack of organizational commitment toward reporting (Vincent et al., 1999). A similar underuse is reported among Italian healthcare workers, and the reasons concern the blame attitude in analyzing errors, fear of mistrust from colleagues, the complexity and overlap of reporting tools, and skepticism toward the benefit of the tool (Albolino et al., 2010). According to Weick and Sutcliffe (2007), incident reporting is not effective for safety if it is not supported in advance by other tools that focus on weak signals and treat anomalies and human error as a resource for organizational learning and not something to hide and blame. In addition, if the goal is to enhance a proper and widespread use of the tools, we claim that they need to be developed through a participatory process embedded in a specific context (Bracco et al., 2011). This is confirmed by the most recent evidence that shows that lean management increases only productivity without positive impacts on healthcare outcomes (Andersen et al., 2014).

The aim of the paper is to propose a method that is suitable to increase the learning culture in organizations where the reporting culture is weak. We present an action-research project that aims to sustain healthcare workers and managers in the development of an organizational culture oriented toward safety and well-being. Safety and well-being were framed as: (i) the main ingredient to maintain the quality of services and the quality of organizational life in the hospital, both for practitioners and for patients, and (ii) supported by tools that focus on weak signals and treat anomalies and human error as a resource for organizational learning.

The proposal was to widen the learning zone on professional practice to introduce cultural changes: it means to move the organizational sensitivity from the top to the base of the accident pyramid.

The specific goals of this project were:

(i) To frame safety as an outcome of organizational wellbeing;

(ii) To develop practitioners' reflective practices and the dissemination of good practices among the colleagues;

(iii) To sustain the participatory development of a tool for the detection of potential threats, their analysis and monitoring.

\section{METHOD}

\section{Context and Participants}

The context is the health care domain, specifically surgery. The project involved 60 nurses and physicians, working in the operating room of six hospitals in the North of Italy. The project was deployed at two different levels:

(i) Project group involved 25 practitioners that worked at the design stage and the implementation stage, through plenary and team meetings, where they engaged their colleagues by using the tool designed during the project;

(ii) Large group involved the above mentioned group and a further 35 doctors and nurses who belonged to the same hospitals, together with hospital risk managers. This second level participated in the initial phase of the project, in the presentation of the project outcomes, and in the last public workshop.

The project lasted 18 months, from June 2010 to February 2011.

\section{Phases of the Project}

The whole project was based both on reflection on practices (Bruno et al., 2011) and on innovative design and on the field experimentation. 
The phases are:

(i) Focus group on health, well-being, safety, and professional practice;

(ii) Presentation of the results of the focus group and discussion on the cultural perspectives on safety and well-being;

(iii) Analysis of work practices through the critical incident technique (Flanagan, 1954);

(iv) Planning of safety and well-being strategies aimed at the development of a tool for the monitoring of practices (as will be described later, this tool was a risk reporting system);

(v) Tool's usability assessment;

(vi) Evaluation of the project's outcomes and participants' experiences;

(vii) Public workshop for the dissemination of the project's outcomes.

\section{Procedures}

Several documents were written during the project: meetings memorandum (52-page document), project teams materials, focus group report. A thematic analysis of these documents was conducted.

\section{OUTCOMES}

The analysis reveals three main thematic areas:

(i) Well-being and safety culture,

(ii) The participatory process,

(iii) The use of the tool.

\section{Well-being and Safety Culture}

Findings reveals that safety and well-being are considered by participants as two intertwined concepts:

"... the definition of well-being is part of and completes the definition of safety,"

"... working under well-being conditions enables people to work safely...,"

"... the definitions of the safety and well-being are based on a single answer..."

And that safety is meant as related both to the patient and the operator:

"...protecting ourselves and the patients at the same time...,"

"... be aware of the actions outcomes, both on me and on the others...."

Training and reflection on practices are considered relevant for dampening risks:

"... we need to invest in training in order to provide a high performance standard. ..,"

"... knowing what I am doing and knowing the tools I am using, being aware of my actions and their consequences both on me and the others...," because sometimes "we keep our fingers crossed... and we hope that no emergency will happen...."
The reporting practice is considered useful:

"... it helps in understanding factors that led to the mistake. ..."

"... the reporting helped us in accomplishing some results...."

However, the reporting culture is quite weak because:

"... we do not have the culture to freely speak about errors. .."

and incident reporting tools are mainly used for serious events. Practitioners do not perceive the immediate benefit of the reporting, since the feedback is often absent, partial or late. In addition, they believe that safety is a matter of culture and it needs a systemic change that should not burden just front-line operators.

They claim their need to manage "small" everyday problems in order to pay more attention to error management:

“... solving small problems makes things easier. . it's like a trickle eroding a mountain, if you don't stop that trickle, sooner or later the mountain will disappear. ..."

The everyday problems are concerning relationships, communication, and organization issues. They are considered the most critical factors because when they are chronic the operators' well-being is perceived at risk.

\section{The Participatory Process}

Participants stressed the need to increase organizational wellbeing and, together with this, the quality of the service provided. These were the premises for the development of a participatory process that aimed to design a tool for the detection and monitoring of critical situations for safety and well-being. This tool (named Critical Situations Detection and Monitoring Form) allowed the participants to clarify problems and their origins and the potential consequences in terms of well-being and safety. Moreover, they were able to clarify possible solutions and identify who could be in charge to implement them. This tool aimed to report critical conditions that act against well-being, since practitioners clearly stated that safety-oriented behaviors could be accomplished in conditions of well-being.

The tool design went through several steps (Table 1). The preliminary step aimed to probe the acceptability of a tool to monitor well-being. This first document was developed according to the incident reporting form for risk management in the operating room. After that, the group revised the checklist in order to simplify it, allowing users to have a quicker and seamless access to questions in the form. Only in a further phase the participants moved their attention from the incident (the tip of the pyramid) to the weak signals (the base of the pyramid). The participants claimed that an effective risk management (both for patients and practitioners) is an essential condition for well-being, therefore they designed the tool with the goal of reporting also potential threats and near-misses. This tool does not aim to substitute other reporting tools already used in case of adverse events, actually, it should be used together with them, because it has a broader perspective. Practitioners' safety and well-being were therefore tackled with a tool divided in two sections: (i) Critical situation detection form, and (ii) Solution analysis form. The two sections of the 
TABLE 1 | The steps of the participatory design.

\begin{tabular}{|c|c|}
\hline Steps & Outcomes \\
\hline $\begin{array}{l}\text { 1. Incident reporting } \\
\text { form }\end{array}$ & $\begin{array}{l}\text { Adaptation of a pre-existing form for risk } \\
\text { management in the operating room }\end{array}$ \\
\hline $\begin{array}{l}\text { 2. Criticalities reporting } \\
\text { form }\end{array}$ & $\begin{array}{l}\text { Form for the reporting of potential threats and } \\
\text { near misses }\end{array}$ \\
\hline 3. Splitting of the form & $\begin{array}{l}\text { A tool divided in two sections: } \\
\text { (i) Critical situation detection form, } \\
\text { (ii) Solution analysis form. }\end{array}$ \\
\hline $\begin{array}{l}\text { 4. Addition of a third } \\
\text { section }\end{array}$ & $\begin{array}{l}\text { A tool divided in three sections: } \\
\text { (i) Critical situation detection form, } \\
\text { (ii) Solution analysis form, } \\
\text { (iii) Monitoring of the solution process. }\end{array}$ \\
\hline $\begin{array}{l}\text { 5. Electronic version of } \\
\text { the tool }\end{array}$ & $\begin{array}{l}\text { Spreadsheet with three sections: } \\
\text { (i) Anomalies detection, } \\
\text { (ii) Problem setting and problem solving, } \\
\text { (iii) Solution process monitoring. }\end{array}$ \\
\hline 6. Tool evaluation & $\begin{array}{l}\text { Evaluation based on AGREE (2003) criteria for } \\
\text { the assessment of the quality of clinical } \\
\text { guidelines: } \\
\text { (i) clarity of the overall objective, } \\
\text { (ii) the target population, } \\
\text { (iii) the stakeholder involvement, } \\
\text { (iv) tool applicability, } \\
\text { (v) resource implications. }\end{array}$ \\
\hline
\end{tabular}

tool are therefore part of a systemic intervention that aims to promote safety and well-being. The first section, where the critical situations are reported, allows operators to share information about their needs, provides them with the responsibility of reporting anomalies and critical conditions in their workplace. Front-line practitioners are the only ones in direct contact with everyday practices, they know the methods used to implement procedures and the critical factors that, over time, can erode safety and well-being. The second section is aimed at making the analysis of the problems reported in the first section explicit. It allows practitioners to find a solution (whenever possible) that is as quick as possible, suitable for their contexts, oriented by internal needs and not controlled by external factors.

Only after the development of the two sections and a preliminary testing, participants proposed to add a third section to the tool. This is about the monitoring of the process which aims to solve the critical situations that were reported and analyzed in the previous sections. In addition, this section can highlight the weak points of the network that is engaged in solving the problems, because it analytically describes the steps of the process and those people in charge of problem management. Sometimes problems are complex and need an iterative process of adjustment of the solution. It is often necessary to reuse these modules several times until there is sufficient agreement and satisfaction about the problem solution.

This three-folded tool could now provide the relevant information about each step of the process and demonstrates that "learning from critical situations" would fail if the process stopped at the first phase, while all three steps are crucial to accomplish effective results. Sections 2 and 3 are therefore what make this tool something different to a traditional incident reporting form, where practitioners are asked to provide data but have no awareness on the problem analysis and any role in its solution.

At the end of the project, participants decided to implement an electronic version of the tool, adapting it to a spreadsheet form. It was designed as a 3-module tool and each section corresponded to one of the 3 phases of the process: (i) Anomalies detection, (ii) Problem setting and problem solving, (iii) Solution process monitoring.

Eventually, participants proposed to evaluate the tool according to the AGREE criteria for the assessment of the quality of clinical guidelines (AGREE, 2003): clarity of the overall objective, the target population, the stakeholder involvement, the evaluation of applicability and resource implications, etc. According to this framework, participants were able to differentiate this tool from already existing methods, tools and practices, and to appreciate its synergy with them.

\section{The Use of the Tool}

Participants involved their colleagues, coordinators, administrators, and finally professional associations in the project, in order to develop the tool, and then make the intermediate results visible.

The project teams related several qualitatively rich experiences in using, monitoring and disseminating the reporting practice; indeed, their overall satisfaction highlighted the specificity of the tool compared to other methods.

In some contexts, the operators expressed strong desire to implement the project, revealing their need to share their experiences about the hardship of daily professional practice. In these cases, the participatory model allowed them to shift from a "complaint" register to an "activation" one. In particular, the involvement of the team coordinator and other institutional key-roles (such as Risk Manager, Quality Manager, Occupational Health Physician, Occupational Health and Safety Manager, Nursing Coordinator) has been a crucial point.

However, where the tool's use presented difficulties, the following critical issues emerged: differences in vision and approach to well-being, poor management clarity in relation to the mandate, and concerns about data misuse. We have also been informed that, in a hospital, the management did not authorize the fieldwork phase. In addition, during the first meeting, some operators expressed their absolute disbelief in the possibility of using data in a non-blaming way and abandoned the project.

\section{DISCUSSION}

The participatory model seems to be suitable to sustain the participants' engagement and responsibility of well-being and safety management. In particular, by starting from the analysis of practices and not from a predefined model, the project allowed the participants to enable open confrontation about inter-professional practices (nurses, anesthetists, surgeons), confrontation among practices in different contexts (health 
units, hospitals) and among different roles (coordinators, safety managers, etc.), and dissemination of good practices. The development of the operators' competencies in reflecting upon their practices and sustaining a participatory process of organizational solutions enables them to reduce their learned helplessness and resignation and to design a report form according to their practices, which was considered suitable and usable in their current work activities.

This participatory model seems to counterbalance incident reporting limits and poor reporting culture (Whitaker and Ibrahim, 2016). In fact, this tool has several advantages: it involves operators in a process of information flow; it reduces the complexity of the reporting practice, which is developed by the user itself; it enables them to manage the process. Feedback is no longer delegated to others, since the reporting system is a traceable process that unifies the problem diagnosis phase and the solution implementation assessment. From this perspective, it is possible to overcome the common bottleneck between anomaly investigation and action planning (Drupsteen et al., 2013), by identifying a specific role in the learning process to take care of the transition from data gathering to data use. Accordingly, the participatory model gives operators the perception of responsibility and ability to intervene and modify their environment. In addition, the tool becomes a database of already solved issues concerning safety and well-being, allowing them to learn from past experiences.

Furthermore, in this kind of participatory process, there are two instances to take into account. Not only is the bottomup process development important, the same attention has to be devoted to the top-down commitment for the tool implementation. If correctly balanced, from the proximity to the front-end practices, the advantage is the adherence to the current work activities and the contextualization of the tool within actual practices and regulations.

\section{REFERENCES}

AGREE (2003). Development and validation of an international appraisal instrument for assessing the quality of clinical practice guidelines: the AGREE project. Qual. Saf. Health Care 12, 18-23. doi: 10.1136/qhc.12. 1.18

Albolino, S., Tartaglia, R., Bellandi, T., and Biggeri, A. (2010). Patient safety and incident reporting: survey of Italian healthcare workers. Qual. Saf. Health Care 19(Suppl. 3), i8-i12.

Andersen, H., Røvik, K. A., and Ingebrigtsen, T. (2014). Lean thinking in hospitals: is there a cure for the absence of evidence? A systematic review of reviews. BMJ Open 4:e003873. doi: 10.1136/bmjopen-2013-003873

Arenas, A., Giorgi, G., Montani, F., Mancuso, S., Perez, J. F., Mucci, N., et al. (2015). Workplace bullying in a sample of Italian and Spanish employees and its relationship with job satisfaction, and psychological well-being. Front. Psychol. 6:1912. doi: 10.3389/fpsyg.2015.01912

Bower, P., Campbell, S., Bojke, C., and Sibbald, B. (2003). Team structure, team climate and the quality of care in primary care: an observational study. Qual. Saf. Health Care 12, 273-279. doi: 10.1136/qhc.12.4.273

Bracco, F., Bruno, A., and Sossai, D. (2011). "Improving resilience through practitioners' well-being: an experience in Italian health-care," in Proceedings of the Fourth Symposium on Resilience Engineering, eds E. Hollnagel, E. Rigaud, and D. Besnard (Paris: Presses des Mines), 43-49.
Managers' commitment for tool implementation is necessary to provide quick and credible feedback, when required, and, most of all, to acknowledge and promote new practices into the organizational culture. Indeed, in contexts where the monitoring process that unifies the problem diagnosis phase and the solution implementation assessment failed, the tool's implementation was not institutionally supported, notwithstanding the initial commitment of the top management. Such a need to sustain the long-term project is evident in the participants' involvement of their colleagues and coordinators. The aim of such efforts is to continuously sustain the good practices realized by the operators, i.e., organizational criticality management for the improvement of safety and well-being of both workers and patients.

\section{AUTHOR CONTRIBUTIONS}

All authors listed, have made substantial, direct and intellectual contribution to the work, and approved it for publication.

\section{FUNDING}

This project was funded by the Liguria Region grant as projects aimed at promoting work safety and social accountability in public administrations (Regional act, 13 of August 2007, n.30, art. 8 and 13 - regional norms about safety and quality of work).

\section{ACKNOWLEDGMENTS}

We wish to thank Dimitri Sossai for his support in the design and deployment of the project, all the participants to the project, and the technical staff that supported us in writing reports. We also wish to thank Mikaela McKellar for proofreading the paper.

Bruno, A., Galuppo, L., and Gilardi, S. (2011). Evaluating the reflexive practices in a learning experience. Eur. J. Psychol. Educ. 26, 527-543. doi: 10.1007/s10212011-0061-x

Dekker, S. W. A. (2007). Why doctors are more dangerous than gunowners: a rejoinder to error counting. Hum. Factors 49, 177-184. doi: $10.1518 / 001872007 X 312423$

Drupsteen, L., Groeneweg, J., and Zwetsloot, I. J. M. (2013). Critical steps in learning from incidents: using learning potential in the process from reporting an incident to accident prevention. Int. J. Occup. Saf. Ergon. 19, 63-77. doi: 10.1080/10803548.2013.11076966

Elfering, A., Semmer, N. K., and Grebner, S. (2007). Work stress and patient safety: observer-rated work stressors as predictors of characteristics of safetyrelated events reported by young nurses. Ergonomics 49, 457-469. doi: $10.1080 / 00140130600568451$

Flanagan, J. C. (1954). The critical incident technique. Psychol. Bull. 51, 327-358. doi: 10.1037/h0061470

Flinn, R., O'Connor, P., and Crichton, M. (2008). Safety at the Sharp End. A Guide to Non-Technical Skills. London: Ashgate.

Gordon, M., Darbyshire, D., and Baker, P. (2012). Non-technical skills training to enhance patient safety: a systematic review. Med. Educ. 46, 1042-1054. doi: 10.1111/j.1365-2923.2012.04343.x

Heinrich, H. W. (1931). Industrial Accident Prevention: A Scientific Approach. New York, NY: McGraw-Hill. 
Henriksen, K., and Dayton, E. (2006). Organizational silence and hidden threats to patient safety. Health Serv. Res. 41, 1539-1554. doi: 10.1111/j.14756773.2006.00564.x

Hoffman, D. A., and Mark, B. (2006). An investigation of the relationship between safety climate and medication errors as well as other nurse and patient outcomes. Pers. Psychol. 59, 847-869. doi: 10.1111/j.1744-6570.2006.00056.x

Hollnagel, E. (2014). Safety-I and Safety-II: The Past and Future of Safety Management. Farnham: Ashgate.

Hollnagel, E., Braithwaite, J., and Wears, R. L. (eds) (2013). Resilient Health Care. Farnham: Ashgate.

Joint Commission (2016). Sentinel Event Statistics Data - Root Causes by Event Type (2004 - 2015). Available at http://www.jointcommission.org/assets/ 1/18/Root_Causes_by_Event_Type_2004-2015.pdf (accessed May 1, 2016).

Kohn, L. T., Corrigan, J. M., and Donaldson, M. (eds) (2000). To Err is Human: Building a Safer Health System. Washington, DC: Institute of Medicine.

Laschinger, S., Heather, K., and Leiter, M. P. (2006). The impact of nursing work environments on patient safety outcomes: the mediating role of burnout engagement. J. Nurs. Adm. 36, 259-267. doi: 10.1097/00005110-20060500000019

Leape, L., Lawthers, A. G., Brennan, T. A., and Johnson, W. G. (1993). Preventing medical injury. Qual. Rev. Bull. 19, 144-149.

Reader, T. W., Cuthbertson, B. H., and Decruyenaere, J. (2008). Burnout in the ICU: potential consequences for staff and patient well-being. Intensive Care Med. 34, 4-6. doi: 10.1007/s00134-007-0908-4

Vincent, C., Stanhope, N., and Crowley-Murphy, M. (1999). Reasons for not reporting adverse incidents: an empirical study. J. Eval. Clin. Pract. 5, 13-21. doi: 10.1046/j.1365-2753.1999.00147.x
Weick, K. E., and Sutcliffe, K. M. (2007). Managing the Unexpected: Resilient Performance in an Age of Uncertainty. San Francisco, CA: Jossey-Bass.

West, M. (2004). Effective Teamwork. Practical Lessons from Organization Research. Oxford: BPS Blackwell.

Whitaker, J., and Ibrahim, F. (2016). Incident reporting feedback experience in a UK secondary care setting. Bull. 98, 82-84. doi: 10.1308/rcsbull.2016.82

Wreathall, J. (2006). "Properties of resilient organizations: an initial view," in Resilience Engineering, Concepts and Precepts, eds E. Hollnagel, D. Woods, and N. Leveson (London: Ashgate), 275-285.

Yassy, A., and Hancock, T. (2005). Patient safety - worker safety: building a culture of safety to improve healthcare worker and patient well-being. Health. Q. 8, 32-38. doi: $10.12927 /$ hcq. 17659

Conflict of Interest Statement: The authors declare that the research was conducted in the absence of any commercial or financial relationships that could be construed as a potential conflict of interest.

The reviewer JP and the handling Editor declared their shared affiliation, and the handling Editor states that the process nevertheless met the standards of a fair and objective review.

Copyright (c) 2016 Bruno and Bracco. This is an open-access article distributed under the terms of the Creative Commons Attribution License (CC BY). The use, distribution or reproduction in other forums is permitted, provided the original author(s) or licensor are credited and that the original publication in this journal is cited, in accordance with accepted academic practice. No use, distribution or reproduction is permitted which does not comply with these terms. 


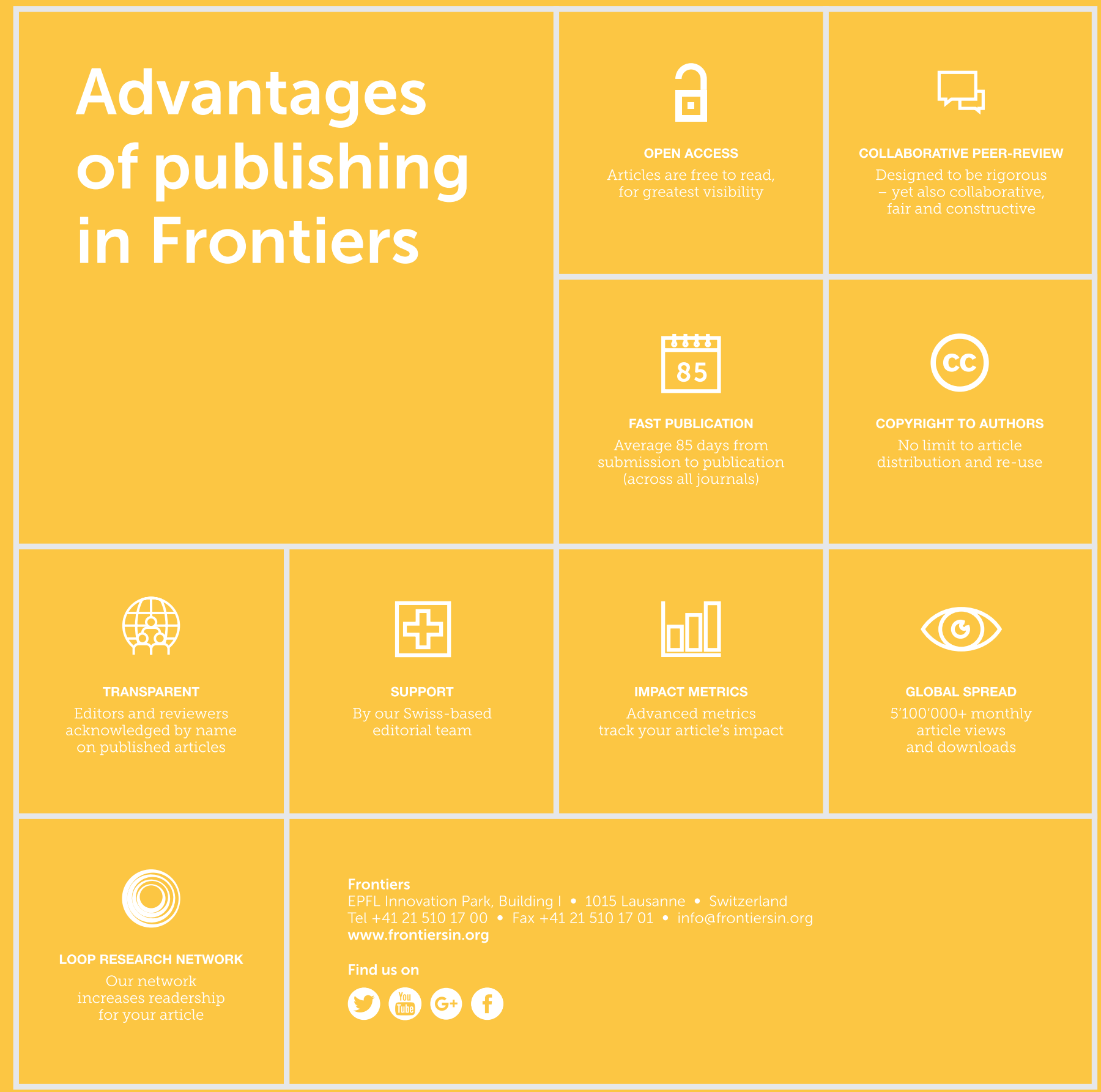

